\title{
Siegfried Marck. Politische Biographie eines jüdisch-intellektuellen Sozialdemokraten
}

\author{
Dissertation \\ zur Erlangung des philosophischen Doktorgrades an der Philosophischen Fakultät \\ der Georg-August-Universität Göttingen \\ vorgelegt von \\ Markus Schulz \\ aus Gehrden
}

Göttingen, im November 2014

1. Gutachter: Prof. Dr. Peter Aufgebauer

2. Gutachter: Prof. Dr. Karsten Rudolph

Tag der mündlichen Prüfung: 27. Januar 2016 
FORSCHUNGSINTERESSE UND FRAGESTELLUNG

FORSCHUNGSSTAND

QUELLENLAGE UND -AUSWAHL $\quad 24$

ZUR BIOGRAPHISCHEN METHODE UND DEREN UMSETZUNG

DER ERSTE KULTURKREIS - BRESLAUER JAHRE

$\begin{array}{ll}\text { Die FAMILIE MARCK } & 35\end{array}$

BILDUNGSBIOGRAPHIE $\quad \mathbf{4 0}$

Die Ehe Mit Lola Landau

DER ÜBERGANG ZUR SOZIALDEMOKRATIE

DIE EHE MIT KLÄRE ROSENSTOCK

WEGGEFÄHRTEN UM DIE BRESLAUER VOLKSWACHT

ALS GEISTIGER ARBEITER

EIN NOVEMBERSOZIALIST ALS StadtVERORDNETER

DIE JUNGSOZIALISTEN - EIN RUCK NACH LINKS

EINE UNLAUTERE BERUFUNG?

IM ZWEITEN KULTURKREIS - IM FRANZÖSISCHEN EXIL

$\begin{array}{ll}\text { ZWISCHEN OPPOSITION UND KAMPFKARTELL } & 151\end{array}$

TÄTIGKEITEN IN DER VOLKSFRONT 161

$\begin{array}{ll}\text { ALS IDEENGEBER DES FREIHEITLICHEN BÜRGERTUMS } & 171\end{array}$

\begin{tabular}{lc} 
IM DRITTEN KULTURKREIS - IM AMERIKANISCHEN EXIL & 187 \\
\hline
\end{tabular}

$\begin{array}{ll}\text { FLUCHT UND FIXIERUNG } & 187\end{array}$

FÜr EINE NEUORDNUNG EURopas - EIN DRITTER WEg 203

DIE „FREUNDSCHAFT“ MIT THOMAS MANN

AUF VORTRAGSREISE NACH DEUTSCHLAND 246

ZUSAMMENFASSUNG UND SCHLUSSFOLGERUNG $\quad 255$

\begin{tabular}{lr} 
LITERATUR & 269 \\
\hline
\end{tabular} 


\section{Einleitung}

Es waren bewegende Momente für Siegfried Marck, als er im Juli 1951 Paul Löbe auf der Dachterrasse des Bundeshauses in Bonn die Hand schütteln durfte. Der etwas untersetze, mittelgroße und sich in seinen Erntejahren befindende Sozialdemokrat, mit lichtem Haar, zog immer wenn er nervös oder besonders angespannt war seine rechte Augenbraue hoch und strich sich mit dem Daumen darüber. So wird es auch gewesen sein, als er dort auf den Alterspräsidenten des Ersten Deutschen Bundestages traf. Für beide hatte dieses Gebäude, im dem nach dem Zweiten Weltkrieg der Deutsche Bundestag und der Deutsche Bundesrat provisorisch eine Unterkunft fanden, eine besondere Bedeutung. Löbe und Marck stammten aus Schlesien und hatten zusammen in Breslau die Zeit des Umbruchs nach dem Ersten Weltkrieg erlebt. Gemeinsam hatten sie 1924 beispielsweise den Bund der Freunde sozialistischer Akademiker in Breslau ins Leben gerufen, um Arbeiterkindern den Weg an die Universität zu ermöglichen. Der eigentlich nationalliberal eingestellte Siegfried Marck schloss sich damals, nach seinen Fronterlebnissen an der Westfront, der Sozialdemokratie, welche der ältere Löbe seit Jahren prägte, an. Dieser Entschluss veränderte Siegfried Marcks Leben einschneidend. Paul Löbe war zu dieser Zeit noch Chefredakteur der Breslauer Volkswacht, des sozialdemokratischen Leitmediums in Schlesien. Dieses fand, besonders in der Zeit des Ersten Weltkrieges, in den Schützengräben großen Absatz. Auch Siegfried Marck, ein Sprössling aus einer der wohlhabendsten jüdischen Breslauer Familien, hatte in den Schützengräben zum ersten Mal die Volkswacht gelesen und trat dort mit Menschen einer anderen Klasse in Kontakt. Nun waren es Arbeiter und weniger die Professorenschaft, mit denen der bereits promovierte Siegfried Marck diskutierte. Er betrat politisches Neuland und es verging kaum ein Abend, an dem er nicht in den Breslauer Arbeiterkneipen referierte. Paul Löbe indes machte politisch Karriere und hielt den Kontakt zu seinem Wahlkreis in Breslau stets aufrecht, trat oft mit Vorträgen dort in Erscheinung. Er wurde Reichstagspräsident über viele Jahre - Reichspräsident wollte er 1925 nach dem Tod Friedrich Eberts nicht werden. Und Siegfried Marck? Dieser versuchte sich ebenfalls auf politischem Terrain zu etablieren und aufzusteigen, kam jedoch nicht über die Breslauer Stadtverordnetenversammlung und den Provinziallandtag hinaus. Stattdessen wurde er in der Erwachsenenbildung und zusammen mit Clara Zils und Ernst Eckstein, Immanuel Birnbaum und Fritz Sternberg bei den Jungsozialisten aktiv, hier konnte er größeren Nachklang 
hinterlassen. Beruflich hatte Marck als Jude und Sozialdemokrat einen schweren Stand an der Breslauer Schlesischen-Wilhelms-Universität, das bemerkte er schnell. Der Neukantianer wäre auch nicht ohne parteipolitische Hilfe von Adolf Grimme an eine ordentliche Professur gelangt, wenngleich er diese nur drei Jahre ausüben durfte, da er Deutschland 1933 den Rücken kehren musste. Von nun an begann seine Odyssee, die ihn zuerst ins französische und darauf ins amerikanische Exil trieb. Paul Löbe indes blieb und wurde mehrfach interniert. Marck jedoch konnte nirgends richtig fußfassen, war getrieben von dem Wunsch, nach der Niederlage des Nationalsozialismus zurück nach Deutschland zu kommen.

Denn vergessen wir nicht: Emigration oder politische Flucht ist immer auch eine Geschichte von einigen Menschen, die mit diesem Bruch besser umgehen konnten und einer Mehrzahl, die an den ihnen neu gestellten Aufgaben und Konstellationen scheiterten. Siegfried Marck war einer von letzteren. Wäre Marck nicht in seiner Zeit in Breslau besonders mit der Redaktion um die Breslauer Volkswacht in Verbindung gewesen, hätte er sich nach seinen Fronterlebnissen im Ersten Weltkrieg nicht der Sozialdemokratie angeschlossen und stets für die Weimarer Republik und deren Verfassung gekämpft, hätte er nicht in der Volksbildungsbewegung mitgearbeitet und hätte er schon gar nicht in der Marxistischen Arbeitsgemeinschaft oder der Sozialistischen Hochschulgemeinschaft gemeinsam mit Clara und Ernst Eckstein, Immanuel Birnbaum und Fritz Sternberg als Ideenstifter für eine Handvoll Jungsozialisten gewirkt, die im ganzen Reich als einer der radikalsten Kreise angesehen wurden, er hätte nicht auf den ersten Listen der Nationalsozialisten gestanden und hätte nicht aus Breslau fliehen müssen. Möglicherweise wäre Siegfried Marck als alter Ordinarius für Philosophie an der Breslauer Schlesischen Wilhelms-Universität in seiner Geburtsstadt gestorben und eine wissenschaftliche Auseinandersetzung mit seiner politischen Biographie wäre nie geführt worden. Dies wäre sehr bedauerlich, weil der Wissenschaft so nicht nur ein Exponat sozialdemokratischer Prominenz der hinteren Reihen, mit dennoch prägender Wirkung, sondern auch eine besonders tragische Figur des politischen Exils entglitten wäre. Denn an Marck lassen sich gut die Schwierigkeiten und Brüche eines politischen Grenzgängers aufzeigen, der in seinem Leben stets nach politischem Halt und wissenschaftlicher Anerkennung suchte.

Der Sozialdemokrat Siegfried Marck stammte aus einer der wohlhabendsten Patrizierfamilien Breslaus. Die meiste Zeit seines Lebens verbrachte er dort, in genau 
dieser Odermetropole, die viele bedeutende Denker und politische Kämpfer seiner Zeit hervorbrachte. Die gesellschaftliche Struktur seiner Heimatstadt, welche die Familie Marck seit mehr als zwei Jahrhunderten mit geformt und geprägt hatte, beeinflusste Marck. Die Odermetropole war geprägt von einem Liberalismus, der den Bürgern, insbesondere den jüdischen, ein „begründetes Recht auf Anderssein“ zusprach. ${ }^{1}$ Bereits in der Zeit des Vormärz war dies deutlich spürbar: Viele jüdische Breslauer unterstützten 1848 die Kämpfe für einen deutschen Nationalstaat mit den in einer modernen Verfassung garantierten bürgerlichen Grundfreiheiten. Beispielsweise nahm Louis Cohn, der später der sozialdemokratischen Partei beitreten sollte, an den blutigen Straßenkämpfen im Mai 1849 in Breslau teil. ${ }^{2}$ Schon einige Jahre zuvor, in den napoleonischen Befreiungskriegen zwischen 1813-1815, kämpften jüdische Freiwillige aus Breslau in den Reihen der Lützowschen Jäger für ihr Vaterland. ${ }^{3}$ Nach 1871 wurde Breslau dann Teil eines föderativen Staatswesens, welches im neugeschaffenen Deutschen Reich seinen Mitgliedsstaaten besondere Befugnisse zukommen ließ: Preußen, Bayern und Sachsen behielten ihre Monarchien - die Stellung Preußens wurde hierdurch gestärkt, denn fortan fungierten die preußischen Monarchen zugleich als deutsche Kaiser. ${ }^{4}$ Dabei ist die Geschichte Breslaus, der Hauptstadt Schlesiens, eigen und nicht unumstritten. Oftmals wird in diesem Zusammenhang vergessen, dass die Odermetropole jahrhundertelang eine polnische Stadt mit dem Namen Wroclaw war und es verwundert nicht, dass die Bürger Breslaus und Polens mehrere, sich überschneidende Identitäten hatten: als Schlesier, mit ihrem eigenen Dialekt, als Preußen, mit strengen Traditionen. Als deutsche Erben einer alten nationalen Kultur fanden sie sich in einem spannungsreichen Handlungsfeld und der zweitgrößten Stadt Preußens wieder. Breslau muss als ein Ort verstanden werden, an dem sich zentrale Entwicklungslinien und Konfliktfelder der deutschen Geschichte im 19. und 20. Jahrhundert bündelten. ${ }^{5}$ Dabei wuchsen diese stetig, nicht zuletzt weil sich zwischen 1861 und 1910 die Einwohnerzahl vervierfachte. Breslau fungierte als Handelszentrum und profitierte von einem ausgedehnten wirtschaftlichen Hinterland und reichen Kohlevorkommen im Südosten. Von den ca. 500.000 Einwohnern, die

\footnotetext{
${ }^{1}$ Vgl. Rahden, Till van: Juden und andere Breslauer. Die Beziehung zwischen Juden, Protestanten und Katholiken in einer deutschen Großstadt von 1869 bis 1925, Göttingen 2000, S. 14ff.

${ }^{2}$ Vgl. Lagiewski, Maciej: Breslauer Juden 1850-1944, Wroclaw 1996, Abb. 131.

${ }^{3}$ Vgl. Ders.: Die Juden in Breslau 1850-1945, in: Kühnel, Horst (Hrsg.): Juden in Breslau 1850-1945. Beiträge zu einer Ausstellung, München 1993, S. 27-43, hier S. 28.

${ }^{4}$ Vgl. Stern, Fritz: Fünf Deutschland und ein Leben. Erinnerungen, München 2007, S. 21f.

${ }^{5}$ Vgl. Rahden, Till van: Juden und andere Breslauer, S. 33.
} 
Breslau 1910 zählen konnte, waren etwa 60 Prozent Protestanten, 35 Prozent Katholiken und etwa 5 Prozent Juden. Die jüdische Gemeinde Breslaus, der die Familie Marck angehörte, zählte zu den drei größten Deutschlands. Und diese Größe, mit dem stark ausgeprägten Gemeindeleben, den neugewonnen Studienmöglichkeiten an der Universität und dem bedeutenden jüdisch-theologischen Seminar, machte Breslau während der großen jüdischen Migration des 19. und frühen 20. Jahrhunderts - insbesondere aus Posen und Schlesien - für viele Menschen jüdischen Glaubens interessant. Fritz Stern, ein in Breslau geborener deutsch-jüdischer Historiker, beschreibt seinen Heimatort in seinen Memoiren als geprägt durch eine „stolze Bürgerschaft mit einem pulsierenden kulturellen Leben, was eng miteinander verflochten war". ${ }^{6}$ Eine der wichtigsten Institutionen des Breslauer Kulturlebens war zweifelsohne die 1811 gegründete Schlesische FriedrichWilhelms-Universität, an der auch Siegfried Marck studieren und lehren sollte. Diese ersetzte die 1702 von Kaiser Leopold I. gegründete katholische Universität und war nun Preußens erste nichtkonfessionelle Universität. ${ }^{7}$ Während der preußische Staat versuchte, auf die Universität Einfluss zu nehmen, bestimmten vor allem die Stadtväter, unter denen seit Generationen immer ein Marck zu finden war, das kulturelle Leben Breslaus. Dies war besonders im Musik- und Theaterleben, aber auch in der Kunstakademie spürbar, die bis $1932 \mathrm{zu}$ den bedeutendsten Bildungszentren auf dem Gebiet der bildenden Künste gehörte. ${ }^{8}$ Zwar konnten diese Akademien mit denen in Berlin, München oder Wien nicht mithalten, doch waren die Breslauer ehrgeizig und erfolgreich. ${ }^{9}$

Die Geschichte der deutschen Juden und insbesondere des Breslauer Judentums ${ }^{10}$ zwischen der Mitte des 19. Jahrhunderts und den zwanziger Jahren des 20. Jahrhunderts bildet einen wichtigen Teil einer Geschichte, in der Fragen nach Vielfalt und Differenz, nach den Mechanismen von Ein- und Ausschluss zum

\footnotetext{
${ }^{6}$ Vgl. Stern, Fritz: Fünf Deutschland und ein Leben, S. $21 \mathrm{f}$.

${ }^{7}$ Vgl. ebd., S. 24.

${ }^{8}$ Vgl. Lagiewski, Maciej: Breslauer Juden 1850-1944, Abb. 196.

${ }^{9}$ Vgl. Stern, Fritz: Fünf Deutschland und ein Leben, S. 25.

${ }^{10}$ In dieser Arbeit soll der Begriff des Breslauer Judentums und nicht die Wendung Preußisches Judentum gebraucht werden, um die spezifischen Bedingungen in Breslau mit zu berücksichtigen. Immerhin hat Stefi Jersch-Wenzel bereits 1991 darauf hingewiesen, dass die regionalen Unterschiede für die Juden in Preußen sehr bedeutsam waren und deshalb nicht leichtfertig von ,preußischen Juden“" gesprochen werden sollte. Vgl. Jersch-Wenzel, Stefi: Juden in Preußen - Preußischen Juden?, in: Tel Aviver Jahrbuch für deutsche Geschichte (TAJB), Bd. 20 (1991), S. 437-448. Genauso verfährt Knud Andresen in seiner Biographie über Heinz Brandt, indem er von Posener Juden spricht. Vgl. Andresen, Knud: Widerspruch als Lebensprinzip. Der undogmatische Sozialist Heinz Brandt (19091986), Bonn 2007.
} 
Kerninteresse historischer Forschung geworden sind. Und die jüdische Integration in das Breslauer Gemeindeleben ist ohne einen hinreichenden theoretischen Rahmen nicht zu beantworten. Till van Rahdens Konzept, Max Webers und Niklas Luhmanns Gedanken zur funktionalen Differenzierung von gesellschaftlichen Teilbereichen in der Moderne mit den Konzepten der Exklusion ${ }^{11}$ und der sozialen Schließung zu verbinden, scheint für die Beschreibung des Zusammenlebens in Breslau als die geeignetste Herangehensweise. ${ }^{12}$ Demnach ist Integration das Resultat vieler Inklusionsprozesse in den zentralen Funktionsbereichen der modernen Gesellschaft. Hierzu zählen Wirtschaft, Politik, Wissenschaft, Erziehung und Recht. Dennoch muss zwischen dem Begriff der Integration als übergeordnete Kategorie und dem der Inklusion unterschieden werden, da es beispielsweise vielen Juden möglich war, am wirtschaftlichen Leben gleichberechtigt teilzunehmen, sie aber von anderen Bereichen, wie etwa der Politik, ausgeschlossen waren. In diesem Fall kann zwar von Inklusion, jedoch nicht von Integration gesprochen werden. Die Marcks jedenfalls waren gesellschaftlich, politisch und wirtschaftlich integriert. Sie besaßen ein gewinnbringendes Bankhaus und fungierten als Jugendrichter, Stadträte und Magistratsmitglieder Breslaus.

Während sich gerade in Breslau die unterschiedlichen Lebensordnungen um die Jahrhundertwende rationalisierten, mehr noch, je größer dort das Ausmaß der funktionellen Differenzierung, also der Herausbildung einzelner Teilsysteme mit einer bestimmten Funktion für das Gesamtsystem, wurde, desto mehr regelten diese gesellschaftlichen Teilbereiche den Zugang für Juden, insbesondere für jene, die aus dem östlichen Europa nach Breslau migrierten. Hier knüpft das Konzept der sozialen Schließung Max Webers, zu verstehen als Ausschluss von Konkurrenz, mit seiner inneren Eigengesetzlichkeit an. In Breslau wurden kollektive, zugeschriebene Zugangsvoraussetzungen wie Ethnizität, Konfession oder Geschlecht durch individuelle, erworbene Qualifikationen wie Besitz, Einkommen oder Bildung verdrängt - davon profitierte die Familie Marck. Was Weber eigentlich als soziale Schließung begreift, bestand jedoch fort, muss aber von der Exklusion unterschieden werden. Exklusion meint in diesem Zusammenhang jede Monopolisierung von Besitz, Status und Macht in den gesellschaftlichen Teilbereichen, die nicht auf

${ }^{11} \mathrm{Zu}$ den Begriffen Inklusion und Exklusion siehe besonders: Luhmann, Niklas: Inklusion und Exklusion, in: Ders.: Soziologische Aufklärung 6. Die Soziologie und der Mensch, Opladen 1995, S. 237-264; Farzin, Sina: Inklusion/Exklusion; Entwicklungen und Probleme einer systemtheoretischen Untersuchung, Bielefeld 2006; Stichweh, Rudolf: Inklusion und Exklusion: Analysen zur Sozialstruktur und sozialen Ungleichheit, Wiesbaden 2009. S. 7-45.

${ }^{12}$ Im Folgenden: Rahden, Till van: Juden und andere Breslauer, S. 18. 
individuellen, sondern auf kollektiven Kriterien wie etwa Ethnie, Geburt, Konfession oder Geschlecht beruht. Und dieses Nebeneinander von Offenheit und Geschlossenheit der modernen deutsch-jüdischen Gruppen- und Identitätsbildung lässt sich nach Till van Rahdens Konzeption als situative Ethnizität bezeichnen und ersetzt bereits erfolgte Deutungsversuche wie die der Subkultur oder des sozialmoralischen Milieus. ${ }^{13}$ Eine ethnische Gemeinschaft beruht auf einer gedachten Ordnung und auf der „Erfindung“ einer Tradition. Zentral für diese gedachte Ordnung ist die Konstruktion von Grenzen, die sozial und kulturell wirken und über Zugehörigkeit oder Ausschluss bestimmen. Doch sind anders als bei einer Milieuschranke die Grenzen nicht so festgesteckt. Die Zugehörigkeit zu einer ethnischen Gemeinschaft schließt nicht die Loyalität gegenüber anderen Sozialformen und Gruppen wie der Klasse, oder auch der Nation aus. Ethnizität ist folglich oft an eine konkrete soziale Situation gebunden. Spielt sie im Familien- oder Vereinsleben eine besondere Rolle, kann sie in anderen Situationen zurücktreten, wenn andere Zugehörigkeitsgefühle bestimmend werden. ${ }^{14}$ So auch bei Siegfried Marck, der 1918 dem Nationalliberalismus, für den seine Familie einstand, den Rücken kehrte, um sich der Sozialdemokratie anzuschließen.

Es gab in Städten wie Breslau, Berlin, Frankfurt oder Königsberg keine starren Grenzen zwischen Juden und Nichtjuden. Die Voraussetzung hierfür war ein hoher jüdischer Bevölkerungsanteil, ein sich über mehrere Jahrzehnte langsam etablierendes jüdisches Bürgertum sowie eine selbstbewusst auftretende jüdische Gemeinde, eine stabile linksliberale Mehrheit in der Stadtverordnetenversammlung und nicht zuletzt eine nichtjüdische Bevölkerung, die bereit war, den jüdischen Mitbewohnern das Recht auf Differenz zuzusprechen. ${ }^{15}$ Dies alles war in Breslau gegeben, Juden galten als Teil einer Vielfalt in der Einheit der Stadt - es herrschte Toleranz.

Vor allem prägten bürgerliche Juden das Vereinswesen ${ }^{16}$, das zum Umfeld des städtischen Linksliberalismus gehörte. So verwundert es nicht, dass die Marcks

\footnotetext{
${ }^{13}$ Vgl. ebd., S. 20. Der Begriff Subkultur wird in diesem Zusammenhang besonders von David Sorkin gebraucht. Dieser geht davon aus, dass die jüdischen Hoffnungen auf eine Integration in der ersten Hälfte des 19. Jahrhunderts nicht erfüllt worden seien und sich darauf eine deutsch-jüdische Subkultur gebildet hat, die einer zweiten bürgerlichen Gesellschaft, neben der Gesellschaft der Mehrheitskultur, die der sozialdemokratischen oder katholischen Milieukultur des Kaiserreichs vergleichbar gewesen sei, vgl. Sorkin, David: The transformation of German Jewry, 1780-1840, New York 1987, S. $112 \mathrm{f}$.

${ }^{14}$ Vgl. Rahden, Till van: Juden und andere Breslauer, S. 20.

${ }^{15}$ Vgl. ebd., S. $27 \mathrm{f}$.

${ }^{16}$ Zur Herausbildung des jüdischen Vereinswesens siehe besonders: Reinke, Andreas: Gemeinde und Verein. Formen jüdischer Vergemeinschaftung im Breslau des 19. und beginnenden 20. Jahrhunderts,
} 
in einer Vielzahl von Vereinen, in der Fürsorge- und Armenpflege tätig waren. Auch wenn sie hier stets auf die Anerkennung und den Zuspruch von protestantischen, katholischen oder glaubensfreien Bürgern angewiesen waren, konnten sie hier selbstbewusst auftreten. Immerhin war die Definition von bürgerlicher Kultur in der Odermetropole nicht das Monopol der protestantischen Mehrheitskultur, sondern vielmehr Gegenstand von Verhandlungen, an denen sich das jüdische Bürgertum, inklusive der Familie Marck, in hohem Maße beteiligte.

Das Aushandeln fiel den Breslauer Juden umso leichter, gerade weil sie im Kaiserreich keine geschlossene Gruppe mit weitreichenden Verhandlungsforderungen bildeten. Sie standen nicht vor der Wahl zwischen der Integration in die allgemeine Stadtgesellschaft oder dem Rückzug in geschlossene, jüdische Räume und sahen sich selbst nicht als Mitglieder einer jüdischen Subkultur. Ihre Identität war nicht zwingend exklusiv - sie war situativ und Teil einer Pluralität von Identitäten. Juden waren Grenzgänger in einer kulturell pluralistischen Welt, glaubten zudem, dass Vielheit und Einheit, Universalität und Differenz zu vereinen seien. ${ }^{17}$ Das hohe Maß an Inklusion in der Breslauer Kommunalpolitik war nicht zuletzt den politischen Umständen geschuldet, beruhte doch diese bis 1918 auf dem Dreiklassenwahlrecht. Als dies mit der Novemberrevolution verändert wurde, verloren viele bürgerliche Juden ihren politischen Einfluss, den sie zuvor genutzt hatten, um den Linksliberalismus zu stärken und den Antisemitismus zu bekämpfen. ${ }^{18}$ Immerhin stellten sie nach dem Dreiklassenwahlrecht 30 Prozent der Wähler bei den Kommunalwahlen, nach 1918 waren es nur noch 5 Prozent. Der Niedergang des Breslauer Linksliberalismus, jener Strömung, die zwischen 1860 und 1918 ununterbrochen die Mehrheit der Mandate gewinnen konnte und am Ende des Kaiserreiches noch 83 Stadtverordnete gestellt hatte, wurde hier eingeleitet. ${ }^{19}$ Die bürgerlichen Juden, die nicht mit der neuen stärksten Kraft, der Sozialdemokratie, zusammenarbeiten wollten, verloren ihre politische Heimat - den Linksliberalismus. Vielleicht schloss sich Siegfried Marck auch deshalb der Sozialdemokratie an.

Ferner muss berücksichtigt werden, dass Breslau durch die erwähnte Bevölkerungszunahme sowie durch das stetige Wirtschaftswachstum ein wichtiger

in: Ders. et al (Hrsg.): In Breslau zu Hause? Juden in einer mitteleuropäischen Metropole der Neuzeit, Hamburg 2003, S. 131-148.

${ }^{17}$ Vgl. Rahden, Till van: Juden und andere Breslauer, $327 \mathrm{f}$.

${ }^{18}$ Vgl. ebd., S. 321.

${ }^{19}$ Vgl. Weisbrod, Bernd: The crisis of bourgeois society in interwar Germany, in: Bessel, Richard (Hrsg.): Fascist Italy and Nazi Germany: comparisons and contrasts, Cambridge University Press 1998, S. 23-39, hier S. 29. 
„politischer Machtfaktor im Staat“ mit gestiegenem Selbstbewusstsein geworden war. $^{20}$ Auf der anderen Seite sahen sich die Breslauer Bürger kulturell gesehen oftmals benachteiligt: „Breslau werde eben vernachlässigt und sei die zurückgebliebene Großstadt", wenngleich das nicht bedeuten soll, dass die Theaterund Kultureinrichtungen nicht mit Subventionen von der Reichsebene versorgt wurden. ${ }^{21}$ Das jüdische Leben in der Odermetropole Breslau war etwas Besonderes. Neben den anderen großen jüdischen Gemeinden in Königsberg oder Berlin hatte sich in Breslau eine Verschmelzung von Judentum und Sozialdemokratie ergeben und letztlich wurde Breslau, ehemals ein Zentrum des Liberalismus, zu einer „sozialdemokratischen Insel“, von einer Gegend umringt, die überwiegend konservativ und katholisch war. ${ }^{22}$

Namen wie Ferdinand Lassalle und Eduard Bernstein zeugen von sozialdemokratischer Provenienz mit jüdischen Wurzeln aus Breslau. Aber auch an der Basis, unter den Arbeitern, war die Nähe zwischen Judentum und Sozialdemokratie bisweilen spürbar und schon gar nicht konfliktfrei. So gründete sich 1919 auch in Breslau die jüdisch-sozialdemokratische Arbeiterorganisation Poale Zion ${ }^{23}$, ein Zirkel jüdischer Arbeiter, der seinen ideologischen Ursprung um die Jahrhundertwende in vielen russischen Städten hatte. Die Veranstaltungen der Arbeiter Zions fanden oftmals in der Breslauer „Neuen Börse“ in der Graupenstraße statt und gerne wurde dort mit Gästen aus Wien das Verhältnis von Judentum und Sozialismus diskutiert. ${ }^{24}$ Zudem war diese Organisation auch auf den 1. MaiDemonstrationen als eigene Gruppe mitmarschiert. ${ }^{25}$ Diese Vereinigung konnte in Breslau nicht sehr viele Mitglieder für sich gewinnen, spaltete sich wie anderen Orts auch 1921 und ging Anfang der 30er Jahre mit Hapoel Hazair zusammen. ${ }^{26}$ Im Juni 1921 kam es unter den jüdisch-sozialdemokratischen Arbeitergruppen zu groben und

\footnotetext{
${ }^{20}$ Vgl. Nipperdey, Thomas: Deutsche Geschichte Bd. II. Machtstaat vor der Demokratie, München 1993, S. 154-163.

${ }^{21}$ Vgl. Breslauer Volkswacht, 23.01.1922, 10.02.1922.

${ }^{22}$ Vgl. Oliwa, Theodor: Die deutsche Arbeiterbewegung in Breslau, S. 3/11, eizusehen im Portal zur Geschichte der Arbeiterbewegung der Bibliothek der Friedrich-Ebert-Stiftung in Zusammenarbeit mit der Universitätsbibliothek Breslau unter: http://library.fes.de/breslau/index.htm.

${ }^{23}$ Erstmals nachweisbar in Breslau durch eine Ankündigung im Vereinskalender der Breslauer Volkswacht, 13.12.1919.

${ }^{24}$ Vgl. Breslauer Volkswacht, 24.01.1920. In Wien hatte diese Organisation, im Gegensatz zu Breslau, sogar ein eigenes Publikationsorgan; von 1919-1923 Freie Tribüne, von 1924-1926 Unsere Tribüne, Jüdische Sozialistische Arbeiterpartei Poale Zion, von 1927-1934 Der Jüdische Arbeiter. Organ der jüdischen sozialdemokratischen Arbeiterorganisation Poale Zion, Wien.

${ }^{25} \mathrm{Vgl}$. Breslauer Volkswacht, 02.05.1921.

26 Persönliche Mitteilung Knut Bergbauers an den Verfasser, 24.10.2011. Die Ortsgruppe der Jüdischen Volkssozialisten „Hapoel Hazair“ gründete sich im Mai 1919 in Breslau, vgl. Breslauer Volkswacht, 16.05.1919.
} 
tiefgreifenden Meinungsverschiedenheiten. ${ }^{27}$ Zuvor hatte sich von der Poale Zion ein linker Flügel abgetrennt und sich den Kommunisten angeschlossen, was folglich für Spannungen sorgen musste: Dieser abgespaltene Teil sammelte im Namen des nicht abgespaltenen Teiles und im Namen der Sozialdemokratie Spenden für eine Arbeiterküche. Dabei wurde die jüdische Arbeiterküche von der „offiziellen“ Poale Zion und vom Hapoel Hazair verwaltet. Zudem sollen noch einige Mitglieder des Jüdischen Arbeitervereines „Bund“ der Breslauer Ortsgruppe an dieser Aktion beteiligt gewesen sein. ${ }^{28}$ So kam es, dass die Sozialdemokraten letztendlich die entscheidenden Stellen innerhalb dieser Arbeiterküche, die zum Teil mit kommunistisch-sympathisierenden Arbeitern besetzt waren, für eigene Genossen freiräumte. $^{29}$ Der Konflikt zwischen Anhängern des „Bundes“ und der Sozialdemokratie sollte andauern, wenn es in kommenden Jahren etwa um die Tolerierungspolitik der Sozialdemokratie ging. ${ }^{30}$

Breslau war ein Ort, an dem seit Mitte der 1920er Jahren das soziale Elend besonders greifbar war. Als Indikator hierfür dienen Berichte des Breslauer Fürsorgeamtes: „Wer als Fremder [...] aus dem Süden oder Westen Deutschlands zum ersten Male Breslau besucht, dem fällt schon auf den Straßen auf, dass die arbeitende Bevölkerung in Aussehen und Kleidung einen ärmlichen und dürftigen Eindruck macht.“31 Zudem herrschte in Breslau eine große Wohnungsnot. Die Anzahl an „Zwergenwohnungen“ in Kombination mit einer sehr hohen Wohndichte ließen die Odermetropole, was die Wohnverhältnisse für Arbeiter anging, mit am schlechtesten in ganz Preußen erscheinen. So verwundert es nicht, dass die Breslauer Wohlfahrtseinrichtungen rege in Anspruch genommen wurden und die Arbeiter somit im starken Kontrast zum Breslauer Bürgertum standen. Bei einem Versuch, die Gründe hierfür zu finden, muss konstatiert werden, dass diese vor allem in der heterogenen Zusammensetzung der Bevölkerung bestanden. Während alteingesessene Breslauer Patrizierfamilien, wie die Marcks, in den besten Gegenden um den Stadtkern lebten, hausten die Arbeiter, bedingt durch die Armutszuwanderung aus den östlichen Gebieten, welche seit dem Versailler Vertrag und der daraus resultierenden Abspaltung Oberschlesiens 1922 stattfand, in den

\footnotetext{
${ }^{27}$ Siehe hierzu die Stellungnahmen, in: Jüdisch-liberale Zeitung, 03.06.1921.

${ }^{28}$ Zum Bund siehe: Pickhan, Gertrud: „Gegen den Strom“. Der Allgemeine jüdische Arbeiterbund „Bund“ in Polen 1918-1939, Stuttgart/München 2001.

${ }^{29}$ Vgl. Breslauer Volkswacht, 08.06.1921.

30 Pickhan, Gertrud: The "Bund" in Poland and German Social Democracy in the Thirties, in: Proceedings of the Twelfth World Congress of Jewish Studies, Jerusalem, July 29 - August 5, 1997 , Division B: History of the Jewish People, Jerusalem 2000, S. 257-263, hier S. 259f.

${ }^{31}$ Vgl. Breslauer Volkswacht, 26.01.1927.
} 
bereits genannten Zwergenwohnungen. Hier darf nicht unterschätzt werden, dass Schlesien nahezu ein Zehntel seines Gebietes an Polen abtreten musste - die ehemals ertragreichen Kohlegebiete lagen nun auf polnischer Seite - und viele Arbeiter in die umliegenden Großstädte flohen. Darüber hinaus war Breslau eigentlich bekannt als Handelsstadt, die Richtung Osten orientiert wirtschaftete. Obendrein konnte die ohnehin vereinzelt angesiedelte Industrie die Not der Wirtschaftskrise nicht so gut verkrafteten wie beispielsweise die in Magdeburg. ${ }^{32}$ Ferner konnte das Wohlfahrtsamt nachweisen, dass in Breslau die Erwerbslosigkeit in den Krisenjahren zwischen 1919 und 1923 zehn Monate eher einsetzte und auch länger anhielt, als in anderen Städten Deutschlands. ${ }^{33}$ Letztlich war Breslau Belastungen ausgesetzt, die während der gesamten Weimarer Republik eine überdurchschnittlich hohe Arbeitslosigkeit mit sich führten. ${ }^{34}$

Franz Walter stellt fest, dass sich die Krise seit 1924 noch verschärfte, weil zu Beginn des Zollkrieges mit Polen Breslau dessen Kosten stellvertretend für das Reich übernommen haben soll und außerdem die traditionellen östlichen Absatzmärkte wegfielen. ${ }^{35}$ Überdies regelten in Breslau besonders niedrige Tariflöhne die Einkommen der Industriearbeiter, unter denen sie folglich litten. Während ein gelernter Metallarbeiter in Berlin knapp 48 Mark in der Woche verdiente, konnte sein Konterpart in Breslau nur mit knapp 33 Mark rechnen und stand damit an unterster Stelle im gesamten Reich. ${ }^{36}$ Spätestens seit 1926 musste sich ein Metallarbeiter eingestehen, dass er in Breslau nicht mehr in einer Stadt, die auf eine florierende Großindustrie blicken konnte, lebte. ${ }^{37}$ Exakt diese Metallarbeiter bildeten dann den Humus für einen intellektuellen Linkssozialismus, wie er seit 1927 von Hans Ziegler und Ernst Eckstein ${ }^{38}$ als Vorsitzender des sozialdemokratischen Vereins, aber auch von Siegfried Marck getragen wurde. ${ }^{39}$

\footnotetext{
${ }^{32}$ Vgl. ebd., 26.01.1927. Hinzu kam, dass Breslau als Grenzstadt im Ersten Weltkrieg besonders viele Lazarette führte, aus denen eine große Anzahl an weiterhin pflegebedürftigen Menschen in der Stadt verblieb und auf Hilfe angewiesen war.

${ }^{33} \mathrm{Vgl}$. ebd.

${ }^{34}$ Vgl. Oliwa, Theodor: Die deutsche Arbeiterbewegung in Breslau, S. 7.

${ }^{35}$ Vgl. Walter, Franz: Nationale Romantik und revolutionärer Mythos: Politik und Lebensweisen im frühen Weimarer Jungsozialismus, Berlin 1986, S. 167f.

${ }^{36}$ Siehe die Zahlen des Statistischen Amtes Breslau, in: Breslauer Volkswacht, 23.12.1925. Unter der Einwohnerzahl stand Breslau damals an siebter Stelle unter den 21 Großstädten. Bezüglich der Löhne jedoch waren die Maurer und Zimmerleute an sechzehnter Stelle, die Bauhilfsarbeiter an zwanzigster, die Facharbeiter im Holzgewerbe an fünfzehnter Stelle. Im Back- und Teigwarengewerbe waren sie an letzter Stelle.

${ }^{37}$ Vgl. ebd., 02.07.1926.

${ }^{38}$ Eckstein war schon 1924 zum Vorsitzenden der Partei gewählt worden, vgl. ebd., 03.06.1924, 04.06.1924.

${ }^{39}$ Vgl. Walter, Franz: Nationale Romantik, S. 168.
} 
Siegfried Marck floh nach Paris, dann weiter nach New York und Chicago. Er machte sich stets Gedanken, wie Deutschland, wie Europa nach dem Nationalsozialismus wieder aufgebaut werden könnten. Er war nahezu mit allen großen Geistern seiner Zeit vertraut und bekannt, unterhielt Briefwechsel mit Heinrich und Thomas Mann, mit Paul Tillich, Albert Einstein, Hermann Broch, Max Horkheimer oder Adolf Grimme. Doch Gehör fand er weder in den USA noch in der Bundesrepublik. Finanziell auf wackeligen Füßen, gesundheitlich angeschlagen und mit seiner dritten Ehefrau auf Vortragsreise, traf er nun Paul Löbe - sie hatten sich einiges zu berichten. 


\section{Forschungsinteresse und Fragestellung}

„In Breslau, der Geburtsstadt Ferdinand Lassalles, ist die sozialdemokratische Arbeiterbewegung später und zaghafter erwacht, als in Mitteldeutschland und im Westen und Norden unseres Vaterlandes“ konstatierte der langjährige Breslauer Parteisekretär Theodor Müller nach 30 Jahren Sozialdemokratie in Breslau. Auch wenn die Breslauer Arbeiter zu den am tiefsten stehenden proletarischen Schichten ganz Deutschlands zählten und von einer modernen Industrie im Breslau in der zweiten Hälfte des 19. Jahrhunderts kaum zu sprechen war, in einer Zeit wo das Wirken Ferdinand Lassalles im übrigen Deutschland das Aufblühen des Allgemeinen Deutschen Arbeitervereins begünstigte, „segelte in Breslau die Arbeiterbewegung noch im Fahrwasser des Manchestertums und der Fortschrittspartei““ ${ }^{40}$

Doch konnte einem als aufmerksamem Bürger Breslaus um die Jahrhundertwende kaum entgehen, wie viele fortschrittliche, engagierte und sicherlich auch ehrgeizige Menschen dort anzutreffen waren, die den deutschen Zeitgeist und die Geschichte der Sozialdemokratie in Zukunft prägen sollten. Eine Geschichte der Sozialdemokratie ohne Rücksicht auf die Persönlichkeiten der Odermetropole zu schreiben, erscheint schier unmöglich.

Es existiert eine lange Reihe politisch-biographischer Arbeiten über sozialdemokratische Spitzenpersönlichkeiten, auch aus Breslau: Ferdinand Lassalle $^{41}$, August Bebel ${ }^{42}$, Eduard Bernstein ${ }^{43}$, Friedrich Ebert ${ }^{44}$, Paul Löbe ${ }^{45}$ oder

\footnotetext{
${ }^{40}$ Vgl. Breslauer Volkswacht, 31.12.1919; Allgemein zur Geschichte der Breslauer Sozialdemokratie siehe Müller, Theodor: Die Geschichte der Breslauer Sozialdemokratie, Bd. I. Bis zum Erlaß des Sozialistengesetzes, Bd. II. Das Sozialistengesetz, Breslau 1925; Zur Breslauer Arbeiterbewegung Binkowski, Johannes: Die Rolle der Arbeiterbewegung in Schlesien, in: Bossle, Lothar et al. (Hrsg.): Nationalsozialismus und Widerstand in Schlesien, Sigmaringen 1989, S. 9-17.

${ }^{41}$ Bspw.: Euchner Walter/Grebing, Helga (Hrsg.): Geschichte der sozialen Ideen in Deutschland, Sozialismus, Katholische Soziallehre, Protestantische Sozialethik, ein Handbuch, S.128-146; Friederici, Hans-Jürgen: Ferdinand Lassalle: eine politische Biographie, Berlin 1985. Na'aman, Shlomo: Ferdinand Lassalle. Deutscher und Jude, Hannover 1968.

${ }^{42}$ Etwa bei: Hermann, Ursula (Hrsg.): August Bebel. Eine Biographie, Berlin 1989; Hirsch, Helmut: August Bebel in Selbstzeugnissen und Bilddokumenten. Reinbek 1973; Schraepler, Ernst: August Bebel. Sozialdemokrat im Kaiserreich, Göttingen [u. a.] 1966; Seebacher-Brandt, Brigitte: Bebel. Künder und Kärrner im Kaiserreich, Berlin/Bonn 1988.

43 Bspw.: Carsten, Francis L.: Eduard Bernstein 1850-1932. Eine politische Biographie, München 1993; Heimann, Horst/Meyer, Thomas (Hrsg.): Bernstein und der demokratische Sozialismus. Bericht über den wissenschaftlichen Kongreß ,Die historische Leistung und aktuelle Bedeutung Eduard Bernsteins', Berlin, Hannover 1978; Löwe, Teresa: Der Politiker Eduard Bernstein. Eine Untersuchung zu seinem politischen Wirken in der Frühphase der Weimarer Republik 1918-1924. Historisches Forschungszentrum, Bonn 2000.

${ }^{44}$ Vgl. Mülhausen, Walter: Friedrich Ebert 1871-1925: Reichspräsident der Weimarer Republik, Bonn 2006; Maser, Werner: Friedrich Ebert: Der erste deutsche Reispräsident: eine politische Biographie, München 1987; Witt, Peter-Christian: Friedrich Ebert: Parteiführer - Reichskanzler Volksbeauftragter - Reichspräsident. 3., überarbeitete und aktualisierte Auflage, Bonn 1992.
} 
Willy Brandt ${ }^{46}$ wären einige Namen, die hier exemplarisch herangezogen werden können. Doch sind dies Biographien von Spitzenpersönlichkeiten, die oftmals einen Blick in die „zweite oder dritte Reihe“ sozialdemokratischer Provenienz vernachlässigen, wenngleich ein Blick in eben jene eine tiefere Erkenntnis in die Strukturen der sozialdemokratischen Bewegung liefern könnte. Schließlich haben die Sozialdemokraten der hinteren Reihen maßgeblich die Erfolge der Partei erkämpft und getragen, obwohl sie vorrangig auf regionaler Ebene arbeiteten und ihnen Spitzenämter verwehrt blieben. ${ }^{47}$ Hier sei gedacht an Persönlichkeiten wie Willi Eichler $^{48}$, Wilhelm Keil ${ }^{49}$ oder Albert Grzesinksi ${ }^{50}$, die ebenfalls biographisch untersucht wurden und ihren Platz im sozialdemokratischen Gedächtnis fanden.

Dieses erinnert, wenn es an Breslau denkt, vor allem an den bekannten Schriftsteller und sozialistischen Politiker Ferdinand Lassalle. Auch an Paul Löbe, den ehemaligen Chefredakteur der Breslauer Volkswacht und späteren Reichstagspräsidenten, dessen Name heute im Berliner Regierungsviertel ein Parlamentsgebäude trägt, wird sicherlich gedacht. Ganz Interessierten wird auch Wilhelm Hasenclever, der ehemalige Vorsitzende des Gründungsparteitages der SPD in Gotha, geläufig sein, der gemeinsam mit Wilhelm Liebknecht das bis heute existierende Parteiorgan, den Vorwärts, gründete. Und nicht $\mathrm{zu}$ vergessen ist sicherlich Eduard Bernstein, der bekannte sozialdemokratische Theoretiker des Revisionismus und zugleich Mitglied des Reichstages für den Wahlkreis BreslauWest, der als Mitbegründer der USPD die bedeutendste Spaltung der Arbeiterbewegung miteinleitete. Breslau verfügte über eine große Anzahl sozialdemokratischer Spitzenpersönlichkeiten, die mit ihrem Wirken für die Gesamtpartei und das Deutsche Reich von enormer Bedeutung waren. Nicht wenige von ihnen waren Juden. Max Kayser war 1878 der Erste und der Jüngste seiner Partei, dem eine Reihe hochrangiger sozialdemokratischer Abgeordneter mit

45 Siehe: Oliwa, Theodor: Paul Löbe. Ein sozialdemokratischer Politiker und Redakteur. Die schlesischen Jahre (1875-1919), Neustadt 2003; Scholz, Arno/Oschilewski, Walther (Hrsg.): Ein großes Vorbild. Paul Löbe zum Gedächtnis. Berlin 1968.

${ }^{46}$ Vor allem: Grebing, Helga: Willy Brandt, Der andere Deutsche, Paderborn 2008.

${ }^{47}$ Zum Blick in die „Zweite Reihe“ siehe: Woyke, Meik: Parteifunktionäre in der „zweiten Reihe“: Kontinuitäten und Brüche sozialdemokratischer Biografien im 20. Jahrhundert, in: Mitteilungsblatt des Instituts für soziale Bewegungen. Biografische Ansätze zur Geschichte der Arbeiterbewegung im 20. Jahrhundert 45(2011), S. 129-145.

${ }^{48}$ Vgl. Müller-Lemke, Sabine: Ethischer Sozialismus und soziale Demokratie. Der politische Weg Willi Eichlers vom ISK zur SPD, Bonn 1988.

${ }^{49}$ Vgl. Mittag, Jürgen: Wilhelm Keil (1870-1968). Sozialdemokratischer Parlamentarier zwischen Kaiserreich und Bundesrepublik. Eine politische Biographie, Düsseldorf 2001.

${ }^{50}$ Vgl. Kolb, Eberhard (Hrsg.): Albert Grzesinskis Erinnerungsbericht: Im Kampf um die deutsche Republik. Erinnerungen eines Sozialdemokraten, München 2009. 
jüdischen Wurzeln auf Reichs- und Landesebene folgen sollten, was auch die jüdischen Gemeinden im Reich guthießen. ${ }^{51}$

„Über die Motive jüdischen Engagements für den Sozialismus ist viel spekuliert worden“52 resümierte Stefanie Schüler-Springorum anlässlich des 150. Jubiläums der Sozialdemokratie. Ob es eine spezifisch jüdische Gerechtigkeitsethik oder auch eigene Diskriminierungserfahrungen gewesen sein mögen ${ }^{53}$ - es ist festzuhalten, dass die große Mehrheit der deutschen Juden keine Sozialisten wurden „und es auch dann nicht [wurden], als kaum noch eine andere politische Alternative zur Verfügung stand“54, nachdem die liberalen Parteien spätestens seit den Reichstagswahlen 1928 nur noch marginal Erfolge erzielen konnten und somit bürgerlichen Juden die politische Heimat wegbrach. Die Leiterin des Zentrums für Antisemitismusforschung macht dabei deutlich, dass diejenigen Juden, die sich für den Sozialismus entschieden, „nicht unbedingt besonders gut gelittene“ waren, immerhin stand das jüdische Bürgertum treu zum Liberalismus und,jedwede revolutionäre Initiative war ihm zutiefst zuwider، ${ }^{65}$. Daher muss hier von Ausnahmeerscheinungen gesprochen werden, die nicht ihre eigentliche politische Heimat, den Liberalismus, vertraten, sondern sich der sozialistischen Idee anschlossen.

Vor dem Ersten Weltkrieg waren diejenigen Juden, die Führungspositionen in der Sozialdemokratie ausübten, ausschließlich Intellektuelle, wenn auch nicht immer mit universitärer Ausbildung. Überhaupt war die Anzahl akademisch gebildeter Fraktionsmitglieder vergleichsweise gering, hatte doch die Fähigkeit solche Ämter auszuführen, nichts mit der Biographie zu tun. So wurden beispielsweise Friedrich Ebert oder Otto Braun, welche lediglich die deutsche Volksschule besuchten, zu bedeutenden sozialdemokratischen Abgebordneten, ohne dass sie ein Studium absolviert hätten. Trotzdem benötigte man nach Ernest Hamburger für besondere Aufgaben, wie die Bewertung geschichtlicher Vorgänge oder rechtlicher Rahmenbedingungen, Akademiker und in dieser Konstellation waren jüdische Funktionäre eher anzutreffen als nichtjüdische. ${ }^{56}$ Eine regionale Betrachtung machte

\footnotetext{
${ }^{51}$ Vgl. Hamburger, Ernest: Juden im öffentlichen Leben Deutschlands: Regierungsmitglieder, Beamte und Parlamentarier in der monarchischen Zeit 1848-1918, Tübingen 1968, S. 405, 416ff; Jüdischliberale Zeitung, 11.05.1928.

52 Schüler-Springorum, Stefanie: Juden, zur Sonne, zur Freiheit, in: Neue Gesellschaft, Frankfurter Hefte, Bd. 05 (2013), S. 18-19, hier S. 19.

${ }^{53}$ Vgl. Hamburger, Ernest: Juden im öffentlichen Leben Deutschlands, S. 404.

${ }^{54}$ Vgl. Schüler-Springorum, Stefanie: Juden, zur Sonne, zur Freiheit, S. 19.

${ }^{55} \mathrm{Vgl}$. ebd.

${ }^{56}$ Vgl. Ernest Hamburger, Juden im öffentlichen Leben Deutschlands, S. 408.
} 
dabei keinen Unterschied, verhielt sich die Aufstellung jüdischer Kandidaten äquivalent zu der nichtjüdischer. Die Sozialdemokratie war eine Partei der Großstädte, aus denen sie jüdische Abgeordnete akquirieren konnte ${ }^{57}$, so auch aus Breslau.

Der Tradierung nahezu entfallen ist der Name eines Sozialdemokraten, der für die Geschichte der Sozialdemokratie und besonders für die des Breslauer und Weimarer Jungsozialismus von besonderer Bedeutung war: Siegfried Marck. Trotz des immensen Einflusses des Breslauer Philosophieprofessors, Sozialisten, Neuhumanisten, Intellektuellen und guten Freundes Thomas Manns auf die Breslauer Sozialdemokratie, die Jungsozialisten, die Volkshochschulbewegung und die Diskussionen um ein Nachkriegsdeutschland, taucht Siegfried Marck in der sozialdemokratischen Überlieferung kaum, oder nur in Fußnoten, auf. Dabei hat Marck in seiner Biographik für die wissenschaftliche Forschung mehrere und besonders reizvolle Elemente, sodass es geradezu fahrlässig erscheint, ihn in Vergessenheit geraten zu lassen. Der jüdische Patriziersohn und Doktor der Philosophie aus Breslau war von seinem universitären Umfeld her Neukantianer und betrieb im Breslauer Stadtrat Kulturpolitik. Zudem war Marck Anhänger des dortigen Bürgertums und ließ sich vom Austromarxismus inspirieren, und nicht zuletzt war er „Novembersozialist“, orientierte sich zuerst am rechten Rand der Sozialdemokratie, von dem er sich später wieder distanzieren sollte. Überdies war der „,bourgeoise Deserteur“658 und politische Grenzgänger Siegfried Marck nicht ohne Hilfe Adolf Grimmes und gegen zwei Gutachten Martin Heideggers an eine große Philosophieprofessur in Breslau gekommen und lehrte zugleich in der Breslauer Volkshochschule und der Jüdischen Volkshochschule Breslaus. Durch seine Aktivitäten war er insbesondere den Jungsozialisten, dem Arbeiterbildungsausschuss und den wenigen sozialistischen Studierenden ein Ansprechpartner.

Siegfried Marck reiht sich in eine Minorität von Intellektuellen innerhalb der deutschen Arbeiterbewegung in die Zeit vor dem Ersten Weltkrieg ein und transferiert diesen Typus in die Zwischenkriegsjahre. In diesem Zusammenhang stellt sich die Frage, was überhaupt einen Intellektuellen, besonders einen Jüdischen und somit auch Siegfried Marck, ausmacht. Der Begriff „Intellektueller“ soll in diesem Zusammenhang verstanden werden als eine Zuschreibung für einen

\footnotetext{
${ }^{57}$ Vgl. ebd., S. 413.

${ }^{58}$ Michels, Robert: Zur Soziologie des Parteiwesens in der modernen Demokratie. Untersuchungen über die oligarchischen Tendenzen des Gruppenlebens (1911). Stuttgart 1989, S. 313.
} 
Menschen, der in relativer Autonomie seine Positionen „schreibend und redend reflektiert“59 und „,kommunikatorisch“ dazu beiträgt, dass diese auch Umsetzung finden. Folglich kann nur derjenige ein Intellektueller sein, der von außen in das politische Feld ,interveniert“ und sich, seiner Autonomie bewusst, einmischt. ${ }^{60}$ Intellektueller war Siegfried Marck auch besonders deshalb, weil er als „Sinndeuter und Sinnvermittler“61 in der Sozialdemokratie verankert war und ,im Dienste eines Ideals an der Umsetzung daraus abgeleiteter allgemeiner und abstrakter Wertvorstellungen in spezifischer Verhaltensweise “62 mitwirkte. Der Breslauer Philosophieprofessor und leidenschaftliche Erwachsenenbildner war in seiner Tätigkeit kein „Arbeiterintellektueller“, der mit seinem umfassenden Themenkatalog sein Leben lang als Vorbild für die weniger Begabten agierte. Diese Rolle übten andere Breslauer jüdische Sozialdemokraten aus. ${ }^{63}$ Marck agierte als Gesellschaftsdiagnostiker.

Versucht man die Gründe für dieses Engagement zu erforschen, so bleibt Folgendes festzuhalten: Insgesamt waren diese jüdischen Intellektuellen unter den Theoretikern und Führern der Arbeiterbewegung überrepräsentiert, was aus dem Zusammenfall von Judenemanzipation und der Entstehung der proletarischen Emanzipationsbewegung zu erklären ist. Sie erkannten, dass ihr Bestreben nach Freiheit und Demokratie, wie sie einst in der Revolution von 1848 gefordert wurden, nur in enger Zusammenarbeit mit der Arbeiterbewegung umgesetzt werden konnte. Ein anderes Moment war ihre eigene unterprivilegierte gesellschaftliche Stellung, die sie ähnlich der Arbeiterklasse bis zum Ende des Ersten Weltkrieges von Gesellschaft und Staat isolierte, obwohl sie in großem Maße dem wohlsituierten Bürgertum angehörten. So verwundert es nicht, dass jüdische Intellektuelle mit einer

\footnotetext{
${ }^{59}$ Vgl. Grebing, Helga: Jüdische Intellektuelle und ihre politische Identität in der Weimarer Republik, in: Mitteilungsblatt des Instituts für soziale Bewegungen, Heft 34 (2005), S. 11-23, hier S. 11; Dies.: Die linken Intellektuellen und die gespaltene Arbeiterbewegung in der Weimarer Republik, in: Alemann, Ulrich von et al. (Hrsg.): Intellektuelle und Sozialdemokratie, Opladen 2000, S. 79-89, hier S. 79.

${ }^{60}$ Vgl. Gilcher-Holtey, Ingrid: Konkurrenz um den „wahren“ Intellektuellen. Intellektuelle Rollenverständnisse aus Zeithistorischer Sicht, in: Kroll, Thomas/Reitz, Tilman (Hrsg.): Intellektuelle in der Bundesrepublik Deutschland. Verschiebung im politischen Feld der 1960er und 1970er Jahre, Göttingen 2013, S. 41-51, hier S. 42f.

${ }^{61}$ Vgl. Dies.: Intellektuelle in der sozialistischen Arbeiterbewegung. Karl Kautsky, Heinrich Braun und Robert Michels, in: Rojahn, Jürgen (Hrsg.): Marxismus und Demokratie, Karl Kautskys Bedeutung in der sozialistischen Arbeiterbewegung, Frankfurt am Main 1992, S. 373-390, hier S. 374. ${ }^{62} \mathrm{Vgl}$. ebd.

${ }^{63}$ Zum Begriff „Arbeiterintellektueller“ siehe besonders: Welskopp, Thomas: „Arbeiterintellektuelle“, „Sozialdemokratische Bohemiens“ und „Chefideologen“: Der Wandel der Intellektuellen in der frühen deutschen Sozialdemokratie, in: Aleman, Ulrich van et al. (Hrsg.): Intellektuelle und Sozialdemokratie, S. 43-58, hier S. 48f; Ders.: Banner der Brüderlichkeit. Die deutsche Sozialdemokratie vom Vormärz bis zum Sozialistengesetz, Bonn 2000, S. $384 \mathrm{ff}$.
} 
aufkeimenden radikalen Emanzipationstheorie wie die des Marxismus sympathisierten. ${ }^{64}$ Letztlich bleibt die Frage, weshalb Juden nach 1918, also folglich in der Zeit einer demokratisch-parlamentarischen Republik und somit auf ihrem bis dahin emanzipatorischen Höhepunkt, weiterhin für die Belange der Arbeiterbewegung eintraten. Deshalb ist es notwendig einzelbiographisch nachzuweisen, weshalb sich Siegfried Marck als jüdischer Intellektueller in der Hochzeit der jüdischen Emanzipation der Sozialdemokratie verschrieb und was seine spezifische Leistung für eben jene gewesen ist.

Dabei weist die Forschung um Biographien bei Persönlichkeiten jüdischer Herkunft auf eine Sonderstellung hin. Juden waren in der Geschichte der christlichabendländischen Gesellschaft oftmals als einzige kulturelle Minderheit inmitten eines Umfeldes vertreten, das sich zum Teil gewaltsam von Juden abgrenzte. Dennoch gehörten sie dazu. ${ }^{65}$ Es erscheint erstaunlich, dass dieser spezifisch biografische Zugriff bisher kaum reflektiert wurde und der in diesem Zusammenhang immanent wichtige Begriff der „Identität“ etwa allenfalls in Ausnahmefällen untersucht wurde. ${ }^{66}$ Dabei gilt es bei dem Begriff der Identität zu differenzieren zwischen jenem einer Person als Individuum einerseits und andererseits einer qualitativen, sich in bestimmten Situationen ergebenen Identität, von denen ,jüdisch“ lediglich einen Aspekt darstellt. Es bleibt die Erkenntnis, dass Studien zu „Grenzgängern“, wie Siegfried Marck es politisch zweifelsohne war, untersuchen müssen, inwieweit Selbst- und Fremdzuschreibung des jüdischen Glaubens auf die $\mathrm{zu}$ untersuchende Person gewirkt haben, ${ }^{67}$ womit dieses Vorgehen an die Herangehensweise Helga Grebings in Form der „nichtidentischen Identität‘ ${ }^{\star 68}$ anknüpft.

Marck brach, anders als viele andere seiner Weggefährten, nie mit seiner religiösen Herkunft. Bis zum Ende seines Lebens lassen sich Verbindungen zwischen Siegfried Marck und dem jüdischen Glauben nachweisen. Auch wenn er aus den Schützengräbern heraus seine Geisteshaltungen änderte, sein Bekenntnis zum Judentum legte er nicht ab, auch nicht, um sich an der Universität bessere Chancen auf eine Professur zu ermöglichen, wie es andere Mitstreiter machten. Als Mitglied

\footnotetext{
${ }^{64} \mathrm{Vgl}$. Grebing, Helga: Jüdische Intellektuelle in der deutschen Arbeiterbewegung zwischen den beiden Weltkriegen, in: Archiv für Sozialgeschichte, 37 (1997), S. 20.

${ }^{65}$ Vgl. Pyka, Marcus: Jewish Studies, in: Klein, Christian (Hrsg.): Handbuch Biographie. Methoden, Traditionen, Theorien, Stuttgart 2009, S. 414-418, hier S. 414.

${ }^{66}$ Ebd.

${ }^{67}$ Vgl. ebd., S. 415.

${ }^{68}$ Grebing, Helga: Jüdische Intellektuelle und ihre politische Identität, S. 11.
} 
des Central-Vereins deutscher Staatsbürger jüdischen Glaubens gehörte er zu dem prominenten Kreis jüdischer Gelehrter, der jegliche antisemitische Anschuldigungen von Seiten der Regierung stark bekämpfte. Der Centralverein verhielt sich bis 1918 ebenso „kaisertreu“, wie er sich in den zwanziger Jahren „republiktreu“69 verhielt, sein Ziel war eine „Symbiose deutsch-jüdischer Durchdringung ${ }^{\text {‘70 }}$. Zu diesem Kreis gehörten auch der Historiker Ernst Fraenkel, der Gemeinderabbiner Dr. Hoffmann oder Mitglieder des bekannten jüdisch-theologischen Seminars wie Dr. Albert Lewkowitz. $^{71}$

Andere Juden lösten sich noch vor ihrem Anschluss an die Sozialdemokratie von ihrer religiösen Herkunft. ${ }^{72}$ So verdeutlicht Susanne Miller, dass sich von den 13 jüdischen Reichstagsabgebordneten von 1912 nur fünf als Juden und acht als Dissidenten bekannten. ${ }^{73}$ Für Ernst Eckstein, einen Freund Siegfried Marcks, den Anführer der linken Breslauer Arbeiterschaft, Jude und Sozialdemokrat, lassen sich solche Schlüsse nicht ziehen, da es von ihm keine Zeugnisse religiöser Zugehörigkeit gibt. Wo andere Sozialdemokraten folglich die Grenze ihrer religiösen Identität überschritten, war es bei Siegfried Marck nur ein Überschreiten der politischen Grenzen, als er der nationalliberalen Partei den Rücken kehrte und sich der Sozialdemokratie anschloss.

Der jüdische Intellektuelle war Mitbegründer des Bundes freiheitlicher Sozialisten, gefördert durch die Rockefeller Foundation als Professor in Dijon und korrespondierte mit Thomas Mann, den er neben Goethe sehr verehrte. Später war er Gastdozent an der New York School for Social Research und Mitbegründer des Roosevelt Colleges in Chicago. Siegfried Marck war stets ein aufmerksamer Beobachter seiner Zeit, die er sowohl intellektuell als auch politisch aktiv mitzugestalten versuchte. Daneben wird es kaum einen Redner auf Breslauer und Pariser Bühnen gegeben haben, der neben Siegfried Marck so oft zu Wort kam - in Breslau mit Ausnahmen von Ernst Eckstein, Immanuel Birnbaum und nicht minder Clara Zils-Eckstein. Ihnen allen ist Siegfried Marck begegnet, er arbeitete mit ihnen zusammen, war mit ihnen befreundet, stritt und diskutierte über die Ausrichtung der

\footnotetext{
${ }^{69}$ Vgl. Hermand, Jost: Juden in der Kultur der Weimarer Republik, in: Grab, Walter/Schoeps, Julius H. (Hrsg.): Juden in der Weimarer Republik, Sachsenheim 1986, S. $17 \mathrm{f}$.

${ }^{70}$ Vgl. Reichmann-Jungmann, Eva: Der Centralverein deutscher Staatsbürger jüdischen Glaubens, in: Dies.: Größe und Verhängnis deutsch-jüdischer Existenz, Heidelberg 1974, S. $22 \mathrm{ff}$.

${ }^{71}$ Vgl. Breslauer Jüdisches Gemeindeblatt, Nr.7 (1926), S. 100.

72 Vgl. Miller, Susanne: Zur Haltung jüdischer Sozialdemokraten im Ersten Weltkrieg, in: Grab, Walter (Hrsg.) Juden und jüdische Aspekte in der deutschen Arbeiterbewegung 1848-1918, Tel-Aviv 1977, S. 229-247, hier S. 230.

${ }^{73}$ Vgl. ebd., S. 231.
} 
Sozialdemokratie - wie sie sich gegenseitig beeinflussten und welche Konfliktlinien sich zwischen diesen unterschiedlichen Charakteren aufzeigten, ist für den Verfasser ein spannendes und aufschlussreiches Unterfangen. Immerhin war Breslau seit Mitte der 1920er Jahre eine Hochburg des Linkssozialismus und Siegfried Marck mit seinen Weggefährten daran nicht unbeteiligt.

Dem übergeordnet ist es Siegried Marcks Denkmuster, lieber Gegensätze zu vereinen als sie zu entschärfen, welches den kritischen Dialektiker so interessant werden lässt. Dieses Muster lässt sich sein gesamtes politisches Leben hindurch beobachten, als Neukantianer genauso wie als radikaler Sozialist, Ehemann, Vater, Thomas-Mann- Verehrer oder Erwachsenenbildner. Ferner gab es in den Zwischenkriegsjahren nicht viele Sozialdemokraten, die sich so früh mit dem Entwurf eines Menschenbildes nach dem Ende des Nationalsozialismus in Deutschland befassten. ${ }^{74}$ Siegfried Marck war 1937 einer der ersten und ist auch bezüglich dieser Gedanken unerforscht. Inspiriert von Emmanuel Mounier befasste er sich schon in der Zwischenkriegszeit mit einem Neuen Humanismus, gar mit einem neuen Menschenbild, während diese Diskussion innerhalb der Nachkriegssozialdemokratie erst mit Alfred Weber und dem Ehepaar Mitscherlich eingeleitet wurde. $^{75}$

Wo bleibt folglich eine politische Biographie zu Siegfried Marck? Welches persönliche und berufliche Umfeld wirkte auf Siegfried Marck? Wie prägte dieser seine Umwelt? Welchen Nachklang hinterließ er bei den sozialistischen Studenten, den Jungsozialisten, überhaupt innerhalb der Erwachsenenbildung, der Sozialdemokratie und den intellektuellen Kreisen, in denen er sich bewegte? Welche Resonanz hatten seine Ideen für ein Nachkriegsdeutschland und was trieb ihn an? Diesen Fragen gilt es innerhalb dieser politischen Biographie nachzukommen.

Jürgen Mittag stellt die in dieser Arbeit auch berücksichtige Forderung auf, in der politischen Biographie Siegfried Marcks eine „stärker vergleichende und übergreifende Sichtweise anzustreben“ “ ${ }^{76}$ In der vorliegenden Arbeit bedeutet dies, wie es Mittag anregt, dass in der Beschreibung der politischen Biographie Siegfried

\footnotetext{
${ }^{74}$ Siehe hierzu: Grebing, Helga: Das Menschbild in der Sozialdemokratie nach dem Holocaust, in: Dies et al. (Hrsg.): Sozialdemokratie und Menschenbild. Historische Dimension und aktuelle Bedeutung, Marburg 2012, S. 133-154.

75 Ebd., S. 133f.

${ }^{76}$ Vgl. Mittag, Jürgen: Biografische Forschung und Arbeiterbewegung: Einleitende Anmerkungen, in: Mitteilungsblatt des Instituts für soziale Bewegungen. Biografische Ansätze zur Geschichte der Arbeiterbewegung im 20. Jahrhundert 45(2011), S. 5-21, hier S. 15.
} 
Marcks vergleichend auf die „Kenntnisse von Handlungsweisen in Konfliktsituationen, über Zwangslagen und Handlungsspielräume, über Kontinuitäten und Brüche“" eingegangen wird. ${ }^{77}$

In Breslau gab es hochpolitische Persönlichkeiten der ,zweiten und dritten Reihe“, wie den genannten Ernst Eckstein, Immanuel Birnbaum, Clara Zils-Eckstein und Max Tockus, die für die Sozialdemokratie arbeiteten und in Vergessenheit geraten sind, wenngleich sie den Humus der sozialdemokratischen Bewegung Breslaus in den 1920er Jahren bildeten. Diese können der politischen Biographie Siegfried Marcks in Teilen als Vergleichsfolie dienen. Deren Biographien weiter zu durchleuchten, in ihren Kontext zu stellen, sollte Aufgabe zukünftiger Forschungen sein.

Der Verfasser ist sich bewusst, dass es nicht „die eine“ politische Biographie geben kann, sondern dass diese Arbeit eine wissenschaftlich ausgelegte Sichtweise auf den Breslauer Intellektuellen darstellt. Überdies will diese Arbeit auch dazu beitragen, die Geschichte der Breslauer Sozialdemokratie in den 1920er Jahren erneut und mit neuen Quellen $\mathrm{zu}$ deuten. Einer Untersuchung der philosophiegeschichtlichen Wirkung Marcks kann an dieser Stelle nicht nachgegangen werden und obliegt weiteren Forschungen, obgleich dessen kritische Dialektikauffassung mit in die Ausarbeitung einfließen muss, um dessen Denkmuster - lieber Gegensätze in sich zu vereinen, als sie zu entschärfen - zu rekonstruieren. 


\section{Forschungsstand}

In der wissenschaftlichen Forschung spielt der Sozialdemokrat Marck bisher eine untergeordnete Rolle. Einen Nachruf, in dem vorwiegend auf seine philosophische Schule eingegangen wird, verfassten Theodor Litt und Wolfgang Ritzel in der Zeitschrift für philosophische Forschung. ${ }^{78}$ Eine erste inhaltlich geführte Auseinandersetzung mit Siegfried Marck führte 1983 Malte Wiedemeyer, der in seiner Dissertation Kritik an der Dialektikauffassung des Breslauer Philosophen übte. $^{79}$

Biographisch war es zuerst Helmut Hirsch, ein früherer Weggefährte und Freund Siegfried Marcks, der den Lebensweg des Philosophen, Soziologen und Sozialisten nachgezeichnet hat. Auch wenn es Hirsch weniger um das politische, als um das philosophische Moment in Siegfried Marcks Leben ging, konnte er dessen Lebensweg gewinnbringend nachzeichnen. Ein Blick in die jungen Jahre des Stadtverordneten, auf den Breslauer Erwachsenenbildner mit seinen Netzwerken und seinem Einfluss auf die Breslauer Sozialdemokratie fehlt jedoch. Ebenso fehlt eine genaue Einordnung Marcks in die Volksfrontbemühungen in Paris sowie dessen Wirken im sozialdemokratischen US-amerikanischen Exil. Gleichwohl geht Hirsch erstmals auf die Freundschaft zwischen Thomas Mann und Siegfried Marck ein. ${ }^{80}$

Interessant ist, dass mit Malte Wiedemeyer und Helmut Hirsch zwei Wissenschaftler gleichzeitig mit Arbeiten zu Siegfried Marck beschäftigt und miteinander im Austausch waren. Während Wiedemeyer in der DDR und an der Humboldt-Universität zu Marcks Dialektikauffassung forschte, reiste Helmut Hirsch mit einem Stipendium der Herzfeldstiftung In die USA. Von Seiten des in Frankfurt befindlichen Institut für Marxistische Studien und Forschungen, das eng mit den entscheidenden Stellen in der DDR zusammenarbeitete, war angedacht und ,initiiert“ worden, Wiedemeyer nach Deutschland einzuladen, um sich dort mit Hirsch auszutauschen. Eine Reise ohne Einladung in das „Nicht-Sozialistische Ausland“, wäre Wiedemeyer kaum möglich gewesen. Daher lockte er Hirsch telefonisch mit

\footnotetext{
${ }^{78}$ Litt, Theodor/Ritzel, Wolfgang: Siegfried Marck, ein Nachruf, in: Zeitschrift für philosophische Forschung, Jg. 11 (1957), S. 602-606.

79 Vgl. Wiedemeyer, Malte: Philosophie der Übergegensätzlichkeit: Eine Kritik der Dialektikauffassung des sozialdemokratischen Theoretikers Siegfried Marck (1889-1957), Berlin 1983.

${ }^{80}$ Vgl. Hirsch, Helmut: Siegfried Marck. Biographisches zur Wiederentdeckung des Philosophen, Soziologen und Sozialisten, in: Papcke, Sven (Hrsg.): Ordnung und Theorie. Beiträge zur Geschichte der Soziologie in Deutschland, Darmstadt 1986, S. 368-386. Ders.: Thomas Mann und Siegfried Marck im US-Exil. Neues zur Biographie, in: Hefte der deutschen Thomas-Mann-Gesellschaft, Heft 6/7 (1987), S. 70-86.
} 
Gestapo-Akten Marcks, die in seinem Besitz sein sollen, doch Hirsch zweifelte an Wiedemeyers Kooperationsabsicht. Für Hirsch wäre eine solche Zusammenarbeit mit Wiedemeyer, dessen Briefstil ihm allein schon unwürdig war, an einer Universität mit ihm zu debattieren, als „Melken des Fleißigen“ zu verstehen gewesen und er lehnte $a b .{ }^{81}$ Hirsch brach den Kontakt zu Winfried Schwarz ab, empfand dessen „Diktion als zu ungeschickt“ und wandte sich an dessen Vorgesetzen Josef Schleifstein. Hirsch selbst fuhr im Juni 1983 nach Ostberlin, um Wiedermeyer dort zu treffen und ihm Einsicht in seine Materialien zu geben. ${ }^{82}$ Für den Verfasser waren die genannten Gestapo-Akten nicht aufzufinden.

Daneben ist es besonders den Arbeiten Franz Walters gedankt, dass Siegfried Marck überhaupt zum Untersuchungsgegenstand wurde. Zuerst in seiner Promotionsschrift über den Weimarer Jungsozialismus wird Marck am Rand behandelt. ${ }^{83}$ Zwei Jahre später in einem Sammelband, zusammen mit Peter Lösche und Michael Scholing über Lebenswege Weimarer Sozialdemokraten herausgegeben, bildet der Göttinger Parteienforscher Marcks Lebensweg ab, jedoch ohne dabei tiefer auf dessen Wirken während des französischen und US-amerikanischen Exils oder auf die Freundschaft mit Thomas Mann einzugehen. ${ }^{84}$ Zudem behandelt Walter den Breslauer Philosophen immer wieder in kleineren Veröffentlichungen, ohne dabei neues und breiteres Quellenmaterial einzubeziehen. ${ }^{85}$

Einen weiteren biographischen Überblick bietet auch ein knapper Artikel von Hans-Holger Paul in der Neue[n] Deutsche[n] Biographie, der die wichtigsten Stationen und Veröffentlichungen Marcks nennt. ${ }^{86}$

Weiterhin taucht der Sozialdemokrat innerhalb wissenschaftlicher Studien als Randfigur auf. So bei Hanno Drechsler, der auf Marcks frühes Schriftgut zur

\footnotetext{
${ }^{81}$ Brief Winfried Schwarz an Helmut Hirsch, 11.11.1982, Hirsch an Schwarz, 13.11.1982, Schwarz an Hirsch, 30.11.1982, Hirsch an Schwarz, 19.12.1982, LBI NY NL Helmut Hirsch (folgend NL HH).

${ }^{82}$ Helmut Hirsch an Josef Schleifstein, 18.08.1983, NL HH.

${ }^{83}$ Vgl. Walter, Franz: Nationale Romantik, S. 149-157.

${ }^{84}$ Ders.: Siegfried Marck (1889-1957). Linkssozialist, Realpolitiker und Neuhumanist, in: Lösche, Peter et al. (Hrsg.): Vor dem Vergessen bewahren. Lebenswege Weimarer Sozialdemokraten, Berlin 1988, S. 251-280.

${ }^{85}$ Ders./Kümmel, Michael: Zwischen Kant und Hegel, zwischen Bürgertum und Arbeiterbewegung. Siegfried Marck zum 100. Geburtstag, in: Jahrbuch der Schlesischen Friedrich-Wilhelms-Universität zu Breslau, 1989, S. 185 ff.; Ders.: Vom Milieu zum Parteienstaat. Lebenswelten, Leitfiguren und Politik im historischen Wandel, Wiesbaden 2010, S. 22-29; Ders.: Kritische Dialektik, in: Frankfurter Allgemeine Zeitung, 02.03.2007; Ders.: „Republik, das ist nicht viel“. Partei und Jugend in der Krise des Weimarer Sozialismus, Bielefeld 2011, S. 279-286; Ders et al. (Hrsg.): Von der Emanzipation zur Meritokratie. Betrachtungen zur 150-jährigen Geschichte von Arbeiterbewegung, Linksintellektuellen und sozialer Demokratie, Göttingen 2013, S. $65 \mathrm{ff}$.

${ }^{86}$ Vgl. Paul, Hans-Holger: Marck, Siegfried, in: Neue Deutsche Biographie (NDB), Jg.16 (1990), S. 121-123.
} 
Sozialdemokratie und dessen Haltung zur Panzerkreuzerdebatte eingeht, wenn er die Abspaltung der Sozialistische[n] Arbeiterpartei Deutschlands (SAPD) untersucht. ${ }^{87}$ Innerhalb des französischen Exils ist es dann vor allem das Werk Ursula Langkau-Alex' über die Deutsche Volksfront, das Marck situativ thematisiert. ${ }^{88}$ Auch die Bedeutung seiner politischen Schriften, vor allem als Neuhumanist und seine Vorstellung eines neuen Menschenbildes, wurden bisher vernachlässigt und sind in den Publikationen nur angedeutet. ${ }^{89}$ Außerdem wurde bisher nicht auf die jüdische Identität Marcks und die besondere Bedeutung dieses Umstandes eingegangen. Selbiges gilt für Marcks Wirken im US-amerikanischen Exil, seine Gedanken zu einem Deutschland nach dem Nationalsozialismus und sein Wirken als Erwachsenenbildner in Chicago. ${ }^{90}$

Dem aktuellen Forschungsstand nach scheint es wirklich so, wie es Peter Lösche und Franz Walter befürchtet haben: Siegfried Marck wurde ,vergessen“ jedoch nur beinahe. Erst die Magisterarbeit des Verfassers dieses Promotionsvorhabens hat die politische Biographie Siegfried Marcks nachgezeichnet. Dabei konnte freilich nicht auf alle Aspekte eingegangen werden, obgleich die Struktur der Arbeit auch alle drei Kulturkreise des Breslauer Sozialdemokraten berücksichtigt. Dem Füllen dieser Forschungslücke wird nun nachgekommen.

\footnotetext{
${ }^{87}$ Vgl. Drechsler, Hanno: Die Sozialistische Arbeiterpartei Deutschlands (SADP). Ein Beitrag zur Geschichte der deutschen Arbeiterbewegung am Ende der Weimarer Republik, Meisenheim am Glan 1965 , S. 32ff

${ }^{88}$ Langkau-Alex, Ursula: Deutsche Volksfront 1932-1939. Zwischen Berlin, Paris, Prag und Moskau, Band 1: Vorgeschichte und Gründung des Ausschusses zur Vorbereitung einer deutschen Volksfront, Berlin 2004; Dies.: Deutsche Volksfront 1932-1939. Zwischen Berlin, Paris, Prag und Moskau. Band 2: Geschichte des Ausschusses zur Vorbereitung einer deutschen Volksfront, Berlin 2004; Dies.: Deutsche Volksfront 1932-1939. Zwischen Berlin, Paris, Prag und Moskau, Band 3: Dokumente, Chronik und Verzeichnisse, Berlin 2005.

89 Vgl. Llanque, Markus: Siegfried Marck und der Neuhumanismus als französisch-deutsche Sammlungsbewegung, in: Alfons Söllner (Hrsg.): Deutsche Frankreich-Bücher aus der Zwischenkriegszeit, Baden-Baden 2011, S. 273-293.

${ }^{90}$ Vgl. Stampfer, Friedrich: Mit dem Gesicht nach Deutschland. Eine Dokumentation über die sozialdemokratische Emigration. Aus dem Nachlass von Friedrich Stampfer, ergänzt durch andere Überlieferungen, herausgegeben von Erich Matthias und bearbeitet von Werner Link, Düsseldorf 1968; Radkau, Joachim: Die deutsche Emigration in den USA. Ihr Einfluß auf die amerikanische Europapolitik 1933-1945, Düsseldorf 1971; Krohn, Claus-Dieter: Wissenschaft im Exil. Deutsche Sozial- und Wirtschaftswissenschaftler in den USA und die New School for Social Research, Frankfurt am Main 1987; Ders.: Der Council for a Democratic Germany, in: Langkau-Alex, Ursula et al. (Hrsg.): Was soll aus Deutschland werden? Der Council for a Democratic Germany in New York 1944-1945. Aufsätze und Dokumente, S. 17-49; Wittebur, Klemens: Die deutsche Soziologie im Exil 1933-1945. Eine biographische Kartographie, Hamburg 1991; Schilmar, Boris: Der Europadiskurs im deutschen Exil 1933-1945, München 2004.
} 


\section{Quellenlage und -auswahl}

Emigranten reisen mit wenig Gepäck und so sind Unterlagen zu Siegfried Marck, der in drei verschiedenen Kulturkreisen - dem deutschen, dem französischen und dem US-amerikanischen - seine Heimat finden sollte, weit verstreut zu finden. Es verwundert daher nicht, dass ein einzelner und umfassender Nachlass Marcks nicht existiert; während andere Nachlässe sozialdemokratischer Provenienz gebündelt und meist in einem einzigen Archiv gelagert anzutreffen sind, sind Aktenmaterialien, Briefe und andere persönliche Dokumente Siegfried Marcks in mannigfachen Archiven in Europa und den USA einzusehen, oftmals nur in vereinzelter Stückzahl. Lediglich ein kleiner Teil seines Nachlasses aus den Jahren der amerikanischen Emigration zwischen 1939 und 1957 ist im Grenander Department of Special Collections and Archives an der University at Albany in New York zu finden. Dieser beinhaltet neben persönlichen Urkunden vor allem Wiedergutmachungskorrespondenz mit der Bundesrepublik Deutschland, sowie einen Briefwechsel zwischen den Anwälten nach der geschiedenen Ehe mit Kläre Marck. Zudem ist dort die Korrespondenz Frederik Apts (Sohn aus der dritten Ehe mit Ilse Apt) mit der geschäftsführenden Leitung der Thomas-Mann-Sammlung über die Veräußerung der Briefe Siegfried Marcks an Thomas Mann vorhanden. Daneben sind dort einige Manuskripte Marcks, die Traueransprachen der Beerdigungsfeier und einige Fotos aus den USA aufzufinden. Im selben Archiv ist es möglich, Einblick in Briefwechsel mit Marcks Freunden Walter Friedländer, Carl Misch und Karl O. Paetel zu erhalten, die in diese Arbeit mit eingeflossen sind und informative Zeugnisse seines Lebens in den USA bilden.

Das soll im Umkehrschluss nicht bedeuten, dass nicht genügend Material zum Verfassen einer politischen Biographie Siegfried Marcks vorhanden wäre - es war lediglich mühsamer und bedurfte großen Geschicks im Umgang mit ausländischen Archiven die nötigen Unterlagen zu sichten, aufzuschlüsseln, zu kategorisieren und in die Biographie Marcks einzuarbeiten.

Siegfried Marck bestritt sein Leben in den drei bereits oben genannten Kulturkreisen. Deshalb erschien es naheliegend, die Gliederung der Arbeit an diesen und seinen politischen und biographischen Brüchen zu orientieren: Um Siegfried Marcks persönliches Umfeld, seine Familiengeschichte und seinen politischen Grenzgang aufzeigen zu können, waren es besonders die „Briefe aus dem Feld“ aus dem Deutschen Literaturarchiv in Marbach, die einen eindrucksvollen Einblick in 
das Gefühlsleben Siegfried Marcks in jenen Jahren ermöglichten. Diese sind in den Nachlässen Lola Landaus und Armin T. Wegners einzusehen. Zudem dienten auch biographische und autobiographische Arbeiten über oder von Lola Landau dazu, ihren ersten Ehemann Siegfried Marck besser in dessen Gedankenwelt zu verorten. Der Briefwechsel zwischen ihm und seiner ersten Ehefrau Lola und nicht minder der zwischen Marck und Armin Theophil Wegner, diente ebenfalls dazu, die familiären Konstellationen nach der Scheidung der Eheleute Marck bis heute zu verstehen. Dazu zählen auch Briefe Kläre Marcks, der zweiten Ehefrau Siegfrieds, neben einigen Zeugnissen der Mutter Rosa und seiner Kinder Alfons, Andreas, Louis und Claudia, die in Marbach eingesehen wurden. Ferner existieren im Leo-Baeck-Institut in New York einige Fotos der Familie Marck sowie ein Familienstammbaum.

Überdies sind dort die Nachlässe Kurt Schwerins und Helmut Hirschs, zweier Weggefährten Marcks, einzusehen. Außerdem war es dem Verfasser möglich, durch Kontaktaufnahme mit Familienangehörigen einen weiteren Stammbaum zu erhalten, der die Familienzusammenstellung historisch noch weitreichender aufzeigen kann. Der Kontakt mit Familienangehörigen der Enkelgeneration erstreckte sich von Israel über Großbritannien bis Deutschland und konnte dem Verfasser nur in Teilen gewinnbringend weiterhelfen. Die Enkel wussten über ihren Großvater nahezu nichts und es wurde ohnehin sehr schnell deutlich, wie das Familiengedächtnis gerne auf Siegfried Marck verzichtet hätte und man sich von ihm distanzierte.

Um Siegfried Marcks Wirken innerhalb Breslaus nach dem Ersten Weltkrieg einordnen $\mathrm{zu}$ können, bot sich für intensive Studien vor allem die Breslauer Volkswacht an. Bereits Franz Walter konstatiert in seiner Promotionsschrift über den Weimarer Jungsozialismus, dass „es wohl eher die Regel als die Ausnahme [sei], dass die Historiker vor der Auswertung von Tageszeitungen zurückschrecken“, bedauert dies und bemerkt, dass diese Studien ,ausgesprochen zeitaufwendig und höchst mühselig“ sind. Diese Ausführungen kann der Verfasser teilen und möchte Franz Walter folgend festhalten, dass „eine systematische Analyse von Tageszeitungen [...] Einsichten in langfristige Abläufe, Zusammenhänge, Verflechtungen, Trendverschiebungen und Stimmungswechsel, die sich über Aktenbestände kaum erfassen lassen" möglich macht. ${ }^{91}$ Anhand dieser war es auch möglich, einen tieferen Blick in das sozialdemokratische Milieu Breslaus, in die Richtungskämpfe und Tagespolitik zu werfen. Als besonders geeignet erweist sich diese Quelle auch deshalb, da sie nahezu protokollartig die Inhalte sämtlicher

\footnotetext{
${ }^{91}$ Walter, Franz: Nationale Romantik, S. 10.
} 
Sitzungen und Ausschüsse des Breslauer Sozialdemokratischen Vereins, der Stadtverordnetenversammlung, von Gastvorträgen und auch Gerichtsverhandlungen wiedergibt. Ferner war die Volkswacht das sozialdemokratische Leitmedium im Breslau jener Jahre, in dem auch die Protagonisten um Siegfried Marck und er selbst schrieben und in dem die aktuellen politischen Debatten auf Reichsebene wiedergegeben wurden. Auch die vielen dort nachzulesenden Berichte $\mathrm{zu}$ den Aktivitäten der Breslauer Jungsozialisten waren hilfreich, Marcks Wirkung auf eben jene zu verdeutlichen. Es war so auch möglich, den „Klüngel“ um die Breslauer Volkswacht zu untersuchen. Informationen zu Ernst Eckstein, Immanuel Birnbaum, Clara Zils und Max Tockus konnten vor allem aus lexikalischen Artikeln, der Breslauer Volkswacht selbst und vereinzelter Sekundärliteratur entnommen werden.

Daneben sind es vor allem die Blätter der Volkshochschule Breslau, das Breslauer Jüdische Gemeindeblatt, die Zeitschrift Kunst und Volk - Monatshefte der Breslauer Volksbühne oder die Jüdisch-Liberale Zeitung, in denen Marck selbst schrieb, desweiteren bietet deren allgemeiner Inhalt einen Einblick in das jüdische und kulturelle Gemeindeleben Breslaus und zeigt zugleich Marcks Tätigkeiten in der Erwachsenenbildung. Um Marcks Brüche, aber auch dessen politische Stoßrichtungen aufzuzeigen und nachvollziehen zu können, wird an dieser Stelle freilich auch auf Marcks politisches Schriftgut eingegangen.

Daneben fließt Material aus dem Geheimen Staatsarchiv Preußischer Kulturbesitz, dem Universitätsarchiv Wroclaw, der Staatsbibliothek Berlin, der Stadtbibliothek Wuppertal, dem Salomon-Ludwig-Steinheim-Institut für DeutschJüdische Geschichte und dem Literaturarchiv Sulzbach-Rosenberg in die Ausarbeitung Siegfried Marcks Breslauer Jahre mit ein. Dazu existieren eine Vielzahl von Memoiren, biographischen Arbeiten und Studien, die mit in diese Arbeit eingeflochten sind. Auch ist das Portal zur Geschichte der Arbeiterbewegung der Friedrich-Ebert-Stiftung hervorzuheben, das eine große Anzahl an Dokumenten der Breslauer Sozialdemokratie online bereitstellt. All dies wird, neben den Standardwerken zur Geschichte der Sozialdemokratie in Breslau sowie zur Geschichte des Breslauer Judentums, bei der Bearbeitung neben den bereits geleisteten wissenschaftlichen Forschungen zu Siegfried Marck berücksichtigt.

Im französischen Exil sind es dann vor allem die Pariser Tageszeitung, die Neue Weltbühne, Die Zukunft sowie das Neue-Tagebuch, die der Arbeit als Quellenmaterial dienen. Auch hier veröffentlichten Marck und sein intellektuelles 
Umfeld. Hinzukommen Briefwechsel etwa mit Lion Feuchtwanger, Heinrich und Thomas Mann, Manfred George oder Max Barth. Diese werden aus dem Thomas Mann Archiv, dem Deutschen Literaturarchiv, aus dem Exilarchiv der Deutschen Nationalbibliothek sowie aus dem Bundesarchiv herangezogen und eingearbeitet. Überdies sind es auch hier - neben den politischen Schriften Marcks selbst - die Standardwerke zur französischen Exilgeschichte und zur deutschen Volksfront, die in die Ausarbeitung verwoben.

Für die genauere Untersuchung des Lebensweges des Breslauer Sozialdemokraten im US-amerikanischen Exil waren es auch dort die sozialdemokratischen Leitmedien, wie die Neue Volkszeitung oder das jüdische Monatsmagazin Der Aufbau, die ein Verständnis der politischen Haltung Siegfried Marcks ermöglichten. Des Weiteren existieren diverse Briefwechsel mit Paul Tillich und der German Labour Delegation, einzusehen in der Harvard University Library, die für die Ausarbeitung beschafft werden konnten. Daneben wurden Briefwechsel mit Helmut Hirsch, Walter Friedländer, Max Horkheimer, Thomas Mann und anderen Vertretern von bedeutender Provenienz eingearbeitet. Für das Verfassen der politischen Biographie Siegfried Marcks stand somit eine Vielzahl von Dokumenten in Form von Zeitungsartikeln, Biographien und Autobiographien, Briefen und Handschriften, Manifesten, politischen Schriften und Sekundärliteratur zur Verfügung. 


\section{Zur biographischen Methode und deren Umsetzung}

„Die deutsche Geschichtswissenschaft hat auf breiter Front die Biographie wiederentdeckt; ja man ist sogar geneigt, geradezu von einem biographischen Boom in der Historie zu sprechen" stellte Wolfram Pyta 2009 fest. ${ }^{92}$ Galt die Biographie innerhalb der Geschichtswissenschaft besonders in den 1970er und 1980er Jahren als atavistische Form der geschichtswissenschaftlichen Forschung und wurde unter dem Generalverdacht des Historismus gar verlacht, mehr noch als ,akademischer Selbstmord“93 bezeichnet, so hat sich diese Entwicklung geändert. ${ }^{94}$ War der Hauptkritikpunkt einst, dass einzelne Personen als autonome Subjekte und aus dem sozialen Kontext gelöst beschrieben wurden, so ist nach Margit Szöllösi-Janze „die Schlacht um die Biographie im Grunde längst geschlagen“. Ohnehin habe „keiner der Kombattanten je behauptet, dass sich individuelles Handeln vollständig aus sozioökonomischen Strukturen ableiten lässt, und umgekehrt vertritt auch niemand ernsthaft die Überzeugung, dass das Individuum ohne Gesellschaft überhaupt denkbar ist ${ }^{\star}{ }^{\circ 95}$.

Mit dieser Entwicklung löste sich die Geschichtswissenschaft von dem „Gewicht sozialwissenschaftlicher Orientierungen“, dem es vorher unter dem Einfluss der Sozial- und Strukturhistoriker ausgesetzt war. Jene wehrten sich gegen die „Reduktion der Geschichte auf das Denken und Wirken von Individuen“, sodass sich in jenen Jahrzehnten lediglich Kollektiv- und Typenbiographien behaupten konnten. ${ }^{96}$ Einen Weg zurück zum Bild des Menschen, wie ihn Norbert Elias historistisch als ein Lebewesen in „einer kleinen Welt für sich, die letzten Endes ganz unabhängig von der großen Welt außerhalb seiner existiert ${ }^{\star 97}$ beschreibt, ist vorerst nicht denkbar.

\footnotetext{
92 Pyta, Wolfram: Geschichtswissenschaft, in: Klein, Christian (Hrsg.): Handbuch Biographie. Methoden, Traditionen, Theorien, Stuttgart 2009, S. 331-339, hier S. 331.

${ }^{93}$ Vgl. Baier, Deirdre: Die Biographie ist akademischer Selbstmord, in: Literaturen 7/8 (2001), S. $38 \mathrm{f}$.

94 Allgemein zur Diskussion siehe: Gestrich, Andreas: Einleitung: Sozialhistorische Biographieforschung, in: Ders. (Hrsg.): Biographie zeitgeschichtlich. 7 Beiträge, Göttingen 1988, S. 5-28; Szöllösi-Janze, Margit: Lebens-Geschichte - Wissenschafts-Geschichte. Vom Nutzen der Biographie für Geschichtswissenschaft und Wissenschaftsgeschichte, in: Berichte zur Wissenschaftsgeschichte 23 (2000) S. 17-35.

${ }^{95}$ Szöllösi-Janze, Margit: Fritz Haber 1868-1934. Eine Biographie, München 1998, S. 12.

${ }^{96}$ Vgl. Bödeker, Hans Erich (Hrsg.): Biographie schreiben, Göttingen 2003, S. $12 \mathrm{f}$.

97 Elias, Norbert: Über den Prozess der Zivilisation. Soziogenetische und psychogenetische Untersuchungen, Band I, Frankfurt am Main 1978, S. IL.
} 
Dennoch muss in diesem Zusammenhang gesehen werden, dass es vor allem die Kritiker wissenschaftlich biographischer Arbeiten waren, die der Biographieforschung wieder wichtige Impulse verliehen haben.

In der Zeit zwischen den beiden Weltkriegen gab Siegfried Kracauer wertvolle Anregungen für die Biographieforschung. Er übte Kritik an der Individualbiographie, die er als „,neubürgerliche Kunstform“ beschrieb. ${ }^{98}$ Für Kracauer verlor die Biographie in den Zwischenkriegsjahren „das seltene Werk der Gelehrsamkeit“ und rutschte in „ein verbreitetes literarisches Zeugnis“. 99 Dabei verstand Kracauer die Aufgabe der Biographie jener Jahre innerhalb des Bürgertums als die „scheinbar notwendige Prosaform“ im „Chaos der gegenwärtigen Kunstübungen“ und folgerte, dass es jenes „stabilisierte Bürgertum“ war, das sich letztlich gezwungen sah, ,allen Erkenntnissen und Formenproblemen, die seinen Bestand gefährden“, aus dem Weg zu gehen. ${ }^{100}$ Kracauer, in der Vorhersicht der Auflösung des Bürgertums und des Individualismus, formulierte weiter:

„Die Biographie als Form der neubürgerlichen Literatur ist ein Zeichen von Flucht; genauer:
der Ausflucht. Um sich nicht durch Erkenntnisse bloßzustellen, die das Dasein der
Bourgeoisie in Frage ziehen, harren die Biographen unter den Schriftstellern wie vor einer
Wand an der Schwelle, bis zu der sie von den Weltereignissen vorangetrieben worden
sind.“101 Mit diesen Ausführungen regte Kracauer an, dass die Biographie innerhalb der Geschichtsschreibung nur dann eine weitere Existenz haben würde, wenn sie sich von einer Individual- zu einer Gesellschaftsbiographie wandeln würde. Kracauer war auch einer der wenigen, der seiner Kritik fruchtbare Taten folgen ließ, indem er 1937 mit einem Werk über Jacques Offenbach eine Gesellschaftsbiographie verfasste. ${ }^{102}$

Pierre Bourdieu beanstandete an dem Begriff der Biographie, mehr noch an dem der Lebensgeschichte, dass dieser „sich in das wissenschaftliche Universum eingeschmuggelt" habe. Dieser, bedacht auf Chronologie oder vielmehr auf eine reine „Abfolge von historischen Ereignissen“, versuche der Existenz einer Persönlichkeit eine Sinnhaftigkeit zu geben. Für den Gesellschaftsdiagnostiker Bourdieu war allein der Versuch eine Lebensgeschichte als eine einmalige und sich selbst genügende Abfolge von Ereignissen $\mathrm{zu}$ verstehen, „deren einziger Zusammenhang in der Verbindung mit einem Subjekt besteht", gleichzusetzen mit

\footnotetext{
${ }^{98}$ Vgl. Kracauer, Siegfried: Die Biographie als neubürgerliche Kunstform, in: Ders.: Das Ornament der Masse, Essays, Frankfurt am Main 1977, S. 75-81.

${ }^{99}$ Vgl. ebd., S. $75 f$.

${ }^{100}$ Vgl. ebd., S. 77.

${ }^{101}$ Ebd., S. 78.

102 Ders.: Jacques Offenbach und das Paris seiner Zeit, Amsterdam 1937.
} 
dem Versuch, die „Fahrt mit einer U-Bahn zu erklären, ohne die Struktur des Netzes zu berücksichtigen“. ${ }^{103}$ Für Bourdieu war das Interesse an Biographien von einer „biographischen Illusion“ geprägt, denn:

„In gewisser Weise besteht beim Subjekt wie beim Objekt der Biographie (beim Interviewer und beim Befragten) das gleiche Interesse, das Postulat des Sinns der - erzählten und implizit jeder - jeder Existenz anzuerkennen. “"

Als Ausweg wollte Bourdieu biographische Arbeiten nicht mehr chronologisch, sondern systematisch sortiert und verfasst wissen, um die verschiedenen Identitäten einer Person konkreter fassen zu können, was wiederum zu Kritik führte. ${ }^{105}$ Dennoch ist der große Gewinn der Überlegungen Bourdieus für die Biographieforschung vor allem in seinen Überlegungen zum Habitus zu sehen. Kaum eine wissenschaftliche Biographie geht nicht auf die Gedanken Bourdieus ein. Dabei wird immer deutlicher, dass ein biographiertes Leben nur im Zusammenspiel mit seinen spezifischen Anforderungen und Bedingungen des Feldes, folglich dem Habitus, zu verstehen ist. $^{106}$

Diese Weiterentwicklung dauert an; biographische Arbeiten erfreuen sich immer größerer Beliebtheit. Der Stuttgarter Historiker Wolfram Pyta fragt, weshalb sich die Biographie, auch als wissenschaftliche Qualifikationsschrift, seit den vergangenen 30 Jahren so in der Geschichtswissenschaft etabliert hat und macht dafür drei Hauptursachen ausfindig: Sie füge sich zum einen bestens in die in der Geschichtswissenschaft vorherrschende hermeneutische Grundauffassung ein, eine gewisse Theorieferne gereiche ihr zum anderen forschungspragmatisch zum Vorteil. Zudem habe sie die an sie gestellten Herausforderungen der Sozialgeschichte verarbeitet und aus der Kulturgeschichte weiteren Vorschub erhalten. ${ }^{107}$

Dabei ist es für das Gelingen gewinnbringender biographischer Arbeiten unabdingbar, durch eine kreative Fragestellung die zur Verfügung stehenden Mittel in geschichtswissenschaftliche Erkenntnis umzusetzen. Vielmehr noch, das dazu nötige retrospektivische Auswerten und das ,phantasievolle Aufschließen der

\footnotetext{
103 Bourdieu, Pierre: Die biographische Illusion, in: Ders.: Praktische Vernunft, zur Theorie des Handelns, Frankfurt am Main 1998, S. 75-83. Das erste Mal aus dem Französischen übersetzt und erschienen sind diese Ausführungen in der Zeitschrift BIOS, vgl. Bourdieu, Pierre: Die biographische Illussion, in: BIOS, Zeitschrift für Biographieforschung und Oral History 3 (1990), S. 75-88.

${ }^{104}$ Ebd., S.76.

${ }^{105}$ Etwa: Niethammer, Lutz: Kommentar zu Pierre Bourdieu. Die biographische Illusion, in BIOS 3 (1990) Heft 1, S. 91-93.

${ }^{106}$ Zum Habitus siehe: Bourdieu, Pierre: Der Habitus als Vermittlung zwischen Struktur und Praxis, in: Ders.: Soziologie der symbolischen Formen, Frankfurt am Main 1974, S. 125-158.

${ }^{107}$ Pyta, Wolfram: Geschichtswissenschaft, S. 331.
} 
Quellen“ 108 hat sich innerhalb der Geschichtswissenschaft etabliert. Die Legitimationsprobleme biographischer Arbeiten erwiesen sich laut Pyta als obsolet, denn: „Von einem hermeneutischen Standpunkt aus betrachtet, ist der biographische Entwurf des Lebens einer Person genauso legitim wie jede auf einen anderen historischen Gegenstand übertragene Sinnstiftung“. Dabei ist die Rolle des biographischen Zugriffs innerhalb der geschichtswissenschaftlichen Forschung eine besonders anspruchsvolle Aufgabe für den Biographen, die vor allem mit einem besonderen Talent im erzählerischen Schreiben einhergehen muss. ${ }^{109}$

Letztlich ist nicht mehr von der Hand zu weisen, dass sich ein Wandel innerhalb der Biographieforschung vollzogen hat. In heutigen wissenschaftlichen Qualifikationsschriften geht es nicht mehr darum, die untersuchte Persönlichkeit in seiner Einzelheit zu sehen, sondern vielmehr um eine systematische Analyse der Beziehungen dieser Person, mit ihren Lebenswelten, ihrer Prägung durch und auf die Familie und den Einfluss des Milieus:

„Die neue, reflektierte Biographie begreift den untersuchten Menschen zwar als ein einzigartiges, moralisch gesprochen autonomes, historisches Individuum, doch zuletzt begreift sie ihn als Teil seiner historischen Lebenswelten. Die untersuchte Person steht nicht mehr länger für sich selbst, sondern wird vielmehr als Teil einer Sozialgruppe interpretiert. “ 110

Nichtsdestoweniger gibt es enorme Herausforderungen, denen sich ein Biograph stellen muss. Eine Hauptaugenmerk wissenschaftlichen Biographierens besteht in der richtigen Umsetzung der Biographischen Trias: Untersuchungsgegenstand, Gesellschaft und Werk müssen dabei angemessen analysiert, zueinander in Beziehung gesetzt und bewertet werden. Dabei stehen diese in keinem hierarchischen Verhältnis, sondern vielmehr in einer Reziprozität. ${ }^{111}$

Eine gewisse Theorieabstinenz gedeiht genau dann zum Vorteil, wenn beim kreativen Zusammensetzen der einzelnen Fragmente ein produktiver Elektizismus zum Tragen kommt. Ferner verlockt sie dazu, multiperspektivische Zugänge zum Untersuchungsgegenstand $\mathrm{zu}$ wählen, was die Ergebnisse besonders fruchtbar macht. $^{112}$

\footnotetext{
${ }^{108}$ Vgl. Fried, Johannes: Wissenschaft und Phantasie. Das Beispiel der Geschichte, in: Historische Zeitschrift 263 (1996), S. 291-316.

${ }^{109}$ Pyta, Wolfram: Geschichtswissenschaft, S. 332.

${ }^{110}$ Bödeker, Hans Erich (Hrsg.): Biographie schreiben, S. 20.

111 Vgl. Klein, Christian: Grundfragen biographischen Schreibens, in: Ders. (Hrsg.): Handbuch Biographie. Methoden, Traditionen, Theorien, Stuttgart 2009, S. 424-428, hier S. 426.

112 Pyta, Wolfram: Geschichtswissenschaft, S. 332.
} 
Hans Erich Bödeker stellt weiter fest, dass sich das Erkenntnisinteresse der „,neuen Biographik“ nicht mehr nur auf die Größe und Bedeutsamkeit einer zu untersuchenden Person beschränken muss, sondern vielmehr nun auch Biographien untersucht werden, die zuvor nicht für untersuchungswürdig gehalten wurden. ${ }^{113}$ Für Bödeker ist die „Renaissance der Biographie“ eine Entwicklung, der er in Zukunft viel Erkenntnisgewinn zuschreibt. ${ }^{114}$ Der Einfluss der Biographie litt innerhalb der Geschichtswissenschaft einst unter dem Aufkeimen der Sozial- und Strukturhistoriker, da ihr der Anschluss an die Theoriediskussion missgönnt war und sie förmlich als ,letzte Auffangstellung des deutschen Historismus“"115 galt.

Dabei sind es insbesondere politische Biographien, oftmals bereits verstorbener Persönlichkeiten des öffentlichen Lebens, die in den Fokus des wissenschaftlichen Nachwuchses gerückt sind, der mit unterschiedlichsten Methoden versuchen will, die politischen Entwicklungen, Brüche und Kontinuitäten des Untersuchungsgegenstandes aufzuzeigen. Anders als vor 30 Jahren sieht die heutige Biographieforschung ihre Aufgabe nicht in der linearen Abhandlung eines Lebens, das eine gewisse Vorherbestimmung erfahren und keine $\mathrm{zu}$ berücksichtigenden Brüche durchlebt hat.

Politische Biographien, insbesondere sozialdemokratische Biographien, die sich mit Personen aus der Arbeiterbewegung auseinandersetzen, sollten nach Volker Depkat zukünftig die Biographieforschung als Sozialisationsforschung begreifen und die „soziobiographische Entschlüsselung“"116, folglich die Fragen nach Herkunft, Generation und Milieu um die Kategorie der „Entscheidung“ erweitern. Es bedarf mehr ,als eine Biografieforschung, die in der Einzelperson mehr sieht als bloß die Konkretisierung des Abstrakten“, es geht vielmehr um eine „Binnendifferenzierung“ innerhalb eines Milieus, einer Generation und letztlich um das Aufzeigen von Möglichkeiten. ${ }^{117}$ Depkat argumentiert weiter, dass die Entscheidung als Schnittstelle zwischen einer Einzelperson und einem Kollektiv zu sehen sei, die besonders untermalt, weshalb ein historisches Individuum in einer bestimmten Situation eine bewusste Entscheidung getroffen habe, aus welchen vorangegangenen Entscheidungen diese sich entwickelt habe und letztlich welche weiteren daraus

\footnotetext{
${ }^{113}$ Bödeker, Hans Erich (Hrsg.): Biographie schreiben, S. 23.

${ }^{114}$ Ebd., S. 12.

115 Oelker, Jürgen: Biographik - Überlegungen zu einer unschuldigen Gattung, in: Neue Politische Literatur 3 (1974), S. 296-309, hier S. 299.

${ }^{116}$ Vgl. Lösche, Peter et al. (Hrsg.): Vor dem Vergessen bewahren. S. 9.

117 Vgl. Depkat, Volker: Zum Ort der Biografik in der Arbeitergeschichtsschreibung, in: Mitteilungsblatt des Instituts für soziale Bewegungen. Biografische Ansätze zur Geschichte der Arbeiterbewegung im 20. Jahrhundert 45(2011), S. 21-37, hier S. 34.
} 
resultierten. Somit zeigt sich eine Entwicklung der zu untersuchenden politischen Identität, die „eben nicht von vornherein gegeben“ sei, sondern durch die „,in historischen Kontexten getroffenen individuellen Entscheidungen“ entstehe. ${ }^{118}$

Helga Grebing verdeutlicht, dass biographische Arbeiten auch immer Aufschluss über den Autor selbst geben, dessen subjektive Sichtweise der Dinge einen besonderen Bestandteil der Interpretation bildet. Dieses bietet nach Grebing die Möglichkeit „,zu vertiefender Empathie gegenüber dem zu Betrachtenden“ und „bildet oft die Grundlage für das Ausmaß der Plausibilität der Forschungsergebnisse“ und steht somit nicht im Widerspruch zur historischen Wahrheit. Dabei ist für Grebing „die Wahrheit“ etwas, das letztlich verborgen bleibt. ${ }^{119}$ Dieser Gedanke der Sozialhistorikerin zum Umgang mit Geschichte wird vom Verfasser dieser Arbeit geteilt. Auch er hält es nicht für möglich, eine Biographie losgelöst von seinen eigenen Interpretationen und Empfindungen $\mathrm{zu}$ verfassen. Dennoch: Bei der Auswertung der Quellen und dem Verknüpfen und Verfassen der Biographie muss Folgendes beachtet werden:

„Der Biograph darf weder den Selbstbeschreibungen, noch den Zuschreibungen, noch den Verarbeitungen des biographischen Sujets durch spätere Generationen trauen. Er muss sie als zeitbedingte Interpretationen im politischen und gesellschaftlichen Kontext analysieren, um sich einer nicht unbedingt gradlinig und sinnvoll verlaufenden Biographie annähern zu können." “120

Für die Umsetzung dieses Forschungsvorhabens ist es notwendig, einen einzelbiographischen Ansatz zu wählen. Dennoch soll es hierbei nicht darum gehen, die Geistes- oder Ideenwelt einer einzelnen Persönlichkeit aufzuzeigen, sondern die Erfassung größerer historischer Zusammenhänge im „Brennsiegel eines Individuums“"121, wie es Dilthey formuliert. Er sieht ein Individuum ,als Kreuzungspunkt für Kultursysteme, Organisationen, in die sein Dasein verwoben

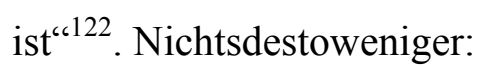

„Eine reflektierte historische Hermeneutik muss jedoch - über Dilthey hinausgehend - jede phänomenologische Engführung vermeiden und der Illusion begegnen, der historische Akteur würde diejenigen Bedeutungen generieren, die er seinem Handeln unterlegt. “" ${ }^{123}$

\footnotetext{
${ }^{118}$ Vgl. ebd., S. 35.

119 Vgl. Grebing, Helga: Die Rezeption Friedrich Eberts im Wandel: Historiografische und persönliche Rückblicke, in: Mitteilungsblatt des Instituts für soziale Bewegungen. Biografische Ansätze zur Geschichte der Arbeiterbewegung im 20. Jahrhundert 45(2011), S. 153-163, hier, S. 153.

${ }^{120}$ Bödeker, Hans Erich (Hrsg.): Biographie schreiben, S. 37.

121 Vgl. Kraus, Hans-Christof: Geschichte als Lebensgeschichte. Gegenwart und Zukunft der politischen Biographie, in: Ders. (Hrsg.): Geschichte der Politik. Alte und neue Wege, München 2007, S. 311-333, hier S. 326.

${ }^{122}$ Dilthey, Wilhelm: Der Aufbau der geschichtlichen Welt in den Geisteswissenschaften, 7. Auflage, Göttingen, 1979, S. 251.

${ }^{123}$ Pyta, Wolfram: Geschichtswissenschaft, S. 332.
} 
Daher besteht das vorrangige Ziel dieser Arbeit darin, biographische Facetten Marcks mit den historischen, den politischen, sozialen und ökonomischen Gegebenheiten $\mathrm{zu}$ verbinden. ${ }^{124}$ Beinahe alle bedeutenden biographischen Arbeiten bedienen sich dieses Grundsatzes Diltheys von 1981, der bewusst auf eine breite theoretische Untermauerung verzichtet. Dieses Verfahren ist genau aus diesem Grund zum Gemeingut historischer Biographien geworden, wie Wolfram Pyta folgerichtig bemerkt. ${ }^{125}$ Es geht bei Biographien nicht um die großen Thesen, sondern um ein dichtes Gewebe von Verknüpfungen, wie es seinerzeit Lothar Gall in seiner Bismarck-Biographie in der deutschen Geschichtswissenschaft etablierte. ${ }^{126}$

Diese Arbeit über Siegfried Marck soll zum einen eine strikte Analyse der geschichtlichen Wirkungszusammenhänge zwischen ihm und der Gesellschaft sein, zum anderen eine Untersuchung seiner unterschiedlichen Möglichkeiten von „Lebensführung“ und nicht minder eine kritische Rekonstruktion - auch der Brüche und Unebenheiten - des Breslauer Sozialdemokraten. Außerdem soll die Arbeit eine genauere Eingrenzung und Bestimmung seines Handlungsspielraumes an bestimmten Zeiten und Orten aufzeigen. ${ }^{127}$

Ferner muss bei dem jüdischen Intellektuellen die Frage nach der Bedeutung seiner jüdischen Identität in seiner Lebenswelt gestellt werden, gerade weil der Verfasser bei Siegfried Marck von einer „nichtidentischen Identität“"128 ausgeht. Demnach bedeutet Jude oder jüdisch sein nicht uneingeschränkt das Bekenntnis zum Judentum, es erschöpft sich auch nicht in der Selbstzuschreibung, wie Helga Grebing verdeutlicht, denn auch hochgradig in der Gesellschaft assimilierte Juden, und Siegfried Marck war ein solcher, blieben kultur-, sozial- und mentalitätsgeschichtlich „Juden im Sinne eines idealtypisch kondensierten Verhaltensmusters“. ${ }^{29}$

\footnotetext{
${ }^{124}$ Vgl. Dilthey, Wilhelm: Der Aufbau der geschichtlichen Welt, S. 246ff.

${ }^{125}$ Vgl. Pyta, Wolfram: Geschichtswissenschaft, S. 333.

${ }^{126}$ Vgl. Gall, Lothar: Bismarck: der weiße Revolutionär, Frankfurt am Main 1980; Schwarz, Hans Peter: Der Historiker als Biograph oder: Was können wir von Lothar Gall lernen?, in: Hein, Dieter et al. (Hrsg.): Historie und Leben. Der Historiker als Wissenschaftler und Zeitgenosse. Festschrift für Lothar Gall zum 70. Geburtstag, München 2006, S. 249-255, hier S. $250 f$.

${ }^{127}$ In Anlehnung an: Kraus, Hans-Christof: Geschichte als Lebensgeschichte, S. 331.

128 Vgl. Grebing, Helga: Jüdische Intellektuelle und ihre politische Identität in der Weimarer Republik, S. 11; Dies.: Jüdische Intellektuelle in der deutschen Arbeiterbewegung zwischen den beiden Weltkriegen, S. $21 \mathrm{f}$.

${ }^{129}$ Vgl. ebd.
} 


\section{DER ERSTE KULTURKREIS - Breslauer Jahre}

\section{Die Familie Marck}

Am 09. März 1889 erblickte Siegfried Ernst Wilhelm Marck in Breslau das Licht der Welt. $^{130}$ Sein Bruder, Ludwig Bernhard Moritz, wurde zwei Jahre später in der Odermetropole geboren und wuchs gemeinsam mit ihm in der Kurfürstenstraße - ein wenig entfernt vom Breslauer Stadtkern, aber in damaligen Jahren in einer der besten Gegenden Breslaus - auf. Siegfried und sein Bruder wurden in eine traditionsreiche jüdische Patrizierfamilie hineingeboren, deren Wurzeln bis $1750^{131}$ nachzuweisen sind und die zu den wohlhabendsten Breslaus zählte. Aus der habsburgerischen Enklave Hotzenplotz kommend, migrierte die Familie Mitte desselben Jahrhunderts nach Breslau, welches sie fortan mitprägen sollten.

Die Marcks waren jüdischen Glaubens und wandten sich nach den Richtungskämpfen ${ }^{132}$ innerhalb der jüdischen Gemeinde zwischen Orthodoxie und Liberalismus in der Mitte des 19. Jahrhunderts der liberalen Kultusgemeinde Breslaus $\mathrm{zu}$, innerhalb derer sie fortwährend und engagiert mitarbeiteten. Dabei gehörte die Familie stets zu den großen und einflussreichen Häusern jener Jahre und prägte das Berufs- und Geschäftsleben der Metropole. Die Familie Marck verstand sich als „deutsche“ Juden, worauf auch der dritte Vorname des jungen Siegfried, „Wilhelm“, in Anlehnung an das Dreikaiserjahr 1888 hinweist.

Siegfried Marcks Urgroßvater und dessen Schwager gründeten 1818 das Bankhaus Prinz\&Marck, welches nach über 100 Jahren zuerst im Jahr 1921 in eine Disconto-Gesellschaft übergehen und 1929 mit der Deutschen Bank fusionieren sollte. ${ }^{133}$ Kurt Schwerin, ein späterer sehr guter Freund Siegfried Marcks und derjenige, der in den USA die Siegfried-Marck-Gesellschaft über ein Vierteljahrhundert fortführen sollte, trat genau in dieser Filiale der Breslauer

\footnotetext{
${ }^{130} \mathrm{Vgl}$. Geburtsurkunde vom 12.03.1889, Grenander Department Special Collection, State University of New York, Albany - folgend nur noch NL SM.

${ }^{131}$ Familienstammbaum, Leo-Baeck-Institut New York.

${ }^{132}$ Erst nach dem Erlass des Preußischen Emanzipationsgesetzes vom 11. März 1812, das auch für Schlesien galt, konnten die oft partiell entstandenen Synagogengemeinden langsam aufgelöst und zu größeren Gemeinden zusammengefasst werden. Innerhalb der jüdischen Gemeinde Breslaus kam es Mitte des 19. Jahrhunderts zu Richtungskämpfen. Nach dem Gemeindestatut vom 06. März 1856 wurde eine Einheitsgemeinde mit zwei getrennten Kultuskommissionen - für die Orthodoxen und die Liberalen - gegründet. Jede Kultusgemeinde besaß ihren eigenen Rabbiner und ihre eigene Schule. Vgl. Brilling, Bernhard: Die Jüdischen Gemeinden Mittelschlesiens. Entstehung und Geschichte, Stuttgart 1972, S. 38ff.

${ }^{133}$ Familienstammbaum.
} 
Disconto-Gesellschaft seine Lehre an. ${ }^{134}$ In dieser Zeit unterstützen die Marcks als großzügige Bankiers-Familie viele soziale Projekte der Stadtgemeinde. So spendeten sie für den Bau des Hospitals in der Breslauer Neudorfstraße. ${ }^{135}$

Joseph Prinz, Mitbegründer des Bankhauses, war zudem einer der ersten Kuratoren der Fraenckelschen Stiftung in Breslau. ${ }^{136}$ Der Platz im Kuratorium sollte sich innerhalb der Familie weitervererben, sodass nach seinem Ausscheiden Siegfried Marcks Großvater dessen Platz innerhalb des Kuratoriums der Stiftung einnahm ${ }^{137}$, später auch Siegried Marcks Vater Alfons und darauf Siegfried selbst. ${ }^{138}$ Der Tod des Großvaters 1888, der sich 1854 promovierte ${ }^{139}$, wurde nach seiner 24jährigen Tätigkeit innerhalb des Kuratoriums tief betrauert. $\mathrm{Zu}$ seinem Gedenken hieß es, er habe sich in schwierigen Lagen stets durch Klugheit, Einsicht und Herzensgüte bewiesen und sich in bedeutender Weise um die Anstalt verdient gemacht. Auch an den Tod Alfons Marcks wurde nach beinahe 30-jähriger Zugehörigkeit innerhalb der Stiftung gedacht. Immerhin habe auch er sich, ähnlich wie sein Vater zuvor, bis in seine letzten Lebenstage in unermüdlicher Arbeit für eine gedeihliche Entwicklung der Anstalt eingesetzt. ${ }^{140}$

Marcks Großvater, der wie Siegfried Marck später über 50 Jahre als Stadtrat und „dienstältester Assessor“ der preußischen Monarchie in Breslau dienen sollte, beriet Ferdinand Lassalle, wahrscheinlich eine der bekanntesten politischen Breslauer Persönlichkeiten, in einer Erbschaftsfrage. Dieser versuchte für seinen Schwager Ferdinand Friedland durch Marcks Großvater ein Monitum vor Gericht einzureichen, damit dessen Prozess voranschritt. ${ }^{141}$

Siegfrieds und Ludwigs Vater Alfons war Jugendrichter ${ }^{142}$, ihre Mutter Rosa die Gründerin der ersten alkoholfreien Gaststätten Breslaus. ${ }^{143}$ Der Tod des Vaters 1917 wurde schwer bedauert. Der einstige Magistrat hatte großes Ansehen in Breslau genossen und sich besonders in Bereichen sozialer Fürsorge engagiert: Seit 1913 war

\footnotetext{
${ }^{134}$ Vgl. Arbeitszeugnis der Disconto-Gesellschaft vom 29.02.1924, in: Nachlass Kurt Schwerin, LBI New York (folgend nur noch NL KS).

${ }^{135}$ Vgl. Ziatkowski, Leszek: Die Geschichte der Juden in Breslau, S. 87.

${ }^{136}$ Vgl. Lagiewski, Maciej: Breslauer Juden 1850-1944, Abb. 319.

137 Vgl. Brann, Marcus: Geschichte des Jüdisch-theologischen Seminars (Fraenkel'sche Stiftung) in Breslau: Festschrift zum fünfzigjährigen Bestehen der Anstalt, Breslau 1904, S. $113 f$.

${ }^{138}$ Ebd., S. 109-113.

${ }^{139}$ Vgl. Nachrichten von der Georg-August-Universität Göttingen und der königlichen Akademie der Wissenschaften zu Göttingen vom Jahre 1854, Nr. 1-17, S. 183.

140 Vgl. Jahresbericht des Jüdisch-theologischen Seminars Fraenkel'scher Stiftung für das 1917, Breslau 1918, S. 4. In seinem letzen Wille hinterließ er dem Seminar 500 Mark, vgl. ebd., S. 9.

${ }^{141}$ Ferdinand Lassalle an den späteren Stadtrat Siegfried Marck vom 13.01.1863, LBI NY.

${ }^{142}$ Andreas Marck an Dr. Schneider, 29.10.1984, im Deutschen Literaturarchiv in Marbach, Nachlass Armin Theophil Wegener (nachfolgend nur noch NL ATW).

${ }^{143}$ Vgl. Hirsch, Helmut: Siegfried Marck, S. 369.
} 
Alfons Marck Vorsitzender der Armendirektion des Waisen- und Kinderfürsorgesamtes gewesen. Zudem hatte er im Ausschuss des Breslauer Hauptverbandes für Armenpflege und Wohltätigkeit sowie in dem Vorstand des Vereines gegen Verarmung und Bettelei fungiert. Er war daneben Leiter der städtischen Armenverwaltung und auch im Breslauer Verschönerungsverein, dem er seit der Gründung angehörte, tätig gewesen. ${ }^{144}$ Wie Siegfried später auch war es seinem Vater ein besonderes Anliegen gewesen, innerhalb seiner Tätigkeit als Stadtrat bildungspolitische Schwerpunkte zu setzen. Die Beerdigung von Siegfried Marcks Vater, der letztlich an Spanischer Grippe gestorben war, war ein „prunkvolles gesellschaftliches Ereignis“. Es verwundert nicht, dass sowohl der Bürgermeister, die Angehörigen des Magistrats sowie hohe Regierungsbeamte und Offiziere dem Sarg folgen sollten. „Als wäre die halbe Stadt aufgebrochen, um den Toten zu ehren“"145 bemerkte Lola Landau, die Alfons Marck stets als sehr fleißigen und akribischen Beamten wahrgenommen hatte. Selbst am Sterbebett soll er sich mehr Sorgen um einzelne Akten und um den Fortgang des Stellungskrieges gemacht haben als um die eigene Gesundheit. ${ }^{146}$ Daneben war Alfons Marck sehr abergläubisch gewesen - besonders die Zahl „11“ soll bei ihm Schreckensszenarien ausgelöst haben, wie Lola Landau bemerkte:

„Er begann nichts Entscheidendes, wenn das Datum für ihn [eine] unglückliche Primzahl aufwies. Er rechnete jeden Morgen auf dem Weg zum Amt die Zahlen der Elektrischen zu einer Quersumme zusammen und ließ den Wagen vorüberfahren, wenn die Zahl ungünstig war. Er betrat kein Haus mit einer verhängnisvollen Hausnummer, telefonierte nicht selbst, wenn ihm die Quersumme der Telefonnummer fatal erschien.“"

Es ist nicht von der Hand zu weisen, dass dieses penible Abwägen, Ausweichen und Umgehen, auf der anderen Seite jedoch ein pedantisches Vorgehen im Umgang mit Pflichten, seinen Sohn geprägt hat. Dennoch war Siegfried Marck in seiner sensiblen Geistigkeit das Gegenteil des ängstlichen Vaters, besonders wenn es um das Zusammenführen sich widersprechender Angelegenheiten und Konstellationen ging - zumindest in jungen Jahren. Auch Siegfried Marck sollte nach dem Tod seines Vaters dem Kuratorium der Fraenkel'schen Stiftung angehören. Er war damit vorerst der Letzte der Familie Marck, der in das Kuratorium eintrat. ${ }^{148}$

Siegfried Marcks Mutter genoss ebenfalls großes Ansehen innerhalb der Stadtgemeinschaft. Sie gehörte immerhin zu dem engen Personenkreis bekannter

\footnotetext{
${ }^{144}$ Vgl. Breslauer Volkswacht, 05.11.1917, 06.11.1917, 07.11.1917.

${ }^{145}$ Landau, Lola: Vor dem Vergessen. Meine drei Leben, Frankfurt am Main 1987, S. 71.

${ }^{146}$ Vgl. ebd.

${ }^{147}$ Ebd., S. 62.

${ }^{148}$ Vgl. Jahresbericht des Jüdisch-theologischen Seminars Fraenkel'scher Stiftung, S. 6.
} 
Breslauer, wie Gewerkschafter, Stadtverordnete, Geistliche und Professoren, der einen sehr vaterlandsliebenden Aufruf für einen Ausschuss $\mathrm{zu}$ Widerstand und Durchhaltevermögen im Krieg gegen England verbreitete. Aus diesem ist sehr deutlich der patriotische Charakter jener Jahre herauszulesen. Den Initiatoren ging es augenscheinlich um die „vaterländische Pflicht“, dem Heer den Rücken zu stärken und „für den Sieg und für den Frieden““149 zu werben. Zudem war die Aufforderung an ein möglichst breites Publikum gerichtet, rief man doch dazu auf, auch in den anderen Städten des Reiches solche Ausschüsse zu bilden. Daneben gehörte Rosa Marck zum Vorstand der Breslauer Ortsgruppe des Jüdischen Frauenbundes. Dort versuchte sie neben Beate Guttmann, der Frau des Rabbiners Jacob Guttmann, dem Leiter des radikal-reformistischen Flügels der Breslauer jüdischen Gemeinde und Vorsitzenden des Bundes der Rabbiner in Deutschland, aktiv das Gemeindeleben zu gestalten. ${ }^{150}$ Dieser Jüdische Frauenbund, der seit 1908 in Breslau existierte, bemühte sich Schutz- und Wohltätigkeitsorganisationen wie Klubs für Mädchen und Jungen oder eine Herberge für bedrohte Mädchen und Frauen ins Leben zu rufen. Und das nicht erfolglos: 1916 wurde auf Initiative des Frauenbundes ein jüdischer Kindergarten gegründet. ${ }^{151}$

Wie aus den Recherchen Till van Rahdens hervorgeht, war es innerhalb der jüdischen Gemeinde besonders Alfons Marck, der sich stets gegen die Etablierung einer reinen jüdischen Schule aussprach und dabei oft mit seiner eigenen Gemeinde, zu deren Vorstand er gehörte, aneinandergeriet. ${ }^{152}$ Die Familie Marck hatte feste Plätze innerhalb der Breslauer liberalen Synagoge, die von ihr hauptsächlich an hohen Feiertagen genutzt wurden. ${ }^{153}$

Ein besonderer Bezugspunkt für Siegfried Marck war seine Mutter. ${ }^{154}$ In der jüdischen Gemeinde Breslaus war sie dafür bekannt, Wohltätigkeitsveranstaltungen

\footnotetext{
${ }^{149}$ Vgl. Breslauer Volkswacht, 29.05.1917.

${ }^{150}$ Vgl. Lagiewski, Maciej: Breslauer Juden 1850-1944, Abb. 96 u. 98. Zu Jakob Guttmann siehe: Lewkowitz, Albert: Festrede zu Eröffnung der Freien Jüdischen Volkshochschule zu Breslau (09. November 1919), Breslau 1919, S. 3-23. Hier auch ein Selbstverständnis der Freien Jüdischen Volkshochschule im Vorwort.

${ }^{151}$ Vgl. Ziatkowski, Leszek: Die Geschichte der Juden in Breslau, S. 63f.

${ }^{152}$ Vgl. Till van Rahden. Juden und andere Breslauer, S. $225 \mathrm{ff}$.

${ }^{153}$ Vgl. Interview Birgitta Hamann mit Andreas Marck vom April 1995, in: Hamann, Birgitta: Lola Landau. Leben und Wert. Ein Beispiel deutsch-jüdischer Literatur des 20. Jahrhunderts in Deutschland und Palästina/Israel, S. 22.

${ }^{154}$ Birgitta Hamann schreibt in ihrer Biografie über Lola Landau von Ute Marck als Mutter Siegfried Marcks. Dies resultiert bei ihr aus einigen Briefen von und an sie aus dem Deutschen Literaturarchiv in Marbach, die von einer Ute Marck unterschrieben sind. Der Familienstammbaum der Marcks verweist auf Rosa Marck, auch die noch lebenden Familienangehörigen sprechen von Rosa und nicht von Ute Marck, weshalb der Verfasser fortan von Rosa Marck schreibt. Obgleich eine vollständige Klärung wohl nicht mehr vollzogen werden kann, nimmt der Verfasser an, insbesondere weil auch
} 
$\mathrm{zu}$ organisieren und sie setzte sich wie ihr Mann für die Belange der Armen ein. Siegfried sollte nach dem Tod seiner knapp 74 Jahre alten Mutter in einem Brief an seinen Freund Walter Friedländer bemerken:

„Ja, meine Mutter hatte das richtige Temperament der sozial arbeitenden Menschen: niemals aufschreiend, taktvoll, vornehm und gütig, aktive und zähe Mitgliedschaft. Ihr öffentliches Wirken, das ihr im Witwenstand zum Ruf wurde, war aber nur die Fortsetzung ihrer im Privaten wirkenden Begabung: für jeden Menschen das richtige Wort zu finden, überall harmonisierend und mit einer bezwingenden Freundlichkeit zu wirken. [...] Ich habe Frauen gekannt, die ,geistiger', genialer, revolutionärer als sie waren, niemals jedoch eine von dieser inneren Ausgeglichenheit und dieser gleichmäßigen und kraftvollen Selbstlosigkeit.“155

Dieses Bestreben nach Harmonie färbte auch auf ihren Sohn ab. Zudem hatte Rosa Marck gute Kontakte in die Stadtpolitik - auch zu Breslauer Sozialdemokraten wie Paul Löbe ${ }^{156}$. Ferner war sie mit der Familie Fritz Sterns gut bekannt. Für die erste Ehefrau ihres noch lebenden Sprösslings Siegfried, Leonore Landau, war der Umgang mit Rosa Marck von besonderer Art, nahm Rosa doch alle Zügel in die Hand und entmündigte Leonore beinahe vollständig.

Die Familie Marck jedenfalls gehörte zu den großen und einflussreichen jüdischen Familien Breslaus. Mit langer Tradition, dem jüdischen Glauben verbunden und mit viel Engagement und Ehrgeiz hatten sie sich ihre wirtschaftliche und gesellschaftliche Stellung erkämpft. Ihre Söhne sollten daran anknüpfen.

Briefe der Enkelkinder an Ute Marck geschrieben wurde, dass es sich um einen Zweitnamen handeln könnte. Andernfalls wäre es auch denkbar, dass es sich um das Kindermädchen handelt, da der Marcksche Nachwuchs vornehmlich und auch von Kindermädchen großgezogen wurde.

155 Marck an Walter Friedländer, 20.05.1941, Grenander Department, Special Collection, State University of New York, Albany, Nachlass Walter Friedländer (folgend nur noch NL WF).

${ }^{156}$ Vgl. Rosa Marck an Paul Löbe, 12.12.1926, in: GStA, Rep 76Va, Sek.4, Tit. IV, Nr. 48 Bd. VIII. 


\section{Bildungsbiographie}

Siegfried Marck besuchte von 1895 bis 1906 das ehrwürdige Johannesgymnasium in der Paradiesstraße 3, mitten im Stadtkern Breslaus. ${ }^{157}$ Diese Schule besaß einen für die damalige Zeit einzigartigen Charakter als Integrationsschule: Sowohl das Lehrerkollegium als auch die Schülerschaft setzte sich aus je einem Drittel Protestanten, Katholiken und Juden zusammen, wobei die Anzahl der jüdischen Schüler stetig wuchs. ${ }^{158}$ Dabei war diese Ausbildungsstätte seit ihrer Eröffnung 1872 und den daraus resultierenden Spannungen zwischen liberalen Magistratsmitgliedern und der konservativen Ministerialbürokratie im Laufe der Jahre zu einer Eliteschule geworden. Immerhin hatte diese Schule im Vergleich $\mathrm{zu}$ den anderen Breslauer Gymnasien und Realschulen nur einen geringen Anteil von „Freischülern“ und auch der Anteil der Kinder aus Stadtratsfamilien war besonders hoch. ${ }^{159}$ Später, während des Ersten Weltkrieges, sollte auch diese Bildungsstätte $\mathrm{zu}$ einem Lazarett umfunktioniert werden und wurde erst im Mai 1919 wieder für Schüler freigegeben. ${ }^{160}$

Ferner war das Johannesgymnasium ein Wirkungsfeld bekannter Breslauer Juden, wie beispielsweise Willy Cohn, der etwa zur selben Zeit wie Marck diese Schule besuchte und danach ebendort lange Zeit als Lehrer tätig war. Aber auch Norbert Elias und Ernst Cassirer, sicherlich zwei der bedeutendsten Kulturwissenschaftler des 20. Jahrhunderts, besuchten diese von Pluralismus gefärbte Bildungsstätte. ${ }^{161}$ Für die Familie Marck, nationalliberal eingestellt, war es selbstverständlich, dass der junge Siegfried und sein Bruder ein so fortschrittliches Gymnasium besuchten. Denn Siegfried und sein Bruder waren Söhne eines Stadtrates - um die Aufbringung des Schulgeldes brauchten sie sich keine Gedanken zu machen.

Wie viele andere Breslauer jüdischen Glaubens studierte Siegfried Marck nach dem Abitur an der Schlesischen Friedrich-Wilhelms-Universität in seiner Heimatstadt Breslau Rechtswissenschaften. Das war soweit nicht ungewöhnlich, hatten doch sein Vater und Großvater das gleiche Fachgebiet studiert. Erst später und

\footnotetext{
157 Vgl. Handgeschriebener Lebenslauf von Siegfried Marck, in: Promotionsakte Marcks im Universitätsarchiv Breslau, Sign. F217 nicht nummeriert, 1910-1911; auch für die Biographie Siegfried Marcks eine interessante kartographische Übersicht des alten Breslauer Stadtkerns findet sich in: Conrads, Norbert (Hrsg.): Willy Cohn. Kein Recht, nirgends. Tagebuch vom Untergang des Breslauer Judentums 1933-1941 Bd.1, Köln 2006.

${ }^{158}$ Vgl. ebd., S. XIf.

${ }^{159}$ Vgl. Rahden, Till van: Juden und andere Breslauer, S. 194ff.

${ }^{160}$ Vgl. Breslauer Volkswacht, 23.05.1919, 25.07.1919.

${ }^{161}$ Vgl. Rahden, Till van: Juden und andere Breslauer, S. 219.
} 
nach einem Studienaufenthalt in Genf entwickelte sich bei ihm das Interesse an Philosophie und er nahm als fleißiger Zuhörer an den Philosophievorlesungen teil. 1908 entschied er sich endgültig für das Studium der Philosophie, welches er in Breslau, Berlin und Freiburg i. Br. mit den Nebenfächern Neuere Literaturgeschichte und Geschichte betrieb. ${ }^{162}$ Dort waren es Personen wie Ernst Cassirer, Hugo Preuß, Richard Hönigswald, der Vertreter der realistischen Kant-Schule Alois Riehl oder neukantianische Dialektiker wie Jonas Cohn und der Kulturphilosoph Heinrich Rickert, deren Gedanken Marck aufmerksam nachging. Ernst Cassirer stand für einen Neukantianismus ${ }^{163}$ nach Marburger Prägung und war Schüler Hermann Cohns. Hugo Preuß, der Staatsrechtler, Politiker und Innenminister, zudem aktives Gründungsmitglied der Deutschen Demokratischen Partei, galt später als Schöpfer der Weimarer Reichsverfassung und war ebenfalls Jude. Alois Riehl, Neukantianer und Herausgeber der Vierteljahresschrift für wissenschaftliche Philosophie, war der Mentor Richard Hönigswalds. ${ }^{164}$ Besonders bestärkt und angezogen fühlte sich Marck von Eugen Kühnemann und eben Hönigswald, die in Breslau die Philosophie des Neukantianismus in der vereinfachten und rhetorisch-enthusiastischen „Marburger“' Form lehrten. ${ }^{165}$

Marck und Kühnemann verband neben der wissenschaftlichen Arbeit an der Breslauer Universität die Idee der Volksbildung. ${ }^{166}$ Dabei war Eugen Kühnemann ein besonderer Charakter mit großer Anziehungskraft. Seine Veranstaltungen an der Universität waren, im Gegensatz zu denen von Siegfried Marck, stets gut besucht. Was Marck und Kühnemann wieder verband, war deren starke Anziehung auf das weibliche Geschlecht. Sowohl der kleine und zartgliedrige Eugen Kühnemann mit seinem Spitzbart, als auch der kräftige und etwas wuchtig und polternd anmutende Marck hatten innerhalb der Studentinnenschaft Verehrerinnen. Kühnemann soll es

\footnotetext{
${ }^{162}$ Vgl. Der Aufbau, 22.02.1957; Lebenslauf in Promotionsakte.

163 Der Neukantianismus war eine philosophische Bewegung, die sich unter Berufung auf die transzendentale Logik und erkenntnistheoretischen Schriften Immanuel Kants gegen den Materialismus wandte. Charakteristisch für den Neukantianismus war außerdem das neu erwachte Interesse an einer geltungstheoretischen Begründung der Geisteswissenschaften und das Interesse an einer philosophischen Begründung der politischen Theorie. So lieferte etwa der Marburger Neukantianismus die theoretische Grundlage für den Revisionismus Eduard Bernsteins und für den Austromarxismus Max Adlers. Vgl. Holzhey, Helmut (Hrsg.): Ethischer Sozialismus. Zur politischen Philosophie des Neukantianismus, Frankfurt 1994.

${ }^{164}$ Vgl. Grassl, Roswitha/Richart-Willmes, Peter: Denken in seiner Zeit. Ein Personenglossar zum Umfeld Richard Hönigswalds, Würzburg 1997, S. 20 u. 105. Zu Hugo Preuß siehe: Friedrich, Manfred: Preuß, Hugo, in: Neue Deutsche Biographie (NDB). Bd. 20, Berlin 2001, S. 708-710.

${ }^{165}$ Vgl. Marck, Siegfried: Große Menschen unserer Zeit: Portraits aus drei Kulturkreisen, Meisenheim am Glan 1954, S. $161 \mathrm{ff}$.

${ }^{166}$ Vgl. Ders.: Das Gesetz, wonach Du angetreten! Kühnemann als praktischer Charakterologe, in: Mann, Alfred (Hrsg.): Festschrift für Eugen Kühnemann zum 28. Juli 1928, Breslau 1928, S. 26-40, hier S. 30.
} 
nicht unangenehm gewesen sein, wenn ihm solche Tendenzen nachgesagt wurden. ${ }^{167}$ Marck indes war stets auf seinen Ruf und den seiner Familie bedacht. Die Leidenschaft, die Siegfried Marck später für Goethe und Thomas Mann entwickeln sollte, hegte der 1868 in Hannover geborene Kühnemann, der seit 1906 als ordentlicher Professor an der Breslauer Universität tätig war, für Friedrich Schiller „An Ihrer Stellung zu Schiller erkenne ich Ihre Stellung zur Nation“"168, soll Kühnemann seinem Kolleg stets eröffnet haben. Hans Georg Gadamer, der Philosoph, der später mit seinem Werk Wahrheit und Methode bekannt wurde, lernte Kühnemann über seinen Vater kennen. Er verdeutlichte, dass Kühnemann ein „amüsanter Mann“ und ein „Meisterredner“ war - seine Vorlesungen stets gut besucht, seine Veranstaltungen jedoch „trivial““ waren. ${ }^{169}$

In einer Tatsache waren Siegfried Marck und Eugen Kühnemann grundauf verschieden. Marck wurde nach dem Ersten Weltkrieg zum Sozialdemokraten und sein Doktorvater Kühnemann blieb Anhänger der Deutschnationalen. Während Marck sich zur Weimarer Republik und zum Demokratiegedanken bekannte, konnte Kühnemann mit diesen Neuerungen nichts anfangen. Auch wenn Kühnemann sich später nicht der NSDAP anschließen sollte, er, der ein entschiedener philosophischer Gegner des Bolschewismus war $^{170}$, sympathisierte er mit deren Zielen und Gedankengut. Und es ist erstaunlich, dass Eugen Kühnemann auch auf Veranstaltungen des von Siegfried Marck mit ins Leben gerufenen Arbeiterbildungsausschusses über Tolstoi bis Schiller referierte und dabei ebenfalls von russischer Musik begleitet wurde. ${ }^{171}$ Dennoch war Kühnemann einer der großen Philosophiedozenten seiner Zeit. Am stärksten verband Marck und Kühnemann außerhalb der Universität der Volksbildungsgedanke, wie Marck in einer Festschrift für Kühnemann bemerkte:

„Und wenn Kühnemann einmal von der Akademie in Posen, deren erster Rektor er war, sagt, dass sie eigentlich ihrer Idee nach eine Volkshochschule im heutigen Sinne bedeutet hat, so können wir in der oft bekannten Liebe zu seiner damaligen Tätigkeit eine Bestätigung sehen, wie sehr Volksbildung für ihn natürliche Lebensäußerung ist. “"172

\footnotetext{
167 Vgl. Bachler, Karl: Student in Breslau, in: Jahrbuch der Schlesischen Friedrich-Wilhelms Universität zu Breslau, Band III (1958), S. 7-20, hier S.8f.

${ }^{168}$ Ebd., S.8.

169 Grassl, Roswitha: Breslauer Studienjahre: Hans Georg Gadamer im Gespräch, Schriften des Forschungsprojektes zu Leben und Werk Richard Hönigswalds, Mannheim 1996, S.10

${ }^{170}$ Pohl, Gerhart: Bin ich noch in meinem Haus? Die letzten Tage Gerhart Hauptmanns, Berlin 1953 , S. $72 \mathrm{f}$.

${ }^{171}$ Vgl. Breslauer Volkswacht, 04.03.1921, musikalisch wurde die Veranstaltung vom 01. BreslauerBalalaika-Klub begleitet siehe: Ebd., 10.03.1921.

${ }^{172}$ Marck, Siegfried: Das Gesetz, wonach Du angetreten, S. 31.
} 
Kühnemann ging 1903 als Gründungsrektor an die königliche Akademie zu Posen. Das Ziel war, in den Gebieten, die nach den Polnischen Teilungen und dem Wiener Kongress an Preußen gefallen waren, mit einem Fortbildungsgedanken im Bereich der Geisteswissenschaften das Deutschtum durch Bildung zu etablieren. Es wurde versucht als Zwischenhöhe von Universität und Volkshochschule zu agieren. ${ }^{173}$

In seinen Beziehungen zu Richard Hönigswald, dessen Nachfolge Siegfried Marck 1930 an der Breslauer Universität antreten sollte, fällt besonders auf, dass Hönigswald, ebenfalls ein Jude aus bürgerlichem Hause, der im Ersten Weltkrieg kämpfte und mit der Familie Marck privat verbunden war ${ }^{174}$, sich nicht durch die Kriegserlebnisse etwa der Sozialdemokratie anschloss, sondern seit 1918 seine politischen Ziele vielmehr in der Deutschen Vaterlandspartei verwirklicht sah. Hönigswald sollte sogar noch einen Schritt weiter gehen als Siegfried Marck, indem er sich nach seiner Promotion dem evangelischen Glauben anschloss und seiner jüdischen Herkunft den Rücken kehrte. ${ }^{175}$ Damit erhoffe er sich eine reelle Chance auf eine ordentliche Professur. Den Schritt unternahmen Jonas Cohn und Siegfried Marck nicht. Dennoch: Sowohl dem Breslauer Sozialdemokraten als auch dessen deutschnationalem Mentor wurden nach der Machtübernahme der Nationalsozialisten aufgrund ihrer jüdischen Herkunft die Doktortitel aberkannt. Hönigswald selbst wurde von den Nationalsozialisten im Konzentrationslager Dachau interniert und konnte, nachdem er von dort entlassen worden war, über die Schweiz in die USA fliehen, wo er 1947 starb. ${ }^{176}$

Siegfried Marcks wissenschaftliche Qualifikationsschriften bertreute stets Eugen Kühnemann. So reichte Marck im April 1911 an der Breslauer Universität das Gesuch ein ihn zu promovieren, nachdem er zuvor von der Breslauer Universität ein Promotionsstipendium erhalten hatte. ${ }^{177}$ Im Mai desselben Jahres legte er sein Rigorosum in den Fächern Philosophie und Psychologie, Neuere Literaturgeschichte sowie in Neuerer Geschichte ab. Den Vorsitz hatte dabei Eugen Kühnemann, der als Dekan die Prüfung leitete. Ein ehemaliger Student Kühnemanns berichtet über den

\footnotetext{
${ }^{173}$ Vgl. Schutte, Christoph: Die königlich Akademie in Posen 1903-1919 und andere kulturelle Einrichtungen im Rahmen der Politik zur „Hebung des Deutschtums“, Marburg 2008. Nach dem Ende des Ersten Weltkrieges und den Bestimmungen des Versailler Vertrages fiel das Gebiet an Polen zurück und die Akademie wurde aufgelöst. Die Einrichtung selbst wurde von der darauf gegründeten Universität Posen übernommen.

${ }^{174}$ Diese Verbindung wird bei Grassl, Roswitha: Breslauer Studienjahre, S. 84 genannt, kann vom Verfasser jedoch nicht belegt werden.

${ }^{175}$ Vgl. Grassl, Roswitha/Richart-Willmes, Peter: Denken in seiner Zeit, S. 1f.

${ }^{176}$ Vgl. ebd., S. 3.

${ }^{177}$ Gesuch auf Promotion, in: Promotionsakte Marcks; hier auch die Gutachten.
} 
Ablauf von Doktorprüfungen und verdeutlicht, was es hieß, bei Kühnemann geprüft zu werden:

„Wenn man bei Eugen Kühnemann ins Examen steigen wollte, tat man wohl daran, sich mit Kant zu beschäftigen, man machte sich ihm damit angenehm und erschien ihm würdig, sich um die Erlangung des Doktorwürde einer Hohen Philosophischen Fakultät der Schlesischen Friedrich-Wilhelms-Universität zu bemühen“. ${ }^{178}$

Seinen Vortrag hielt Siegfried Marck über „Platos Erkenntniskritik in ihrer Beziehung zu Kant" ${ }^{\text {179 }}$ und damit sollte Marck das Wohlwollen Kühnemanns erhalten haben. Das Prüfungsfach Neue Literaturgeschichte schloss Marck mit Auszeichnung ab, Philosophie bei Kühnemann und Baumgarten ebenfalls mit Bestnote, nur in der Neueren Geschichte schloss Marck mit „cum laude“ ab, was an der Gesamtnote nichts ändern sollte. ${ }^{180}$ Was Marck nie gewusst haben wird, ist die nachträgliche Aberkennung seines Doktortitels und damit die wissenschaftliche Degradierung durch die Nationalsozialisten am 22.11.1938, wie ein weiterer Blick in die Promotionsakte Marcks verrät. ${ }^{181}$

Es ist erstaunlich, dass Siegfried Marck auch wissenschaftlich nur eine Randposition einnahm, immerhin bewegte er sich in einem Umfeld, in dem er mehr Spuren hinterlassen hätte müssen. Nicht nur Siegfried Marck promovierte und habilitierte sich bei Kühnemann. Auch Paul Tillich hatte bei Kühnemann seinen Doktortitel erhalten. Bei Hönigswald promovierte sich der Soziologe Norbert Elias, der ebenfalls um die Jahrhundertwende in Breslau geboren wurde, jüdischer Herkunft war und genau wie Siegfried Marck das dortige Johannesgymnasium besuchte. Zwischen Richard Hönigswald und Jonas Cohn indes herrschte nach außen hin eine große persönliche Distanz, immerhin waren beide Konkurrenten um die William-Stern-Nachfolge $1916^{182}$ in Breslau gewesen. Für die persönlichen Beziehungen zwischen den beiden war nicht nur Stern, der Vorgänger Hönigswalds, von Bedeutung, sondern eben auch Siegfried Marck, der zwischen den beiden wissenschaftlich zwar so manche Verwandtschaft sah, aber in den zentralen Punkten doch eine große Verschiedenheit konstatieren musste: In der Philosophie Hönigswalds ist nach Marck die Dialektik ein Nebenprodukt, während sie in der Philosophie Cohns eine zentrale Rolle spielt. Ferner gehörte Hönigswald zu dem

\footnotetext{
${ }^{178}$ Bachler, Karl: Student in Breslau S. 9.

${ }^{179}$ Gesuch auf Promotion; Später wurde Marck Vorsitzender der Breslauer Kant-Gesellschaft, vgl. Breslauer Volkswacht, 23.11.1926.

${ }^{180}$ Promotionsakte Marck.

181 Handschriftliche Notiz auf dem von Marck zu seiner Dissertation eingereichten Lebenslauf, Promotionsakte.

${ }^{182}$ Vgl. Grassl, Roswitha/Richart-Willmes, Peter: Denken in seiner Zeit, S. 22f.
} 
Denktypus, den Cohn den „,beherrschenden“ nannte, während Hönigswald selbst dem „verstehenden“" zuzurechnen war. ${ }^{183}$

Als Schüler von Cohn aber auch von Hönigswald wirkte Marck als Bindeglied zwischen beiden. Er musste so handeln, um wissenschaftlich weiterzukommen. Er hatte zwar 1911 bei Eugen Kühnemann promoviert und auch habilitiert, in den beigefügten Lebensläufen hatte er jedoch zusätzlich Richard Hönigswald seinen besonderen Dank ausgesprochen. In der Zusendung seiner Doktorarbeit an Jonas Cohn betonte Marck:

„Indem es mir heute eine Freude ist, den Männern, denen ich Anregungen während meines Studiums verdanke, als ein Zeichen meines Dankes meine erste Arbeit zu senden, gedenke ich besonders gern des philosophischen Seminars, das Sie damals abhielten. Es waren schöne Abende in dem Zimmer der alten Bibliothek, wo im Laufe des Semesters die ganz große Schar von Geistern der Reihe nach heraufbeschworen wurden und unter den Vertretern so mannigfach verschiedene Köpfe auftauchten [...]. Es ist dies eine der liebsten Erinnerungen an meine Studienzeit.“ ${ }^{184}$

Überhaupt war die Beziehung zu Jonas Cohn eine besondere: Es entwickelte sich in den folgenden Jahren ein Briefwechsel, der über den fachlichen Austausch hinausging. So gratulierte Jonas Cohn dem jungen Ehepaar Marck-Landau zu deren Verlobung und Marck beschrieb ihm seine ersten Eindrücke seiner Militärzeit:

„Von den Schrecknissen des Krieges bin ich bisher verschont. Im März war ich als [...] ]enfanterist eingezogen, wurde aber wegen des Herzens wieder entlassen; seit Oktober bin ich [...] vorläufig noch im Garnisonsdienst beschäftigt. Aus dem südwestdeutschen Kreise hat der Krieg auch schon manches Opfer gefordert, dessen unersetzlich das schwerste natürlich Lask ist. Auch der Tod des wundervollen Jünglings Ehrenberg hat mich tief geschmerzt. “185

Siegfried Marck sah durch den Krieg, mit seinen für die Wissenschaft besonders schmerzvollen Verlusten, vor allem aber seine wissenschaftliche Laufbahn und sein Fortkommen in Gefahr. Eugen Kühnemann ging 1914 für Vortragsreisen nach Amerika $^{186}$ und damit war auch ,jede Wirksamkeit für die Sache [Habilitation Marcks] natürlicherweise jetzt erschöpft“. Marck sah dies mit Argwohn und musste bemerken, dass Kühnemann, „der damals im Siegesrausch der Augustschlachten

\footnotetext{
${ }^{183}$ Vgl. Marck, Siegfried: „Am Ausgang des jüngeren Neukantianismus. Ein Gedenkblatt für Richard Hönigswald und Jonas Cohn“, in: Archiv für Philosophie, Jg. 3 (1949), 33-41, hier S. 38f.

${ }^{184}$ Marck an Jonas Cohn, 05.10.1911, Jonas Cohn Archiv, 467-B-144-001; vgl. Model, Anselm: „Ich“ und „Selbst“. Zur Auseinandersetzung Jonas Cohns mit der Denkpsychologie Richard Hönigswalds, in: Schmied-Kowarzik, Wolfdietrich (Hrsg.): Erkennen - Monas - Sprache. Internationales RichardHönigswald-Symposium, Kassel 1995, S. 145-159, hier S.148. Das Seminar, um das es sich handelte trug den Titel: Das Verhältnis der Kunst zum Leben bei den großen deutschen Denkern von Kant und Herder bis Nietzsche.

${ }^{185}$ Marck an Jonas Cohn, 26.12.1915, 470-B-144-004. Der südwestdeutsche Neukantianer Emil Lask wurde in der Nähe seines Geburtsortes in Galizien erschossen.

${ }^{186}$ Vgl. Holz, Friedbert, „Kühnemann, Eugen“, in: Neue Deutsche Biographie 13 (1982), S. 205 f.
} 
1914 Deutschland verließ“, zum Stellungskrieg nicht geschaffen war. ${ }^{187}$ Marcks Habilitation musste also warten.

Marck sprach sich stets für eine kritische Dialektik und damit für eine dialektische Aufhebung der Gegensätze aus. Er vermochte dann auch früh die Bedeutung beider Denker Cohn und Hönigswald in seiner Promotionsschrift hervorzuheben, indem er beide in seinem Werk Die Dialektik in der Philosophie der Gegenwart nebeneinander stellte. ${ }^{188}$ Sowieso sah Marck, ganz anders als Martin Heidegger später bemerken musste, die kritische Dialektik als den Typus des zukunftsreichsten Philosophierens. „Sie ist nicht ein Standpunkt, sondern eine Grundmethode.“189 Die Orientierungspunkte seines frühen Hauptwerkes waren Jonas Cohns Theorie der Dialektik, Richard Hönigswalds Denkpsychologie, Bruno Bauchs Ideenlehre, Paul Natrops Lehre vom Grenzdenken, Nicolai Hartmanns Aporetik, Ernst Cassirers philosophische „Anthropologie“ und nicht zuletzt Max Adlers neukantianischer Marxismus. ${ }^{190}$

Seine Dialektikauffassung war aber allein deshalb kritisch, da er sie gegen die Dialektik Hegels und damit auch gegen den Marxismus stellte. So musste er auch immer wieder mit Georg Lukács, der ebenfalls den Versuch unternahm, die marxistische Philosophie zu erneuern, aneinandergeraten, wie Franz Walter bemerkt. ${ }^{191}$ Walter fasst Marcks philosophische Denkweise treffend zusammen:

\footnotetext{
„Siegfried Marck beschäftigte sich sein ganzes Leben lang intensiv mit der Hegelschen Dialektik und war dauerhaft darum bemüht, sie kantianisch gegen den Strich zu bürsten, um dadurch den Marxismus aus seiner teleologischen Sackgasse herauszuholen, um ihn mittels der Inspiration der 'Kritischen Dialektik' neu zu konstituieren. [...] Der Breslauer Professor der Philosophie insistierte demgegenüber [der Hegelschen Dialektik] auf der dialektischen Aufbewahrung der Gegensätze, auf der zwieträchtigen Harmonie, auf dem Beisammensein widersprüchlicher Elemente als Treibstoff für gesellschaftliche Entwicklung.“ ${ }^{192}$
}

Aber auch die südwestdeutsche Form des Neukantianismus war Marck nicht fremd. Von Heinrich Rickert, einem Hauptvertreter dieser Schule, dessen „Kritischer Idealismus“ ganze Generationen von Philosophiestudenten beeinflusste und zu

\footnotetext{
${ }^{187}$ Marck an Jonas Cohn, 26.12.1915.

${ }^{188}$ Vgl. Marck, Siegfried: Die Dialektik in der Philosophie der Gegenwart, 2 Halbbände, Tübingen 1929/31. Bereits zuvor versuchte Marck Cohn und Hönigswald nebeneinander zu stellen. Siehe: Ders.: Dialektisches Denken in der Philosophie der Gegenwart, in: Logos: Zeitschrift für systematische Philosophie, Bd. 15 (1927-1928), S. 21-46.

${ }^{189}$ Vgl. Ders.: Die Dialektik in der Philosophie der Gegenwart, Zweiter Halbband, Vorwort.

${ }^{190}$ Vgl. Ders.: Die Dialektik in der Philosophie der Gegenwart, Erster Halbband, Vorwort.

${ }^{191}$ Vgl. Walter, Franz: Siegfried Marck (1889-1957), S. 270.

192 Ders.: Vom Milieu zum Parteienstaat, S. 27.
} 
dessen engstem Kreis er, neben Richard Kroner ${ }^{193}$, in Breslau gehörte, wollte er sich später gerne lossagen. ${ }^{194}$ Immerhin war Rickert ein starker Sympathisant von Alfred Hugenberg und ein Fürsprecher der „,nationalen Regierung“(195, „doch alledem zum Trotz durchzieht das oberste philosophische Denkprinzip Rickerts, das der synthetischen Einheit, auch das Lebenswerk seines einstigen Studenten.“"196 Als Student war Marck nicht nur durch ein besonders breites geistiges Umfeld geprägt, er mischte sich früh in die Diskussion, wirkte in diesen balancierend, ausgleichend und konsensorientiert, ganz wie es seiner Dialektikauffassung entsprach.

Noch während des Ersten Weltkrieges in Breslau und auch in den Schützengräben selbst, befasste er sich mit seiner Habilitation. Doch Marck wurde vorerst wegen eines Herzfehlers für nicht tauglich befunden und erst gegen Kriegsende an die Front berufen. Seine Dissertation zur Erkenntniskritik, Psychologie und Metaphysik nach ihrem inneren Verhältnis in der Ausbildung der platonischen Ideenlehre wurde von der philosophischen Fakultät Breslaus prämiert. Eugen Kühnemann, sein Doktorvater, war von der Schrift schlichtweg begeistert. ${ }^{197}$ Im Alter von 28 Jahren und beinahe zeitgleich mit der Abberufung an die Westfront, hatte sich Marck nun doch bei Kühnemann mit einer Gegenüberstellung der Grundbegriffe bei Kant und Hegel, in der Kant eindeutig besser wegkam, ebenfalls bei Kühnemann habilitiert.

Ab 1922 erhielt er an der ehrwürdigen Universität Breslau einen Lehrauftrag für Rechts- und Staatsphilosophie. Die Philosophische Fakultät der Breslauer Universität war ein regelrechtes Sammelbecken hochkarätiger Professoren, war sie doch auch mit 83 Hochschullehrern die zahlenmäßig stärkste Breslauer Fakultät. An der Universität arbeiteten im Sommersemester 1924 insgesamt 163 Wissenschaftler und Ärzte - unter den 45 außerplanmäßigen Professoren gab es mittlerweile 15

\footnotetext{
193 Richard Kroner gründete mit deutschen und russischen Freunden 1910 die philosophische Zeitschrift Logos, in der auch Marck schrieb. Bis 1938 leitete er deren Herausgabe. Ähnlich wie Marck hatte auch Kroner Kontakt zu Paul Tillich, gehörte jedoch eigentlich der südwestdeutschen Schule des Neukantianismus an. Im Frühjahr 1940 emigrierte Kroner nach New York, zog sich dort aus der Diskussion um das „andere Deutschland“ heraus, vgl. Holz, Friedbert: Kroner, Richard, in: Neue Deutsche Biographie (NDB), Bd. 13, Berlin 1982, S. 84-86. Richard Kroner war überdies ebenfalls jüdisch und ließ sich taufen, weil er darin eine bessere Chance für eine Universitätskarriere sah, vgl. Grassl, Roswitha: Breslauer Studentenjahre: Hans Georg Gadamer im Gespräch, S. 17.

${ }^{194}$ So geschehen spätestens im Pariser Exil, als er dem „kritischen Idealisten“ Rickert eine „feige Anpassungsphilosophie“ vorwarf, vgl. Das Neue Tagebuch, 18.07.1936.

${ }^{195}$ Vgl. ebd. Marck schildert Rickerts Worte einer letzten Unterhaltung im März 1933 mit Blick auf Hugenberg: „So lange der in der Regierung ist, kann man nur völliges Vertrauen haben.“

${ }^{196}$ Vgl. Walter, Franz: Siegfried Marck (1889-1957), S. 254f.

${ }^{197}$ Vgl. Hirsch, Helmut: Siegfried Marck, S. 371. Davon zeugt folglich auch das Prädikat „,summa cum laude“ vgl. Promotionsakte.
} 
Juden $^{198}$. An der Philosophischen Fakultät waren von 83 Dozenten im Jahre 192461 Protestanten, 13 Katholiken und sieben Juden sowie zwei religionslose Akademiker.

Dies muss Siegfried Marck ein wenig fremd gewesen sein, ihm, der doch die fortschrittlichen Gedanken am Breslauer Johannesgymnasium genossen hatte. Nun sah er sich in einem Umfeld, in dem Juden stark unterrepräsentiert waren. Und schon bald sollte er in der Studentenschaft auf antisemitische Ressentiments stoßen. Als einer von vier jüdischen Privatdozenten und dazu noch als Sozialdemokrat an der Breslauer philosophischen Fakultät, musste er feststellen, dass viele Studenten seine Veranstaltungen mieden. Ferner darf in diesem Zusammenhang nicht vergessen werden, dass Privatdozenten im Vergleich $\mathrm{zu}$ ordentlichen Professoren deutlich schlechter bezahlt wurden. Dies führte auch innerhalb der Universität zu sozialen Spannungen zwischen den einzelnen Lehrenden. ${ }^{199}$ Wäre Siegfried Marck nicht aus so wohl situierten Verhältnissen gekommen, er hätte seinen beruflichen Werdegang nicht bestreiten können. Nur das Privatvermögen der Familie Marck konnte ihm den nötigen Rückhalt geben. Dennoch überlegte der Breslauer Philosophiedozent, seine wissenschaftliche Karriere zu beenden. Bereits 1922 im Zuge der Teuerung und der Unterhaltszahlungen an seine erste Ehefrau Lola Landau konstatierte Marck in einem Brief an Armin T. Wegner, dass er über einen Berufswechsel nachdächte. Siegfried Marck und seine zweite Ehefrau Kläre machten zu diesem Zeitpunkt Urlaub im Riesengebirge und mussten feststellen, dass sie dort wesentlich billiger leben konnten als in Breslau, insbesondere wenn Kläre dort selbst wirtschaftete und nicht eine Angestellte für sie beide. ${ }^{200}$ Marck bezifferte sein Einkommen in jenen Jahren auf rund 234 Reichsmark im Monat, von denen er monatlich 50 Mark an Lola für den Unterhalt der Kinder gab. Dies war mehr als ein Fünftel seines Einkommens. Seine Mutter, die ihn sonst unterstützte, konnte ihm nur noch durch den Verkauf von Hausrat unter die Arme greifen. ${ }^{201}$ Überhaupt fühlte Marck sich den Kindern gegenüber verpflichtet. So verkaufte er 1922 Wertgegenstände in Höhe von 20.000 Mark, um für seine Kinder Reservefonds für deren Ausbildung einzurichten. ${ }^{202}$

\footnotetext{
${ }^{198}$ Vgl. Ebert, Andreas D.: Jüdische Hochschullehrer an preußischen Universitäten (1870-1924). Eine quantitative Untersuchung mit biografischen Skizzen, Frankfurt am Main 2008, S. 480.

${ }^{199} \mathrm{Zu}$ den Problemen der Privatdozenten siehe Breslauer Volkswacht, 22.06.1920.

${ }^{200}$ Vgl. Marck an Wegner, 12.10.1922, NL ATW.

${ }^{201}$ Vgl. Marck an Wegner, 20.06.1924, NL ATW.

${ }^{202}$ Vgl. Marck an Wegner, 28.05.1922, NL ATW.
} 
1924 wurde Marck zum außerordentlichen Professor ernannt und lehrte Rechtsphilosophie und Soziologie. ${ }^{203}$ Doch letztlich wollte sich die Breslauer Studentenschaft eher von völkisch-nationalistischen Gedanken treiben lassen und da war ihnen der Jude und Sozialdemokrat Marck ein Dorn im Auge. Trotzdem hielt er Vorlesungen, die auch an der juristischen Fakultät angekündigt waren, über die philosophischen Grundfragen des Marxismus oder die Entwicklung der politischen Ideologien von 1914 bis $1924^{204}$ und konnte einen kleinen Kreis von politischinteressierten Studenten, die meist der Sozialistischen Studentengruppe angehörten, für sich gewinnen. Verstärkt wurde die Missgunst gegenüber Marck auch dadurch, dass er eine polemische Rede des Historikers Siegfried Kähler gegen den Versailler Vertrag in der Breslauer Volkswacht kritisierte. ${ }^{205}$

Siegfried Marck war „dran“ an den großen Denkern seiner Zeit, studierte bei ihnen, vermittelte zwischen diesen und pflegte seine Kontakte. Seine Lehrer und Vorbilder bestimmten die wissenschaftlichen Diskurse seiner Fachdisziplin, in der er selbst kaum einen Nachklang hinterließ. Sein Bekenntnis zur Sozialdemokratie, auf das an anderer Stelle vertieft eingegangen wird, stand einer großen wissenschaftlichen Karriere im Weg.

\footnotetext{
203 Vgl. Lowenthal, Ernst G.: Juden in Preußen. Biographisches Verzeichnis. Ein repräsentativer Querschnitt, Berlin 1981, S. 150; Breslauer Volkswacht, 17.06.1924. Darin auch der Verweis, dass es im deutschen Universitätswesen nur wenige Professoren gab, die den Marxismus lehrten.

${ }^{204}$ Vgl. ebd., S. 484ff u. S. 489.

${ }^{205}$ Vgl. Walter, Franz: Siegfried Marck (1889-1957), S. $258 f$.
} 


\section{Die Ehe mit Lola Landau}

Siegfried Marck, „von gedrungener Gestalt, mit kurzem Hals und schnellen Bewegungen; mit flinken, wissbegierigen und neugierigen Blicken, [der] ein wenig Ähnlichkeit mit einem Hasentier [hatte] ${ }^{‘ 206}$ hielt mit den Worten: „Glauben Sie nicht, dass zwei Menschen wie wir beide Ergänzung in einer Einheit finden könnten?“ 1915 um die Hand Leonore Landaus an. Lola, wie sie genannt werden sollte, stammte aus einer wohlhabenden jüdischen Familie aus Berlin. Marck hatte dabei den festen Glauben, dass man bei der Wahl des Lebenspartners nicht dem Instinkt, sondern der höheren Vernunft, die eine geistige Verwandtschaft bejaht, folgen sollte. ${ }^{207}$

Diesem Antrag ging bereits zwei Jahre zuvor ein zähes und langes Werben Marcks um die Gunst Lola Landaus voraus. Wie Marck 1913 zum ersten Mal Kontakt zu Lola Landau aufgenommen haben soll, beschreibt Birgitta Hamann in ihrer Promotionsschrift sehr präzise: Es entstand ein reger Briefwechsel, aus dem eine erste Begegnung in Berlin resultierte, der eine weitere während eines Skiurlaubes der Familie Landau im Riesengebirge folgte. ${ }^{208}$ Dabei hatte es Marck nicht einfach. Im Mai 1914 bei einer weiteren Begegnung in Berlin sollte er mit seiner Umwerbung zum ersten Mal scheitern, obgleich er ihr in einem Brief verdeutlichte, „,dass ich Sie würde lieben müssen, dass in Ihnen eine Seele lebt, wie alle meine Fantasien sie suchen, und dass gemeinsame Rasse und Geistigkeit mich zu Ihnen würde ziehen müssen [...]“، ${ }^{\text {209 }}$ Letztlich benötigte Siegfried Marck vier Verlobungsversuche, um Lola von einer Ehe zu überzeugen.

In seinen vielen Briefen an Lola, die im Deutschen Literaturarchiv Marbach einzusehen sind und mit einer großen emotionalen Tiefe und Feinfühligkeit verfasst sind, sprach der scharfgeistige Breslauer Philosophiedozent Lola Landau mit der Anrede „Mein geliebtes Reh“ an. Interessanterweise ist es genau dieser Ausdruck, der exakt das eheliche Verhältnis der beiden widerspiegelt und es sind genau

\footnotetext{
${ }^{206}$ Vgl. Landau, Lola: Vor dem Vergessen, S. 15.

${ }^{207}$ Vgl. ebd., S. $15 \mathrm{ff}$.

${ }^{208}$ Leider war es dem Verfasser nicht möglich, an die Briefe dieser Zeit zu gelangen, da sich diese im Privatbesitz des Sohnes Andreas Marck, respektive nun im Besitz des Enkels Ilan Mark in Israel befinden. Birgitta Hamann hatte im Rahmen ihrer Promotionsverfahrens die Möglichkeit, diese Briefe einzusehen und zudem 1995 Interviews mit den Hinterbliebenen zu führen und dieses Material für ihre Arbeit zu verwenden, weshalb hier auf deren Arbeit zurückgegriffen werden muss. Vgl. Hamann, Birgitta: Lola Landau. Leben und Werk, S. 18f.

${ }^{209}$ Marck an Landau, 23.03.1914 in Privatbesitz von Ilan Marck, zitiert in: Ebd., S. 19.
} 
dieselben Worte, die einst Lola Landaus Vater stets an seine Tochter richtete. ${ }^{210}$ Lola war für Marck, genauso wie für Lolas Vater zuvor, ein kleines Mädchen, das es zu beschützen galt. Sie war nicht die gleichberechtigte Partnerin. Siegfried Marck und Lola Landau heirateten im Einvernehmen der Eltern im Juni 1915 nach jüdischer Zeremonie in Berlin, gingen von dort auf Hochzeitsreise und sollten fortan in Breslau, in der Nähe des Marck'schen Elternhauses leben. Birgitta Hamann betont, dass Lola Landau mit der Familie Marck einen „ersten, wenn auch noch distanzierten Zugang zur jüdischen Religiosität" erhielt, da die Marcks ihren Glauben stärker auslebten als die Landaus. ${ }^{211}$

Dass das Ehepaar zu Beginn des Ersten Weltkrieges heiratete und dabei patriotisch zum Kaiserreich eingestellt war, verwundert nicht. Sowohl der Philosoph Marck als auch die Lyrikerin Landau waren in den ersten Kriegsjahren von diesem Krieg überzeugt, wie der Briefwechsel zudem belegt - eine Haltung, die beide im Kriegsverlauf und mit dem Eintritt Siegfried Marcks in den Kriegsdienst ablegen sollten. Birgitta Hamann findet in dem Briefwechsel der Eheleute Marck Schlüsselbegriffe und Phrasen, wie „heiliger Krieg“, „Idee die höher steht als das Geschick des Einzelnen“ oder „Volkstum“, die ein nationales Gedankengut beider erkennen lassen. ${ }^{212}$ Für bürgerliche Juden in dieser Zeit war das nicht ungewöhnlich, immerhin erhoffte man sich im Streben für ein nationalliberales Deutschland als Nebenprodukt die vollständige Assimilation in diese Gesellschaft.

Dennoch stellte sich das Paar die Frage, ob es in Berlin oder in Breslau leben wollte. Lola wäre sicherlich gerne in ihrer Heimatstadt geblieben, bei ihrer Familie und deren Gesellschaft. Marck indes machte stets deutlich, dass er aus beruflichen Gründen in Breslau leben wollte, auch weil er dort an gewisse universitäre Verpflichtungen gebunden war. ${ }^{213}$

Mit der Heirat entwickelte sich auch ein besonderes Verhältnis zwischen Lola und Marcks Mutter Rosa, welche die Ehefrau ihres Sohnes stets bevormundete. Marck selbst konstatierte: „Mutter sorgt schon, dass das Richtige geschieht ${ }^{\text {‘214 }}$ und positionierte sich so eindeutig. Zudem war es Rosa Marck, die das Ehepaar finanziell

\footnotetext{
${ }^{210}$ Die Anrede „Mein geliebtes Reh“ beispielsweise in den Briefen von Theodor Landau an Lola Landau während Lolas Englandaufenthalt, 29.10.1909, 18.01.1910, 15.02.1910, 09.03.1910, 22.03.1910, 29.03.1910, 05.04.1910, 03.05.1910, 10.05.1910, 14.06.1910, 28.06.1910, 05.07.1910, NL ATW.

${ }^{211}$ Vgl. Hamann, Birgitta: Lola Landau. Leben und Werk, S. $21 \mathrm{f}$.

${ }^{212}$ Vgl. ebd., S. 20.

${ }^{213}$ Vgl. Marck an Landau, 04.01.1919, NL ATW.

${ }^{214}$ Landau, Lola: Vor dem Vergessen, S. 94.
} 
unterstütze und nicht Theodor Landau. ${ }^{215}$ Dennoch: Birgitta Hamann deutet die ersten Ehejahre als glücklich, die Spannungen und Zerwürfnisse seien erst mit dem Ersten Weltkrieg und dem Fronteinsatz von Marck entflammt. ${ }^{216}$ Nichtsdestoweniger scheiterte die Ehe schon früh. Siegfried Marck bemerkt selbst in einem Brief an Armin T. Wegner, dass es neben den Kriegsereignissen und der daraus resultierenden zeitlichen Trennung der Eheleute besonders die „Startschwierigkeiten“ waren, welche die Ehe hatten erlahmen lassen müssen:

„Keine wurzelhafte chronische Krankheit der Ehe wie es nachträglich Tantenwitz und Liebesfanatismus mit mir bestimmenden Menschen darstellen wollten, führte ihr Ende herbei. Ein akutes Fieberrasen brachte sie um, das seinen "Herd" gewiss im Mangel des für eine Ehe aber nicht absolut konstitutiven Magnetismus unserer Beziehung (Problematik unserer Verlobung!) fand. Dann aber war die Ehe gute warme Kameradschaft und herzlichste Liebe geworden, bis Kriegstrennung und Revolutionspsychosen ihre Fundamente lockerten. Auch Lola war von diesen Krankheiten befallen, aber ihre starke im Grunde gesunde Natur hätte die Krise überwunden, hatte sie bereits überwunden. ${ }^{\text {‘2217 }}$

Wenngleich der Krieg dafür sorgte, dass das Ehepaar zeitweise getrennt leben musste, so war es doch genau dieser, der bei beiden dafür sorgte, dass sie sich zum Pazifismus bekannten. Landau engagierte sich in bürgerlich-pazifistischen Frauenclubs, während Marck sich den Sozialisten anschloss. Ferner wurde der erste Sohn, Andreas, geboren, was das Paar enger zusammenbrachte.

Zudem war es die aus dem Krieg resultierende Nahrungsmittelknappheit, die beide spürten und bei ihnen ein Umdenken anregte. Die Geburt des zweiten Sohnes im letzten Kriegsjahr, der stark untergewichtig zu Welt kam, sollte das Ehepaar zusammenschweißen: Lola selbst war zu schwach, um ihren Sohn Alfons zu stillen, sodass diese Aufgabe, ärztlich verordnet, einer Bauerstochter aus dem Breslauer Umland übertragen wurde. Rosa Marck organisierte ein sechzehn Jahre altes Mädchen, die uneheliche Mutter Bertha, die sich mit einem russischen Kriegsgefangenen eingelassen hatte und nun als Amme den Marck'schen Sprössling am Leben erhalten sollte. Dass dies im Umkehrschluss bedeuten sollte, dass die Amme das Leben ihres eigenen Kindes damit aufs Spiel setzte, war Lola Landau bewusst. $^{218}$ Was Lola vorerst nicht wusste war, dass das bezahlte Kostgeld, das die Marcks für das Wohl des Ammenkindes zahlten, von der sich kümmernden Großmutter anderweitig verwendet wurde. Dies hörend verfiel die Amme in Depressionen, sodass sie Alfons Marck nicht mehr mit Muttermilch versorgen konnte. Diese Situation bedrückte das Ehepaar Marck so sehr, dass es in Berthas

${ }^{215}$ Vgl. Marck an Wegner, 08.07.1920, NL ATW.

${ }^{216}$ Vgl. Hamann, Birgitta: Lola Landau. Leben und Werk, S. 22.

${ }^{217}$ Marck an Wegner, 06.12.1920, NL ATW.

${ }^{218}$ Vgl. Landau, Lola: Vor dem Vergessen, S. 78f. 
Dorf fuhr, um das gebürtige Kind der Amme $\mathrm{zu}$ begutachten. Aufgrund seines schlechten körperlichen Zustandes entrissen Siegfried und Lola der Großmutter das Kind und nahmen es mit nach Breslau, wo sie für dessen Wohl sorgen wollten.

Lola Landau schreibt in ihren Lebenserinnerungen sogar, dass das Kind mit Absicht verhungern sollte, da sich die Großmutter die Frage stellte, was „das unglückliche Wurm [sic]“ überhaupt auf der Welt sollte. ${ }^{219}$ Für Siegfried war diese Frau kein Unmensch, vielmehr war „sie ein Opfer der Umstände“, an denen die „Gesellschaft, Dummheit und Aberglaube, künstlich aufrechterhalten von der oberen Kaste“, die Schuld trage. Ursachen seien die Armut der Menschen und der Krieg. Lola machte sich große Vorwürfe, sie „habe einen Menschen gekauft“ und dies nur, weil sie und ihr Mann reich sind, während Marck ein uneheliches Kind gerne vom Staat versorgt gesehen hätte. ${ }^{220}$

Diese Erlebnisse genügten nicht für den Fortbestand der Ehe. Es entflammte ein tiefer Streit zwischen den Eheleuten, als sich herauskristallisierte, dass sich sowohl der Privatdozent als auch Lola Landau neu verliebt hatten. Landau in den Schriftsteller Armin Theophil Wegner, den sie in Breslau 1917 während eines Vortrages über die Vertreibung der Armenier aus der Türkei kennenlernte und Siegfried Marck in eine seiner Philosophiestudentinnen, Kläre Rosenstock, die er etwa zeitgleich traf. Wenngleich sich eigentlich beide einig waren, dass sie ihr Glück in der jeweils neuen Beziehung finden würden, waren es doch die Wertvorstellungen von Ehe und die gesellschaftliche Moral, die beide vorerst an der Ehe festhalten ließen. Gerade wegen der zwei in den Ehejahren geborenen Söhne glaubte man, an der unglücklichen Ehe beharren zu müssen. Vor allem Siegfried Marck glaubte an eine zweite Chance für seine Ehe. Dem ungeachtet kam es zum Streit, wie Marck in einem Brief verdeutlichte:

„Wenn ich Dir jetzt schreiben will, fühle ich, dass sich tatsächlich Abgründe zwischen uns geöffnet haben. $\mathrm{Ob}$ sie sich jemals schließen können erscheint mir zweifelhaft, weil dazu Liebe gehört, das Wesentliche schließlich jener Beziehung von Mensch zu Mensch. “21

„Noch heute weiß ich nicht, was mich eigentlich in diese Ehe trieb, eine reine Vernunftehe“ musste Lola Landau im Nachhinein, nach der Trennung 1919, konstatieren. ${ }^{222}$ Für Marck war ein in Freundschaft mögliches Auseinandergehen nicht denkbar, da Lolas Eltern ihm die Schuld an der Trennung gaben, auch um sein

\footnotetext{
${ }^{219}$ Vgl. ebd., S. 91.

${ }^{220}$ Vgl. ebd., S. $92 \mathrm{ff}$.

${ }^{221}$ Marck an Landau, 31.12.1919, NL ATW.

${ }^{222}$ Landau, Lola: Vor dem Vergessen, S. 14ff.
} 
Gewissen zu belasten. ${ }^{223}$ Die Gräben zwischen beiden waren so groß, dass die Kommunikation phasenweise nur zwischen Siegfried Marck und Armin T. Wegner stattfand. Letztlich sollte es zu einer großen Aussprache kommen. Sowohl Siegfried Marck mit seiner neuen Lebensgefährtin als auch Lola Landau mit Armin T. Wegner trafen sich zu viert, um das weitere Vorgehen zu besprechen. Besonderes Augenmerk muss hierbei der Tatsache zugesprochen werden, dass es Siegfried Marck und Armin T. Wegner waren, die in einer Vielzahl von Briefen über die Situation und ohne das Wissen Lola Landaus und Kläre Rosenstocks diskutierten und eigentlich alle weiteren Angelegenheiten geregelt hatten, bevor sich die vier zusammensetzten. ${ }^{224}$ Es war Marck, der auf Wegner zuging, da er in ihm jemanden zu finden hoffte, der „Menschliches menschlich sieht und frei ist von konventionellen Maßstäben.“225 Und Marck sah sich „vor dem Zusammenbruch seiner Nerven“ als jemanden, „der sich seelisch an einer Martinswand befindet, bei der er keinen Schritt vorwärts und rückwärts machen kann. “226 Marck schlug die Initiierung eines „Rates der Vier“ vor, um endlich Klarheit zu schaffen. Er sah die Chancen für seine neue Beziehung mit Kläre dann besonders hoch, wenn Armin und Lola heirateten. ${ }^{227}$

Dennoch waren sich die Beteiligten auch nach dem „Vierergespräch“, wie es im Nachhinein heißen sollte, einig, dass sie in Frieden und Freundschaft auseinandergehen wollten, wenngleich insbesondere die Eltern Lola Landaus und Rosa Marck einer Scheidung vehement entgegenstanden. Theodor Landau, der Vater, sollte seine Tochter sogar verleugnen. Diese Kräfte, die an einer zwanghaften Bindung zwischen ihm und Lola festhalten wollten, stießen bei Siegfried Marck, der sich in der Zwischenzeit eindeutig zu seiner neuen Lebensgefährtin bekannte, auf keinen fruchtbaren Boden:

„Lass Dich doch von mir einen Augenblick zurückversetzen in die Atmosphäre als wir damals zu viert über die Angelegenheit sprachen. Damals hatten sich noch nicht die Eltern $[\ldots]$ in unsere Dinge hineingemischt. ${ }^{، 228}$

Theodor Landau und seine Frau Philippine waren Republikaner und distanzierten sich von ihrer Tochter. ${ }^{229}$ Mit den Wirren nach dem Ende des Ersten Weltkriegs und dem daraus resultierenden Einsetzen der von ihnen befürchteten Arbeiterregierung

\footnotetext{
${ }^{223}$ Vgl. Marck an Lola Landau: ohne Datum (wahrscheinlich 1920), NL ATW.

${ }^{224}$ Siehe die Briefe Marcks an Wegner, 08.10.1919, 18.10.1919, 27.10.1919, 04.12.1919, 20.01.1920, 22.03.1920, 13.05.1920, 08.07.1920, 06.10.1920, 17.01.1921, 10.02.1921, 20.04.1921, 17.07.1921, 13.08.1921, 19.09.1921, NL ATW.

${ }^{225}$ Marck an Wegner, 08.10.1919, NL ATW.

${ }^{226}$ Vgl. Marck an Wegner, 27.10.1919, NL ATW.

${ }^{227}$ Vgl. ebd.,; 04.12.1919, 20.01.1920, NL ATW.

${ }^{228}$ Marck an Landau, ohne Datum, wahrscheinlich Anfang 1920.

${ }^{229}$ Marck an Wegner, 20.01.1920.
} 
nach dem Vorbild Russlands konnten sie nur spöttisch umgehen. „Die Revolution verlief doch so vorschriftsmäßig wie ein Parademarsch“, wurde beim Kartenspielen mit Freunden festgestellt. ${ }^{230}$

Dass ihre Tochter mit dieser Bewegung sympathisierte, war ihnen vorerst nicht gegenwärtig. Später musste auch Theodor Landau vernehmen, dass revolutionäre Studenten eigenmächtig die Breslauer Universität schlossen und den Lehrkörper entließen und dass seine Tochter Lola dies begrüßte. Letztlich litt Lola seiner Meinung nach an „Revolutionsmasern“ wie all die anderen, die versuchen wollten, die Wissenschaft zu politisieren. ${ }^{231}$

Das, was die Schwiegereltern Landau durch die Auflösung der Ehe befürchtet hatten, nämlich eine Rufschädigung der Familie in gewissen gesellschaftlichen Kreisen, war letztlich derselbe Vorwurf verbunden mit Angst, den Lola an Siegfried Marck richtete. Landau befürchte, dass Marck in Breslau schlecht über sie geredet habe, insbesondere in den Breslauer Kreisen, in denen sie sich nie besonders wohl gefühlt hatte. In einem Brief an Landau negierte Marck, dass er dies forciert und Gerüchte in die Welt gesetzt habe:

„Wer sorgte dafür, dass Dein Name nicht mit Schmutz beworfen wird? [...] Gott ist mein Zeuge, dass ich nie etwas anderes als ein Auseinandergehen in Friede und Freundschaft mit Dir gewollt habe. [...] Wenn dieses Auseinandergehen in Friede und Freundschaft nicht geht, so sind im Wesentlichen Deine Eltern daran Schuld, die das tun, um mein Gewissen zu belasten. “232

Neben der Angst vor gesellschaftlichem Spott, den es nachweislich in Breslauer Kreisen gab, ${ }^{233}$ bildeten das Sorgerecht für die Söhne Andreas und Alfons und der Umgang und ihnen einen Konfliktherd. Lola und Fried befürchteten durch die Trennung und die neuen Lebenspartner deren Entwicklung zu schaden. Dazu kam die Forderung nach Unterhaltskosten. Besonders Siegfried Marck sah es nur ungern, wenn Armin T. Wegner die Rolle des Vaters für seine Söhne einnahm, wie folgende Zeilen in einem Brief an Lola verdeutlichen:

„Es gibt für die Kinder nur dort die Mutter und hier den Vater aber der Gatte der Mutter gehört zu dieser und die Gattin des Vaters zu ihm. Zentrale Beziehungen in der Ehe können nicht von einem Teile allein gepflogen werden - das hat unser Leben und Schicksal eingepaukt. Armins Wort von den zwei Vätern ist nur bedingt richtig, es bleibt der Vater der Vater und mehr noch vielleicht die Mutter die Mutter.“234

\footnotetext{
${ }^{230}$ Landau, Lola: Vor dem Vergessen, S. 107f.

${ }^{231}$ Vgl. ebd., S. 112.

${ }^{232}$ Marck an Landau, ohne Datum, wahrscheinlich Anfang 1920.

${ }^{233}$ Marck an Wegner, 22.03.1920, NL ATW.

${ }^{234}$ Marck an Landau, 21.03.1922, NL ATW.
} 
Für die Kinder muss die Situation schwierig gewesen sein. Sowohl Andreas als auch der zwei Jahre jüngere Alfons pendelten zwischen Neu-Globsow am Stechliner See, Berlin, wo Lola und Armin lebten, und Breslau, wo Siegfried mit seiner Mutter und seiner zweiten Frau Kläre lebte. Dennoch war es Rosa Marck, welche die Kinder in Breslau gerne zu sich nahm, wenngleich ihr Gesundheitszustand das nicht immer zuließ und es ihr auch den Schlaf raubte, wie Marck immer wieder in seinen Briefen betonte. $^{235}$ Das Sorgerecht für die Kinder hatte Lola bekommen und die Unterhaltszahlungen brachten Siegfried Marck in schwere finanzielle Nöte. Er, der doch eigentlich aus sehr wohlhabendem Elternhaus kam, konnte es sich vorerst nicht leisten, mit Kläre zusammenzuziehen. Marck verdeutlichte:

\begin{abstract}
„Mein Arbeitseinkommen incl. Kinder und Frauenzulage beträgt monatlich M 234. Die M 50 die ich Lola seit Dezember jetzt schicke bedeuten mehr als ein Fünftel meines Einkommens und sind der Ausdruck meines Willens das mir Höchstmögliche für den Unterhalt der Kinder zu leisten. [...] Es ist überflüssig zu sagen, dass diese Abgabe von meinem Einkommen eine sehr erhebliche Einschränkung des Lebensunterhaltes meiner Breslauer Familie bedeutet, da ich keine anderen Einnahmen habe und das Einkommen meiner Frau sehr gering ist. Außerdem ist das Einkommen meiner Mutter, die uns sonst etwas unterstützte jetzt gleich null sodass sie sich nur mühselig durch Verkauf von Hausrat erhalten kann.““236
\end{abstract}

Folglich verkauften die Marcks Möbel, die seit Jahrzehnten in Familienbesitz waren, auch weil Siegfried als Privatdozent kein großes Einkommen hatte, wie er Wegner verdeutlichen musste:

„Ich kann Ihnen aber versichern, dass wir gerade das ungefähre Existenzminimum eines gehobenen geistigen Arbeiters zur unserer Verfügung haben, dass wir dabei uns eine unsere Verhältnisse eigentlich weit übersteigende Wohnung halten müssen, dass meine Arbeitseinkünfte sich nicht gesteigert haben sondern in meinem eigentlichen Beruf immer noch 0 betragen, wir uns also auch auf das äußerste einschränken müssen. “237

Mehr noch war es Rosa, die schon zuvor für das Leben von Siegfried und Lola in Breslau aufgekommen war, die sich nun mit Lola zerstritt ${ }^{238}$ und auch jetzt ihren Sohn nebst Kläre unterstützte. Zudem verkaufte Rosa Wertgegenstände in Höhe von 20.000M, um ihren Enkeln Reservefonds einzurichten, die von Lola und Armin verwaltet wurden. ${ }^{239}$ Die Fronten waren verhärtet.

Interessanterweise setzte Marck seine Kriegserlebnisse aus dem Ersten Weltkrieg mit der Trennung seiner Ehe gleich:

„Ich benutzte in dem Kampf gegen das Verantwortungsgefühl für Erhaltung der Ehe die Bourgeoisie-Massstäbe zu meinen Gunsten. Ich benutze sie als ich meine Mutter umstimmte am grausigen Weihnachtsabend 1919. Ich benutzte sie als Druckmittel in den Widerlichkeiten des späteren juristischen Kampfes. Dies bleibt ein Flecken, den ich mein

\footnotetext{
${ }^{235}$ Vgl. ebd.

${ }^{236}$ Marck an Wegner, 20.06.1924, NL ATW.

${ }^{237}$ Marck an Wegner, 20.04.1921, NL ATW.

${ }^{238}$ Marck an Wegner, 08.07.1920, NL ATW.

${ }^{239}$ Marck an Wegner, 28.05.1922, NL ATW.
} 
Leben lang mit mir tragen werde. Was dann im Kampfe der Familien und in den Widerwärtigkeiten einer Eheauflösung alles zerstört wurde, ist grauenhaft. Es war wie beim Weltkrieg: nach dem Losgehen der Gewehre schwand alle Ritterlichkeit, der Mechanismus der Situation - sollen nun unsere Beziehungen für alle Zukunft so verschüttet bleiben? Hart auf ein jeder Menschlichkeit bares Vertragsrecht gestellt? ‘240

Erst zwei Jahre später war es Siegfried und Lola möglich, sich wieder auszutauschen. $^{241}$

Nicht nur privat hatten sich die Weichen Siegfried Marcks neu gestellt. Auch politisch vollzog er einen Grenzgang, der für sein weiteres Wirken von großer Bedeutung war - er kehrte während seiner Ehe mit Lola Landau seiner nationalliberalen Geisteshaltung den Rücken. Ein Verhalten, das es genauer zu untersuchen gilt.

\footnotetext{
${ }^{240}$ Marck an Wegner, 06.12.1920, NL ATW.

241 Siehe etwa die Briefe Marcks an Landau, 21.03.1922, 31.03.1922, 01.03.1924, 04.04.1924, 26.04.1924, 05.05.1925, 26.05.1931, NL ATW.
} 


\section{Der Übergang zur Sozialdemokratie}

Immer wenn Siegfried Marck nervös war, zog er seine rechte Augenbraue hoch und strich sich heftig mit dem Daumen darüber. Ursprünglich war dies eine Bewegung, an der man dem Breslauer Philosophiedozenten ansehen konnte, dass er auf einen neuen und anregenden Gedanken gestoßen war. In den kommenden vier Jahren sollte diese Geste ein wenig umgemünzt werden - sie diente fortan dazu „die Bilder des Grauens fortzuwischen“. ${ }^{242}$ Bei besonderer Anspannung fing sein Kopf zudem an zu zittern. So war es auch, als er nach der ärztlichen Untersuchung für den Kriegsdienst als untauglich befunden wurde. Sich „Für wertlos befunden und verworfen“ fühlend in der für ihn schmerzvollen Einsicht, dass ,geistige Begabung dem Vaterland jetzt nicht nützen kann“, trat Siegfried Marck seiner Ehefrau Lola Landau nach der ärztlichen Untersuchung entgegen, so beschämt als wäre er seiner Manneswürde beraubt worden. ${ }^{243}$ Siegfried Marck hatte einen angeborenen Herzfehler, der ihm große körperliche Anstrengung nicht erlaubte und war zudem farbenblind. Doch der Breslauer Philosophiedozent suchte nach einer Möglichkeit, wie er seinem Vaterland nun doch dienen könnte. Immerhin wollte auch er seinen Beitrag leisten. Deutsche Staatsgesinnung sollte der Titel einer kurzen Abhandlung werden, für die sich Siegfried Marck in den Jahren nach dem Ersten Weltkrieg schämen sollte. Erschienen ist diese Schrift in der renommierten Beck'schen Verlagsbuchhandlung in München. Gewidmet hat Marck diese Abhandlung seinem Bruder Lutz, der 1914 im Krieg gegen England verwundet worden und in Breslau an den Verletzungen gestorben war. $^{244}$

Für Marck war Deutschland damals „heilig“, einmalig, der Einzelne unverzichtbar; Deutschland mit seiner besonderen Kultur, seiner Musik, seiner Dichtung und seiner Philosophie. „Man hat es umkreist, man will es vernichten. Sollen wir das dulden?“245 Mit dieser Grundhaltung reihte sich der nationalliberale Marck in die Gedanken vieler innerhalb des Breslauer Bürgertums ein, insbesondere im jüdischen Bürgertum, das sich in seinem Dienst für das Vaterland einen weiteren Schritt in Richtung seiner vollständigen Assimilation erhoffte. Und für Marck war es ein Wunder, im positiven Sinne, dass sich Deutschland im Weltkrieg befand. Die

\footnotetext{
${ }^{242}$ Landau, Lola: Vor dem Vergessen, S. 59.

${ }^{243}$ Vgl. ebd., S. 33.

244 Vgl. Louis Marck an den Archivleiter des LBI New York mit Ergänzungen zum dortigen Familienstammbaum, 05.10.1983, LBI NY; Innerhalb der Familie wurde dies immer als ein wichtiger Aspekt genannt, weshalb Siegfried Marck seine Einstellung zum Krieg änderte, vgl. Persönliche Nachricht von John March an den Verfasser, 29.10.2011.

${ }^{245}$ Vgl. Landau, Lola: Vor dem Vergessen, S. 34.
} 
Grundlage für dieses Wunder bildete die deutsche Staatsgesinnung, „die vollkommene ureigne Ursprünglichkeit, mit der der Deutsche seinen Staat erlebt, bildet die vornehmlichste und am glänzendsten bewiesene Überlegenheit gegenüber allen anderen europäischen Nationen.“"246 Bemerkenswert ist innerhalb der Abhandlung die Bezugnahme auf die andere neue treibende Kraft, den Sozialismus:

\begin{abstract}
„Die sittliche Staatsidee heischt die Aufhebung wirtschaftlicher Vorrechte, um alle Bürger zu den gleich Pflichten gegen alle anderen heranzuziehen. Wo die wirtschaftliche Stellung des Einzelnen oder einzelner Stände geradezu eine Gefahr für die bürgerliche Freiheit wird, hat der Staat die unbedingte Pflicht zum Eingreifen. Dann öffnet er gleichsam das Ventil des Druckes über den unteren Klassen, nicht lediglich aus Menschenliebe, sondern um ihre ganze ungeteilte Kraft in seinen sittlichen Sinn einbeziehen zu können. Hier verfährt der moderne Staat dem Sozialismus gegenüber ähnlich, wie es die Männer der preußischen Reform mit den Ideen der französischen Revolution taten: von einem anderen Ausgangspunkt aus machen sie diese nutzbar, um aus Untertanen Vollbürger zu machen und sie für den Staat zu gewinnen.[...] So nimmt die deutsche Staatsgesinnung, die von den Wirtschaftskämpfen des 19. Jahrhunderts geboren war, die moderne Bewegung des Sozialismus in sich auf und verspricht diesem eine neue Zukunft. Sie hat die Mission, ihn zu entkapitalisieren und wieder ganz zum Idealismus zu erheben, von dem er - Marx - Hegel - ! abgefallen war. Die deutsche Staatsgesinnung ist in der Tat der idealistisch verstandene Sozialismus. “247
\end{abstract}

Aber umso mehr verdeutlichte Marck innerhalb dieser Schrift sein nationalliberales Gedankengut, indem er den deutschen Staat und dessen Geschichtsauffassung als wahrhaft europäisch beschreibt:

„Tut eure Furcht ab, Ihr europäischen Nationen, vor der deutschen Strenge und Kraft. Deutschland wird für Europa dasselbe werden, was Preußen für Deutschland war: der Führer, Erzieher und kraftvolle Schirmer. Heute lautet für Europa die Alternative: Deutschland oder England, wie sie einst für Deutschland Preußen oder Österreich hieß.“248

Dabei verwendet Marck innerhalb der gesamten Schrift gerne die Vokabeln des ,jüngeren“ und „härteren Volkes“ und betont dabei, dass Deutschland „gegenwärtig gegen Europa den Kampf für Europa“ kämpfte, vielmehr noch hätte Deutschland bereits gesiegt, wenn nicht „die ganze Welt, wenn nicht Japan und die Vereinigten Staaten alles aufbieten würden, um zu der Niederlage des kommenden Führers von Europa mitzuwirken“. 249

Siegfried Marck vertrat aufgrund der Tatsache, dass die Universität während des Krieges geschlossen war, einen Gymnasiallehrer und brachte zwölfjährigen Jungen Latein bei. Am meisten beeindruckte ihn das Wesen des Schülers Hans Kliem, eines schmalen Jungens mit hellblondem Haar, frisch und immer fragelustig bis zur Frechheit:

\footnotetext{
${ }^{246}$ Marck, Siegfried: Deutsche Staatsgesinnung, München 1917, S. 1f.

${ }^{247}$ Ebd., S. 33f.

${ }^{248}$ Ebd., S. $71 \mathrm{f}$.

${ }^{249}$ Vgl. ebd., S. $61 \mathrm{ff}$.
} 
„Dieser Bursche Hans Kliem ist so unbeschwert, so unbelastet. Vielleicht ist es das, was mich, einen Menschen von komplizierter Geistigkeit, anzieht. Das Unproblematische, das...nun, das Unjüdische vielleicht.“.250

Mit der Frage Lolas konfrontiert, ob der werdende Vater Siegfried Marck seinen damals kurz vor der Geburt stehenden Sohn Andreas später genauso sehen möchte, wie seinen Lieblingsschüler Hans, verneinte Marck dies mit den Worten: „Ach nein, Bebu [so wurde der Ungeborene genannt] soll ein nachdenkliches, denkendes Wesen werden.“251 In ihrer Autobiographie konstatiert Lola Landau ihrem Mann einen typischen geistigen Hochmut, dieses Überlegenheitsgefühl des assimilierten deutschen Juden, das doch eigentlich einem Minderwertigkeitsgefühl entspringe und dessen Unsicherheit sich mit der Sehnsucht nach einem völligen Aufgehen im anderen Volke mische. ${ }^{252}$

Interessanterweise war es genau zu dieser Zeit, dass ihm zum ersten Mal offener Antisemitismus entgegengebracht wurde. Als Marck anlässlich einer Siegesfeier in der Aula einen Vortrag halten sollte, war es der Geschichtslehrer des Gymnasiums, ein Reserveoffizier, der ihm vorwarf, dass der Vortrag viel zu allgemein, viel zu intellektuell und nicht volkstümlich genug gewesen sei. Vielmehr noch brauche die Jugend heute nationales Brot und keine geistigen Leckerbissen, diagnostizierte der Offizier der Reserve weiter, „Aber woher sollten Sie das geben können, es liegt Ihnen nicht, bei Ihrer anderen Herkunft.“253 Ein einschneidender Moment für den jüdischen und nationalliberalen Intellektuellen. Aber es war nicht nur der Lehrkörper, der offenem Antisemitismus ausgesetzt war. Direkt nach dem Ende des verlorenen Ersten Weltkrieges waren die Ressentiments gegenüber jüdischen Mitbürgern in Breslau vor allem in staatlichen Einrichtungen zu vernehmen. So wurde besonders das Realgymnasium am Zwinger zu einem Ort, an dem zwischen Juden und Christen unterschieden wurde und antisemitische Propaganda ihre Verbreitung fand. Insbesondere bei Schulausflügen sollen jüdische Schüler aufgrund ihrer religiösen Herkunft nachteilig behandelt worden sein sowie antisemitische Flugblätter unter den Schülern kursiert haben, ${ }^{254}$ was strikt von der Direktion der Bildungsstätte geleugnet wurde. ${ }^{255}$ Dass dabei auch mancher Lehrer selbst die Judenhetze in Schulen vorantrieb, verdeutlicht ein weiteres Beispiel aus

\footnotetext{
${ }^{250}$ Landau, Lola: Vor dem Vergessen, S. 36

${ }^{251}$ Ebd., S. 37.

${ }^{252}$ Vgl. ebd.

${ }^{253}$ Ebd., S. 38.

${ }^{254}$ Vgl. Breslauer Volkswacht, 01.07.1919.

${ }^{255}$ Vgl. ebd., 04.07.1919.
} 
dem alt ehrwürdigen Breslauer Magdalenen-Gymnasium, das immerhin eines der traditionsreichsten deutschsprachigen Gymnasien seiner Zeit war. Ein dortiger Lehrer, Professor Türk, titulierte in seiner „Rede an die Dummen“ jüdische Schüler und Arbeiterkinder als „Esel“, „Maulhelden“, „Schafsköpfe“ oder „Lügner“ und missbilligte die Errungenschaften der Revolution. ${ }^{256}$ Diese Tendenzen waren auch viele Jahre nach diesem Vorfall in diesem Gymnasium spürbar. Fritz Stern war als evangelisch getaufter Jude selbst Schüler an dieser Bildungsstätte und berichtet ebenfalls von offenem Antisemitismus. ${ }^{257}$ Dieser Antisemitismus wurde durch die Einwanderung von ca. 15.000 jüdisch-gläubiger Menschen aus dem Baltikum angefacht, die nach dem dortigen Revolutionsbeginn geflüchtet waren. ${ }^{258}$

In der Abschlussphase der Deutschen Staatsgesinnung, im Herbst 1916, als diese noch zur Korrektur beim Verleger war, während an der Ostfront die Lücken geschlossen werden sollten, wurde Siegfried Marck doch frontdienstfähig geschrieben und ins Feld geschickt. Trotz des Herzfehlers meinte der untersuchende Arzt:

„Dein Herz ist schnellschlägig. Es hat ein etwas zu schnelles Tempo. Nun, Tempo ist das, was wir jetzt brauchen. Auch wenn Du nicht gerade im Sturmangriff mithalten kannst - am Telefon im Schützengraben sitzt es sich ganz bequem. Dafür reicht es. ${ }^{\text {‘259 }}$

Nach sechswöchiger Grundausbildung im Übungslager sollte Marck direkt an die Front geschickt werden. Zu seinen Sachen packte er zwischen Hemden und Socken philosophische Bücher, insbesondere eine Handausgabe von Goethes Faust, viele weiße, unbeschriebene Briefbogen und gespitzte Bleistifte - „das Handwerkzeug, die Waffen des Geistes, die er nicht abliefern wollte“. ${ }^{260}$ Während des Abschiedsabendessens bei seinen Eltern offenbarte auch der Vater Siegfrieds sein nationales Gedankengut. Sein Vater war offenkundig Mitglied der Nationalliberalen und fand dort seine politische Heimat. Innerhalb der prächtig ausgeschmückten

\footnotetext{
${ }^{256}$ Vgl. ebd., 05.07.1919.

257 Vgl. Stern, Fritz: Fünf Deutschland und ein Leben, S. 151-163. Stern war der letzte jüdische Schüler des Magdalenengymnasiums und verließ dieses kurz vor dessen Flucht in die USA im September 1938.

${ }^{258}$ Zahlen dazu sowie die Stellung der Breslauer Sozialdemokratie: „Die ostjüdische Einwanderung“ in: Breslauer Volkswacht, 28.02.1920; zu „Ostjuden“ siehe: Heid, Ludger: Die Kultur der osteuropäischen Juden im Deutschland der Weimarer Republik, in: Erler, Hans et al. (Hrsg.): Jüdisches Leben und jüdische Kultur in Deutschland. Geschichte, Zerstörung und schwieriger Neubeginn, Frankfurt am Main 2000, S. 174-201; Ders.: „Dem Ostjuden ist Deutschland das Land Goethes und Schillers“. Kultur und Politik von ostjüdischen Arbeitern in der Weimarer Republik, in: Archiv für Sozialgeschichte, 37 (1997), S. 179-206; Ders.: „Proletarier zu sein und Jude dazu, das bedeutet unsägliches Leid...“. Sozialisten zur „Ostjudenfrage“, in: Ders. et al. (Hrsg.): Juden und deutsche Arbeiterbewegung bis 1933, S. 177-193; Maurer, Trude: Ostjuden in Deutschland: 19181933, Hamburg 1986.

${ }^{259}$ Landau, Lola: Vor dem Vergessen, S. 44.

${ }^{260}$ Vgl. ebd., S. 45.
} 
Ahnengalerie der Familie Marck, von der noch ein Bild im Leo-Baeck-Archiv in New York zu finden ist, soll zu Zeiten des Ersten Weltkrieges eine große Landkarte Europas angebracht worden sein. Davor wurde sich versammelt und mit Hilfe von Stecknadeln der Vormarsch der deutschen Truppen nachgezeichnet. ${ }^{261}$

Überhaupt sog Marck in den ersten Kriegsjahren, wie viele andere auch, euphorisch die patriotischen Gedanken und Gefühle jener Jahre in sich auf. Alois Riehl, der Mentor Richard Hönigswalds, war einer der 93 Unterzeichner des Aufrufes an die Kulturwelt und verstand ebenso wie Marck den preußischen Militarismus als Träger und Schützer der deutschen Kultur. Auch Eugen Kühnemann sah das deutsche Volk, besonders nach dem Eintritt der USA in die Kriegsgeschehnisse, aber auch schon im Vorhinein, von der proenglischen und kriegsbereiten Einstellung der amerikanischen Regierung bedroht. ${ }^{262}$

Was es dann wirklich hieß in den Krieg zu ziehen, auch wenn er vorerst „nur“ als Funker tätig war, sollte Siegfried Marck bald verstehen, wie der Briefwechsel zwischen Siegfried Marck und Lola Landau innerhalb diverser Feldpostbriefe beweist. Eine grundlegende Neuerung brachte die Situation auch mit sich: Der Angehörige des Breslauer Bürgertums, der nationalliberale jüdisch-intellektuelle Philosophiedozent lernte zum ersten Mal Menschen aus einer anderen Klasse und anderem Kulturkreis kennen:

\begin{abstract}
„Bisweilen tauchten in Frieds Briefen die Gesichter einiger Kameraden auf. Da war Reinhold, der lange magere Schuhmacher, der langsam und gewichtig die Worte zwischen seinen hohlen Wangen kaute, um platte tröstliche Lebensweisheiten von sich zu geben. [...] Da war Max, der dicke Schlosser, dessen schwarze kleine Augen in dem massigen roten Gesicht verschwanden, wenn er lachte oder unanständige Witze erzählte. Da war Heinrich, der schweigsame Bergarbeiter, der hinter seinen bläulichen, unrasierten Stacheln und mürrisch geschwollenen Backen stumm Tabak kaute, bis er plötzlich auffuhr und lange sozialistische Parteireden hielt, als stünde er auf einem Podium.“" ${ }^{663}$
\end{abstract}

Es war der erste Kontakt mit einfachen Arbeitern, mit denen Siegfried Marck in den Schützengräben kämpfte, oftmals waren es Sozialisten. Er lieh sich deren Zeitungen aus, darunter sicher auch die Breslauer Volkswacht, las Flugschriften der Arbeiterklasse und ließ sich von deren Argumenten überzeugen. ${ }^{264}$ Von hier an änderte sich im Leben Siegfried Marcks alles. Beim Vorrücken der Front nahm Siegfried Marck einem gefallenen englischen Offizier einen Brief an dessen Frau ab und schickte diesen Lola, damit diese ihn über das Rote Kreuz in der Schweiz an die

\footnotetext{
${ }^{261}$ Vgl. ebd.

${ }^{262}$ Vgl. Schwabe, Klaus: Wissenschaft und Kriegsmoral. Die deutschen Hochschullehrer und die politischen Grundfragen des Ersten Weltkrieges, Göttingen 1969, S. 103.

${ }^{263}$ Landau, Lola: Vor dem Vergessen, S. 50.

264 Vgl. Osterroth, Franz: Biographisches Lexikon des Sozialismus, Bd.1. Verstorbene Persönlichkeiten, Hannover 1960, S. 211.
} 
Frau des Toten schicken konnte. Marck war es offenbar wichtig, dass die Frau des Gefallenen Gewissheit über dessen Tod hat. ${ }^{265}$ Zudem musste er erkennen, dass der englische Offizier letztlich genau dieselben Gedanken, Befürchtungen und Ängste seiner Frau vermittelte, wie er es auch tat. Für Lola war dieser Brief ein Wendepunkt in ihrer Einstellung zum Krieg, den sie fortan in der „Liga der Mütter“ bekämpfen wollte. $^{266}$

Acht Tage Sonderurlaub erhielt Siegfried Marck. Sein Vater litt an Spanischer Grippe, der er letztlich auch erlag. Es ist erstaunlich, wie die Schilderungen Lola Landaus in ihrer Autobiographie diesen Mann beschreiben. Wie er sterbenskrank bis zu seinem Tod seinen strategischen Heimatkrieg fortführte. ${ }^{267}$ Sein Filius hingegen berichtete Lola von den schrecklichen Ereignissen an der Front:

„In Wirklichkeit sieht ein Vormarsch anders aus. Eine Treibjagd von Menschen, von Angreifern und Angegriffenen. Man wird von hinten getrieben, muß laufen, man trampelt über durchlöcherte Erde, über zerrissenen Stacheldraht, über Leichenhaufen. Eine Granate zischt, man wirft sich eine Sekunde nieder, dann läuft man weiter. Das Bewußtsein ist ausgelöscht. “268

Einst die deutsche Staatsgesinnung bejahend, musste sich Marck nun eingestehen, dass es zum jetzigen Zeitpunkt unmöglich war, gegen das ausgeklügelte System der Armee, „in dem jeder vor dem nächsten Übergeordneten erstarrt, gegen diesen blinden automatischen Gehorsam“ zu kämpfen, was Lola sehr begrüßte. „Das Denken wird amputiert, das Bewusstsein ausgeschaltet. Wir sind Maschinenteile“ berichtete Marck ernüchtert von den ersten Kriegserlebnissen. ${ }^{269}$

Nachdem er ein zweites Mal von der Front nach Hause kam, um die Geburt seines zweiten Sohnes Alfons mitzuerleben, musste er sich die Niederlage Deutschlands eingestehen:

„Der Zusammenbruch an der Front ist unaufhaltsam. Nur noch einige Monate, und alles kracht zusammen. Aber es ist mehr als eine nationale Niederlage. Es ist ein Zusammenbruch des ganzen Systems. Ihr wißt es noch nicht. Aber draußen wissen wir es alle. Die Front der bürgerlichen Gesellschaft bricht zusammen, sie hat abgewirtschaftet, sie hat sich selbst zum Tode verurteilt. Vielleicht führt der Weg durch das Chaos, die Revolution. Wir müssen hindurch. “270

Marck machte sich viele Gedanken, was für ihn nun der richtige politische Weg sei. Fest stand für ihn, dass sich alles politisiert hatte. Und wie sollte er seiner Mutter, zu der er ein sehr enges Verhältnis hatte, insbesondere nach dem Tod des Vaters, erklären, dass er sich den Sozialisten anschließen wollte? Es war dann genau dieser

\footnotetext{
${ }^{265}$ Vgl. Landau, Lola: Vor dem Vergessen, S. $51 \mathrm{f}$.

${ }^{266}$ Vgl. ebd., S. 64.

${ }^{267}$ Vgl. ebd., S. 61ff, S. 66ff.

${ }^{268}$ Ebd., S. 63f.

${ }^{269}$ Vgl. ebd., S. 64.

${ }^{270}$ Ebd., S. 85.
} 
Einfluss der Mutter, der Siegfried Marck zögern ließ, sich voll und ganz bereits während des Krieges den Sozialisten anzuschließen:

„Fried, um Gotteswillen, das darfst du nicht tun. Du ruinierst dein Leben. [...] Du machst dich unmöglich an der Universität. Du stempelst dich zum Vaterlandsfeind. Du zerstörst deine Laufbahn. Was wir so mühsam erreicht haben, setzt du auf's Spiel; diene der Zukunft als Gelehrter. Das ist dein Leben, nicht die schmutzige Politik. ${ }^{\text {‘271 }}$

Doch Marck wusste, dass sein Leben nicht mehr von der Politik zu trennen war. Für ihn durchdrangen die rückschrittlichen Kräfte, mit ihren Werten von Sicherheit und Ordnung, für die seine Familie seit Generationen innerhalb Breslaus eingestanden war, alles was für ihn öffentlich von Bedeutung war - „Kirche, Schule, Universität“. Damit stand Marck zwischen seiner auf Ordnung und Sicherheit bedachten Mutter und seiner dem Sozialismus sehr zugetanen Frau Lola und beschloss, bevor er wieder zurück an die Front geschickt wurde:

„Ich werde meinen Anschluß an die Sozialisten vertagen. Es ist verfrüht. Meine Mutter ist nicht nur eine kluge, sondern auch eine weise Frau. Ich könnte im Augenblick niemandem nützen, es würde nur meine eigene Stellung unterhöhlen. Gerade in meiner Stellung an der Universität aber kann ich später in meinen Kreisen Einfluß ausüben [... $]^{\text {‘2272 }}$

War der Breslauer Philosophiedozent noch mit großer Begeisterung in den Krieg gezogen, wo er zuerst nur als Funker an der Front diente, so änderte sich seine geistige Einstellung - vom national-liberal getragenen Gedanken für das Vaterland in den Krieg zu ziehen hin zu der Einsicht innerhalb des aufkeimenden Sozialismus seinen Weg $\mathrm{zu}$ suchen. Seine alte politische Heimat schien für ihn zusammengebrochen und die Ereignisse in den Schützengräben, die Luft- und Gasangriffe, der Kontakt zu einfachen Arbeitern und die Beschäftigung mit dem Sozialismus änderten die politische Einstellung Marcks. Auch die Geburten seiner Söhne Andreas und Alfons machten ihm immer mehr bewusst, „für diese Kinder, für die nächste Generation müssen wir kämpfen, sie sollen keinen Krieg mehr erleben“،273. Auch die Einwände seiner Mutter fruchteten nicht mehr. Nahezu in Satzfragmenten schreibt Siegfried Marck seiner Ehefrau kurz vor seiner Heimreise von der Front:

„Kurz vor Eins werde ich fahren. Bin sehr gespannt. Werde mächtig loslegen für Sozialdemokratie gegen Bolschewismus aber auch gegen die stark werdenden Mächte der Gegenrevolution. Vielleicht liest Du es aus den Zeitungen.[...] $]^{\text {‘274 }}$

Siegfried Marck wurde Sozialdemokrat und schloss sich der Sozialdemokratischen Partei $a^{275}$, als er 1918 nach Breslau zurückkehrte. Es war sein fester Entschluss:

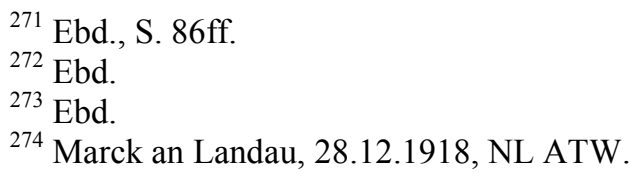


„Ich werde in den Rat der geistigen Arbeiter eintreten. [...] Die Zeit für Preußens Juncker ist vorbei! Sie haben nur Unglück gebracht. [...] Nieder mit der Gegenrevolution! Nieder mit der Anarchie!“6276 Mit roter Armbinde kehrte Siegfried Marck zurück nach Breslau, überzeugt von der sozialistischen Idee und dem Friedensgedanken: „Unsere Niederlage wird einen Sinn haben. Nicht nur für Deutschland. Für Europa. Ein neues Völkerrecht muss entstehen. Dies war der letzte Krieg“'277. Aus dem nationaldenkenden, abstrakt wirkenden Wissenschaftler wurde ein Pazifist, ein Europäer, der sich der Arbeiterbewegung zuwandte. Auch seine damalige Frau Lola Landau wurde in jenen Jahren politisiert. Sie soll die Revolution als notwendige Konsequenz aus dem Krieg gesehen, die Monarchie abgelehnt und die Republik begrüßt haben. ${ }^{278}$

Siegfried Marck wurde, als 1918 in Deutschland die Revolution ausbrach, von der Armeeabteilung A einstimmig zu deren Sprecher gewählt. Das, was er scherzhaft als Beförderung empfand, verdankte er zum einen der Tatsache, dass er „ohne Punkt und Komma“ reden konnte und zum anderen seinen Französischkenntnissen, die ihm schon bei Verhandlungen zum Austausch von Kriegsgefangenen hilfreich gewesen waren. ${ }^{279}$ Es waren bewegende Monate nachdem sich Marck entschlossen hatte, sich der Sozialdemokratie anzuschließen, wie Lola Landau verdeutlicht:

„Ich sprach viel mit Fried über die Forderungen der Tagespolitik, ich begleitete ihn in die Versammlungen, ich lachte und spielte mit den Kindern, mein Heim schwirrte von Besuchern, neuen politischen Freunden Frieds; das Klappern der Schreibmaschine, in die mir Fried seine Reden diktierte, hörte man oft bis in die späte Nacht.[...] Er kam kaum zur Besinnung. Die politische Maschinerie, das laufende Band, drehte ihn von Sitzung zu Sitzung, von Versammlung zu öffentlicher Massenkundgebung. ‘ ${ }^{\text {‘280 }}$

Marck fungierte zu der Zeit als Leiter des Demobilisierungsrates in Breslau und empfing in seinem Büro täglich eine Vielzahl von Soldaten, denen er bei der Erstattung von Reisekosten oder bei der Beschaffung von ein paar neuen Stiefeln half. Dabei glich er letztlich einem Fürsorgebeamten, der sich auf die deutsche Republik einschwor und dabei auch den Konflikt mit seiner Mutter nicht mehr scheute. Rosa Marck war indes froh, dass ihr Sohn unversehrt aus dem Krieg

275 Ebd. Hier schreibt Marck in Klammern, dass er von der Sozialdemokratischen Partei (Scheidemann) spricht.

${ }^{276}$ Ebd.

277 Ebd.

${ }^{278}$ Vgl. Hamann, Birgitta: Lola Landau, S. 32.

${ }^{279}$ Vgl. Landau, Lola: Vor dem Vergessen, S. 119.

${ }^{280}$ Ebd., S. 121. 
zurückgekehrt war, hegte jedoch großen Zweifel an dessen neuer politischer Stoßrichtung. ${ }^{281}$

Siegfried Marck nahm vom 16. bis 21. Dezember 1918 am Allgemeinen Kongress der Arbeiter- und Soldatenräte im Berliner Abgeordnetenhaus teil. Dort wird er auch Paul Löbe getroffen haben, der damals als Redakteur der Breslauer Volkswacht und als Mitglied des Stadtrates für die Sozialdemokraten sowie als Mitglied des Provinziallandtages tätig war. ${ }^{282}$ Marck war einer der rund 300 Delegierten der MSPD von insgesamt 514 Delegierten des Kongresses. Etwa 100 Delegierte waren der USPD zuzuordnen, andere waren linksliberal oder parteilos. ${ }^{283}$ Diesen Mehrheitsverhältnissen war es zu verdanken, dass in der entscheidenden Frage, die Verfassung der sozialistischen Republik auf das Rätesystem oder auf eine parlamentarische Demokratie zu gründen, mit großer Mehrheit zu Gunsten Letzterer abgestimmt wurde. So wurde beschlossen, die Wahlen zur verfassunggebenden Nationalversammlung am 19. Januar 1919 durchzuführen. Damit wurde zugleich die große Konfliktlinie zwischen der MSPD und USPD verbreitert. ${ }^{284}$

Als der Breslauer Philosophiedozent an das Rednerpult trat, warf er die Frage auf, wie sich ein sozialisiertes Deutschland gegenüber dem kapitalistischen Ausland verhalten solle. Immerhin sei in Deutschland, bedingt durch den Ersten Weltkrieg und die Niederlage des Kapitalismus, die politische Revolution gekommen, die soziale Revolution müsse darauf folgen. Marck argumentierte für eine schrittweise Sozialisierung des Wirtschaftslebens. Auf Russland blickend attestierte er den Revolutionären dort die Unfähigkeit, das Problem des Sozialismus in der Welt zu lösen. Russland verfüge objektiv nicht über die vollkommene Reife des kapitalistischen Systems, zu der Deutschland gekommen sei, zudem fehle es der russischen Sozialdemokratie an einer marxistischen Schulung. Für Marck stand fest, dass es Aufgabe der deutschen Sozialdemokratie sein müsse, das Problem des Sozialismus in der Welt zu lösen:

„Es muß der Ruhm der deutschen Sozialdemokratie sein, dem Geiste Karl Marx treu zu bleiben, [...]. Das ganze Ausland sieht in der deutschen marxistisch geschulten

\footnotetext{
${ }^{281}$ Vgl. ebd., S. $119 \mathrm{f}$.

${ }^{282}$ Vgl. Allgemeinen Kongreß der Arbeiter- und Soldatenräte Deutschlands vom 16.-21. Dezember $1918 \mathrm{im}$ Berliner Abgeordnetenhaus. Stenographische Berichte. S. 206, auf: http://edoc.huberlin.de/ebind/hdok/hp08_stenogr_berichte_1_1918/XML/ [zuletzt aufgerufen am 13.04.2013].

${ }^{283}$ Vgl. Winkler, Heinrich August: Der lange Weg nach Westen. Deutsche Geschichte von 18061933, München 2000, S. 385.

${ }^{284}$ Vgl. ebd., S. 385ff; Ders.: Weimar 1918-1933. Die Geschichte der ersten deutschen Demokratie, München 1993, S. 50ff.
} 
Sozialdemokratie seine Lehrmeisterin, weil sie auf wissenschaftlichem Fundament steht und infolgedessen keine überstürzten Experimente macht [...].“285

Dieser Wandel könne sich folglich nur ereignen, wenn dies in wirklich marxistischem Geiste geschehe:

„[...] im Unterschied zu dem dramatischen Feuerwerk und dem Putschismus der Russischen Revolution, kann die Umstrukturierung der Gesellschaft nur in wissenschaftlicher Besonnenheit und Selbstkritik geschehen. ${ }^{\circ 286}$

Doch für ihn stand auch fest, dass nur in einer neuen, demokratischen Gesellschaft eine pazifistische Lösung des Kriegsproblems möglich sei und positionierte somit den Pazifismus gegen den Imperialismus. ${ }^{287}$

Dies war ein wenig außergewöhnlich, bekannten sich doch nur wenige jüdische Intellektuelle direkt nach dem Ersten Weltkrieg zum Pazifismus. ${ }^{288}$ Zudem schloss sich Marck nicht dem Reichsbund jüdischer Frontsoldaten zur Abwehr des Antisemitismus an, der versuchte öffentlichkeitswirksam darauf hinzuweisen, dass es ca. 85.000 Juden waren, die im Ersten Weltkrieg für ihr Vaterland gekämpft und gestorben waren.

Dennoch gibt es Belege, dass sich Siegfried Marck auch nach seinem Grenzgang zur Sozialdemokratie weiterhin innerhalb der jüdisch-liberalen Gemeinde engagierte und für Pazifismus und ethischen Sozialismus eintrat. Innerhalb der Jüdischen-liberalen Zeitung machte er in einem Artikel über das Judentum und den Internationalismus deutlich, was für ihn die Losung eines jeden Juden sein müsse:

\begin{abstract}
„Aus der Sehnsucht nach seiner Überwindung [Marck meint hier einen negativen Internationalismus, der für ihn in der nationalen Entwurzelung des jüdischen Volkes zu suchen ist, Anmerkungen des Verfassers] durch einen nationalen Gehalt ist sowohl der Ruf nach Aufgehen im Deutschtum wie der Zionismus geboren. Hier heißt es sich entscheiden, ob man die nationaljüdische oder die nationaldeutsche Eigenart in sich pflegen will. Wie jede letzte praktische Stellungnahme lässt sich diese Frage nicht ausschließlich mit Vernunftgründen entscheiden, sondern fordert den auf innere Selbstgewissheit gegründeten persönlichen Entschluss. Nur eins kann von der in die Leere eines negativen Internationalismus gefordert werden: dass man sich überhaupt entscheide, dass man sich aus Halbheiten und Unklarheiten als dem bösen Erbteil unserer Geschichte heraus zum nationalen Bewusstsein durchdringe! ${ }^{6289}$
\end{abstract}

Die Familie Marck war über Jahrzehnte für ersteren Typus eingetreten. Auch für Siegfried Marck war die Pflege des Nationalgefühls notwendig für die Überwindung des negativen Internationalismus. Diese versuchte er jedoch durch den

\footnotetext{
${ }^{285}$ Siegfried Marck auf dem Allgemeinen Kongreß der Arbeiter- und Soldatenräte, S. 206f. 286 Ebd.

${ }^{287}$ Vgl. Marck, Siegfried: Imperialismus und Pazifismus als Weltanschauungen, Tübingen 1918, S. 22 u. 29.

288 Sieg, Ulrich: Jüdische Intellektuelle im Ersten Weltkrieg. Kriegserfahrungen, weltanschauliche Debatten und kulturelle Neuentwürfe, Berlin 2001, insb. S. 53-69.

${ }^{289}$ Marck, Siegfried: Judentum und Internationalismus, in: Jüdisch-liberale Zeitung, 18.03.1921.
} 
Menschheitsgedanken und sozialistische Gedanken positiv zu färben, indem er den Kapitalismus mit dem negativen Internationalismus gleichsetzte und seinen neu entdeckten Sozialismus, den er ethisch einzufärben versuchte, als Übernationalismus ansah. Für Marck stand die Ethik des Judentums sowohl zum ethischen Sozialismus als auch den Ideen des Völkerbundes und den Idealen der Menschheit in inniger Beziehung. Ihm zufolge war das Judentum dazu berufen, auch „in den Wogen des Hasses“ diese „messianische Idee hochzuhalten und sie vor jeder Verwechselung mit dem zersetzenden Internationalismus zu bewahren“. ${ }^{290}$ Später sollte es sein Sohn Alfons sein, der zweite Sohn aus der ersten Ehe mit Lola Landau, der nach Israel auswanderte um dort dem zweiten jüdischen Lebensentwurf nachzugehen.

Mit den Ereignissen des 9. November 1918 sollten sich auch in Oberschlesien die politischen Verhältnisse neuordnen. In Mittel- und Niederschlesien, folglich auch in Breslau, war von dieser Radikalität nicht viel zu spüren, was besonders den dortigen Arbeiterführern Paul Löbe und Fritz Voigt und nicht minder Personen wie Hermann Lüdemann, Karl Mache oder Gustav Scholich zu verdanken gewesen sein soll. $^{291}$ Als wesentlicher Grund dafür wurde der in Breslau gebildete Zentrale Volksrat gesehen, der sich von Beginn an aus Vertretern der „marxistischen“ und der bürgerlich-liberalen Parteien zusammensetzte. Die Berliner Regierung sorgte dafür, dass diesem Zentralen Volksrat die Arbeiter- und Soldatenräte und die Behörden unterstellt waren, sodass die Schlüsselpositionen von Mehrheitssozialisten, Angehörigen des Zentrums und Demokraten besetzt werden konnten. ${ }^{292}$

\footnotetext{
${ }^{290}$ Ebd.

291 Erst im Februar 1919 kam es zu Unruhen, als die USPD eine Arbeitslosendemonstration organisierte, bei der 17 Menschen starben, vgl. Oliwa, Theodor: Die Geschichte der Arbeiterbewegung in Breslau, S. 6.

${ }^{292}$ Vgl. Birke, Ernst: Schlesien, in: Aschenbrenner, Viktor et al. (Hrsg.): Die Deutschen und ihre östlichen Nachbarn: ein Handbuch, Frankfurt am Main 1967, S. 206-223; Matull, Wilhelm: Ostdeutschlands Arbeiterbewegung, Abriß ihrer Geschichte, ihrer Leistung und Opfer, Ostdeutsche Beiträge aus dem Göttinger ArbeitskreisWürzburg Band LIII, Würzburg 1973, S. 65
} 


\section{Die Ehe mit Kläre Rosenstock}

Kurz vor seiner Abreise zurück an die Front, nachdem sein Vater gestorben und das Kind der Amme gerettet worden war, hielt Siegfried Marck in der Breslauer Humboldtakademie einen Vortrag über die Philosophie des „Als ob“. Als besonders aufmerksame Zuhörerin während des Vortrages zeigte sich eine junge Philosophiestudentin, die Tochter des örtlichen Wäschefabrikanten, mit gewölbter Stirn und hellem Haar, Kläre Rosenstock, die beim Philosophiedozenten Marck ein Seminar besuchte und in seinen Augen als „[...] begabt. Für eine Frau sogar außergewöhnlich logisch“" galt. $^{293}$

Marck verliebte sich in seine Studentin, deren Bruder ebenfalls am Ende des Ersten Weltkrieges gefallen war. ${ }^{294}$ In einem Brief an Armin ließ er keinen Zweifel daran: „Ich bin vollständig verstrickt in eine Leidenschaft, die ich nur in einer neuen Ehe erfüllen könnte und wollte.“ ${ }^{295}$ Doch wusste er, dass er erst nach der einvernehmlichen Trennung von Lola eine ernsthafte Beziehung mit Kläre eingehen konnte. Marck und Landau trennten sich, wenn auch nicht ohne Hindernisse. Von nun an sollte Siegfried Marck ein anderer werden. Und Kläre, die von Beobachtern gerne als Typus „Neue Frau““296 beschrieben wurde, konnte mit dem späteren Professor für Philosophie ein intellektuelles Zusammenleben eingehen, das sich weit über die politischen Ereignisse hinaus besonders in der Literatur- und Kunstkritik der Breslauer Öffentlichkeit äußerte. Fritz Stern beschrieb Kläre als „herausfordernd modern in Erscheinung und Selbstbewusstsein, mit Zigarette im Mundwinkel““. Zudem munkelte man in Breslau, „sie sei gefährlich selbstständig und abenteuerlustig. “297 Noch vor ihrer Hochzeit war Kläre politisch aktiv und schrieb unter anderem Briefe an Hermann Hesse. ${ }^{298}$

\footnotetext{
${ }^{293}$ Vgl. Landau, Lola: Vor dem Vergessen, S. 95f.

${ }^{294}$ Persönliche Anmerkungen von Louis Marck zum Stammbaum der Marcks, LBI NY, 05.10.1983.

${ }^{295}$ Marck an Wegner, 08.10.1919, NL ATW.

${ }^{296}$ Die Idee der „Neuen Frau“ als emanzipative Vision einer Frau der Zukunft, die sich besonders durch soziale und ökonomische Selbstständigkeit oder durch die Ausbildung einer eigenen weiblichen Persönlichkeit und nicht zuletzt durch gleichberechtigten Zugang zu Bildung und Politik sowie freier Liebe und Partnerwahl auszeichnete, entstand Ende des 19. Jahrhunderts, siehe: Graf, Rüdiger: Die Zukunft der Weimarer Republik: Krise und Zukunftsaneignungen in Deutschland 1918-1933, München 2008, S. 236f. Zur „Neuen Frau“ siehe: Kessemeier, Gesa: Sportlich, sachlich, männlich. Das Bild der „Neuen Frau“ in den Zwanziger Jahren. Zur Konstruktion geschlechtsspezifischer Körperbilder in der Mode der Jahre 1920-1929, Dortmund 2000, S. 25.

${ }^{297}$ Vgl. Stern, Fritz: Fünf Deutschland und ein Leben, S. 105.

${ }^{298}$ Einzusehen im Schweizerischen Literaturarchiv - Hesse Archiv, Briefsammlung Ms L 84, Breslau 1916.
} 
Vorerst konnten sie es sich nicht leisten, in eine eigene Wohnung zu ziehen, auch wegen des Rechtsstreites und der Alimente an Lola. ${ }^{299}$ Und die Spannungen zwischen den neuen Konstellationen waren deutlich spürbar, wenngleich Siegfried immer versuchte, beschwichtigend, ausgleichend und konsensorientiert $\mathrm{zu}$ vermitteln. Für Lola war Kläre die „fremde Tante“, die mit „,den Marcks gar nichts zu tun" hatte und Lola sprach stets schlecht über sie. ${ }^{300}$ Zudem warf sie Siegfried vor, er hätte den Geburtstag seines Sohnes vergessen. ${ }^{301}$ Der Kontakt wurde seltener - die Marcks und die Landaus orientierten sich um.

Nach der Hochzeit zwischen Siegfried und Kläre am 09. Dezember $1920^{302}$ wurde deren Haus fortan zu einem lebhaften Ort. Der erste Sohn aus der Ehe zwischen Siegfried und Kläre, Ludwig Fritz Georg, der am 20. November 1921 geboren wurde ${ }^{303}$, beschrieb in einem Brief das Breslauer Haus der Familie Marck als eine ständige Begegnungsstätte vieler politisch, kulturell und fortschrittlich gebildeter Leute. $^{304}$

Beide waren sehr interessiert an der Frauenbewegung jener Jahre. ${ }^{305}$ Siegfried mischte sich gerne unter die Zuhörer bei Vorträgen der Breslauer Ortsgruppe der Internationalen Frauenliga für Frieden und Freiheit, bei denen er beispielsweise Helene Stöcker nach einem Vortrag über ihr Verständnis des Verhältnisses von Pazifismus und starker Roter Armee befragte. Auch Kläre sympathisierte mit der Frauenrechtsbewegung: Sie war Mitglied der Ortsgruppe der Frauenliga in Breslau, leitete dort später Versammlungen und hielt mit Siegfried gemeinsam Vorträge. ${ }^{306}$

Bewundernd sandte sie in der Volkswacht die besten Glückwünsche an Lida Gustava Heymann zum 60. Geburtstag, eine der bekanntesten Frauenrechtlerinnen der damaligen Zeit und Herausgeberin der Zeitschrift Die Frau im Staat sowie Gründungsmitglied des Internationalen Frauenbundes für Frieden und Freiheit. ${ }^{307}$

Kläre war nahezu in allen Institutionen aktiv, in denen Siegfried wirkte: Der Volkshochschule ${ }^{308}$, dem Arbeiterbildungsausschuss ${ }^{309}$, der Freien-Jüdischen-

\footnotetext{
${ }^{299}$ Marck an Landau, 31.03.1922, NL ATW.

${ }^{300}$ Marck an Landau, 26.04.1924, 13.05.1920, NL ATW.

${ }^{301}$ Dies geht aus dem Antwortbrief hervor, vgl. Marck an Landau, 05.05.1925, NL ATW.

${ }^{302}$ Heiratsurkunde Siegfried und Kläre Marck, NL SM, Heiratsanzeige in: Breslauer Volkswacht, 11.12.1920.

${ }^{303}$ Geburtsanzeige in: Ebd., 22.11.1921.

${ }^{304}$ Vgl. Hirsch, Helmut: Siegfried Marck, S. 383.

305 Siehe hierzu die Vorträge und Artikel von Kläre Marck in: Breslauer Volkswacht, 25.01.1923, 01.02.1923, 27.09.1923.

${ }^{306}$ Vgl. ebd., 11.02.1925.

${ }^{307}$ Vgl. ebd., 15.03.1928.

${ }^{308}$ Vgl. ebd., 08.10.1928.
} 
Volkshochschule ${ }^{310}$ und nicht minder in der Breslauer Sozialdemokratie. Überhaupt wurde sie durch Siegfried auch in den Kreis um die Breslauer Volkswacht eingeführt, veröffentlichte als Kriegsgegnerin ihre ersten Artikel $^{311}$ und sollte fortan oft $\mathrm{zu}$ literarischen Themen und Fragestellungen schreiben ${ }^{312}$. Dass diese Themen innerhalb des Parteiblattes Gehör fanden, war auch den Bemühungen ihres Mannes zu verdanken, der sich seit 1921 stets für eine Erweiterung der Unterhaltungsbeilage der Volkswacht aussprach, in der ja auch er gern veröffentlichte. ${ }^{313}$ Beide agierten in der Anti-Kriegsbewegung Breslaus, sprachen über Jugend und Völkerverständigung für sie stand fest, dass Sozialismus und Frieden zusammengehörten. ${ }^{314}$

Ab 1928 wurde Kläre auch politisch aktiver, profitierte sie doch im Januar 1928 von den Anstrengungen der Genossin Reventlow ${ }^{315}$. Else Reventlow arbeitete zusammen mit ihrem Mann Rolf zwischen 1927 und 1933 bei der Volkswacht. Die Lehrerin, Frauenrechtlerin und Sozialdemokratin war zuerst als Kulturkritikerin tätig, dann als Redakteurin und Korrespondentin. Zuvor war sie Vorsitzende der sozialistischen Studentengruppe in Berlin und seit 1918 Mitglied der SPD. Mit Blick auf den Wahlkampf 1928 beklagte Reventlow den Mangel an Referentinnen innerhalb der Partei. In einem Antrag an den Stadtverband wollte sie diesen durch Frauen wie Kläre Marck beheben. ${ }^{316}$

Doch auch neben dieser Tätigkeiten befasste sich Kläre weiter mit Literatur, berichtete den Breslauer Arbeitern über Erich Kästner und setzte sich mit Persönlichkeiten wie beispielsweise Carl Hauptmann oder dessen älteren Bruder Gerhart auseinander. ${ }^{317}$ Siegfried und Kläre Marck ergänzten sich gut in jenen Jahren.

\footnotetext{
${ }^{309}$ Für diesen Schrieb sie Briefe an Gerhart Hauptmann bezüglich der Gerhart Hauptmann Festspiele, die sie und ihr Mann organisierten.

${ }^{310}$ Vgl. Breslauer Jüdisches Gemeindeblatt, Nr.10 (1927), S. 158

${ }^{311}$ Vgl. Breslauer Volkswacht, 29.07.1922.

${ }^{312}$ Vgl. Blätter der Volkshochschule Breslau, Nr.08 (1922), Nr.10 1922.

${ }^{313}$ Vgl. Breslauer Volkswacht, 29.04.1921.

${ }^{314}$ Vgl. ebd., 29.07.1924, 01.08.1924, 02.08.1924, 19.08.1924.

${ }^{315}$ Vgl. Jessen-Klingberg, Manfred: Reventlow, Grafen zu, in: Neue Deutsche Biographie (NDB). Bd. 21, Berlin 2003, S. 474-476.

${ }^{316}$ Vgl. Breslauer Volkswacht, 24.01.1928.

${ }^{317}$ Vgl. ebd., 16.11.1929, 01.09.1928.
} 


\section{Weggefährten um die Breslauer Volkswacht}

Nach dem Ersten Weltkrieg sammelte sich in Breslau ein kleiner „Klüngel“ von Mitarbeitern und Funktionären um das sozialdemokratische Parteiblatt Breslauer Volkswacht, dem auch Siegfried Marck zuzuordnen war. Um zu verstehen, welches Gewicht dieses Blatt und dessen Umkreis für die Breslauer Arbeiterschaft, für Siegfried Marck und insbesondere für die Mehrheitssozialdemokratie hatte, sollen an dieser Stelle kurze einleitende Worte $\mathrm{zu}$ deren Entstehungsgeschichte diese Bedeutung unterstreichen folgen. Dabei wird auch auf die Breslauer Weggefährten Siegfried Marcks eingegangen, um die Figur Siegfried Marck in seinem politischen und organisationalen Umfeld besser verorten zu können.

1890 wurde in Breslau, der aufkeimenden Odermetropole, von vier Arbeitern die Breslauer Volkswacht gegründet, eine Tageszeitung, die knapp dreißig Jahre später zum sozialdemokratischen Leitmedium Breslaus und dessen Grenzen hinaus bekannt werden sollte. Dabei ,stand die Volkswacht im Laufe der dreißig Jahre mit an der Wiege aller Einrichtungen der Arbeiterschaft“, wie dem Gewerkschaftskartell und allen Gewerkschaften, dem Arbeitersekretariat, dem Parteisekretariat, der Zentralbibliothek, dem Gewerkschaftshause oder auch dem Konsumverein „Vorwärts“ und begleitete alle Bildungsbestrebungen der Arbeiterschaft. ${ }^{318}$

Das Blatt selbst wurde insbesondere in diesen ersten dreißig Jahren, ausschließlich von Arbeitern und nicht von Akademikern geführt, und im Nachhinein fragte sich Ernst Zahn, ein Gründungsmitglied, wie er so viel Mut aufbringen konnte, war er doch immer Strafanzeigen ausgesetzt und hatte überdies keine Erfahrung in der Erstellung von Tageszeitungen. Zudem waren viele Redakteure Dauergäste in den Gefängnissen. ${ }^{319}$ Daneben wurde die Volkswacht auch von Bruno Geiser, einem Schwiegersohn Wilhelm Liebknechts, geführt. ${ }^{320}$

Paul Löbe, der bei der Volkswacht 1898 als Setzer zu arbeiten anfing und später Präsident des Deutschen Reichstages werden sollte, schildert in seinen Lebenserinnerungen sehr eindrucksvoll, wie die Verhältnisse innerhalb der Redaktion auf ihn wirkten:

\footnotetext{
${ }^{318}$ Vgl. ebd., 01.11.1920.

319 Vgl. Matull, Wilhelm: Ostdeutschlands Arbeiterbewegung, S. 65. Zur Gründungsredaktion gehörten Julius Bruhns, ein Bremer Zigarrenmacher, der Schuhmacher Ernst Zahn sowie der Buchbinder Emil Neukirch. Später stießen noch der spätere Reichstagspräsident Paul Löbe, der Buchdrucker und spätere „Vorwärts“-Redakteur Franz Klühs sowie der Bildhauer Richard Schiller und der Schneider Reinhold Darf hinzu, vgl. ebd. S. 65f. Eine exakte Liste mit der Anzahl der Monate der Gefängnisstrafen nach Redakteur sortiert findet sich in: Breslauer Volkswacht, 01.11.1920.

${ }^{320}$ Vgl. Löbe, Paul: Der Weg war lang. Lebenserinnerungen, Berlin 1954, S. 46.
} 
„Zunächst zählten wir in der Redaktion vier Mann, aber zwei davon saßen abwechselnd im Gefängnis, denn Breslau war der heißeste Boden im ganzen Königreich Preußen. Willkommenskränze begrüßten den Neuling nicht, dagegen nagelte mir bei meiner Ankunft ein Tags zuvor aus dem Gefängnis entlassener Kollege die letzte Scheibe trockenes Schwarzbrot auf den dürftigen Schreibtisch, damit ich mir über meine Zukunft kein falsches Bild machen sollte. Gegen ihn selber schwebten zu dieser Zeit 42 Anklagen.“321

Folglich hatten die Redakteure schwer mit den politischen Machthabern zu kämpfen, litten für ihre Ideale. Erschwerend kam die Konkurrenz mit den anderen Breslauer Tageszeitungen hinzu, wie Löbes folgende Ausführungen verdeutlichen:

„Unserer Volkswacht allerdings taten die vielen Strafen und Verfolgungen nicht gut. Waren wir doch ohnehin das Aschenbrödel unter den Breslauer Zeitungen, arm an Geld, arm an Papier. Dort erschien die alte freikonservative ,Schlesische Zeitung', in der ab und zu die ,graue Exzellenz' Herr von Holstein, anonym ihre giftigen Pfeile abschoß: da verfügte ein parteiloser ,Generalanzeiger“ über 150.000 Abonnenten, die klerikale ,Schlesische Volkszeitung' besaß ihren festen Leserstamm. Schwerer rangen die beiden gut geleiteten deutschfreisinnigen Organe ,Breslauer Zeitung und ,Breslauer Morgenzeitung'. Gegen sie alle sich zu behaupten, war bei vier Seiten Umfang und bei dem Verbot für alle Staatsarbeiter und -angestellten, uns zu abonnieren, nicht leicht[...] Erst von 1908 bis 1910 konnte sich die ,Volkswacht' in Breslau einen einigermaßen geachteten Platz erobern. ${ }^{\text {‘322 }}$

Mit dem Ersten Weltkrieg kam für die Breslauer Volkswacht die Wende, wenngleich diese während des Krieges nur in abgeschwächter und sanktionierter Form weiter vertrieben werden durfte. Kritische Aussagen zum Kriegsverlauf und die Forderung nach einem baldigen Verständigungsfrieden wurden in das Blatt hineingeschmuggelt. Davon profitierte die Volkswacht, traf sie doch innerhalb Breslaus damit den Zeitgeist vieler Bürger, besonders der Arbeiter. War der Straßenverkauf in Breslau zuvor nicht üblich gewesen, so setzte die Volkswacht nun durch eben diesen 15.000 bis 18.000 Exemplare täglich ab. ${ }^{323}$ Ferner gelangte die Zeitung an die Front und in die Schützengräben und konnte sich auch dort einer breiten Leserschaft erfreuen, wie Paul Löbes reüssiert:

„Was aber noch überraschender war - die Soldaten im Felde warteten auf unser Blatt. Der Bewegungskrieg war an vielen Fronten zum Stellungskrieg erstarrt. Bald war die ,Volkswacht' in den Schützengräben und Unterständen in Flandern und auf den Vogesen, in Riga und in den Sümpfen des Pripjet zu finden. Unsere Zeitung fuhr mit den Lastwagenkolonnen über den Taurus ins Heilige Land und fehlte auf keinem unserer Kriegsschiffe. Hunderte von Soldatenbriefen stellten die Verbindung zwischen dem Landser und der Redaktion her [...] Etwa 17.000 bis 20.000 Nummern unseres Blattes sandten wir täglich ins Feld [...] Kaum eine Zeitung war über das tägliche Leben der Landser so gut unterrichtet wie wir. Nur die Chemnitzer, Volksstimme‘, in der Ernst Heilmann und Gustav Noske gewirkt haben, wies eine ähnliche Entwicklung auf. ${ }^{324}$

Das Ende des Krieges führte auch innerhalb der Redaktion zu einigen Neuerungen, immerhin bedeuteten die Wahlsiege der Sozialdemokratie bei den Wahlen zur

${ }^{321}$ Ebd., S. 48.

${ }^{322}$ Ebd., S. 51. Die Schlesische Volkszeitung bewarb sich im Übrigen selbst als die größte katholische Tageszeitung Deutschlands, vgl. Sallama, Hans: Breslau und Umgebung. Broschüre des Breslauer Verkehrsvereins, Breslau o. J.

${ }^{323}$ Vgl. Löbe, Paul: Der Weg war lang. S. 67.

324 Ebd., S. $67 \mathrm{f}$. 
Nationalversammlung und zum Preußischen Landtag, dass viele derjenigen, die in Breslau bis zum Ende des Ersten Weltkrieges noch lokal gearbeitet hatten, nun eine größere parlamentarische Tätigkeit wahrnehmen sollten. So auch Paul Löbe, der seinem Posten als Chefredakteur der Volkswacht nicht mehr nachkommen konnte. Ihm als Chefredakteur folgte Immanuel Birnbaum, ein aus Königsberg stammender, besonders fähiger Journalist, ${ }^{325}$ der seinen Dienst im Juli 1920 genau in der Stadt antrat, in der sein Großvater mütterlicherseits zu Schule gegangen war. Diese Stadt zog Immanuel Birnbaum förmlich an, wie seine folgende Aussage unterstreicht:

„Breslau mit seinen 17 historischen Kirchen, seiner modernen Stadtverwaltung, seiner starken Arbeiterbewegung, die einst meinen väterlichen Freund Eduard Bernstein, den Vater des Revisionismus, in den Reichstag geschickt hatte, mit seinen großen und lebendigen Hochschulen erschien mir nicht nur als eine der schönsten deutschen Städte, die ich gesehen hatte, in seiner neuen Grenzlage zu wiedererstandenen Polen war es auch ein politisch wichtiges und aufgabenreiches Zentrum geworden.“326

Birnbaum fand neben seiner Arbeit für die Volkswacht innerhalb dieses „aufgabenreichen Zentrums“ besonders in der Arbeiter- und Jugendbildung ein Wirkungsfeld, in dem er auch über Breslau hinaus aktiv mitwirkte. ${ }^{327} \mathrm{Er}, 1894$ in Königsberg geboren und damit aus einer anderen großen jüdischen Gemeinde stammend, war aus der Breslauer Sozialdemokratie nicht mehr wegzudenken. Sein Vater Eduard war jüdisch, seine Mutter Protestantin ${ }^{328}$; einige Familienmitglieder mütterlicherseits sollen in der Revolution 1848 gekämpft haben. ${ }^{329}$ Eduard Birnbaum arbeitete als Oberkantor, Komponist und Musikhistoriker. Das Familienbild war von Liberalität und Toleranz geprägt. ${ }^{330}$ Immanuel hatte zwei Geschwister ${ }^{331}$ - seine Schwester Margarete emigrierte 1939, sein Bruder Paul wurde 1942 in Polen während der deutschen Besatzung erschossen. ${ }^{332}$

Immanuel Birnbaum studierte Rechtswissenschaften und Philosophie in Freiburg, Königsberg und München und konvertierte, genau wie Siegfried Marck, in

325 Immanuel Birnbaum zu „Sieben Jahre Volkswacht“, in Matull, Wilhelm: Ostdeutschlands Arbeiterbewegung, S. 75ff; zur Einführung Birnbaums in die Volkswacht-Redaktion siehe auch: Breslauer Volkswacht, 01.10.1920.

${ }^{326}$ Ebd.

${ }^{327}$ Vgl. ebd., 23.05.1925.

${ }^{328}$ Dies ist exemplarisch als ,nichtidentische Identität“ anzusehen. Birnbaum war halb jüdisch und wurde ständig antisemitischen ausgesetzt, obgleich er sich nicht besonders für das Judentum interessierte.

${ }^{329}$ Vgl. Breslauer Volkswacht, 02.06.1922.

${ }^{330}$ Vgl. Munzinger: Internationales biographisches Archiv 31/1982 vom 26. Juli 1982.

${ }^{331}$ Dies geht auch aus der Todesanzeige der Mutter Birnbaums vom 04.01.1922 aus der Volkswacht hervor, in der die Angehörigen genannt werden.

332 Alle biographischen Angaben beziehen sich auf den Lebenslauf Immanuel Birnbaums, in: Nachlass Immanuel Birnbaum 12.08.1894- 22.03.1982. Findbuch, bearbeitet von Claudia Bartels, Institut für Zeitungsforschung in Dortmund, 2005; Glotz, Peter: Der weiße Elephant, in: Süddeutsche Zeitung, 17.05.2010. Birnbaum, Immanuel: Achtzig Jahre dabeigewesen. Erinnerungen eines Journalisten, München 1974. 
den Schützengräben 1917 zur Sozialdemokratie. Noch zuvor war er der Vorsitzende der Freien Studentenschaft der Nichtkorporierten in München gewesen und kämpfte im bayerischen Infanterieregiment. Der Freien Studentenschaft, die sich überwiegend aus Mitgliedern der neuen Mittelschicht zusammensetzte, gehörten unter anderem auch die Literaten Walter Benjamin, Alfred Döblin, Lion Feuchtwanger oder die Sozialdemokraten Adolf Grimme, Carl Landauer und Ernst Heilmann an. Diese Studentenschaft bildete ein Sammelbecken für diejenigen, die bisher keiner Verbindung angehörten und wurde zum Wegbereiter für die heutige studentische Selbstverwaltung. ${ }^{333}$

Nach dem Ersten Weltkrieg und mit seinem politischen Grenzgang auf die Seite der Arbeiterbewegung, fand Birnbaum sein berufliches Interesse im Journalismus: Nach Tätigkeiten bei der Münchener Post und der Frankfurter Zeitung wurde er 1919 leitender Redakteur des Bremer Volksblattes, bevor er in Breslau 1921 die Stelle als Chefredakteur der Breslauer Volkswacht antrat. „Er war ein hochpolitischer Mensch, der Macht genau einschätzen konnte.“, hält Peter Glotz in einem Nachruf auf Birnbaum fest. Mehr noch war er „ein Differenzierer, ein kultureller Zwischenträger“, der als Sozialdemokrat, Kenner von Max Weber und Anhänger Eduard Bernsteins und eben als „Wortführer des Münchener Asta 1919 Max Weber zu seinen großen Vorträgen „Wissenschaft als Beruf“, „Politik als Beruf" einlud.“334 Birnbaum war ein Netzwerker, kommentiert Glotz weiter immerhin ist von einem seiner Freunde, Bruno Kreisky, überliefert: „Was der Birnbaum nicht weiß, das braucht man nicht zu wissen. “335 Das kam auch der Volkswacht zu Gute: Paul Löbe sollte weiter aus Berlin Artikel für die Volkswacht schicken, zu grundsätzlichen Fragen schrieb Eduard Bernstein, nachdem er wieder zur SPD zurückgekehrt war. Aus der Arbeiterbewegung in Oberschlesien und der Tschechoslowakei konnte Birnbaum Johann Kowoll aus Kattowitz und Josef Hofbauer als ständige Berichterstatter gewinnen. Aus dem Landtag in Preußen berichtete Ernst Hamburger. Lokalredakteur wurde Reinhold Darf, ein ehemaliger Schneider und Jugendfreund Paul Löbes, der später ebenfalls öfter gemeinsam mit Siegfried Marck auf Parteiveranstaltungen sprach. ${ }^{336}$

\footnotetext{
${ }^{333}$ Vgl. Jarausch, Konrad: Deutsche Studenten 1800-1970, Frankfurt am Main 1984, S. 94-103; Wipf, Hans Ulrich: Studentische Politik und Kulturreform. Geschichte der Freideutschen Bewegung 18961918, Schwalbach 2005.

${ }^{334}$ Glotz, Peter: Der weiße Elephant; Immanuel Birnbaum: Achtzig Jahre dabeigewesen, S. 79ff.

335 Ebd.

${ }^{336}$ Immanuel Birnbaum zu ,Sieben Jahre Volkswacht“”, S. 75ff.
} 
In Universitätskreisen gehörte Siegfried Marck neben dem Nichtparteimitglied Levin Ludwig Schücking, einem bekennenden Pazifisten und Anglisten sowie Mitglied der DDP von 1919-1930, dem Kreis um die Breslauer Volkswacht an. ${ }^{337}$ Schücking selbst war von 1918 bis 1925 Vorsitzender der schlesischen Abteilung der Deutschen Friedensgesellschaft ${ }^{338}$, der auch Siegfried und Kläre Marck des Öfteren beiwohnten. 339

Insgesamt war es Birnbaum gelungen, die Volkswacht konkurrenzfähig zu machen und den führenden Parteiblättern in Hamburg, Berlin oder Leipzig gleichzustellen. Immanuel Birnbaum ging im Juli 1927 nach Warschau, seine Nachfolge übernahm der ehemalige Chefredakteur des Thüringer Parteiblattes Das Volk, Albert Kranold.

Ein Name wird im sozialdemokratischen Gedächtnis stets mit der Breslauer Volkswacht verbunden sein: Max Tockus, dem am 21. Juli 1963 im SPD-Parteihaus in Frankfurt am Main eine besondere Ehrung zuteilwurde. Tockus war seit 1893 Mitglied der Sozialdemokratie und seit 1897 Mitglied der Gewerkschaft. ${ }^{340}$ Selbst zu diesem Zeitpunkt, in seinem 90. Lebensjahr, soll der gute Freund Paul Löbes sowohl körperlich als auch geistig in guter Verfassung gewesen sein. An ihm, dem aus der Angestelltenbewegung stammenden Schwager des späteren Reichskanzlers Hermann Müller $^{341}$, lassen sich eine Vielzahl an Brüchen sowie mitunter die spannendsten Facetten sozialdemokratischer Politik der vergangenen 150 Jahre ablesen: 1875 in Breslau geboren, aus einer einfachen jüdischen Familie stammend, schloss sich Max Tockus im Alter von 15 Jahren der Sozialdemokratie an. Tockus' Einfluss besonders auf die jungen Leute war enorm. Besonders stark wirkte er auf den damals gerade zwölf oder dreizehn Jahre alten Fritz Sternberg, für den er eine Art „Mentorenrolle“ einnahm:

„Tockus war es auch, der Sternberg darüber aufklärte, dass es im Interesse der Arbeiterklasse läge, den wohlhabenden Vater die Ausbildung des künftigen Klassenkämpfers bezahlen zu lassen und sich folglich nicht vom Elternhaus zu trennen. “342

\footnotetext{
${ }^{337}$ Ebd., S. 78; zur Biographie Schückings siehe: Haenicke, Gunta: „Schücking, Levin Ludwig“, in: Neue Deutsche Biographie 23 (2007), S. 633-634.

${ }^{338}$ Ebd.

${ }^{339}$ Vgl. Breslauer Volkswacht, 25.11.1925.

${ }^{340}$ Sozialdemokratischer Pressedienst, 20.07.1963, S. 5.

${ }^{341}$ Immanuel Birnbaum zu „Sieben Jahre Volkswacht“, S. 78.

${ }^{342}$ Grebing, Helga: Fritz Sternberg (1895-1963), in: Lösche, Peter et al (Hrsg.): Vor dem Vergessen bewahren, S. 391-406, hier S. 391f.
} 
Von der Jahrhundertwende bis zur Machtergreifung durch die Nationalsozialisten avancierte Tockus zum Verlagsleiter der Breslauer Volkswacht. Dabei hatte er insbesondere nach dem Ersten Weltkrieg die Aufgabe, das Breslauer Parteiblatt auf Kurs zu halten. Zudem war er Verlagsleiter und Geschäftsführer des Breslauer Konsum- und Sparvereins „Vorwärts“, der auch unter den Folgen des Ersten Weltkrieges zu leiden hatte. ${ }^{343}$ Speziell der Papiermangel kollidierte mit der stetig steigenden Anzahl der Volkswachtleser. So wundert es nicht, dass die Verlagsleitung der Breslauer Volkswacht die Gründung vieler neuer Zeitungen innerhalb Breslaus, insbesondere der politisch linkeren und rechteren Parteien, mit Argwohn beobachtete. ${ }^{344}$ Tockus war darüber hinaus Stadtverordneter innerhalb des Magistrats der Odermetropole und ständig überarbeitet, ${ }^{345}$ doch vermochte er in manchen Punkten sogar die Deutschnationalen von seinen Ideen zu überzeugen. So etwa als es 1920 um Regelungen beim Arbeitslosengeld ging. ${ }^{346}$ Dennoch: Sein Hauptaugenmerk sah er in der Arbeit für die Volkswacht und unterstrich diese zunehmend. $^{347}$ Dabei wurde er immer wieder zum Opfer der Unabhängigen Sozialdemokraten und deren Presseorgan, der Schlesischen Arbeiterzeitung. Etwa als er von diesen als „Feigling“ bezeichnet wurde, da er sich auf Parteiversammlungen der Unabhängigen nicht couragiert zu Wort gemeldet habe. ${ }^{348}$

Reinhold Darf und Max Tockus sollen laut Arbeiterzeitung bei einer Diskussionsveranstaltung der Unabhängigen anwesend gewesen sein und sich nach mehrfacher Aufforderung nicht zu Wort gemeldet haben, was die Volkswacht im Nachhinein negierte. ${ }^{349}$

Tockus konstatierte, dass sich der Inhalt der Volkswacht veränderte und dies mit der Beteiligung der Sozialdemokratie an der Regierung zu tun habe; denn aus der Opposition sei anders zu berichten als von der Regierungsbank, ${ }^{350}$ wenngleich das Parteiblatt nie seine Ideale als „Kämpfer für den Sozialismus“ und „die Verwirklichung des Menschheitsideals“ in Frage stellen wollte. ${ }^{351}$

\footnotetext{
${ }^{343}$ Vgl. Breslauer Volkswacht, 17.03.1919, 11.06.1919.

${ }^{344}$ Vgl. ebd.,, 25.03.1919.

345 Jahresbericht des sozialdemokratischen Vereins Breslau für 1919, in: Ebd., 16.06.1920.

${ }^{346}$ Vgl. ebd., 08.10.1920.

${ }^{347}$ Dies wurde besonders während des Buchdruckerstreikes 1919 in Breslau deutlich, als Tockus die Streikenden ermahnte, sie hätten doch trotzdem am ersten Streiktag die Volkswacht drucken können, genauso wie sie das mit den bürgerlichen Blättern auch gemacht hätten. Vgl. ebd., 19.06.1919.

${ }^{348}$ Vgl. ebd., 17.06.1919.

${ }^{349}$ Vgl. ebd.

${ }^{350}$ Vgl. ebd., 28.07.1919, 07.03.1922.

${ }^{351}$ Vgl. Selbstverständnis der Breslauer Volkswacht, in: Ebd., 03.07.1919.
} 
Da die Volkswacht keine eigene Druckerei besaß und von der Kriegswirtschaftsstelle nur wenig Material bereitgestellt wurde, litt die Tageszeitung unter einer besonders schlechten Druckqualität. ${ }^{352}$ Tockus wollte endlich gern eine Druckerei sein Eigen nennen, was jedoch nur mit einer deutlich höheren Abonnentenzahl zu rechtfertigen gewesen wäre und appellierte stets an die Arbeiterschaft für sein Blatt zu werben. ${ }^{353}$ Hatte die Breslauer Volkswacht im Jahr 1917 noch 70.000 tägliche Leser, so waren es zwei Jahre später knapp 102.000 Werktätige, welche ihr Parteiblatt lasen - ein Anstieg, der durch die Gründung vieler Provinzblätter auch wieder abflachen sollte. ${ }^{354}$ Zudem wurde zur Festigung und Bewerbung des Blattes beschlossen, eine „Rote Woche“ zur Agitation der Volkswacht durchzuführen, an deren Veranstaltungen sich auch Siegfried Marck und Ernst Eckstein beteiligten. ${ }^{355}$

Um Ernst Eckstein, der wohl, wenn er den Nationalsozialismus überlebt hätte, innerhalb der Sozialdemokratie eine große Karriere angestrebt und einen nachhaltigen Eindruck hinterlassen hätte, ranken sich manche Mythen: So soll er schon in seiner Schulzeit, während seine Mutter mit ihm in die Konditorei ging, mehr Interesse an den dortigen Zeitungen gehabt haben, als an dem dort verkäuflichen Kuchen. ${ }^{356}$ So wird der Sohn armer Eltern, der später in Breslau als Anwalt arbeitete, einen ersten Überblick über die Breslauer Presselandschaft gewonnen und auch die Überschriften der Breslauer Volkswacht gelesen haben. Jener Zeitschrift, für die er zukünftig gerne tätig wurde und mit der, oder vielmehr mit deren Kreis, er sich nach seinem Parteiausschluss überwarf.

Ernst Eckstein wurde im Februar 1897 geboren und war damit knapp acht Jahre jünger als Siegfried Marck. Sein Vater war früh gestorben, sodass seine Mutter durch eine Arbeit als Köchin in der jüdischen Gemeinde für das Wohl der Familie sorgen musste. Bereits 1914 wurde der siebzehnjährige Eckstein zum Militärdienst eingezogen und überlebte den Ersten Weltkrieg mit zwei Verwundungen, war zudem bereits Sozialist geworden. ${ }^{357}$ Wie Knut Bergbauer herausgefunden hat, kämpfte Eckstein bereits während seiner Schulzeit mit den überwiegend deutschnationalen Schulkameraden, ein Verhalten, das ihn bis zu seinem Lebensende nicht loslassen

\footnotetext{
${ }^{352}$ Beispielsweise: Ebd., 02.07.1919, 25.07.1919.

${ }^{353}$ Vgl. ebd., 28.08.1920.

${ }^{354}$ Vgl. ebd., 28.07.1919.

355 Vgl. ebd., 11.03.1922, 18.03.1922. Mit mäßigem Erfolg. 1924 ging es der Volkswacht wirtschaftlich nicht besonders gut, es kam zur Entlassung vieler Mitarbeiter, vgl. Ebd., 02.09.1924.

${ }^{356}$ Vgl. Seydewitz, Ruth und Max: Unvergessene Jahre. Begegnungen, Berlin 1984, S. 32.

${ }^{357}$ Vgl. Bergbauer, Knut: Ernst Eckstein, in: Neue Gesellschaft, Frankfurter Hefte Bd. 5 (2013), S. 32-33.
} 
sollte und letztlich auch einen weiteren Mythos um den Breslauer Arbeiterführer darstellt.

Eckstein, mit blassem Gesicht, mit seinen sich bei Erregung rötenden Wangen, seinen weißen hervorstehenden Zähnen und seiner mit starken Gläsern versehenen runden Brille, war vor allem durch seine Fähigkeit des Zuhörens bei seinen Klienten beliebt. ${ }^{358}$ Darüber hinaus war Eckstein der Kopf der linken Breslauer Arbeiter, dazu ein Jude und promovierter Jurist, den Bergbauer, der sich kürzlich eingehender mit der Person Ernst Ecksteins befasste, zutreffend mit einem Zitat Lion Feuchtwangers zu Eckstein beschreibt:

„Es war klar, dass ein Mann wie er den Hitlerleuten ein Dorn im Auge sein musste. Dieser Mensch, so zart und friedlich von Gehabe, war im Kampf der wildeste Draufgänger, der vor der großen persönlichen Gefahr nicht zurückscheute. [...] er war in jedem Sinn das Haupt der Arbeiterschaft seiner Stadt. Ihn zu treffen, hieß diese Arbeiter zu treffen. “ ${ }^{\text {} 359}$

Über Eckstein wusste die wissenschaftliche Forschung bisher nicht viel zu berichten. Lediglich zwei knappe lexikalische Einträge existieren über den „Anwalt der Armen“, wie er im sozialdemokratischen Gedächtnis tradiert wurde. ${ }^{360}$ Ferner existieren Fragmente und Erinnerungen an den „Anwalt der Verfolgten“. ${ }^{361}$ Dabei war Eckstein einer der einflussreichsten Wegbegleiter vieler Breslauer Sozialdemokraten und Jungsozialisten - auch Siegfried Marcks. Oft sprachen sie gemeinsam auf Parteiveranstaltungen, doch Eckstein war in Vielem radikaler als Marck, scheute den Konflikt mit den Nationalen weniger als der Breslauer Philosophiedozent.

Eckstein, der eine ihm angebotene Stellung im Staatsdienst ablehnte, da er dem Staat der Weimarer Republik, mit seiner Klassenjustiz, nicht dienen wollte, ${ }^{362}$ prägte das Bild der Breslauer Sozialdemokratie. Er gehörte $\mathrm{zu}$ den führenden sozialdemokratischen Persönlichkeiten Mittelschlesiens, war er doch nicht ohne Konflikte und als Linkssozialist ab 1927 Vorsitzender der Breslauer SPD und zugleich Mitglied des Bezirksvorstandes geworden. Auch auf den sozialdemokratischen Parteitagen in Kiel, Magdeburg und Leipzig scheute er nicht

\footnotetext{
${ }^{358}$ Vgl. Seydewitz, Ruth und Max: Begegnungen, S. 32.

359 Lion Feuchtwanger zitiert in: Bergbauer, Knut: Ernst Eckstein, S. 32. Zu Ernst Eckstein wird demnächst ein größerer Beitrag von Stefanie Schüler-Springorum erscheinen, der aus einem Projekt von Arno Herzig zur Geschichte des Judentums in Schlesien und einer darauf stattgefundenen Tagung resultiert.

360 Bandur, G.: Eckstein, Ernst, in: Geschichte der deutschen Arbeiterbewegung. Biographisches Lexikon, Berlin 1970, S. 108-109; Institut für Marxismus-Leninismus beim Zentralkomitee der SED (Hrsg.): Deutsche Widerstandskämpfer 1933-1945, Biographien und Briefe, Band 1, Berlin 1970, S. 206-208.

${ }^{361}$ So beispielweise bei: Seydewitz, Ruth und Max. Begegnungen, S. 32-38.

${ }^{362}$ Vgl. ebd., S. 32.
} 
die Konfrontation mit seinen Parteigenossen. Letztlich leitete Eckstein die Abspaltung der SAP mit ein, wurde in Breslau deren Vorsitzender und geriet mit vielen Jungsozialisten auf einen anderen Weg als Marck. Eckstein sah als Aufgabe des sozialistischen Politikers, folglich auch die seinige, den Klassenkampf, den er als „elementare Erscheinung vorhanden“ und nicht künstlich geschaffen verstand, „Zweckmäßig zu organisieren“. ${ }^{363}$

Politisch waren es besonders Hugo Haase, Eduard Bernstein und Paul Levi, die den jungen Parteikämpfer Eckstein beeinflussten. ${ }^{364}$ Dabei ist zu bemerken, dass eben jene ebenfalls Juden waren. Es wird seit Mitte der 1920er Jahre wohl kaum einen Sozialdemokraten in der Odermetropole gegeben haben, der so präsent bei öffentlichen Veranstaltungen und Parteitreffen war wie Ernst Eckstein - vielleicht mit Ausnahme seiner Frau Clara Zils.

Aus einer Vielzahl an gemeinsamen Interessen und Vorträgen entwickelte sich eine feste Beziehung zwischen dem Arbeiterführer Ernst Eckstein und der Kämpferin für die Rechte der Frauen Clara Zils ${ }^{365}$, die auch bald innerhalb Breslaus immer mehr auf sich aufmerksam machte und die Parteileiter stets hinaufstieg.

Clara Zils, so betont Hedwig Wachenheim, stellte das ,sozialistische Gewissen“ einer jeden Tagung dar ${ }^{366}$ und war die erste, „die in Schlesien das Gestrüpp der Vorurteile gegen die Bestrebungen der Arbeiterwohlfahrt durchbrochen hat" und damit im Grunde „eine rein politische Persönlichkeit [gewesen ist]; dazu geschaffen, ohne Unterschied des Geschlechts Schulter an Schulter mit den männlichen Kampfgenossen zu streiten““. ${ }^{367}$ In ihrem Wesen stand sie ihrem Ehemann Ernst Eckstein in nichts nach. Sie kämpfte für ihre Belange und „wehe dem, der mit ihr die Klinge kreuzte. Er hatte keinen leichten Stand“, wenn die „liebenswürdig und sanftmütig“ scheinende Zils mit ihrem Kontrahenten ins Gericht ging. 368

Clara Zils war ein schlesisches Proletarierkind, das es 1921 aus Westpreußen nach Breslau zog, um dort als Sekretärin im Bezirksparteisekretariat ${ }^{369}$ vor allem für

\footnotetext{
${ }^{363}$ Vgl. Eckstein, Ernst: Politik und Politiker, in: Breslauer Volkswacht, 18.03.1924.

${ }^{364}$ Vgl. Bergbauer, Knut: Ernst Eckstein, S. 32-33.

${ }^{365}$ Vgl. Verlobungsanzeige, in: Breslauer Volkswacht, 02.06.1923, Anzeige der Ehe ebd., 20.12.1924.

${ }^{366}$ Vgl. Wachenheim, Hedwig: Mitteilungen. Clara Zils-Eckstein, in: Arbeiterwohlfahrt 6 (1931), Heft 6. S. 184

${ }^{367}$ Vgl. Mache, Karl: Clara Zils-Eckstein, in: Arbeiterwohlfahrt, 6 (1931), Heft 9, S.274-277, hier S. 274.

${ }^{368}$ Vgl. ebd.

${ }^{369}$ Vgl. Breslauer Volkswacht, 21.07.1923.
} 
die Gewinnung der Frauen für die Sozialdemokratie zu arbeiten. „Sie lehnte energisch alle Vorstöße, die darauf zielten, den Frauen, auch den Genossinnen innerhalb der Partei, besondere Vorrechte zu verschaffen, ab“, hielt Karl Mache, der zweite Bürgermeister Breslaus und Parteigenosse, nach ihrem Ableben fest. ${ }^{370}$

Clara Zils war unermüdlich in ihren Bemühungen, die insbesondere durch ihre Fahrten in die ländlichen Regionen um Breslau genährt wurden:

\begin{abstract}
„Grenzenloses Elend, das sie besonders unter dem Landproletariat vorfand, erinnerte das ehemalige Landarbeiterkind an die fast gleichartigen Verhältnisse in ihrer westpreußischen Heimat. Kampf diesem System der Unterdrückung und Ausbeutung; aber in der Zwischenzeit alles tun, um diese unglücklichen, verzweifelten Klassengenossen nicht untergehen zu lassen, sondern ihnen zu helfen, wo es nur irgend möglich ist, das war die Erkenntnis, die sie dazu brachte, mit besonderem Feuereifer sich auch den Aufgaben der Arbeiterwohlfahrt zu widmen. “371
\end{abstract}

Zils gründete zusammen mit Karl $\operatorname{Mache}^{372}$ den Bezirksausschuss für Arbeiterwohlfahrt in Mittelschlesien und wurde dessen Vorsitzende. Es gelang ihr, die Arbeiterwohlfahrt von allen wichtigen Behörden anerkennen und gleichberechtigt behandeln zu lassen. Das Elend von Kindern und Jugendlichen rief bei ihr ein starkes Sozialempfinden hervor. Daher trieb sie in Breslau die Einrichtung von Tageserholungsheimen für Kinder voran, in denen hunderte Kinder über mehrere Wochen Erholung und Kräftigung finden sollten. Daneben etablierte sie zwei Montessori-Kindergärten in der Odermetropole und ein Obdachlosenheim. Ferner wirkte sie als Breslauer Stadtverordnete, im Jugendamt und als Lehrerin in der Frauenberufsschule. ${ }^{373}$

Gemeinsam mit Ernst Eckstein, Siegfried Marck und Immanuel Birnbaum war sie bei den Breslauer Jungsozialisten aktiv ${ }^{374}$ und des Öfteren fanden ihre Veranstaltungen mehr Zuhörer als die ihrer männlichen Kollegen. ${ }^{375}$ Letztlich starb Zils an einer typischen Proletarierkrankheit, der Tuberkulose, die sie ihr Leben lang körperlich geschwächt hatte. ${ }^{376}$ Marck widmete sein Buch „Sozialdemokratie“ der Verstorbenen. Den Tod „,[u]nsere[r] Clarissa“, wie sie die Breslauer Genossen und

\footnotetext{
${ }^{370}$ Mache, Karl: Clara Zils-Eckstein, S. 274.

${ }^{371}$ Ebd.

372 Karl Mache war früher Bäckergeselle und wurde zum Ortssekretär der Breslauer Sozialdemokraten, zuletzt war er zweiter Bürgermeister der Odermetropole und wurde 1944 durch die Nationalsozialisten im Konzentrationslager Groß-Rosen ermordet, vgl. (BIOSP) Biographien Sozialdemokratischer Parlamentarier in den deutschen Reichs- und Landtagen 1867-1933, in: http://biosop.zhsf.uni-koeln.de/biosop_db/biosop_db.php [zuletzt eingesehen am 09.07.2013].

${ }^{373}$ Vgl. Mache, Karl: Clara Zils-Eckstein, S. 276f.

${ }^{374}$ Beispielsweise: Breslauer Volkswacht, 02.06.1921, 05.08.1921, 08.08.1921, 12.08.1921.

${ }^{375}$ Vgl. ebd., 19.08.1921.

${ }^{376}$ Matull, Wilhelm: Ostdeutschlands Arbeiterbewegung, S. 78.
} 
insbesondere die Jungsozialisten nannten, hat ihr Mann Ernst Eckstein nie richtig verwunden. ${ }^{377}$

${ }^{377}$ Vgl. Seydewitz, Ruth und Max. Unvergessene Jahre S. 35; Dies: Alle Menschen haben Träume Meine Zeit, mein Leben, Berlin 1976, S. 105. 


\section{Als geistiger Arbeiter}

Siegfried Marck sollte Wort halten. Als er Lola Landau mit den letzten Kriegserfahrungen im Gedächtnis und sich auf der Rückreise nach Breslau befand schrieb er ihr, dass er sich dem Rat der geistigen Arbeiter Breslaus anschließen wollte. $^{378}$ Der Rat der geistigen Arbeiter Breslaus war einer von vielen im Reichsgebiet. Auch in anderen großen Städten wie München oder Berlin wurden solche Räte gegründet. So waren in der bayerischen Landeshauptstadt beispielsweise Personen wie Heinrich Mann oder Oskar Maria Graf innerhalb dieser Räte vertreten. $^{379}$

Ein genauerer Blick in die Geschichte der Erwachsenenbildung der Stadt Breslau verrät, dass diese in den Anfangsjahren ohne Marck nicht so viel Schwung gehabt hätte, öffentlich weniger präsent und organisiert gewesen wäre. Nach dem Ersten Weltkrieg gab es in Breslau wohl kaum einen Kreis, eine Vereinigung oder eine Veranstaltung zum Thema Erwachsenenbildung, an der Marck nicht beteiligt oder ihr zuzurechnen war.

Ein wenig später, nach der Gründung des Rates der geistigen Arbeiter, etablierte sich im Juli 1919 auch in Breslau der Bildungsausschuss des Sozialdemokratischen Vereins, den Siegfried Marck mit initiiert hatte. Innerhalb der regelmäßig stattfindenden Kurse, welche die Genossen Siegfried Marck zu Verfassungsfragen, Eugen Bandmann zu Rechtsfragen aber auch Theodor Müller zu Fragen der Parteibewegung abwechselnd jeden Freitag in Vorlesungsform halten sollten, war der Andrang von Beginn an groß. Etwa 150 Kursteilnehmer meldeten sich; eine Anzahl, die verdeutlicht, wie groß der Bildungswunsch innerhalb der Parteigenossen war. ${ }^{380}$ Siegfried Marck verglich in seinen Vorträgen gern die Verfassungen von 1848, 1871, die amerikanische und französische Verfassung sowie den damaligen Preußischen Verfassungsentwurf, den er für keineswegs vollkommen hielt. $^{381}$

Daneben war Marck durch seine Lehraufträge natürlich an die Arbeit in der Universität gebunden. Seine Veranstaltungen waren jedoch von den meist nationalliberal eingestellten Studierenden sehr schwach besucht, was Marck sicherlich traf. Einer seiner Studenten war Kurt Schwerin, ebenfalls Jude, den er

\footnotetext{
${ }^{378}$ Marck an Landau, 28.12.1918, NL ATW.

${ }^{379}$ Vgl. Töpner, Kurt: Gelehrte Politiker und politisierende Gelehrte: Die Revolution von $1918 \mathrm{im}$ Urteil deutscher Hochschullehrer, Göttingen 1970, S. 50f.

${ }^{380}$ Vgl. Breslauer Volkswacht, 23.07.1919.

${ }^{381}$ Vgl. ebd., 02.08.1919, 14.10.1919.
} 
später im amerikanischen Exil unter anderen Vorzeichen wiedertreffen sollte. Schwerin selbst war während seiner Breslauer Jahre von 1927 bis 1933 für die Deutsche Demokratische Partei eingetreten, hatte zudem für die Breslauer liberale Presse geschrieben und war an der Universität der Vorsitzende des Republikanischen Studentenbundes. Diesem gehörten Studenten des sozialistischen Lagers genauso an wie Studierende, die den Demokraten oder dem Zentrum nahe standen. Schwerin, der spätere Professor der Rechtswissenschaften, hatte die Vorlesungen und Seminare Marcks in seinen Anfangsjahren zusätzlich zu seiner Ausbildung und seiner Tätigkeit im Buchhandel besucht. ${ }^{382}$ Seine geplante Promotion konnte er nach der Machtübernahme der Nationalsozialisten nicht beenden und holte diese später in den Vereinigten Staaten nach. Schwerin lebte seinen jüdischen Glauben aus und war stark verwoben in die Arbeit der Breslauer jüdischen Gemeinde. Genau diese Zugehörigkeit zum Judentum sorgte letztlich auch dafür, dass er in seiner Tätigkeit als Aushilfe in der Pressestelle der Breslauer Universität seinen Platz räumen musste. Der Leiter der Pressestelle, Prof. Andreae, wurde kurz nach der Machtergreifung der Nationalsozialisten sowohl vom Rektor als auch vom Nationalsozialistischen Deutschen Studentenbund angewiesen, Schwerin, der auch für das Breslauer Jüdische Gemeindeblatt schrieb, zu entlassen. ${ }^{383}$

Der nationalliberale Geist der Studierenden, die den Veranstaltungen Siegfried Marcks fernblieben, verbunden mit seinem geringen Einkommen als Lehrbeauftragter und Privatdozent bis zu seiner Berufung, können sicherlich als Gründe gesehen werden, weshalb Marck auf anderem Terrain Betätigung suchte und auch fand. Die Arbeiter- und Erwachsenenbildung wurde Marcks eigentliche Passion, die er auch im Exil in Frankreich und später in den Vereinigten Staaten weiter betrieb: Schon 1919 als Mitglied des Rates der Geistigen Arbeiter setzte er sich intensiv für die Volkshochschulbewegung in seiner Heimatstadt ein. Ziel der Volkshochschulen jener Jahre, die sich in den Jahren 1918/19 überall im Reich gründeten ${ }^{384}$, war nicht weniger als die Überwindung der Klassengesellschaft und die

\footnotetext{
${ }^{382}$ Vgl. Abgangszeugnis Kurt Schwerins der Breslauer Schlesischen Friedrich-Wilhelms-Universität vom 31.07.1925. Kurt Schwerin hatte erst 4 Semester Philosophie studiert, bevor er sein Studienfach wechselte. In dieser Zeit hat er auch Veranstaltungen von Siegfried Marck besucht, mehr noch bei Eugen Kühnemann. Später entschied er sich für das Studium der Geschichte und Deutschen Literatur; Copy of official Application to U.S. Department of Justice to extend time of Admission, 25.03.1941; Arbeitsbescheinigung der Breslauer Zeitung vom 13.10.1937, NL KS.

${ }^{383}$ Vgl. Breslauer Zeitung, 29.04.1933.

${ }^{384}$ Dass diese Gründungsversuche jedoch auch aus parteipolitischen Gründen scheitern konnten, ist am Beispiel Landshut zu sehen, wo die Deutschnationale Volkspartei die Initiierung der VHS in ihrer Anfangszeit bekämpfte, vgl. Breslauer Volkswacht, 08.01.1920.
} 
Schaffung einer wahren Volksgemeinschaft. ${ }^{385}$ Marck betrachtete die Volkshochschulen als Wirkungsfeld, in dem „die Arbeiterschaft nach ihrer politischen Befreiung und neben ihrer wirtschaftlichen, ihre geistige Emanzipation bewerkstelligen“3886 könne. Für ihn war die Volksbildungsbewegung „die wichtigste Kulturbewegung nach 1918 “. ${ }^{387}$

Der Breslauer Rat der geistigen Arbeiter aus den Revolutionstagen, dem die bekanntesten Persönlichkeiten Breslaus, die besten Gelehrten der Stadt zusammen mit jungen „Geistesrevolutionären“ angehörten, war eigentlich nie über seine eigenen Vorstandswahlen hinausgekommen. Er zerfiel in Sektionen, von denen nur eine, die pädagogische, übrigblieb. Diese Sektion gilt als die Gründerin der Breslauer Volkshochschule. ${ }^{388}$

In Breslau schielte man vor der Errichtung einer eigenen Volkshochschule nach Dänemark, dessen Volkshochschulwesen einen rasanten Aufschwung erlebt hatte. Immer das Vorbild im Auge lagen die Unterschiede zwischen Dänemark und Deutschland auf der Hand: Dänemark war geprägt durch die Landwirtschaft, Deutschland durch die Industrie; sie waren einfach nicht vergleichbar. Konnte man in Dänemark während der langen Winterzeit Menschen auf Wochen oder Monate in Volksschulheimen unterbringen und sie dort „heranziehen“, war dies im industriellen Deutschland unmöglich, weshalb die Lehrtätigkeit in Abendlehrgängen angeboten werden musste. ${ }^{389}$ Der Vergleich mit Dänemark barg dabei das Problem der Ablehnung innerhalb der nationalliberalen Bevölkerung. Wurde betont, dass die Volkshochschule eigentlich ein Modell aus Dänemark sei, konnte man diesen in Deutschland neu gegründeten Einrichtungen einen „fremdländischen Geist“ zuschreiben, der „die Zersetzung des deutschen Volkstums“ beförderte. ${ }^{390}$

Demgegenüber muss darauf hingewiesen werden, dass Nikolai Frederik Severin Grundtvig, der „Vater der dänischen Volkshochschule“, während seiner Studienzeit in Kopenhagen besonders von Heinrich Steffens, der in Breslau zum Freiheitskampf gegen den napoleonischen Imperialismus aufgerufen hatte und zudem mit Goethe, Schiller und besonders Schelling verkehrte, beeinflusst wurde. ${ }^{391}$

\footnotetext{
${ }^{385}$ Vgl. Walter, Franz: Siegfried Marck (1889-1957), S. $257 \mathrm{f}$.

${ }^{386}$ Vgl. Breslauer Volkswacht, 09.10.1919.

${ }^{387}$ Ebd., 15.10.1926.

${ }^{388}$ Vgl. Blätter der Volkshochschule Breslau, Nr. 06 (1922), S. 13f.

${ }^{389}$ Vgl. ebd., Nr. 05 (1922), S. 4.

${ }^{390}$ Vgl. ebd., S. 3.

${ }^{391}$ Vgl. ebd., S. 4.
} 
Hatte man auch in Dänemark erfahren müssen, dass der Aufbau einer Volkshochschule nicht allein am Schreibtisch geschehen konnte, sah man im Oktober 1919 auch in Breslau die Notwendigkeit einer Zusammenarbeit von Intellektuellen und Arbeitern. Dort lag die Gewalt beim Verwaltungsausschuss, dem drei Abgeordnete aus dem Magistrat (ab 1920/21), sechs Stadtverordnete, vier Personen aus freien Gewerkschaften, jeweils ein Mitglied der Hirsch-Dunckerschen Gewerkschaften sowie christlichen Gewerkschaften, aber auch fünf Vertreter der Schülerschaft (seit 1919) und ein Vertreter des Breslauer Lehrerverbandes angehörten. Besonders die starke Stellung der Schülerschaft war den Gründern wichtig, sollte sich doch zwischen Schülern und Lehrern eine lebendige Beziehung entwickeln, um eine möglichst fruchtbare Arbeit hervorzubringen. Für Marck stand fest:

\begin{abstract}
„Mehr noch als früher ist der Arbeiter zur Ausnutzung jeder gebotenen Bildungsmöglichkeit verpflichtet. War alles Wissen, das er sich aneignete früher in erster Weise eine Waffe in seiner politischen und wirtschaftlichen Befreiungskampfe, so wird jetzt seine Weiterbildung die notwendige Voraussetzung für die Festigung und Verbreiterung des Einflusses, den sich das Proletariat im öffentlichen Leben errungen hat, wird sie zu einer Pflicht der Arbeiter gegenüber dem Volksganzen. “392
\end{abstract}

Dabei sollte nach Marck die Volkshochschule eines der Instrumente werden, mit dem die Arbeiter nach ihrer politischen Befreiung und nach ihrer wirtschaftlichen die geistige Emanzipation bewerkstelligen und vorantreiben könnten. Unabdingbar für eine erfolgreiche Arbeit war daher der Achtstundentag. ${ }^{393}$ Siegfried Marcks großes Ziel war letztlich die Schaffung einer Volksuniversität und, vielmehr noch, einer Arbeiterhochschule. Zu seiner eigenen Rolle als Dozent an der Volkshochschule bekannte er:

„Die Männer und Frauen, die die Kurse leiten, sind sich bewusst, dass die volkstümliche
Darstellung ihrer Wissenschaft eine der schwierigsten Aufgaben ist, die Dozenten gestellt
werden kann. Nicht verflachtes oder halbes Wissen wollen sie bieten, sondern lernhafte und
tiefe Bildung zu solcher Klarheit und Einfachheit durchdenken und darstellend gestalten, dass
sie jedem zugänglich und verständlich werden muss. Nicht fertige Resultate sollen den
Hörern in Vorlesungsform dargelegt werden, der Lehrende soll mit ihnen gemeinsam lernen,
in Übungen sollen die Ergebnisse gemeinsam erarbeitet werden. ${ }^{394}$ Die Breslauer Volkshochschule verstand sich stets als Mittel zur Überwindung des Klassengegensatzes. Immerhin richtete sie ihr Hauptaugenmerk auf Handarbeiter, Kleingewerbetreibende und untere Beamte, die abhängig von ihrer Region und Sozialisation innerhalb Deutschlands unterschiedlich zu unterrichten waren und gerade einmal, wenn überhaupt, die Volksschule besucht hatten. Es kam der Leitung

\footnotetext{
${ }^{392}$ Marck, Siegfried: Meldet Euch zur Volkshochschule, in: Breslauer Volkswacht, 09.10.1919.

${ }^{393}$ Vgl. ebd., 18.02.1924.

${ }^{394}$ Marck, Siegfried: Meldet Euch zur Volkshochschule.
} 
der Breslauer Volkshochschule nicht ungelegen, dass es keine einheitliche Planung und keine Uniformierung auf Reichsebene gab. Das hätte für die Breslauer Hochschule in einem bürokratischen Wirrwarr geendet. ${ }^{395}$

Siegfried Marck, der mittlerweile Stadtverordneter geworden war, arbeitete ab Herbst 1920 im Verwaltungsausschuss der Breslauer Volkshochschule. Marck sah seine Aufgabe damals als Organisator und Lehrtätiger in der Vermittlung von Grundwissen und stellte die Wissenschaft vor die Parole der Weltanschauung:

„Vermittlung von Wissen, Erziehung zu wissenschaftlichem Denken, stellt auch für die Volkshochschule wie für jede andere Schule die erste Aufgabe dar; die höhere bleibt dann, von dieser Basis aus, Weltanschauung nicht zu übermitteln; denn diese bleibt Durchbruch des Persönlichen, aber vorzubereiten. “ 396

Erst ab 1922 war er mit Veranstaltungen in der Volkshochschule vertreten und gab Einführungskurse über die Philosophie der Gegenwart. ${ }^{397}$ Unter anderem hielt der Philosophieprofessor 1923 in der Augustaschule in der Schweriner Straße einen Vortrag über die „Philosophischen Motive in der Dichtung der jüngsten Gegenwart““

Es verging im Folgenden kaum ein Halbjahr, in dem Marck keine Lehrveranstaltung anbot. ${ }^{398}$ In besonderem Maße versuchte Marck den Arbeitern die Grundgedanken Max Webers nahezubringen, dessen Arbeiten er sehr schätzte. ${ }^{399}$ Der Verwaltungsausschuss wurde zudem seit 1921 durch einen besonderen Lehrplanausschuss ergänzt, dem auch Marcks Doktorvater Eugen Kühnemann beisaß. ${ }^{400}$ Dieser war in jenen Jahren als geheimer Regierungsrat und als Leiter der Beratungsstelle für Volkshochschulwesen an der Breslauer Universität tätig. ${ }^{401}$

Siegfried Marck hielt Festreden $\mathrm{zu}$ besonderen Anlässen der Volkshochschule, wie der Beethoven-Feier am 14. Juni 1921, ${ }^{402}$ oder referierte über Goethe. $^{403}$ Das Ziel des Verwaltungsausschusses und letztlich auch seines, die Breslauer Volkshochschule zu verstaatlichen, wurde sowohl von Oberbürgermeister Wagner als auch vom Stadtverordneten Ernst Moering abgelehnt, was die finanzielle Abhängigkeit vom Stadtrat erhöhte. ${ }^{404}$

\footnotetext{
${ }^{395}$ Vgl. ebd., 04.09.1920, 18.09.1920.

396 Marck, Siegfried: Vernunft und Wissenschaft, in: Blätter der Volkshochschule Breslau., Nr. 09 (1922), S. 42.

${ }^{397}$ Vgl. Breslauer Volkswacht, 09.10.1922, 10.10.1922.

${ }^{398}$ Auch Immanuel Birnbaum war regelmäßig in der VHS aktiv, vgl. ebd., 04.10.1924.

399 Vgl. Marck, Siegfried: Max Weber, in: Blätter der Volkshochschule Breslau., Nr. 01 (1923), S. 103.

${ }^{400}$ Vgl. ebd., Nr. 06 (1922), S. $17 \mathrm{ff}$.

${ }^{401}$ Vgl. ebd., S, 16.

${ }^{402}$ Vgl. ebd., Nr. 07 (1922), S. 25.

${ }^{403}$ Vgl. Breslauer Volkswacht, 03.10.1922, 29.04.1924.

${ }^{404}$ Vgl. ebd., Nr. 06 (1922), S. 16.
} 
Waren die ersten Volkshochschulen im Reich besonders in Schleswig- Holstein als „Abwehrstätten“ gegen Dänemark und als Institutionen für die Schärfung des „deutschen Bewusstseins“ gegen die dänischen Ansprüche zu sehen, so sah man sich in Breslau, auch nach der Abtretung Oberschlesiens, vom Staat allein gelassen. Wie sollte sich so eine Volkshochschule als starkes Bollwerk deutscher Kultur im Osten behaupten können? Doch in Breslau ging es nicht um einen Kampf gegen fremdes Volkstum, sondern vielmehr darum, den Menschen des „weggenommenen“ Ostoberschlesiens nach dem Ersten Weltkrieg die Chance zu geben, ihr „deutsches Bewusstsein“ beizubehalten und zu schärfen. ${ }^{405}$ Wichtig für die innere Ausgestaltung der Volkshochschule war die im Sommer 1921 eingeführte Aufteilung der Lehrgänge in Vortragsreihen (mit Aussprachen), Rundgespräche, reine Arbeitsgemeinschaften und Gesamtunterricht. Besonders die Lehrgänge wurden von der Arbeiterschaft dankend angenommen. Zudem wurden besondere Lehrgänge für Angehörige derjenigen werktätigen Bevölkerung angesetzt, wie Feuerwehrleute oder Straßenbahnfahrer, deren Arbeitsschichten sie an der Teilnahme der regelmäßigen Abendkurse hinderten. Zur allgemeinen Unterstützung hatte sich die Leitung der städtischen Lesehallen und Volksbüchereien dazu bereit erklärt, die Arbeiter mit Büchern zu versorgen. Zu den Lehrgängen kamen ab Herbst 1920 die „literarischen Sonntagvormittage“, die sehr stark besucht wurden. ${ }^{406}$ Ihren Höhepunkt erlebte die Volkshochschule wohl im Winterhalbjahr 1921/22, als sie über 2.200 Teilnehmer an ihren 71 angebotenen Lehrgängen begrüßen durfte. ${ }^{407}$ In der Zeit danach litt sie unter Geldmangel $^{408}$, insbesondere da die Zuschüsse vom Stadtrat nicht mehr so hoch ausfielen. $^{409}$

Bedeutend mehr als in der städtischen Arbeiterbildung engagierte sich Siegfried Marck in der Freien Jüdischen Volkshochschule Breslaus. Diese Volkshochschule folgte dem Vorbild des Freien Jüdischen Lehrhauses in Frankfurt am Main und die Teilnehmer der Kurse waren, anders als in „deutschen“ Volkshochschulen, vor allem Mitglieder des gehobenen Bürgertums. Orthodoxe Juden indes boykottierten oftmals

\footnotetext{
${ }^{405}$ Vgl. ebd., S. 11.

${ }^{406}$ Vgl. ebd., Nr. 07 (1922), S. 25.

${ }^{407}$ Vgl. ebd., S. 23.

408 Es kam immer wieder zu Aufrufen in der Volkswacht, die dazu animieren sollte, die schlecht besuchte VHS aufzusuchen, vgl. Breslauer Volkswacht, 07.01.1925.

${ }^{409}$ Siehe hierzu die Protestresolution der Breslauer Volkshochschule-Gemeinde, die von mehr als 600 Teilnehmern (Schülern und Lehrern) unterzeichnet wurde und Protest an der Herabsetzung der Zuweisung durch den Magistrat anprangerte, ebd., 18.03.1922; zur Finanzierung der Volkshochschule siehe auch ebd., 11.07.1924.
} 
solche Lehrhäuser. Dort vermochte Marck seit Anfang der zwanziger Jahre regelmäßig den Gemeindemitgliedern zumindest ein Basiswissen über Politik, Philosophie, Literatur und Geschichte zu vermitteln. Immerhin hatte das Breslauer Jüdische Gemeindeblatt eine Auflage von 10.000 Exemplaren und war innerhalb der jüdischen Schriften in Deutschland besonders auflagestark. ${ }^{410}$ Betrachtet man die Vorlesungsverzeichnisse seit Mitte der 1920er Jahre, die unter anderem im Breslauer Jüdischen Gemeindeblatt angekündigt wurden, so fällt doch eine ständige Wiederkehr bekannter Breslauer Gemeindemitglieder auf, die hier lehrten: An erster Stelle wurde meist Willy $\mathrm{Cohn}^{411}$, der bekannte Gymnasiallehrer am Breslauer Johannesgymnasium, werbewirksam genannt, der in seinen Vorlesungen versuchte, das Judentum in der damals zeitgenössischen Literatur kenntlich $\mathrm{zu}$ machen. Professor Michael Guttmann, der bekannte Rabbiner am jüdisch-theologischen Seminar Breslaus, führte in den Talmud ein und versuchte so die Gemeinde zu stärken. ${ }^{412}$ Diese Volkshochschule war der jüdischen Gemeinde ein wichtiges Anliegen, zelebrierte man doch jedes Halbjahr die Eröffnung des Semesters. Oft kamen hochgerühmte Schriftsteller, wie Max Brod, Felix Salten oder Arthur Holitscher, um bei den festlichen Veranstaltungen Vorträge zu halten. ${ }^{413}$

Siegfried Marcks Kurse waren anders als die der übrigen Dozierenden: Er hielt - abweichend von der Norm - oftmals keine Vorlesungen, sondern bildete im neo-sokratischen Sinne ${ }^{414}$ Arbeitsgemeinschaften über „Porträts jüdischer Sozialisten (Karl Marx, Ferdinand Lassalle, Ludwig Frank, Viktor Adler, Rosa Luxemburg)““. 415 Der Philosophiedozent, Jude und Sozialdemokrat Siegfried Marck sah sich als Bindeglied zwischen liberalem Judentum und Sozialdemokratie. In den Sälen des Realgymnasiums, dem „Zwinger“ am Schlossplatz in Breslau, gegenüber des Stadttheaters, hielt Marck weitere Arbeitsgemeinschaften ab, in denen er - auch oft

\footnotetext{
${ }^{410}$ Vgl. Lagieswki, Maciej: Die Juden in Breslau 1850-1945, S. 39.

411 Willy Cohn ließ sich zudem 1920 zu den Repräsentanten-Wahlen der liberalen „Vereinigten Jüdischen Parteien“ aufstellen, vgl. Anzeige des Wahlausschusses, in: Ebd., 28.02.1920. In ihrem Wahlprogramm forderten sie die Demokratiesierung des Gemeindewahlrechts, das Wahlrecht der Frauen, die Berücksichtigung des jüdischen Handwerks bei allen von der Gemeinde zu vergebenden Arbeiten sowie eine ausreichende Fürsorge für die Ostjuden, vgl. ebd., 06.03.1920.

${ }^{412}$ Vgl. Breslauer Jüdisches Gemeindeblatt, Nr. 10 (1925), S. 151.

${ }^{413}$ Vgl. ebd., Nr. 10 (1925), S. 151, Nr. 09 (1926), S. 128, Nr. 09 (1927), S. 134.

${ }^{414}$ Für Marck waren die Arbeitsgemeinschaften besonders wichtig. Die „Sokratische-Methode“ mit ihrem „lebendigen Gespräch“, stellte für ihn den Prototyp der Arbeitsgemeinschaft dar, auf das er sich gerne berief. Die Idee des „(Neo-)Sokratischen Gesprächs“ wurde von Leonard Nelson und Gustav Heckmann weiterentwickelt. Die Wissensvermittlung funktionierte nun nicht mehr dialogisch, sondern in moderierten Gruppengesprächen. Mit dieser Methode versuchte Marck seine Schüler fortwährend zu eigenständigem Denken anzuregen. Vgl. Marck, Siegfried: Das Gesetz, wonach Du angetreten!, S. 30. Zum Sokratischen Gespräch siehe: Birnbacher, Dieter/Krohn, Dieter: Das sokratische Gespräch, Stuttgart 2002.

${ }^{415}$ Vgl. Breslauer Jüdisches Gemeindeblatt, Nr. 10 (1925), S. 151.
} 
zusammen mit seiner Frau Kläre - „Rathenau als Philosoph der Wirtschaft und Politik“ aber auch „Religiöse Stoffe in der Dramatik der Gegenwart“ thematisierte und zudem in ,die gedankliche und stilistische Eigenart der letzten Werke Arnold Zweigs und Jakob Wassermanns: Sergeant Grischa, Fall Maurizius“ einführte. ${ }^{416}$ Mit Walther Rathenau kannte er sich besonders gut aus, hatte er doch vermehrt Rezensionen zu dessen Neuerscheinungen geschrieben ${ }^{417}$ und referierte nach dessen Ermordung gern auf Gedenkfeiern über ihn. ${ }^{418}$ Immerhin war Rathenau Jude gewesen und seine Ermordung musste Siegfried Marck auch als Angriff auf die Demokratie und die Republik werten. ${ }^{419}$ Diese Gedenkfeiern wurden in nationalistischen Kreisen gern als „öffentliches Ärgernis“ “ bezeichnet. ${ }^{420}$ Demgegenüber gab er auch einen Einblick in die „Lehre und [das] Schicksal des Kämpfers Gustav Landauer“421, der Ende des 19. und Anfang des 20. Jahrhunderts einer der führenden Theoretiker und Aktivisten des Anarchismus gewesen war.

\footnotetext{
${ }^{416}$ Vgl. ebd., Nr. 09 (1926), S. 128, Nr. 09 (1927), S. 134, Nr. 09 (1928), S. 162.

${ }^{417}$ Vgl. Marck, Siegfried: Rathenau als Denker, in: Logos: Zeitschrift für systematische Philosophie, Bd. 11 (1922-1923), S. 181-191.

${ }^{418}$ Vgl. Breslauer Volkswacht, 14.06.1923, 25.06.1923.

419 Zur Rathenauermordung siehe Sabrow, Martin: Der Rathenaumord. Rekonstruktion einer Verschwörung gegen die Republik von Weimar, München 1994; Gall, Lothar: Walther Rathenau. Portrait einer Epoche, München 2009, S. $220 \mathrm{ff}$.

${ }^{420}$ Vgl. Breslauer Volkswacht, 21.06.1923.

${ }^{421}$ Vgl. Breslauer Jüdisches Gemeindeblatt, Nr. 10 (1929), S. 183.
} 


\section{Ein Novembersozialist als Stadtverordneter}

Direkt nach dem Ersten Weltkrieg und zurück in Breslau ordnete sich Siegfried Marck - anders als viele seiner Leidensgenossen, die in den Schützengräben zum Sozialismus konvertierten - eher am rechten $\operatorname{Rand}^{422}$ der Sozialdemokratie ein. Andere glitten $\mathrm{ab}$ in einen radikalen Sozialismus, traten für anarchistische und kommunistische Zielsetzungen ein, Marck nicht. Somit lässt sich auch in der Biographie des späteren Neuhumanisten das Grundsatzproblem der Weimarer Sozialdemokratie ablesen - „das Verhältnis der SPD zur staatlichen Macht in der parlamentarischen Republik“. ${ }^{423}$

Der Breslauer sozialdemokratische Ortsverein, in dem er von Anfang an aktiv mitarbeitete, war froh über den Eintritt Siegfried Marcks. Immerhin stammte Marck aus einer angesehenen, aber traditionell nationalliberal gesonnenen Familie. Siegfried Marck war für die ,alten“ Parteigenossen ein Novembersozialist.

Das Wort Novembersozialist wurde durch die Geschichte der Sozialdemokratie geprägt und diente letztlich ein wenig abfällig der Unterscheidung zwischen dem „alten Stamm“ von Sozialisten und den neu hinzugekommen, „nicht vollwertigen“ Parteimitgliedern nach der Revolution 1918. Dennoch gab es im Nachhinein vereinzelt Stimmen, welche diese Bezeichnung und die daraus resultierende Trennung nicht guthießen. Immerhin soll eine Vielzahl dieser Novembersozialisten seit langem die Inhalte des Erfurter Parteiprogramms begrüßt haben, sich aber wegen ihrer Lebenssituation, ihrer Anstellung bei Behörden oder Kommunen, nicht erlaubt haben können, sich offen der Bewegung anzuschließen. ${ }^{424}$

Siegfried Marck gehörte zu den „Neuen“ und war damit erfolgreich. Er wurde von seinen Parteigenossen gleich auf die Liste zu den Stadtverordnetenwahlen 1919 gesetzt. Angeführt wurde die Liste von Paul Löbe, der damals noch als Chefredakteur der Breslauer Volkswacht arbeitete. Auch der Geschäftsführer des sozialdemokratischen Blattes, Max Tockus, kandidierte auf Platz 25 für die Stadtverordnetenwahlen. Der Rechtsanwalt Eugen Bandmann, der das Breslauer Leitmedium vor dem Ersten Weltkrieg oftmals in Prozessen verteidigt hatte, kandidierte auf Listenplatz zwölf. Bandmann hatte sich damals noch nicht der Sozialdemokratie angeschlossen, um nicht als „Geschäftssozialist“ zu gelten. Mit

\footnotetext{
${ }^{422}$ Er befand sich rechts von der damals vorherrschenden Parteilinie Paul Löbes, vgl. Walter, Franz: Revolutionärer Mythos, S. 152.

${ }^{423}$ Vgl. Winkler, Heinrich August: Der Schein der Normalität. Arbeiter und Arbeiterbewegung in der Weimarer Republik 1924-1930, Berlin/Bonn 1985, S. 332.

${ }^{424}$ Vgl. Breslauer Volkswacht, 25.11.1919.
} 
dem Ersten Weltkrieg trat er der SPD bei und lehnte später einen Ruf ins Justizministerium ab, mit der Begründung, dass er in Breslau seinen Platz habe. ${ }^{425}$ Der Privatdozent Siegfried Marck wurde auf Platz 47 und damit etwa in der Mitte dieser Liste aufgestellt, die insgesamt 102 Kandidaten umfasste. ${ }^{426}$ Marck war der einzige Kandidat der Breslauer Sozialdemokratie, der seinen Lohn und Brot an der Universität fand und damit besonders wertvoll. Alle anderen waren vorwiegend Gewerkschafter, Parteifunktionäre, einfache Arbeiter, aber auch vereinzelt Ärzte. ${ }^{427}$

Doch auch wenn Marck nur auf Platz 47 gesetzt wurde, konnte er vom Aufwind der MSPD in der Odermetropole seit Anfang 1919 profitieren: Die MSPD erreichte damals die absolute Mehrheit mit 52 von $102 \mathrm{zu}$ vergebenen Sitze. Die Wahlbeteiligung mit 60 bis 65 Prozent zu den Stadtverordnetenwahlen 1919 war hingegen schwach. ${ }^{428}$ Damit lagen die Mehrheitssozialdemokraten deutlich vor den Stimmen des Zentrums, der Deutschnationalen, der Demokraten und auch der Unabhängigen Sozialdemokraten. ${ }^{429}$ Bereits vor der Wahl konnten Stimmen innerhalb der Breslauer Stadtverordnetenversammlung vernommen werden, die diesen politischen Wechsel und die daraus resultierende Neuorientierung vorhersahen. ${ }^{430}$ Angedeutet wurde diese nicht zuletzt in den Wahlen zur Nationalversammlung, als die Sozialdemokraten in Breslau rund 160.000 Stimmen und damit beinahe drei Mal so viele Stimmen wie die Deutschen Demokraten erhielten. Auch in Mittelschlesien sah es nicht anders aus. Die sozialdemokratische Bewegung sorgte auch hier mit über 210.000 Stimmen für eine deutliche Mehrheit vor den Deutschen Demokraten und vor dem Zentrum. Überhaupt sorgte die Bewegung innerhalb des Deutschen Reiches für gewaltige politische Erosionsprozesse, wie Zahlen aus der Breslauer Volkswacht belegen. ${ }^{431}$

\footnotetext{
${ }^{425}$ Vgl. ebd., 07.05.1924.

${ }^{426}$ Vgl. ebd., 10.02.1919, 24.02.1919.

427 Vgl. ebd. Überhaupt war der Anteil der Professoren, die sich parteiübergreifend auf den Wählerlisten befanden, gering. So kandidierten bei der DDP lediglich zwei Professoren, beim Zentrum ebenfalls zwei, selbiges bei den Deutschnationalen. Bei der VOA (Vereinigte Organisation der kaufmännischen Angestellten), nicht verwunderlich, kein Mitglied der Universität, auch innerhalb der USPD kein Professoraler auf den Wählerlisten, vgl. Wahlvorschläge für die StadtverordnetenNeuwahlen in Breslau, in: Ebd., 24.02.1919.

${ }^{428}$ Vgl. ebd., 05.03.1919.

${ }^{429}$ Vgl. ebd., 03.03.1919, 04.03.1919, 05.03.1919, 16.05.1919. Insgesamt kamen die MSPD auf 52 Mandate, das Zentrum auf 18 Mandate, 15 Mandate fielen auf die Deutschnationale Volkspartei, 14 Mandate an die Deutschen Demokraten, 2 Mandate für die Handelsangestellten und 1 Mandat für die USPD, vgl. ebd., 08.03.1919.

${ }^{430}$ Vgl. ebd., 28.02.1919. Die ersten Auseinandersetzungen zeigten sich insbesondere zwischen dem Zentrum und der Mehrheitssozialdemokraten, als es um die Wahl des Stadtverordnetenvorstehers ging. Eugen Bandmann von den Mehrheitssozialdemokraten wurde nur zum zweiten Vorsteher gewählt, Adolf Heilberg von den Deutschen Demokraten wurde Vorsteher, vgl. ebd., 18.03.1919. ${ }^{431}$ Vgl. ebd., 20.01.1919.
} 
Durch die Folgen des Ersten Weltkrieges galt es auch in Breslau einige Lücken innerhalb der Reihen der Sozialdemokraten zu füllen. Immerhin hatten durch den Krieg zwei Vorstandsmitglieder, zwölf Distriktführer, 25 Gemeindevertreter, 48 Bezirksführer und rund 400 Mitglieder nicht mehr den Weg zurück nach Breslau und dessen Umgebung finden können. ${ }^{432}$ Novembersozialisten wie Siegfried Marck wurden somit benötigt.

Doch wie nun der Kontakt mit den Arbeitern aussah, wenn er nicht mehr in den Schützengräben war, begriff der bürgerliche Marck schnell. Sofort wurde er in die Grabenkämpfe zwischen MSPD und USPD hineingezogen, die sich oftmals in blutigen Zusammenstößen entluden: Marck hatte zugesagt, in einer Arbeitergegend zu sprechen, in der die Bevölkerung mit den Radikalen sympathisierte. Gemeinsam mit seiner Frau Lola betrat er einen sehr überfüllten, mit Rauch getränkten Saal, eigentlich eine Bierhalle, in dem auch seine Geliebte Kläre als Zuhörerin anwesend war, und bestieg das Rednerpult:

„Aber schon nach den ersten Sätzen wurde er von Zwischenrufen unterbrochen, höhnische
Anklagen gegen die Regierung, eine sozialistische Regierung, welche die eigenen Genossen
unterdrückte. Die Zwischenrufe prasselten gegen den Redner, zerhackten, zerstückelten seine
Sätze, dass er immerzu innehalten musste. Fried versuchte lauter zu sprechen, um die Störer
zu übertönen. Seine Stimme überschlug sich.“4333 Dass die Störungen einem einstudierten System entsprangen, hatte Marck bald erkannt, dennoch versuchte er abzuwarten, kreuzte die Arme und wartete mit überlegenem Lächeln bis sich die Stimmung beruhigte, um dann erneut anzusetzen. Auch einige „Gemäßigte“ fanden den Weg in die Versammlung und brüllten von verschiedenen Tischen, dass sie hören wollten, was Marck zu sagen habe. Es kam darauf wieder zu Zwischenrufen, welche die Situation eskalieren ließen:

„Erzählst uns nichts Neues. Aufgewärmter Salat! Das ist ein Vornehmer. Professor, schwatze das deinen Studenten vor! [...] Das ist derjenige, der über die Philosophie des ,als $\mathrm{ob}^{\text {‘ }}$ so gut gesprochen hat. Als ob er ein Sozialist wäre. Als ob die Regierung einer Arbeiterregierung wäre“‘434

Es kam zu eine wilden Schlägerei zwischen den Anhängern der „Gemäßigten“ und den „Radikalen“, die nur von der Polizei beendet werden konnte. Marck wurde dabei am Kopf verletzt. Lola sollte diese gewalttätige Auseinandersetzung später als „instinktiven Haß der Arbeiter gegen den Intellektuellen, den Bürgerlichen, der sich in ihre Reihen gedrängt hatte“ beschreiben. ${ }^{435}$ Dieses Erlebnis sorgte bei Marck für

\footnotetext{
${ }^{432}$ Vgl. ebd., 16.04.1919, eine genaue Übersicht mit Namen:16.05.1919.

${ }^{433}$ Landau, Lola: Vor dem Vergessen, S. 133.

${ }^{434}$ Vgl. ebd., S. 134. Marck hatte zuvor an der Universität einen Vortrag über die Philosophie des ,als ob" gehalten, worauf sich die Anspielungen beziehen.

${ }^{435}$ Vgl. ebd.
} 
erste Zweifel an seiner neuen politischen Grundhaltung. Es war auch der Einfluss seiner Geliebten, Kläre, die ihn stets zu solchen Veranstaltungen begleitete und seine Zweifel verstärkte ${ }^{436}$ :

„Ich werde ihrem Rat folgen. Ich werde mich von der Parteipolitik zurückziehen [...]. Seit Wochen hat mich Kläre gebeten, mich von diesem unwürdigen Demagogenspiel zu befreien. Ich kann vom Lehrstuhl, von einer höheren Plattform, eindringlicher wirken, auch für die politischen Ideen, die ich vertrete [...] Ich kam mir in dieser politischen Zirkusschreierei wie ein Clown vor. Und heute, dieser politische Boxkampf. Entwürdigend!“‘37

Auch seine anfängliche Euphorie für die Arbeit als Soldatenrat wich der Tatsache, dass er die Arbeit als „stumpfsinnig und geistestötend“ empfand. „Wider den Geist leben, das rächt sich““438, gestand Marck sich ein.

Dennoch blieb Siegfried Marck der Breslauer Sozialdemokratie treu und er zog sich nicht zurück, gegen alle Zweifel, die ihm sein privates Umfeld aufdrückte. Der Dozent der Philosophie war von kaum einer Parteiveranstaltung wegzudenken. Während seiner vielen Reden und besonders in der Zeit nach dem Kapp-Putsch geriet er jedoch immer wieder in zum Teil gewalttätige Auseinandersetzungen zwischen linken und rechten Gruppen, bei denen auch sein Freund und Parteikollege Ernst Eckstein mitwirkte.

Für Eckstein war das nicht ungewöhnlich. Er stürmte mit ein paar Genossen eine deutschnationale Rednerveranstaltung, um auf dieser das Wort zu ergreifen. Die Deutschnationalen wussten sich nur mit dem Rausreißen der Stühle und dem Attackieren der Sozialdemokraten zu helfen. Während der Schlägerei, die selbst nach der Räumung durch die Polizei bis spät in den Abend auf den Breslauer Straßen weitergeführt wurde, wurden viele Anwesende verletzt, darunter auch mehrere Gymnasiasten, die „,in sehr enge Berührung mit Arbeiterfäusten“ kamen. ${ }^{439}$ Dieser Konflikt zwischen Eckstein und den Deutschnationalen schwelte bei ihm seit seiner Schulzeit. Immer wieder warf man ihm vor, Anstifter illegaler Demonstrationen zu $\operatorname{sein}^{440}$ oder mit seinen Arbeitern Veranstaltungen deutschnationaler Verbindungsstudenten ,gestürmt“ ${ }^{\text {zu haben. }}{ }^{441}$

Das Stürmen von „,fremden“ Parteiveranstaltungen hätte Siegfried Marck sich nicht getraut. Er war Pazifist und scheute die körperliche Auseinandersetzung.

\footnotetext{
${ }^{436}$ Vgl. ebd.

${ }^{437}$ Ebd., S. 135 f.

${ }^{438}$ Ebd., S. 136.

${ }^{439}$ Vgl. Breslauer Volkswacht, 03.06.1920.

${ }^{440}$ Vgl. ebd., 14.05.1920.

${ }^{441}$ Vgl. ebd., 22.05.1920.
} 
Vielmehr versuchte er fortwährend argumentativ das deutschnationale Gedankengut $\mathrm{zu}$ widerlegen, was nicht bedeuten soll, dass es in diesen Zusammenhängen nicht zu Pöbeleien gekommen sei und diese Veranstaltungen nicht geräumt wurden. ${ }^{442}$ In diesem Gefüge muss bedacht werden, dass der Kapp-Putsch 1920 einen Angriff auf die Demokratie und die Republik bedeutete, folglich gegen die Werte, die Marck als Anhänger der „rechten“ Breslauer Sozialdemokraten vertrat und die für ihn von enormer Bedeutung waren.

Im Januar 1919, auf einer Wahlversammlung, auf der die Sozialdemokraten eigentlich Anhänger der freien Berufe und Künstler eingeladen hatten, entwickelte sich eine rege Diskussion zu den Verbindungen von Wissenschaft und Arbeitern. Marck machte ganz deutlich klar, dass es für ihn nicht auf das Programm einer Partei, sondern auf den Geist des Volkes ankomme. Dabei griff er seine eigene politische Herkunft und die seiner Familie an, indem er der Deutschnationalen Volkspartei attestierte, sie sei noch nicht vom reaktionären Geist losgekommen, was innerhalb der Versammlung für großen Beifall sorgte. Politisch ein wenig näher als den Deutschnationalen fühlte er sich sicherlich zur Deutschdemokratischen Partei. Das Verhältnis der SPD zur Demokratischen Partei, folglich auch seins, schilderte Marck wie folgt:

„Das Programm der Demokratischen Partei unterscheidet sich von dem der Sozialdemokratie
nur wenig, aber haben die Demokraten je für ihre Ideale gelitten, für sie Opfer gebracht, sind
sie mit Leidenschaft für sie eingetreten? Ein sicheres Gewässer bietet nur die
Sozialdemokratie. Die Liebe allein kann die Welt erlösen und nur die deutschen Sozialisten
können zu ihren Gesinnungsfreunden in den anderen Ländern sagen: Bruder, Mitmensch
vereinigen wir uns wieder! Was den Gebildeten nottut, ist die Einsicht, dass nur von einem
Bunde der Denkenden und der Leidenden das Heil kommt.“443 Es ist schon verwunderlich, dass der bürgerliche Patriziersohn sich so stark mit dem Leidensempfinden seiner sozialdemokratischen Genossen identifizierte und von einer Art Sockel herab seine alte und seine neue politische Heimat zu verbinden versuchte. Er selbst, akademisch gebildet und ohne große finanzielle Not, war sich der Bedürfnisse der armen Industriearbeiter bewusst und musste sich in dieser Position sicherlich als Bindeglied verstehen. Durch die Fronterlebnisse spielten für ihn nun Begriffe wie Solidarität und Nächstenliebe eine wichtige Rolle.

Wenige Tage nach der Wählerversammlung waren die Worte Marcks wieder gegen die Deutschnationalen gerichtet. Auf einer Gedenkfeier für die Ermordeten Karl Liebknecht und Rosa Luxemburg hielt der Privatdozent vor ca. 2.500 Zuhörern eine Rede, die einer vernichtenden Abrechnung glich. Er verdeutlichte, dass er die

${ }^{442}$ Vgl. ebd., 05.06.1920.

${ }^{443}$ Ebd., 15.01.1919. 
Schuld für eine Verlängerung des Krieges innerhalb der konservativ-nationalen Kreise sah. Diese Ausdehnung des Krieges sei letztlich auch Urheber der Revolution gewesen, die für ihn nicht gemacht wurde, sondern mit brachialer Naturgewalt hereingebrochen sei. Dabei verteidigte Marck auch die Arbeit der Arbeiter- und Soldatenräte in der Übergangszeit, die für ihn in den Tagen des allgemeinen Zusammenbruchs zwar manche Missgriffe getan, aber dennoch wichtige Vorarbeit geleistet hätten. Nun müsse, wenn in Deutschland Ordnung und Freiheit wiederhergestellt werden sollten, nicht den nationalistischen Parteien, sondern der Sozialdemokratie das Vertrauen geschenkt werden. ${ }^{444}$

Die Breslauer Sozialdemokraten warben um das Beamtentum. Immerhin habe die Umwälzung in Deutschland auch den Beamten die politische Bewegungsfreiheit gebracht, die ein großer Teil aus Gewohnheit noch nicht zu nutzen wüsste. Große Teile, so glaubte man, sympathisierten bereits mit den Ideen der Sozialdemokratie, es müsse nur um sie geworben werden, damit sie sich vollends dieser Bewegung anschlössen. $^{445}$ Nach den Stadtverordnetenwahlen wurde innerhalb der Stadtverordnetenversammlung des Öfteren über die Beamtengehälter gesprochen und entschieden, bei denen die Sozialdemokraten, von Siegfried Marck vertreten, keinen Zweifel mehr an der Sympathie für die einst verborgene Wählerschicht ließen. ${ }^{446}$

„Kultur“ war das Schlagwort Siegfried Marcks in jenen Jahren. Er wies oft darauf hin, „daß [die Deutschen] nicht nur ein niedergebrochenes, sondern vor allem ein überanstrengtes Volk sind“" und deshalb auf kulturellem Gebiet zu allerletzt gespart werden dürfe. Folglich auch nicht in der Schule, weshaln Marck für die Erhöhung der Lehrergehälter eintrat. ${ }^{447}$ Siegfried Marck ging es vor allem um die junge Generation und dabei insbesondere um die Arbeiter, denen er gern über die Geschichte der Philosophie oder das Leben einiger Staatsdenker referierte. Beinahe jeden Mittwochabend und im ständigen Wechsel der Referenten Marck, Eckstein und Birnbaum, konnten die Arbeiter für 1,10 Reichsmark an diesen Vortragsabenden teilnehmen. Neben Vorträgen gab es auch ein besonderes Kursprogramm, das ab 1923 in der katholischen Realschule am Niklaistadtgraben stattfand. ${ }^{448}$ Der Breslauer

\footnotetext{
${ }^{444}$ Vgl. ebd., 18.01.1919.

${ }^{445}$ Vgl. ebd., 20.02.1919. So wurden etwa gesonderte Beamtenversammlungen abgehalten, zu denen alle Beamte der Stadt nebst Frauen eingeladen wurden und die großen Zuspruch fanden, vgl. ebd., 07.01.1919, 10.01.1919.

${ }^{446}$ Beispielsweise ebd., 20.02.1920, 27.02.1920.

${ }^{447}$ Vgl. Ebd., 03.04.1920, 09.09.1920, 25.06.1920.

${ }^{448}$ Vgl. ebd., 06.01.1923.
} 
Privatdozent lehrte beispielsweise über Rousseaus Werk ${ }^{449}$, welcher für Marck nicht nur als Philosoph interessant, sondern ihm noch vielmehr als Staatsphilosoph „der Verkünder der modernen Demokratie“ war. Auch galt er ihm als „Apostel des allgemeinen und gleichen Wahlrechts“, der „keine Abstufung der Menschen nach Bildung und Besitz“ vornahm und die „gleichen politischen Rechte für jeden Bürger“ einforderte. ${ }^{450}$ Marcks Credo war eindeutig: „Bildung macht frei““451 und es galt, den Arbeitern sozialistische Literatur nahezubringen. ${ }^{452}$

Auch Clara Zils sah die Republik als eine politische Umgebung, in der sich die Jugend besonders wohlfühlte, wie sie auf einer Revolutionsfeier der Arbeiterjugend bemerkte. ${ }^{453}$ Dennoch musste Zils auch konstatieren, dass junge Arbeiter in dieser Republik deutlich schlechter verdienten als ältere und forderte einen Mindestlohn. ${ }^{454}$ Somit galt es sich um die jungen Arbeiter zu kümmern: Jeden dritten Sonntag im Sommer 1922 wurden ab Mai in der Umgebung Breslaus Wanderungen für die Arbeiter mit deren Kindern organisiert und unternommen, an denen knapp 280 Arbeiter teilnahmen. ${ }^{455}$ Diese reihten sich in die Arbeiterbildungsbestrebungen der Breslauer Sozialdemokratie ein, auf die Siegfried Marck Einfluss hatte. Anfang 1920 hatten die sozialdemokratischen Abgeordneten der Stadtverordnetenversammlung einstimmig und gegen großen Widerstand der alten Eliten dafür votiert, eine Einheitsschule einzurichten. Ihnen war wichtig, dass schnellstmöglich „die Sechsjährigen aus dem Arbeiterhause und aus der Villa, aus der Mietskaserne und aus dem Schlosse auf die selbe Schulbank gehen“456. Marck sprach sich immer wieder gegen Pläne der konservativ-nationalen Kräfte aus, die Schulgelder für die Mittelschulen zu erhöhen, was für Arbeiter, Handwerker und kleine Beamte eine große Last gewesen wäre. ${ }^{457}$ Er selbst wollte seine Kinder Andreas und Alfons, auch gegen den Wunsch Lola Landaus und Armin T. Wegners, nicht auf eine Privatschule schicken, sondern auf die Volksschule:

„Ich trete jederzeit privat und öffentlich für die Volksschule für alle Kreise ein. Der Besuch von Andreas in einer Privatschule widerspräche meinen Grundsätzen und brächte mich

\footnotetext{
${ }^{449}$ Vgl. ebd., 28.01.1921, 29.01.1921.

${ }^{450} \mathrm{Ebd}$

451 Vgl. seine angekündigte Kursreihe über die Kulturlehre des Sozialismus, ebd., 19.01.1923, 24.04.1923.

${ }^{452}$ Vgl. ebd., 03.10.1923, 10.10.1923.

${ }^{453}$ Vgl. ebd., 10.11.1922.

${ }^{454}$ Vgl. ebd., 12.01.1923.

${ }^{455}$ Vgl. ebd., 02.05.1922.

${ }^{456}$ Ebd., 09.01.1920.

${ }^{457}$ Ebd., 19.11.1920.
} 
dadurch auch äusserlich in eine unangenehme Situation. In die Kleinburger Volksschule gehen einfache aber nette Kinder, nicht ausgesprochenes 'Proletariat'." 458

Marck sah in den Breslauer Privatschulen die „Treiber“ für soziale Ungleichheit im Schulwesen. ${ }^{459}$

Neben der Bildungs- und Kulturpolitik waren Marck die Rechte der Frauen von besonderer Bedeutung. So setzte er sich für eine Etablierung der Sozialen Frauenschule ein, die nun auch in Breslau gegründet wurde. ${ }^{460}$ Das Thema Frauenwahlrecht war ihm ein weiteres Anliegen. Gern sprach er im Breslauer Verein für Frauenwahlrecht über die politische Lage. ${ }^{461}$ Sicherlich war dies auch dem Einfluss seiner Ehefrauen Lola und Kläre geschuldet, immerhin setzten sich beide intensiv mit der sozialistischen Idee und einer Neuorientierung nach der Revolution von 1918 auseinander beziehungsweise schlossen sich dieser Idee an. Lola, die Anfang 1919 in den Vorstand des Weimarer Schriftstellerbundes der Ortsgruppe Breslau gewählt und als Mitglied in den Lyceum-Club aufgenommen wurde ${ }^{462}$, bekräftigte ihr Engagement für die Interessen der Frauen, wenn auch eher in einer bürgerlichen Zusammensetzung. Die Lyceum-Clubs, die sich von England aus nach ganz Europa ausbreiteten und so auch den Weg nach Deutschland fanden, versuchten die Synthese aus Frauenemanzipation und Kultur zu erreichen, indem unter anderem den Künstlerinnen und Wissenschaftlerinnen Hilfestellung bei Ausstellungen oder Veröffentlichungen gegeben wurde. Mit diesen Clubs sind ebenfalls Namen wie Marie-Elisabeth Lüders, Alice Salomon, Helene Lange oder auch Bertha von Suttner und Käthe Kollwitz verbunden. ${ }^{463}$

Vielleicht war es jedoch mehr der Einfluss Kläres, der Philosophiestudentin, die überhaupt nicht mit der Arbeit für die Sozialdemokratie fremdelte, auch in den Folgejahren für die Volkswacht schrieb, sich auf Parteiversammlungen eimischte und mit ihrem Mann im Arbeiterbildungsausschuss tätig war.

\footnotetext{
${ }^{458}$ Marck an Wegner, 29.11.1921, NL ATW.

${ }^{459}$ Vgl. Breslauer Volkswacht, 26.09.1924.

${ }^{460}$ Eine Übersicht der Frauenschulen in Deutschland siehe: Rundschau der Frau, Jahrgang III Nr. 5 (September 1932). Zu Hans Herschels Biographie besonders: Webersinn, Gerhard: Dr. Hans Herschel. Jahrbuch der Schlesischen Friedrich-Wilhelms-Universität, Band XII 1967 S. 246ff.

${ }^{461}$ Vgl. Breslauer Volkswacht, 26.04.1919.

${ }^{462}$ Vgl. Hamann, Birgitta: Lola Landau, S. 34.

${ }^{463}$ Vgl. Sander, Sabine: Nur für geladene Gäste. Der „Deutsche Lyzeumsclub“, in: Zwaka, Petra et al. (Hrsg.): „Ich bin meine eigene Frauenbewegung“. Frauenansichten aus der Geschichte einer Großstadt, Berlin 1991, S. 52-57.
} 
Auch Ernst Eckstein war in Breslau auf Versammlungen anzutreffen, die sich dem Thema Frauenwahlrecht widmeten. Immerhin galt es auch diese Wählerschicht bei den kommenden Wahlen für sich zu gewinnen und den Wählerinnen klar zu zeigen, weshalb auch sie davon profitieren würden, Sozialdemokratinnen $\mathrm{zu}$ werden. ${ }^{464}$ Eckstein machte in seinen Reden immer wieder deutlich, dass das politische Zentrum nie für die Rechte der Frauen eingestanden sei oder gar dafür gekämpft habe und es nicht aus Überzeugung täte: „Wenn das Zentrum heute Zugeständnisse an die Arbeiter macht, so tut es das, weil es muss, nur, um überhaupt existieren zu können, aber von Herzen kommt es nicht.““465 An dieser Stelle darf nicht vergessen werden, dass die Sozialdemokratie die einzige Bewegung war, die das Frauenwahlrecht zuvor in ihr Parteiprogramm aufgenommen hatte. Die bürgerliche Frauenbewegung bekam erst durch die sozialdemokratisch geprägte Arbeiterinnenbewegung ein breiteres und in der Öffentlichkeit verstärktes Bild. Allerdings stieß das Frauenwahlrecht, wie es die SPD 1863 in ihr Programm aufgenommen hatte, bei den sozialdemokratischen Männern nicht zwingend auf breite Zustimmung. ${ }^{466}$ „Es gibt Sozialisten, die der Frauenbewegung nicht weniger abgeneigt gegenüberstehen, wie der Kapitalist dem Sozialismus“ soll August Bebel 1883 geschrieben haben. ${ }^{467}$ Dieser Ausführung Bebels lagen Ängste oder vielmehr die wahrgenommene Gefahr zugrunde, dass sich durch die Einführung des Frauenwahlrechts das rechte und konservative Wählerpotential vergrößern und es somit der SPD mehr schaden als nützen könne. ${ }^{468}$ Und auch wenn August Bebel mit seiner Forderung nach dem gleichen Wahlrecht auf dem Parteitag in Gotha 1875 scheitern sollte, da die Delegierten dieses Vorhaben aus „taktischen“ Gründen ablehnten, konnte dieses Anliegen auf dem Erfurter Parteitag 1891 besonders durch das Wirken Clara Zetkins durchgesetzt werden. Vier Jahre später wurde ein entsprechender Gesetzentwurf im Reichstag behandelt, der mit Ausnahme der Stimmen der SPD abgelehnt wurde. ${ }^{469}$ Die Bemühungen um das Frauenwahlrecht auch auf internationaler Ebene trugen Früchte. Besonders nachdem etwa innerhalb der im August 1907 gegründeten Sozialistischen Fraueninternationale - (Socialist International Women, SIW) mit dem Ausbruch des

\footnotetext{
${ }^{464}$ Vgl. Breslauer Volkswacht, 12.09.1919, 20.09.1919, 23.09.1919, 03.05.1920, 05.05.1920.

${ }^{465}$ Ebd., 19.08.1919.

${ }^{466}$ Vgl. Notz, Gisela: „Her mit dem allgemeinen, gleichen Wahlrecht für Mann und Frau!“”. Die internationale sozialistische Frauenbewegung zu Beginn des 20. Jahrhunderts und der Kampf um das Frauenwahlrecht, Bonn 2009, S. 15f.

${ }^{467}$ Zetkin, Clara: Zur Geschichte der proletarischen Frauenbewegung Deutschlands, Berlin 1958, S. 145.

${ }^{468}$ Vgl. Notz, Gisela: „Her mit dem allgemeinen, gleichen Wahlrecht für Mann und Frau!“, S. 16.

${ }^{469}$ Vgl. ebd., S. $17 f$.
} 
Ersten Weltkrieges die Bemühungen um das Frauenwahlrecht zum Erliegen kamen. Dass sich auch die Frauenbewegung nach der Bewilligung der Kriegskredite mit von der Sozialdemokratie abspaltete, ist nur folgerichtig, nachdem sie doch gegen Rüstung und Krieg mobilisierte. ${ }^{470}$ Erst das nahende Kriegsende sorgte dafür, dass die bürgerliche und die sozialistische Frauenbewegung gemeinsam arbeiteten. Für die sich abgespaltenen Frauenrechtlerinnen wie Clara Zetkin galt dies als Beweis, dass die Frauenbewegung nicht mehr die bürgerliche Ordnung stürzen, sondern schützen würde. ${ }^{471}$

Erst nachdem der Rat der Volksbeauftragten Mitte November 1918 das Dreiklassenwahlrecht abgeschafft hatte, wurde das Volk bei den Wahlen zum Reichstag 1920 mit 8,7 Prozent von Frauen vertreten. Das waren immerhin 37 Frauen von 467 Parlamentariern, wobei USPD und Mehrheitssozialdemokratie zusammen 22 Parlamentarierinnen für sich aufstellen konnten. ${ }^{472}$ Die Wahlbeteiligung war mit 82,4 \% der wahlberechtigten Männer und 82,3\% der wahlberechtigten Frauen so hoch, wie sie bis 1930 nicht mehr werden sollte.

Marie Juchacz, eine bekannte weibliche Persönlichkeit der Mehrheitssozialdemokratie jener Jahre, die sich mit dieser Entwicklung verbinden lässt, war immerhin die erste Frau, die im Parlament das Wort ergriff und trat die Nachfolge Clara Zetkins an, die politisch nun andere Wege ging. Jucharcz wurde Frauensekretärin im zentralen Parteivorstand und übernahm die Redaktion der Gleichheit. $^{473}$ Eine Kandidatenliste der sozialdemokratischen Partei in Mittelschlesien für die Wahlen 1920 verdeutlicht das weibliche Engagement von Breslauer Frauen innerhalb der Partei, gerade weil mit Marie Ansorge auf Platz 5 der Liste eine einfache Ehefrau hinter den etablierten Kandidaten Paul Löbe oder Franz Feldmann gelistet war. ${ }^{474}$ Marie Ansorge, ehemalige Landarbeiterin, Textilarbeiterin und Zeitungsausträgerin, fand 1905 den Weg zur Sozialdemokratie und sollte daraufhin Mitarbeiterin der Schlesischen Bergwacht und Leiterin der Arbeiterwohlfahrt in Waldenburg werden. Sie gehörte von 1924 bis 1933 dem Reichstag an. ${ }^{475}$

\footnotetext{
${ }^{470}$ Vgl. ebd., S. 37-41.

${ }^{471}$ Vgl. Zetkin, Clara: Zur Geschichte der proletarischen Frauenbewegung Deutschlands, S. 220.

472 Bei den Wahlen zur Nationalversammlung waren es 9,6 Prozent, vgl. Notz, Gisela: „Her mit dem allgemeinen, gleichen Wahlrecht für Mann und Frau!“‘, S. 45.

${ }^{473}$ Vgl. ebd., S. $41 \mathrm{f}$.

${ }^{474}$ Vgl. Breslauer Volkswacht, 14.05.1920.

${ }^{475}$ Vgl. Reichstagshandbuch, 1. Wahlperiode 1920, S. 165; Nach dem Zweiten Weltkrieg wurde sie Mitglied der Bundesversammlung und gehörte zeitweilig dem Bundestag an; mehr zu Marie Ansorge
} 
Clara Zils war zu Beginn der 20er Jahre in Breslau zur Wortführerin der Frauenbewegung avanciert. Juchacz und Zils kannten sich auch persönlich, traten sie doch gemeinsam auf Veranstaltungen in der Odermetropole auf. ${ }^{476}$ Das Thema Frauenrechte war das, was Zils in den nächsten Jahren, bis zu ihrem verfrühten Tod, nicht mehr loslassen sollte:

„Frauen und Mütter, in unserem Schoß wird das große Wunder des heiligen Lebens Wirklichkeit. In uns ist die Liebe zu allem Werdenden, unser menschliches Empfinden stärkt sich gegen Unrecht, Bosheit, Vernichtung. Nun sind die Tore der Kerker, die um die Frauen aufgerichtet waren, gesprengt. Treten wir mit ein in die Schar der Kämpfer für das Gute, hüten und mehren wir das heilige Feuer, das auf dem Altar der Menschlichkeit entzündet ist. [...] Unsere heilige Heimat die Erde, unsere Familie die Menschlichkeit, unser Stern die Freiheit." 477

Diese Worte, die Clara Zils an die Leser der Volkswacht zum 1. Mai 1921 richtete, bekräftigten ihr Engagement für die Sozialdemokratie, die sie als „Kämpfer für das Gute“ empfand und mit den Werten der Menschlichkeit und Freiheit verbunden sah. Für Zils war die Beteiligung von Frauen an der Umsetzung der sozialdemokratischen Idee unabdingbar. Insbesondere nachdem diese Bewegung für ihr Wahlrecht gekämpft hatte, müsse die SPD die Partei der Frauen werden. Zils selbst hatte wenige Tage vor der Veröffentlichung ihres Artikels zum ersten Mal den Weg zu den Sozialdemokratischen Frauenversammlungen in Breslau gefunden. Diese Veranstaltungen, die monatlich stattfanden, hätten zwar größeren Zuspruch haben können, wie Zils auch merken musste - dennoch: Als sie ihren ersten Vortrag am „Nikolaitor“ hielt, wurde dieser sehr beifällig aufgenommen. Auch Ernst Eckstein war auf dieser Veranstaltung als Redner anwesend ${ }^{478}$ und ließ es sich nicht nehmen, die Frage zu beantworten, „Wer uns und unsere Kinder aus der Not der Zeit“ rettet. $^{479}$

Ein Blick in den Jahresbericht des Breslauer Sozialdemokratischen Vereins verrät, dass rund ein Drittel aller Genossen der Odermetropole Frauen waren. ${ }^{480}$ Später musste Zils erkennen, dass Frauen eher konservativ und bürgerlich wählten, ganz wie es August Bebel befürchtet hatte. Beispielsweise bei den Wahlen in

siehe: Notz, Gisela: Maria Ansorge - „um unsere sozialistischen Ideen zu verwirklichen, dafür sind wir nie zu alt“, in: Jahrbuch für Forschungen zur Geschichte der Arbeiterbewegung, Heft III 2002.

${ }^{476}$ Vgl. Breslauer Volkswacht, 28.01.1922.

${ }^{477}$ Zils, Clara: Aufwärts, in: Ebd., 30.04.1921.

478 Vgl. ebd., 21.04.1921. In der Regel waren etwa 200 Frauen bei solchen Veranstaltungen anzutreffen. Zudem war Clara Zils von Beginn an auch zugleich auf den Distrikversammlungen aktiv, siehe ebd., 16.04.1921.

${ }^{479}$ Vgl. ebd., 17.07.1920, 21.08.1920.

${ }^{480}$ Jahresbericht des Sozialdemokratischen Vereins Breslau, für das Geschäftsjahr 1920/21, in: Ebd., 26.04.1921. Der Verein hatte in diesem Geschäftsjahr insgesamt 24.131 Mitglieder, davon 18.175 Genossen und 5.956 Genossinnen. 
Thüringen 1924 hätte Zils es gern gesehen, wenn Frauen sich der Sozialdemokratie angeschlossen hätten - ähnlich positiv wie im Wien jener Jahre. ${ }^{481}$ Immerhin habe ihr zufolge das Bürgertum das Vaterland zerstört und es sei an der Sozialdemokratie, es nun für alle Bürger gleichbewertet, gleichberechtigt und gleichermaßen an Kultur beteiligt wieder zu errichten. ${ }^{482}$

Zils wurde schnell für die Arbeit der Volkswacht eingespannt, schrieb vermehrt, was Frauen für die Sozialdemokratie tun könnten, ${ }^{483}$ nicht zuletzt, weil seit 1924 der Beilagen-Teil der Volkswacht um die Kategorie „Für die Frauen“ erweitert wurde. $^{484}$ Zudem hielt sie viele Vorträge zu ihren Kernthemen Frauenrechte und Armutsbekämpfung. ${ }^{485}$ Ihrem Engagement für den Wohlfahrtsgedanken konnte sie auf einem bevölkerungspolitischen Kongress in Köln nachgehen und über diesen in dem Breslauer Parteiblatt berichten. ${ }^{486}$ Sie stieg durch ihr Engagement sehr schnell innerhalb der Parteihierarchie auf und wurde vom Vorstand zur Delegierten der Reichsfrauenkonferenz ernannt ${ }^{487}$ und zudem auf dem sozialdemokratischen Bezirksparteitag für Mittelschlesien neben Gustav Scholich in den Parteiausschuss gewählt. $^{488}$

Über Siegfried Marcks Wirken für die Sozialdemokratie losgelöst von Kläre zu schreiben, ist nicht $\mathrm{zu}$ denken. Durch sie fand er in Breslau seinen ersten thematischen Zugang. Nach der Trennung von Lola und der Heirat mit Kläre konnten beide ihre weiteren politischen Standpunkte verfestigen - gegen den Krieg, für Bildung und Kultur. Überhaupt waren es besonders die Maifeiern, auf denen Marck die Republik und den Menschheitsgedanken verteidigte. Beinahe in jedem Jahr war er es, der für die Sozialdemokratie, aber noch vielmehr in seinem Selbstverständnis als Demokrat sprach und dabei deutlich machte: „Die Maifeier betrachte ich als Symbol der Republik [...] Im Übrigen gehe der Menschheitsgedanke, der diesem 1. Mai zugrunde liegt, über das Parteipolitische. Der reine Klassenkampf soll an dem Tage ausgeschaltet werden “489. Siegfried Marck war Demokrat, Sozialdemokrat, Republikaner. Alles, was einen Angriff auf das ihn nun tragende System bedeutete,

\footnotetext{
${ }^{481}$ Vgl. ebd., 06.03.1924.

${ }^{482}$ Vgl. ebd., 27.03.1924.

${ }^{483}$ Beispielsweise: Ebd., 10.02.1923, 17.03.1923, 14.01.1924, 07.03.1925, 25.09.1925.

${ }^{484}$ Vgl. ebd., 29.03.1924.

${ }^{485}$ Vgl. ebd., 03.08.1925, 07.08.1925, 23.10.1925.

${ }^{486}$ Vgl. Zils, Clara: Bevölkerungspolitischer Kongreß in Köln, in: Ebd., 31.05.1921.

${ }^{487}$ Vgl. ebd., 23.07.1921.

${ }^{488}$ Vgl. ebd., 18.11.1921. Ihre Vertreterin war im Übrigen Marie Ansorge.

${ }^{489}$ Ebd., 30.04.1920.
} 
Putschversuche, politische Morde und reaktionäre Tendenzen musste er strikt ablehnen.

Der Breslauer Anwalt Eckstein wurde zum Initiator einer Breslauer Gruppe des republikanischen Führerbundes. Er hielt einen Vortrag, in dem er „die Niederringung der Reaktion“ verdeutlichte. Dabei müssen Ecksteins Worte großen Anklang gefunden haben, da sich direkt nach dessen Rede eine Ortsgruppe mit 80 Mitgliedern gründete. ${ }^{490}$ Der Führerbund war eine Vereinigung von Offizieren und Unteroffizieren, welche der Sozialdemokratie nahe stehend die antirepublikanischen Tendenzen innerhalb des Militärs zu bekämpfen versuchten. ${ }^{491}$ Innerhalb dieses Zusammenschlusses kritisierte Eckstein den „reaktionären Charakter des Wehrgesetzentwurfes" und gab den Mitgliedern des Bundes einen historischen Abriss über das Verhältnis von Armee und Politik im kaiserlichen und republikanischen Deutschland. Eckstein selbst sah insbesondere in den Paragraphen 19, 29 und 36 des Entwurfes die rückschrittlichen Tendenzen. Diese verdeutlichten ihm vielmehr noch die Entrechtung der Soldaten, denen der Bund entschieden entgegenstand. ${ }^{492}$ Die Einwände Ecksteins erreichen ihr Ziel nicht: Die von ihm beanstandeten Paragraphen, die vor allem die Verpflichtung von Soldaten mit einer Dienstzeit von zwölf Jahren vorsahen sowie scheinbar zu einer lebenslangen Bindung des Soldaten an das Heer führen sollten, wurden in das Gesetz aufgenommen und verabschiedet. Insbesondere der Paragraph 36, der den Soldaten jegliche politische Zugehörigkeit und Mitarbeit untersagte, musste dem ehemaligen Kriegsteilnehmer und nun linken Sozialdemokraten Eckstein missfallen. ${ }^{493}$

Ferner sah Eckstein seine Arbeit innerhalb des Bundes als Kampf gegen die Organisation Escherich, kurz Orgesch ${ }^{494}$ und verdeutlichte sein Bekenntnis zur sozialistischen Republik. „Die muss leben, und wenn wir sterben müssen“ ließ er im Rahmen einer weiteren Veranstaltung verkünden. ${ }^{495}$ Diese Aussage Ecksteins verdeutlicht seine, im Gegensatz zu Siegfried Marcks, eher handlungsorientierte Denkweise. So ist es nicht verwunderlich, dass Eckstein sich gelegentlich vor Gericht verantworten musste ${ }^{496}$, gerade wenn ihm vorgeworfen wurde, eine Orgesch-

\footnotetext{
${ }^{490}$ Vgl. ebd., 20.04.1920.

491 Vgl. Winkler, Heinrich August: Weimar 1918-1933: Die Geschichte der ersten deutschen Demokratie, München 1993, S. 116.

${ }^{492}$ Vgl. Breslauer Volkswacht, 10.08.1920.

${ }^{493}$ Vgl. Reichswehrgesetz vom 23.03.1921, in: Reichs-Gesetzblatt 1921, S. 329-341.

494 Zur Organisation Escherich „Orgesch“ siehe: Nusser, Horst: Konservative Wehrverbände in Bayern, Preußen und Österreich 1918-1933, S. $173 \mathrm{ff}$.

${ }^{495}$ Vgl. Breslauer Volkswacht, 04.09.1920.

${ }^{496}$ Eckstein trat auch als Nebenkläger auf, vgl. ebd., 29.05.1925.
} 
Verantaltung gesprengt oder sich der Festnahme durch die Schutzpolizei entzogen zu haben. Dabei vertrat sich Eckstein nicht selbst vor Gericht - Eugen Bandmann kam dieser Aufgabe nach. ${ }^{497}$

Siegfried Marck stellte sich am Anfang seiner poltischen Arbeit die Frage, wie die Einheit von Diktatur und Demokratie zu verstehen sei, und allein seine Fragestellung verdeutlicht sein Denkmuster: lieber Gegensätze zu vereinen als sie zu entschärfen. Marck sah die Diktatur der Demokratie als die Forderung der Stunde und wollte diese als „Wahrung der Demokratie“ begreifen. Für ihn ging es dabei um das unabdingbare Annehmen der Verfassung, um die Anerkennung des Stimmrechtes, des Mehrheitsprinzips und letztlich um die Anerkennung der gesetzlich gewählten Organe, was nur eine „Diktatur“, nach Marck eine „starke, rücksichtlose Durchführung des demokratischen Willens، ${ }^{\star 498}$, leisten könne. Dabei geht Marck auch auf das Rätesystem ein:

„Die Demokratie, die wir meinen, fällt nicht ausschließlich mit Parlamentarismus oder Formaldemokratie zusammen. Auch das Rätesystem kann demokratisch sein, der Fortschritt und bessere Ausbau des Rätegedankens kann mit der Gesamtvolksvertretung durchaus zusammen bestehen. Nicht das Rätesystem als solches, nur die Alleinherrschaft der Arbeiterräte unter Ausschaltung der politischen Demokratie ist ,bolschewistisch“"،. ${ }^{499}$

Marck betont weiter, dass, wenn sich die radikalen Sozialisten zu taktischer Mitarbeit auf dem Boden der demokratischen Republik bereit erklären, sie Deutschland, dem Sozialismus und damit dem Sozialismus Europas eine großen Dienst erweisen würden:

„Hoffentlich kommt nach der Kapp-Affäre der Zusammenschluss der sozialistischen und darüber hinaus der entschieden demokratischen Parteien auf dem Boden radikaler republikanischer und sozialer Demokratie, eine Kombination von Parlamentarismus und Rätegedanken. Das diktatorische Rätesystem nach russischem Muster können wir uns nach wie vor in Deutschland der Entente wegen nicht leisten und kämen meiner festen Überzeugung nach auf diesem Wege zu den Zuständen Ungarns. Wohl aber bleibt uns der Weg den die geeinte radikale deutsch-österreichische Sozialdemokratie mit politischem Erfolg gegangen ist. Der Pazifismus der "Gewaltlosen" steht tief im Kurse: zuletzt bleibt nur weisse oder rote Gewalt! ‘500

Die anfängliche Euphorie Marcks für die Sozialdemokratie wich der Erkenntnis, dass sich eben jene bei den Reichstagswahlen im Abwärtstrend befand. „Bei den Reichstagswahlen 1920 habe die Sozialdemokratie sicherlich Fehler gemacht, die den Verhältnissen geschuldet gewesen seien“"501, so Marck, der im Rückblick auf das

\footnotetext{
${ }^{497}$ Dabei wurde Eckstein meist freigesprochen, vgl. ebd., 19.05.1922.

${ }^{498}$ Marck, Siegfried: Diktatur der Demokratie, in: Ebd., 08.04.1920.

499 Ebd. Marck spricht zu diesem Thema nicht auf den Distriktversammlungen, obwohl es sein Kernthema ist; Ernst Eckstein indes schon, vgl. ebd., 10.01.1920.

${ }^{500}$ Marck an Wegner, 22.03.1920, NL ATW.

${ }^{501}$ Vgl. Breslauer Volkswacht, 15.06.1920.
} 
Ergebnis festhielt, dass „die Macht der Arbeiterschaft zwar begrenzt sei, aber auch die Macht der anderen ihre Grenzen habe, denn mit 10,5 Millionen sozialistischen Stimmen können die Rechtsparteien auch nicht machen, was sie wollten“. ${ }^{502}$ Die Weimarer Koalition hatte unter den Reichstagswahlen von Juni 1920 erhebliche Verluste von 16 Prozent bei den Sozialdemokraten, rund sechs Prozent beim Zentrum und mehr als zehn Prozent bei der DDP erlitten. Somit gewannen die radikalen Parteien gewaltig an Stimmen und bezeugten die republikfeindlichen Tendenzen vieler Bürger im Deutschen Reich.

Siegfried Marck selbst bemerkte, wie ihn seine Arbeit ganz und gar einnahm, sodass er für familiäre Bedürfnisse kaum noch zur Verfügung stand. Wenn es beispielsweise darum ging, dass er seinen Sohn Andreas in jenen Jahren zu sich nach Breslau holen wollte, musste er feststellen, dass dieser nur „Gast, Besuch [...], zwischen 2 Kollegs, 2 Fraktionssitzungen und 4 Vorträgen in Unruhe und in Hast ${ }^{\star 503}$ war. In anderen Fällen hatte Marck seine Kinder immer zu seiner Mutter Rosa gegeben, die jedoch jetzt gesundheitlich nicht mehr in der Lage war, auf die Kinder aufzupassen. ${ }^{504}$ Auch wenn Siegfried Marck sich der sozialdemokratischen Idee angeschlossen hatte, er für Bildung, Gleichberechtigung und Demokratie kämpfte, ließ ihn in privater Hinsicht sein bürgerlicher Standesdünkel nie los. Immerhin wurden seine Kinder von Dienstmädchen großgezogen und Hauspersonal hatte die Familie Marck immer besessen. Über Andreas konnte er nur berichten:

„Er ist der Mittelpunkt, kleiner Prinz, seine geistige Überlegenheit über Clara [das Kindermädchen] ist ihm schon bewusst, er kommandiert, er weiss vor allen Dingen, dass sich schliesslich alles um ihn dreht, dass alles was er tut, interessiert. “505

Kaum ein anderer Redner war in jenen Jahren auf den Breslauer Bühnen so oft zu hören wie Siegfried Marck. Neben den Vorträgen, die er in seiner Tätigkeit als Volkshochschullehrer hielt, war er ein oft gebuchter Referent in vielen Bereichen des öffentlichen Lebens. Er trat als Redner bei Distrikts-Versammlungen, Funktionärskonferenzen und Generalversammlungen auf, war aber oftmals auch als Zuhörer und Redner auf Kulturveranstaltungen und nicht zuletzt auf Revolutionsfeiern $^{506}$ ergriff er mehrfach das Wort und mischte sich in die Diskussionen ein. Dabei war Marck nicht konfliktscheu. Ernsthafte ${ }^{502} \mathrm{Ebd}$.

${ }^{503}$ Marck an Landau, 31.03.1922, NL ATW. Dass Siegfried Marck wirklich kaum einen Vortrag ausließ, zeigt etwa seine Ansprache bei den Naturfreunden Breslaus, denen er im Gewerkschaftshaus selbst als Mitglied gern seine Zeit opferte, vgl. Breslauer Volkswacht, 03.04.1920.

${ }^{504} \mathrm{Vgl}$. ebd.

505 Ebd.

${ }^{506}$ Vgl. ebd., 12.03.1923, 19.03.1923. 
Auseinandersetzungen gab es innerhalb der Diskussion um das Görlitzer Parteiprogramm. Dieses sollte 1921 mit seinem Kurswechsel hin zum Bekenntnis zur Weimarer Republik auch die Abgrenzungsbestrebungen der Sozialdemokratie gegenüber den linkeren USPD und KPD bestärken und führte auch zwischen Siegfried Marck und Ernst Eckstein zu heftigen Auseinandersetzungen. Innerhalb Breslaus wurde die Debatte über den Programmentwurf zu großen Teilen in der Breslauer Volkswacht und in der Stadtverordnetenversammlung geführt - jedem Parteigenossen wurde die Möglichkeit eingeräumt, sich in sachlicher Aussprache diesem Thema zu widmen. ${ }^{507}$

Ernst Eckstein lehnte in der Aussprache den Staat, zu dem sich die Sozialdemokratie nun bekennen sollte, als „ein Klassenkampfmittel der bürgerlichen Gesellschaft" ab. Ihmzufolge sollten die Arbeiter versuchen, diesen Staat zu „erobern“, zu „zertrümmern“ und versuchen, darauf eine „sozialistische Gesellschaft" zu errichten. Hier müsse das Programm viel mehr Farbe bekennen - es sei $\mathrm{zu}$ schwammig und weise keine eindeutige Handlungsmaxime für die Arbeiterklasse auf. ${ }^{508}$ Der promovierte Jurist machte folgende Anmerkung:

„Die gesellschaftliche Umwandlung kann nur das Werk der arbeitenden Klasse sein, weil alle anderen Klassen, trotz der Interessenstreitigkeiten unter sich, auf dem Boden des Privateigentums und Produktionsmittel stehen, sie kann nicht vom Staate dekretiert werden." ${ }^{6509}$

Diese Worte Ecksteins konnte Siegfried Marck nicht unwidersprochen stehen lassen. Zwei Tage später stellte er ebenfalls in der Volkswacht fest, dass er keinen Unterschied zwischen bürgerlichem Staatssozialismus und Arbeitersozialismus sehe, solange das Endziel, der Sozialismus auf marxistischer Grundlage, umgesetzt würde. Marck sprach sich damit eindeutig gegen einen staatslosen Syndikalismus aus und attestierte dem Ecksteinschen Vorschlag, dass „dieser wegen der Unklarheit bezüglich der Auseinanderhaltung von Gegenwarts- und Zukunftsstaat und wegen seiner syndikalistischen Färbung [...]Verwirrung stiftet.“ Zudem stellte er fest, dass „wohl niemand mehr auf den Erfahrungen der Kriegswirtschaft die Sozialisierung als Bürokratisierung“ wolle, sondern vielmehr eine „weitgehende Heranziehung dezentralistisch aufgebauter, sich selbst verwalteter genossenschaftlicher Kooperationen“. ${ }^{510}$ Für Marck stand fest: „Diese gesellschaftliche Umwandlung kann

\footnotetext{
${ }^{507}$ Vgl. ebd., 20.07.1921.

${ }^{508}$ Vgl. ebd.

${ }^{509}$ Ebd.

${ }^{510}$ Vgl. ebd., 22.07.1921.
} 
nur das Werk der den demokratischen Staat zugleich mit ihren eigenen Organisationen in den Dienst der Sozialisierung stellender Arbeiterklasse sein.“511

Doch was war für Marck die Arbeiterklasse? Erste gewalttätige Auseinandersetzungen hatte er erfahren und erkannt, dass die Arbeiterklasse sich nicht geeint zur Republik bekannte. Immerhin gab es neben der MSPD noch die USPD, doch Marck betonte daraufhin auch immer wieder und gerade in Bezug auf die Möglichkeit einer baldigen Wiedervereinigung, dass er die Einheitsfront im Kampf gegen Rechts für unbedingt notwendig halte, „allerdings dürfe man sich nicht der Illusion eines vereinigten Proletariats hingeben, die Kommunisten würden ja auf jeden Fall fernbleiben. “512 Für Marck war das Schicksal der USPD:

„eine deutliche Warnung dafür, daß nicht Vermischung sozialdemokratischer und kommunistischer Ideologie, sondern nur eine Radikalisierung auf dem Boden sozialdemokratischer Gedankengänge - etwa im Sinne des Linzer Programms - Ansätze für die erneute Konzentration der Arbeiterklasse zu geben vermag. “513

Knapp ein Jahr später kam es zu einer kurzfristig ausgehandelten Verschmelzung von ehemaligen USPD-Mitgliedern und der SPD. ${ }^{514}$ Die Unabhängigen waren vor dem Zusammenschluss beinahe zerfallen, zählten sie doch in Breslau nur noch 183 Mitglieder, wie der Jahresbericht des Sozialdemokratischen Vereins für 1922/23 belegt. $^{515}$

Diese Koalition ging Marck gern ein. 1921 indes, bei möglichen Koalitionsverhandlungen mit der Volkspartei, sprach er sich gegen dieses Unterfangen aus. ${ }^{516}$ Auch Immanuel Birnbaum machte deutlich, dass ein Zusammengehen von SPD und Volkspartei nach den Preußenwahlen 1921 für ihn nicht möglich sei. Er befürchtete, dass die Sozialdemokraten in eine Minderheit geraten und sie letztlich als Dekoration dienen würden. ${ }^{517}$ Bei den Wahlen zum Preußischen Landtag hatten sowohl die Sozialdemokraten als auch die Demokratische Partei an Stimmen verloren. Deutschnationale, die KPD und die Deutsche Volkspartei konnten ihren Stimmenanteil ausbauen und das Zentrum und die DDP versuchten die Deutsche Volkspartei in die Regierung einzugliedern. Die Sozialdemokratie stand dem entschieden entgegen. So kam es nicht von ungefähr,

\footnotetext{
511 Ebd.

${ }^{512}$ Vgl. ebd., 23.07.1921.

${ }^{513}$ Marck, Siegfried: Sozialdemokratie, S. 27.

${ }^{514}$ Vgl. Niemann, Heinz et al.: Die Geschichte der deutschen Sozialdemokratie 1917-1945, Berlin 1982, S. 109f.

515 Vgl. Jahresbericht des Sozialdemokratischen Vereins 1922/23, in: Breslauer Volkswacht, 25.04.1923.

${ }^{516}$ Vgl. ebd., 30.09.1921.

${ }^{517}$ Vgl. ebd., 05.03.1921.
} 
dass die Breslauer Sozialdemokraten diejenigen Genossen, die innerhalb der Koalition Ministerämter ausführen sollten, aufforderten, „unverzüglich die Konsequenzen zu ziehen, wenn sich eine ersprießliche Arbeit auf dem Gebiete der inneren Politik und der Wirtschaft als unmöglich erweist““. ${ }^{518}$ Ernst Eckstein sah vor allem in der fehlenden Steuerpolitik der Volkspartei einen Grund, nicht mit dieser zusammenzuarbeiten und kritisierte den eigenen Parteivorstand. ${ }^{519}$ Auf dem Görlitzer Parteitag sollte die SPD die Haltung zu dieser Koalitionsfrage ändern.

Für Marck bot das Programm mit seinem Bekenntnis zur republikanischen Republik den Humus seines politischen Handelns, verstand er sich doch schon zuvor und fortwährend als „Mitglied eines republikanischen Blocks“ ${ }^{520}$ Marck sprach es, nachdem Paul Löbe in ähnlichen Tönen in Breslau für eine Regierungsbeteiligung der SPD warb, offen aus:

„In Bayern, im Stegerwaldschen Preußen und in der Reichspolitik unter Fehrenbach und Simons hätten wir erlebt, wie großen Schaden rein bürgerliche Regierungen heute den ohnehin nicht allzu festen Grundlagen der Republik und unserer Wirtschaft zufügen können. Für den demokratischen Ausbau der Republik unter Selbstverwaltung sorgen, wie die Haltung des Kommunalfreisinns in der Wahlrechtsfrage zeigt, nur die Sozialdemokraten. “521

Damit stellte Marck seinen Kampf für den Sozialismus zugunsten einer Regierungsbeteiligung seiner Partei zurück. Auch in einer zentralen Bedingung des Versailler Vertrages - der Kürzung des Wehretats - musste Marck, trotz allen Engagements für die Friedensbewegung, klarstellen, dass eine solche für ihn eine „Unmöglichkeit“ darstelle. Ernst Eckstein indes sprach sich klar für die Abschaffung der Reichswehr aus ${ }^{522}$ und kämpfte gegen den „Reichswehr-Geist“. ${ }^{523}$

In den Jahren des Ruhrkampfes war es Ernst Eckstein, der auf Protestversammlungen gegen die Ruhrbesetzung besonders oft $\mathrm{zu}$ hören ${ }^{524}$ war und die Breslauer SPD machte in einer Resolution deutlich, dass die Besetzung der neuen deutschen Gebiete zeige, „dass die heutigen französischen Regierungsmänner den deutschen des wilhelminischen Zeitalters gleichwertig“ seien und dass dem „militärischen Moloch Goldmilliarden“ geopfert würden, die besser in der Aufbauarbeit ausgegeben werden könnten. ${ }^{525}$ Eckstein machte deutlich, dass:

\footnotetext{
${ }^{518}$ Ebd., 13.05.1921. Siehe auch die Diskussionen nach einer Rede Carl Severings in Breslau, in die sich auch Birnbaum und Eckstein mischten, in: Ebd., 02.11.1921.

${ }^{519}$ Vgl. ebd., 23.12.1921.

${ }^{520}$ Vgl. ebd., 12.06.1922.

${ }^{521}$ Ebd., 03.06.1922.

${ }^{522}$ Vgl. ebd., 11.08.1922.

${ }^{523}$ Vgl. ebd., 21.09.1922.

${ }^{524}$ Beispielsweise ebd., 15.01.1923, 19.01.1923.

${ }^{525}$ Vgl. ebd.
} 
„Wenn Poincard heute versucht, das wirtschaftliche und politische Problem der Reparationen mit militärischen Maßregeln zu lösen, ist er nichts weiter als ein gelehriger Schüler Wilhelm II. und seiner Generäle“. 526

Eckstein schloss ein Zusammengehen mit den Nationalisten aus, ähnlich in dieser Haltung war Clara Zils. Siegfried Marck ging in seiner Argumentation noch ein wenig weiter. Neben der Kritik an der Besetzung des Ruhrgebietes durch die Belgier und Franzosen, machte er vor allem deutlich, dass der Kampf, der dort geführt werde, ein Kampf zwischen Militarismus und arbeitender Bevölkerung sei: „Der Weltkrieg war kein Volkskrieg, aber der gegenwärtige wirtschaftliche Krieg, welcher jetzt im Ruhrrevier geführt wird, ist ein wahrer Volkskrieg. “527 Wenn die Reparationsforderungen im Versailler Vertrag auch von Siegfried Marck als zu hoch festgeschrieben wurden, konnte er letztlich nur eine Verelendung der Massen daraus ableiten. Folglich trat Marck in der Stadtverordnetenversammlung für eine finanzielle Hilfe von 3 Millionen Reichsmark zugunsten der Ruhrhilfe ein. ${ }^{528}$

Eckstein sprach sich stets gegen Koalitionsverhandlungen aus, was nicht ohne Diskussionen innerhalb des sozialdemokratischen Lagers blieb. ${ }^{529}$ In diesem Zusammenhang muss gesehen werden, dass sich trotz der Wiedervereinigung von SPD und USPD die Lage der Sozialdemokratie in Breslau nicht verbesserte. Der Kapp-Putsch, der Ruhrkampf, aber auch die hohe Erwerbslosigkeit und Kurzarbeit verunsicherten viele Sozialdemokraten, sodass der Sozialdemokratische Verein Breslaus 1923 knapp die Hälfte seiner Mitglieder und damit auch viele Beitragszahler verlor. ${ }^{530}$ Doch war man sich einig, dass ,jede Koalitionspolitik abzulehnen“ sei. ${ }^{531}$ Ecksteins Haltung fand breite Zustimmung bei den Breslauer Sozialdemokraten, immerhin wurde er kurz darauf zum Vorsitzenden gewählt. ${ }^{532}$ Der Jurist bemängelte das Erscheinungsbild des Staates, der für ihn nach außen hin eine Demokratie, nach innen jedoch eine Monarchie, in welcher der Reichspräsident zu

\footnotetext{
${ }^{526}$ Ebd., 21.02.1923.

527 Ebd.

${ }^{528}$ Vgl. ebd., 09.02.1923.

${ }^{529}$ Vgl. ebd., 17.05.1924, 21.05.1924.

${ }^{530}$ Vgl. ebd., 04.06.1924.

${ }^{531}$ Vgl. ebd., 21.05.1924.

${ }^{532}$ Vgl. ebd., 03.06.1924. Interessant ist bei der Ämtervergabe, dass Siegfried Marck nicht in den Bildungsausschuss gewählt wurde, obwohl er sich doch für solche Themen stark machte; Immanuel Birnbaum indes schon.
} 
viel Macht besäße, darstelle ${ }^{533}$ und plädierte für eine sozialistische deutsche Republik. $^{534}$

Siegfried Marck setzte auf den Stadtverordnetenversammlungen, die meist monatlich stattfanden, weitere Schwerpunkte. Hier trat er besonders für die Erwachsenenbildung ein, in der er zeitgleich stark tätig war, aber auch für Kultureinrichtungen, wie das Stadttheater ${ }^{535}$ und den Rundfunk. Zugleich trat er als schulpolitischer Sprecher auf. Marck avancierte zum Parteitheoretiker, nahm 1925 positiv Stellung zum Heidelberger Parteiprogramm, indem er es mit den vorhergegangenen Parteiprogrammen verglich. Er betonte, dass in diesem Programm wieder der Begriff des „Klassenkampfes“ eingeführt werden müsse. ${ }^{536}$ Für ihn bildete dieser „den Ausdruck eines wissenschaftlichen Sozialismus“ und markierte somit klar die Abgrenzungen zu den anderen Parteien. ${ }^{537}$ Dennoch: Siegfried Marck war ein Bekenner der demokratischen Republik, der die Spaltung ,in Bürgerliche hier, Sozialisten da“ bedauerte. ${ }^{538}$ Er war ein „Sozialpatriot“", bei dem die „Ideologie der Landesverteidigung“ und „die Bejahung des eigenen Staates in all seiner Unvollkommenheit als Schützer der Kulturnation“" eine bedeutende Rolle einnahm. ${ }^{539}$ Während andere Sozialdemokraten mit den Deutschnationalen innerhalb der Stadtverordnetenversammlung noch darüber diskutierten, einige Plätze, die an den Kaiser und Adelige erinnern, innerhalb Breslaus umzubenennen, sprach er sich in Anlehnung an Frankreich für die Einführung eines „Platzes der Republik“ aus und bekam die nötige Zustimmung. ${ }^{540}$

Beinahe zur selben Zeit sprach sein späterer Freund und besonderes Vorbild Thomas Mann in Berlin über die deutsche Republik. Mann begann überaus positiv über Gerhart Hauptmann zu sprechen, dem diese Rede zu dessen 60. Geburtstag gewidmet war. Er pries Hauptmann ,als das geistige Haupt des republikanischen

\footnotetext{
${ }^{533}$ Vgl. ebd., 20.06.1924.

${ }^{534}$ Vgl. ebd., 24.06.1924.

${ }^{535}$ Marck befand sich seit März 1922 im Aufsichtsrat des Stadttheaters, vgl. ebd., 22.03.1922; sorgte als Magistratsmitglied für Subventionen für das Theater, vgl. ebd. 30.01.1925, 15.05.1925, 04.12.1925.

536 Vgl. ebd., 25.07.1925. Das Vorgängerparteiprogramm, folglich das Görlitzer Programm, beinhaltete nicht die Begriffe „Klassenkampfes“ oder „Arbeiterklasse“.

${ }^{537}$ Vgl. Marck, Siegfried: Zum neuen Programmentwurf unserer Partei, in: Ebd., 01.08.1925.

${ }^{538}$ Vgl. ebd., 12.06.1922.

${ }^{539}$ Marck, Siegfried: Sozialdemokratie, S. $23 \mathrm{f}$.

${ }^{540}$ Vgl. Breslauer Volkswacht, 24.01.1923, 26.01.1923. Franz Walter weist darauf hin, dass die Diskussion um die Umbenennung bereits 1922, unter dem Eindruck des Mordes an Walter Rathenau geführt wurde. Ein entsprechender Antrag wurde von den Deutschnationalen, der DVP und dem Zentrum angelehnt, vgl. Walter, Franz: Nationale Romantik, S. 152.
} 
Deutschlands“ an. ${ }^{541}$ Mehr noch sprach er sich besonders für den „freundlichen und bescheidenen“" sozialdemokratischen Reichspräsidenten Friedrich Ebert aus. ${ }^{542}$

Für Thomas Mann war der Staat zur Angelegenheit aller geworden und es sei falsch sich gegen die neu entstandene Republik zu wenden, immerhin sei diese „kein Ergebnis der Niederlage und der Schande, sie sei vielmehr entstanden in einer Stunde der Erhebung, in der auch alle die Jugendlichen sie begrüßten, die sie heute so gehässig ablehnen““. ${ }^{53}$ Der spätere Literaturnobelpreisträger und stets konservative Schriftsteller machte in diesem Zusammenhang auch deutlich, dass in seinen Äußerungen kein Widerspruch zu seinen Betrachtungen von 1918 bestand. Zwar fühle er sich stets „konservativ im Sinne der Wahrung des wertvollen Alten“, jedoch müsse dies seiner Ansicht nicht ein Festhalten an der alten Staatsform bedeuten. Vielmehr sah er in der neuen Staatsform eine der Humanität, „die die Gemeinschaft der Staatsgenossen gewährleiste“ und sprach sich offen gegen den von Frankreich dozierten Nationalismus aus: „, Nationalismus solle man den Franzosen überlassen. Das Volk, das den Witz hatte, ihn zu erfinden, wird auch Witz genug haben, ihn wieder abzuschaffen“ referierte Mann. ${ }^{544}$ Thomas Mann versuchte mit dieser Rede besonders auf die Intellektuellen und die studentische Jugend zu wirken, welche die neue Staatsform in Frage stellten und vollzog mit ihr auch eine Kehrtwende in seinem politischen Denken, die nicht zuletzt durch die Ermordung Walter Rathenaus kurz zuvor beeinflusst worden sein soll. ${ }^{545}$ Zudem schloss sich Thomas Mann den deutschen Demokraten an.

Siegfried Marcks Einsatz innerhalb der Breslauer Sozialdemokratie wurde ihm gedankt, rückte er doch bereits im Februar 1924 auf Platz acht der Breslauer SPDListe vor. Max Tockus, Ernst Eckstein und Immanuel Birnbaum wurden weit hinter Siegfried Marck, auf den Plätzen 13, 51 und 79 gelistet. ${ }^{546}$ Doch Marck wurde vorerst nur auf Platz drei der Kandidatenliste für die anstehenden Reichstagswahlen gewählt. Vor ihm landeten die amtierenden Reichstagsabgeordneten Paul Löbe und Max Seppel. ${ }^{547}$ Interessant ist in diesem Zusammenhang, dass Rudolf Hilferding, der bei der Vorauswahl eigentlich weniger Stimmen als Marck erhalten hatte, letztlich

\footnotetext{
${ }^{541}$ Vgl. Mann, Thomas: Von deutscher Republik, Berlin 1923.

${ }^{542}$ Vgl. Breslauer Volkswacht, 17.10.1922.

${ }^{543}$ Vgl. ebd.

${ }^{544}$ Vgl. ebd.

${ }^{545}$ Vgl. Darmaun, Jacques: Thomas Mann, Deutschland und die Juden, Tübingen 2003, S. 136.

${ }^{546}$ Vgl. Breslauer Volkswacht, 25.04.1924.

${ }^{547}$ Vgl. ebd., 12.01.1924.
} 
doch vor diesem gelistet wurde, als es darum ging, die Kandidaten der Bezirkskonferenz zur Wahl vorzuschlagen. ${ }^{548}$ Letztlich rutschte Marck in der offiziellen Aufstellung sogar auf Platz sieben der Vorschlagsliste für die anstehende Reichstagswahl. ${ }^{549}$ Dies muss für Siegfried Marck von großer Bedeutung gewesen sein, auch im Hinblick auf seine sicherlich angedachte Parteikarriere. Immerhin hätte er mit Platz drei auf der Kandidatenliste eine reelle Chance gehabt, Reichstagsabgeordneter zu werden - doch dieser Sprung blieb ihm verwehrt. Paul Löbe und Max Seppel zogen in den Landtag ${ }^{550}$, Rudolf Hilferding wurde Reichsfinanzminister. Nichtsdestoweniger konnte der Breslauer Privatdozent die Sozialdemokratie zeitweise im Landtag der Provinz vertreten. ${ }^{551}$

Die Reichstagswahlen von 1924 führten für die Sozialdemokraten Breslaus zu herben Verlusten. Die radikalen Parteien gewannen mehr und mehr die Oberhand. Vor allem die Deutschnationalen konnten im Wahlkreis Breslau mehr Stimmen als die Sozialdemokraten gewinnen. In der Odermetropole selbst lagen die Sozialdemokraten dennoch vor den Deutschnationalen. ${ }^{552}$ Wenngleich keine Regierungsbildung gelang, die SPD bei den Neuwahlen im Dezember 1924 leicht zulegen konnte, ${ }^{553}$ muss 1924 ein schmerzhaftes Jahr für die Breslauer Sozialdemokratie gewesen sein. Dennoch wuchsen seitdem die Mitgliederzahlen wieder an. ${ }^{554}$

Siegfried Marck glaubte weiterhin an die Republik und nachdem der „Gründer und Garant der Republik“ - Friedrich Ebert - verstorben war, versuchte er beispielsweise die Arbeiter von der außerordentlichen Bedeutung der Reichspräsidentenwahlen 1925 zu überzeugen. Ernst Eckstein kritisierte stets den für ihn spürbaren amerikanischen Einfluss auf die Wahlen zum Reichspräsidenten, die mittlerweile mit sehr viel Geld geführt wurden und plädierte dafür, das Hauptaugenmerk auf den Kandidaten und nicht auf das Programm zu legen. Für Eckstein war der passende Kandidat im ersten Wahlgang noch Otto Braun. ${ }^{555}$ Neben dem ebenfalls an der Breslauer Volkshochschule engagierten Karl Wendemuth und dem 1928 in den Reichstag gewählten Karl Mache rief Siegfried Marck nach dem

\footnotetext{
${ }^{548}$ Vgl. ebd., 15.01.1924. Auch Clara Zils wurde aufgestellt, jedoch deutlich hinter Marie Ansorge, vgl. ebd., 04.02.1924.

${ }^{549}$ Vgl. ebd., 29.03.1924.

${ }^{550}$ Vgl. Übersicht der gewählten Breslauer Sozialdemokraten, in: Ebd., 09.12.1924.

${ }^{551}$ Vgl. k.r.gr.: Siegfried Marck, , o. O ,o .D, NL SM.

${ }^{552}$ Die genauen Zahlen bei: Oliwa, Theodor: Die Geschichte der Arbeiterbewegung in Breslau, S. 8.

${ }^{553} \mathrm{Vgl}$. Breslauer Volkswacht, 08.12.1924.

${ }^{554}$ Vgl. Oliwa, Theodor: Die Geschichte der Arbeiterbewegung in Breslau, S. 8.

${ }^{555}$ Vgl. Breslauer Volkswacht, 09.03.1925.
} 
Tod Friedrich Eberts im zweiten Wahlgang zu den Reichspräsidentenwahlen 1925 zur Wahl Wilhelm Marx` auf und sprach sich gegen Paul von Hindenburg aus. ${ }^{556}$ Daneben hielt Marck einige Vorträge zum „Kampf um Eberts Erbe“, wie er in der Volkswacht tituliert wurde ${ }^{557}$ und unterzeichnete einen Aufruf der schlesischen Akademiker, die sich für die Wahl von Wilhelm Marx einsetzten. ${ }^{558}$

Das Wahlergebnis war ernüchternd. Selbst in Breslau erhielt der ehemalige Generalfeldmarschall von Hindenburg die Mehrheit der Stimmen und wurde zum Reichspräsidenten nach Friedrich Ebert gewählt. ${ }^{559}$ Dieses Ergebnis führte freilich zu Diskussionen innerhalb der Breslauer Sozialdemokratie, in denen sich Marck, Eckstein und Birnbaum einig waren:

„Es sei unverantwortlich nach dem Siege Hindenburgs keine weiteren Vorstöße der Rechten gegen die Demokratie zu erwarten. Nur durch Bejahung des schwarz-rot-goldenen Staates sei der Kampf gegen den schwarz-weiß-roten und nur auf diesem Boden der Kampf um den Sozialismus möglich. “560

Siegfried Marcks Bestrebungen nach Bildung und Kultur für die Arbeiter sollten nicht abreißen. Zu wichtig waren diese im Kampf gegen die Rechten. Noch im selben Jahr setzte sich Marck für das schwach besuchte Breslauer Stadttheater ein. Die Stadt habe, nicht nur im Interesse der Kunst, sondern auch im Interesse der großen Organisationen, die Pflicht, dem Theater finanziell zu helfen. Immerhin stelle das Breslauer Stadttheater Schützlingen der Wohlfahrtspflege regelmäßig Freikarten zur Verfügung und habe allein deshalb für die Stadt eine besondere Bedeutung. Die kommunistischen Abgeordneten sprachen sich jedoch gegen den Antrag Marcks aus, was bei ihm Entsetzen hervorrief, auch die Hetzkampagnen von konservativer Seite gegen die leitenden Stellen im Stadtheater konnte er nur schwer verarbeiten. Letztlich wären mit der Schließung des Theaters auch 300 Arbeitnehmer brotlos gewesen und den Kommunisten sollte der Begriff der „proletarischen Kultur“ geläufig sein. ${ }^{561}$ Marck machte seinem Kontrahenten Wilhelm Thum von den

\footnotetext{
${ }^{556}$ Ebd., 20.03.1925, 24.3.1925. Nachdem es im ersten Wahlgang keinen Sieger gab und im zweiten Wahlgang die relative Mehrheit genügte, wollte die Weimarer Koalition lieber einen Zentrumspolitiker, als einen Sozialdemokraten als gemeinsamen Kandidaten zur Wahl stellen. Ferner war es so möglich, Otto Braun mit Hilfe des Zentrums zum Preußischen Ministerpräsidenten zu machen, vgl. Winkler, Heinrich August: Arbeiter und Arbeiterbewegung in der Weimarer Republik, S. 236; Ders.: Weimar 1918-1933. Die Geschichte der ersten deutschen Demokratie, München 1993, S. 279; Longerich, Peter: Deutschland 1918-1933. Die Weimarer Republik. Handbuch zur Geschichte, Hannover 1995, S. 229. Karl Wendemuth gehörte überdies ab 1924 bis 1933 für die SPD dem Reichstag an und war einer der 44, die gegen das Ermächtigungsgesetz stimmten.

${ }^{557}$ Vgl. Breslauer Volkswacht, 20.03.1925, 25.03.1925.

${ }^{558} \mathrm{Zu}$ den Unterzeichnern gehörten auch Ernst Hamburger und Waldemar von Grumbkow, vgl. ebd., 23.04.1925.

${ }^{559}$ Vgl. ebd., 27.04.1925.

${ }^{560}$ Ebd., 06.05.1925.

${ }^{561}$ Vgl. ebd., 30.01.1925.
} 
Deutschnationalen klar: Wenn die Stadtverordnetenversammlung nicht der Subvention des Theaters nachkomme, dann könne die Breslauer Sozialdemokratie nicht der Subvention der Oper zustimmen. ${ }^{562}$

Das Engagement Siegfried Marcks für die Breslauer Kultureinrichtungen kam nicht von ungefähr. Schon Ende 1921 stand das Breslauer Stadttheater vor dem Aus und man befürchtete den Untergang der Breslauer Kulturinstitution. ${ }^{563}$ Zudem war es auch Kläre Marck, die sich in diesen Kreisen besonders engagierte und Siegfried so für ihre Arbeit begeisterte. Sie schrieb mittlerweile regelmäßig für die Monatshefte der Breslauer Volksbühne und sorgte dafür, dass die Familie Marck Geld für die Breslauer Theater spendete. ${ }^{564}$ Für die Marcks bestand keine Trennung zwischen Kultur und Zivilisation, wie sie das Bürgertum gerne gesehen hätte, vielmehr ging es ihnen um „die Kultivierung des Proletariats“ und nicht um die „Proletarisierung der Kultur“, wie Marck gern betonte. ${ }^{565}$

Nicht selten sorgte Marck auf den Stadtverordnetenversammlungen für Furore, und dass ihm seine religiöse Herkunft politisch zum Verhängnis werden sollte, auch innerhalb des eigentlich eher liberalen Breslauer Magistrats, wird im Oktober 1924 sicherlich auch ihn überrascht haben, als völkische Rüpeleien gegen jüdische Wohlfahrtsorganisationen innerhalb der Stadtverordnetenversammlung zu vernehmen waren. Die gesamte Debatte entlud sich bei einer Diskussion, die erklären sollte, weshalb der Magistrat dagegen gestimmt hatte, einen Abgesandten zur Verfassungsfeier des Reichsbanners zu entsenden. Sie mündete in eine Bedrohung Siegfried Marcks durch einen ehemaligen Schüler und endete mit einer Klage. Der Magistrat hatte sich gegen die Entsendung eines Abgebordneten entschieden, da er sich bereits an der offiziellen Feier im Schauspielhaus hat vertreten lassen und die Feier des Reichsbanners als eine rein private Angelegenheit verstand. ${ }^{566}$

Karl Mache, der die Ausführungen in die Versammlung einbrachte, hatte mit vielerlei Zurufen der Hakenkreuzler zu kämpfen, denen er couragiert entgegnete:

„, Ihr habt Euch verkrochen zu der Zeit, als es Deutschland wieder aufzurichten galt. An der Verfassungsfeier haben sich Millionen beteiligt, die Ihr niemals auf die Beine bringen könnt. Im Dreck auf dem Bauche gelegen hat Euer Ludendorff erst neulich wieder in München.“ 567

\footnotetext{
${ }^{562}$ Vgl. ebd., 13.04.1926.

563 Zur Breslauer Theaterfrage ebd., 06.12.1921, 13.12.1921, 16.12.1921. Auch die Breslauer Volkshochschule hatte große finanzielle Probleme und $\mathrm{zu}$ wenig Kursteilnehmer, vgl. ebd., 04.10.1923.

${ }^{564}$ Vgl. Kunst und Volk. Monatsheft der Breslauer Volksbühne, Heft 4 (1931), S. 124.

${ }^{565}$ Vgl. Breslauer Volkswacht, 30.01.1924.

${ }^{566}$ Vgl. ebd., 03.10.1924.

${ }^{567} \mathrm{Ebd}$.
} 
Die Hakenkreuzler selbst mussten das Reichsbanner als „Landplage“6568 bezeichnen und begrüßten die Ablehnung des Magistrats, keinen Gesandten zur Verfassungsfeier des Reichsbanners zu schicken. Während der Auseinandersetzung sollen die Reichsfarben von einem der Hakenkreuzler beleidigt worden sein. Als dieser vom Stadtverordnetenvorsteher Eugen Bandmann aufgefordert wurde, seine sanktionierbaren Formulierung zu wiederholen, redete er sich heraus, was Siegfried Marck zu dem Zuruf brachte, „Er kneift wie Ludendorff“. 569

Interessanterweise war derjenige, den Marck dort meinte, ein ehemaliger Student des Breslauer Philosophieprofessors. Helmuth Brückner, der wie Marck freiwillig im Ersten Weltkrieg gekämpft hatte, danach in Breslau sein Studium der Geschichte, Geographie, Philosophie und Volkswirtschaftslehre wieder aufnahm und bald danach abbrach, sollte später Oberpräsident und NSDAP-Gauleiter von Schlesien werden. Nach dem Hitlerputsch und dem daraus resultierenden Verbot der NSDAP war er innerhalb der Breslauer Stadtverordnetenversammlung zwischen 1924 bis 1926 intensiv an der Aufhebung des Verbotes beteiligt. Brückner, der damals Redakteur der Schlesischen Volksstimme war, wurde 1930 Mitglied des Reichstages und 1932 in den Preußischen Landtag gewählt. Nach der Machtübernahme durch die Nationalsozialisten wurde der Sohn eines Volksschullehrers zum Oberpräsidenten der Provinz Niederschlesien ernannt. ${ }^{570}$ Bemerkenswerterweise wurde Edmund Heines zu seinem Stellvertreter ernannt. Dieser sollte später als Fememörder im Konzentrationslager Dürrgoy bekannt werden und unter anderem für den Tod von Ernst Eckstein oder die Inhaftierung Paul Löbes verantwortlich zu machen sein. Auf den Einwurf Marcks bei der Stadtverordnetenversammlung entgegnete Brückner:

„Wenn Herr Dr. Marck Wert auf Ehre legte, würde ich ihn auf Pistolen fordern, für das was er mir zugerufen hat. So aber werde ich ihn verklagen. Er ist mein Lehrer gewesen, aber das wird mich nicht abhalten." ${ }^{571}$

Marck konterte, indem er zugestand, dass sein Zuruf nicht ganz parlamentarisch gewesen sein mag. Deshalb würde er ihn zurücknehmen, wenn Helmuth Brückner

\footnotetext{
$568 \mathrm{Ebd}$.

${ }^{569}$ Vgl. ebd.

Vgl. Rothe, Wolfram: Von Hitler verbannt, unter Stalin umgekommen: Helmuth Brückner - vom Gauleiter zum Gulag-Häftling, in: Zeitgeschichte regional Bd. 12 (2008), S. 46-53; Jakubaschk, Paul Willi: Helmuth Brückner: sein Kampf und Sieg um Schlesien; vom Frontsoldaten und Selbstschutzkämpfer zum schlesischen Führer, Oberpräsident und Staatsrat, Hirschberg 1933. Sowohl Brückner als auch Heines wurden 1934 aus der NSDAP ausgeschlossen. Grund dafür sollen homosexuelle Äußerungen gewesen sein vgl. Hüttenberger, Peter: Die Gauleiter. Studie zum Wandel des Machtgefüges in der NSDAP, Stuttgart 1969, S. 200.

${ }^{571}$ Breslauer Volkswacht, 03.10.1924.
} 
ihm nicht bereits mit Klage gedroht hätte und konstatierte, ,als Schüler hat er von mir nicht viel gelernt, wie sein Auftreten zeigt ${ }^{\text {‘572 }}$. Es müssen folglich zweierlei Umstände gewesen sein, die Marck getroffen haben. Zum einen der Vorwurf, keine Ehre zu besitzen, obwohl er einst freiwillig in den Krieg gezogen war, zum anderen der antisemitische Unterton Brückners, mit dem die Äußerungen getätigt wurden und in dessen Rahmen sich die Diskussion bewegte. Immerhin ging der Diskussion um die Verfassungsfeier eine große Aussprache innerhalb der Stadtverordnetenversammlung voraus, in der ein deutsch-völkischer Antrag diskutiert wurde, der das Streichen sämtlicher Juden von den Wahllisten zur Vorstandmitgliederwahl der Mittelstandkommission vorsah, da 20 Prozent aller vorgeschlagenen Personen offensichtlich Juden seien. ${ }^{573}$ Diese Mittelstandskommission war zuständig für den Bereich der Wohlfahrtspflege und der Armenfürsorge, für den in Breslau besonders Menschen jüdischen Glaubens ehrenamtlich tätig waren oder Stiftungen ins Leben gerufen hatten. ${ }^{574}$

Die Völkischen forderten insbesondere das Zentrum und die Deutschnationalen auf, dem Antrag zuzustimmen. Dennoch war man sich parteiübergreifend zwischen SPD, Zentrum und Demokraten einig, dass ein solcher Antrag die „niedrigste Judenhetze“ darstellte, sodass die Abgeordneten den Saal verließen, als der Abgeordnete Dr. Fritsch von der Deutschvölkischen Freiheitspartei DVFP zur Rede ansetzte. ${ }^{575}$ Dass der Magistrat war nicht frei von Antisemitismus war, zeigte sich schnell. Immerhin sorgte ein Unterausschuss dafür, dass sechs Vorsitzende des Mieteinigungsamtes Breslaus entlassen wurden, weil sie Juden waren, um diese Positionen später mit Nichtjuden zu besetzen. ${ }^{576}$ Bereits in dieser Angelegenheit und nach der missglückten Kandidatur für die Wahl in höhere Ämter 1923, wird sich Siegfried Marck langfristig nicht mehr als Magistratsmitglied gesehen haben, wenngleich er um die Tradition und die Verantwortung seiner Familie gewusst haben wird. Siegfried Marck war Sozialdemokrat und Jude, er wusste, dass er trotz aller Assimilierung einen schweren Stand hatte.

Daher setzte er sich immer wieder besonders für die Bildung der Jugend und der Benachteiligten ein. Als es im Breslauer Stadtrat 1926 um die Genehmigung der Aufbauschule ging, warf er der preußischen Staatsregierung Sabotage vor: „Die

\footnotetext{
572 Ebd.

${ }^{573}$ Vgl. ebd.

${ }^{574}$ Vgl. ebd.

${ }^{575}$ Vgl. ebd.

${ }^{576}$ Vgl. ebd., 13.03.1925.
} 
Sabotage der Einrichtung einer Schule sist eines Kulturstaates nicht würdig. Man scheint Breslau wie ein ausländisches Gebiet behandeln zu wollen. “577 Auch die geplante Erhöhung des Schulgeldes war für ihn untragbar. Wenngleich die Stadt durch die Abschaffung des Schulgeldes an den unteren Schulen erhebliche Mehrbelastungen hat, so könnte die Erhöhung des Schulgeldes an den höheren Lehranstalten dem entgegenwirken. Verärgert musste Marck am Ende der Sitzung mit großem Befremden feststellen, dass die preußische Staatsregierung die Genehmigung zum Ausbau der evangelischen Realschule I zu einer Oberrealschule aus nichtigen Gründen verweigerte und die Eröffnung einer Aufbauschule in „unerträglicher Weise“ hinauszögerte. Die Stadtverordnetenversammlung sah hierin eine Überspannung des staatlichen Aufsichtsrechtes und einen unberechtigten Eingriff in das Selbstbestimmungsrecht der Stadt. ${ }^{578}$ Dabei war die Etablierung der Oberschule für Marck besonders wichtig, sein Engagement für die Bildungsform seit 1923 offensichtlich. ${ }^{579}$

Oft stieß Marck an seine eigenen Grenzen bei solchen Veranstaltungen und musste Niederlagen einstecken: Als die Stadtverordnetenversammlung versuchte, andere Instanzen $\mathrm{zu}$ umgehen und allein für die Wiederbesetzung des anthropologischen Lehrstuhls an der Breslauer Universität im Kultusministerium zu werben, ging das für Marck zu weit - der Versuch wurde trotzdem unternommen und scheiterte. $^{580}$

Immer mehr wurde er zum Experten für sozialistische Theorie, insbesondere für den Staatsgedanken des Sozialismus ${ }^{581}$, obgleich er gerne seine philosophischen Denkrichtungen mit in die Argumentationen einfließen ließ. Marcks dialektisches Gedankengut durchstreifte nicht nur den Redner, sondern auch seine Objekte. Oft versuchte er anhand besonderer Persönlichkeiten auch deren dialektische Züge kenntlich zu machen. Anlässlich des 100. Geburtstages von Ferdinand Lassalle, einer der schillerndsten Breslauer Persönlichkeiten und einer Person, auf die sich Marck immer wieder gerne berief ${ }^{582}$, verdeutlichte er in der Breslauer Volkswacht dessen Gegensätze. Für Marck war Lassalle zweifelsohne ein großer Führer der

\footnotetext{
577 Ebd., 13.04.1926. Bereits ein Jahr zuvor setzte Marck sich im Schlesischen Städtetag für die Etablierung der Aufbauschule ein, die auch von Mädchen besucht werden sollte vgl. ebd., 26.01.1925, 30.10 .1925 .

${ }^{578}$ Vgl. ebd., 13.04.1926.

${ }^{579}$ Vgl. ebd., 06.04.1923, 11.04.1923, 13.04.1923, 20.04.1923, 13.11.1925.

${ }^{580}$ Vgl. ebd., 14.01.1926.

${ }^{581}$ Vgl. ebd., 02.02.1924.

${ }^{582}$ Marck und Lassalle betonten beide, dass für sie Wissenschaft und Arbeiterschaft nicht voneinander zu trennen seien. Vgl. ebd., 06.12.1928.
} 
Arbeiterbewegung, der zwar kein „dialektischer Denktypus“, aber ein „ethischprophetischer" Denker war. Auch Lassalle sei geprägt von dialektischem Gedankengut, nähme es aber nicht an, so Marck. ${ }^{583}$

Auch sein Umgang mit dem Verhältnis von Sozialismus und Religion war für Marck bezeichnend. Beides musste sich nicht ausschließen und war zu vereinen, wie Marck auf einem Schulungsabend der Breslauer SPD betonte. Doch musste für ihn die Trennung von Kirche und Staat deutlich spürbar sein. Der Kampf galt dem Klerikalismus, der politischen Öffentlichkeit der Kirche. In diesem Zusammenhang betonte er auch, dass der historische Materialismus der Marxisten und der philosophischen Materialisten der radikalen Freidenker zweierlei seien und der Sozialismus deshalb nicht religionsfeindlich zu sein brauche. Ein neuer Kulturkampf müsse verhindert werden, denn von diesem würden sicherlich nur die Deutschnationalen profitieren. ${ }^{584}$

Siegfried Marck distanzierte sich vom rechten Rand der Sozialdemokratie immer mehr. Diese Entwicklung begann nicht zuletzt mit seiner Amtsniederlegung als Stadtverordneter im März $1927{ }^{585}$ Zur selben Zeit ließ er sich ebenfalls an der Universität beurlauben, um eine „Philosophie des Sozialismus“ ausarbeiten zu können. ${ }^{586}$ Trotzdem blieb Marck aktiv. Auf einer Funktionärsversammlung der Breslauer SPD hielt er ein Referat über die Veralltäglichung des Politischen. Für ihn waren viele Fragen nach Reparationen, Bolschewismus, Faschismus, aber auch nach dem Anschluss Österreichs und dem Einheitsstaat ungeklärt. Außerordentlich beschäftigte ihn die Frage um die Auseinandersetzung von Kapitalismus und Sozialismus. Zudem machte er eine „Panzerkreuzernachlese“587, behandelte den Ruhrkampf und mischte sich in die Diskussion um die Große Koalition.

\footnotetext{
${ }^{583}$ Vgl. ebd., 11.04.1925. Ernst Eckstein schrieb indes über Lassalle als Juristen.

${ }^{584}$ Vgl. ebd., 23.11.1927.

${ }^{585}$ Vgl. ebd., 15.03.1927. Für ihn führte von nun an Alfred Großmann, ein Gewerkschaftsangestellter, sein Amt als Stadtverordneter aus.

${ }^{586}$ Vgl. Tilitzki, Christian: Die deutsche Universitätsphilosophie in der Weimarer Republik und im Dritten Reich, Berlin 2002, S. 294.

${ }^{587}$ Der Streit darum, ob sich die krisengeschüttelte Weimarer Republik den Bau neuer größerer Kampfschiffe überhaupt leisten könne, wurde 1928 als sogenannte Panzerkreuzer-Debatte im Reichstag ausgetragen und führte zu einer Regierungskrise. Zur Panzerkreuzerkrise und den einzelnen Haltungen innerhalb der SPD siehe besonders: Drechsler, Hanno: Die Sozialistische Arbeiterpartei Deutschlands (SADP). Ein Beitrag zur Geschichte der deutschen Arbeiterbewegung am Ende der Weimarer Republik, Meisenheim am Glan 1965, S. 32ff.
} 
Ernst Eckstein hatte sich auf dem Magdeburger Parteitag zur Panzerkreuzerdebatte zu Wort gemeldet und sollte am Rednerpult kein gutes Wort über die Regierung Hermann Müllers verlieren:

„Unter der Führung des Parteivorsitzenden Hermann Müller haben wir das Wahlversprechen
gegeben, den Panzerkreuzer nicht zu bauen, und unter dem Reichskanzler Hermann Müller
wird der Panzerkreuzer gebaut. Unter der Führung des Parteivorsitzenden Hermann Müller
haben wir das Wahlversprechen der Kinderspeisung gegeben, und unter dem Reichskanzler
Hermann Müller werden die Mittel für die Kinderspeisung gestrichen. Unter der Führung des
Parteivorsitzenden Hermann Müller haben wir das Wahlversprechen gegeben, den
Reichswehretat auf 500 Millionen zu senken; unter dem Reichskanzler Hermann Müller wird
dieses Versprechen ebenso wie das der Demokratisierung der Reichswehr nicht
ausgeführt.“.588

Ecksteins oppositionelle Haltung zum Kurs der Großen Koalition war mit dieser Aussage auf dem Parteitag nicht mehr von der Hand zu weisen und es war klar, dass weitere Schritte seinerseits folgen würden. Marck indes hoffte, dass ein sofortiger Bruch der Großen Koalition wegen der Panzerkreuzerfrage ${ }^{589}$ der SPD eine Erweiterung des Erfolges vom Mai 1928 bringen würde. ${ }^{590}$ Für den Philosophieprofessor gab es „keine bessere Bestätigung der These, daß Koalitionen nur eine Verlagerung des Kriegsschauplatzes im Klassen- und Parteikampf in die Kabinette selbst darstellen, als die Regierung Hermann Müller.“591 In der Panzerkreuzerdebatte musste Marck konstatieren, dass die Parteigeschichte später einmal urteilen werde, „die Partei hat im Mai 1928 nach Rückschlägen ihren neuen Vormarsch angetreten, da wurde ihre Front von vier Männern von hinten erdolcht“. ${ }^{592}$ Für ihn, der er 1918 als Pazifist aus den Schützengräben zurückgekehrt war, bildete dies ein System, das zu 1914 geführt habe und es stand fest: „Wir müssen in der Führung der Partei einen Umschwung herbeiführen. “593

Generell war die Große Koalition damals ein Streitpunkt innerhalb der Weimarer SPD, so natürlich auch in Breslau. Denn es ging hier immerhin um die strittige Frage, ob und wie man in der Republik agieren wollte. War Marck, der sich seit Beginn seines Engagements eher am rechten Rand der Breslauer Sozialdemokratie orientiert hatte, immer staatsbejahend und für die Republik und zudem für die Weimarer Koalition eingetreten, so änderte er dies zunehmend. Lag für ihn einst der Sinn in der Unterstützung der bürgerlichen Regierung, in der Sicherung einer friedlichen Außenpolitik und generell in der Erhaltung der Republik,

\footnotetext{
${ }^{588}$ Seydewitz, Ruth und Max: Begegnungen, S. 33.

${ }^{589}$ Vgl. Marck, Siegfried: Sozialdemokratie, S. 42ff; siehe auch: Mommsen, Hans: Die verspielte Freiheit. Der Weg der Republik von Weimar in den Untergang. 1918 bis 1933, Berlin 1989, S. $331 \mathrm{ff}$.

${ }^{590}$ Vgl. ebd.

${ }^{591}$ Ebd., S. 41.

${ }^{592}$ Vgl. Breslauer Volkswacht, 21.08.1928.

${ }^{593}$ Ebd.
} 
konstatierte Marck diese Zielsetzungen 1927 als erreicht und argumentierte gegen die Haltung Carl Severings zur Großen Koalition. ${ }^{594}$

Severing hatte als preußischer Innenminister, von 1920 bis 1926 im Amt, entscheidend an der Demokratisierung der Republik mitgewirkt. Der eher zum rechten Parteiflügel zu zählende Sozialdemokrat warb darauf für die Große Koalition zwischen SPD, DDP, Zentrum, DVP und BVP, der er von 1928 bis $1930 \mathrm{im}$ Amt des Reichinnenministers beiwohnen sollte. ${ }^{595}$

Marck sah die Gefahr auf der rechten Seite der Republik. Diese habe sich allmählich der „zwangsläufigen Außenpolitik“ und der feststehenden Staatsform gebeugt, damit sie die Republik vollkommen kapitalistisch und konservativ ausrichten könne. ${ }^{596}$ Marcks präferierter Bündnispartner war nicht mehr der Bürgerblock, vielmehr ging es ihm bei der „Eroberung der sozialistischen Mehrheit“ jetzt um die Kommunisten, mit denen er zusammen eine ,sozialdemokratischkommunistische Abwehrmehrheit" zu bilden wünschte, um die Wiederkehr eines „schwarz-blauen Blocks“ unmöglich zu machen. In Bezug auf die preußische Koalition machte Marck deutlich, dass er zwar nicht für die Sprengung der bestehenden Koalition eintreten wolle, er die Aufkündigung der Koalition von anderer Seite jedoch nicht fürchte. Die Sozialdemokratie müsse ihren grundsätzlichen Standpunkt, besonders in der Kultur-und Schulpolitik zum Ausdruck bringen. ${ }^{597}$ Marck kritisierte noch Anfang der 1930er Jahre die konservativen Tendenzen innerhalb der Sozialdemokratie, griff radikal die Koalitionspolitik an und attestierte ihr volksgemeinschaftlichen Charakter. Den Staatserhaltungstendenzen seiner Partei attestierte er genau den Konservativismus, den er für die SPD für besonders gefährlich hielt. ${ }^{598}$

Marcks für die damalige Zeit fortschrittlichen Gedanken zur Einheit der Arbeiterbewegung forderten eine Einheit dieser Bewegung, nachdem die Arbeiterbewegung in die Defensive gedrängt und nachdem der Staat - auch äußerlich - ein reiner „Kapitalistenstaat“ geworden war. Diese Einheit ist mindestens als eine gemeinsame „Abwehrfront“ gegen die legale Konterrevolution, gegen den

${ }^{594}$ Vgl. ebd., 12.02.1927.

$595 \mathrm{Zu}$ Carl Severing siehe besonders: Alexander, Thomas: Carl Severing. Sozialdemokrat aus Westfalen mit preußischen Tugenden, Bielefeld 1992.

596 Vgl. Breslauer Volkswacht, 12.02.1927. Marck beruft sich hier auf die Rede des DVPVorsitzenden Ernst Scholz, der im ostpreußischen Insterburg klar erkennen ließ, dass die Übereinstimmungen zwischen den Deutschnationalen und den Parteien der bürgerlichen Mitte natürlich größer seien, als die mit der SPD. Dies musste der SPD einer Kriegserklärung gleichkommen, vgl. Winkler, Heinrich August: Weimar, 1918-1933, S. 318.

${ }_{597}$ Vgl. Breslauer Volkswacht, 12.02.1927.

${ }^{598}$ Vgl. Mitteilungsblatt des Sozialdemokratischen Intellektuellenbundes Nr. 5 (1930), S. 13f. 
Imperialismus und nicht zuletzt gegen den Faschismus immer notwendiger geworden, um die Spaltung in ,putschistische Sekten“ und „legal opportunistische Partei“'599 nicht weiter voranzutreiben.

Diese Gedanken Marcks kamen nicht von ungefähr - immerhin hatten sie in der österreichischen Sozialdemokratie seit dem Linzer Parteiprogramm ein aktives Vorbild. Auch sein Buch über Reformismus und Radikalismus in der Sozialdemokratie, 1927 herausgegeben von der Reichsleitung der Jungsozialisten mit Unterstützung von Max Adler, dem Theoretiker des Austromarxismus, bezeugt die Verbindungen. ${ }^{600}$ Ihm selbst ging es darum, dass „die Jugend möglichst klar und über die üblichen Schlagworte hinaus den objektiven Sinn der miteinander ringenden Richtungen erkennt, bevor oder besser: indem sie sich entscheidet.“601 ${ }^{601}$ Marck liefert den Beweis, dass es einen „engen geistigen Zusammenhang“ zwischen sozialdemokratischer Linksopposition und dem austromarxistischen Gedankengut gab und bekannte sich zum marxistischen Radikalismus. ${ }^{602}$

Gerne griff er in jenen Jahren auf Rosa Luxemburg zurück und verdeutlichte, dass es um die dialektische Einheit von Sozialrevolution und Sozialreform gehe. Diese Einheit fand er am stärksten im Linzer Programm der deutsch-österreichischen Sozialdemokratie verwirklicht. ${ }^{603}$ Für Marck bedeutete das nicht zuletzt „die Überwindung der jahrelangen Krise des Marxismus, die sich in den unfruchtbaren Gegensätzlichkeiten von Theorie und Praxis, Revolution und Reform, Masse und Führer, Demokratie und Sozialismus ausgedrückt habe. “604 Für ihn war das Linzer Programm der theoretische Niederschlag einer marxistischen Praxis der Politik, der weit über die Grenzen Österreichs $\mathrm{zu}$ beobachten gewesen sei. So sei der Austromarxismus des Linzer Programms Marxismus als praktische Theorie und theoretisch durchdrungene Praxis zu verstehen. Auch verdeutlichte Marck hier die Koalitionspolitik als „Notwendigkeit einer vorübergehenden Maßnahme“ und unterstrich sein Bekenntnis zur demokratischen Republik als Boden des Klassenkampfes zwischen Proletariat und Bourgeoisie. ${ }^{605}$ In einer Rezension des Buches „Sozialdemokratie, Religion und Kirche“ des österreichischen

\footnotetext{
599 Vgl. Marck, Siegfried: Reformismus und Radikalismus in der deutschen Sozialdemokratie. Geschichtliches und Grundsätzliches, Berlin 1927, S. 44ff.

${ }^{600}$ Bereits 1924 wird diese Verbindung deutlich, vgl. Breslauer Volkswacht, 08.10.1924.

${ }^{601}$ Marck, Siegfried: Radikalismus und Reformismus, S. 5.

${ }^{602}$ Vgl. Walter, Franz/Storm, Gerd: Weimarer Linkssozialismus und Austromarxismus. Historische Vorbilder für einen „Dritten Weg“ zum Sozialismus?, Berlin 1984, S. 14.

${ }^{603}$ Vgl. Marck, Siegfried: Reformismus und Radikalismus, S. 46.

${ }^{604}$ Vgl. Walter, Franz/Storm, Gerd: Weimarer Linkssozialismus und Austromarxismus, S. 13.

${ }^{605}$ Vgl. Marck, Siegfried: Linzer Programm und österreichische Binnenpolitik, in: Der Klassenkampf, Nr. 05 (1927), S. 144f.
} 
Sozialdemokraten Otto Bauer beschreibt er Österreich als Vordenker der Bewegung, der andere europäische Staaten folgen müssten, damit die Eroberung der Staatsmacht gelänge und hebt das Linzer Parteiprogramm hervor. ${ }^{606}$

Schon vorher und nach dem Ausscheiden als Stadtverordneter interessierte sich Marck für die Geschehnisse innerhalb der österreichischen Sozialdemokratie. Zum zehnjährigen Jubiläum des Attentats Friedrich Adlers auf den österreichischen Ministerpräsidenten Karl Graf Stürgkh verfasste er einen Artikel in der Breslauer Volkswacht, in dem er Adler bedingungslose Opferbereitschaft für seine Partei zuschrieb:

„So glaubte er [Friedrich Adler], nicht aus Romantik und Nervenüberreizung, sondern aus klarer Überlegung allein durch eine Tat revolutionärer Demonstration, bei der er sein Leben zum Opfer brachte, der von ihm vertretenen Sache des Friedens und der Internationale gegen die österreichischen Machthaber und die Leitung der eigenen Partei dienen zu können. “607

Als Augenzeuge der „Wiener Bluttage“ berichtete er auf der Breslauer Parteiversammlung später von den Geschehnissen und zog eine große Masse an interessierten Zuhörern ${ }^{608}$ in den großen Saal des Breslauer Gewerkschaftshauses. Bei allen Versuchen objektiv die Geschehnisse zu beschreiben, musste Marck doch dem Polizeiapparat die Hauptschuld an der Eskalation der Ereignisse geben. Zugleich betonte er, dass ein aufstachelndes Eingreifen von Kommunisten, das eigentlich nur durch die begangenen Fehler der Polizei möglich geworden war, nicht von ausschlaggebender Bedeutung gewesen sei. Letztlich musste Marck der Wiener Arbeiterschaft, ähnlich wie zuvor den russischen Revolutionären, attestieren, dass der richtige Zeitpunkt für den Kampf um die Staatsmacht in Wien damals noch nicht gekommen war. Die Arbeiter wären seiner Einschätzung nach bei einem Erfolg des Aufstandes von den Nachbarstaaten militärisch erdrückt worden. ${ }^{609}$ Kämpferisch betonte er auf der Versammlung:

„Das Bürgertum hat damals das Feld behauptet, hat aber nicht gewagt, einen Nachstoß gegen den geordneten Rückzug der Arbeiter auszuführen, sodaß eine Art von Gleichgewicht der Klassenkräfte wieder hergestellt ist. [...] Die Lehre von Wien ist: Verstärkung des

\footnotetext{
${ }^{606}$ Vgl. Breslauer Volkswacht, 04.06.1927. Hierbei macht Marck auch deutlich, dass in Österreich der Kerntrupp des Bürgertums dem Klerikalismus angehöre. Dessen gewollte Überwindung, durch die Gewinnung der proletarischen Landarbeiter, führte mit den Freidenker-Gruppen auf dem Linzer Parteitag zu Spannungen.

${ }^{607}$ Ebd., 21.10.1926.

${ }^{608}$ Auch für die sächsische Arbeiterschaft, der Julius Deutsch zu dem Thema „Wehrmacht und Sozialdemokratie“ die Geschehnisse in Wien zu verdeutlichen versuchte, waren die „Wiener Bluttage" von besonderem Interesse und auch sie kamen in sehr großer Zahl zu den Veranstaltungen. Vgl. Walter, Franz/Storm, Gerd: Weimarer Linkssozialismus und Austromarxismus, S. 65f.

${ }^{609}$ Vgl. Breslauer Volkswacht, 27.07.1927. Eine genaue Schilderung der Ereignisse und Ursachen vor den „Wiener Ereignissen“ schildert Marck in einem gesonderten Artikel in der Breslauer Volkswacht, auf den er in seiner Rede vor den Parteimitgliedern zurückgreift, vgl. Marck, Siegfried: Eindrücke der Wiener Sturmtage, in: Ebd., 23.07.1927.
} 
Die spätere Gründung der SAP im Oktober 1931 resultierte nicht zuletzt daraus, dass Kreise der Sozialdemokratie weiter der „Tolerierungspolitik“ anhingen und nicht dem Ratschlag Max Adlers folgten, dem Kabinett Brüning den Dienst zu verweigern. ${ }^{611}$ Dies musste zwangsläufig zu einer Radikalisierung der Parteilinken führen, die besonders von Jungsozialisten und Mitgliedern des SPD-Ortsvereins Breslau, auch von Siegfried Marck, getragen wurde. ${ }^{612}$ Meist waren es junge Mitglieder der SPD, die ihrer Partei den Rücken kehrten. Kurt Rosenfeld stellte fest, dass die Führung der SAP zu wenig, ,über die vielen aus den großen Parteien ausgeschiedenen Splittergruppen, die ein Unterkommen in der neu gegründeten Partei suchten“ wusste. Vielmehr noch sah er in dem Zusammenschluss eine „unüberschaubare Sammlung von Wirrköpfen“. ${ }^{613}$ Siegfried Marck sympathisierte mit einigen dieser „Wirrköpfe“, war gut mit ihnen befreundet und arbeitet mit ihnen zusammen, wenngleich er sich nicht von der SPD abspaltete, wie sie es taten. Die Abspaltung bedeutete auch, dass nun die Deutschnationalen zur stärksten Fraktion in der Breslauer Stadtverordnetenversammlung wurden und nicht mehr Eugen Bandmann, sondern der deutschnationale Rechtsanwalt Walter Friedrich Stadtverordnetenvorsteher wurde. ${ }^{614}$

Dennoch bleibt die Frage, wie es zu diesem politischen Linksdrift Siegfried Marcks kam? Besonderen Anteil daran hatten die Breslauer Jungsozialisten und einige seiner Weggefährten um den Kreis der Breslauer Volkswacht. Ein tieferer Blick wird diesen Linksdrift verdeutlichen.

\footnotetext{
${ }^{610}$ Ebd.

${ }^{611}$ Zur Gründung der SAP siehe: Niemann, Heinz (Hrsg.): Auf verlorenem Posten? Linkssozialismus in Deutschland, Berlin 1991, S. 97-174.

${ }^{612}$ Vgl. Walter, Franz/Storm, Gerd: Weimarer Linkssozialismus und Austromarxismus, S. 37.

${ }^{613}$ Seydewitz, Max und Ruth: Unvergessene Jahre, S. 25.

${ }^{614}$ Vgl. Jahresbericht für 1932, in: Breslauer Volkswacht, 26.01.1933.
} 


\section{Die Jungsozialisten - ein Ruck nach links}

Ein besonderes Anliegen, sowohl für Siegfried Marck, als auch für Clara Zils, Ernst Eckstein, Max Tockus und Immanuel Birnbaum, war die Arbeit mit den Breslauer Jungsozialisten. Unter ihnen wurde diese Gruppe im März 1920 in Breslau ins Leben gerufen, um jungen Arbeitern, die der Arbeiterjugend entwachsen waren, weiterhin eine politische Heimat zu bieten. Ein Zusammenschluss auf Bezirksebene sollte 1922 folgen. ${ }^{615}$ Schon vor dem Ersten Weltkrieg bestanden in Schlesien Arbeiterjugendgruppen, eine davon in Liegnitz, die von Paul Löbe ins Leben gerufen worden war. ${ }^{616}$ Nach dem Krieg kam es, wie im gesamten Reichsgebiet, ausgehend von Hamburg und Berlin, zur Bündelung dieser Gruppen zur Sozialistischen Arbeiterjugend, der allein in Breslau etwa 290 Jugendgruppen angehört haben sollen. $^{617}$

Soweit ist dies nichts Besonderes, doch:

,[...] in keiner anderen Juso-Gruppe des Reiches haben die Mitglieder eine theoretisch so anspruchsvolle, thematisch derart stringente Bildungsarbeit betrieben wie hier; dichter als anderswo bestand in Breslau ein Milieu radikal-linkssozialistischer Intellektueller und Studenten, die sich mit den jungsozialistischen Facharbeitern verbanden.“ ${ }^{6618}$

Mehr noch gelang es den Jungsozialisten, die Mehrheitsverhältnisse in Breslau durch gezielte Parteiarbeit umzukehren, linksozialistisch zu färben und über die Grenzen Schlesiens bekannt zu machen. ${ }^{619}$ Ein wichtiger Grund hierfür war die hohe Anzahl an jüdischen Intellektuellen, wie Siegfried Marck, Fritz Sternberg, Ernst Eckstein oder Immanuel Birnbaum, die den Jungsozialisten in den regelmäßig stattfindenden Arbeitsgemeinschaften mindestens ein Basiswissen an marxistischer Theorie vermittelten. Hinzu kam die Nähe zu der von Marck ins Leben gerufenen Sozialistischen Studentengemeinschaft, der vor allem recht wohlhabende jüdische Studenten angehörten. ${ }^{620}$

In der Mitte der 1920er Jahre bestand der Kreis der Jungsozialisten aus etwa 120 Mitgliedern $^{621}$, dem vor allem junge Facharbeiter ${ }^{622}$ zwischen 18 und 25 Jahren

\footnotetext{
${ }^{615}$ Vgl. ebd., 02.06.1922.

${ }^{616}$ Vgl. Matull, Wilhelm: Arbeiterbewegung in Schlesien, S. 103.

${ }^{617}$ Ebd., S.102ff.

${ }^{618}$ Walter, Franz: Nationale Romantik. S 132.

${ }^{619}$ Vgl. ebd.

${ }^{620}$ Vgl. ebd., S. 136. Walter betont, dass Arbeiterstudenten diesem Kreis kaum angehörten und sich die Breslauer Sozialistische Studentengemeinschaft damit deutlich von den anderen sozialdemokratischen Studentengruppen in Deutschland unterschied.

${ }^{621}$ Genauer Zahlen liegen nicht vor, doch wird in Berichten um 1927 diese Zahl erwähnt, vgl. Breslauer Volkswacht, 25.01.1927.

${ }^{622}$ Es sollen vor allem junge Buchdrucker und Schriftsetzer gewesen sein, vgl. Walter, Franz: Nationale Romantik, S. 134.
} 
angehörten, wie sie Siegfried Marck zum ersten Mal in den Schützengräben begegnet waren. Jenen stand der Breslauer Philosophieprofessor bis zu seiner Flucht nach Frankreich sehr nahe - in vielen Vorträgen versuchte er auf sie zu wirken, sprach über den Staatsgedanken, die Revolutionen von 1848 und 1918, las ihnen Dostojewski vor. ${ }^{623}$ Anders herum hatten die Jungsozialisten großen Einfluss auf das Ehepaar Siegfried und Kläre Marck.

Oberste Bedingung für die Aufnahme bei den Jungsozialisten war das Bekenntnis zu den Grundwerten der Sozialdemokratie. Zudem galt es die Arbeiterbildung zu lesen, wenngleich nicht nur ernste geistige Arbeit betrieben werden sollte, sondern auch das gemeinsame Unternehmen von Ausflügen auf der Tagesordnung stand. ${ }^{624}$ Der Elektriker Max Rausch, dessen Schwester Erna, Eduard Wolf, Max Scholz, Alfred Firlus, der Schneidergeselle Oskar Krumschmidt, Fritz und Ruth Lewy ${ }^{625}$ oder Hedel, die in der Schneiderstube der Eltern von Lewys arbeitete, sind letztlich nur einige wenige junge Menschen dieses Sammelbeckens aus Jungsozialisten und sozialistischen Studenten. ${ }^{626}$ Ruth Lewy dient nachstehend als Exponat für eine Jungsozialistin, die in ihrer Biographie sowohl Eckstein, Sternberg, Adler und Marck vereinen kann.

Ernst Eckstein fungierte innerhalb der Jungsozialisten als wichtiger Multiplikator. So fand beispielsweise die aus Oppeln stammende Ruth Lewy über Max Rausch den Weg zu ihm. Oppeln war die Regierungsstadt der Provinz Oberschlesien, in der insbesondere das Kleinbürgertum sowie eine große Zahl an Beamten anzutreffen waren. Ruth Lewy war Jüdin und Bürgerstochter, stammte folglich aus ähnlichen Verhältnissen wie Siegfried Marck. Spätestens 1924, mit der Etablierung der Marxistischen Arbeitsgemeinschaft unter Fritz Sternberg, werden sich Siegfried Marck und Ruth Lewy kennen gelernt haben. An ihr und ihrem Umfeld lassen sich gut die Konstellationen zwischen der SPD, der Sozialistischen Hochschulgemeinschaft und den Jungsozialisten innerhalb Breslaus ableiten.

Wenngleich ihre Eltern keinesfalls orthodox waren, schickten sie ihre 1905 geborene Tochter auf ein jüdisches Mädchengymnasium. ${ }^{627}$ Bevor Ruth Lewy sich den Breslauer Jungsozialisten anschloss, trat sie dem zionistischen Jugendverband

\footnotetext{
${ }^{623}$ Beispielsweise Breslauer Volkswacht, 13.03.1922, 30.03.1922. 14.11.1922, 04.08.1923. Es gab aber auch Vortragsabende zu wirtschaftspolitischen Themen, in denen Marck über die Geschichte des Wirtschaftens referierte, vgl. ebd., 22.06.1922, 28.06.1922.

${ }^{624}$ Vgl. ebd., 14.06.1921, 22.06.1921.

${ }^{625}$ Bekannter als Ruth Seydewitz. Der Name Ruth Lewy wird bis zur Hochzeit zwischen ihr und Max Seydewitz 1929 verwendet.

${ }^{626}$ Diese Namen werden genannt in: Vgl. Seydewitz, Ruth: Alle Menschen haben Träume, S. 47,65f.

${ }^{627}$ Vgl. ebd., S. 13,16, 23.
} 
„Blau-Weiß“ bei. Einen ihrer Gründe für diesen Anschluss sah sie selbst in der Begegnung mit einem armen jüdischen Mädchen, was die Bürgerstochter tief traf. Doch dieser speziell jüdischen Jungendbewegung gehörte sie nicht lange an, auch weil sie dem „Eisernen Mann“ und seinem Krieg skeptisch gegenüber stand und sich „als genauso gute Deutsche wie die Klassenkameradinnen, die an dem christlichen Religionsunterricht teilnahmen“ wahrnahm. Zudem wollte sie schon gar nicht „NeuHebräisch lernen oder an der großen Mauer beten“. ${ }^{628}$

Das Abitur und ein anschließendes Studium waren ihr vorerst vorenthalten. Sie absolvierte stattdessen eine Schneiderlehre und besuchte währenddessen gern das Breslauer Stadttheater, während ihr fünf Jahre älterer Bruder Fritz in Breslau Nationalökonomie studierte und sich 1927 bei Siegfried Marck promovierte. ${ }^{629}$ Fritz Lewy avancierte gemeinsam mit Oskar Krummschmidt zu den Wortführern der Breslauer Jungsozialisten. ${ }^{630}$ Ruth Lewy liebte das Theater. Ihr bedeutendstes Theatererlebnis waren für sie die von Siegfried und Kläre Marck initiierten GerhardHauptmann-Festspiele, die bei der jungen Bürgerstochter das Gespür für die eigene Herkunft schärften. Infolge dieser lehnte sie die bürgerliche Gesellschaft nun mehr instinktiv als bewusst $a b^{631}$. Besonders das bekannteste Werk des schlesischen Schriftstellers hinterließ bei ihr einen bleibenden Nachklang:

„Als ich Hauptmanns „Die Weber“ erlebte, spürte ich zum erstenmal [sic!] deutlich, dass es Menschen gab und gibt, die sich nicht nur über die Zustände innerlich empören, sondern offen gegen sie auftreten. ${ }^{\text {“632 }}$

Dass die Festspiele überhaupt in der Odermetropole aufgeführt wurden, ist Siegfried Marck zu verdanken. Er stritt 1921 innerhalb der Stadtverordnetenversammlung für die Einrichtung eines Garantie-Fonds für Gerhart-Hauptmann-Festspiele - vorerst ohne Erfolg. ${ }^{633}$ Aufgrund einer fehlenden Finanzierung waren die Festspiele bereits 1913 nicht in Breslau gegeben worden, aber auch wegen der pazifistischen Ausrichtung der Festspiele von 1913 lehnte man diese Garantie-Fonds damals ab. ${ }^{634}$ Auch 1921 fanden die Festspiele aus Geldmangel nicht statt. Im darauffolgenden Jahr konnten die Festspiele jedoch zwischen dem 8. und 21. August in Breslau ausgerichtet werden. Sowohl in der dafür hergerichteten Jahrhunderthalle, als auch

\footnotetext{
${ }^{628}$ Vgl. ebd., S. 26.

${ }^{629}$ Lewy, Fritz: Die soziologische Methode, Karlsruhe 1927, Vorwort.

${ }^{630}$ Vgl. Walter, Franz: Nationale Romantik, S. 139.

${ }^{631}$ Seydewitz, Ruth: Alle Menschen haben Träume, S. 42.

${ }^{632}$ Ebd., S. 43.

${ }^{633}$ Vgl. Aufruf des Schlesischen Bundes für Heimatschutz, den Marck auch unterzeichnete. in: Breslauer Volkswacht, 01.04.1922.

${ }^{634}$ Vgl. ebd., 14.10.1921.
} 
im Stadt- und Lobetheater konnte der Zuschauer dem Lebenswerk Gerhart Hauptmanns folgen. ${ }^{635}$

Überhaupt nahm der schlesische Schriftsteller und Literaturnobelpreisträger Gerhart Hauptmann, aber auch dessen Bruder Carl, für das Ehepaar Siegfried und Kläre Marck eine besondere Rolle ein - vor allem für Kläre: Sie schrieb in den Monatsheften der Breslauer Volksbühne gern über das Leben und Wirken Carl Hauptmanns. ${ }^{636}$ Etwas mehr als elf Jahre nach dem Ringen um die Garantie-Fonds trat sie 1932 im Auftrag des Arbeiterbildungsausschusses Breslaus in Kontakt mit Gerhart Hauptmann, den sie für einen Vortrag zur Breslauer Gerhart-HauptmannFeier im Breslauer Konzerthaus einladen wollte. Kläre versuchte mit einer festen Zusage Hauptmanns besonders den nichtintellektuellen Teil der werktätigen Bevölkerung für die Veranstaltung des Arbeiterbildungsausschusses zu gewinnen, was ihr schließlich auch gelang. ${ }^{637}$ Mit Johanna Hauptmann, der Schwester Gerhart Hauptmanns, besuchte Kläre gelegentlich Theateraufführungen. ${ }^{638}$

Ein Blick in die weitere Korrespondenz zwischen Kläre Marck und Gerhart Hauptmann verrät, wie hochrangig das Publikum besetzt gewesen sein muss: So waren etwa Wilhelm Bölsche, Samuel Fischer und Käthe Kollwitz zu dieser Veranstaltung nach Breslau geladen, die mit Festreden und Rezitationen aus dem Werk Hauptmanns ausgeschmückt werden sollte. ${ }^{639}$ Nach den Maßstäben Kläres war die Veranstaltung ein voller Erfolg, wie sie in einem Brief an Hauptmann im Nachgang deutlich macht:

\begin{abstract}
„Wenn ich Ihnen sage, dass nicht nur ich im Innersten ergriffen wurde, nicht nur meine „,intellektuellen“ Freunde, sondern gerade auch die Menschen, für die unsere Feier in erster Reihe bestimmt war, so wird Ihnen das, denke ich, eine besondere Genugtuung sein. Ich habe am gestrigen Tage noch eine Reihe schlichter „Parteigenossen“ gesprochen, ich habe mit meinen Freunden von der Arbeiterjugend geredet - überall begegnete mir eine Begeisterung, eine innige Dankbarkeit, dass wir in diesen düsteren Tagen mit Ihnen eine solche Freudenfeier erleben durften. Gerade die Stimmen der Jugendgenossen, der arbeitslosen und oft so freudlosen, waren mir besonders wichtig. “640
\end{abstract}

Doch zurück zu Ruth Lewy. Diese schloss sich nach einem gemeinsamen Auftritt mit anderen Jungsozialisten im Breslauer „Volkshaus“, in dem sie das erste Mal vor Arbeitern Klavier spielte, den Jungsozialisten und der Sozialdemokratischen Partei

\footnotetext{
${ }^{635}$ Vgl. ebd., 10.05.1922.

${ }^{636}$ Vgl. Marck, Kläre: Carl Hauptmann. Zu seinem 70. Geburtstag, in: Kunst und Volk. Monatsheft der Breslauer Volksbühne, Heft 9 (1928), S. 262-266.

${ }^{637}$ Vgl. Kläre Marck an Gerhart Hauptmann, 04.08.1932. Stadtbibliothek zu Berlin - Preußischer Kulturbesitz, Handschriftenabteilung, GH Br NL BIIA, Nr. 21: 61 (Marck, Kläre).

${ }^{638}$ Vgl. Kläre Marck an Gerhart Hauptmann, 26.08.1932, Nr. 21: 68.

${ }^{639}$ Vgl. Kläre Marck an Gerhart Hauptmann, 16.08.1932, Nr. 21: 63.

${ }^{640}$ Vgl. Kläre Marck an Gerhart Hauptmann, 05.09.1932, Nr. 21: 83.
} 
an. ${ }^{641}$ „Und damit begann für mich ein neues Leben. Max Rausch und sein Freundeskreis, Genossen der Jungsozialisten, haben sehr viel dazu beigetragen, dass ich sehr bald dazugehörte, einer der ihren wurde" konstatierte Lewy im Nachhinein. Doch war es nicht die Theorie des Marxismus, sondern vielmehr die Abneigung, der Hass gegen das Unrecht, die Ungleichheit, mehr noch der Trotz gegen das Elternhaus und ein warmes Gefühl der Sympathie für alle Unterdrückten gewesen, welche sie zu diesen Schritt bewegten. ${ }^{642}$

Auch wollte sie nicht hinnehmen, dass nur ihr älterer Bruder studieren durfte. Ruth Lewy hörte an der Breslauer Universität als Gasthörerin Vorlesungen in Kunstgeschichte und Philosophie, wenngleich sie mit letzterer nicht so viel anzufangen wusste wie mit den Vorträgen zur Kunstgeschichte. „Viel interessanter war es, den Gesprächen zu lauschen“ schilderte Lewy. Die Gespräche, die sie meinte, waren vor allem die Diskussionen zwischen Siegfried Marck und den Jungsozialisten, oder des ihr besonders „klug und interessant erscheinenden Fritz Sternberg", für den sie darauffolgend Manuskripte tippen sollte. ${ }^{643}$ Aus diesem Kreis heraus sollte sie auch den aus Österreich stammenden linken Theoretiker und Universitätsdozenten Max Adler kennenlernen, etwa als Adler im Rahmen des Arbeiterbildungsausschusses für einen Vortrag nach Breslau kam, ${ }^{644}$ oder als er auf Einladung des Bundes der Freunde sozialistischer Akademiker über die Bedeutung der Gesellschaftswissenschaften sprach - in die Diskussion mischten sich auch Siegfried Marck und Fritz Sternberg. ${ }^{645}$ Diese Bekanntschaft kam Lewy sehr entgegen, konnte sie so doch bei ihm gastieren, als sie in Wien versuchte ihre Ausbildung fortzusetzen. Zudem verfolgte sie dort Max Adlers Vorlesungen und nahm zusammen mit ihm an Arbeiterversammlungen teil. ${ }^{646}$ Es waren die Einflüsse von Sternberg, Eckstein, Siegfried Marck und Max Adler, nicht minder aus dem Kreis der anderen Jungsozialisten, welche die junge Oppelner Schneiderin prägten. Am engsten schien jedoch der Kontakt zu Max Adler und Ernst Eckstein. Auch Clara Zils war in diesen Kreis eingebunden. Sie und Max Scholz arbeiteten eng zusammen, reisten gemeinsam auf den Reichstag der Jungsozialisten 1921 nach Bielefeld. ${ }^{647}$

\footnotetext{
${ }^{641}$ Vgl. Seydewitz, Ruth: Alle Menschen haben Träume, S. 49.

${ }^{642}$ Vgl. ebd.

${ }^{643}$ Vgl. ebd., S. 47.

${ }^{644}$ Vgl. Breslauer Volkswacht, 06.09.1924.

${ }^{645}$ Vgl. ebd., 08.12.1925, 10.12.1925, 21.12.1925.

${ }^{646}$ Vgl. Seydewitz, Ruth: Alle Menschen haben Träume, S. 51.

${ }^{647}$ Vgl. Breslauer Volkswacht, 05.08.1921, 08.08.1921, 12.08.1921.
} 
Bei den Breslauer Jungsozialisten, denen Marck auch gerne privat durch materielle Zuwendung half, genoss er großes Ansehen, er lud sie zu sich nach Hause ein, sie saßen häufig zusammen und diskutierten. „Die Erwartungen, die er an die jungen Facharbeiter herantrug, verrieten auch in seinem Falle deutlich alle Merkmale der eigenen sozialen Herkunft.“648 Das Selbstverständnis der Jungsozialisten müsse dahin gehen, den Kampf um den Sozialismus „zu vergeistigen“ und mit „adligen Waffen“ zu führen. Antagonistisch zum Bürgertum verstand er die Jungsozialisten als „Stätten der Kultur“ und nicht als Sinnbilder von „Eigensucht" oder „materialistische[n] Gesinnungen““ ${ }^{649}$ Diese Wertvorstellungen sollten Ruth Lewy, ihren Bruder Fritz oder Max Rausch prägen. Die Breslauer Jungsozialisten verstanden sich als ,junge Kämpfer für die Überwindung des Unrechts, das die kapitalistische Wirtschaftsordnung mit sich bringt“, dabei war ihr Ziel „die grundlegende Umgestaltung unserer wirtschaftlichen Lebensbedingungen“, die Etablierung einer „neuen Kultur“, die nur auf diesen Grundwerten fußen konnte. Man konstatierte bei sich selbst „eine starke Sehnsucht nach edler, höherer Lebensgestaltung“. Überdies war in jenen der Wunsch, ,die grauenvollen Reste einer barbarischen Epoche zu tilgen" und sie versuchten so, an die Stelle des „Kriegsgötzen“ das „Ideal der Humanität, des Menschentums“ zu setzen. ${ }^{650}$

Wenn Siegfried Marck und Fritz Sternberg besonders in universitären Kreisen auf die Jungsozialisten wirkten, so war es an der Basis, auf der Parteiebene, sonderlich der linke Breslauer Parteiführer Ernst Eckstein, der den Jungsozialisten gerne half und auch dafür bekannt war: Ruth Lewy drohte beispielsweise von Seiten der Oppelner Sozialdemokratie der Parteiausschluss, weil der Jungsozialistin vorgeworfen wurde, durch die Initiierung von Engels-Lesekreisen und „LeninLiebknecht-Luxemburg Feiern“ „kommunistische Zersetzungsarbeit“ betrieben zu haben. Der Oppelner Parteivorsitzende Kühn kündigte darauf ein Parteiausschlussverfahren gegen die junge Schneiderin an. Der Breslauer Jungsozialist Max Rausch riet Lewy sodann, den Rat Ernst Ecksteins einzuholen, der ihr entgegnete: „Lass dich ruhig ausschließen. [...] Wir nehmen dich dann gleich in die Breslauer Parteiorganisation auf ${ }^{\text {“651 }}$,und lest und studiert das Manifest

\footnotetext{
${ }^{648}$ Walter, Franz: Nationale Romantik, S. 151.

${ }^{649} \mathrm{Vgl}$. Breslauer Volkswacht, 29.04.1924.

${ }^{650}$ Das Selbstverständnis der Breslauer Jungsozialisten geht aus einem Artikel von Clara Zils-Eckstein hervor, die gemeinsam mit Max Scholz die Reichsjugendkonferenz in Bielefeld besuchte und von dort und den unterschiedlichen Richtungen innerhalb der Jungsozialisten berichtete. Vgl. ebd., 08.08.1921. ${ }^{651}$ Vgl. Seydewitz, Ruth und Max: Unvergessen Jahre, S. 34.
} 


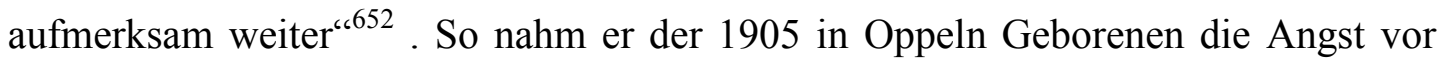
dem drohenden Parteiausschluss, dessen Verfahren letztlich im Sande verlief. Bereits hier deutete sich eine Konfliktlinie an, die in Breslau einen für das Reichsgebiet einzigartigen Verlauf nahm: Eine starke, nahezu dominierende Stellung der Breslauer Jungsozialisten, die aus ihrer Randposition Front machten gegen ihrer eigene Partei und letztlich den Linkssozialismus in der Breslauer SPD über mehrere Jahre etablierten. ${ }^{653}$

Ernst Ecksteins Verhalten war nur folgerichtig, wenn man zugrunde legt, wie er selbst auf Marx-Gedenkfeiern oder Revolutionsfeiern der Breslauer Arbeiterjugend sprach. ${ }^{654}$ Ernst Eckstein, seine Frau Clara Zils und Immanuel Birnbaum leiteten unter anderem das Bildungsprogramm der Jungsozialisten. So konnten diese nach ihrer Gründung 1920 etwas über „die Parteigeschichte der Sozialdemokratie“ bei Ernst Eckstein ${ }^{655}$ und über „die Geschichts- und Staatsauffassung des Sozialismus“ bei Immanuel Birnbaum ${ }^{656}$ oder die deutsche Frauenbewegung ${ }^{657}$ hören.

Siegfried Marck sollte erst später dazu stoßen und war 1921 vermehrt bei der sozialistischen Hochschulgemeinschaft anzutreffen. ${ }^{658}$ Marck gehörte neben dem Oberpräsidenten Lüdemann, dem Landgerichtspräsidenten Eisner, dem Rechtsanwalt Bandmann sowie dem Vorsitzenden des Provinziallandtags und Stadtverordnetenvorsteher Leißner und nicht zuletzt Ernst Eckstein dieser Gemeinschaft an. Es ging ihm dabei um die Verbindung zwischen sozialistischen Studierenden, Altakademikern und befreundeten Genossen. ${ }^{659}$

Für den vergeistigten Theoretiker Marck, der als Sozialdemokrat und zugleich als Jude eine Ausnahme unter den Lehrenden der Breslauer Universität war und der immer mehr an den linken Parteirand abdriftete, war eines besonders klar: Der akademische Nachwuchs werde für den Sozialismus gebraucht. Insbesondere dann, wenn die bisherige Hochschulausbildung nur einer Klasse zu Gute komme, müsse es auch seine Aufgabe sein, den Kindern des Proletariats den Weg an die Universitäten $\mathrm{zu}$ öffnen. Schon Anfang der zwanziger Jahre hatte er auf

\footnotetext{
${ }^{652}$ Dies.: Alle Menschen haben Träume, S. 68.

${ }^{653}$ Siehe insbesondere die Ausführungen Franz Walters, der diese Oktroyierung der Jungsozialisten eindrucksvoll beschreibt, vgl. Nationale Romantik, S. $163 \mathrm{ff}$.

${ }^{654}$ Vgl. Breslauer Volkswacht, 11.03.1921, 16.03.1921, 17.11.1921

${ }^{655}$ Vgl. ebd., 02.04.1921, 05.04.1921.

${ }^{656}$ Vgl. ebd., 25.04.1921, 09.05.1921.

${ }^{657}$ Vgl. ebd., 02.06.1921, 04.06.1921.

${ }^{658}$ Vgl. ebd., 01.06.1921, 28.01.1924.

${ }^{659}$ Vgl. ebd., 14.12.1928.
} 
Parteiveranstaltungen für die Jugend und deren Rolle in der Sozialdemokratie plädiert. ${ }^{660}$ Auf Initiative von Paul Löbe, Ernst Eckstein und nicht zuletzt Siegfried Marck, bildete sich 1924 ein schlesischer Bund der Freunde sozialistischer Akademiker, der, aus Akademikern und Sozialdemokraten bestehend, versuchte, Arbeiterkindern durch finanzielle Hilfen den Weg an die Universität zu erleichtern. ${ }^{661}$ Gerade in der finanziellen Förderung sah der vorbereitende Ausschuss die Möglichkeit, dass sich durch eben jene ein freier sozialistischer Geist innerhalb der Hochschulen entwickeln und verbreiten konnte.

Dabei war dieser Gedanke nicht neu: Bereits ein Jahr zuvor war es in Österreich, in Sachsen und in Thüringen zu Gründungen solcher Vereinigungen gekommen, die meist mit der Unterstützung von Partei-, Gewerkschafts- oder Genossenschaftskreisen getragen wurden und innerhalb kurzer Zeit Erfolge erzielten. ${ }^{62}$ Diesem Gedanken wollten die Breslauer Funktionäre nicht nachstehen und es wurde eine „Kampfgemeinschaft der sozialistischen Akademiker und ihrer Freunde" gegründet, die sich für alle geistig interessierten Genossen offen zeigen wollte. Es sollte mit verwandten Organisationen wie etwa der „Sozialistischen Arbeiterjugend“ oder der „Sozialistischen Hochschulgemeinschaft" kooperiert werden, ohne dabei eine Sonder- oder Führerstellung innerhalb der Partei einzunehmen. ${ }^{663}$

Für den aus einfachen Verhältnissen stammenden Ernst Eckstein muss die Initiierung dieser Gemeinschaft ein besonderes Anliegen gewesen sein. Immerhin hatte er sich den Weg an die Universität erkämpft und wusste, wie schwer dieser Weg für Nichtbürgerliche war. Er wird nur durch schwierigste Sonderprüfungen das Recht erhalten haben, an der Universität zu studieren. Vorläufiger Schriftführer wurde der Student Berndt Hoffmann, an den die Beitrittserklärungen zu richten waren. $^{664}$

Es war die Aufgabe Siegfried Marcks, den Eröffnungsvortrag zu halten. Anschließend wollte er auf dem Bezirksparteitag im Breslauer Gewerkschaftshaus zu dem Thema „Der Akademiker von heute und der Sozialismus“ referieren. ${ }^{665}$

\footnotetext{
${ }^{660}$ Vgl. ebd., 07.02.1920.

${ }^{661}$ Vgl. ebd., 27.10.1924.

${ }^{662} \mathrm{Vgl}$. ebd.

${ }^{663}$ Vgl. ebd.

${ }^{664} \mathrm{Vgl}$. ebd.

665 Vgl. ebd., 31.10.1924, 01.11.1924. Zur Geschichte des Breslauer Gewerkschaftshauses siehe insbesondere: Festschrift und Programm zur Einweihung des neuen Eigenheims der Breslauer freien Arbeiterschaft, Breslau 1913.
} 
Dass Marck es ernst mit der Unterstützung für notleidende Studierende meinte, verdeutlicht weiterhin sein Engagement innerhalb der Breslauer Stadtverordnetenversammlung für einen Antrag zur Bewilligung von 3.000 Reichsmark, der notleidenden Studierenden finanzielle Unterstützung bieten sollte. ${ }^{666}$ Damit stellte sich Marck deutlich auf die Seite des Zentrums und der Professorenschaft und er sprach in seiner Begründung von „völlig proletarisierenden Verhältnissen“ und argumentierte zugleich gegen die Kommunisten, welche die Mittel des Magistrats lieber in der Erwerbslosenhilfe gesehen hätten. ${ }^{667}$ Zugleich setzte sich Marck innerhalb der Stadtverordnetenversammlung erfolgreich dafür ein, ein Arbeiter-Studentenwohnheim mit 20.000 Reichsmark zu unterstützen. Auf diese Weise wollte er sein Ziel erreichen, „das Märchen der Kulturfeindlichkeit der Sozialdemokratie zu zerstören" und zugleich aufzeigen, dass:

„der Kern der Breslauer Studentenschaft, der nach den letzten schweren Jahren an ernste Arbeit denke und sich von Äußerlichkeiten fernhalte, nicht mit dem nationalistischen Studententum auf eine Stufe gestellt zu werden verdient" ${ }^{668}$.

Der Bund der Freunde sozialistischer Studenten war von Anfang an recht erfolgreich. Immerhin gelang es in Zusammenarbeit mit der Sozialistischen Studentengemeinschaft den besonders sachkundigen Fritz Sternberg für zwei Vorträge über die „Grundprobleme des Kapitalismus“ und den „Imperialismus“ zu gewinnen. ${ }^{669}$ Fritz Sternberg war in jenen Jahren sehr aktiv innerhalb der Breslauer Sozialdemokratie, besonders unter den Jungsozialisten war er gut bekannt und beliebt. Der ebenfalls in der Odermetropole und als Jude geborene Sternberg hatte sich deutlich früher als Marck dem Sozialismus angeschlossen. Auch er hatte genau wie Siegfried Marck die Novemberrevolution in Breslau erlebt, wo er ebenfalls als Soldatenrat tätig war. ${ }^{670}$ Sternberg war auch für eine Zeit lang involviert in den „Klüngel“ um die Breslauer Volkswacht, insbesondere, um den Lesern die Gefahren des internationalen Imperialismus aufzuzeigen oder eine Einführung in Rosa Luxemburgs „Nationalökonomie“" zu geben. ${ }^{671}$

666 Vgl. ebd., 21.11.1924. Dieser Antrag wurde vom Stadtverordneten und ebenfalls als Universitätsprofessor tätigen Franz Seppelt im Auftrag der in der Stadtverordnetenversammlung vertretenden Universitätsprofessoren gestellt, zu denen bekanntlich auch Marck zu zählen war. Der Antrag wurde dann in doppelter Höhe von 10.000 RM angenommen.

${ }^{667}$ Vgl. ebd., 21.11.1924.

${ }^{668}$ Ebd., 15.10.1920.

${ }^{669}$ Vgl. ebd., 09.12.1924, 13.12.1924.

${ }^{670} \mathrm{Zu}$ Fritz Sternberg siehe insbesondere: Grebing, Helga (Hrsg.): Fritz Sternberg - Für die Zukunft des Sozialismus, Köln 1981.

671 Vgl. Breslauer Volkswacht, 29.11.1924, 03.12.1924, 13.12.1924, 16.12.1924, 22.12.1924; Sternberg veröffentliche zwei Jahre später sein Opus Magnum über den Imperialismus vgl. Sternberg, Fritz: Der Imperialismus, Berlin 1926; Ders: Der Imperialismus und seine Kritiker, Berlin 1929. 
In den Anfangsjahren war es besonders Marck, der in vielen Vorträgen zu den sozialistischen Studenten sprach und so als Multiplikator innerhalb der Universität agierte. ${ }^{672}$ Auf der Revolutionsfeier der sozialistischen Studentenschaft, die im Audi Max der Breslauer Universität auch vor der deutschnationalen Studentenschaft stattfinden sollte, versuchte Marck in leicht verständlichen Darlegungen ein geschichtsphilosophisches Verständnis von der Revolution 1918 zu erwecken. Marck erklärte, dass diese Revolution von keiner Partei „gemacht“" worden, sondern vielmehr das Ergebnis einer gewissen Kriegsmüdigkeit gewesen sei, die bei allen Völkern der Erde in ein Reizstadium getreten sei. Weiter sei für ihn die Niederlage der deutschen Militärmacht als Grund für diese Kriegsmüdigkeit zu sehen und habe mit einer „Naturnotwendigkeit“ das alte Regime beseitigt. Ferner räumte Marck ein, dass die Revolutionsregierung ein Fiasko erlebt habe, dies aber nicht durch die eigene Schuld verursacht worden sei, sondern die Verantwortung bei den Alldeutschen und ihren Gesinnungsgenossen bei der Entente liege. Am Ende seines Vortrages machte Marck deutlich, dass er nach dem Rückblick auf das vergangene Revolutionsjahr wieder zu ruhigen und segenvollen Jahren der Arbeit und des Aufbaues gelangen wollte und eine zweite Revolution, gar eine Gegenrevolution, nur neues Unheil bringen könne. ${ }^{673}$

Auch Ernst Eckstein war an diesem Abend anwesend und wies darauf hin, dass sich die sozialistischen Studierenden vor allem als Proletarier begreifen sollten und erst in zweiter Linie als Akademiker und mahnte dabei besonders die deutschnationalen Studenten, dass ja auch sie in Wahrheit nur auf Kosten des arbeitenden Volkes studieren könnten. ${ }^{674}$ Ebenfalls ging Immanuel Birnbaum auf die Proletarisierung der Studentenschaft ein, verdeutlichte deren Ursachen und Auswirkungen. ${ }^{675}$

Hier wird besonders der unterschiedliche Bildungsgedanke zwischen dem bürgerlichen Siegfried Marck und dem aus der Arbeiterschaft stammenden Ernst Eckstein sichtbar. Obwohl beide befreundet waren, zusammen für die sozialistische Studentenschaft und die sozialistische Arbeit innerhalb der Gremien wirkten, waren es doch genau die habituellen Unterschiede, die in diesem Punkt deutlich machen,

672 Beispielsweise Breslauer Volkswacht, 06.11.1919, 08.11.1919, 11.11.1919, 07.12.1921, 16.12.1922, 14.06.1923, 28.01.1924, 02.02.1924, 02.11.1924.

${ }^{673}$ Vgl. ebd., 11.11.1919.

${ }^{674} \mathrm{Vgl}$. ebd.

${ }^{675}$ Vgl. ebd., 19.11.1921. 
wie viel radikaler, forscher und fordernder Eckstein in dieser Situation agierte. Marck indes wird den Gedanken, dass die Studierenden auf Kosten der Arbeiterschaft ihre Ausbildung ableisteten, höchst wahrscheinlich nicht nachvollzogen haben können, war für ihn doch der Weg an die Universität nicht so schwer gewesen, wie für manch ein Arbeiterkind, für das er sich jetzt einzusetzen versuchte. Nichtsdestoweniger ist auffällig, dass es Sozialdemokraten und Juden waren, die in Breslau an der Universität ihr Intellektuellentum auslebten.

Auch Eduard Bernstein sollte vor den Breslauer sozialistischen Studenten einen Vortrag halten. Marck und Eckstein war es gelungen, diese bekannte Breslauer Persönlichkeit in das Breslauer Gewerkschaftshaus zu laden - Bernstein musste jedoch absagen, sodass Gustav Scholich seinen Part übernahm. Die Anzahl der sozialistischen Studierenden gemessen an der Gesamtstudierendenzahl wird nicht besonders hoch gewesen sein und der Großteil, besonders der deutschnationalen Studenten, machte die Sozialdemokratie für die Kriegsniederlage verantwortlich und verzichtete dabei nicht auf antisemitisches Vokabular. Überhaupt führte diese Konstellation $\mathrm{zu}$ einem Parteiantisemitismus. ${ }^{676}$ Marck konterte solche Anfeindungen und betonte, dass „der leitende Gedanke in dem schweren Werk des Aufbaus die Treue gegen die neue Verfassung sein“ müsse, „die durchaus auch Entwicklungsmöglichkeiten für den Sozialismus bietet“. Ernst Eckstein indes sagte den Deutschnationalen stets den „schärfsten Kampf“ in der Universität an und legte für die sozialistischen Studenten das Bekenntnis ab, an der Seite des Proletariats, als Proletarier, den schweren Befreiungskampf führen zu wollen. ${ }^{677}$

Die Bemühungen Marcks, Löbes, Sternbergs, Birnbaums und Ecksteins waren auch bitter nötig: Bei den Hochschulwahlen im November 1921 hatten die sozialistischen Gruppen keine einzige Stimme bekommen. Der Grund hierfür war darin zu finden, dass die Liste wegen formaler Fehler im Vorfeld für ungültig erklärt worden war und der Studentenausschuss der Breslauer Universität daher „sozialistenrein“ bleiben sollte ${ }^{678}$ Dennoch lohnt sich ein Blick in das Wahlergebnis, das einen Einblick in die studentischen Strukturen der Breslauer Universität gibt. So wurde die deutschvölkische Gruppenliste mit 15 von 40 möglichen Sitzen gewählt, gefolgt von der christlich-nationalen Fraktion mit 12 Sitzen, der wiederum die jungstudentische

\footnotetext{
${ }^{676}$ Vgl. Walter, Franz: Nationale Romantik, S. 138.

${ }^{677}$ Breslauer Volkswacht, 08.11.1919.

${ }^{678}$ Vgl. ebd., 28.11.1921.
} 
Liste mit 5 Sitzen und die deutschen Finkenschaft mit 3 Sitzen folgen sollten. Hervorzuheben sind in diesem Zusammenhang die deutsch-jüdische Liste mit 3 Sitzen sowie die Jüdische Liste mit 2 Stimmen. ${ }^{679}$

Mit dem Tod Friedrich Eberts und der Wahl des neuen Reichspräsidenten, bei der sich die Sozialdemokratische Partei für die Wahl des Zentrumspolitikers Wilhelm Marx aussprach, positionierten sich die Breslauer Jungsozialisten eindeutig zum kommunistischen Kandidaten Ernst Thälmann. Ohnehin hätten sich in jener Zeit einige Fäden zur kommunistischen Partei gespannt. ${ }^{680}$ Auch nach dem Ausscheiden Siegfried Marcks aus der Breslauer Stadtverordnetenversammlung blieb dieser bei den Jungsozialisten, die sich stets für den Linkssozialismus starkmachten, und in universitären Kreisen aktiv. Doch setzte er andere Prioritäten: Für den Reichstagswahlkampf 1928 schrieben er und seine zweite Frau Kläre ein Theaterstück mit dem Titel „Hoppla, wir wählen“6681, dem tausende Zuschauer in Breslau auf dem Marktplatz Zuspruch bekundeten. Darsteller waren die Jungsozialisten, auch das Ehepaar Marck nahm aktiv teil. Weitere Revuen sollten folgen. ${ }^{62}$ Für Franz Walter ist es erstaunlich, dass der Breslauer Philosophieprofessor nicht den geringsten Einfluss auf die Radikalisierung der Jungsozialisten nach links ausübte. ${ }^{683}$ Die Breslauer Jungsozialisten führten in diesen Jahren den radikal-linken Flügel der reichsdeutschen jungsozialistischen Bewegung an. Dort herrschte ein Kampf zweier Positionen: Die „rechten Hofgeismarer“, die für eine nationalbewusste und staatsbejahende Politik eintraten, standen den ,linken Hannoveranern“ gegenüber, die den revolutionären Sozialismus und eine internationalistische Gesinnung propagierten. Auch wenn Marck in der Hochburg der revolutionär sozialistisch angehauchten Geisteshaltungen lebte und dozierte, vertrat er doch eine Position, die eher dem Umkreis der Hofgeismarer zuzurechnen war. ${ }^{684}$ Auch in der Staatsfrage bekannte sich Marck fortwährend zur „Staatsidee“ und zum „nationalen Kulturstaat“". 685

\footnotetext{
${ }^{679}$ Vgl. ebd.

${ }^{680}$ Vgl. Seydwewitz, Ruth: Alle Menschen haben Träume, S. 69ff.

${ }^{681}$ Vgl. Breslauer Volkswacht, 03.05.1928, 14.05.1928. Dies geschah sicherlich in Anlehnung an Ernst Tollers Drama „Hoppla, wir leben!“ aus dem Jahr 1927.

${ }^{682}$ Vgl. ebd., 30.10.1929 bis 16.11.1929 „In Stadt und Land Ihr Arbeitsleute“ (wurde insgesamt 15 Mal zu den Wahlen der Stadtverordnetenversammlung und dem Provinziallandtag aufgeführt); 02.09.1930 „Der Bürgerblock am Hakenkreuz“.

${ }^{683}$ Vgl. Walter, Franz: Nationale Romantik, S. 151.

${ }^{684}$ Vgl. Ders.: Siegfried Marck (1889-1957), S. 263.

${ }^{685}$ Vgl. Marck, Siegfried: Marxistische Staatsbejahung, Breslau 1924, 29ff.
} 
Anders Ernst Eckstein, der 1927 erneut zum Parteivorsitzenden gewählt wurde. ${ }^{686}$ Mit seiner Wahl entwickelte sich ein Flügelkampf, der über Jahre andauern sollte und für den Breslauer Sozialdemokratischen Verein in einem Schisma enden sollte: Eckstein sammelte um sich die Jungsozialisten, linke Metallarbeiter unter Hans Ziegler und intellektuelle Kreise, zu denen auch Siegfried Marck gehörte. Auf der anderen Seite befanden sich die Gewerkschaften und Angehörige des Reichsbanners. Als sich der damalige Parteivorstand unter Eckstein gegen die Finanzierung eines Friedrich-Ebert-Denkmals, folglich gegen das Aufstellen einer Person, die als „Garant der Republik“ galt, aussprach ${ }^{687}$, das nun von den Gewerkschaften und dem Reichsbanner finanziert wurde ${ }^{688}$, verhärteten sich die Fronten, die sich letztlich in der Gründung der SAP manifestierten. ${ }^{689}$

Siegfried Marck wäre es Anfang der 1930er Jahre lieber gewesen, wenn alle SPDFlügel die von ihm prognostizierte Zusammengehörigkeit von Reformismus und Radikalismus eingesehen, akzeptiert und sich zusammengerauft hätten. ${ }^{690}$ Innerhalb des Richtungskampfes der Breslauer SPD verdeutlichte Marck, dass für ihn ein solcher Kampf eigentlich schon immer bestanden habe, dieser aber nicht bedeutend sei, solange die Maxime der Marxismus ist. In dieser Zeit war der Begriff der „Judokratie“ in Breslau oft zu hören. ${ }^{691}$ Die Verschmelzung von Jungsozialisten und Intellektuellen, die damals oft abfällig beurteilt wurde, führte innerhalb Breslaus zu einem auch für Marck spürbaren ,antisemitischen Antiintellektualismus und Antijungsozialismus ${ }^{\text {“692 }}$. Seitdem sprach er tief getroffen und nun auch abwertend von einer „Bonzokratie“6993 und hielt solidarisch zu den Jungsozialisten und linken Intellektuellen, die immer mehr die Oberhand im Parteiapparat gewinnen konnten. ${ }^{694}$

\footnotetext{
${ }^{686}$ Vgl. Breslauer Volkswacht, 25.01.1927.

${ }^{687}$ Vgl. ebd., 09.02.1928.

${ }^{688}$ Vgl. ebd., 21.02.1928.

${ }^{689}$ Vgl. Walter, Franz: Nationale Romantik, S. 164. Mehr zu den Grabenkämpfen und den Gründen, weshalb Breslauer der einzige Ort war, an dem es den linken Jungsozialisten gelungen war, aus einer Minderheit nunmehr über mehrere Jahre die Mehrheit in einer Großstadt zu stellen, siehe ebenda S. $164 \mathrm{ff}$.

${ }^{690}$ Vgl. ebd., S. 156; Marck, Siegfried: Zur innerparteilichen Verständigung, in: Breslauer Volkswacht, 17.04.1931.

${ }^{691}$ Auch Immanuel Birnbaum, der Chefredakteur der Volkswacht und gern gehörter Redner vor den sozialistischen Studenten, war früh nachdem er die Leitung der Zeitung übernommen hatte, antisemitischem Gedankengut ausgesetzt, wurde er doch offen von der Schlesischen Tagespost beschuldigt, aus dem Blatt ein Judenblatt gemacht zu haben.

${ }^{692}$ Vgl. Walter, Franz: Nationale Romantik, S. 155.

${ }^{693}$ Vgl. Breslauer Volkswacht, 06.12.1928.

${ }^{694}$ Vgl. Walter, Franz: Siegfried Marck (1889-1957), S. 267; Hierzu insbesondere die Chronologie, vgl. Ders.: Nationale Romantik, S. 164ff.
} 
Der Kampf zwischen den Linkssozialisten um Eckstein und den Parteirechten um Karl Mache oder den Angehörigen der Gewerkschaften spitzte sich zu - viel zu unterschiedlich waren die Positionen.

Neben den Treffen und Diskussionen mit den Jungsozialisten, waren es wohl die Referate und Debatten, die seit 1924 in Breslau in der sich treffenden Marxistischen Arbeitsgemeinschaft, der jüdische Intellektuelle und junge Facharbeiter aus SPD und KPD angehörten, die Siegfried Marck stark beeinflussten. Fritz Sternberg hielt in dieser Zeit in der Odermetropole ökonomische Bildungskurse ab und beschloss mit seinen Kursteilnehmern, die Marxistische Arbeitsgemeinschaft zu gründen. ${ }^{695}$ Es ist nicht nachzuweisen, ob Siegfried Marck mit zu den Gründungsmitgliedern gehörte, auch zu Ernst Eckstein kann eine solche Aussage nicht getroffen werden, wenngleich es bei ihm recht wahrscheinlich ist. Nichtsdestoweniger war das Ziel der Arbeitsgemeinschaft nicht die Gründung eines neuen und weiteren Vereines, sondern allwöchentlich die ,systematische Schulung und Vertiefung auf der Grundlage der Marxistischen Lehre und ihre Anwendung auf die geistigen, politischen und ökonomischen Probleme der Gegenwart““ ${ }^{696}$ ganz, wie es die Jungsozialisten kannten und guthießen. Siegfried Marck und Ernst Eckstein fungierten selbst als Kursleiter und referierten gemeinsam über das Heidelberger Parteiprogramm. ${ }^{697}$ Marck bewunderte besonders die Redegewandtheit des sechs Jahre jüngeren Breslauer Linkssozialisten Fritz Sternberg und ließ sich von dessen Überzeugungen treiben. ${ }^{698}$

Das ging nicht nur Marck so. Auch Personen wie Bertolt Brecht oder Walter Benjamin fanden durch Fritz Sternberg, der durch Vortragsreisen und Schulungswochen im gesamten Reichsgebiet bei den Jungsozialisten bekannt war, den Zugang zum Marxismus. In den Jahren 1924 bis 1926 fand Sternberg dort immer mehr Gehör, die Arbeitsgemeinschaft wurde $\mathrm{zu}$ einem ,geistigen Kristallisationspunkt", nicht zuletzt weil er ein begnadeter Rhetoriker gewesen sein soll. Danach kam er nur noch sporadisch nach Schlesien, um dort seine Familie zu besuchen ${ }^{699}$, was dem Linkssozialismus in Breslau keinen Abbruch bescherte.

Fritz Sternberg ist im Nachhinein betrachtet eine Persönlichkeit, die Siegfried Marck in seinem reinen Werdegang nicht unähnlich war, obgleich er sich nach dem

\footnotetext{
695 Die Ergebnisse der Diskussionen fasste Sternberg 1926 in seinem Werk „Imperialismus“ zusammen, vgl. ebd., S. 159.

${ }^{696}$ Vgl. Breslauer Volkswacht, 06.05.1925.

${ }^{697}$ Vgl. ebd., 30.10.1925, 25.11.1925.

${ }^{698}$ Vgl. Walter, Franz: Siegfried Marck (1889-1957), S. 266.

${ }^{699}$ Vgl. Ders.: Nationale Romantik, S. 157; Breslauer Volkswacht, 05.03.1925.
} 
Ersten Weltkrieg anders radikalisierte als Marck - Sternberg strahlte jedoch weiter aus als der Breslauer Philosophieprofessor, er hinterließ einen größeren Nachklang, er war einfach präsenter als Marck. Beide emigrierten später in die USA, begünstigt durch Mittel der Rockefeller Foundation und beide waren bemüht in Paul Tillichs Council for a Democratic Germany das Hitlerregime zu bekämpfen.

In Breslau wurde Siegfried Marck im Herbst 1927 Mitarbeiter der SPDHalbmonatsschrift Der Klassenkampf: Marxistische Blätter, die von namhaften linken Sozialdemokraten - Max Adler, Paul Levi oder Kurt Rosenfeld herausgegeben wurde und schrieb dort Beiträge, die keine Zweifel mehr an seiner politischen Stoßrichtung ließen. ${ }^{700}$ Kurt Rosenfeld, Sohn eines Fabrikbesitzers, lebte seit der Jahrhundertwende als studierter Rechtsanwalt und Ökonom in Berlin und war wie Marck demnach Akademiker. 1877 geboren, war er jedoch deutlich älter als sein Breslauer Parteigenosse. ${ }^{701}$ Diese Zeitschrift hatte für die Breslauer Jungsozialisten eine besondere Bedeutung, gerade wenn an den Gruppenabenden die einzelnen Artikel vorgelesen und diskutiert wurden. Das Blatt wurde als „Anleitung zum Handeln“ und als „echte Grundlage für die Diskussionen in die Ortsgruppenveranstaltungen“" verstanden. Insbesondere wenn Max Adler zu einem Vortrag nach Breslau kam, war das für die jungen Sozialdemokraten eine Pflichtveranstaltung. ${ }^{702}$

Diese verließen im Breslauer Richtungskampf und mit der Gründung der SAP die Sozialdemokratie und vertrauten nunmehr Rezepten „leninistischer Kaderbildung““703. Die anderen kamen aus der „parlamentarischen Defensive“ nicht heraus und verloren allmählich, wie Marck befürchtet hatte, den Rückhalt in der industriellen Arbeiterschaft. ${ }^{704}$ Für Marck wollte „,der Instinkt der proletarischen Massen [...] Sammlung, nicht Zersplitterung im Abwehrkampfe gegen den Faschismus ${ }^{6705}$. Ihm war klar, dass diese Absplitterung um seinen Freund Ernst

\footnotetext{
${ }^{700}$ Marck, Siegfried: Liberalismus, Fascismus, Sozialismus. Ein Kapitel politischer Ideologie, in: Der Klassenkampf, Nr.12 (1929), S. 373-377; Ders.: Opportunistische Wehr, „Dialektik“, ebd., Nr. 5 (1929), S. 154-157; Ders.: Max Adlers Lehrbuch der materialistischen Geschichtsauffassung, ebd., Nr. 24 (1930), S. 760-763.

${ }^{701} \mathrm{Zu}$ Rosenberg siehe die persönlichen Erinnerung von Max und Ruth Seydewitz: Unvergessene Jahre, S. 22f.

${ }^{702}$ Vgl. Dies.: Alle Menschen haben Träume, S. 74ff.

${ }^{703}$ Walter, Franz: Nationale Romantik, S. 157. Überhaupt schien Lenin von bedeutender Rolle für die Jungsozialisten. Immerhin schenkten die Breslauer Gruppierung Ruth und Max Seydewitz ein großes Lenin-Porträt zu deren Hochzeit, vgl. Seydewitz, Ruth: Alle Menschen haben Träume, S. 87.

${ }^{704}$ Vgl. ebd., S. 156f; Marck, Siegfried: Sozialdemokratie, Berlin 1931, Vorwort. Darin geht Marck auch auf die aktuelle Spaltung und den Richtungskampf ein.

${ }^{705}$ Marck, Siegfried: Sozialdemokratie, Vorwort.
} 
Eckstein zum Kommunismus getrieben werden würde, allein deshalb, weil er für eine „Mittelpartei“ zwischen SPD und KPD keinen „soziologischen Raum“ sah. ${ }^{706}$

Auch Ruth Lewy folgte dem Ruf Ernst Ecksteins und schloss sich der SAP an, heiratete den Reichstagsabgeordneten und Mitherausgeber des Klassenkampfes Max Seydewitz, wurde Verlegerin und arbeitete in der linken sozialdemokratischen Fraktion auf Reichsebene mit. Dieser gehörten neben ihrem Mann auch Paul Levi und Kurt Rosenfeld an.

Max Rausch indes wurde als Parteisekretär der engste Mitarbeiter Ernst Ecksteins. Beide wohnten im Stadtteil Zimpel, einem kleinen entlegenen Breslauer Vorort und sie begleiteten sich oftmals gegenseitig auf ihrem Heimweg wegen der Gefahr, von rechten Schlägern überfallen zu werden. Danach saßen beide am 30 . Januar 1933 im selben Polizeigefängnis - Eckstein wurde ins Konzentrationslager Dürrgoy verschleppt, gefoltert und starb später, Max Rausch kam wieder frei. ${ }^{707}$

Die Familie Seydewitz blieb Anlaufstelle für die Breslauer Jungsozialisten. Diese sahen sich enttäuscht von der eigenen Parteiführung in Person von Herman Müller und über den von der Partei gelebten „Hurra-Patriotismus“. Sie verstanden nicht, weshalb ein Zusammengehen mit der KPD nicht möglich war. ${ }^{708}$ Sicherlich werden daran tradierte Ressentiments gegenüber den Kommunisten eine Rolle gespielt haben, genauso wie in dem einen oder anderen Fall auch die Sorge um das finanzielle Auskommen, das mit einem Parteienwechsel weggebrochen wäre. Auch aus dieser Zwangslage und in Solidarität mit den ausgeschlossenen Rosenfeld und Seydewitz gründete sich die Sozialistische Arbeiterpartei als eine der ersten Ortsgruppen in Breslau - ein „Experiment“, das sich bereits seit 1927 in der Klassenkampf-Gruppe angedeutet hatte und das scheitern musste. ${ }^{709}$ Dennoch waren besonders in Breslau große Teile der Anhängerschaft der Sozialdemokratie zur SAP übergelaufen, darunter auch 15 Stadtverordnete. Zwischen der linken Absplitterung und der Mutterpartei war die Stimmung innerhalb Breslaus mehr als angespannt. Insbesondere durch die Gründung einer eigenen Zeitung in Form der Sozialistischen Arbeiter Zeitung, die sich als Sprachrohr und Kampforgan der revolutionären

\footnotetext{
${ }^{706}$ Vgl. ebd.

${ }^{707}$ Vgl. Seydewitz, Ruth: Alle Menschen, S. 36ff. Auch er hatte wie Eckstein und Marck im Ersten Weltkrieg gekämpft und war stolz auf die Errungenschaften der Revolution, die Absetzung des Kaisers und die Einführung des allgemeinen Wahlrechts. Über die Tolerierungspolitik seiner Partei, der er seit 1919 angehörte, echauffierte er sich genauso wie sein Mentor Ernst Eckstein, brach mit der der SPD und schloss sich der SAP an, vgl. Seydewitz, Max und Ruth: Unvergessene Jahre, S. 39-45.

708 Die Oppelner Jungsozialisten in einem Brief an Ruth Seydewitz, in: Seydewitz, Ruth: Alle Menschen, S. 110f.

${ }^{709}$ Vgl. ebd, S. 127ff, S. 133; Matull, Wilhelm: Ostdeutschlands Arbeiterbewegung, S. 128.
} 
Arbeiterschaft begriff und damit natürlich in Konkurrenz zur etablierten Breslauer Volkswacht stand, wurde der Konfliktgraben verbreitert. Der Breslauer Vorsitzende der SAP Ernst Eckstein rechnete in der ersten Ausgabe des Blattes mit der Sozialdemokratie ab:

„Die SPD ist zu konsequenter Klassenkampfpolitik nicht mehr fähig. Sie setzt die Tolerierungspolitik fort, weil ihr Apparat sachlich und persönlich so stark mit dem Schicksal des bürgerlichen Staates verbunden ist, dass dieser Partei eine wirkliche Opposition gegen den Staat und seine Regierung Brüning unmöglich ist. [...] Die SPD toleriert weiter, sie toleriert alles. Zwischen der SPD und der SAPD bestehen heute bereits grundsätzlich tiefe Unterschiede. Die SPD konserviert den sinnlos gewordenen Kapitalismus, die SAPD will ihn stürzen." ${ }^{\text {“710 }}$

Die Antwort ließ nicht lange auf sich warten. Nachdem Eckstein, Ziegler und Seydewitz von ihren Ämtern enthoben worden waren und die SAP gründeten, hetzte die Volkswacht gegen diese und die Jungsozialisten, die sich mit abgespalten hatten. Eckstein wurde von Seiten des Blattes offen attackiert, etwa indem ihm unterstellt wurde, er habe zur Unterschlagung von Parteigeldern aufgerufen, um der Sozialdemokratie zu schaden. ${ }^{711}$ Sie hätten mit Bauernschlauheiten und Tricks bewusst die Spaltung forciert. ${ }^{712}$ Überhaupt muss es daneben im Magistrat zu heftigen Auseinandersetzungen gekommen sein, wie Berichte in den jeweiligen Medien belegen. ${ }^{713}$ Auch für die Arbeit der Sozialistischen Studentengemeinschaft bedeutete die Abspaltung einen Einschnitt, nachdem der Berliner Vorstand eindeutig deklarierte, dass „Genossen, die sich zur SAP bekennen, außerhalb der Organisation stehen“. ${ }^{714}$ Dennoch versuchte man in Breslau diese Organisation überparteilich weiterzuführen. $^{715}$

Das Ergebnis bei den Reichstagswahlen im Juli 1932 sollte für Ernüchterung sorgen, erhielt die SAP in Breslau doch nur 0,7 Prozent der Stimmen. ${ }^{716}$ Siegfried Marck stand am Ende - seinen realpolitischen Anspruch nie verlierend - mitten im Konflikt des linken und rechten Flügels innerhalb der SPD. Während die Breslauer Linkssozialisten „Brüning-Faschismus“ und „Hitler-Faschismus“ gleichsetzten und die Tolerierungspolitik der sozialdemokratischen Mehrheit verachteten, erkannte Marck die Tolerierungspolitik seiner Partei an. Es müsse alles dafür getan werden,

\footnotetext{
${ }^{710}$ Eckstein, Ernst: Unsere Zeitung, in: Sozialistische Arbeiter Zeitung, 21.10.1931.

${ }^{711}$ Vgl. ebd., 28.10.1931.

${ }^{712}$ Vgl. Breslauer Volkswacht. 03.10.1931.

713 Beispielsweise „In Sachen gegen die Volkswacht“, in: Sozialistische Arbeiterzeitung, 29.10.1931; 31.10.1931; Breslauer Volkswacht, 26.10.1931.

${ }^{714}$ Vgl. ebd.

${ }^{715} \mathrm{Vgl}$. ebd.

${ }^{716}$ Vgl. Matull, Wilhelm: Ostdeutschlands Arbeiterbewegung, S. 130.
} 
dass die Nationalsozialisten nicht an die Regierungsmacht kämen, doch dürfe auch nicht einseitig in der Defensive verharrt werden. ${ }^{717}$

Ein Zusammenschluss mit der KPD, gar ein Überlaufen, war für den Breslauer Philosophiedozenten vorab undenkbar, wenngleich er sich doch stark dem linken politischen Spektrum angenähert hatte. Später, in der Emigration in Paris, war das Zusammengehen von SPD und KPD ein Gedanke, der vor allem von Siegfried Marck getragen werden sollte, ganz wie es seinem neukantianischen Naturell entsprach. 


\section{Eine unlautere Berufung?}

Siegfried Marck hatte von Anfang an einen schweren Stand an der Breslauer Universität. Die Studentenschaft, die überwiegend nationalliberal eingestellt war, mied seine Veranstaltungen und die Anzahl „seiner“ Studenten aus der sozialistischen Hochschulgemeinschaft war überschaubar, sodass er sich in seinem universitären Wirkungsfeld nicht sonderlich gut vernetzt und verankert gefühlt haben wird. Ohnehin hatte die Breslauer Universität nicht mehr den Ruf, den sie noch zu Zeiten Wilhelm Diltheys gehabt hatte, weil dessen Schüler an andere Universitäten gewechselt waren. Lediglich der Neukantianismus, dem Marck und seine vielen jüdischen Kollegen am Philosophischen Seminar zuzurechnen waren, hatte mit Breslau wissenschaftliches Gehör. Somit war diese Bildungsstätte nur noch eine „Provinz-Universität, bestenfalls ein Sprungbrett für eine bedeutendere Universität“، ${ }^{718}$ Davon machte Dilthey genauso Gebrauch wie Richard Hönigswald.

Siegfried Marck jedenfalls hatte es geschafft, über viele Lehraufträge und seine Privatdozententätigkeit 1924 eine außerplanmäßige Professur zu erhalten. Er selbst wird kaum daran geglaubt haben, eine ordentliche Professur zu erhalten. Doch diese sollte ihm nach einem berufspolitischen Konflikt, der in seiner Heftigkeit und parteipolitischen Polarisierung für die Zeit nach 1924 ungewöhnlich war, zugesprochen werden. ${ }^{719}$ Es ging um die Lehrstuhlnachfolge Richard Hönigswalds, der nach München berufen worden war. Eigentlich sollte sein Nachfolger als anerkannter Fachmann die Bereiche der Psychologie und der Pädagogik verbinden, damit der Schwerpunkt des ehemals so hochgelobten Hönigswalds nicht verloren ginge. In erster Instanz hielt man hierfür Denk-und Sprachpsychologen wie Karl Bühler, Vertreter der südwestdeutschen Schule des Neukantianismus wie Bruno Bauch $^{720}$, der auch besonders von Heinrich Rickert beeinflusst wurde, oder Ernst Hoffmann $^{721}$, dem Platon ein besonderes Anliegen war, für sehr geeignet. ${ }^{722}$ Aber

\footnotetext{
${ }^{718}$ Vgl. Kapferer, Norbert: Die Nazifizierung der Philosophie an der Universität Breslau 1933-1945, S. $20 \mathrm{f}$.

719 Tilitzki, Christian: Die deutsche Universitätsphilosophie in der Weimarer Republik und im Dritten Reich, S. 290.

${ }^{720}$ Nach dem Ersten Weltkrieg wandte sich Bauch eher einer völkisch-nationalen antijüdischen „deutschen Philosophie“ zu. Auch Bauch war Mitherausgeber der Kant-Studien, vgl. Varga, Alexander: Bauch, Bruno, in: Neue Deutsche Biographie (NDB). Bd. 1, Berlin 1953, S. 630-631.

${ }^{721}$ Ernst Hoffmann war 1916/17 Frontsoldat; 1923 wurde er Mitglied der DDP. Auf eigenen Antrag wurde er als ,jüdischer Mischling“ 1935 vom Amt des Leiters der Cusanus-Kommission der Heidelberger Akademie der Wissenschaften beurlaubt, vgl. Wilpert, Paul: Ernst Hoffmann, in: Zeitschrift für philosophische Forschung, Bd. 7, Nr. 2 (1953), S. 265-275.

${ }^{722}$ Vgl. Tilitzki, Christian: Die deutsche Universitätsphilosophie, S. $290 f$.
} 
was war mit Siegfried Marck, einem der Schüler Hönigswalds, der an der Breslauer Universität bisher eher durch seine sozialistische Hochschulgruppe aufgefallen war?

Als der Landtagsabgeordnete Ernst Hamburger einen Brief an den damals zuständigen preußischen Kultusminister Carl Becker schrieb, begann sich die Angelegenheit zu politisieren. Siegfried Marck und Ernst Hamburger kannten sich noch von den Bildungskursen für Beamte, anlässlich derer sie in Breslau etwa zum Görlitzer Parteiprogramm, der Reichsverfassung oder der Entwicklung der Wirtschaftsformen, der Sozialdemokratie, der Schule und des Strafrechts referiert hatten. ${ }^{723}$ Hamburger verdächtigte in diesem Schreiben die Fakultät, Siegfried Marck aus politischen Motiven nicht berücksichtigt zu haben:

„[...] Ich habe die Hoffnung, daß Sie, sehr geehrter Herr Minister, die Gelegenheit dieser Neubesetzung benutzen werden, um Dr. Marck als einen tüchtigen Wissenschaftler eine ordentliche Professur zu übertragen, und damit zugleich einen Schritt zur Beseitigung der sicher auch von Ihnen als Minister als Mißstand angesehenen völligen Fernhaltung sozialdemokratischer Gelehrter von den Ordinariaten in Breslau zu tun.“ ${ }^{724}$

Becker wäre diesem Wunsch Hamburgers sicherlich nie nachgekommen, hatte er doch schon während der Greifswalder Berufungsverhandlung 1921 im Fall des Sozialdemokraten Paul Ferdinand Linke gegen die Sozialdemokratie entschieden. Ende Januar 1930 hatte sich das Blatt gewendet, denn nun war der sozialdemokratische Kulturpolitiker Adolf Grimme ${ }^{725}$ ins Amt des Kultusministers getreten und wollte die Personalpolitik strenger nach parteipolitischen Kriterien ausrichten und hierfür bot sich der Fall Marck an. ${ }^{726}$

Das liberale Judentum, für dessen Organ, die Jüdisch-liberale Zeitung, der Breslauer Philosophieprofessor schrieb, erblickte in der Ernennung Adolf Grimmes nicht nur Gutes. Immerhin sah man das Ministerium für „das Sein und Werden der deutschen Judenheit von größter Bedeutung““727. Bruno Woyda, der seit 1929 Geschäftsführer der Jüdischen Reform Gemeinde in Berlin war, erklärte in einem Artikel weiter, dass Adolf Grimme mit seinem Ministerium letztlich einen wichtigen Teil der preußischen Öffentlichkeit darstellte und er „das geistige Gesicht der deutschen Öffentlichkeit entscheidend“ mitgestaltete und es daher unabdingbar sei, sich vielmehr mit der Persönlichkeit des neuen Kultusministers zu befassen, als sich

\footnotetext{
${ }^{723}$ Vgl. Jahresbericht des Sozialdemokratischen Vereins Breslau 1922/23, in: Breslauer Volkswacht, 25.04.1923, 26.04.1923

${ }_{724}$ GStA PK, Rep. 76Va, Sek. 4, Tit. IV, Nr. 48, Band IX, B1. 460; Vorschlag vom 27.11.1929.

${ }^{725}$ Grimme war der letzte Kultusminister einer demokratisch gewählten Staatsregierung in Preußen, die während des „Preußenschlages“ abgesetzt wurde.

726 Tilitzki, Christian: Die deutsche Universitätsphilosophie, S. 291.

${ }^{727}$ Woyda, Bruno: Der neue Kultusminister, in: Jüdisch-liberale Zeitung, 26.02.1930.
} 
auf dessen politische Ausrichtung oder dessen Berufungspolitik zu konzentrieren, wie Woyda dies der Tagespresse vorwarf. ${ }^{728}$

Für Marck war das sicherlich die letzte Chance: Wie auch seine Mutter in einem Brief an den Reichstagspräsidenten und Freund der Familie Paul Löbe hervorhob, hatte Marck wegen seines „reaktionären Geistes“ keine Berufungschance an deutschen Universitäten. ${ }^{729}$ Überhaupt war es die Mutter Siegfried Marcks, die seit 1918 immer wieder Bedenken an seinem politischen Wandel äußerte und die damit verbundende Angst erkennen ließ, dass ihr Sohn genau deswegen den für ihn vorgesehen Lebensweg, eine Karriere an der Universität, nicht beschreiten könne:

„Du machst dich unmöglich an der Universität. Du stempelst dich zum Vaterlandsfeind. Du zerstörst deine Laufbahn. Was wir so mühsam erreicht haben, das setzt du aufs Spiel; deine Zukunft als Gelehrter. Das ist dein Leben, nicht die schmutzige Politik [...] Denke nicht an mich. Denke nur an dich selbst. Bleibe in deiner geistigen Region. Laß dich nicht herunterzerren in diesen gräßlichen Sumpf von Parteienzwist.“ 730

Die Fakultät wehrte sich und wollte Marck nicht auf die Ergänzungsliste setzen, wie ein Schreiben an das Kultusministerium eindrucksvoll belegt:

„Die Fakultät wird in dem Schreiben des Herrn Ministers aufgefordert, sich im
Zusammenhange mit ihrer neuen Liste auch über den nicht-beamteten ausserordentlichen
Professor Dr. Siegfried Marck zu äussern: Die Fakultät konnte und kann ihn schon aus dem
Grunde nicht auf die Vorschlagsliste setzen, weil er den Arbeitsgebieten, um die es sich bei
dieser Professur handelt und handeln muss, völlig fernsteht. Ihn für diese Professur zu
nennen, wäre, abgesehen von der sachlichen Unmöglichkeit, auch eine Ungerechtigkeit
gegen die anderen nicht-beamteten Dozenten des Fachs, Kynast, Löwi, Heyse, die im Gebiet
der Pädagogik, bzw. der Psychologie sich mit Erfolg betätigt haben. “731 Adolf Grimme setzte sich schließlich durch, sodass Marck im Sommersemester 1930 sein Amt antreten konnte, nun auch gleich als Direktor des Philosophischen Seminars. $^{732}$ Damit bekleidete Siegfried Marck eine Professur, die bisher nicht seinem Arbeitsschwerpunkt entsprach. Wie sollte er einer solchen Aufgabe gewachsen sein? Darüber lässt sich nur spekulieren. Auffällig bleibt, dass Marck auch als ordentlichem Professor nicht das große wissenschaftliche Werk gelang. Interessant ist im Zusammenhang mit dem Berufungsverfahrens und den Briefen zwischen Fakultät und Ministerium der Verweis der Fakultät auf die niedrige

\footnotetext{
${ }^{728}$ Ebd. Bruno Woyda emigrierte 1939, nach einer Haft im Konzentrationslager, nach England und starb 1970. Als eines der jüngsten Mitglieder engagierte sich der Ingenieur ab 1930 Repräsentantenversammlung und stammte eigentlich aus der liberalen Jugendbewegung, innerhalb derer er den linken Flügel vertreten haben soll, vgl. Szanto, Alexander: Im Dienste der Gemeinde 1923-1939, LBI NY.

${ }^{729}$ Vgl. GStA PK, Rep. 76Va, Sek. 4, Tit. IV, Nr. 48, Band IX, B1. 485; Rosa Marck an Paul Löbe Ebd. Band VIII, vom 12.12.1926.

${ }^{730}$ Landau, Lola: Vor dem Vergessen, S. 87.

${ }^{731}$ GStA PK, Rep. 76Va, Sek. 4, Tit. IV, Nr. 48, Band X, Bl. 10.

${ }^{732}$ Vgl. GStA PK, Rep. 76Va, Sek. 4, Tit. IV, Nr. 48, Band X, B1. 26.
} 
Teilnehmerzahl an Marcks Veranstaltungen ${ }^{733}$ und die Betonung auf die anderen Kandidaten, die eben nicht sozialdemokratisch oder jüdischer Abstammung waren. Reinhard Kynast etwa war eher als Mann der politischen Mitte zu sehen, dem nie der Sprung auf eine ordentliche Professur gelang, sondern dem der Weg in den Schuldienst blieb. ${ }^{734}$

Damit war die Berufung Marcks eine politische Entscheidung. Die Schlesische Zeitung wunderte sich über das schnelle Verfahren, mit dem Adolf Grimme seinem späteren Freund und Parteigenossen in Amt und Würde verhalf:

„Die Meldung von dieser Nachfolge Hönigswalds überrascht außerordentlich. Selten hat man sich im Kultusministerium so beeilt mit einer immerhin wichtigen Entscheidung. Die Nachfolge eines Denkers wie Hönigswalds verpflichtete auf jeden Fall zur Verhandlung mit anderen Anwärtern in der Fachwelt"“735

Es ist nicht verwunderlich, dass die Breslauer Volkswacht diesen Schritt Grimmes ebenso sehr begrüßte und von einer erfreulichen „Bereicherung“ schrieb, wie ihn die Schlesische Zeitung gleichsam bedauerte. ${ }^{736}$ Desgleichen missbilligte die Berliner Börsenzeitung das Vorgehen Grimmes und mahnte die Sozialdemokratie, in Zukunft bei Personaldebatten einen Blick auf die eigenen aktuellen Geschehnisse zu werfen. ${ }^{737}$ Aber es war insbesondere die deutschnationale Breslauer Studentenschaft, die ihrem Unmut Ausdruck verlieh und um diese Entscheidung mit den wenigen sozialistischen Studenten stritt:

„Der Vorstand der Freien Breslauer Studentenschaft a. d. U. gestattet sich, Ew. Magnificenz folgendes geziemend zu unterbreiten: Laut Erlaß des Herrn Preußischen Kultusministers, Herrn Dr. Grimme, ist der a. o. Professor der Philosophie an der Universität Breslau, Herr Prof. Dr. Marck, zum ordentlichen Honorarprofessor und Ordinarius der philosophischen Fakultät an der hiesigen Universität bestimmt worden. Da sich bei den Hochschulwahlen die Breslauer Studentenschaft überwiegend $\mathrm{zu}$ der Freien Breslauer Studentenschaft an der Universität bekannt hat, glaubt der Vorstand der Freien Breslauer Studentenschaft an der Universität Ew. Magnificenz höflichst darauf aufmerksam machen zu dürfen, daß die Breslauer Studentenschaft mit diesem Schritt des Herrn Ministers nicht einverstanden ist. Die Breslauer Studentenschaft sieht darin einen weiteren Schritt in der Politisierung der Hochschulen. “738

Diese Äußerungen der Freien Breslauer Studentenschaft wurden von den sozialistischen Studenten als „Überheblichkeit“" abgetan. ${ }^{739}$ Die Breslauer Philosophische Fakultät indes beschwerte sich schriftlich bei Adolf Grimme:

„Die Fakultät glaubt Recht und Pflicht zu haben, sich über die vom Ministerium gewählte Behandlungsform zu beklagen, um so mehr, als sie auf Grund von Nachrichten aus parlamentarischen Kreisen, die sie als unterrichtet ansehen muss, die Befürchtung nicht von

\footnotetext{
${ }^{733}$ Vgl. ebd., Bl. 10.

${ }^{734}$ Vgl. Tilitzki, Christian: Die deutsche Universitätsphilosophie, S. $163 \mathrm{f}$.

${ }^{735}$ Schlesische Zeitung, 31.03.1930.

${ }^{736}$ Vgl. Breslauer Volkswacht, 31.03.1930.

${ }^{737}$ Vgl. Berliner Börsenzeitung, 27.06.1930.

${ }^{738}$ Der Jungdeutsche, 17.07.1930, in: GStA PK I HA Rep 76/Sekt 4/Tit IV/48 Bd. 1c, B1. 70.

${ }^{739}$ Vgl. ebd.
} 
der Hand weisen kann, dass bei der Entscheidung des Ministers politische Einflüsse mitgesprochen haben. “" 740

Mit seiner Berufung war Siegfried Marck einer der wenigen Hochschullehrer seiner Zeit, die sich explizit zur Weimarer Republik und deren Verfassung bekannten. ${ }^{741}$ Adolf Grimme bewies in der Berufung Siegfried Marcks große Entschlossenheit, setzte er sich doch gegen die zwei deutlich negativen Gutachten Martin Heideggers durch, in denen dieser Marck nicht für einen solchen Posten geeignet sah. Zwar bescheinigte er Marcks Werk „Dialektik der Philosophie in der Gegenwart“ einen sehr hohen Wert für die Philosophie, doch hielt er ihn für die Besetzung des renommierten Hönigswald-Lehrstuhls nicht geeignet:

„Die Auseinandersetzung mit mir war bis dahin die beste, die mir zu Gesicht gekommen. Ich habe das Herrn M. auch mitgeteilt, ohne meine grundsätzlichen Bedenken zu verschweigen. Sie betreffen den völligen Mangel einer positiven Begründung der Kritik und die gänzlich verfehlte Einordnung meiner Untersuchungen in gewisse theologische Strömungen [...] Und so fehlt denn diesem Buch, ebenso wie dem gleichgearteten des Frankfurter Privatdozenten Heinemann jede Substanz und alles Schwergewicht [...] Es erübrigt sich, daß ich weiter hier auf das Buch eingehe, weil es überhaupt nicht in die Klasse der Veröffentlichungen gehört, die als Qualifikationsbeweis für eine Professur in Frage kommen.“742

Für Heidegger war das Thema Dialektik ein Modeproblem, und auch Marck unternahm seiner Ansicht nach nicht den Versuch, das Problem der Dialektik in seiner Verwurzelung $\mathrm{zu}$ fassen oder auch nur in gründlicher historischer Untersuchung geschichtlich zu entwickeln. ${ }^{743}$ Eine zweite von der Fakultät erbetene Stellungnahme Martin Heideggers fiel noch negativer und herablassender aus:

,[...] Marck wird immer geschickt über das gerade Moderne zu reden wissen, er wird aber nie das Schwergewicht aufbringen, mit wirklichen Fragen in die Aufgaben der Philosophie einzugreifen. Die Art von Philosophiedozenten ist unser Ruin.“ 744

Sicherlich könnten Heidegger an dieser Stelle judenfeindliche Ressentiments unterstellt werden, doch hatte Heidegger ein Jahr zuvor mit seinem Gutachten Kurt Lewin, einem der Sozialdemokratie nahestehenden Sozialpsychologen und Juden, ins Amt verholfen, was diese Anschuldigungen entkräften könnte. ${ }^{745}$

Dennoch war Marck allein durch seine Zugehörigkeit zur Sozialdemokratie und in seiner sozialistischen Anschauungsweise sehr präsent, aber nicht geschätzt an

\footnotetext{
${ }^{740}$ GStA PK, Rep. 76Va, Sek. 4, Tit. IV, Nr. 48, Band X, Bl. 51.

${ }^{741}$ Kapferer, Norbert: Die Nazifizierung der Philosophie, S. 26.

${ }^{742}$ GStA PK, Rep. 76Va, Sek. 4, Tit. IV, Nr. 48, Band IX, B1. 15-16.

${ }^{743}$ Vgl. Kapferer, Norbert: Diese Art von Philosophiedozenten ist unser Ruin. Zwei Gutachten Martin Heideggers aus den Jahren 1929/1930, in: Neue Zürcher Zeitung, 09.09.2001. Der Streit Marcks und Heideggers setzte sich auch im amerikanischen Exil Marcks fort, Siehe: Marck, Siegfried: Zum Fall Heidegger, in: Aufbau, 29.03.1946; Ders.: Gegen Marcuses Heidegger-Wertung, in: Ebd., 02.12.1949. ${ }^{744}$ GStA PK, Rep. 76Va, Sek. 4, Tit. IV, Nr. 48, Band IX, B1. 17-18.

${ }^{745}$ Vgl. Tilitzki, Christian: Die deutsche Universitätsphilosophie, S. 293.
} 
der Universität und es war klar, dass seine Berufung auf den Widerstand der anderen Professoren stieß, wie Hans-Georg Gadamer später berichtete. Antisemitismus existierte sicherlich als eine Art ,akademische Selbstverteidigung“ unter den Professoren, berichte Gadamer weiter, was natürlich dazu führen musste, dass Grimme Marck aus seiner schlechten Stellung als Privatdozenten zu befreien und auf eine Professur zu setzen versuchte. ${ }^{746}$ Seinem parteilosen Vorgänger, Carl Heinrich Becker, wurde von Seiten der Sozialdemokraten vorgeworfen, er sei gegen die „antidemokratischen Umtriebe an den preußischen Universitäten“ nicht genug vorgegangen. Grimmes Ernennung durch Otto Braun führte auch in der Öffentlichkeit zu der Äußerung, Grimme sei ein „Partiebuchsozialist““ ${ }^{747}$ Er hatte als Kultusminister das Recht, Lehrstühle nach seinem Willen zu besetzen, was er besonders bei den Rechtswissenschaften auch tat. ${ }^{748}$ In Kai Burkhardts Biographie über Grimme lässt sich gut herauslesen, dass Grimme - selbst ein religiöser Sozialist - ebenso gern Gleichgesinnte auf Lehrstühle berief, wie es im Fall Günther Dehns in Halle der Fall war. ${ }^{74}$ Und nun berief er Siegfried Marck, gegen den Willen der Fakultät in Breslau. Marck war also kein Einzelfall. Auch die jüdische Gemeinde Breslaus war froh über die Berufung ihres hoch geschätzten Professors Marck, der in den Vorlesungen und Arbeitsgemeinschaften innerhalb der jüdischen Volkshochschule stets eine große Anziehungskraft besaß. ${ }^{750}$ Letztlich war es im April $1930^{751}$ keine Entscheidung Grimmes gegen die Psychologie und für die Philosophie und auch nicht für das Judentum, sondern vielmehr eine Entscheidung zugunsten der Sozialdemokratie. Bedeutender in diesem Zusammenhang ist, dass Siegfried Marck und Adolf Grimme Freunde waren. Grimme schrieb ihm:

„Ich denke immer noch gern an unser letztes Zusammentreffen in Breslau zurück. Damals las mir Ihre Frau Gedichte von Erich Kästner vor, von denen ich eins, wie ich mich entsinne, an dem Abend dann gleich in einer Versammlung in Brieg verwendet habe“6752

Im Juni 1949 wurde ihre freundschaftliche Verflechtung noch deutlicher. Siegfried Marck schildert in einem Brief an Grimme, der mittlerweile Vorsitzender des Nordwestdeutschen Rundfunkes war:

\footnotetext{
${ }^{746}$ Vg. Grassl, Roswitha: Breslauer Studentenjahre. Hans-Georg Gadamer im Gespräch, Mannheim 1996, S. 16.

${ }^{747}$ Vgl. Kai Burkhardt: Adolf Grimme (1889-1963): eine Biographie, S. 86ff.

${ }^{748}$ Vgl. ebd., S. $135 f$.

${ }^{749}$ Vgl. ebd., S. 136.

${ }^{750}$ Vgl. Breslauer Jüdisches Gemeindeblatt, Nr. 04 1930, S. 61.

${ }^{751}$ Vgl. Appointment of the supernumerary Associate Professor Dr. Siegfried Marck as Professor in Ordinary, Prussian Ministry of Science, Art and Public Education, Berlin, 23.April 1930, NL SM.

${ }^{752}$ Grimme an Marck, 02.11.1941, in: GStA PK VI. HA NL Grimme Nr. 2076.
} 
„Da ich Ihre jetzige Andresse nicht kenne, habe ich Genossen Hamburger um Beförderung beiliegender Briefe gebeten, da er ja schon früher - soll ich sagen in grauer Vorzeit? zwischen uns ein glücklicher Vermittler war“"753

Marck erhielt dank seines Parteibuches eine Professur, für die er eigentlich nicht ausgebildet war. Finanziell schien er nun abgesichert und er hätte viele Jahre später als alter Ordinarius in Breslau sterben können. Mit der Machtübernahme der Nationalsozialisten änderte sich die Situation und Marck verließ Breslau, anders als sein Weggefährte Ernst Eckstein. Dieser hatte zwar auch die Möglichkeit zu fliehen gehabt, erklärte jedoch, dass er lieber bei seinen Arbeitern bleiben wolle und fiel der Willkür Wilhelm Hennies im Konzentrationslager Dürrgoy zum Opfer.

Immanuel Birnbaum orientierte sich in der Zeit des Nationalsozialismus nach Osten, emigrierte über Lettland nach Helsinki und von dort weiter nach Stockholm, wo er zwischen 1940 und 1943 im Lager Smedsbo interniert war. Später kam Birnbaum zurück in die Bundesrepublik Deutschland, wo er das außenpolitische Ressort der Süddeutschen Zeitung leitete und zudem stellvertretender Chefredakteur wurde. $^{754}$

Auch Max Tockus floh vor den Nationalsozialisten. In Karlsbad wirkte er in der Leitung des Neuen Vorwärts und musste nach dem Einmarsch deutscher Truppen erneut fliehen. Willy Cohn, ebenfalls ein guter Freund von Max Tockus, der ihn noch kurz vor dessen Flucht in die Tschechoslowakei in der Redaktion der Volkswacht besuchte, weil auch er „,besonders in diesen Zeitläufen das Gefühl [hatte], dass man

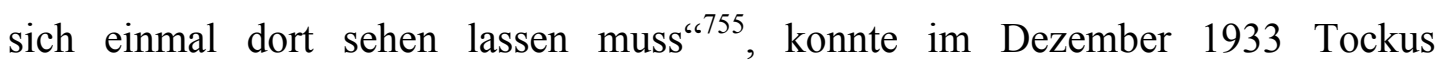
Vertreibung nur bedauern, gerade weil er ihn für einen der ,anständigsten Menschen, die es gibt" hielt. ${ }^{756}$ Er wanderte aus nach Palästina, von wo aus es ihn 1948 in die USA zog. In beiden Exilen arbeite er als Landarbeiter und Lehrer. Dennoch wollte er seinem Heimatland nicht vollends den Rücken kehren und ging 1956 nach Deutschland zurück und lebte bis zu seinem Tod in einem jüdischen Altersheim in Frankfurt. $^{757}$

\footnotetext{
${ }^{753}$ Marck an Grimme, 06.06.1949, ebd.

${ }^{754}$ Vgl. Lebenslauf, in: Findbuch Immanuel Birnbaum; Peter Glotz. Der weiße Elefant.

${ }^{755}$ Vgl. Conrads, Norbert: Willy Cohn. Kein Recht, nirgends. Tagebuch vom Untergang des Breslauer Judentums 1933-1941 Bd.1, Köln 2006, S. 9.

${ }^{756}$ Vgl. ebd., S. 117, 122.

${ }^{757}$ Vgl. Sozialdemokratischer Pressedienst, 20.07.1963, S. 5, 26.06.1967 S. 5.
} 
Siegfried Marck hatte in Breslau einen politischen Grenzgang vollzogen und schloss sich - gegen alle Bedenken seinerseits und seiner Familie - nach seinen Fronterlebnissen im Ersten Weltkrieg der Sozialdemokratie an. Er entsagte seinem nationalliberalen Standesdünkel, wenngleich er sich auch vorerst am „rechten Rand“ seiner neuen politischen Heimat ansiedelte. Dabei war er als Vertreter innerhalb der Stadtverordnetenversammlung stets ein Bekenner der Republik, anders als ein Ernst Eckstein, und Marck erhoffte sich bis 1924 innerhalb seiner Partei aufzusteigen. Marck musste die vielen Angriffe auf die Republik negativ bewerten. Wäre die Weimarer Republik unterhöhlt worden, hätte dies für ihn erneute Orientierungsschwierigkeiten mit sich gebracht, die er nicht einzugehen bereit war. Zeitgleich mit der Revolution, seinem Übergang zur Sozialdemokratie und den Schwierigkeiten an der Breslauer Universität, hatte Marck persönlich lange mit dem Scheitern seiner ersten Ehe zu kämpfen. Marck vollzog somit nicht nur politisch sondern auch moralisch einen Grenzgang, wenn er die Beziehung mit Lola, für die er so lange gekämpft hatte, auflöste und seine Studentin Kläre ehelichte.

Doch ein Aufstieg in höhere politische Ämter wurde ihm verwehrt, sodass er sich gezwungen sah sich umzuorientieren. Seinen Fokus hatte Marck, der wie sein Doktorvater, Eugen Kühnemann, ein glänzender Redner war, auf die Arbeiter- und Erwachsenenbildung gelegt und es verging kaum eine Woche, in der seine Vorträge nicht innerhalb der Breslauer Volkswacht, in dessen „Klüngel“ er mitarbeitete, angekündigt wurden.

Ab 1924 orientierte Marck sich um, besuchte die Veranstaltungen der Marxistischen Arbeitsgemeinschaft, auf denen Fritz Sternberg oder Max Adler gerne referierten. Marck arbeitete jetzt mehr und mehr mit den Jungsozialisten und „seinen“ sozialistischen Studenten zusammen und versuchte diese für den Kampf für den Sozialismus mit „geistigen und adeligen Waffen“ $\mathrm{zu}$ formen. Diese Verschmelzung von Jungsozialisten und Intellektuellen, die in Breslau überwiegend jüdisch waren, wurde innerhalb der Stadtverordnetenversammlung sehr misstrauisch beäugt. Es fehlte nicht an antisemitischem Gedankengut und Marck legte sein Amt 1927 nieder, schloss sich der Klassenkampfgruppe an und musste erleben, wie sich ein Großteil seiner Weggefährten von der Sozialdemokratie abspaltete und in Breslau die SAP gründete. Obschon Siegfried Marck sich in jenen Jahren deutlich dem linken Flügel seiner Partei zuzuordnen lässt, schloss er sich dieser Abspaltung nicht an. Kurz zuvor war er nicht ohne Hilfe seines Parteikollegen Adolf Grimme an eine ordentliche Professur gekommen, für die er eigentlich nicht ausgebildet war. Er war 
nun dort angekommen, wo er eigentlich sein wollte - er besaß eine ordentliche Professur und damit ein geregeltes Einkommen, war innerhalb seiner Partei gut vernetzt und führte eine glückliche Ehe. 


\section{Im zweiten Kulturkreis - im französischen Exil}

\section{Zwischen Opposition und Kampfkartell}

Es ist wenig erstaunlich, dass Siegfried Marck nach Inkrafttreten des Gesetzes zur Wiederherstellung des Berufsbeamtentums an der Breslauer Universität seines Amtes enthoben wurde. Aufgrund des Paragraphen 4 des Beamtengesetzes vom 07. April 1933 wurde er zuerst zwangsbeurlaubt und im September 1933 ganz aus der Stellung des Professors entlassen. ${ }^{758}$ Der Breslauer Philosophieprofessor war damit einer der ersten 15 Professoren, die diesem Gesetz zum Opfer fielen. Neben Marck betraf dies beispielsweise auch Emil Lederer, Eduard Heimann, Paul Tillich oder Max Horkheimer. Wie aus dem Entlassungsschreiben hervorgeht, wurde Marck nicht aufgrund seiner jüdischen Herkunft, sondern wegen seiner „politischen Unzuverlässigkeit"“ aus dem Amt entfernt. ${ }^{759}$

Von seinen Kollegen kamen keine Einwände und das ist nicht verwunderlich, hatte sich die Fakultät doch schon beim Berufungsverfahren deutlich positioniert. Auch wohlwollende Worte Eugen Kühnemanns, seines Doktorvaters, blieben aus. ${ }^{760}$ Seine wenigen Studenten waren sozialistisch und damit selbst dem Zugriff der Nationalsozialisten ausgesetzt, von den deutsch-nationalen Studenten konnte er keine Fürsprache erwarten.

Marck selbst bemerkte knapp 13 Jahre später in einem Brief an Adolf Grimme, dass es für ihn im Vergleich zu anderen „eine glückliche Fügung“ war, $1933 \mathrm{zu}$ den ersten in Preußen entlassenen Professoren gehört zu haben, da er „damals niemals die ganz akute Sorge um die Existenz gehabt“ habe. ${ }^{761}$ Andere seiner Weggefährten sorgten sich nicht nur um ihre finanzielle, sondern auch um ihre physische Existenz.

Zur selben Zeit galt der von Ernst Röhm eingesetzte Breslauer Polizeipräsident Edmund Heines als eine der am meisten gefürchteten und gehassten Führungsfiguren der Nationalsozialisten in Schlesien. Fritz Stern, der noch nicht aus Breslau geflohen war, nannte Heines einen „,verabscheuungswürdigen Mann“.762 Immerhin errichtete er gleich mit dem Konzentrationslager Dürrgoy, seinem „Privat-

\footnotetext{
758 Siegfried Marck an das Regierungsbezirksamt für Wiedergutmachung in Neustadt a.d.W., 23.01.1954, NL SM.

${ }^{759}$ Vgl. Kapferer, Norbert: Die Nazifizierung der Philosophie, S. 63.

${ }^{760}$ Ebd.

${ }^{761}$ Marck an Grimme, 13.10.1946, GStA PK VI. HA, Nl Grimme, A., Nr. 2076 (nachfolgend nur noch NL AG).

${ }^{762}$ Vgl. Stern, Fritz: Fünf Deutschland und ein Leben, S. 138.
} 
Lager“", eine der ersten Folter- und Verbrechenswirkstätten, in dem viele ehemalige Stadtverordnete der Arbeiterparteien oft öffentlichkeitswirksam in „Schutzhaft“ genommen wurden. Auch Marck fürchtete wegen seiner Betätigung als Stadtverordneter der sozialdemokratischen Partei von 1919-1926, als Mitarbeiter der Zeitungen und Zeitschriften dieser Richtung und als häufig in Versammlungen auftretender Redner, dem „Fememörder“6763 in die Hände zu fallen. Marck entkam, einige seiner Freunde, die nicht rechtzeitig flohen, fielen Heines zum Opfer: Sein guter Freund Ernst Eckstein, der stellvertretende sozialdemokratische Bürgermeister von Breslau Karl Mache, der Oberpräsident der Provinz Niederschlesien Hermann Lüdemann und nicht zuletzt der ehemalige Reichstagspräsident Paul Löbe. ${ }^{764}$ Wie dieses Lager betrieben wurde, ist in den Lebenserinnerungen Löbes nachzulesen. Er selbst wurde gar aus Rache von Berlin nach Dürrgoy überführt, da er Edmund Heines, aufgrund der Misshandlung eines abtrünnigen NSDAP-Parteikameraden, noch vor der Machtergreifung für drei Monate aus dem Reichstag ausgeschlossen hatte. Löbe selbst blieben im Lager grobe Misshandlungen erspart, nicht zuletzt weil seine Frau Beschwerde bei den Behörden einreichte. ${ }^{765}$ Anders bei Lüdemann:

,[Er] hatte, in ein Harlekinkostüm gesteckt, eine Stunde durch die Straßen von Breslau zum Lager Dürrgoy gehen müssen, war auf diesem Wege durch ein aufgerufenes Spalier von SA und NSDAP beschimpft, angespuckt und im Lager so geprügelt worden, dass er vom Hals bis $\mathrm{zu}$ den Kniekehlen von blutunterlaufenen Schwielen bedeckt war. “7766

Das Lagerleben selbst begann jeden Morgen mit einer Reihe seelischer Demütigungen. So waren Löbe, Lüdemann sowie Mache für das Säubern der Toiletten eingeteilt. Vielen Häftlingen wäre sicherlich, besonders den älteren unter ihnen, der Freitod viel lieber gewesen, als die täglichen Misshandlungen hinzunehmen, wie einer Äußerung Löbes aus seinen Erinnerungen entnommen werden kann: „Nein, es war der geistige Zusammenbruch und die Angst vor den täglich und nächtlich sich wiederholenden körperlichen Quälereien“‘767.

\footnotetext{
${ }^{763}$ Protokoll der Reichstagssitzung am 12. Mai 1932. Als Fememörder wurde Heines aus Kreisen der Arbeiterbewegung bezeichnet, da dieser am 12. Mai 1932 an einem tätlichen Angriff auf den sozialdemokratischen Journalisten Helmuth Klotz im Restaurant des Reichstages beteiligt war. Klotz war zuvor Mitglied der NSDAP gewesen und hatte Briefe, welche die Homosexualität Ernst Röhms thematisieren, veröffentlicht. Siehe auch: Linder, Herbert: Von der NSDAP zur SPD. Der politische Lebensweg des Dr. Helmuth Klotz (1884-1943), Konstanz 1995, S. 177ff.

${ }^{764}$ Vgl. Rudorff, Andrea: Breslau-Dürrgoy, in: Wolfgang Benz, Barbara Distel (Hrsg.): Der Ort des Terrors. Geschichte der nationalsozialistischen Konzentrationslager, Bd. 2: Frühe Lager, Dachau Emslandlager, München 2005, S. 83-86.

${ }^{765}$ Vgl. Löbe, Paul: Der Weg war lang, S. $221 \mathrm{ff}$.

${ }^{766}$ Ebd., S. 222f.

${ }^{767}$ Ebd., S. $228 f$.
} 
Zur selben Zeit sprach Siegfried Marck mit Thomas Mann in Lugano über die Möglichkeit einer „Emigranten Universität““768. Ernst Eckstein überlebte, anders als Löbe und Lüdemann, das Lager Dürrgoy und die dortigen Misshandlungen nicht. Dabei hatte er nach der Machtübernahme durch die Nationalsozialisten die Möglichkeit zur Flucht ins Ausland gehabt. Dennoch hatte sich der ehemalige Parteiführer und „Anwalt der Armen“ entschlossen, bei „seinen“ Breslauer Arbeitern zu bleiben. ${ }^{769}$ Diese Haltung ist aus heutiger Sicht beeindruckend, war er doch bereits vor der Machtübernahme der Nationalsozialisten bedroht und sein Haus mit Brandanschlägen versehen worden. ${ }^{770}$ Konrad Reisner, ein damaliger Freund Ecksteins, traf sich noch vor dessen Festnahme mit ihm zum Mittagessen und versuchte ihn zur Flucht zur ermutigen. Eckstein indes soll ihm entgegnet haben: „Wie kannst du annehmen, dass ich unsere Genossen hier verlassen kann; dass ich weggehe und die anderen bleiben hier، ${ }^{\text {،771 }}$. Eckstein hielt Wort - er blieb in Breslau.

Direkt nach dem Reichstagsbrand wurde er verhaftet, genau wie sein engster Mitarbeiter und Jungsozialist Max Rausch und musste beim Aufbau des Lagers Dürrgoy helfen. Er soll dort in seinen letzten Hafttagen misshandelt dazu bedroht worden sein und unternahm am 28. April einen Selbstmordversuch und wurde ins Allerheiligenhospital eingeliefert. Daraufhin wurde er in eine Nervenheilanstalt eingewiesen, wo er am 08. Mai 1933 verstarb. ${ }^{772}$ Die Nachricht vom Tod Ernst Ecksteins verbreitete sich wie ein Lauffeuer unter den Arbeitern. Die Todesanzeige der Mutter, „Mein Sohn, Dr. Ernst Eckstein, hat ausgelitten [... $]^{6 / 773}$, die auch den Weg in die bürgerliche Breslauer Presse fand, deutete unmissverständlich und für viele Wegbegleiter auf die wahren Todesumstände. Aus der eigentlich klein geplanten Trauerfeier, auf der Max Rausch die Traueransprache hielt, wurde eine große Demonstration, zu der sich tausende Arbeiter am Grab Ecksteins einfanden.

\footnotetext{
${ }^{768}$ Mann, Thomas herausgegeben von Peter de Mendelssohn: Tagebücher 1933-1934, Frankfurt am Main 1977, S. 61. (Die genauen Umstände sind nicht mehr zu rekonstruieren, auch nicht die der Pläne um eine solche „Emigranten-Universität“.

${ }^{769}$ Vgl. Matull, Wilhelm: Ostdeutschlands Arbeiterbewegung, S. 76.

${ }^{770}$ Vgl. Seydewitz. Ruth: Alle Menschen, S. 36; Bergbauer, Knut: Ernst Eckstein (1897-1933), S. 3233; Matull, Wilhelm: Ostdeutschlands Arbeiterbewegung S. 128.

${ }^{771}$ Stenzel, Elke (Hrsg.): „Den Nazis eine schallende Ohrfeige versetzen“. Zeitzeugen erinnern sich, Berlin 2009, S. 125f. Konrad Reisner war Mitglied der Friedensbewegung, der er sich nach dem Ersten Weltkrieg in Breslau anschloss und war Mitglied der Deutschen Liga für Menschenrechte. Er floh vor den Nationalsozialisten nach Paris und kämpfte dort auch für die Ossietzky-Freilassung, vgl. Holl, Karl: In Memoriam Konrad Reisner, in: Neuer Nachrichtenbrief der Gesellschaft für Exilforschung, Nr. 24 (2004), S. 11-12.

${ }^{772}$ Vgl. Bergbauer, Knut: Ernst Eckstein (1897-1933), S. 32-33.

${ }^{773}$ Cohn, Willy: Kein Recht nirgends, Bd I, S. 42 (10.05.1933).
} 
Auffallend viele junge Arbeiter zeugten vom Einfluss Ecksteins, den er auf sie ausübte. ${ }^{774}$ Letztlich wurde:

,[S]eine Beisetzung die letzte stumme, wenn auch unerhört eindrucksvolle Massenprotestkundgebung gegen den Nationalsozialismus und dessen bereits angetretene Herrschaft. Der Hügel seiner Grabstätte wurde noch wochenlang immer wieder mit frischen Blumen und Kranzgewinden geschmückt, die Mitglieder der Arbeiter-Jugend mit List und unter Gefahren auf den von Schergen beobachteten Friedhof schmuggelten." ${ }^{775}$

Siegfried Marck befand sich auf dem Weg nach Freiburg, floh aus Breslau und ließ jeden Kontakt abreißen. Auch mit vielen der Jungsozialisten kam er während und nach der Zeit des Nationalsozialismus nicht mehr in Verbindung. Max Adler blieb und starb 1937 in Wien. ${ }^{776}$ Nur Fritz Sternberg, der 1936 sein Schweizer Exil verließ, traf Marck noch im französischen Exil, wenngleich dieser auf der Seite der SAP gegen den Faschismus kämpfte. Der Vorstand der SAP hatte auf Initiative von Fritz Sternberg, der auch den finanziellen Grundstock legte, im französischen Exil zur Unterstützung notleidender oder gefangener Genossen eine Unterstützungskasse, den Ernst Eckstein-Fonds, ins Leben gerufen. Im Rahmen der Volksfrontbemühungen tat sich der Fond, der ohnehin über wenig Mittel verfügte, mit anderen deutschen Hilfsorganisationen wie der Arbeiterwohlfahrt oder der Roten Hilfe zusammen. ${ }^{777}$

Kläre floh getrennt von Siegfried zuerst nach Genf, dann nach Shanghai ${ }^{778}$, bis sie 1934 nach Dijon kam. ${ }^{779}$ Marck floh nach Freiburg, in das Haus seines ehemaligen Lehrers Jonas Cohn, indem er für die Ausreisegenehmigung einen Philosophenkongress in Italien vortäuschte. ${ }^{780}$

Cohn zu besuchen hatte Marck schon länger überlegt, immerhin erinnerte er sich gern an die Zeit in den Freiburger Seminaren und hatte sich mit Cohn wissenschaftlich ausgetauscht. Seinen eigentlichen Plan, Cohn Mitte März 1933 in Güntherstal zu besuchen, verwarf Marck rasch. Bereits Anfang März 1933 und schon in Freiburg kontaktierte er Cohn mit der Bitte, früher anreisen $z u$ dürfen. ${ }^{781}$ Jonas Cohn wusste, dass Siegfried Marck an der Breslauer Universität allerlei erlebt hatte. Wie Marck ihm berichtet hatte, hielt er seine Vorlesungen unter „Begleitung von

\footnotetext{
${ }^{774}$ Seydewitz, Ruth und Max: Begegnungen S. 37f.

${ }^{775}$ Der Sozialdemokrat, 28.03.1947.

${ }^{776}$ Vgl. Pfabigan, Alfred: Max Adler. Eine politische Biographie, Frankfurt am Main 1982.

${ }^{777}$ Vgl. Bremer, Jörg: Die Sozialistische Arbeiterpartei Deutschlands (SAP). Untergrund und Exil 1933-1945, Frankfurt am Main 1978, S. 116f.

${ }^{778}$ Im Shanghaier Ghetto lebten zeitweilig 20.000 jüdische Flüchtlinge. Wie und warum Kläre ohne Siegfried dorthin reiste, ist nicht mehr zu rekonstruieren.

${ }^{779}$ Hirsch, Helmut: Siegfried Marck, S. 384.

${ }^{780}$ Ebd., S. 373

${ }^{781}$ Marck an Cohn, 03.03.1933, 473-B-144-007, Cohn-Archiv im Solomon Ludwig Sternheim Institut für Deutsch-Jüdische Geschichte.
} 
Gesangsvorträgen und sonstiger Betätigung der Krawallmacher bei einem einer Schupo-Kaserne gleichenden Zustand“ ${ }^{\text {ab. }}{ }^{782}$ Auch die Festsetzungen seiner Parteifreunde, die er nur missbilligend vernehmen konnte, hinterließen bei Marck ein „gewisses Gefühl des Unbehagens“، ${ }^{783}$ Mehr noch musste Marck in einem Brief an Jonas Cohn feststellen, dass am „Kampfabschnitt Universität [...] ein Stück Vorspiel des Bürgerkrieges ausgefochten“ würde. ${ }^{784}$ Dennoch irrte er, wenn er in dem gleichen Brief die Chancen auf „100\% Faschismus“ als gering erachtete. Marck glaubte bisweilen an eine Renaissance der Monarchie mit „stark parlamentarischem Einschlag“, wenngleich er sich eingestand, dass „wilde Zeiten vor uns [liegen], in denen tatsächlich Zeit, Leib und Leben nicht mehr sicher sind.“" ${ }^{785}$ Siegfried Marck wurde schließlich am 15. Juli 1935 wegen „staatsfeindlicher“ Betätigung individuell ausgebürgert, seine wertvolle Bibliothek in der Breslauer Kurfürstenstraße wurde beschlagnahmt, seine Familie im April 1937 ganz des Landes verwiesen. ${ }^{786}$

Auch bei Jonas Cohn im Güntherstal konnte Marck 1933 nicht bleiben. Hier war er vor den Nationalsozialisten nicht sicher. Er floh, sicherlich ein wenig im Zwiespalt über die beiden potentiellen Fluchtziele, in das für politisch Verfolgte besonders attraktive Frankreich. Hier verschaffte die Genfer Konvention allen Eingereisten - ob legal oder illegal - die Möglichkeit einen Pass zu beantragen. ${ }^{787} \mathrm{Er}$ floh nicht nach Prag, wo das öffentliche Leben von der deutschen Kultur mitgeprägt wurde, wo sich auch der sozialdemokratische Parteivorstand ansiedelte, um dort im Widerstand gegen den Nationalsozialismus tätig zu sein. Er ging nach Paris, das auch ein eigenes Stück deutscher freiheitlicher Tradition beherbergte: Schon hundert Jahre zuvor gab es in Paris Handwerkervereine, in denen sich Männer wie Wilhelm Weitling,

\footnotetext{
${ }^{782}$ Marck an Cohn, 06.12.1932, 471-B-144-005.

${ }^{783}$ Marck an Cohn, 03.03.1932, 471-B-144-007.

${ }^{784}$ Marck an Cohn, 05.02.1933, 472-B-144-006.

${ }^{785}$ Ebd.

786 Siegfried Marck an das Regierungsbezirksamt für Wiedergutmachung Neustadt a.d.W., 23.01.1954. Das „Reichsbürgergesetz“ vom 15. September 1935 verschärfte die Judenverfolgung in Deutschland dramatisch: Die erste Verordnung veranlasste, dass jüdische Beamte mit Ablauf des 31 . Dezembers 1935 automatisch in den Ruhestand treten. Die zweite Verordnung vom 21 Dezember 1935 entzog dann auch allen nichtverbeamteten Dozenten die Lehrbefugnis, vgl. Reichsgesetzblatt, Teil 1, Jg. 1935, S. 1333.

${ }^{787}$ Vgl. Langkau-Alex, Ursula: Deutsche Volksfront 1932-1939. Zwischen Berlin, Paris, Prag und Moskau, Bd. 1: Vorgeschichte und Gründung des Ausschusses zur Vorbereitung einer deutschen Volksfront, Berlin 2004, S. $61 \mathrm{ff}$.
} 
Heinrich Bauer und Karl Schapper gesammelt hatten. ${ }^{788}$ Paris war ein Ort, der in jenen Jahren für politisch Verfolgte attraktiv war.

Es war wohl auch die Aussicht auf eine Lehrtätigkeit an den altehrwürdigen französischen Universitäten in Paris und Dijon, neben der geografischen Nähe zu Freiburg, der Grund für Marcks Emigration nach Frankreich. Nach einer Gastdozentur an der Universität Paris bekam er in Dijon ebenfalls eine Dozentur, ermöglicht durch Mittel der Rockefeller Foundation, indem diese ein Drittel seines Gehaltes als Dozent für Philosophiegeschichte und Literatur in Dijon zahlte. ${ }^{789}$ Diese Stiftung, die neben der Carnegie-Stiftung zu den größten Förderwerken in den Vereinigten Staaten gehörte, förderte besonders die Wissenschaftler, die Deutschland hatten verlassen müssen, indem sie die Zahlung ihrer Gehälter übernahm und damit eine besonders wichtige Rolle für den Kulturtransfer hatte. Zwei Drittel der Gelder, die für die Aufnahme und Integration von Wissenschaftlern in die USA bereitgestellt wurden, kamen von der Rockefeller Foundation. ${ }^{790}$

Damit traf es Siegfried Marck besser als viele andere Sozialdemokraten, die emigrierten, hatte er so doch wenigstens ein geregeltes Auskommen. Es ist nicht auszuschließen, dass der Philosoph Lucien Lévy-Bruhl Marck unterstützte, immerhin hatte Ersterer vielen emigrierten Wissenschaftlern mit „seiner schlichten und zuverlässigen Art einen Halt gegeben“, wie es Marck selbst in einem Artikel des Neuen-Tagebuchs festhielt. ${ }^{791}$

Wenn Siegfried Marck in Breslau der politische Aufstieg auf Reichsebene nicht gelang, so kann für die Zeit in der Pariser Emigration - und damit unter unglücklichen Umständen - behauptet werden, dass Marck durch den Krieg, die Vertreibung und seine Flucht erneut die Chance erhielt, an erster Stelle für die

${ }^{788}$ Vgl. Höppner, Joachim/Seidel-Höppner, Waltraud: Der Bund der Geächteten und der Bund der Gerechtigkeit, in: Reinalter, Helmut (Hrsg.): Politische Vereine, Gesellschaften und Parteien in Zentraleuropa 1815-1848/49. Schriftenreihe der Internationalen Forschungsstelle „Demokratische Bewegungen in Mitteleuropa 1770-1850“, Bd. 38. Frankfurt/Main u. a. 2005, S. 89-153.

${ }^{789}$ Vgl. National Ministry of Education. Department for Scientific Research, 27.01.1939, NL SM. Überhaupt trat die Rockefeller Foundation in Konkurrenz mit den anderen beiden großen Wissenschaftsstiftungen, der Carnegie Foundation sowie dem erst 1931 gegründeten Oberleander Trust. Doch mit über 1,4 Millionen Dollar für die Rettung der vertriebenen Wissenschaftler nur in den USA, stellte die Rockefeller Foundation mehr als die Hälfte aller Mittel zur Verfügung, vgl. Krohn, Claus-Dieter: Wissenschaft im Exil. Deutsche Sozial- und Wirtschaftswissenschaftler in den USA und die New School for Social Research, Frankfurt am Main 1987, S. 37ff.

${ }^{790}$ Ders.: Deutsche Wissenschaftsemigration seit 1933 und ihre Remigrationsbarrieren nach1945, in: Bruch, Rüdiger vom/Kaderas, Brigitte (Hrsg.): Wissenschaften und Wissenschaftspolitik. Bestandsaufnahme zu Formationen, Brüchen und Kontinuitäten im Deutschland des 20. Jahrhunderts, Stuttgart 2002, S. 437-453, hier S. 441.

${ }^{791}$ Marck, Siegfried: Zum 80. Geburtstag Lévy Bruhls, in: Das Neue-Tagebuch, 10.04.1937. Dieser Artikel wurde von Schwarzschild gefordert, siehe: Telegramm Schwarzschild an Marck, 23.03.1937, Antwort Marck an Schwarzschild, 14.04.1937, BArch R 8046 Neues Tagebuch Paris, 252, 253. Zum Tod Bruhls schrieb Marck in der Pariser Tageszeitung, 18.03.1939. 
Belange der Sozialdemokratie einzutreten. Sicherlich wird Marck eine hohe innere Motivation für den Kampf gegen den Nationalsozialismus besessen haben, obschon er sich der Schwierigkeiten bewusst gewesen sein wird. Bereits in Breslau musste er genug Erfahrungen mit Parteizwistigkeiten machen.

In Frankreich wurde der ehemalige Anhänger des Klassenkampfkreises sogleich im Widerstand aktiv. Marck wurde nach starken Auseinandersetzungen der einzelnen politischen Gruppen Vorsitzender der Ortsgruppe des Restbestandes der SPD in Paris und leitete diese Gruppe von seiner Wohnung aus. Zuvor war die Gruppe von Gerhard Kreyssig, einem Mitglied des Reichsbanners, geleitet worden. Ihr schlossen sich relativ viele junge Sozialdemokraten und Kommunisten an, nachdem diese aufgrund von Spannungen zwischen der Pariser Ortsgruppe und dem Prager Parteivorstand auseinanderfiel. ${ }^{792}$ Marck befand sich in einem Umfeld, das er als Breslauer unter den Jungsozialisten bereits sehr genossen hatte, nur unter anderen Vorzeichen. Besonders dominierend in der Pariser SPD waren vor Marcks Leitung diejenigen gewesen, die den Sprung zur SAP nicht gewagt hatten, wie Alexander Schifrin oder Kurt Glaser, aber auch Mitglieder aus dem Umfeld der Gruppe NeuBeginnen und junge Kommunisten, die den Weg nach Paris gefunden hatten. Doch diese „setzten die Taktik der deutschen Parteien fort“ und sahen „stalinistisch“ den Hauptfeind bei den ,anderen Arbeiterparteien““. ${ }^{793}$ Die Pariser Gruppe der SPD unter Gerhard Kreyssig versuchte geschlossen zu wirken und modifizierte im November 1933 das drei Monate zuvor beschlossene Grundsatzprogramm und erweiterte es von 13 auf 14 Thesen. Es formulierte entgegen der SOPADE, nach der allein die Lüge den Faschismus am Leben erhalte und er deshalb durch ein bloßes Verbreiten der Wahrheit zu besiegen sei, das, was man als „wahren Marxismus“ verstand: Ein positiver Kampf für den Sozialismus anstelle eines negativen Antifaschismus vor Zusammenbruch des Reiches. ${ }^{794}$ Von nicht minderer Bedeutung war eine grundsätzliche Absage an den Reformismus der eigenen Partei und an die bürgerlichdemokratische Republik, folglich an die Werte, für die Siegfried Marck in Breslau bis 1924 stets eingetreten war. Überdies ging es der Gruppe um die Propagierung der Einheit der deutschen Arbeiterklasse. Diese Einheit, in Kartellen organisiert, sollte unter Führung von Sozialdemokraten, „die mit der Vergangenheit nicht belastet

\footnotetext{
${ }^{792}$ Vgl. Langkau-Alex, Ursula: Deutsche Volksfront 1932-1939, Bd. 1, S. 128ff.

793 „Junge Sozialisten in der Emigration, die Arbeit der einzelnen Gruppen“, in: Pariser Tageblatt, 17.01.1934.

${ }^{794}$ Vgl. Langkau-Alex, Ursula: Deutsche Volksfront 1932-1939, Bd. 1, S. 130.
} 
sind“, vollzogen werden. ${ }^{795}$ Man verstand sich als Antagonist zum Prager Parteivorstand. Daher ist es nicht erstaunlich, dass die Pariser Ortsgruppe auf ihrer Mitgliederversammlung am 08. Februar 1934 das Prager Manifest des Parteivorstandes, welches zwar einen revolutionären Umsturz forderte, darauf jedoch einen bürgerlichen Staat zu etablieren versuchte ${ }^{796}$, ablehnte. ${ }^{797}$ Vielmehr bahnte sich im Juli 1934 eine Zusammenarbeit mit der SAP an. ${ }^{798} \mathrm{Zu}$ einem vollständigen Bruch mit dem Prager Parteivorstand sollte es vorerst nicht kommen, der vorherrschende Antikommunismus oder vielmehr der Antistalinismus war auch in Paris zu spüren. So wurden im März 1934 viele Mitglieder aus der Pariser Gruppe ausgeschlossen, da ihnen „Fraktionsarbeit im stalinistischen Interesse“ attestiert wurde. ${ }^{799}$ Letztlich zerrieb sich der Rest der Pariser Ortsgruppe, Gerhard Kreyssig trat zurück, viele verließen die Ortsgruppe und schlossen sich den Internationalen Kommunisten Deutschlands (IKD) oder der Linken Opposition (LO) an ${ }^{800}$ - den „Restbestand“ übernahm Marck.

Die Kartellidee, gleichberechtigt und gemeinsam Widerstand zu leisten, lebte auch unter Marck weiter. In ihrer vier Punkte umfassenden Richtlinie erklärte sich die Gruppe selbst zu einem Bestandteil der in Deutschland wirkenden revolutionären sozialistischen Bewegung, versuchte die kampfwilligen revolutionär-marxistischen „Großen Mitglieder“ zu erfassen und lehnte letztlich den Parteivorstand der SPD als politische Instanz ab. Vielmehr ging es der Gruppe unter der Führung Marcks darum, die organisatorische und politische Vereinheitlichung der revolutionären sozialistischen Bewegung, die einst aus der Arbeiterbewegung hervorgegangen war, im Reiche und in der Emigration voranzutreiben. ${ }^{801}$ Ein Unterfangen, das zu der damaligen Zeit unmöglich schien: Die verhärtete Frontstellung zwischen SPD und KPD, die sich in der gesamten Vorkriegszeit innerhalb der Sozialdemokratie herauskristallisiert hatte und während der Weimarer Republik nicht nur parteipolitisch, sondern auch tief in die Gesellschaft und in die Köpfe der Menschen

\footnotetext{
${ }^{795}$ Vgl. ebd., S. 131.

796 Manifest abgedruckt in: Abendroth, Wolfgang: Aufstieg und Krise der deutschen Sozialdemokratie, Köln 1978.

${ }^{797}$ Vgl. Langkau-Alex, Ursula: Deutsche Volksfront 1932-1939, Bd. 1, S. 130ff.

798 Vgl. Die Neue Weltbühne, 12.07.1934. Zur Entwicklung dieser Kooperation siehe: Niemann, Heinz: Geschichte der deutschen Sozialdemokratie, S. 277f.

${ }^{799}$ Vgl. Langkau-Alex, Ursula: Deutsche Volksfront 1932-1939, Bd. 1, S. 133.

${ }^{800}$ Vgl. ebd., S. 134.

${ }^{801}$ Vgl. ebd.
} 
eingepflanzt worden war $^{802}$, war auch nach der Machtübernahme der Nationalsozialisten weiterhin prägend für die Politik der Arbeiterparteien und ihrer Vertreter im Exil. ${ }^{803}$ Willy Brandt, der damals als Anhänger der SAP agierte und der die schweren Zerwürfnisse der Exildeutschen selbst erfahren hatte, musste in seinen Memoiren leidlich konstatieren: „Man hätte ironisch feststellen können, das Exil sei eine Fortsetzung von Weimar mit anderen Mitteln.“ ${ }^{\text {804 }}$

Doch ging es der Gruppe um Marck nicht um ein Kampfkartell mit den Kommunisten, sondern vielmehr um das Schaffen einer Handlungsgrundlage gegen den Faschismus zusammen mit der Auslandszentrale der SAP, folglich jener Partei, an die in Breslau nicht ohne die Jungsozialisten und die guten Freunde Siegfried Marcks, Ernst Eckstein und Fritz Sternberg zu denken gewesen war. ${ }^{805}$ Obgleich es der Gruppe um Marck, die ohne nennenswerte Verbindung ins Reich versuchte, ihr politisches Gewicht dadurch $\mathrm{zu}$ erhöhen, dass sie an die Kartell-Idee der deutschsprachigen Sozialistischen Gruppen anknüpfte, nicht gelang, zusammen mit der KPD zu operieren, so klappte doch wenigstens der Schritt zur Bildung eines „Kampfkartells“ gemeinsam mit der Auslandszentrale der SAP, die knapp 40 Mitglieder besaß. ${ }^{806}$ Gemeinschaftlich versuchte man nun, die Prinzipien und die Organisation einer revolutionär-sozialistischen Partei zu erarbeiten, welche die proletarische Einheit verwirklichen sollte. Als Grundlage diente ein revolutionärer Marxismus. ${ }^{807}$

Gemeinschaftlich versuchte man nun, die Prinzipien und die Organisation einer revolutionär-sozialistischen Partei $\mathrm{zu}$ erarbeiten, welche die proletarische Einheit verwirklichen sollte. Als Grundlage diente ein revolutionärer Marxismus. ${ }^{808}$

Auch wenn die Mitglieder beider Gruppen den Kartellvertrag billigten, scheiterte - wenig verwunderlich - der Versuch, eine revolutionär-sozialistische

\footnotetext{
${ }^{802}$ Vgl. zur Weimarer Sozialdemokratie insbesondere Winkler, Heinrich August: Der Weg in die Katastrophe. Arbeiter und Arbeiterbewegung in der Weimarer Republik 1930 bis 1933, Berlin und Bonn 1987.

${ }^{803}$ Vgl. Gmeiner, Jens/Schulz, Markus: Deutsche Volksfront ohne Volk. Manifeste des Widerstandes, in: Lorenz, Robert/Klatt, Johanna (Hrsg.): Politische Manifeste, Göttingen 2011, S. 169-198.

${ }^{804}$ Brandt, Willy: Links und frei. Mein Weg 1930-1950, Hamburg 1982, S. 141.

${ }^{805}$ Zur SAP(D) Auslandszentrale im Pariser Exil siehe: Bremer, Jörg: Die Sozialistische Arbeiterpartei Deutschlands (SAP): Untergrund und Exil 1933-1945, Frankfurt am Main 1978, S. 113-116; Vorholt, Udo: Die Sowjetunion im Urteil des sozialdemokratischen Exils 1933-1945. Eine Studie des Exilparteivorstandes der SPD, des Internationalen Sozialistischen Kampfbundes, der Sozialistischen Arbeiterpartei und der Gruppe Neu Beginnen, Frankfurt am Main 1991, S. 160-180

${ }^{806} \mathrm{Vgl}$. Ein wegweisendes Beispiel. Ein Schritt zur revolutionären Einheit, in: Neue Front 2 (1934), 13, in: Die Presse der Sozialistischen Arbeiterpartei Deutschlands im Exil 1933-1945, herausgegeben von der Deutschen Bibliothek Frankfurt am Main, Sammlung Exilliteratur, München 1981, S. 343.

${ }^{807}$ Vgl. Abschrift des Kartellvertrages zwischen den Pariser Gruppen der SPD und der SAP von NeuBeginnen, IISG, zitiert, in: Langkau-Alex, Ursula: Deutsche Volksfront 1932-1939, Bd. 1, S. 135. ${ }^{808} \mathrm{Vgl}$. ebd.
} 
Einheitspartei ,jenseits der reformistischen SPD und der stalinisierten KPD zu bilden.“ Es gelang nicht einmal, ein gemeinsames Publikationsorgan zu etablieren, wie es der Kartellvertrag eigentlich vorsah. ${ }^{809}$ Der Grund hierfür lag in der Pariser Gruppe der SPD, die trotz ihres Richtlinienprogramms nicht geschlossen agierte. $\mathrm{Zu}$ sehr orientierten sich die parteivorstandsoppositionellen Mitglieder der Pariser SPD in andere Richtungen, pendelten zwischen Sozialdemokratie, Neu-Beginnen oder den Revolutionären Sozialisten, was für einen Parteibildungsprozess hinderlich war. Siegfried Marck konnte die Gruppe nicht zusammenhalten und wurde Ende 1934, nach neunmonatiger Tätigkeit als Vorsitzender, ersetzt. Er war dem Anspruch der Gruppe nicht gewachsen und befand sich wieder in der Zwangslage, zwischen den einzelnen Kombattanten zu stehen, die er doch eigentlich gern vereint gesehen hätte. Der Pariser Ortsgruppe fehlte nun eine Führungspersönlichkeit, die diesen äußerst heterogenen Zusammenschluss beisammen hielt. Für die Ortsgruppe der Pariser Sozialdemokratie bedeutete dies den Niedergang - sie schlief danach ein, „wer noch handelte, tat dies allein. “810

\footnotetext{
${ }^{809}$ Vgl. ebd., S. 136.
}

${ }^{810}$ Ebd., S. 136ff. 


\section{Tätigkeiten in der Volksfront}

Marck gesellte sich nun zu dem Kreis, der in Paris Mitte der dreißiger Jahre versuchte, eine deutsche Volksfront ${ }^{811}$ ins Leben zu rufen. Etwas vereinfacht kann die Volksfront als ein Bund all derer verstanden werden, die entschlossen waren, sich für Freiheit und Wohlstand des deutschen Volkes einzusetzen. Auf sozialdemokratischer Seite waren das vor allem Rudolf Breitscheid, Max Braun, Toni Sender, Albrecht Grzesinski, Siegfried Aufhäuser, Alexander Schifrin und Siegfried Marck. Unter den kommunistischen Vertretern fanden sich Persönlichkeiten wie Walter Ulbricht, Herbert Wehner oder Willi Münzenberg. Auch Mitglieder der SAP waren daran beteiligt: Willy Brandt, Walter Fabian und Jacob Walcher. Eigen war dem Zusammenschluss die Angehörigkeit vieler Intellektueller und scheinbar unabhängiger Persönlichkeiten wie Lion Feuchtwanger, Arno Zweig, Heinrich Mann, Ernst Toller, Ernst Bloch, Max Seydewitz, Anna Siemsen oder Kurt Rosenfeld. $^{812}$

Orientierte sich die deutsche Volksfront hier längst an der französischen front populaire $^{813}$, die unter Léon Blum zeigte, dass ein Zusammengehen von linken Parteien möglich war, schien dieses im französischen Exil für die unterschiedlichen Auslandsleitungen der einst so großen deutschen Bewegung geradezu unmöglich. Auch hier waren die Gräben zwischen den beiden Arbeiterparteien und den anliegenden Organisationen $\mathrm{zu}$ tief, die Sozialfaschismusthese, folglich das Verständnis der Sozialdemokraten als linkem Flügel des Faschismus, war noch deutlich in den Köpfen der Handlungsführer und in deren Umfeld implementiert. ${ }^{814}$ Zwar war man sich im Exil einig, wenn es um die Formulierung des gemeinsamen Gegners ging, doch fehlte eine gemeinsame Politik. In seiner Eigenschaft als Philosoph wies Siegfried Marck früh auf das Grundproblem der Exilanten, auf deren Sammlung und deren Philosophie hin und forderte, dass die Philosophie „nach

${ }^{811}$ Zum Begriff der Volksfront und seiner Genese siehe insbesondere: Langkau-Alex, Ursula: Zur Genesis des Begriffes „Volksfront“ 1932 bis 1934/35, in: Haupt, Heinz-Gerhard (Hrsg.): Soziale Bewegungen. Geschichte und Theorie. Jahrbuch 1: Arbeiterbewegung und Faschismus, Frankfurt am Main 1986, S. 82-105.

${ }^{812}$ Diese Namen sind exemplarisch zu sehen. Vgl. Osterroth, Franz/Schiller, Dieter: Chronik der deutschen Sozialdemokratie, Bd. II. Vom Beginn der Weimarer Republik bis zum Ende des Zweiten Weltkrieges, Bonn 1980.

${ }^{813}$ Vgl. Langkau-Alex, Ursula: Versuch und Scheitern der deutschen Volksfront, in: Exil H. 2 (1986), S. 19-37, hier S. 21.

${ }^{814}$ Zur Strategie der KPD vor dem VII. Weltkongress siehe: Weber, Hermann: Die Ambivalenz der kommunistischen Widerstandsstrategie bis zur „Brüsseler“ Parteikonferenz, in: Schmädeke, Jürgen/Steinbach, Peter (Hrsg.): Der Widerstand gegen den Nationalsozialismus. Die deutsche Gesellschaft und der Widerstand gegen Hitler, München 1985, S. 73-85. Zur Strategie der SPD siehe: Mühlen, Patrick von zur: Die SPD zwischen Anpassung und Widerstand, in: Ebd., S. 86-98. 
Orientierung für die Zukunft" suchen und sich nicht in die Metaphysik flüchten dürfe. ${ }^{815}$ Doch Realpolitik sah anders aus, auch im Exil.

Siegfried Marck engagierte sich nach dem Zerfall der Pariser Ortsgruppe in dem von Radikalsozialisten wie Pierre Cot oder konservativen Pazifisten wie Lord Robert Cecil seit 1935 geführten Rassemblement Universel pour la Paix (RUP), der Weltbewegung für den Frieden, und kämpfte dort für die „Wiedererringung der demokratischen Freiheiten“ ${ }^{\text {(616 }}$ in Deutschland. Hier traf Marck zum ersten Mal auf Willi Münzenberg ${ }^{817}$, der bei ihm Spuren hinterließ - immerhin versuchte Marck 1940 aus den Vereinigten Staaten heraus, seine Kontakte zu American Guild zu nutzen, um Münzenberg die Flucht in die USA zu ermöglichen. Marck stellte bewundernd fest, dass: „Neunzehntel von allem, was die politische deutsche Emigration in Frankreich an Aktivität entfaltete“ von Münzenberg ausging. ${ }^{818}$ So verwundert es auch nicht, dass Marck Münzenberg gern als Gastredner an der Freien Deutschen Hochschule sah. ${ }^{819}$ Dass Münzenberg zum Zeitpunkt des Briefes bereits tot war, war Marck nicht bekannt.

Auch wenn sich Willi Münzenberg noch lebend und im Auftrag von Dimitroff bemühte, das RUP für die Komintern und das Weltkomitee gegen Krieg und Faschismus (WKKF) nutzbar zu machen, versuchte die Bewegung:

„das Odium einer Massenorganisation der Komintern, wie es dem WKKF noch anhing, abzustreifen und als übernationale Organisation auf breiter Grundlage - d.h. von Links bis Konservativ, vom Proletarier bis zum Kapitaleigner, vom Freidenker bis zum hohen Kleriker - den Völkerbund weltweit durch Propaganda und Agitation in seiner Funktion als Wahrer und Organisator des Friedens gleichsam ,von unten` zu stärken. “620

Viele Emigranten aus Deutschland hatten als Einzelpersonen seit der Gründung des RUP ihren Anschluss an selbiges erklärt: Neben dem antagonistischen Brüderpaar Heinrich und Thomas Mann waren es unter anderem Friedrich Stampfer, ein ehemaliges Mitglied der SPD Programmkommission, der marxistische Philosoph

\footnotetext{
${ }^{815}$ Vgl. Marck, Siegfried: Sozialismus und Philosophie, in: Neuer Vorwärts, 16.09.1934. Weitere Ausführungen bei Marcus Llanque: Siegfried Marck und der Neuhumanismus als französischdeutsche Sammlungsbewegung, S. 279f.

${ }^{816}$ AdsD, Emigration Sopade, 197: Memorandum, vorgelegt dem Weltfriedenskongress zu Brüssel von einem Kreis deutscher Friedensfreunde, mit einem Vorwort Heinrich Manns. Kapitel V. S. 3f, in: Langkau-Alex, Ursula: Deutsche Volksfront 1932-1939, Bd. 2, S. 146.

${ }^{817} \mathrm{Zu}$ Willi Münzenbergs bedeutender Rolle im französischen Exil siehe: Gross, Babette: Willi Münzenberg: eine politische Biographie, Stuttgart 1967; Wessel, Harald: Münzenbergs Ende: ein deutscher Kommunist im Widerstand gegen Hitler und Stalin: die Jahre 1933-1940, Berlin 1991; Schulz, Markus: Der Konsensmacher, in: Spiegel-Online, 01.12.2009.

${ }^{818}$ Marck an American Guild for German Culture and Freedom, 26.08.1940, Exilarchiv der Deutschen Nationalbibliothek, American Guild - EB 70/117.

819 Marck an Münzenberg, 22.01.1938, Akademie der Künste, Heinrich-Mann-Archiv, TNL IV (nachfolgend nur noch AdK, NL HM), Sign. 2130.

${ }^{820}$ Langkau-Alex, Ursula: Deutsche Volksfront 1932-1939, Bd. 2, S. 142.
} 
Ernst Bloch oder gesellschaftskritische Schriftsteller wie Alfred Döblin, die sich zum RUP als Teil der Weltfriedensbewegung zugehörig sahen. ${ }^{821}$ Doch ähnlich wie im WKKF war auch bald im RUP die ideologische Linie umstritten: Ihre Bedeutung für die späteren Volksfrontbemühungen kann ab 1937 als gering angesehen werden. ${ }^{822}$

Mit dem VII. Weltkongress der Komintern änderten sich die Konstellationen, auch im französischen Exil. Hier erkannte die Komintern unter der Führung von Georgi Dimitroff eigene Fehler im Kampf gegen Hitler an und wich von der zuvor unüberbrückbaren Sozialfaschismusthese ab. Von nun an wandelte sich der Vorwurf des Sozialfaschismus in Folge der strategischen und organisatorischen Schwäche der Kommunisten zu einem Bündnisangebot an die Sozialdemokraten und bürgerlichdemokratischen Kräfte in den jeweiligen Ländern. Damit versuchte die Komintern einen ersten Versuch zu verstetigen, der im Frühjahr 1934 in Paris geglückt war: Dort entwickelte sich im Zuge einer Massendemonstration gegen die rechtsextreme und nationalistische Action Française ${ }^{823}$ eine Zusammenarbeit zwischen den kommunistischen und den sozialistischen Organisationen, die letztlich in einer Einheitsfront mündete. ${ }^{824}$ Erst darauf aufbauend konnte sich im Pariser Exil, im Hotel Lutetia, unter der Leitung Heinrich Manns und unter Mitwirkung Willi Münzenbergs, ein Ausschuss zur Vorbereitung einer deutschen Volksfront treffen, dem Mitglieder aller widerständischen Parteien angehörten. Dabei muss betont werden, dass es die Kommunisten waren, wenngleich anfangs nur wenige, die von ihrer Linie abrückten und eben nicht die Sozialdemokraten oder die Anhänger bürgerlicher Parteien. ${ }^{825}$

Willi Münzenberg war, wie bereits angedeutet, einer der politischen Multiplikatoren im Paris jener Jahre. Er versuchte seit Mitte der 1930er Jahre, den Volksfrontgedanken im französischen Exil zu etablieren. Gemeinsam mit Heinrich Mann konnte er am 02. Februar 1936 im Hotel Lutetia in Paris ein erstes Treffen verschiedener politischer Gruppen organisieren, an dem auch Marck teilnahm. Aus diesem Treffen resultierte ein Amnestie-Appell, der auf die Gefangenschaften von

\footnotetext{
${ }^{821}$ Vgl. Deutsche Volks-Zeitung, 10.05.1936.

${ }^{822}$ Vgl. Langkau-Alex, Ursula: Deutsche Volksfront 1932-1939, Bd. 2, S. 153.

823 Zur Genese der Action Française 1899-1944: Nolte, Ernst: Die Action Francaise, in: Vierteljahreshefte für Zeitgeschichte, Jg. 9 (1961), Heft 2, S. 124-164, hier S. 153ff.

${ }^{824}$ Langkau-Alex, Ursula: Fritz Lieb und die Volksfront-Politik. Der Weg zum „Bund freiheitlicher Sozialisten“, in: Karnetzki, Manfred/Rese, Karl-Johann (Hrsg.): Fritz Lieb. Ein europäischer Christ und Sozialist, Berlin 1992, S. 105-147, hier S. 105.

${ }^{825}$ Ebd., S. 106.
} 
Ernst Thälmann, Carlo Mierendorff und Carl von Ossietzky aufmerksam machte und „die Einleitung einer grossen internationalen Amnestiebewegung“, mehr noch eine Sammlung aller „Gegner des gegenwärtigen deutschen Regimes“ forcieren sollte:

„Verhindert das Schlimmste! Rechtschaffene Menschen der ganzen Welt, denkt daran, dass Euresgleichen im Dritten Reich verfolgt werden, schrecklich leiden und grausam sterben müssen [...] Fordert die Amnestie! ${ }^{\circ 826}$

Dies war ein Versuch der Volksfront, in Manifesten und Aufrufen gegen das NSRegime zu wirken - weitere folgten. Die Volksfront von Lutetia versuchte stets, aus Frankreich heraus eine Gegenöffentlichkeit $\mathrm{zu}$ schaffen, indem sie in ihren Manifesten auf die Missstände im deutschen Reich und auf die aggressive Außenpolitik Hitlers aufmerksam machte und zugleich zu einem vereinten Kampf gegen Hitler-Deutschland aufrief. Auch Siegfried Marck begrüßte diesen doch sehr heterogenen Kreis und unterzeichnete dessen Aufrufe. ${ }^{827}$ Dennoch verdeutlichte Marck in einem Schreiben an Leopold Schwarzschild, dass er sich der Volksfront „lediglich wegen der Bejahung des Gedanken als solchem“ angeschlossen habe, dessen ungeachtet habe er ,innere Reservate“ gegen diesen Kreis, die er jenem auch kenntlich machte. ${ }^{828}$ Marcks Bedenken sind nicht überliefert, doch wird seine Erfahrung der Zusammenarbeit mit den Kommunisten als Leiter der SPD-Ortsgruppe eine Rolle gespielt haben. Marck wurde, nachdem er den Pariser SPD-Vorsitz abgegeben hatte, in den Aufrufen zunächst nicht mehr als der Sozialdemokratie zugehörig betrachtet, sondern neben Heinrich Mann, Leopold Schwarzschild, Ernst Toller, Fritz Lieb und anderen als „Vertreter des Freiheitlichen Bürgertums“ genannt. ${ }^{829}$ Im Aufruf an das deutsche Volk, dem programmatischen Höhepunkt der Volksfront von Lutetia, änderte sich dies wieder, nun wurde der Professor der Philosophie wieder der Sozialdemokratie zugeordnet. Vertreter des freiheitlichen Bürgertums, die einen fehlenden Unterbau vermissten, wurden nicht mehr gesondert, sondern ihrer Parteiherkunft nach aufgeführt. ${ }^{830}$ Marck befürwortete die Aktivitäten der Volksfront mehr und mehr - besonders lobend sprach er sich gegenüber der Tatsache aus, dass im Exil Juden und Nichtjuden gemeinsam gegen Hitler zu

\footnotetext{
${ }^{826}$ Aufruf unter anderem abgedruckt in: Pariser Tageszeitung, 28.02.1936.

${ }^{827}$ Für ihn war die Propaganda ein sehr wichtiges Element um „Kulturgüter ins Land“ zu tragen, vgl. Marck, Siegfried: Die Emigration als psychologisches Problem, in: Ebd., 23.07.1937; Ders.: Die Zukunft der Freiheit, in: Ebd., 12.11.1937; Ders.: Kulturphilosophie und Propaganda, in: Ebd., 05.07.1937.

${ }^{828}$ Marck an Schwarzschild, 30.12.1936, BArch, R 8046 Neues Tagebuch Paris, 246.

829 Vgl. Eine Erklärung der deutschen Opposition zur Rheinlandbesetzung und zu Hitlers Kriegspolitik, in: Pariser Tageblatt, 21.05.1936.

${ }^{830}$ Vgl. ebd., 12.04.1937.
} 
kämpfen versuchten ${ }^{831}$ - wirkte an diesen jedoch eher am Rande mit. Dass es vor allem Intellektuelle waren, dazu noch jüdische mit journalistischer Tätigkeit, die sich für die Bildung einer Volksfront und damit für die Etablierung einer Gegenöffentlichkeit einsetzten, wurde zum Teil auch aus den eigenen Reihen stark kritisiert. Immerhin sei der Antisemitismus in Deutschland deutlich auch fernab vom Nationalsozialismus zu spüren. Und welchen Sinn sollte es haben, eine Gegenöffentlichkeit zu etablieren, die ein mit Antisemitismus sozialisiertes Volk erreichen wollte? Wilhelm Sollmann äußerte seine Bedenken deutlich: In einem Brief an Paul Hertz schrieb er, dass Georg Bernhard, als Anhänger des freiheitlichen Bürgertums, zwar „allerlei Qualitäten“ hätte, ,aber sich gerade [nicht] gut als Sturmbock gegen Hitler" mache. ${ }^{832}$ Ähnliche Worte waren auch von Albert Grzesinski zu vernehmen. ${ }^{833}$

Den Manifesten und Aufrufen hingegen mangelte es an Multiplikatoren, die in Deutschland eine breitere Basis hätten schaffen können. Das Maß an Gemeinsamkeit war spätestens nach den Moskauer Prozessen verbraucht. Die „Stalinisierung“ der KPD war nun nicht mehr von der Hand zu weisen, das Verhandlungsklima sehr angespannt. Letztlich hatte man sich innerhalb eines Jahres durch vielerlei programmatische und organisatorische Fragen selbst den Wind aus den Segeln genommen und musste nun doch eine deutliche Differenz in der AntiHitler-Politik konstatieren. Während Siegfried Marck an die Weiterführung der Volksfront-Sache glaubte, erwiderte ihm Leopold Schwarzschild, dass „die sogenannte Volksfront-Sache durch die Moskauer Prozesse moralisch zerstört ist" und sah keine Möglichkeit diese Front mit „Parteikommunisten“ aufrechtzuerhalten, wenngleich er ein militärisches Zusammengehen zwischen Frankreich und Russland gegen Nazi-Deutschland begrüßte. ${ }^{834}$ Schwarzschilds Protest an den Moskauer Prozessen blieben nicht ohne Folgen. Nachdem er vom Schutzverband deutscher Schriftsteller (SDS) aufgrund dieser Kritik an den Prozessen ausgeschlossen wurde, gründete er gemeinsam mit Hans Sahl den Bund Freie Presse und Literatur (BFPL), der sich gegen jede totalitäre Form der Bevormundung von Schriftstellern wandte. ${ }^{835}$

\footnotetext{
${ }^{831}$ Vgl. Marck, Siegfried: Das herausgeforderte Abendland, in: Ebd., 04.11.1938.

${ }^{832}$ Sollmann an Hertz, 20.01.1936, IISG, NL Hertz, S. 18, zitiert in: Langkau-Alex, Ursula: Deutsche Volksfront, Bd. 1, S. 326.

${ }^{833}$ Ebd.

${ }^{834}$ Schwarzschild an Marck, 26.02.1937, BArch, R 8046 Neues Tagebuch Paris, 250.

${ }^{835}$ Vgl. Papcke, Sven: Deutsche Soziologie im Exil. Gegenwartsdiagnose und Epochenkritik 19331945, Frankfurt am Main 1993, S. 13-37, hier S. 26; Schiller, Dieter: „In bewusstem Gegensatz zu der kommunistisch-ullsteinschen Bande“. Schwarzschilds Bund Freie Presse und Literatur in Paris, in:
} 
Marck hielt zu dieser Zeit immer weiter am Volksfrontgedanken fest. Mit Schwarzschild, dem Herausgeber des Neuen Tagebuchs, für das er auch schrieb, geriet er nun mehr und mehr aneinander. So etwa als ein verabredeter Artikel über ein Buch von Hugo Marx über das Schicksal der deutschen Juden in der Krise erschien, der darin forderte, „Palästina [...] von den Juden erobern zu lassen, andernfalls das Ende des Weltjudentums gekommen sei. “836 Marck erwiderte darauf, dass er sich selbst zwar nicht als Zionisten begreife und „noch weniger Sympathie für die Revisionisten habe“, ihm jedoch im Hinblick auf die Ereignisse des vergangenen Jahres [Marck wird hier auf den Arabischen Aufstand von 1936 anspielen] der Gedanke, „dass die Juden den von ihnen bebauten Boden auch mit der Waffe in der Hand wenigstens verteidigen müssen, nicht so ,gespenstisch grotesk ““ findet wie Schwarzschild. ${ }^{837}$

Dennoch schrieb Marck vorerst weiter für das Neue Tagebuch, fragte bei Schwarzschild an, ob er etwa einen Nachruf auf Max Adler, seinen guten Bekannten aus Breslauer Jahren, schreiben dürfe. ${ }^{838}$ Gleichwohl bemerkte er, dass in jenem Blatt „der Zweifrontenkrieg gegen den Faschismus und Moskau immer mehr zur Spezialität“" wurde und ihm zufolge „dieser Kampf in eine Sackgasse führt“. Marck brach, als er sich im Sommer 1937 in der Schweiz befand, vollends mit Schwarzschild und dem Neuen Tagebuch: „Auch dem glänzendsten Schriftsteller und tapfersten Moralisten aber kann man nicht in eine politische Sackgasse folgen. “ ${ }^{\text {(839 }}$, so Marck. Mit seinem Bruch verteidigte Marck den Volksfrontgedanken, auch nach den Moskauer Prozessen. Mehr noch warf er in seinem Selbstverständnis als einer der ihren einigen Intellektuellen vor, diesen Gedanken aufgegeben zu haben, während die Parteikommunisten trotz der „erschütternden Ereignisse an der Volksfront-Politik“ festhielten. ${ }^{840}$ Zwar erkannte Marck die Schrecknisse der Prozesse an und setzte diesen Werte wie „Freiheit, Menschenrecht, Gesetz und Humanität“" entgegen, die man niemals ungestraft auf die Dauer außer Kraft setzten könne, ,aber jede Revolution, jeder Krieg müsse vorübergehend mit einer solchen

Anne Saint Sauveur-Henn (Hrsg.): Fluchtziel Paris. Die deutschsprachige Emigration 1933-1940. Metropol, Berlin 2002, S. 215-229.

${ }^{836}$ Vgl. Schwarzschild an Marck, 22.04.1937, BArch, R 8046 Neues Tagebuch Paris, 254.

${ }^{837}$ Vgl. Marck an Schwarzschild, 25.04.1937, BArch, R 8046 Neues Tagebuch Paris, 255.

${ }^{838}$ Vgl. Marck an Schwarzschild, 30.06.1937, BArch, R 8046 Neues Tagebuch Paris, 258.

839 Marck an Schwarzschild, 31.08.1937, BArch, R 8046 Neues Tagebuch Paris, 261. Marck bat Schwarzschild, diesen Brief im Neuen Tagebuch zu veröffentlichen. Dieser kam diesem Wunsch jedoch nicht nach, wie das Antwortschreiben belegt, siehe: Schwarzschild an Marck, 06.09.1937, BArch, R 8046 Neues Tagebuch Paris, 263.

${ }^{840}$ Marck an Schwarzschild, 31.08.1937. 
Möglichkeit rechnen.“ Marck bezog sich dabei auf das Notwehrrecht, „in dem eigentlich seit fünfzehn Jahren jeder Demokrat dem Faschismus gegenübersteht. “‘841

Sowjet-Russland begriff Marck damals im „ruhigen Aufbau eines Wohlfahrtstaates“, der „fast jede Minute seiner bisherigen Existenz von den fanatischen Hassern seines der Umwelt entgegengesetzten politischen und wirtschaftlichen Systems bedroht war.“ Mehr noch war die Losung der Volksfront damals Antifaschismus und der Faschismus ,hat auf dem Planeten solche Dimensionen angenommen, dass er ohne Mitwirkung Sowjet-Russlands und der Kommunistischen Partei in allen Ländern nicht mehr geschlagen werden könne.“ ${ }^{\text {(42 }}$ Schwarzschild sah dies natürlich anders, hatte er doch den Geschehnissen in Russland „widerwärtigen Ausnahmecharakter“ attestiert, die in Russland auch noch Beifall fänden. ${ }^{843}$

Ähnlich wie bereits in Breslau war Siegfried Marck in Frankreich ein gern gehörter Redner. Seine Vorträge wurden nicht selten in eindringlichen Exil-Medien wie der Pariser Tageszeitung ${ }^{844}$ angekündigt. Auch wenn sie sicherlich nicht mehr in einer so hohen Intensität wie in den Breslauer Jahren vorkamen, so mangelte es ihnen nicht an Schärfe: Auf einem Vortrag in der Liga der Menschenrechte resümierte er die einjährige Herrschaft der NSDAP und appellierte an das ,ethische Weltgewissen“, indem er versuchte, den Faschismus als ,endgültigen Sturz des bürgerlichen Liberalismus“ zu deuten. ${ }^{845}$ Dieser Anti-Hitler-Vortrag hatte Folgen für Marck: Er wurde darauf von den Nationalsozialisten individuell ausgebürgert und gehörte damit zu den ersten hundert Persönlichkeiten Deutschlands, die das gleiche Schicksal teilten. ${ }^{846}$

Daneben gestaltete sich dieser Vortragsabend zu einem Abschiedsabend für Emil Julius Gumbel, den Präsidenten der Liga für Menschenrechte, mit dem Marck später aneinandergeraten sollte. Er würdigte dessen Verdienste für diese Institution, die Gumbel verließ, um in Lyon eine Professur anzutreten und später ${ }^{847}$, wie Marck

\footnotetext{
841 Ebd.

${ }^{842}$ Vgl. ebd.

${ }^{843}$ Schwarzschild an Marck, 06.09.1937. In diesem Zusammenhang muss berücksichtigt werden, dass Schwarzschild beschuldigt wurde, als Gestapo-Agent für Goebbles gearbeitet zu haben und er nur knapp der Exekutierung entgangen war.

${ }^{844}$ Das Pariser Tageblatt unter dem Chefredakteur Georg Bernhard existierte nach 1936 als Pariser Tageszeitung weiter, vgl. Maas, Liselotte: Handbuch der deutschen Exilpresse: 1933-1945, München 1976.

${ }^{845}$ Vgl. Pariser Tageblatt, 24.01.1934.

${ }^{846}$ Marck an Grimme, 13.10.1946, NL AG.

${ }^{847}$ Vgl. ebd.
} 
auch, in die USA zu emigrieren. Ebenfalls 1934, höchst wahrscheinlich bei derselben Rede, die Marck im Zuge dieser Massenprotestversammlung zur ersten Wiederkehr der nationalsozialistischen Machtergreifung in Paris hielt, wurde sein späterer Freund und Kollege im amerikanischen Exil, Helmut Hirsch, auf den redebegabten Siegfried Marck aufmerksam. ${ }^{848}$ Aus diesem Treffen entwickelte sich eine Freundschaft im amerikanischen Exil, die nicht ohne Schwierigkeiten und Unstimmigkeiten zwischen den beiden Kombattanten, insbesondere wenn es um Fragen um ein Nachkriegsdeutschland gehen sollte, auskam.

Siegfried Marcks Redegewandtheit sorgte dafür, dass er auf der Trauerfeier des ermordeten ehemaligen Führers des Hamburger Roten Frontkämpferbundes Edgar André, sprechen durfte. ${ }^{849}$ André wurde am 04. November 1936, trotz allen Engagements für eine Amnestie der politischen Gefangenen im nationalsozialistischen Deutschland, hingerichtet. Jedoch sorgte dessen Ermordung dafür, ,alle Auseinandersetzungen um die Zusammenarbeit mit den Kommunisten, um die Vorgänge in Moskau und das spanische Problem von Krieg und Revolution in den Hintergrund zu schieben“. 850

Auch in der Notgemeinschaft der deutschen Wissenschaft, Kunst und Literatur versuchte Marck auf deren Eröffnungsfeier, die „scheinbare Niederlage des Liberalismus geschichtsphilosophisch aus der Entwicklung im Hegel'schen Sinne“ $\mathrm{zu}$ erklären. Er versuchte in diesem Vortrag klarzustellen, dass ein „lebendiger Liberalismus“ trotz der Radikalismen rechts und links nicht tot sei, sondern die „Idee der lebendigen Freiheit" fortbestehe und nicht zuletzt Programm der „Notgemeinschaft“ bilde. ${ }^{851}$ Im Zusammenhang mit der von Emigranten getragenen Kulturarbeit entstanden Einrichtungen wie die Deutsche Volkshochschule Paris oder die Notgemeinschaft der deutschen Wissenschaft, Kunst und Literatur nicht nur in Paris, sondern auch in Kopenhagen, Stockholm, Shanghai und London. Deren angekündigte Programme konnten wahrscheinlich nicht immer realisiert werden. Die im Juli 1934 gegründete „Notgemeinschaft“ verfolgte, unter Ausschluss der Politik, die „Förderung geistiger Menschen“, die in Deutschland keine Arbeitsmöglichkeiten mehr besaßen. Der kommunistische Wirtschaftswissenschaftler und ehemalige Leiter

\footnotetext{
${ }^{848}$ Vgl. Leserbrief von Helmut Hirsch, Frankfurter Allgemeine Zeitung, 17.03.2007. Dieser Leserbrief sollte der Ergänzung des Artikels von Franz Walter in der FAZ zu Siegfried Marck mit dem Titel: „Kritische Dialektik“ vom 02.03.2007 dienen.

${ }^{849}$ Vgl. Pariser Tageblatt, 14.11.1936. Zu Edgar André siehe: Kraushaar, Luise: Deutsche Widerstandskämpfer 1933 bis 1945, Bd. 1, Berlin 1970, S. $51 \mathrm{ff}$.

${ }^{850}$ Langkau-Alex: Deutsche Volksfront, Bd. 2, S. 230.

${ }^{851}$ Vgl. Pariser Tageblatt, 26.12.1934. Zur Geschichte und Programmatik der „Notgemeinschaft“ siehe: Ebd., 02.09.1934, 08.10.1934, 13.11.1934, 09.01.1935, 13.01.1935.
} 
der Marxistischen Arbeiterschule in Berlin, Johann Lorenz Schmidt, begründete 1935 in Paris eine Deutsche Volkshochschule, die mit der Freien deutschen Hochschule vereint wurde. Dieser ging es um die Vermittlung von Fachwissen in Vorlesungen und Übungen. ${ }^{852}$ Auch hier war Marck ein gern gesehener Redner, das kannte er aus Breslau. Neben Vorträgen über „die Lage der Wissenschaft im Dritten Reich“, die für ihn durch „faschistische Ungeistigkeit“ geprägt war ${ }^{853}$, ging es ihm auch um die ,geistige Geschichte Frankreichs“ und die französische Philosophie der Gegenwart oder die Philosophie des Nationalsozialismus. ${ }^{854}$

Scheinbar versuchte Marck auch Thomas Mann für einen Vortrag nach Paris zu locken, doch geht aus dem Antwortschreiben Manns hervor, dass dieser bereits für ein Jahr in Princeton zugesagt hatte und er „wegen der Freien Deutschen Hochschule im Augenblick keine Versprechungen machen“ könne. ${ }^{855}$ Hier deutet sich bereits ein engeres Verhältnis zwischen Siegfried Marck und Thomas Mann an, das in den Vereinigten Staaten an Intensität zunahm. Siegfried Marck indes versuchte in der Emigration französischen und deutschen Studenten, während Vorträgen beispielsweise, die Existenz-Philosophie Martin Heideggers, eines seiner wissenschaftlichen Opponenten, und die Philosophie Karl Jaspers zu erklären. ${ }^{856}$ Doch es waren nicht nur Studenten, sondern auch Schriftsteller und Besucher der Deutschen Volkshochschule in Paris, denen er gerne über Neuhumanismus und Marxismus referierte. ${ }^{857}$ Marck bekräftigte auch im französischen Exil seine Arbeit für den Volksbildungsgedanken. Dieser war für Marck nach wie vor notwendig und unter den Vorzeichen des Nationalsozialismus unabdingbar für jegliche Form der Aufklärung und des Widerstandes.

Siegfried Marck war sicherlich enttäuscht über die schleppenden Verhandlungen innerhalb der Volksfront - hatten sich doch bereits viele Literaten aus Enttäuschung

${ }^{852}$ Vgl. Tippelt, Rudolf/Hippel, Aiga von (Hrsg.): Handbuch Erwachsenenbildung/Weiterbildung, Wiesbaden 2010, S. 46ff.

${ }^{853}$ Vgl. Pariser Tageszeitung, 24.03.1937, 08.03.1938.

${ }^{854}$ Vgl. ebd., 08.03.1938, 09.03.1938.

855 Thomas Mann an Marck, 02.06.1938, Original in: Deutsche Bibliothek Frankfurt, Abteilung Exilliteratur 1933-1945 Signatur 70/117, ebenfalls: Thomas-Mann-Archiv in Zürich; Bürgin, Hans: Die Briefe Thomas Manns: Regesten und Register, Bd. II die Briefe von 1934 bis 1943, Frankfurt am Main 1980, S. 213.

${ }^{856}$ Vgl. Pariser Tageszeitung, 13.12.1934; in der Zeitschrift für freie deutsche Forschung vom März 1939 wird dieselbe Veranstaltung nochmals angekündigt - Marck floh jedoch alsbald in die USA und konnte diese Vorlesung nicht halten.

${ }^{857}$ Vgl. ebd., 24.03.1937. Marck hielt vor dem Schutzverband Deutscher Schriftsteller (S.D.S.) auch einen Vortrag über „Thomas Manns politische Sendung“, siehe: Der deutsche Schriftsteller Heft 11 (1938), S. 2. 
von den Volksfrontaktivitäten zurückgezogen - und sprach in diesem Zusammenhang von der „notwendig volksfrontmäßigen Orientierung“ des Neuhumanismus als politischer Philosophie. Bei aller Distanzierung dem Marxismus als Philosophie gegenüber, könnten militante Humanisten von heute nicht wie Liberale von ehemals einen „ideologischen Zweifrontenkrieg“ bejahen. Sowohl der Vortrag als auch die daran anschließende Diskussion spiegeln in sehr charakteristischer Weise die Dialektik, die Marck zu transponieren versuchte, wider, in der Neuhumanismus und Marxismus sich einander annäherten und wieder voneinander entfernten. ${ }^{858}$ Es fällt auf, dass Siegfried Marck in diesen Jahren anderen und neuen Einflüssen ausgesetzt gewesen sein muss. Neuhumanismus, Personalismus oder Liberalismus waren neue Vokabeln seines Wortschatzes.

${ }^{858}$ Vgl. ebd. Zu Marcks Verständnis vom Neuhumanismus insbesondere: Marck, Siegfried: Der Neuhumanismus als politische Philosophie, Zürich 1938; Ders.: Vom romantischen Idealismus zum sozialistischen Neuhumanismus, in: Gumbel, Emil Julius (Hrsg.): Freie Wissenschaft. Ein Sammelbuch aus der deutschen Emigration, Strasbourg 1938, S. 113-124. 


\section{Als Ideengeber des freiheitlichen Bürgertums}

Marcks neuhumanistisches Gedankengut kam nicht von ungefähr. In der zweiten Hälfte der 1930er Jahre gesellte er sich zu einem Kreis französischer Neuhumanisten unter der geistigen Führung Emmanuel Mouniers ${ }^{859}$ und der Zeitschrift Esprit. ${ }^{860}$ In der Zeit zwischen 1934 und 1937 konnte dieser Kreis, der zuvor eigentlich christlich orientiert war, neben den sogenannten Linkskatholiken auch Sozialisten und NeuLiberale in sich vereinen. Es ist schon etwas eigenartig, dass sich Marck diesem Kreis zuwandte, immerhin hatte er zuvor nichts mit französischem Katholizismus zu tun gehabt, besonders nicht als Mensch jüdischen Glaubens. Doch sah er wohl in dem Personalismus Mouniers, der die Stellung des Menschen in der Gemeinschaft betonte, die Möglichkeit, den Brückenschlag zwischen Personalismus und Sozialismus zu vollziehen. ${ }^{861}$ Siegfried Marck gestand sich ein:

„Man muss in dieser Epoche - wenn man nicht restlos verzweifeln will - sozialistischer Humanist sein: das heißt aber, man darf vor lauter Humanismus nicht die sozialistischen Lösungsmöglichkeiten vergessen, und ebenso wenig kann man sich einem dogmatischen Sozialismus verschreiben, der die rettende Renaissance des Humanismus verkennt." 862

Er selbst bezeichnete diesen Kreis als eine Art „humanistische Konzentration““863 oder als ein „humanistisches Manifest, dessen Grundgedanke verschiedenartig gesicherte Elemente zusammenfassen konnte. “864 Seine Intention diesem Kreis beizutreten war nicht minder seiner Bewunderung der starken Stellung Frankreichs innerhalb des „Völkerkreises“ geschuldet. Es war eben jene französische Mentalität, die nicht „ewig unterwegs zu sich selbst“ wie die der Deutschen sei, sondern ihre Erfüllung in sich bereits gefunden habe, die er bewunderte. ${ }^{865}$ Für ihn ergänzten sich eine neuhumanistische Philosophie, die das Eigenrecht der menschlichen Person und die Anerkennung zeitlos gültiger Werte unterstreicht, und eine marxistische Soziologie und Politik wechselseitig. Restlose Einigkeit zwischen Neuhumanismus und Marxismus bestand nach Marck in ihrer kompromisslos antifaschistischen

\footnotetext{
${ }^{859} \mathrm{Zu}$ Mounier: Seeger, Wolfgang: Politik und Person Der Personalismus Emanuel Mounier's als politischer Humanismus, Freiburg 1968.

${ }^{860}$ Vgl. Marck, Siegfried: Personalismus, in: Pariser Tageszeitung, 01.01.1938. Die Zeitschrift Esprit war linkskatholisch orientiert; von Emigrantenseite publizierte dort vor allem Paul Ludwig Landsberg, der ehemalige Bonner Privatdozent der Philosophie, siehe insbesondere: Betz, Albrecht: Exil und Engagement. Deutsche Schriftsteller im Frankreich der dreißiger Jahre, München 1986, S. 133ff, $246 \mathrm{ff}$.

${ }^{861}$ Marcus Llanque: Siegfried Marck, S, 285f.

${ }^{862}$ Marck an Schwarzschild, 31.08.1937.

${ }^{863}$ Vgl. Protokoll der Gründungskonferenz des Bundes freiheitlicher Sozialisten in Dijon am 11. und 12. Dezember zu finden im Nachlass Fritz Lieb, zitiert in: Langkau-Alex, Ursula: Fritz Lieb, S. 135. ${ }^{864}$ Vgl. Marck, Siegfried: Persönlichkeit und Ideologie, in: Pariser Tageszeitung, 04.07.1938. ${ }^{865}$ Vgl. ebd.
} 
Einstellung. ${ }^{866}$ Gleichwohl sah Marck im Personalismus Mouniers auch Gefahren. Während Siegfried Marck stets auf den Rechtsstaat und das Parteiensystem als Instrumente baute, wollte Mounier an diese Stelle ein kirchenähnliches Gebilde treten lassen, das Politiker eher beruft als wählt. ${ }^{867}$ Doch Marck konnte dem Personalismus, den Mounier in seinem personalistischen Manifest ${ }^{868}$ propagierte, eine Menge abgewinnen, bewundernd schrieb er allzu oft in der Pariser Exil-Presse über das, was diesen für ihn ausmachte. ${ }^{869}$ Dessen Sinn sah er in der „wiedergewonnenen Idee der Freiheit“, die sich „positiv“ mit dem Marxismus auseinander setzen müsse. Musterhaft standen für ihn Paul Tillich, Nikolai Berdiajew $^{870}$ oder Thomas Mann als Exponate jenes Typus Mensch, der diese Synthese für ihn bereits vollzogen hatte. ${ }^{871}$ Dies ließ er Thomas Mann auch wissen. In einem Brief mit Neujahrsgrüßen versehen, schrieb Marck:

„Für mich ist Ihr Schaffen ein ständiger Begleiter. Aber diese Einwirkungen gliedern sich gemäß den Jahresringen. [...] Gegenwärtig ist mir die Kontinuität des Unpolitischen mit dem Proskribierten des Dritten Reiches sehr wesentlich. Konservative, liberale, sozialistische Motive - sie müssen alle in den Schmelztiegel eines neuen Humanismus hinein. In einer Hegelschen ,Aufhebung' des Faschismus wird das konservative Motiv eine wesentliche Rolle spielen. “872

Die Hauptfeinde des neuhumanistischen Personalismus waren nach Marck der Faschismus und nicht minder der Sowjetkommunismus, „da sich dort die Machtapparate gegen die Menschen verselbstständigt haben und die Gemeinschaftsansprüche bis zur Knechtung und Vernichtung der Individuen überspannt waren.“" ${ }^{873}$ In einem Brief an Thomas Mann und im Nachgang zu den Ereignissen der ersten Moskauer Prozesswelle stand für ihn Ende 1936 fest, dass:

,in einer Hegelschen ,Aufhebung‘ des Faschismus [...] das konservative Motiv eine wesentliche Rolle spielen [wird]. Vielleicht hat es bei der gegenwärtigen Weltsituation für Deutschland sogar eine größere realpolitische Chance, als das kommunistische sie haben kann. ${ }^{\text {(8874 }}$

\footnotetext{
${ }^{866}$ Vgl. Pariser Tageszeitung, 24.03.1937.

${ }^{867}$ Marck, Siegfried: Neuhumanismus, S. 179. Überhaupt schwankte Mounier nach 1940 stark in seiner politische Strahlkraft, er konnte sowohl als Unterstützer des Vichy-Regimes als auch als prostalinistischer Intellektueller eingruppiert werden, siehe: Judt, Tony: Past Perfect. French Intellectuals, 1944-1945, Berkely 1992. S. 86ff.

${ }^{868}$ Siehe hierzu: Mounier, Emmanuel: Das personalistische Manifest, Paris 1936.

${ }^{869}$ Zudem hatte Marck seine eigene Rubrik in der Pariser Tageszeitung, in der er einen „Überblick über die freien deutschen Zeitschriften“"gab. Besonders ging er stets auf die Zeitschrift Mass und Wert ein, die von Thomas Mann herausgegeben wurde. Vgl. Pariser Tageszeitung, 21.01.1938, 02.04.1938, 23.04.1938.

${ }^{870}$ Berdiajews religiösen Sozialismus sieht er zwar skeptisch, erkennt jedoch sein Streben für den Neu-Humanismus und dessen Engagement in der Arbeiterbewegung an, vgl. Marck, Siegfried: Grundfragen des religiösen Sozialismus, in: Ebd., 06.01.1937.

${ }^{871}$ Vgl. Marck, Siegfried: Was ist Neu-Humanismus?, in: Ebd., 11.11.1936.

${ }^{872}$ Marck an Thomas Mann, 30.12.1936. TMA.

${ }^{873}$ Walter, Franz: Siegfried Marck (1889-1957), S. 274

${ }^{874}$ Marck an Thomas Mann, 30.12.1936, TMA.
} 
Das Menschenbild des personalistischen Neu-Humanismus orientierte sich an einer selbstbestimmten Persönlichkeit, an dem losgelösten geistigen Wesen, „das durch freiwillige Zustimmung in einer Hierarchie der Werte und durch autonome Einordnung in transpersonale Gemeinschaften Selbstbestimmung und Erfüllung sucht. “ ${ }^{\text {(875 }}$ Marck selbst attestierte dem alten Humanismus, dem althergebrachten Liberalismus und überhaupt der gesamten „bürgerlichen Epoche“ den Tod. Es ging ihm um die Schaffung eines „,neuen“ Humanismus, aber:

[...] wie diese [die bürgerliche Epoche] nicht auf Kontinuität mit dem christlichen Mittelalter und wie die christliche Welt nicht auf der Kontinuität mit der Antike verzichten konnte, so wird die nachbürgerliche Zeit den Zusammenhang mit der humanistischen Idee des klassischen Bürgertums zu wahren haben." ${ }^{\circ 76}$

Dieser „neue“ Humanismus müsse aus seiner „Verdeckung durch die kritischen, missverständlichen materialistischen Partien befreit und in den Vordergrund gestellt werden.“677 Faschismus dagegen war für Marck immer konservativ und vulgär zugleich. Mit seinem Rassismus und der Führerideologie besitze er seine eigenen Elemente. ${ }^{878}$ Mit ihm war für Marck die „Dumpfheit““ an die Macht gelangt. Das mit Minderwertigkeitskomplexen bestückte Kleinbürgertum könne dort bestens seine Ressentiments gegen die Kultur und die Zivilisation ausleben. ${ }^{879}$ Ganz im Sinne Karl Mannheims sah er den Faschismus als eine Art „politischen Behaviorismus“, in dem der ,gleichgeschaltete Mensch, der am laufenden Band des faschistischen Kommandos und der faschistischen Propaganda" rein psychologisch funktioniert. ${ }^{880}$ Der Faschismus fußt nach Marck besonders auf konservativen Bedürfnissen: „der Drang zur Dauer, der Sinn für Disziplin und Aufgabe, der Wunsch nach einer Rangordnung“, wobei besonders der Drang zur Dauer, vielmehr „das Bedürfnis“ sich gegen die ,zeitliche Vergänglichkeit“" zu wehren, das entscheidende Motiv sei. ${ }^{881}$ Für Marck war es auch kein Zufall, dass die konservative Ideologie allein in faschistischer, also in entstellter Form in reaktionär-demagogischem Missbrauch, zu politischer Wirksamkeit gelangte: Als reine Reaktion trete der Konservativismus stets in Epochen auf, deren „soziologische Dynamik“ produktive konservative

\footnotetext{
${ }^{875}$ Ebd.

${ }^{876}$ Marck, Siegfried: Politischer Humanismus, in: Das Neue Tagebuch, 18.04.1936.

877 Ders.: Vom romantischen Idealismus zum sozialistischen Neuhumanismus, in: Gumbel, Emil Julius (Hrsg.): Freie Wissenschaft, S. 122. Dieser Band wurde in dem von Willi Münzenberg in Straßburg gegründeten Verlag Sebastian Brant veröffentlicht. Weitere Autoren waren etwa Anna Siemsen, Theordor Geiger, Fritz Lieb, Julius Lips, Carl Misch und Arthur Rosenberg.

${ }^{878}$ Vgl. Marck, Siegfried: Wieder einmal: Prozess Hegel, in: Das Neue Tagebuch, 28.12.1935.

${ }^{879}$ Ders.: Nehumanismus als politische Philosophie, S. 67.

${ }^{880}$ Vgl. Ders.: Rationale Totalität, in: Ebd., 04.04.1936.

${ }^{881}$ Ders.: Die konservativen Bedürfnisse, in: Ebd., 26.12.1936.
} 
Dynamiken ausschließe. ${ }^{882}$ Der Faschismus missbrauche sozusagen den Konservativismus sophistisch und sei eigentlich der „reinste Typus“683 einer hysterischen Aktion auf ausweglos scheinende Nöte. Auch in der Massenarbeitslosigkeit nach der Weltwirtschaftskrise sah Marck eine ökonomisch bedingte Ursache für den Nationalsozialismus. Er argumentierte, dass in der „Ära des Monopolkapitalismus die Wirtschaft in der Krise zu sterben“ schien und dass „das Krebsgeschwür der lang andauernden Massenarbeitslosigkeit mit der Chirurgie der Mobilmachung“" entfernt wurde. ${ }^{884}$

Noch früher als viele andere sah der Philosoph, der den Nationalsozialismus stets als bloße „Anti-Philosophie“ verstand ${ }^{885}$, die Lösung des Problems als eine rein europäische Aufgabe an. Eine „Heilung“ Deutschlands vom Nationalsozialismus könne nur in der Auseinandersetzung mit Europa - nur mit der Schaffung eines Europas - erreicht werden. Immerhin könne Deutschland auch die „europäische Krankheit zum Tode“ werden: Sowohl mit einem Sieg der Nationalsozialisten über Europa wie auch bei einem Sieg Europas und einem daraus resultierenden vernichteten Deutschland müsse Europa mit genau der großen Unruhe leben, die seit 1919, folglich seit dem Ende des Ersten Weltkrieges, auf dem Kontinent existent sei und würde unendlich - auch den Großmächten USA und der Sowjetunion gegenüber - geschwächt. ${ }^{886}$

Ein halbes Jahr später räumte Marck einer dauerhaften europäischen Einigung nach der Überwindung des Hitler-Regimes keinerlei Realisierungschancen ein. Der „Münchener Scheinfrieden“ ${ }^{687}$ sowie der „heilige Egoismus“ der miteinander ringenden imperialistischen Mächte machten für Marck jegliche EuropaKonzeptionen höchst angreifbar. ${ }^{888}$ In diesem Zusammenhang darf nicht übersehen werden, dass nach der Annexion Österreichs, dem Münchener Abkommen, dem Einmarsch deutscher Truppen in die Tschechoslowakei und letztlich mit der „Opferung“ des Sudetenlandes für den Frieden Europas, viele Emigranten den

\footnotetext{
${ }^{882}$ Ebd.

${ }^{883}$ Vgl. Ders.: Schöpferische Mitte?, in: Pariser Tageszeitung, 28.04.1937; Ders.: Über Felix Weltschs Philosophie der schöpferischen Mitte, in: Jüdische Revue Nr. 10 (1937), S. 619-621.

${ }^{884}$ Vgl. Ders.: Zehn Jahre „Tausendjähriges Reich“, in: Neue Volkszeitung, 30.01.1943.

${ }^{885} \mathrm{Zu}$ Marcks Verständnis vom Nationalsozialismus siehe insbesondere: Ders.: Zur Philosophie des Nationalsozialismus, in: Zeitschrift für freie deutsche Forschung, Nr.1 Juli 1938, S. 40-52.

${ }^{886}$ Vgl. Ders.: Deutschland und Europa, in: Pariser Tageszeitung, 07.02.1938.

${ }^{887}$ Das Münchener Abkommen sorgte allgemein bei den Exilanten in Paris für großes Entsetzen, siehe: Schopf, Wolfgang: Pariser Echo in der Krise: Das Münchener Abkommen in der Publizistik des Exils, in: Boyer-Weinmann, M. et al. (Hrsg.): Das Münchener Abkommen und die Intellektuellen. Literatur und Exil in Frankreich zwischen Krise und Krieg, Tübingen 2008, S. 217-226.

${ }^{888}$ Vgl. Marck, Siegfried: Ein gemeinsames Weltbild, in: Die Zukunft, 04.11.1938.
} 
bevorstehenden Krieg vorhersahen. Der von Marck konstatierte „Scheinfrieden“, der letztlich nur die „Kapitulation Großbritanniens und Frankreichs vor Hitler“ bedeute, habe die Kriegsgefahr nur noch erhöht. ${ }^{889}$

Nach dem Scheitern der deutschen Volksfrontbemühungen wollte Marck den Kampf gegen den Nationalsozialismus nicht aufgeben und hielt an dem Gedanken einer Volksfront fest, nur diesmal in einer anderen Form, mit einer anderen Gewichtung.

Heinrich Mann sah dies ähnlich. Für ihn lag ein besonderes Problem der Volksfront darin, dass die Intellektuellen bisher nur als Einzelpersonen und nicht als geschlossene Gruppe in die Verhandlungen gegangen seien. Dem wollte er entgegenwirken und „eine Gruppe oder Vereinigung intellektueller und unabhängiger Anhänger“ in der Volksfront etablieren. Heinrich Mann machte deutlich, dass diese Intellektuellen unabhängig, auch in finanzieller Hinsicht, von einer politischen Partei und frei von Antikommunismus agieren sollten. Besonders letzterer würde ,jeden Befreiungskampf der Deutschen vergeblich machen“, gerade wenn „große Massen der Deutschen, die nach Freiheit verlangen, sich kommunistisch nennen.“ Für Heinrich Mann war die Etablierung der Gruppe der Intellektuellen „die Forderung der Stunde“, da die Deutschen vor allem den „geistigen Antrieb“ benötigten. ${ }^{890}$ Dem konnte Marck nur zustimmen und gründete gemeinsam mit Heinrich Mann, Georg Bernhard, Emil Julius Gumbel und Fritz Lieb, die sich alle bereits aus Zeiten der Volksfrontbewegung kannten, Ende des Jahres 1937 in Dijon den Bund freiheitlicher Sozialisten. Für die Namensgebung war Marck verantwortlich, obgleich andere Vorschläge zur Debatte standen. So hätten Heinrich Mann und Siegfried Marck gern den Namen „liberal-sozialistische Vereinigung“ gewählt ${ }^{891}$, konnten sich jedoch nicht durchsetzen. ${ }^{892}$ Der Name liberal-sozialistische Vereinigung wurde zuerst von Gumbel, später von anderen beanstandet, wie Mann in einem Brief an Marck erläutert. Etwas spöttisch konstatiert er:

„Der Namen liberal-sozialistische Vereinigung ist zuerst von Herrn Gumbel, dann noch von mehreren beanstandet worden, weil das Wort "liberal" dank Hitler und Konsorten in schlechten Ruf gekommen wäre. Nun von dem Wort "Freiheit" ließe sich dasselbe sagen, es

\footnotetext{
${ }^{889}$ Vgl. ebd.

${ }^{890}$ Heinrich Mann an PEN, Zentrum deutschsprachige Autoren im Ausland, 02.09.1937, DNB ExilArchiv, EB 75/177 A.I.2.

${ }^{891}$ Briefe Marck an Heinrich Mann, 05.10.1937, 14.10.1937, AdK, NL HM 2054, 2055.

892 Vgl. Langkau-Alex, Ursula: Deutsche Volksfront 1932-1939, Bd. 2, S. 431. Ein weiterer Namensvorschlag war beispielsweise „Liberal-sozialistischer Intellektuellenbund“. Interessant ist, dass in diesem Zusammenhang auch der Name „Bund Neues Deutschland“ gefallen ist, der jedoch mit dem Überlaufen von Hugo Simon und Hans Siemsen von diesen beansprucht wurde und überführt wurde. Siehe Langkau-Alex, Ursula: Fritz Lieb, S. 134.
} 
Die Entscheidung für die Namensgebung fiel letztlich auf der Gründungsversammlung. Dennoch: Den Initiatoren, insbesondere Heinrich Mann entging nicht, dass es den bürgerlichen Vertretern innerhalb der Volksfront an Schlagkraft mangelte, da diese keine Organisation hinter sich hatten, anders als die Vertreter der politischen Parteien. ${ }^{894}$ Für Marck blieb die Frage, ob die Volksfront überhaupt die Gruppe integrieren könne und wolle, ob sie überhaupt noch über genug „Lebenskraft““ verfüge. ${ }^{895}$ Doch für Heinrich Mann stand fest, dass die Gruppe mit Gumbel, Breitscheid und ihm selbst bereits zum engsten Kern der Volksfront gehörte, es nur darum ginge, Breitscheid zu überzeugen - dafür wollte Mann Willy Münzenberg bitten, von Breitscheid „seine ausdrückliche Zustimmung“ einzuholen. ${ }^{896}$ Mehr noch: „Mir scheint nur eins durchaus geboten, die betonte Einreihung der Gruppe in die Volksfront. Gerade das wird im Lande erwartet. “ ${ }^{\text {897 }}$

Den Vorsitz übernahm Heinrich Mann; Siegfried Marck war vorerst Mitglied des Arbeitsausschusses neben Bernhard, Gumbel und Mann. ${ }^{898}$ Es war wohl die engste Zeit zwischen Heinrich Mann und Siegfried Marck. Bei gemeinsamen Mittagessen der Familie Marck und Heinrich Mann, bei denen die Tochter Siegfrieds und Kläres, Claudia, gemeinsam mit Heinrich am Esstisch spielte, wie es Kläre rückwirkend lebendig beschreibt, werden sie über den Bund diskutiert haben. ${ }^{899}$

Die Prämisse des Bundes war „einen inneren Ausgleich zwischen der Idee der Freiheit und den Zielen des Sozialismus zu schaffen“. Immerhin habe der Faschismus nur siegen können, ,weil er die um die Fahne der Freiheit gescharten Heerhaufen und die Arbeiterbataillone des Sozialismus voneinander trennen und sie einzeln schlagen konnte ${ }^{\text {(900 }}$. Sein Ziel war, unter Erhaltung der Ideen von 1789 ${ }^{901}$, die bürgerliche Komponente im Kampf gegen den Nationalsozialismus innerhalb einer neu erstarkten Volksfront zu kräftigen, denn freilich war in den Gedanken vieler Antifaschisten das Fehlen einer Organisation des Bürgertums auch ein

\footnotetext{
${ }^{893}$ Heinrich Mann an Marck, 23.10.1937, AdK, NL HM 2056.

${ }^{894}$ Langkau-Alex, Ursula: Fritz Lieb, S. 128.

${ }^{895}$ Marck an Heinrich Mann, 14.10.1937.

${ }^{896}$ Heinrich Mann an Marck, 17.10.1937, AdK, NL HM 2055.

${ }^{897}$ Heinrich Mann an Marck, 23.10.1937.

${ }^{898}$ Nachlass Fritz Lieb, Aa 711: Heinrich Mann an Lieb, 19.01.1938, zitiert in: Landkau-Alex, Ursula: Fritz Lieb, S. 135. Später wurden Fritz Lieb aufgenommen sowie Willi Münzenberg, nachdem dieser aus dem ZK der KPD ausgeschlossen wurde. Münzenberg wurde sogar Kassierer des Bundes.

${ }^{899}$ Vgl. Marck, Kläre: Stunden in Frankreich, in: Aufbau, 17.03.1950.

${ }^{900}$ Marck, Siegfried: Freiheitlicher Sozialismus, S. 3.

${ }^{901}$ Ebd., S. 4.
} 
elementarer Grund für das Scheitern der Volksfront gewesen. Viel zu sehr war es ein Kampf zwischen Parteien, Fraktionen und den einzelnen Apparaten gewesen, denen das freiheitliche Bürgertum nichts entgegensetzen konnte, ${ }^{902}$ oder ein „,von tagespolitischer Konstellation bestimmter Zweckverband“'903, dem die Weitsicht fehlte. Dabei ging es um die „Wiederherstellung eines modernen Rechtsstaates mit wirksamen Rechtsgarantien“, um die Etablierung eines Parlamentarismus, getragen von einem starken Staat, „,der eine kräftige Exekutive ermöglichen wird““.904

Den theoretischen und öffentlichkeitswirksamen Rahmen lieferte Marck mit der Schrift Freiheitlicher Sozialismus im Aufrag Heinrich Manns ${ }^{905}$, dem er Proben aus seiner Arbeit über den Neuhumanismus geschickt hatte. ${ }^{906}$ Aus dem Briefwechsel zwischen Heinrich Mann und Siegfried Marck in jenen Jahren geht hervor, dass Heinrich Mann zwar stets an Marcks Schriften über den Neuhumanismus für die zu etablierende Gruppe gedacht hatte, er doch zuerst auf einen Aufsatz, der in der Zeitschrift „Mass und Wert“‘907 erschien, zurückgreifen wollte. Da dieser jedoch eine Sammelpublikation war, folglich keine Namen genannt werden konnten, was bei einer neu zu errichtenden Gruppe aber oft hilfreich ist, griff Heinrich Mann auf Marcks Überlegungen zum Neuhumanismus zurück:

\begin{abstract}
„Andererseits fände auch ich es nützlicher, wenn wir unsere erste Kundgebung selbst zeichnen könnten. Ich habe dafür Ihren Namen gewünscht, längst bevor Sie die Güte hatten, mir Ihre Arbeit über den Neuhumanismus zugänglich zu machen. Bis jetzt glaubte ich Ihnen die Mühe nicht zumuten zu dürfen. Ihr Manuskript zeigt mir, dass es von Ihrer Seite eigentlich nur noch einer redaktionellen Herrichtung bedarf: die Sache selbst ist vorhanden, in Gestalt Ihrer meisterhaften Darstellung. Ich kann es nur vermuten, aber Ihre Erklärung wenn Sie denn Ihr Buch zu einer grundsätzlichen Erklärung zusammenziehen wollten, würde von den Mitgliedern der Gruppe ausnahmslos alle Stimmen erhalten. Der christliche Beitrag, die neu zu Tage getretene Relativität des Freiheitsbegriffs und des Humanismus, der künftig steht und fällt mit dem Sozialismus, - ich glaube, dass wir genau das haben wollen. Ich bin hier nur ein Antreiber, in diesem Fall sogar ein unbescheidener. Sie selbst müssen urteilen, ob Sie das Wesentliche Ihres Denkens, aus der philosophischen Sprache in die propagandistische übersetzt, auf 16 Druckseiten bringen wollen. “908
\end{abstract}

\footnotetext{
${ }^{902}$ Vgl. Langkau-Alex, Ursula: Fritz Lieb, S. 128.

${ }^{903}$ Marck, Siegfried: Freiheitlicher Sozialismus, S. 4.

904 Ebd., S. 5 ff.

${ }^{905}$ Hierbei muss berücksichtigt werden, dass Marck zwar der Autor der Schrift ist, aber Fritz Lieb (Kapitel „Eine Ideologie der Sammlung) und Georg Bernhard (Kapitel „Warum Sozialismus?“) deutlich daran mitgeschrieben haben, vgl. Langkau-Alex, Ursula: Fritz Lieb, S. 135ff. Zu Heinrich Manns Verständnis vom Bund freiheitlicher Sozialisten siehe: Mann, Heinrich: Verteidigung der Kultur. Antifaschistische Schriften und Essays, Berlin 1960, S. 483-486. Stellung zur Volksfront S. 256-299.

${ }^{906}$ Dass diese Schrift unter den Emigranten weite Verbreitung gefunden hat und als besonders ,geistig fruchtbar" eingestuft wurde, verdeutlicht Willi Eichler in seinen Ausführungen, die er in der Sozialistischen Warte tätigte, vgl. Lompe, Klaus/Neumann Lothar F.(Hrsg.): Willi Eichlers Beiträge zum demokratischen Sozialismus. Eine Auswahl aus dem Werk, Bonn 1979, S. 125-130.

${ }^{907}$ Nach einem freundlichen Hinweis von Ursula Langkau-Alex, wird sich um das Vorwort in der ersten Ausgabe von Maß und Wert handeln.

${ }_{908}$ Heinrich Mann an Marck, 17.10.1937, AdK NL HM, 2055.
} 
Diese Zeilen Heinrich Manns begriff Siegfried Marck als große Ehre und willigte ein - mit einer Bedingung:

„Wenn an den illegalen Vertrieb in Deutschland vor Januar [1938] gedacht ist, so wäre mir allerdings die Namensgabe durch ein anonymes Kollektiv, d. h. durch die Gruppe selbst lieber als die Zeichnung mit meinem Namen. Meine 70 jährige Mutter will - die Überwindung leichter Schwierigkeiten vorausgesetzt - Ende dieses Jahres zu uns nach Frankreich auswandern. Ich möchte nicht gerade in diesem Augenblick die Aufmerksamkeit der Gestapo zu stark auf sie lenken. Nach diesem Termin wäre dieses Bedenken nicht mehr vorhanden." "909

Damit stellte Siegfried Marck seine persönlichen Belange vor die Politischen - wenn auch aus verständlichen Motiven. Das sah auch Heinrich Mann so, der dieser Bitte Marcks nachkommen wollte. ${ }^{910}$ Darüber hinaus muss beachtet werden, dass der Begriff des Humanismus und die Diskussionen darum im französischen Exil nicht neu waren: Sowohl Heinrich als auch sein jüngerer Bruder Thomas Mann hatten mit „Jugend des Henri Quatre“ und „Achtung, Europa!“ dazu beigetragen, den Begriff zu etablieren. ${ }^{911}$ Marck berührte folglich kein begriffliches Neuland.

Deutlich grenzte Marck in dieser Schrift den Bund, der sehr stark mit der Idee des Personalismus an die Bestrebungen der linkskatholischen Gruppe um die Zeitschrift Esprit und Emmanuel Mouniers ${ }^{912}$ angrenzte, von der sozialdemokratischen und der marxistischen Tradition ab. Das ist erstaunlich: Sah Siegfried Marck, der sich nach dem Ersten Weltkrieg stets als Sozialdemokrat, als Jude, als Anhänger eines republikanischen Blocks, als Klassenkämpfer und als Verfechter der Demokratie begriff, nunmehr keinen Grund für die Zusammenarbeit mit der Sozialdemokratie, da diese ,ihre geschichtliche Mission“ erfüllt habe, ,als sie in den Wahlen zur Nationalversammlung 1919 den Fortbestand eines deutschen Reiches rettete und sich selbst dabei als Partei verbrauchte“"? ${ }^{913}$ Nicht ganz. Für Marck konnte die Sozialdemokratie eine solche Herkulesaufgabe für „,eine zweite Republik“ nicht erneut erfüllen, wenngleich die einzelnen Gruppen der Sozialdemokratie für den Aufbau einer Volksfront unentbehrlich schienen. Marck ging es um die Suche „nach neuen Formeln jenseits der sozialdemokratischen und

${ }^{909}$ Marck an Heinrich Mann, 21.10.1937, AdK NL HM, 2056.

${ }^{910}$ Heinrich Mann an Marck, 23.10.1937, AdK NL HM, 2056.

${ }^{911}$ Vgl. Betz, Albrecht: Exil und Engagement. Deutsche Schriftsteller im Frankreich der 30er Jahre, München 1986, S. 88-98; Mann, Thomas: Politische Schriften und Reden, Bd. 2, hrsg. von Hans Bürgin, Frankfurt 1968, S. 316-324.

912 Der Bund freiheitlicher Sozialisten nahm nach Beschluss der Gründungsversammlung auch Verbindung zu der Gruppe um Mounier auf, vgl. Protokoll der Gründungskonferenz des Bundes freiheitlicher Sozialisten in Dijon am 11. Und 12. Dezember, in Nachlass Fritz Lieb, zitiert in: Langkau-Alex, Ursula: Fritz Lieb, S. 139. Die Bewegung Mouniers nahm ihren Ausgangspunkt in der Weltwirtschaftskrise von 1929 siehe: Hellman, John: Emmanuel Mounier and the Creation of the New Catholic Left 1930-1950. Toronto 1981.

${ }^{913}$ Marck, Siegfried: Freiheitlicher Sozialismus, S. 4. 
marxistischen Tradition“, die sein freiheitlicher Sozialismus anwenden konnte. ${ }^{914}$ In Weimar war für Marck die Sozialdemokratie tragisch hineingezogen worden „in den Verfallsprozess der spezifisch bourgeoisen Demokratie“ und überhaupt habe der gesamte Marxismus teilgenommen an „der Dekadenz der bürgerlichen Kultur in ihrer Richtung zum Materialismus“. ${ }^{915}$ Der Bund freiheitlicher Sozialisten knüpfte auch, insbesondere mit Emil Julius Gumbel, in personeller und in ideeller Weise, an den Sozialistischen Intellektuellenbund vom Ende der Weimarer Republik an. ${ }^{916}$ Ferner kam das Gros der Befürworter aus dem sozialdemokratischen Milieu. ${ }^{917}$ Siegfried Marck wollte letztlich den kleinsten gemeinsamen Nenner für alle in Frankreich lebenden Emigranten definieren, um intellektuell gegen den Faschismus anzutreten. Zudem ist in dieser Schrift nicht mehr viel von Marcks pazifistischer Haltung, mit der er aus den Schützengräben des Ersten Weltkrieges heimkehrte, zu bemerken. Seit der „faschistischen Bedrohung“ sah Marck die Welt immer mehr vor die Alternative von Freiheit und Frieden oder Faschismus gestellt. Der „Zwischenstaatliche Pazifismus“ und das Versagen des Völkerbundes verdeutlichten dem Bund:

„Wer der Freiheit dienen will, muss diese Lage klar erfassen. Wer die deutsche Freiheit zurückerkämpfen will, muss der Kriegsbereitschaft des herrschenden Systems die Bereitschaft gegenüberstellen, dass der Faschismus und nur er allein die für demokratische Staatswesen veraltete Parole: Umwandlung des imperialistischen Krieges in den Bürgerkrieg rechtfertigt. “918

Freiheitskämpfer müssten Personalisten sein und in dieser Eigenschaft auch militant, so formulierte es Marck. Mehr noch sprach er vor allem die Vorkriegs- und Kriegsgeneration an, die Jugend sei bereits zum „Herdentum“ erzogen worden. Was Siegfried Marck in der Mitte der 1930er Jahre an Geschehen in seinem Heimatland von Frankreich aus beobachtete, muss ihn an seine Erlebnisse in den Schützengräben des Ersten Weltkrieges erinnert haben. Die Formeln und Metaphern, die Marck in seiner Schrift zum freiheitlichen Sozialismus anwandte, ähneln denen seiner Briefe an Lola Landau aus dem Felde. Marck schreibt auch hier von Menschen als

\footnotetext{
${ }^{914}$ Ebd.

${ }^{915}$ Ebd. Das erste Kapitel zudem abgedruckt, in: Deutsche Mitteilungen Paris, 10.02.1938.

${ }^{916}$ Vgl. Langkau-Alex, Ursula.: Die Zukunft der Vergangenheit oder die Zukunft der Zukunft?, in: Roussel, Helene/Winckler, Lutz (Hrsg.): Deutsche Exilpresse und Frankreich 1933-1940, S. 123-157, hier S. 124. Zum Sozialdemokratischen Intellektuellenbund sieh: Walter, Franz: Sozialistische Akademiker- und Intellektuellenorganisation in der Weimarer Republik, Bonn 1990.

${ }^{917}$ Langkau-Alex, Ursula: Fritz Lieb, S. 141.

${ }_{918}$ Marck, Siegfried: Freiheitlicher Sozialismus, S. 7.
} 
„funktionierende Teilchen von Organisationen“, oder von „dressierten Herdentieren“. 919

Doch wie wollte man eine breitere Masse erreichen? Bereits in der Volksfront herrschte ein Missstand an Multiplikatoren für deren Manifeste und Aufrufe. Daher wandte sich der Bund in erster Linie an „freischwebende ${ }^{\text {“920 }}$ Intellektuelle, für die kein „Parteistempel“ mehr so richtig passe. Diese sah er als „Rekrutierungsgebiet““921 für seine Zielsetzungen, gerade weil viele Intellektuelle, die bis 1933 eindeutig einer Partei zugehörig schienen, dies nun nicht mehr wären. Mehr noch wandte sich der Bund an

,[...]Intellektuelle, die sich zu Recht und Freiheit bekennen, an die Jugend, die eine neue Übereinstimmung zwischen Politik und Moral sucht, mit eingeschlossen alle Männer und Frauen, die zu einem kräftigen Freiheitsbewusstsein durch den Druck unmenschlicher Gewalt erwacht sind. “922

Dabei verstand Siegfried Marck unter einem „,personalistischen“ Intellektuellen nicht einen reinen „Kopfarbeiter“ oder einen „geistigen Arbeiter“ mit universitärer Ausbildung und verdeutlichte, dass diese ,überhaupt nicht - weder positiv noch negativ - als soziologische Schicht oder Klasse zu bestimmen“ seien. Vielmehr sei intellektuell, wer als „frei schöpferischer Mensch“ auftrete, der „,von einem Reiche des Geistes aus [...] an die Wirklichkeit die Frage nach ihrem Sinn“ stellt. ${ }^{923}$ Genau in diesem Deutungsmuster wird sich auch Siegfried Marck in jenen Jahren eingeordnet haben, er, der ein wenig losgelöst von der Sozialdemokratie Kritik und Protest gegen die Gleichschaltungspolitik der Nationalsozialisten üben wollte und dies als seine ,solidarische Pflicht" sah. ${ }^{924}$

Programmatisch versuchte der Bund die Synthese von Christentum, nicht ökonomisch verstandenem Liberalismus und Sozialismus $\mathrm{zu}$ entwickeln und orientierte sich aus soziologischer Hinsicht an der französischen Radikalsozialistischen Partei, die sowohl das Bürgertum als auch kleinbürgerliche Massen für sich gewinnen konnte. Der Bund verstand sich als „Extrakt der Volksfrontgesinnung “925, „grundsätzlich antitotalitär“, mit der Absicht, nach dem

\footnotetext{
919 Ebd.

${ }^{920}$ Marck nimmt hier Bezug auf Hendrik de Man, der den Begriff des „Freischwebens“ als Kategorie der Intelligenz geprägt hat, vgl. de Man, Hendrik: Die Intellektuellen und der Sozialismus, Jena 1926.

${ }^{921}$ Begriff zuerst genannt von Marck, vgl. Marck an Mann, 14.10.1937.

${ }^{922}$ Pariser Tageszeitung, 19.12.1936; siehe auch: Langkau-Alex, Ursula: Deutsche Volksfront 19321939, Bd. 3: Dokumente, Chronik und Verzeichnisse, Berlin 2005, Dokument 27, S. 196ff.

${ }_{923}$ Marck, Siegfried: Freiheitlicher Sozialismus, S. 17ff.

${ }^{924}$ Ebd., S. 20.

${ }^{925}$ Ebd., S. 17. Freilich verstand man sich unabhängig von den Schwankungen innerhalb einer erneut möglichen Volksfront-Organisation.
} 
Nationalsozialismus eine Gesellschaft zu errichten, die auf christlichen, liberalen und sozialistischen Elementen basierte. ${ }^{926}$

Zudem lieferte Marck in seiner Schrift gleich das für ihn nachfaschistisch anzuwendende Wirtschaftsystem, in dem der Mensch „im Mittelpunkt aller Wirtschaft“" steht, mit. Ihm zufolge sollte „die Überführung der Produktionsmittel in die öffentliche Hand“, besonders der Monopole in der Schwerindustrie und im Versicherungswesen, vollzogen werden. ${ }^{927}$ Daneben sprach sich der Bund für die Säkularisation im nachfaschistischen Deutschland aus und machte dabei deutlich, dass es im Nachkriegsdeutschland keine Parteien auf konfessionellen Grundlagen mehr geben sollte. ${ }^{928}$ Überdies wollte dieser Personalismus dem Kollektivismus und dem Individualismus in gleicher Weise gegenüberstehen und bildete somit einen Dritten Weg. ${ }^{929}$

Obgleich die Zahl der Sympathisanten größer als der Kreis der Initiatoren gewesen sein mag, war die Resonanz der meisten angeschriebenen Intellektuellen dennoch vergleichsweise gering. Lediglich Lion Feuchtwanger, Paul Ludwig, Rudolf Olden, Maximilian Beck, Julius Lips und Paul Tillich stimmten der Gründung des Bundes zu. ${ }^{930}$ Das Bekenntnis zur alten SPD, die Ablehnung einer Zusammenarbeit mit Kommunisten und Zweifel an der Wirkungsfähigkeit dürfen wohl als die Hauptbegründungen für ein Fernbleiben angesehen werden. Personen wie Hugo Simon oder Hans Simsen, die noch an den Vorüberlegungen teilnahmen, sprangen noch vor der Gründungstagung ab. Ihnen ging es mehr darum, die „Schweigenden und Unpolitischen“ zu sammeln, was sie später in ihrer Organisation Bund Neues Deutschland (BND) unter dem prominenten Vorsitz Thomas Manns auch versuchten. Diesem Namen gegenüber, der auch innerhalb des Bundes freiheitlicher Sozialisten zur Debatte stand, machte Thomas Manns älterer Bruder Heinrich deutlich:

Man will: "Bund neues Deutschland" und ich wundere mich, wie viel Zustimmung der Vorschlag findet. Für meine Ohren wenigstens klingt dieser Name nach Emanzipation und Absonderung. Nun hat die deutsche Opposition schon jetzt genug selbstständige Gebilde: Deutsch Freiheitspartei, Deutsche Front, was weiss [sic]ich noch, und alle versprechen mehr

\footnotetext{
${ }^{926}$ Vgl. ebd., S. $16 \mathrm{f}$.

${ }^{927}$ Ebd., S. 11f. Dies sollte nicht für kleine und mittlere Betriebe gelten. Für den Bund war es wichtig, dass die Produktionsmittel stets im Dienst der Allgemeinheit, folglich im „Obereigentum der Gemeinschaft" bestehen.

${ }^{928}$ Ebd., S. 15f.

${ }^{929}$ Ebd., S. 6.

${ }^{930}$ Langkau-Alex, Ursula: Deutsche Volksfront 1932-1939, Bd. 2, S. 433.
} 
oder weniger, dereinst "vereint zu schlagen". Die einzige Aussicht, überhaupt je zu schlagen, hat aber die Volksfront." 931

Überhaupt sah die Gruppe um die freiheitlichen Sozialisten diese Bemühungen vom „rechten und klassisch-liberalen Flügel des Bürgertums“ für die eigenen Bemühungen als störend an. ${ }^{932}$

Und mit Blick auf die Tagespolitik erscheint es zunächst erstaunlich, dass weder die Sozialdemokraten, noch die Sozialisten, oder die Anhänger des Bundes freiheitlicher Sozialisten gegen den Anschluss Österreichs protestierten, obschon sie die „ultimative Art des Vorgehens Hitlers“ missbilligten. Für die meisten unter ihnen gehörte Österreich ohnehin zu Deutschland und die Trennung der Sozialdemokratie in zwei nationale Teile (Deutschland und Österreich) konnte von ihnen ohnehin nicht gutgeheißen werden. ${ }^{933}$

Der Bund wünschte ein „loyales Bündnis“ mit den existierenden Arbeiterparteien, obgleich man die Verschmelzung dieser zu einer Einheitspartei auf demokratischer Basis gern forciert hätte. Und obwohl der Kreis sich zuerst nur an Intellektuelle und Angehörige des freiheitlichen Bürgertums wandte, erkannte er, dass die soziologische Basis nach dem Sieg über den Faschismus mindestens um die des Kleinbürgertums erweitert werden müsse:

„Darüber hinaus hängt das Schicksal des freiheitlichen Sozialismus von der Möglichkeit ab, in den Boden des aus einer ungeheuren politischen Erfahrung auftauchenden Kleinbürgertums einzuschlagen. Dieses ist durch Pseudopolitisierung zugleich geweckt und enttäuscht worden. Das Kleinbürgertum wird es aller Voraussicht nach satt haben, als Gefolgschaft von Führer-Cliquen und von aubeutenten [sic] Profitjägern weiter zu dienen."“934

Deshalb fokussierte der Bund nicht zuletzt die Schaffung einer deutschen Freiheitspartei. ${ }^{935}$ Nicht zuletzt nach dem Wegbrechen der liberalen Parteien der Weimarer Republik schien dies ein sinnvolles Unterfangen zu sein. Letztlich ging es dem Bund um die Konzeption einer organisatorischen Eigenständigkeit, die neben dem Industrie-Proletariat und dessen Parteien existieren sollte. Als geschlossen nichtproletarische Gruppe wollte der Bund versuchen, die Reste des freiheitlichen Bürgertums sowie die für den Faschismus besonders anfälligen kleinbürgerlichen Massen in einer großen sozialistischen Sammlungspartei spätestens nach Hitler und

\footnotetext{
${ }^{931}$ Heinrich Mann an Marck, 23.10.1937.

${ }^{932}$ Vgl. Langkau-Alex, Ursula.: Deutsche Volksfront 1932-1939, Bd. 2, S. 433.

933 Ebd., S. 437; Miller, Susanne: Kommentare aus der deutschen Exilpresse zur Annexion Österreichs, in: Kreisler, Felix (Hrsg.): Fünfzig Jahre danach - der „Anschluss“ von Innen und Außen gesehen, Wien 1989.

${ }_{934}$ Marck, Siegfried: Freiheitlicher Sozialismus, S. 21.

${ }^{935}$ Vgl. ebd. Gemeint ist in diesem Zusammenhang nicht die Deutsche Freiheitspartei, die von Carl Spiecker und Otto Klepper um die Jahreswende 1936/37 ins Leben gerufen wurde. Deren Organ waren die Deutschen Freiheitsbriefe. Dennoch sympathisierte man mit dieser.
} 
auf demokratischer Basis $^{936} \mathrm{zu}$ vereinen und koppelte sich von spezifisch marxistischen Gruppen ab. ${ }^{937}$

Das Scheitern war umso bedauerlicher, als der Bund freiheitlicher Sozialisten ganz in der Manier Siegfried Marcks versuchte, gleichzeitig als nicht-proletarischer Block, die dritte Kraft und als Mittler zwischen Sozialdemokraten und Kommunisten zu agieren $^{938}$ und im „loyalen Bündnis“, nicht in Konkurrenz, mit den bestehenden Arbeiterparteien $\mathrm{zu}$ arbeiten - zumindest im Exil. Dabei verdeutlichte er sein Bekenntnis zum Personalismus. Er verstand sich als Zusammenführung von „schöpferischen Einzelnen“. Er glaubte, „dass die Massen als solche nur in grossen [sic] historischen Stunden der Aufwallung [...] wirklich schöpferisch sind“, die Impulse müssten ihnen von außen, folglich von den freiheitlich sozialistischen Intellektuellen, von Siegfried Marck und seinen Mitstreitern, gegeben werden. ${ }^{939}$ Sowjet-Russland verstand man, trotz aller Bedenken, als das „grosse sozialistische Experiment, um das herum sich die Dramen der Weltgeschichte seither abspielen und abspielen werden““. ${ }^{940}$ Dennoch gab es innerhalb des Bundes verschiedene Pole, die bezüglich der Person Willi Münzenbergs uneinig waren. Während Heinrich Mann und Siegfried Marck sich stets für eine Zusammenarbeit mit den Kommunisten und mit Münzenberg aussprachen, standen Georg Bernhard und Emil Julius Gumbel einer Zusammenarbeit skeptisch gegenüber. Auch war es Gumbel, der trotz seines Angebotes, die Richtlinien an diverse in Frage kommende Befürworter $\mathrm{zu}$ verschicken, diesem nicht nachkam. ${ }^{941}$

Trotzdem: Münzenberg war in die Arbeit des Bundes involviert und er konnte die beiden Flügel wieder näher zueinander bringen. ${ }^{942}$ Immerhin sah auch er, ähnlich wie Marck, den Bund als Mittler zwischen den Sozialisten und den Kommunisten und zugleich als dritte Kraft in einer wiederzubelebenden Volksfront. ${ }^{943}$

Doch das von Marck verfasste Programm stieß nicht auf viel Resonanz und der Bund kam eigentlich nie über die Veröffentlichung dieser Schrift hinaus. Rudolf

\footnotetext{
${ }^{936}$ Ebd., S. 22.

${ }^{937}$ Ebd., S. 21.

${ }^{938}$ Vgl. Langkau-Alex, Ursula: Fritz Lieb, S. 128ff.

${ }^{939}$ Marck, Siegfried: Freiheitlicher Sozialismus, S. 22.

${ }^{940}$ Ebd., S. 23.

${ }^{941}$ Vgl. Marck an Heinrich Mann, 11.01.1938. AdK, NL HM, 2058. Marck sah dies jedoch nicht als mutwillig, vielmehr als „Verquickung“ von verschiedenen Angelegenheiten, da Gumbel wohl Probleme mit seinem Carrefourverlag gehabt haben soll.

${ }^{942}$ Langkau-Alex, Ursula: Fritz Lieb, S. 142ff.

${ }^{943}$ Münzenberg an Marck, 25.04.1938, in NL Fritz Lieb zitiert in: Langkau-Alex, Ursula: Fritz Lieb, S. 142.
} 
Olden, der einer Gründung des Bundes einst schriftlich zugestimmt hatte, übte im Neuen Tagebuch harsche Kritik an dem Programm. ${ }^{944}$ Diese Kritik drang auch zu Thomas Mann vor, der in seinen Tagebüchern notierte: „Nach dem Abendessen Lektüre deutsche Zeitschriften. R. Olden im „Tage-Buch“ vorwurfsvoll über den Bruder." ${ }^{\text {9945 }}$

Das Scheitern hinterließ bei Siegfried Marck Spuren, auch in seinem Selbstverständnis als Sozialdemokrat und zugleich Anhänger des freiheitlichen Bürgertums. Ihm war schon zuvor jeglicher Partei- oder Gruppenpatriotismus fremd geworden. Wie er in einem Brief an Paul Hertz verdeutlichte, fühlte er sich selbst als „deutsche Volksfront" und wenn man ihn bei öffentlichen Kundgebungen ohne sein Zutun zum Vertreter des freiheitlichen Bürgertums zählte, zu dem er sich soziologisch zugehörig fühlte, war ihm das auch recht. ${ }^{946}$ Das Scheitern des Bundes wird dieses Gefühl erneut bestärkt haben. Siegfried Marck schrieb im August 1938 in einem Brief aus London an Heinrich:

„Lange hatten wir nichts Unmittelbares voneinander gehört. Es wäre schön wenn wir im Herbst, den Bund freiheitlicher Sozialisten reaktivieren könnten. Aber auch über jede andere Form aktiver Zusammenarbeit mit ihnen würde ich sehr glücklich sein.“947

So wundert es nicht, dass sich Marck im September 1938 auch dem Heinrich MannAusschuss anschloss, der mit Blick auf die Sudentenkrise ins Leben gerufen wurde und unterzeichnete die Aufrufe Heinrich Manns. ${ }^{948}$ Ohnehin war für Siegfried Marck und seine Frau Kläre Heinrich Mann ein „Vorkämpfer‘ ${ }^{\star 949}$, um dessen Mut sie ihn sicherlich $\mathrm{ab}$ und zu beneideten. Danach schloss sich Marck im Sommer 1939 der von Willi Münzenberg gegründeten Union Franco Allemande an und befand sich wieder in einem zum Scheitern verurteilten, fragilen Bündnis, dem es neben der Solidarität der Friedensmächte um die Aufrechterhaltung des Friedens in Europa ging. ${ }^{950}$

\footnotetext{
${ }^{944}$ Vgl. Olden, Rudolf. Ein Parteiproramm, in: Neues Tagebuch, 10.09.1938. Olden ertrinkt auf seiner Flucht in die Vereinigten Staaten, nachdem sein Fluchtschiff von einem deutschen Torpedo getroffen wurde. Er wollte in New York einem Ruf an die New York School for Social Research folgen. Zuvor hatte er wohl mehrfach versucht, die Engländer im Kampf gegen Hitler zu unterstützen - ohne Erfolg. Vgl. Lehmann, Klaus-Dieter (Hrsg.): Deutsche Intellektuelle im Exil. Ihre Akademie und die American Guild for German Cultural Freedom, München, 1993, S. 426.

945 Tagebücher Thomas Mann, Mai 1939, S. 492.

${ }^{946}$ Marck an Paul Hertz vom 16.10.1936, in: Nachlass Paul Hertz, Internationaal Instituut voor Sociale Geschiedenis (IISG), zitiert in: Langkau-Alex, Ursula: Fritz Lieb, S. 141.

${ }^{947}$ Heinrich Mann an Marck, 31.08.1938, AdK NL HM, 2061.

${ }^{948}$ Vgl. Deutsche Volkszeitung, 02.10.1938.

${ }^{949}$ Telegramm zu Heinrich Manns Geburtstag von Siegfried und Kläre Marck, ohne Datum. AdK, NL HM, 2064.

950 Vgl. Stampfer, Friedrich: Mit dem Gesicht nach Deutschland. Eine Dokumentation über die sozialdemokratische Emigration. Aus dem Nachlass von Friedrich Stampfer ergänzt durch andere
} 
Ende August 1938 stand für Siegfried Marck fest, dass er Frankreich den Rücken kehren wollte. Doch tat er das nicht aus Furcht vor den Nationalsozialisten, wie es unlängst innerhalb der wenigen existierenden wissenschaftlichen Studien vermutet wurde. Siegfried Marck wollte Frankreich wegen einer „Herzensangelegenheit“ verlassen. „Ich möchte im nächsten Jahr Gastvorlesungen in USA halten mit dem Ziele, dauernd dort eine Stelle zu bekommen“ schrieb er an Heinrich Mann. Marck verdeutlichte: „Hier frage ich Sie nun: Könnten Sie mir durch amerikanische Beziehungen helfen, dass ich zu Vorträgen eine Einladung bekomme?“. Er hätte es gern gesehen, wenn Heinrich bei seinem jüngeren Bruder Thomas ebenfalls ein gutes Wort in dieser Angelegenheit für ihn einlegte. In dem gleichen Brief nennt Siegfried Marck auch die genaueren Umstände dieser für ihn besonderen Angelegenheit:

„Ich habe an der Schwelle der Fünfzig die große Liebe des Lebens gefunden. Aber nicht nur ich, auch meine Freundin ist ehelich gebunden an Partner, die wir achten und lieb haben. Beide haben wir Kinder mit denen sie besonders in leidenschaftlicher Zärtlichkeit verknüpft ist. Beide sind wir damals aus glänzenden wirtschaftlichen Verhältnissen in die Verarmung der Emigration geraten." “951

Ilse Apt kehrte vorerst zu ihrem Gatten nach New York zurück, der sich in New York mühsam eine Existenz als Arzt aufgebaut hatte, und „überführte“ ihm die Kinder aus Europa. Aus diesem Brief Siegfried Marcks sticht ein geradezu entschuldigender Ton hervor. Marck versuchte sich gegenüber Heinrich Mann, mit dem er in einer Vielzahl an Bündnissen zusammenarbeitete, zu rechtfertigen, dass er der Liebe wegen das Land verlassen wollte und damit den Kampf gegen den Faschismus an der „Frontlinie“ aufgab, wenngleich er den Spieß ein knappes halbes Jahr später ein wenig umdrehte:

„Im Falle, dass sich Frankreich gegen die Lebensgefahr, in der es schwebt, wehrt, würde ich zuzukommen suchen. Im Falle einer neuen Kapitulation würde ich mich drüben zu fixieren suchen und meine Familie nachkommen lassen. ${ }^{6952}$

Siegfried Marck ging, erlebte den Einmarsch deutscher Truppen in Frankreich nicht mehr und versuchte sich fortan in den Vereinigten Staaten zu „fixieren“, dennoch: Siegfried Marcks Intention und sein Verdienst für die deutsche Emigration waren letztlich, dass er die ihm gebotene intellektuelle Situation Frankreichs, mit Einflüssen von Heinrich und Thomas Manns Schriften, von Emmanuel Mounier ${ }^{953}$ und den

Überlieferungen, herausgegeben von Erich Matthias und bearbeitet von Werner Link, Düsseldorf 1968, S. 109f. Zur Union Franco Allemande siehe: Langkau-Alex, Ursula: Deutsche Volksfront 19321939, Bd. 2. S. 460f, Bd. 3, S. 329, 349.

${ }_{951}$ Marck an Heinrich Mann, 31.08.1939, AdK NL HM, 2061.

${ }_{952}$ Marck an Heinrich Mann, 18.03.1939, AdK NL HM, 2064.

953 Marck und Mounier hatten nach Marcks Emigration in die USA keinen Kontakt mehr. Auch nannte er den Personalisten nicht an erster Stelle, wenn es um dieses Bewegung ging, sondern Thomas Mann. Siehe weiter bei Llanque, Marcus: Siegfried Marck, S. $285 \mathrm{ff}$. 
Diskussionen um die Volksfront, analysierte, aufbereitete und zu dem Schluss kam, dass der Faschismus nur besiegt werden könne, wenn Bürgertum und Arbeiterbewegung zusammenarbeiten. Dabei verstand Marck Frankreich als das Wirkungsfeld der Volksfront und begriff dieses als den Keim eines neuen Europa nach dem Faschismus. ${ }^{954}$ Siegfried Marck war Träger zwischen den Kulturen ${ }^{955}$ und damit als Sozialdemokrat im französischen Exil allein.

\footnotetext{
${ }^{954}$ Marck selbst sah auch zunehmend in Frankreich die Gefahr des Faschismus, wie er in einem Brief an Münzenberg deutlich machte. Er schätze die politische Lage im Januar 1938 ähnlich bedrohlich ein, wie am 06. Februar 1934, als sich das antiparlamentarische Potential Frankreichs entlud, vgl. Marck an Münzenberg, 22.01.1938.

${ }^{955}$ Vgl. Llanque, Marcus: Siegfried Marck, S. 289.
} 


\section{Im dritten Kulturkreis - Im amerikanischen Exil}

\section{Flucht und Fixierung}

Siegfried Marck verließ Frankreich aus Herzensgründen. „Es wäre für mich lebenswichtig (dies nicht nur aus beruflichen sondern auch aus Gründen schicksalhafter menschlicher Verbundenheit) ${ }^{\star 9956}$, betonte Marck. Dabei genügte es ihm vorerst, in den USA als Visitor mit Gastvorlesungen tätig zu sein, doch fehlte ihm die Finanzierung. Hierfür setzte er alle Hebel in Bewegung. In Frankreich war er von der Rockefeller Foundation unterstützt worden und Marck warb auch dort für seinen Wunsch, in die USA zu gehen. Er schrieb Briefe an Heinrich und Thomas Mann, außerdem an Hubertus Prinz zu Löwenstein ${ }^{957}$, ob sie ihm helfen und ihre Kontakte für ihn nutzen könnten. ${ }^{958}$ Schon im Sommer 1939, in den Ferien der Universität Dijon, ging Marck nach London, um dort eine englische Sprachschule zu besuchen. ${ }^{959}$ Doch die ihm zur Verfügung stehenden Mittel für eine eigenständige Reise in die Vereinigten Staaten reichten nicht aus und ohne die nötigen Bürgschaften hätte er ohnehin nicht dauerhaft in den USA bleiben dürfen. Marck hatte sich, trotz der auch für ihn immer spürbareren Gefahr und der stetigen und sich steigernden Aggression der Nationalsozialisten aus seiner alten Heimat, lieber Geld für die Veröffentlichung seiner Bücher geliehen, als dieses für eine Flucht seiner Familie zu verwenden. ${ }^{960}$

Die Rockerfeller Foundation half ihm erneut und Marck emigrierte mit einem Besuchervisum in die USA, was große Hürden nach sich zog. Immerhin war Marck nur „Visitor“ mit Ambitionen länger zu bleiben. Dabei ließ Siegfried Marck seine Frau Kläre und seine zwei Kinder Louis und Claudia in Frankreich zurück, was ihm im Familiengedächtnis der Marcks langfristig verübelt wurde. Die Söhne Andreas und Alfons aus erster Ehe waren ohnehin bei Lola und Armin geblieben. Andreas wurde Zionist, ging 1936 nach Palästina und wurde zum Mitbegründer der jüdischen

\footnotetext{
${ }_{956}$ Marck an Prinz zu Löwenstein, 19.09.1939, DNB American Guild - EB 70/117.

${ }^{957}$ Vom 21.-24.06. auf dem XV. Internationalen PEN-Kongress sprach Hubertus Prinz zu Löwenstein auf der Abschlussversammlung im Théâtre Athéneé und teilt dort die Gründung der Deutschen Akademie der Künste und Wissenschaften mit, vgl. Pariser Tageszeitung, 25.06.1937. Dies wird der erste Kontakt Siegfried Marcks mit Hubertus Prinz zu Löwenstein gewesen sein, wenngleich nicht bewiesen werden kann, dass Marck an der Sitzung teilnahm, geht der Verfasser davon aus, dass er mindestens in der Pariser Tageszeitung davon gelesen hat.

${ }_{958}$ Brief Marck an Prinz zu Löwenstein, 18.10.1938, 19.09.1939. DNB American Guild - EB 70/117.

${ }^{959}$ Marck an Prinz zu Löwenstein, 19.09.1939.

${ }^{960}$ Marck an Deutsche Akademie im Exil (Fragebogen), Mai 1938, DNB Exil-Archiv. Marck lieh sich 650 frs.s, um seinen „Neuhumanismus“ bei Oprecht unterzubringen.
} 
Siedlung Moshav Shitufi Moledet. Alfons zog es nach Großbritannien. Er lebte in Oxford $^{961}$ und arbeitete dort als Administrator der medizinischen Forschungsabteilung an der Oxford University.

Während sich Siegfried mit seiner neuen Liebschaft in die USA absetzte, wurde seine Familie um Kläre in Frankreich interniert. Sein Sohn Louis kam in ein Arbeitslager $^{962}$ und kämpfte später im Widerstand gegen die Nationalsozialisten mit schweren Folgen. Fortan litt er unter einem „Shellshock“, 963 war damit ein Kriegszitterer, bei dem die Bombenangriffe und Kriegserlebnisse einen bleibenden Schaden hinterließen. „Der andere Teil der Familie hat leider nicht den Mut aufgebracht, sich dem Flüchtlingsstrom anzuschließen“, konstatierte Marck. „Sie bleiben in Dijon und so ist alle Verbindung mit ihnen abgeschnitten." Nur Louis versuchte er Geld in das unbesetzte Gebiet zu schicken, damit er es Kläre und Claudia zuleiten konnte. ${ }^{964}$ Marck wandte sich an das Genfer Rote Kreuz, in der Hoffnung etwas über seine Angehörigen aus Breslau, insbesondere seiner Mutter, zu erfahren - ohne Erfolg. ${ }^{965}$ Siegfried Marck zog die Entscheidung seines Sohnes Louis, in Frankreich zu bleiben, um aktiv gegen die Nationalsozialisten zu kämpfen, nicht für sich in Betracht. Ohnehin war Dijon für ihn nur noch eine „Angelegenheit“":

„Eine sehr schwere Correspondence mit Dijon über das Notwendige, was für die Zukunft zu geschehen hat, erleichtert das Leben nicht. Aber die Arbeit und unser Zusammensein [mit Ilse] macht es doch recht lebenswert. Im Übrigen kann ich nur wiederholen, dass meine in Frankreich befindende Familie weiter sehr zuvorkommend behandelt wird. Hoffentlich hören Sie auch bald Besseres von Ihrem Sohn. Die Behandlung der Emigranten bleibt trotz aller mildernden Umstände ein Schmutzfleck auf Frankreichs reinem Schilde.“"966

Damit blieben Kläre mit Claudia vorerst in Dijon, das 1940 von den Deutschen bombardiert und besetzt wurde. Nach Auffassung Marcks wurden sie dort gut behandelt. Formal hatten sowohl Kläre als auch die Kinder das Recht mit einer NonQuota-Einreiseregelung in die Vereinigten Staaten zu gelangen, da Siegfried und Kläre noch verheiratet waren. Die Einreiseregelungen verschärften sich mit Kriegsausbruch und nun benötigten auch sie ein Affidavit, folglich eine Bürgschaft, die sich Siegfried Marck von Thomas Mann erhoffte und die dieser gerne gab. Marck selbst hatte seine Bürgschaften von Heinrich und Thomas Mann erhalten. Aus dem gleichen Brief geht hervor, dass Marck versuchte, für Rolf Reventlow ebenfalls Hilfe von Thomas Mann zu bekommen, welcher „Reventlows Fall weiter im Auge

\footnotetext{
${ }^{961}$ Anmerkungen von Louis Marck zum Nachlass, LBI NY.

${ }_{962}$ Marck an Budzislawski, 19.10.1941, AdK NL Budzislawski (nachfolgend AdK NL BL) Mappe 64.

${ }^{963}$ Persönliche Nachricht von John March an den Verfasser, 09.04.2014.

${ }^{964}$ Marck an Budzislawski, 19.10.1941.

${ }^{965}$ Marck an Friedländer, 07.09.1940, NL WF.

${ }^{966}$ Marck an Broch, 02.03.1940, DLA Marbach, NL Broch (nachfolgend NL HB).
} 
behalten“ wollte. ${ }^{967}$ Reventlow und Marck kannten sich aus Breslau, aus der gemeinsamen Zeit bei der Volkswacht. Rolf Reventlow gelangte nicht in die USA, sondern arbeitete weiterhin als Dolmetscher und Journalist auf dem Kontinent. In diesem Zusammenhang muss berücksichtigt werden, dass die Einreiseregelungen in die USA nicht zugunsten von politisch Verfolgten ,justiziert“ wurden. Das Quotensystem sah vor, dass jährlich maximal 156.000 Menschen in die Vereinigten Staaten einreisen durften, wovon allein England 65.000 „Plätze“ erhielt und der Anteil deutscher Exilanten bei knapp 25 Prozent liegen durfte. ${ }^{968}$ Auch ein Urteil über die Behandlung deutscher Emigranten in Frankreich kann nicht besser ausfallen. Was Siegfried Marck in seinem Brief an Hermann Borch als „Schmutzfleck auf Frankreichs reinem Schilde“ bezeichnete, findet in den Schilderungen Lion Feuchtwangers, der zweimal in Frankreich interniert wurde, diese Worte:

„Gleich zu Beginn des Krieges freilich war ich dann darüber belehrt worden, wie falsch ich es gemacht hatte. Nicht nur wollten die Franzosen von einer Mitarbeit von uns deutschen Antifaschisten nichts wissen, sie sperrten uns vielmehr schon damals alle ein. Mich hatten englische Proteste schon nach wenigen Tagen aus dem Konzentrationslager befreit, und die französische Regierung hatte sich damals bei mir entschuldigt und meine Internierung als einen Mißgriff subalterner Organe bezeichnet. Aber das Ausreisevisum, das ich nach dieser üblen Erfahrung verlangt hatte, war mir nicht bewilligt worden.“969

So blieb Lion Feuchtwanger, der auf der ersten Ausbürgerungsliste Deutschlands zu finden war und dessen Bücher in Deutschland verbrannt wurden, vorerst in Frankreich. Er gestand sich auch ein, dass er ungern gegangen wäre. Nicht wieder herausgerissen zu werden, die ,innere Behaglichkeit des Lebens dort, die Schönheit des Ortes“ und seine geliebte Bibliothek hielten ihn in Gedanken in der Kulturnation. ${ }^{970}$ Doch Feuchtwanger wurde erneut interniert und schildert eindringlich das Lagerleben:

„Jede Scham hatte man sich im Lager schnell abgewöhnt. Niemand scheute sich, seine Häßlichkeiten und Gebrechen zu zeigen, die des Körpers wie der Seele. [...] Etwa zwanzig Minuten nach dem Aufstehen brachten je zwei Mann aus jeder Gruppe ihren Leuten den Eimer mit Kaffee und die tägliche Ration Brot. Jeder holte sich mit seinem Becher seinen Teil Kaffee und tunkte sein Brot hinein. Über die Qualität des Brotes wurde viel geklagt, einige Ärzte erklärten, dieses Brot sei eine der Hauptursachen der Krankheiten, von denen wir alle befallen wurden. “971

Siegfried Marck entging diesem Schicksal. Obgleich Thomas und Heinrich Mann sich stark für ihn bei den entsprechenden Stellen einsetzten, sodass er - wie bereits in

\footnotetext{
${ }^{967}$ Bürgin, Hans: Die Briefe Thomas Manns: Regesten und Register, Bd. II die Briefe von 1934 bis 1943, Frankfurt am Main 1980, S. 501.

968 Vgl. Durzak, Manfred: Die Exilsituation in den USA, in: Ders. (Hrsg.). Deutsche Exilliteratur 1933-1945, Stuttgart 1973, S. 145ff.

${ }^{969}$ Feuchtwanger, Lion: Der Teufel in Frankreich. Ein Erlebnisbericht, München 1983, S. 17.

${ }^{970}$ Vgl. ebd., S. $17 f$.

${ }^{971}$ Ebd., S. 55.
} 
Frankreich - durch die Rockefeller Foundation finanziert nun in den Vereinigten Staaten Lehraufträge annehmen konnte, betonte Marck: „Die Rockefeller Foundation hat mich durch eine erstickende Umarmung von Frankreich hierher getrieben. “972 Für ihn war diese Umarmung erstickend, da Rockefeller zu Marcks Gunsten von den französischen Stellen unerfüllbare Bedingungen ${ }^{973}$ verlangte und ihn dann in den USA fallen ließ. Diese Aussagen Siegfried Marcks erscheinen undankbar gegenüber seinen Rettern.

Siegfried Marck hielt als Visitor zuerst Gastvorlesungen in der New Yorker New School for Social Research und an der Columbia University. Gerade in den ersten Monaten in den Vereinigten Staaten war es der Jungsozialist und ehemalige Student Marcks, der ältere Bruder von Ruth Seydewitz, Fritz Lewy, der Marck, seinem ehemaligen Doktorvater, sehr behilflich war. ${ }^{974}$ Mit ihm traf er sich des Öfteren in New York und als Marck um die Jahreswende 1941/42 einen leichteren Herzanfall erlitt, soll Fritz in dieser Zeit „die Zuvorkommenheit selbst“ gewesen sein. ${ }^{975}$ Dabei hatte Lewy, nachdem er Siegfried Marck 1933 aus den Augen verloren hatte, einiges erlebt. Er floh nach der Machtübernahme in die CSR und arbeitete dort aktiv im Widerstand mit. Auf einer Kurierfahrt wurde er festgenommen, im Konzentrationslager Hohenstein gefangen genommen und entkam dort. Daraufhin kämpfte er 1936 im Spanischen Bürgerkrieg in internationalen Brigaden. ${ }^{976}$ Wie er schließlich in die USA gelangte, ist nicht nachzuweisen, aber für Siegfried Marck war es ein Glücksfall.

Die von Alvin Johnsen geleitete New York School for Social Research spielte in der Stellenvermittlung für emigrierte deutsche sozialdemokratische Professoren eine besondere Rolle ${ }^{977}$ : Im Jahr 1919 als Abendschule für Berufstätige gegründet, wurde sie im Jahr 1933 zu einer „Universität im Exil““ umgestaltet, an die Johnsen vertriebene Nationalökonomen und Soziologen berief. Ehemaligen deutschen Sozialdemokraten wie Hans Simons, Hans Staudinger, Eduard Heimann, aber eben auch Siegfried Marck wurde so eine gute Gelegenheit geboten, in den USA Fuß zu fassen. Bei Kriegsausbruch waren an der Schule 56 deutsche Lehrer tätig, doch nicht

\footnotetext{
972 Marck an Prinz zu Löwenstein, 09.10.1939, DNB EB 86/2 I.A. 52.

${ }^{973}$ Es ist nicht mehr zu rekonstruieren, um welche Bedingungen es sich hier handelte.

${ }^{974}$ Marck an Budzislawski, 19.10.o.J. AdK NL BL.

${ }^{975}$ Marck an Friedländer, 26.01.1942, NL WF.

976 Röder, Werner et al. (Hrsg.): Biographisches Handbuch der deutschsprachigen Emigration nach 1933, München 1980, S. 441.

977 Vgl. Lepsius, Rainer M.: Die Sozialwissenschaftliche Emigration und ihre Folgen, in: Ders. (Hrsg.): Soziologie in Deutschland und Österreich 1918-1945. Materialien zur Entwicklung, Emigration und Wirkungsgeschichte, Sonderdruck der Kölner Zeitschrift für Soziologie und Sozialpsychologie Nr. 23, S. 461-487, hier S. 469ff.
} 
alle konnten bleiben. Marck wäre sicherlich gern geblieben, doch ein Angebot seitens der Schule erfolgte nicht. So zog es ihn nach Chicago, vermittelt durch seinen Freund Eduard Heimann, der neben Paul Tillich zu den führenden religiösen Sozialisten seiner Zeit zählte. ${ }^{978}$ Die meisten anderen Akademiker, wie beispielsweise Max Horkheimer oder Carl Landauer, aber auch Albert Einstein und Thomas Mann, fanden an den bereits bestehenden Universitäten in Princeton, Berkeley oder an der Columbia University in New York eine Möglichkeit, sich weiter mit ihren Forschungen $\mathrm{zu}$ beschäftigen - oftmals auch mit nicht unerheblichem Interesse der Universitäten selbst. ${ }^{979}$ Während Siegfried Marck in das für ihn wegen des schlechten Wetters später so gehasste Chicago gehen wollte, um sein Fortkommen in den USA zu sichern, lebten und dozierten viele andere Intellektuelle deutscher Provenienz an den bessergestellten Universitäten des Landes. Auch das traf Siegfried Marck, der in den „grausamen Wintern“ in Chicago oft krank wurde und für mehrere Wochen ausfiel ${ }^{980}$, sehr. Ilse, seine dritte Frau, zog sich ebenfalls Infekte $\mathrm{zu}^{981}$, oder brach sich bei Glatteis den Knöchel. ${ }^{982}$ Auch die Sommermonate waren mit der feuchten Luft, den Gewittern und dem Staub für Marck kaum zu ertragen. ${ }^{983}$ Zudem fühlten sich Marcks in Chicago isoliert, da der größere Teil ihrer Freunde in Los Angeles lebte. ${ }^{984}$

Das sich in jener Zeit im Aufbau befindende YMCA College in Chicago unterbreitete Marck das Angebot, vorerst für ein Jahr dort eine Lehrtätigkeit aufzunehmen und sowohl die Rockefeller Foundation als auch das Emergency Committee (Drury-Duggan) stellten ihm die Finanzierung hierfür in Aussicht, wenn das College sich anteilig an den Kosten beteiligen und die Stelle verfestigen sollte, doch:

„Nachdem das Angebot des Colleges vorlag, begannen große Schwierigkeiten bei beiden Comités. In Bezug auf die Frage der Permanenz kam das College einen Schritt entgegen und erklärte in verklausulierter Form, vielleicht wäre die Stelle bei einem großen Lehrerfolg doch ausbaufähig, sie werde zunächst aber nur gegeben, um mir die Einwanderung zu ermöglichen. “985

\footnotetext{
${ }^{978}$ Marck an Prinz zu Löwenstein, 09.10.1939. Tillich war auch mit Adolf Grimme, der auch dem religiösen Sozialismus nahestand, befreundet, siehe: Burkhardt, Kai: Adolf Grimme (1889-1963): eine Biographie, Köln 2007, S. 50.

${ }^{979}$ Vgl. Stampfer, Friedrich: Mit dem Gesicht nach Deutschland, S. 144f.

${ }^{980}$ Beispielsweise Lungenentzündung vgl. Marck an Friedländer, 27.08.1944, NL WF.

${ }^{981}$ Marck an Friedländer, 15.10.1947, NL WF.

982 Marck an Friedländer, 31.03.1949, NL WF.

983 Marck an Friedländer, 15.07.1951, NL WF.

${ }^{984}$ Marck an Friedländer, 20.09.1949, NL WF.

${ }^{985}$ Marck an Prinz zu Löwenstein, 09.10.1939. Weiterhin soll es die Möglichkeit gegeben haben, am Goucher College in Baltimore unterzukommen, vgl. Brief Marck an American Guild, 30.08.1939, DNB. Dies wurde jedoch von Marck nicht weiter verfolgt.
} 
Marck bemühte sich für sich und seine Bekannten in „Chicago oder anderswo patrons für eine vom College gegebene finanzielle Basis $\mathrm{zu}$ gewinnen“ - ohne Erfolg. Immerhin gelang es, den Oberländer Trust zu einer Zahlung von monatlich 50 Dollar als Basis für Marcks Gehalt zu bewegen. Das Emergency Committee zog nun nach und wollte ebenfalls 100 Dollar im Monat geben, falls von irgendeiner anderen Seite (College oder Stiftung) ebenfalls 100 Dollar bereitgestellt werden würden, sodass der Ball wieder zurück zu Rockefeller gespielt wurde. Siegfried Marck wartete knapp ein Jahr auf eine Entscheidung von Rockefeller, worunter seine Psyche litt. Sichtlich verbittert schrieb er: „Ist es nicht ein Tragikomisches, und da jeder wollte zahlen, zahlte keiner von den beiden?!“汭6 Dass diese Angelegenheit, die ja auch für den Verbleib Marcks in den USA nicht unerheblich war, für eine große Belastung, Unruhe und Angst sorgte, verdeutlichen folgende Zeilen Marcks an Hubertus Prinz zu Löwenstein vom American Guild for German Cultural Freedom (kurz Guild):

„Ich glaube, dass zur Durchbrechung der Formalismen und der erstickenden Umarmung ein einfacher und durchaus erlaubter Weg möglich wäre, der aber nur von sehr wohlwollender, mir vertrauender und diskreter Seite aus beschritten werden kann. Ich habe diese Frage auch mit unserem gemeinsamen Freunde Hermann Broch besprochen. Zur Not kann ich mit \$150 im Monat, von denen ich etwa die Hälfte meiner noch in Dijon befindlichen und in diesem Augenblick von akuter materieller Not bedrohten Familie schicken würde, auskommen. So könnten die \$1200 im Jahre, an deren Hergabe nun einmal die anderen \$1200 hängen, fiktiv d. h. dem College direkt und real, mir aber in der Form eines Darlehens gegeben werden, zu dessen sofortiger monatlicher Zurückzahlung ich mich verpflichten würde. Technisch würde ich mir den Weg folgendermaßen vorstellen: dem College wird von einer Organisation oder von privater Seite aus mitgeteilt, dass ihm monatlich $\$ 100$ für meine Bezahlung zur Verfügung stehen. Dem College werden auch tatsächlich diese \$100 monatlich überwiesen, die es mir als Gehalt auszahlt. Ich aber übernehme der betreffenden Organisation gegenüber die Verpflichtung, diese mit zugewandten $\$ 100$ sofort nach Erhalt zurückzuzahlen. Um dem Emergency Committee gegenüber, welches sich über die Quellen der zusätzlichen Bezahlung nicht weiter zu informieren gedenkt, völlig dicht zu halten, wäre es gut, wenn das Arrangement restlos zwischen mir und der betroffenen Organisation bleibt und selbst das College nicht über die Zurückzahlung unterrichtet wird.“"987

Es ist ein geschickter und nachvollziehbarer Schachzug Marcks, wenngleich moralisch schwierig zu bewerten. Ihm war klar, dass er mit diesem Plan nur an Menschen herantreten konnte, die ihn gut kannten. Ein solcher schien Prinz zu Löwenstein zu sein. Die Guild selbst versuchte sich für die Erhaltung des deutschen Geistesgutes einzusetzen und die Akademie der Künste und Wissenschaften, als Unterorganisation der Guild, wollte eine ,oberste geistige Schutzherrschaft über das deutsche Kulturgut außerhalb Deutschlands ausüben.“998 Es muss hierbei beachtet werden, dass Marcks Aufenthaltserlaubnis wenige Tage nach Verfassen des Briefes

\footnotetext{
986 Ebd.

987 Ebd.

${ }^{988}$ Lehmann, Klaus-Dieter (Hrsg.): Deutsche Intellektuelle im Exil, S. 108.
} 
ausgelaufen wäre und er in der Umsetzung des Plans die Möglichkeit sah, die NonQuota-Einwanderung zu versuchen. ${ }^{989}$ Ob der von Marck vorgeschlagene Plan umgesetzt wurde, ist nicht mehr zu rekonstruieren. Festzuhalten bleibt jedoch, dass Marck nach Chicago ging, beim YMCA-College seine Arbeit aufnahm und nicht ausgewiesen wurde. Ferner war Marck mit der Abzahlung von Schulden an diverse Comités belastet. ${ }^{990}$

Viele Emigranten wussten nicht, dass es für Exilanten aus Deutschland eine Einreisequote gab und diese seit langem und insbesondere nach dem Anschluss Österreichs und den Novemberpogromen ausgeschöpft war. Selbst Personen, die über ein sogenanntes Affidavit, folglich über eine beglaubigte Bürgschaftserklärung verfügten, was eigentlich die Einreise vereinfachen sollte, mussten warten. Helmut Hirsch etwa hatte ein solchen Affidavit of Support erhalten, nachdem er im Oktober 1938 Kontakt zur Guild aufgenommen hatte. Dennoch wurde Hirsch nach Kriegsbeginn in Frankreich interniert und konnte erst Mitte Juni 1941 in die USA einreisen. ${ }^{991}$ Dabei wurde er in den Anfangsjahren besonders von Prinz zu Löwenstein und Volkmar Zühlsdorff unterstützt. Er ging nach Chicago, arbeitete einige Monate in einem Warenlager, bevor er sein Studium an der University of Chicago wieder aufnehmen konnte. ${ }^{992}$ Dort, im Lesesaal der Bibliothek, traf er zum zweiten Mal auf Siegfried Marck. Beide befanden sich in der Bibliothek, um ihre jeweiligen Studien voranzutreiben, als Siegfried Marck Helmut Hirsch wiedererkannte. Auch Hirsch war ein wenig verwundert, denjenigen Redner, den er knapp zehn Jahre zuvor in Paris auf einer Massenprotestversammlung zum ersten Mal eindrucksvoll erlebt hatte, nun in einer Bibliothek in Chicago wieder zu treffen. ${ }^{993}$ Aus diesem Zusammentreffen entwickelte sich eine Freundschaft mit Sprengkraft. Immerhin war Hirsch Anhänger der Kommunistischen Partei und verortete die Umsetzung des Sozialismus exakt dort, während Marck als Sozialdemokrat seine Partei stets als Wiege des Sozialismus verstand.

Wenngleich Siegfried Marck einst an den altehrwürdigen Universitäten in Breslau und Dijon tätig gewesen war, so fand er sich nun in einem drittklassigen College mit „einigen Korridoren, rußgeschwärzten Klassenräumen und überfüllten

\footnotetext{
${ }^{989}$ Marck an Prinz zu Löwenstein, 09.10.1939.

${ }^{990}$ Marck an Broch, 02.03.1940, NL HB.

${ }^{991}$ Hirsch benötigte neben einem Affidavit auch ein Affidavit of Sponsorship und hatte eine weitaus schwierigere Emigration in die Vereinigten Staaten als Siegfried Marck, vgl. Lehmann, Klaus-Dieter (Hrsg.): Deutsche Intellektuelle im Exil, S. 485-493.

${ }^{992}$ Ebd., S. 493.

${ }^{993}$ Hirsch, Helmut: Onkel Sams Hütte. Autobiographisches Garn eines Asylanten in den USA, Leipzig 1994, S. 159.
} 
Hintertreppen-Aufzügen“" wieder, einer kleinen Schule, im Stadtkern gelegen, in der jährlich 2.400 Schülern eine gewisse Grundbildung vermittelt wurde. ${ }^{994}$ Helmut Hirsch beschrieb seine ersten Eindrücke dieses YMCA-Colleges wie folgt: „Auf den ersten Blick fällt auf, dass die Kundschaft dieses akademischen Unternehmens viele Angehörige ,unterprivilegierter“ Minderheiten zählt.“995 Der Anteil der „Farbigen“ lag 1944 bei etwa 25 Prozent, dazu kamen viele Emigranten, circa 800 Juden, 96 Japaner und circa 400 Katholiken. ${ }^{996}$ Auch war die Bildungseinrichtung ein gemischtes College, in dem Frauen und Männer gemeinsam unterrichtet wurden. Es kam fortwährend zu Spannungen zwischen dem Präsidenten der Lehranstalt, Edward Sparling, und dem Träger, dem konservativen YMCA. Sparling wurde aufgrund dieser Differenzen entlassen. ${ }^{997}$ Mit ihm ging ein großer Teil des Lehrkörpers und der Studenten - sie gründeten das Roosevelt College in Chicago, das nun von Marshall Field III und der Rosenwald Stiftung finanziert wurde. ${ }^{998}$ Das College verfügte in den Anfangsjahren nicht mal über eine eigene Bibliothek, einen Campus oder eine Stiftung und erst als es gelang, das Auditorium Building in der Michigan Avenue für einen Dollar zu erhalten, etablierte sich dieses College.

Marcks Entlohnung am College war sehr gering. Eine seiner Schülerinnen, Ruth Asch, verdiente nach ihrem Abschluss als Highschool-Philosophielehrerin schon mehr als Marck, der diese wohl als physisch recht anziehend empfand, doch soll sie „hohnlachend“ gesagt haben, ,sie würde ihn auch nicht nehmen, wenn er ihr auf einem silbernen Tablett serviert würde“. 999

Siegfried Marck war einer derjenigen, der sich gegen die diskriminierende Stimmung im YMCA-College auflehnte. Die Leitung der Bildungsstätte wollte Quoten für Farbige, Juden und Emigranten einführen, was Marck nicht gutheißen konnte. Er reichte seine Kündigung ein erreichte mit den anderen Professoren und Studenten, die dieser Limitierung kritisch gegenüberstanden, das Roosevelt College. ${ }^{1000}$ Dies ist Marck hoch anzurechnen, hatte er doch lange für seine

\footnotetext{
${ }^{994}$ Vgl. ebd., S. 160.

995 Ebd.

996 Interview of Edward James Sparling by Daniel Perlman, 10 $0^{\text {th }}$ December 1971, in: http://www2.roosevelt.edu/library/oralhistory/06-Sparling.pdf [zuletzt eingesehen am 12.05.2014].

${ }^{997} \mathrm{Zu}$ den Differenzen siehe: American Council on Education. College Study in Intergroup Relations, Bd. 1 (1950), S. 156ff; Segal, Ben: Color and the Chicago YMCA, in: The Crisis 1945, July 1945, S. 197, 206; Hirsch, Helmut: Onkel Sams Hütte, S. 159-168.

${ }_{998}$ Hirsch, Helmut: Onkel Sams Hütte, S. 163.

${ }^{999}$ Ebd., S. 326.

${ }^{1000}$ Marck an Sparling, 20.02.o. J., NL HH. Marck an Grimme, 13.10.1946, NL AG. Marck taucht jedoch nicht, im Gegensatz zu Helmut Hirsch, in den Spenderlisten für das Roosevelt College auf, vgl. Spenderlister, NL HH.
} 
„Fixierung“ in den USA gekämpft und setzte so sein finanzielles Auskommen aufs Spiel. 1950 war Marck eines von 36 Fakultätsmitgliedern, die gegen das Berufsverbot von James Kutcher protestierten, der als Kriegsteilnehmer seine Beine verloren hatte. ${ }^{1001}$ Dennoch: Mit den Universitäten in Breslau, Genf, Freiburg, Dijon und Paris konnte das Roosevelt nicht mithalten, auch nicht mit den großen und namenskräftigen Universitäten der amerikanischen Ost- und Westküste - eben jenen Universitäten, an die andere Emigranten und Bekannte Marcks „vermittelt“ wurden. Zudem gab es in Chicago die University of Chicago, die anders als das Roosevelt College über die nötige Provenienz verfügte und beispielsweise andere jüdische Intellektuelle wie Hannah Arendt beschäftigte.

Um überhaupt die Möglichkeit zu bekommen, seine wissenschaftlichen Werke zu publizieren, war Siegfried Marck auf finanzielle Zuschüsse angewiesen. Schon einmal hatte der ehemalige Breslauer Philosophieprofessor von der Guild Mittel erhalten, indem er von dort einen Druckkostenzuschuss für sein Werk „Neuhumanismus als politische Philosophie“ bekam. ${ }^{1002}$ Begutachtet wurde Marcks Schrift von Thomas Mann, welcher der Guild wenigstens eine Zeit lang vorsaß ${ }^{1003}$ und nicht minder von dessen Bruder Heinrich:

„Ich bestätige Ihnen also gern, dass ich Ihr Werk, nachdem ich es im Manuskript mit großem Anteil gelesen, einer solchen Beihilfe durch die ,Guild for German cultureal Freedom“ durchaus für würdig halte. Es wäre mir eine wirkliche Freude, wenn die Guild auf meines Bruders und meine Empfehlung sich entschlösse, einen Zuschuss zu leisten.“ “1004

Damit war Siegfried Marck einer von vielen, aber dennoch im Angesicht der politischen Lage zu wenigen Stipendiaten der Deutschen Akademie im Exil. Ohnehin waren die Mittel bis zum Ausbruch des Zweiten Weltkrieges beinahe verbraucht und 163 Literaten, Wissenschaftler, Publizisten und Intellektuelle erhielten direkte Stipendien oder einmalige Nothilfen. Dabei kam das Gros der geförderten Personen aus Frankreich, gefolgt von den Vereinigten Staaten, der Tschechoslowakei, der Schweiz, England, Österreich, Holland, Belgien, Italien und Palästina. ${ }^{1005}$ Ein Blick in die Stipendiaten-Liste verdeutlicht, dass dort vor allem Personen zu finden sind, mit denen Siegfried Marck während seiner politischen Arbeit weiterhin Kontakt

\footnotetext{
${ }^{1001}$ Hirsch, Helmut: Siegfried Marck, S. 385.

1002 Marck an Deutsche Akademie im Exil, Lebenslauf, Mai 1938. DNB. Interessanterweise nennt Marck im Zusammenhang mit seiner Bewerbung auch den Namen Anna Seghers, die durch die Guild gefördert wurde und sich ,gewiss dafür [seine Schrift] interessieren“ würde. Wieder ein Indiz, dass Marck sich gern mit den Namen anderer schmückte - mit Erfolg.

1003 Thomas Mann trat Anfang 1940 nach Spannungen aus der Guild aus.

1004 Thomas Mann an Marck, 02.06.1938. TMA.

${ }^{1005}$ Vgl. Zühlsdorff, Volkmar: Deutsche Akademie im Exil, Berlin 1999, S. 169ff.
} 
haben sollte. $\mathrm{Zu}$ den Geförderten gehörte unter anderem Hermann Broch, Hermann Budzislawski, Oskar Maria Graf, Kurt Hiller, Helmut Hirsch und auch Marcks Mentor Richard Hönigswald neben Karl O. Paetel und Anna Siemsen. ${ }^{1006}$

Im Dezember 1941 reiste Kläre mit den Kindern Louis und Claudia auf der „Serpa Pinto“, einem portugiesischen Schiff, in die USA. ${ }^{1007}$ Louis wurde darauf in einem Veteranen-Krankenhaus der Army behandelt und konnte am New Yorker University College Dank der G.I. Bill studieren. ${ }^{1008} 1942$ bekam er einen ersten Job durch die Hilfe des YMCA. ${ }^{1009}$ Er graduierte zum PhD an der New York University und lebte ab Ende 1945 bei Kläre. Seinen Vater enttäuschte er wissenschaftlich sehr. ${ }^{1010}$ Marck hatte sich ohne Frage mehr für seinen Sohn erhofft. Nach diversen Lehraufträgen erhielt dieser keine Professur, sodass er letztlich als Deutschlehrer an der New York Berlitz School, einer Sprachschule, unterrichtete, um zu überleben. Es muss zwischen ihm und seinem Vater zum Zerwürfnis gekommen sein, anders ist das Testament Frieds nicht zu bewerten. Er hinterließ Louis 1 Dollar, der Rest ging an Ilse Apt, seine dritte Ehefrau. Seine Tochter Claudia sowie seine Söhne Andreas und Alfons sind nicht einmal erwähnt. ${ }^{1011}$

Dennoch - und das muss in aller Deutlichkeit betont werden - konnten die Marcks in die USA einreisen und so den Folgen des Nationalsozialismus entkommen. Andere, auch Bekannte von Siegfried Marck aus Zeiten der Volksfront, hatten es weitaus schwerer, wie Hubertus Prinz zu Löwenstein dem Schriftsteller Hermann Borch berichtete:

„Bestimmte Leute, Emigranten und andere, haben ihre Günstlinge vorgeschoben, ja mehr noch: es gab sogar Fälle privater Rache, dadurch ausgeübt, dass gegen die Einreise von Emigranten, die in Frankreich in dauernder Todesgefahr sind, intrigiert wurde!! Ich weiß dies z.B. im Fall von Lion Feuchtwanger, der schon längst hier sein könnte. Ein Beamter in Washington sagte mir: , die deutsche Emigration in Amerika scheint ihren 4. Juni gegen andere Emigranten zu betreiben. $، 1012$

\footnotetext{
${ }^{1006}$ Listen, in: Ebd., S. 239f; Lehmann, Klaus-Dieter (Hrsg.):Deutsche Intellektuelle im Exil, S. 559.

${ }^{1007}$ Ilse Marck an Bezirksamt für Wiedergutmachung, 31.12.1958, NL SM.

1008 Marck an Friedländer, 29.09.1946, NL WF. Die G.I. Bill of Rights wurde 1944 erlassen, um Soldaten, die im Zweiten Weltkrieg dienten, die Eingliederung ins Berufsleben zu erleichtern, das beinhaltete neben einer Art Arbeitslosengeld und günstigerer Kredite auch den Zugang zur Universität - mit weitrechenden Folgen für Amerika, siehe: Humes, Edward: Over Here: How the G.I. Bill Transformed the American Dream. Harcourt, New York 2006.

${ }^{1009}$ Marck an Friedländer, 26.01.1942, NL WF.

1010 Dies wird auch innerhalb der Familie tradiert, siehe Nachricht John March an Verfasser, 21.02.2012.

${ }^{1011}$ Last Will and Testament, NL SM.

1012 Prinz zu Löwenstein an Broch, 30.07.1940, NL HB.
} 
Feuchtwanger, der selbst der Deutschen Akademie angehörte, dort Gutachten für eine Vielzahl von Emigranten schrieb ${ }^{1013}$ und überhaupt unter den Exilanten präsenter war als Marck, kam zu spät zu der Einsicht, Frankreich verlassen zu müssen und wurde dort interniert. ${ }^{1014}$ Er selbst nannte die Bürokratie und die Schlamperei der Bürokraten als das größte Hindernis seiner Ausreise in die Vereinigten Staaten:

"Ich war in Deutschland geneigt, die Bürokratie als ein typisch deutsches Laster anzusehen,
als einen Exzess des deutschen Ordnungs- und Organisationstriebes. Dann sah ich in der
Sowjetunion, dass es dort noch schlimmer war. Dann erlebte ich in dem freien,
individualistischen Frankreich eine noch mehr gesteigerte Bürokratie, nur gemildert durch
die Lässigkeit und Schlamperei der Beamten, und schließlich sah ich mich auch in Amerika
verstrickt in ein endloses Geschlinge von Bürokratie."

Feuchtwanger unterstellte den französischen Behörden keine böswillige Absicht, doch attestierte er diesen Schlamperei, Gedankenlosigkeit, Herzensträgheit, Konvention und Routine im Umgang mit den Internierten. ${ }^{1016}$ Überhaupt galt es für die vielen geflohenen Intellektuellen, die in den Lagern interniert wurden, die Professoren, Geheimräte und Ministerialdirektoren, an ihrer Bildung festzuhalten, um nicht in der Bedeutungslosigkeit zu verschwinden. ${ }^{1017}$

Hermann Broch, der 1909 dem Judentum abschwor und Katholik wurde, der von den Nationalsozialisten 1938 zeitweilig festgesetzt wurde, emigrierte wie Marck, dank der Fürsprache von Thomas Mann und Albert Einstein, in die Vereinigten Staaten. ${ }^{1018}$ Er schrieb im Nachgang seiner Emigration an Marck, dass Löwenstein eine Befreiungsaktion für die Opfer des französischen Bürokratismus plane, „der allerdings in mancher Beziehung verständlich ist, da sich unter den Juden tatsächlich, so ungern man es glaubt, Gestapo-Agenten befunden haben“،“"1019 Auch der Sohn Brochs saß im Internierungslager. ${ }^{1020}$

Feuchtwanger indes hatte oft um sein Leben zu fürchten. Er wurde zum zweiten Mal interniert und war den französischen Behörden ausgeliefert. In Frankreich entwickelte sich ein Chaos, das sich bei dem Zusammenbruch der Demokratie nach der Niederlage gegen die Deutschen verstärkte, da die Vorschriften der Bürokratie erhalten blieben und noch absurder wirkten als vorher, ja in vielen

\footnotetext{
${ }^{1013}$ Lehmann, Klaus-Dieter (Hrsg.):Deutsche Intellektuelle im Exil, S. 82, 85, 102, 103-108.

${ }^{1014}$ Zu Feuchtwanger Exil siehe: Specht, Heike: Die Feuchtwanger. Familie, Tradition und jüdisches Selbstverständnis, Göttingen 2006, S. 311-377.

${ }^{1015}$ Feuchtwanger, Lion: Der Teufel in Frankreich, S. 51.

1016 Ebd., S. 42f.

${ }^{1017}$ Dies verdeutlichen Feuchtwangers Schilderungen, vgl. ebd., S. 54f.

${ }^{1018} \mathrm{Zu}$ Broch siehe: Lützeler, Paul Michael: Hermann Broch. Eine Biographie. Frankfurt am Mai 1985.

1019 Broch an Marck. 28.02.1940, NL HB.

${ }^{1020}$ Dies geht aus einem Brief von Marck an Broch hervor, 02.03.1940, NL HB.
} 
Fällen tödliche Folgen haben konnten. ${ }^{1021}$ Feuchtwanger jedenfalls floh, trotz sabotierender Konsularbeamten. Mit Hilfe seiner Frau und als selbige verkleidet gelangte er mit Hilfe der Mafia aus dem Lager. Darauf konnte er über Lissabon in die Vereinigten Staaten fliehen. ${ }^{1022}$ Dort wurde er Nachbar von Thomas Mann.

Siegfried Marck hatte in Chicago regen Kontakt mit Walter Friedländer, der ihm nicht nur in seinen Gedanken zu Erwachsenenbildung sehr nah gewesen sein wird. Dieser war jahrelang als Vorsitzender des Fachausschusses „Jugendwohlfahrt“ in Deutschland aktiv gewesen und publizierte regelmäßig in der Arbeiterwohlfahrt. Friedländer, der 1891 in Berlin geboren wurde und mit pazifistischen Strömungen sympathisierte, kam aus einer sozialdemokratisch gefärbten Familie. Sein Onkel war Hugo Haase, der nach August Bebels Tod den Vorsitz der SPD übernommen hatte und später die USPD mitbegründete. ${ }^{1023}$ Er studierte Rechtswissenschaften, Philosophie und Nationalökonomie in Berlin und München, zog unfreiwillig in den Ersten Weltkrieg und lehnte 1918 das Stellenangebot Kurt Rosenfelds im Justizministerium ab, um das Studium der Rechtswissenschaften zu beenden. Friedländer wurde nach seinem Examen Stadtrat und Leiter des Jugendamtes im Berliner Bezirk Prenzlauer Berg. Zudem lehrte er gemeinsam mit aller jugendwohlfahrtsangehauchten Provenienz. ${ }^{1024}$ Nach der Machtübernahme wurde Friedländer von seinem Cousin Ernst Haase geraten, Deutschland zu verlassen. So floh er zuerst nach Genf und dann weiter nach Paris, wo er eigentlich eine Flüchtlingsberatungsstelle leiten sollte. Da ihm jedoch die Behandlung der meist jüdischen Familien missfiel, lehnte er dieses Angebot Hellmut von Gerlachs ab. Stattdessen gründete er die Arbeiter-Wohlfahrt Paris, die ohne Finanzhilfen des sozialdemokratischen Parteivorstandes nicht hätte weiter bestehen können. ${ }^{1025}$ Es liegt nahe, dass Siegfried Marck und Walter Friedländer bereits in Paris miteinander Kontakt hatten, doch ist dies nicht zu belegen. Friedländer erhielt 1936 ein Lehrangebot an der Universität von Chicago und hatte Bürgschaften von Kurt

\footnotetext{
${ }^{1021}$ Vgl. Köpke, Wulf: Die Flucht durch Frankreich. Die zweite Erfahrung der Heimatlosigkeit in Berichten der Emigranten aus dem Jahre 1940, in: Koebner, Thomas et al. (Hrsg.): Das jüdische Exil und andere Themen. Jahrbuch der Gesellschaft für Exilforschung, Bd. 4/1986, S. 229-242, hier S. 239.

${ }^{1022}$ Feuchtwanger, Lion: Der Teufel in Frankreich, S. 255ff. Auch Marck vernahm aus dem Aufbau, dass Feuchtwanger fliehen konnte, vgl. Brief an Friedländer 07.09.1940. NL WF.

${ }^{1023}$ Füssl, Karl Heinz: Deutsch-amerikanischer Kulturaustausch im 20. Jahrhundert, Frankfurt am Main 2004, S. 150.

${ }^{1024}$ Ebd., S. 150-168

${ }^{1025}$ Ebd., S. $160 \mathrm{ff}$.
} 
Rosenfeld und J.Cesar Guggenheimer, was ihm und seiner Familie die Einreise in die Vereinigten Staaten ermöglichte. ${ }^{1026}$

Was Siegfried Marck und Walter Friedländer in Chicago auch verband, war die gemeinsame Arbeit in einer Chicagoer Selbsthilfegruppe für Emigranten. Der religiöse Sozialist Paul Tillich, der sich wie Siegfried Marck bei Eugen Kühnemann in Breslau promovierte, hatte in New York eine Selbsthilfeorganisation für Emigranten aufgebaut und forderte nun Friedländer auf, eine solche auch in Chicago zu etablieren. Friedländer kam dem nach und leitete bis zu seinem Weggang nach Berkeley Ende 1943 diese Organisation. Die Chicagoer Selbsthilfegruppe war, anders als ihr New Yorker Pendant, von ehrenamtlicher Tätigkeit geprägt. ${ }^{1027}$ Dabei ging es um die Beratung von Neuankömmlingen in Fragen der Arbeit und um das Beschaffen von Bürgschaften sowie das Bereitstellen von Unterkünften oder Rechtsberatungen. ${ }^{1028}$ Als erste profitierte die mittlerweile 65 Jahre alte Marie Juchacz, die in Weimar Wegbereiterin und Vorbild für Clara Zils-Eckstein und Kläre Marck gewesen sein mag, von dieser Gruppe. Doch konnte diese sich in den USA nicht einleben und ging 1948 nach Deutschland zurück. ${ }^{1029}$ Auch Siegfried Marck wurde für diese von Friedländer geführte und von Tillich geforderte Gruppe aktiv. ${ }^{1030}$ Ihm wird diese Arbeit nicht fremd gewesen sein, da diese seiner in den Umbruchjahren geleisteten Tätigkeit im Demobilisierungsrat in Breslau glich, wo er mit ähnlichen Problemen konfrontiert gewesen sein wird.

Siegfried Marck jedenfalls nahm sich aus der Arbeit für andere Exilanten nicht heraus. Er erinnerte sich an Helmut Hirsch und brachte diesen mit dem Roosevelt College in Kontakt. Hirsch unterrichtete bald darauf an der Fakultät für Geschichte. Zudem machte sich Siegfried Marck zu Gunsten Hermann Budzislwaskis stark, der weiterhin in Frankreich festsaß und den er noch aus dem RUP kannte. Dieser war ebenfalls Jude und als Chefredakteur der Weltbühne den Nationalsozialisten ein Dorn im Auge, gerade weil die Weltbühne Verbindungen zu kommunistischen Kreisen hatte und pazifistisch sowie sozialistisch ausgerichtet war. Auch die Guild versuchte sich für Budzislawski einzusetzen, wenngleich sie zu Beginn des Krieges nur über knappe Mittel verfügte. Besonders Prinz zu Löwenstein, der sich im Januar 1940, als Budzislawski schon im Internierungslager saß, an den

\footnotetext{
${ }^{1026}$ Ebd., S. 163f.

${ }^{1027}$ Näheres zu dieser Gruppe bei Schwerin, Gertrude: Lebenserinnerungen, LBI NY S. 84ff.

${ }^{1028}$ Füssl, Karl Heinz: Deutsch-amerikanischer Kulturaustausch, S. 164.

${ }^{1029}$ Ebd., S. 164f.

${ }^{1030}$ Hirsch, Helmut: Onkel Sams Hütte, S. 261; Bspw. Aufbau, 22.10.1949, 12.11.1949.
} 
französischen Botschafter in Washington wandte, nannte Budzislawski in einer Reihe mit Paul Dreyfuss, Hans Siemsen, Siegfried Kracauer oder Walter Mehring. Prinz zu Löwenstein erläuterte dort, weshalb diese Personen zu Unrecht interniert worden seien. ${ }^{1031}$ Das Verfahren dauerte an, sodass Budzislawski im August 1940 mit der Bitte an Marck schrieb, für ihn Geld und Einwanderungsmöglichkeiten zu beschaffen. Marck kam diesem Wunsch nach:

„Er [Budzislawski] wurde nach dem französischen Zusammenbruch aus dem Lager in Südfrankreich entlassen und es gelang ihm, sein nacktes Überleben zu retten. Er sitzt nun in der Drodogné mit seiner Familie, darunter einem alten Vater völlig mittellos. Er beschwor mich, für ihn in Amerika eine kleine Summe Geldes und Einwanderungsmöglichkeiten aufzutreiben." ${ }^{1032}$

Aus diesen Zeilen Marcks an die Guild wird ein weiteres Problem deutscher Exilanten in Frankreich deutlich. Wenngleich sie aus den Internierungslagern entlassen wurden, waren sie keineswegs gerettet, da der Artikel 19, Paragraph 2 des Waffenstillstandsvertrages vom 28.06.1940 vorsah, dass die französische Regierung sich verpflichtete, alle Deutschen, die von der deutschen Regierung namentlich genannt werden, auszuliefern. ${ }^{1033}$ Folglich galt es unterzutauchen und unter fingierten Namen und Adressen den Kontakt zu potentiellen Fürsprechern aufrechtzuerhalten, so wie es Budzislawski mit Marck tat. Marck wandte sich auch an Hedwig Wachenheim, die für die SPD-Mitglieder in Washington sehr erfolgreich interveniert haben soll und hoffte, dass auf diese Weise auch Budzislawski einen Platz finden könnte. Doch seine Hoffnungen wurden enttäuscht: „Sie teilte mir aber mit, dass diese Liste, bei der scheinbar Präferenzvisen gewährt werden sollen, bereits abgeschlossen ist." Siegfried Marck bemühte sich auch bei Manfred George, dem Chefredakteur des Aufbaus, um die Rettung Budzislawskis, doch dessen Antwort ist nicht mehr zu rekonstruieren. ${ }^{1034}$ Im selben Schreiben machte sich Marck auch für Willi Münzenberg stark, der zu diesem Zeitpunkt jedoch bereits tot war.

Es ist offensichtlich, dass mit Budzislawski ein Sozialdemokrat mit Kontakt zu den Kommunisten an Marck herantrat, dass Marck insbesondere mit Münzenberg jemanden zu retten versuchte, der Mitglied der Kommunistischen Partei war und dass er Helmut Hirsch, einem bekennenden Kommunisten, eine Stelle vermittelte. Somit half Marck Personen, denen die Einreise in die USA auch deshalb schwer gemacht wurde, da sie genau in diesem Kontakt mit dem Kommunismus standen. Marck verstand sich wieder als Bindeglied zwischen linken Sozialisten und

${ }^{1031}$ Lehmann, Klaus-Dieter (Hrsg.):Deutsche Intellektuelle im Exil, S. 427ff.

1032 Marck an Wolfgang Sauerländer (Guild), 26.08.1940, DNB.

${ }^{1033}$ Lehmann, Klaus-Dieter (Hrsg.):Deutsche Intellektuelle im Exil, S. 429

${ }^{1034}$ Marck an Wolfgang Sauerländer (Guild), 26.08.1940. 
„selektierenden“ Rettungsorganisationen. Doch an eine Rettung der Emigranten ohne eine tatkräftige und einflussreiche Organisation war nicht zu denken. Ende Juni 1940 gründete sich das Emergency Rescue Committee, das sich fortan allen entsprechenden Fällen annahm, um eine Zersplitterung der Rettungsarbeiten zu verhindern. Der Guild war es weiterhin vorbehalten, für die Emigranten Affidavits zu beschaffen. ${ }^{1035}$ Budzislaswki flüchtete letztlich über Lissabon in die Vereinigten Staaten ${ }^{1036}$ und blieb in Kontakt mit Siegfried Marck. Nachdem Budzislawski in die USA eingereist war, schrieb Marck in einem Brief:

„Diese Zeit hat wahrhaft homerische Erlebnisse wieder geschaffen und gewiss haben Sie neben "Hündischen", das Sie wie der Bettler Odysseus erfahren haben, auch manches Gute an Menschen konstatieren können. Die Leistung der Amerikaner für die Errettung so vieler unserer Freunde ist ein großartiges Ruhmesblatt.“1037

Als Odyssee wird auch Siegfried Marck seine damalige Situation begriffen haben. Mit der Flucht aus Breslau war er Eduard Heines entkommen, er floh nach Freiburg und Paris, wo er sich neu verliebte und beruflich wiederum kein Fortkommen sah. Er emigrierte in die USA, wo er vorerst nicht auf Dauer bleiben konnte, getrennt von seiner Familie, seiner Mutter und seinen Kindern. Daher gab er Budzislawski folgenden Rat:

„Für Ihre Jobsuche (in der Tat ist ja dieses Wort das erste und wichtigste, das der Immigrant hier lernt) möchte ich Ihnen empfehlen, sich an Professor Nathan 121 West 11 St. von der School of Commerce der University of New York zu wenden. Er ist ein wirklich hilfsbereiter Mann, allerdings außerordentlich beschäftigt und möglicherweise jetzt auch von manchen Schicksalsgenossen bereits in Anspruch genommen. Vielleicht schildern Sie ihm brieflich Ihre ganze Situation und bitten ihn um ein Appointment. Schreiben Sie ihm, dass Sie gehört haben, wie viel er für andere getan hat und berufen Sie sich auch auf mich. Im Allgemeinen werden solche Geschichten, aber Sie werden bald konstatieren, dass das amerikanische Tempo außerordentlich langsam ist, oft noch langsamer, als das französische. Am meisten Amerika in dieser Hinsicht gab es wohl in Berlin. Vielleicht schreiben Sie auch einen Brief an Professor Borgese hier in Chicago, Hotel Windermeere. Ich weiß nicht, ob er etwas für Sie tun kann, meine Beziehungen zu ihm sind auch sehr locker, er ist ein Schwiegersohn von Thomas Mann, italienischer Antifaschist.“1038

Diese Aussage Marcks untermauert sein Gefühl, einer Irrfahrt ausgesetzt zu sein. Interessant ist, dass Siegfried Marck hier Bezug auf seine Beziehungen zu Thomas Mann nimmt, dessen Freundschaft für ihn eine besondere Rolle einnahm. Budzislawski jedenfalls hatte er geholfen, in die Vereinigten Staaten zu gelangen.

\footnotetext{
${ }^{1035}$ Neben dem Affidavit galt es für Personen, die mit einem Special-Emergency-Visum einreisten, bei dem es folglich um ein Besuchervisum handelte, ein weiteres Affidavit, ein Affidavit of Sponsorship zu beschaffen. Dieses konnte nur von einem amerikanischen Staatsbürger ausgestellt werden, der sich für die politische und moralische Integrität des Empfängers verbürgte, vgl. Lehmann, Klaus-Dieter (Hrsg.):Deutsche Intellektuelle im Exil, S. 432.

${ }^{1036}$ Ebd., S. 501.

${ }^{1037}$ Marck an Budzislawski, 19.10.1941, AdK NL BL.

${ }^{1038}$ Ebd.
} 
Als dieser dann innerhalb der USA Karriere machte und Ghostwriter von Dorothy Thompson wurde, trat Marck ein knappes halbes Jahr später erneut an ihn heran:

„Nun komme ich heute mit einer Bitte, die sich auf Ihre guten Beziehungen zur journalistischen und politischen Prominenz der USA gründet. Meine Frau hat in Frankreich einen sehr guten Freund zurückgelassen, der ein exceptioneller [sic]Mensch zu sein scheint und um dessen Schicksal sie sich außerordentlich sorgt. Er ist ein Wiener Maler, Nicola Fechner, der sehr erfolgreich war, arisch, katholisch, von den Nazis nach der Besetzung wegen anti-hitlerischen Karikaturen gesucht. Er war mit meinem Sohn zusammen interniert und hat sich dann im unbesetzten Frankreich mit Porträtzeichnungen von Offizieren, Kleinbürgern etc. durchgeschlagen. Er hat ein Affidavit [wahrscheinlich von Marck, Anmerkung des Verfassers] und ein zweites ist zu beschaffen. Schiffe gehen ja wohl auch von Zeit zu Zeit. Die Schwierigkeit, die immens große Schwierigkeit liegt beim State Department, das im Augenblick nicht nur keine neuen Visen ausgibt, sondern bereits erteilte zurückzieht. Immerhin wird es vielleicht auch dort Ausnahmen geben, und Österreicher sind ja nach der neuen Bestimmung nicht enemy aliens. Sie würden mir einen ganz großen Dienst tun, wenn Sie etwas in der Sache tun könnten. Die Bearbeitung des Emergency Rescue Committee und des State Departments würde in Frage kommen. “1039

Über den Verbleib Nicola Fechners und dessen Person überhaupt konnte nichts herausgefunden werden. Marck jedenfalls versuchte weiter für Immigranten zu agieren, auch noch 1948, als der Zweite Weltkrieg längst beendet war. Doch Marcks Einfluss war begrenzt, trotz aller Anstrengungen, die er auf sich nahm. Walter Friedländer erkundigte sich bei Marck, ob er für Benedikt Kautsky, den Sohn Karls, der erst in Dachau interniert, dann von Buchenwald nach Auschwitz und wieder nach Buchenwald deportiert wurde, etwas tun könne. Marck sollte bei Rockefeller, der Carnegie und der Guggenheim Foundation nachfragen, ob es dort nicht Möglichkeiten gäbe, Kautsky ein Research Fellowship zu besorgen. ${ }^{1040}$ Marck nannte Friedländer zwar seine Kontakte bei den jeweiligen Stiftungen ${ }^{1041}$, doch mehr konnte er nicht tun. ${ }^{1042}$

\footnotetext{
${ }^{1039}$ Marck an Budzislawski, 19.02.1942, AdK NL BL.

${ }^{1040}$ Friedländer an Marck, 25.07.1948, NL WF.

${ }^{1041}$ Marck an Friedländer, 01.08.1948, NL WF.

${ }^{1042}$ Aus der Korrespondenzübersicht in Kautskys Nachlass wird ersichtlich, dass er wohl keinen der Kontakte Marcks angeschrieben beziehungsweise Nachricht erhalten hat, siehe Benedikt Kautsky Papers, International Institute of Social History Amsterdam, Korrespondenz 1947 - 1949 (Mappe 1225).
} 


\section{Für eine Neuordnung Europas - ein Dritter Weg}

Für Siegfried Marck war Frankreich nach seiner Flucht „tot“ - er bedauerte die Niederlage der Ideen von 1789, prognostizierte jedoch zugleich, dass die „Kulturnation nun in Amerika weiterexistieren, die Trikolore im Sternenbanner weiterleuchten würde“. ${ }^{1043}$ Der Niedergang Frankreichs musste Siegfried Marck, wie viele andere Emigranten, geschockt haben. Immerhin war für ihn die „Kulturnation“ die Wiege des Humanismus, welchen Marck antifaschistisch genutzt gern wiederbelebt und sozialistisch eingefärbt hatte. Mehr noch war in den Köpfen der Exilanten der „Mythos des unbesiegbaren Frankreichs““1044 - jenes Landes, das einige der Intellektuellen, darunter auch Siegfried Marck, im Ersten Weltkrieg bekämpft und nicht besiegt hatten - zerstört. Darüber hinaus schien mit der Niederlage Frankreichs die eigentliche Niederlage Europas eingeleitet ${ }^{1045}$, ein Kampf gegen den Nationalsozialismus und für ein freies Europa nahezu obsolet. Marck bezeichnete Frankreichs Haltung nach dem Ausbruch des Zweiten Weltkrieges als „Satyrspiel nach der Tragödie“ und verdeutlichte: „Aber schließlich weiß man ja, dass es auch in der Völkerpsychologie eine Flucht in die Psychose gibt, und außerdem war in der Tat die Verrottung des französischen Bürgertums größer als man annehmen konnte. “1046

Ein demokratisches Europa war für Marck weiterhin ohne den Einfluss des Sozialismus nicht möglich, eine erstarrte Demokratie dagegen vielmehr der „Boden des Faschismus“. ${ }^{1047}$ Er begriff sich nach wie vor als freiheitlicher Sozialist, der seine Kontakte in den USA nutzen wollte. Nach dem Zerfall des Bundes freiheitlicher Sozialisten in Frankreich sollte diese Sammlungsbewegung mit ihrer Anschauung aus den USA heraus weiter forciert werden, um diese Idee weiter zu verbreiten. Eduard Heimann, der Sohn des Sozialdemokraten Hugo Heimann, der wiederum mit August Bebel, Karl Kautksy oder Clara Zektin befreundet gewesen war, gehörte auch dem Kreis religiöser Sozialisten um Paul Tillich an. Eduard Heimann, Hermann Broch und Siegfried Marck trafen sich in New Yorker Cafés und diskutierten über die gegenwärtige politische Lage. Ihnen war es wichtig, ihre Gedankengänge der Weltöffentlichkeit aufzuzeigen, im besten Fall mit einer wirkungsmächtigen Publikation. Marck und Broch diskutierten schon gemeinsam mit Thomas Mann über eine solche Publikation, doch konnte dieser sich nicht

\footnotetext{
${ }^{1043}$ Marck, Siegfried: Frankreich ist tot - es lebe Frankreich!, in: Neue Volkszeitung, 13.07.1940.

1044 Köpke, Wulf: Die Flucht durch Frankreich, S. 229.

1045 Ebd.

${ }^{1046}$ Marck an Friedländer, 07.09.1940, NL WF.

${ }^{1047}$ Vgl. Marck, Siegfried: Frankreich ist tot - es lebe Frankreich!.
} 
durchringen. ${ }^{1048}$ Dies war insbesondere wichtig, da durch die Haltung der Kommunisten innerhalb der Volksfront und der großen „Säuberungsprozesse“ große Verwirrung gestiftet wurde und Marck, Heimann und Broch glaubten, dass eine Abgrenzung gegen jeden reaktionären Missbrauch des Liberalismus und gegen die erneute kommunistische Preisgabe der Freiheitsidee notwendig wäre. Doch wie soll es mit Deutschland nach dem Krieg weitergehen? Wie soll mit den Deutschen umgegangen werden? Broch, Heimann und Marck sprachen sich stets gegen eine Zerschlagung und harte „Bestrafung“ Deutschlands nach dem zu verlierenden Krieg aus, anders als es beispielsweise Leopold Schwarzschild noch in Frankreich tat. Marck verdeutlichte in einem Brief an Albert Einstein, wie er zu dessen Haltung stand:

„Meiner Auffassung nach ist es gleich unerträglich, dass in Frankreich Dr. Schwarzschild mit
seinem restlosen ,Ententismus‘, seiner oft proklamierten Verteidigung von Versailles, das er
heute verschärft wünscht, offizieller Vertreter der deutschen Emigration ist, wie auf der
anderen Seite der kommunistische Verleumdungsfeldzug gegen den Westen nicht
hingenommen werden kann. ${ }^{\text {(1049 }}$ In dem gleichen Schreiben trat Siegfried Marck sicherlich auch im Auftrag von Hermann Broch und Eduard Heimann an Albert Einstein heran und unterbreitete ihm ein Angebot:

„Es ist uns klar, dass Sie und Sie allein heute an der Spitze einer neuen Sammlung treten können, die bewusst auf das verzichtet, was nicht mehr gesammelt werden kann. Es ist aber dabei nicht an eine einmalige Kundgebung zu denken, die verhallt, auch wenn sie vom stärksten Namen getragen wird. Dr. Broch und mir schwebte eine Publikation vor, die von Ihnen herausgegeben wird, deutsch und englisch, vielleicht auch französisch sprechendes Publikum zugleich erreicht, und an der eine Reihe Autoren mitarbeiten, die von konvergierenden Grundüberzeugungen aus nach einer Klärung der uns wichtigen Fragen ernsthaft forschen." ${ }^{1050}$

Marck schlug daran anknüpfend weiter vor, Einstein in Princeton zu besuchen, um dort mit ihm weitere Details zu besprechen. Ob es wirklich zu diesem Treffen kam, ist nicht mehr zu rekonstruieren, auch die geplante Veröffentlichung, die Marck in seinem Schreiben andeutet, ist nicht vorhanden. Einen der „großen“ Exilanten hatten sie mit Einstein nicht erreichen können, doch Broch, Marck und Heimann überlegten weiter, wie sie eine solche Publikation vorantreiben könnten. Broch hätte gerne Marck beauftragt, sich nun dieser Aufgabe anzunehmen, da er sich selbst der Aufgabe nicht gewachsen fühlte:

„Bei Ihnen hingegen, der Sie stets innigen Kontakt mit der Politik gehalten haben und auf eine viel weitere und intensivere Leistung zurückblicken können, steht es ganz anders, und da

\footnotetext{
${ }^{1048}$ Mann, Thomas herausgegeben von Peter de Mendelssohn: Thomas Mann. Tagebücher 1937-1939, Frankfurt am Main 1980, S. 502.

${ }^{1049}$ Marck an Einstein, 06.11.1939, NL HB.

${ }^{1050}$ Ebd.
} 
Sie sich zweifelsohne jeden Tag mehr ins Amerikanische einordnen werden, in dessen Getriebe Sie sich nunmehr befinden, so meine ich, dass Ihnen meine Anregungen eigentlich nicht unsympathisch sein könnten, ja , dass sie eigentlich auf ihrer Linie liegen dürften.“1051

Broch verdeutlichte zudem, dass es „dringlicher und dringlicher“" werde, sich die Frage zu stellen, welche Auswirkungen die Hitlerische Politik auf Amerika haben konnte. Heimann und Broch waren sich einig, dass ein Gegenstoß „einzig und allein von Amerika ausgehen“ konnte. Mehr noch: Wenn sie als freiheitliche Sozialisten nicht nur „radikale Intellektuelle“ sein wollten, „die für den Amerikaner als konservativ-europäische Utopisten“ galten, so mussten sie „rein akademischdeduktiv Diskussionen über Humanitätspolitik tunlichst vermeiden“ und sich im Rahmen der ihnen gebotenen Möglichkeiten mit den Tatsachen in den USA auseinandersetzen. ${ }^{1052}$ Marck indes glaubte nicht, dass der Gegenstoß gegen den Totalitarismus nur von Amerika ausgehen könne, da er die ,innere Lebenskraft der europäischen Westmächte“ höher einschätzte, als es bei den meisten deutschen Emigranten der Fall war. ${ }^{1053}$ Überhaupt lag Marcks Naturell eine solche Aufgabe nicht, er war nie der Mann an vorderster Stelle gewesen, der anklagend, intellektuell und tatkräftig in Erscheinung treten konnte. Damit ging es nie über den Versuch dieser Veröffentlichung hinaus.

Schon früh machte Marck sich Gedanken, wie eine Katastrophe gleich dem Nationalsozialismus in Zukunft verhindert werden konnte. Diejenigen Konstruktionsfehler, die den 1918/19 ins Leben gerufenen Völkerbund zugrunde gerichtet hatten, könnten in einem neuen föderativ organisierten Europa vermieden werden. Deshalb warb er für einen rein europäischen Völkerbund. Zentrum dieses Europabundes sollte seiner Ansicht nach ein enger Schulterschluss Deutschlands, Frankreichs, Italiens und Großbritanniens sein, aus denen jeweils Regierungsvertreter in ein Direktorium entsandt werden sollten, das als Bundesexekutivorgan fungieren sollte. Dieses Zentrum würde dann die kleineren europäischen Staaten um sich bündeln. ${ }^{1054}$ Mit dieser Ansicht widersprach Marck der Linie des eigenen Parteivorstandes, besonders der von Friedrich Stampfer, der sich

\footnotetext{
${ }^{1051}$ Broch an Marck, 28.02.1940, NL HB.

1052 Ebd.

${ }^{1053}$ Marck an Broch, 02.03.1940, NL HB.

${ }^{1054}$ Vgl. Marck, Siegfried: Vom alten zu einem neuen Genf, in: Neue Volkszeitung, 06.01.1940.
} 
für die vollkommene Gleichstellung aller Mitgliedstaaten in einem föderativ europäischen System aussprach. ${ }^{1055}$

Von Marcks politischem Linksdrift, wie er ihn Mitte der 1920er Jahre in Breslau vollzog, war nicht mehr viel zu vernehmen, auch er selbst ordnete sich spätestens ab 1942 zum „rechten Flügel“ der Sozialdemokratie und verdeutlichte, „dass [sein] Marsch zum rechten Flügel auf sachlichen und weltanschaulichen Motiven beruht und mit dummen persönlichen Zänkereien nichts zu tun hat “. ${ }^{1056} \mathrm{Er}$ schrieb nun des Öfteren für die Neue Volkszeitung ${ }^{1057}$, der Nachfolgerin der zur Zeit des Bismarckschen Sozialistengesetzes gegründeten New Yorker Volkszeitung, die jahrelang das führende Organ der Sozialisten in den USA gewesen war. Mit sinkenden Leserzahlen und der Umgestaltung ergriff der rechte Flügel der Sozialisten, der sich deutlich vom Kommunismus distanzierte, die Initiative. Redakteure waren nun vornehmlich deutsche Neu-Immigranten. ${ }^{1058}$ Der alte Teil der Redaktion, der nicht übernommen wurde, gründete die Zeitschrift Das Kampfsignal und war namenstechnisch somit identisch mit dem Organ der SAPD in Deutschland, die sich 1931 unter Kurt Rosenfeld und Max Seydewitz, mit Ernst Eckstein und dem Jungsozialisten Fritz Lewy, von der SPD abgespalten hatte. Beide Gruppen waren miteinander verbunden und hegten Beziehungen $\mathrm{zu}$ den Trotzkisten, deren Publikationsorgan im amerikanischen Exil jedoch nicht ertragreich war.

Redaktionsleiter der Neuen Volkszeitung wurde Gerhart Seger, der wie Marck vor 1933 eher dem linken Flügel der SPD angehört hatte, war er doch von 1923 bis 1928 Generalsekretär der Deutschen Friedensgesellschaft gewesen und hatte sich seither gegen jegliche Form der Rüstung ausgesprochen. Seger, der in Dessau von 1928 bis 1933 Chefredakteur des Volksblattes für Anhalt gewesen und selbst aus dem Konzentrationslager Oranienburg geflohen war, veröffentlichte die von Heinrich Mann eingeleitete Broschüre Oranienburg und erlangte somit auch in den USA Publizität. ${ }^{1059} 1940$ wurde dieser allmählich vom ehemaligen Chefredakteur des Vorwärts, Friedrich Stampfer, verdrängt. In die Redaktion des „deutschamerikanischen Winkelblättchens“ gesellten sich der ehemalige Chefredakteur der Rheinischen Zeitung, Wilhelm Sollmann und (zumindest eine Zeit

\footnotetext{
${ }^{1055}$ Vgl. Schilmar, Boris: Der Europadiskurs im deutschen Exil 1933-1945, München 2004, S. 226.

${ }^{1056}$ Marck an Friedländer, 01.10.1942, NL WF.

1057 Marck verdeutlichte hier stets zur Jahreswende die Ereignisse des vergangenen Jahres, vgl. „Schicksalswende 1940-1941?, 04.01.1941; „Am Ende eines gewaltigen Jahres“, 03.01.1942; „Die Welt am Jahresende“, 02.01.1943; „Erfolge und Enttäuschungen“, 30.12.1944, in: Neue Volkszeitung. ${ }^{1058}$ Vgl. Cazden, Robert Edgar: German exile literature in America 1933-1950, Chicago 1970, S. 32f. 1059 Vgl. Radkau, Joachim: Die deutsche Emigration in den USA. Ihr Einfluß auf die amerikanische Europapolitik 1933-1945, Düsseldorf 1971, S. 144ff.
} 
lang) auch Willi Schlamm, der ehemalige Chefredakteur der Roten Fahne in Wien und der Neuen Weltbühne in Prag. ${ }^{1060}$ Immerhin verstand sich die Neue Volkszeitung nicht explizit als Exil-Organ, auch die Leserschaft bestand nicht vornehmlich aus kürzlich Emigrierten, sondern aus länger ansässigen Deutschamerikanern und begriff sich „,als führende Zeitung der deutsch-amerikanischen Arbeiterbewegung“. ${ }^{1061}$

Eigentlich hätte die Neue Volkszeitung nach dem Ende des Neuen Vorwärts 1940 und den nur noch monatlich erscheinenden Sozialistischen Mitteilungen die führende Stellung innerhalb der Exil-Sozialdemokratie einnehmen können. Doch mit einer „cliquenhaften Abgrenzung“ von links konnte man kein Forum für verschiedene sozialdemokratische Richtungen darstellen. ${ }^{1062}$ Siegfried Marck war, ähnlich wie Sollmann, in der Neuen Volkszeitung für Buchrezensionen und Betrachtungen zum Zeitgeschehen zuständig. Dabei war für ihn die Demokratie „die größte konservative Macht des Zeitalters“ und er pflegte einen „Konservatismus Thomas Mannschen Stils“ ${ }^{1063}$, dessen gelebte Bürgerlichkeit er mit seinem neuen Humanismus gleichsetzte. ${ }^{1064}$ Auf der anderen Seite war er zugleich einer der wenigen Gegner des Antikommunismus innerhalb der NVZ-Redaktion. ${ }^{1065}$ Marcks Eigenheit, sein Denkstil und sein besonderes Temperament, lieber Gegensätze in sich zu vereinen, als sie zu verschärfen, wird in dieser Situation besonders deutlich.

Der Angriff Deutschlands auf die Sowjetunion schuf generell eine neue Situation - für Marcks Europabild und auch für die Neue Volkszeitung. Während diese immer noch am Antikommunismus festhielt, war für Marck klar, dass ,an der Herstellung einer einheitlichen interalliierten Kriegsführung mit Russland wahrscheinlich der Gewinn des Krieges“ liegen würde. Doch dass eine langfristige Kooperation mit Russland in einer Föderation der Weltdemokratien vorerst nicht denkbar war, musste auch Marck konstatieren. ${ }^{1066}$ Viele Sozialisten im Exil teilten die Hoffnungen auf einen innersowjetischen Demokratisierungsprozess. Nur Paul Tillich wich von der Linie der in den USA ansässigen deutschen Sozialdemokraten

\footnotetext{
${ }^{1060}$ Vgl. ebd., S. 146.

${ }^{1061}$ Vgl. Cazden, Robert Edgar: German exile literature, S. II.

1062 Vgl. Radkau, Joachim: Die deutsche Emigration in den USA, S. 148. Auch wenn der Kreis der Neuen Volkszeitung als „totalitär“ oder „Monopol“ bezeichnet werden konnte, so bot sie, mit Ausnahme von Rudolf Katz (Justizminister in Schleswig Holstein 1947-1950) und Max Brauer (Oberbürgermeister von Hamburg 1953-1957/1960), doch kein Sprungbrett in die höheren Positionen in der Nachkriegs-SPD.

${ }^{1063}$ Vgl. Neue Volkszeitung, 11.10.1941.

1064 Marck, Siegfried: Thomas Mann as a thinker, in: Ethics, Vol. LXVII No. 1, October 1956, Seite 53-56, hier S. 53.

${ }^{1065}$ Vgl. Vgl. Radkau, Joachim: Die deutsche Emigration in den USA, S. 153.

${ }^{1066}$ Vgl. Marck, Siegfried: Einheitsfront oder Zweckallianz?, in: Neue Volkszeitung, 28.06.1941.
} 
ab, bewertete die Frage nach der Teilnahme Sowjetrusslands an einer europäischen Föderation positiver und befand sich im krassen Gegensatz zu Marck, Stampfer oder Katz. ${ }^{1067}$ Auch in der Frage nach einer Teilung Deutschlands nach dem Krieg prophezeite Marck zusammen mit Gerhart Seger, und anders als Tillich, die Teilung des europäischen Kontinents nicht in zwei, sondern in drei Blöcke: den englischfranzösischen Block mit Nord-und Westeuropa, den Mitteleuropablock zwischen Russland und Deutschland sowie den Balkanblock mit Österreich. ${ }^{1068}$ Doch die Lösung oder vielmehr die Auflösung eines so „konfliktträchtigen Kräftefeldes“ oder mehr noch die Relativierung des sich anbahnenden Ost-West-Konfliktes könne nur geschehen, wenn die antikommunistischen Gedanken in Deutschland und im deutschen Exil zurückgestellt würden und Deutschland als Brücke oder Bindeglied zwischen Ost und West diene. Andernfalls würde jede weitere Anspannung zwischen Russland und dem Westen schicksalhafte Einflüsse auf die deutsche Politik haben. ${ }^{1069}$

Marck forderte für ein langfristiges föderatives Zusammengehen mit der Sowjetunion eine stärkere „Sozialisierung der Demokratien“ sowie eine „stärkere Demokratisierung Russlands“1070, auf der anderen Seite aber auch eine Neugliederung Europas mit amerikanischem Beistand, da die Kriegsereignisse des Jahres 1940 zeigten, dass ein Eingreifen der USA in die Kriegshandlungen zugunsten von Frieden und Freiheit wäre. ${ }^{1071}$

Mit seinen Thesen zur Russlanddebatte startete Marck einen Generalangriff auf die Politik der Neuen Volkszeitung-Redaktion und verdeutlichte seine Ansicht, dass Russland „nicht nur der unentbehrliche, sondern der entscheidende Bundesgenosse der Weltdemokratie geworden“" sei. ${ }^{1072}$ Immerhin sei das Ansehen Russlands in der Welt nach dem Gegenangriff der Roten Armee ungeheuer gestiegen, obgleich dies weder den ,ideologischen Bankrott“ der Komintern verhindere, noch die „Rechtfertigung aller bolschewistischen Regierungsmethoden“ legitimierte. Auch wenn Marck den Widerstand Russlands als Erfolg des FünfJahres-Planes wertete, war dieses System für ihn weder sozialistisch und schon gar nicht marxistisch, auch wenn es „materiell und ideologisch stark sozialistische Züge“

\footnotetext{
${ }^{1067}$ Vgl. Tillich, Paul: Wessen Kriegsziele?, in: Albrecht, Renate/Henel, Ingebord (Hrsg.): Paul Tillich gesammelte Werke, Bd. 13: Impressionen und Reflexionen: ein Lebensbild in Aufsätzen, Reden und Stellungnahmen, Stuttgart 1972, S. 264-269, hier S. 266.

${ }^{1068}$ Vgl. Marck, Siegfried/Seger, Gerhart: Germany: To Be or Not To Be?, New York 1943, S. $132 \mathrm{ff}$.

${ }^{1069}$ Vgl. ebd., S. 136f.

${ }^{1070}$ Vgl. Ders.: Am Ende des gewaltigen Jahres, in: Neue Volkszeitung, 03.01.1942.

${ }^{1071}$ Vgl. Ders.: Schicksalswende 1940-1941?, in: Ebd., 04.01.1941.

${ }^{1072}$ Vgl. Ders.: Thesen zur Russland-Debatte, in: Sozialistische Mitteilungen, Nr. 37 (1942), S. 7.
} 
trage. Mit diesem Argument versuchte er der vorherrschenden Meinung innerhalb der Neuen Volkszeitung zu widersprechen. Gerade weil das russische System materiell und ideologisch stark sozialistische Züge trage, sei es ,ungerechtfertigt, dieses System einen roten Faschismus zu nennen." Für Marck war die Sozialdemokratie weiterhin die genuin marxistische Partei, während beispielsweise Wilhelm Sollmann schon damals gern den Marxismus den Kommunisten überließ. ${ }^{1073}$ Auch zeigte Marck den Unterschied zwischen Faschismus und der Haltung der Sowjets auf, indem er auf „die Einstellung zum Weltfrieden, zur Sozialpolitik, zum Rassenproblem, zur Frau und zur Wissenschaft“, verwies. ${ }^{1074}$ Der Philosoph und Sozialdemokrat verdeutlichte, dass der Widerspruch zwischen russischem Nationalismus und proletarischem Internationalismus innerhalb der Komintern niemals aufzuheben sei. Mit einer Dialektik kam man mit Aufhebung der Gegensätze zwischen Nationalismus und Internationalismus, die sich besonders in tagespolitischen Diskursen zeigten, nicht weit. Und auch die zwiespältige Haltung der Kommunisten innerhalb der Volksfront in Frankreich ließ für Marck eigentlich nur den Schluss zu, dass die „Auflösung der Komintern“ sowohl ein „Dienst für die Arbeiterbewegung der Zukunft“ als auch für eine „positive Gestaltung der angelsächsisch-russischen Beziehungen, von denen das Schicksal des Planeten abhängen mag“, die beste Lösung des Problems sei. ${ }^{1075}$ Das Schicksal Polens, der Tschechoslowakei, Zentraleuropas und der Balkanländer sowie überhaupt das Problem der Rekonstruktion Europas, das mit einem Fortbestehen der Komintern nach dem erfolgreichen Kampf gegen den Nationalsozialismus nur noch verschärft werden würde, zeige, dass Stalins Verzicht auf weltrevolutionäre Propaganda und expansiven Kommunismus die gesamte Situation und den notwendigen Ausgleich mit der westlichen Welt erleichtern könnte. ${ }^{1076}$ Aber auch Marck musste sich eingestehen, dass eine Demokratisierung Russlands nicht allzu wahrscheinlich war. Vielmehr noch sprach er der Sowjetunion jegliche Form der Demokratie ab, da für ihn das ,monopolitische Ein-Partei-System überall den eigentlichen Widerspruch zur Demokratie“"1077 darstellte.

Die Neue Volkszeitung hatte die Tendenz zur Isolation, sie verschrieb sich dem Antikommunismus. Diese Haltung bewies sicherlich auch Siegfried Marck, eine

\footnotetext{
${ }^{1073}$ Vgl. Radkau, Joachim: Die deutsche Emigration in den USA, S. 162.

${ }^{1074}$ Vgl. Marck, Siegfried: Thesen zur Russland-Debatte, S. 8.

${ }^{1075}$ Vgl. ebd., S. 9.

${ }^{1076}$ Vgl. ebd.

${ }^{1077}$ Vgl. ebd., S. 10.
} 
mangelnde Bereitschaft der Redaktion, dort überhaupt Politik betreiben zu wollen. Ein Verhandeln, die Bereitschaft Kompromisse zu schließen und gemeinsam bestimmte Ziele durchzusetzen, waren der Redaktion abhanden gekommen. Diese Abschirmung musste letztlich die Neue Volkszeitung darauf beschränken, einzig „rhetorische Opposition gegen die alliierte Deutschland-Politik zu betreiben.““1078 In Folge dieser Divergenzen ging Marck auf Distanz zur Neuen Volkszeitung und bewegte sich nun wieder vermehrt in bürgerlich-intellektuellen Kreisen. Danach waren seine Beziehungen zum Blatt sehr gedrosselt und er schrieb an seinen Kollegen Helmut Hirsch: „Wenn ich dort je wieder mitarbeite, möchte ich es nicht mit etwas sehr persönlich Gefärbtem tun.“1079

Thomas Mann, der sich mit Gerhart Seger, dem Redakteur der Neuen Volkszeitung traf, schrieb an Marck, dass ihm „die Russenfresserei der Volkszeitung auf die Nerven gehe“. ${ }^{1080}$ Marck selbst schrieb fortan nicht mehr über Politik für dieses Blatt, lediglich Buchbesprechungen für seine Freunde, wie etwa für Helmut Hirsch, sind nachzuweisen. ${ }^{1081}$ Dabei geriet Siegfried Marck mit einer Rezension über ein Buch seines Freundes Helmut Hirsch in die Schusslinie von Oskar Maria Graf. „In der letzten Nr. der NZ haben Sie das Büchlein Ihres Kollegen Helmut Hirsch: Amerika, Du Morgenröte besprochen, und ich muss Ihnen offen gestehen, dass ich mich dabei für Sie schämte“. ${ }^{1082}$ Hirsch schrieb seine „Verse eines Flüchtlings“ in seiner ihm eigenen Sprache. Graf fand die „Reimereien“, über die er selbst für den Aufbau schreiben sollte, „einfach unmöglich“. Für ihn war es zwingend notwendig, dass der Literatur, und besonders der deutschen Literatur, nur ein gewisses Ansehen verschafft werden könne, „wenn man mit größter Verantwortung und Unbestechlichkeit urteilt und die Elaborate irgendwelcher Nichtskönner [...] ausschließt.“"1083 Marck indes soll auf Hirschs Buch in seiner Rezension noch ein Loblied gesungen haben und dazu noch in einer sozialistischen Zeitung, die doch „Kultur fördernd wirken will“ - das konnte Graf nicht gutheißen. Vielmehr warf er Marck vor, nicht den notwendigen Unterschied zwischen „Berufenen und Unberufenen“ gezogen zu haben. ${ }^{1084}$ Ein hartes Urteil über Helmut Hirsch, das Marck nicht unbeantwortet lassen konnte. Ähnlich persönlich ging er

\footnotetext{
${ }^{1078}$ Vgl. Radkau, Joachim: Die deutsche Emigration in den USA, S. 168f.

${ }^{1079}$ Marck an Hirsch, 04.05.1945, NL HH.

1080 Thomas Mann an Marck, 15.04.1944. TMA

${ }^{1081}$ Marck an Hirsch, 02.05.1948, 11.03.1948, NL HH.

1082 Oskar Maria Graf an Marck, 11.03.1948, NL HH.

1083 Ebd.

1084 Ebd.
} 
Graf an: „Das berühmte Bajuvarentum, das bei Ihnen solche Haltung ja psychologisch verständlich machen mag, hat mir niemals imponiert. Indessen bezweifle ich, dass Ihnen nur Ihr rein künstlerisches Gewissen den überflüssigen Erguss diktierte" und Marck verbat sich diesen von Graf angeschlagenen Ton. Immerhin hätten Helmut Hirsch und er niemals den Anspruch erhoben, dass sich Hirschs Buch in die Kategorie „eigentlicher Dichtung“ einreihen ließe. ${ }^{1085}$ Hirsch jedenfalls erhoffte sich von der Marckschen Replik hohe Verkaufszahlen. ${ }^{1086}$

Das deutsche sozialdemokratische Exil stand von Beginn an, aber besonders in den Vereinigten Staaten, vor einem Problem. Anders als europäische Exilregierungen, wie beispielsweise die Bewegung France Libre ${ }^{1087}$, die sich nach der Zerstörung ihrer Souveränität durch die deutsche Armee parteiübergreifend bilden konnte, waren die Nationalsozialisten keine Okkupanten. Sie sind vielmehr aus der deutschen Gesellschaft - ohne lange demokratische Tradition hervorgegangen. $^{1088}$ Der erste Versuch des politischen Exils $\mathrm{zu}$ einer parteiübergreifenden Verständigung scheiterte mit dem Ausschuss zur Vorbereitung einer Deutschen Volksfront in Paris bereits in den Anfängen. Immerhin gelang es dort eine Integrationsfigur wie Heinrich Mann für die zum Teil stark rivalisierenden Gruppen zu gewinnen. Eine solche Strukturvoraussetzung war auch bei der Gründung des Council for a Democratic Germany, einem zweiten Versuch angesichts des zu erwartenden Sieges über Deutschland, unabdingbar. ${ }^{1089}$ Zusammen wollten die gewichtigen Repräsentanten des „anderen Deutschlands“ jenseits von Parteien zu einem kollektiven Selbstverständnis kommen, um beim Aufbau eines neuen Deutschlands programmatisch Gehör zu finden. Der Council fungierte als eine Art „Exilrat“ und es fällt auf, dass die meisten der Mitglieder Begünstigte der Akademie gewesen waren: Heinrich Mann, Bertolt Brecht, Lion Feuchtwanger, Veit Valentin, Wolfgang Stresemann, Karl Paetel, um hier nur einige zu nennen, aber auch Siegfried Marck gehörte diesem Kreis an. ${ }^{1090}$ Die Anzahl war stets schwankend,

\footnotetext{
${ }^{1085}$ Marck an Graf, 15.03.1948, NL HH.

${ }^{1086}$ Hirsch an Marck, 18.03.1948, NL HH.

1087 Zur Forces Françaises Libres, (kurz: France Libre) siehe: Crémieux-Brilhac, Jean-Louis: La France libre: de l'appel du 18 juin à la Libération, Paris 1996.

${ }^{1088}$ Vgl. Krohn, Claus Dieter: Der Council for a Democratic Germany, in: Langkau-Alex, Ursula/ Ruprecht, Thomas M. (Hrsg.): Was soll aus Deutschland werden? Der Council for a Democratic Germany in New York 1944-1945. Aufsätze und Dokumente, S. 17-49, hier S. 17.

1089 Vgl. ebd., S. 18.

${ }^{1090}$ Zühlsdorff, Volkmar: Deutsche Akademie im Exil, S. 201.
} 
doch besonders sozialdemokratisch gefärbt. Auch Marcks Freund Walter Friedländer unterzeichnete die Council-Declaration. ${ }^{1091}$

Gerade New York, das wie keine zweite Metropole einen Mikrokosmos des deutschen Exils darstellte, bot den verschiedensten Intellektuellen einen Ort für derartige Tätigkeiten. Als Reaktion auf die Gründung des Nationalkomitees Freies Deutschland (NKFD) 1943 aus exilierten Kommunisten in Moskau und Kriegsgefangenen der Stalingrad-Armee wurden hier besonders die Gruppe NeuBeginnen um Karl B. Frank alias Paul Hagen sowie Vertretern der American Friends of German Freedom mit den prominenten protestantischen Theologen Reinhold Niebuhr und Paul Kellogg aktiv. Hervorgegangen war letztere Bewegung aus dem Zusammenschluss von Repräsentanten des Jewish Labor Committee, einer jüdisch dominierten und europäisch orientierten, sowie besonders in der Textilindustrie ansässigen Gewerkschaft, deren Gründung vor allem von Ostjuden um Baruch Charney Vladeck und eben jenen linksliberalen Intellektuellen ausging. ${ }^{1092}$ Auch die sich in New York kurz vor Ausbruch des Krieges gebildete sozialdemokratische German Labor Delegation (GLD), die „in grotesker Verkennung der Lage“ beanspruchte, offiziell die Sozialdemokratie $\mathrm{zu}$ vertreten, nachdem der alte Parteivorstand nach der Niederlage Frankreichs faktisch auseinandergefallen war, schloss sich, wenn auch nur kurz, dem Council an. ${ }^{1093}$ Politisch agierte die German Labor Delegation, in der auch Marck Mitglied war, auf der gleichen Linie wie der Sopade-Vorstand in London. Während es in London gelungen war, die verschiedenen Richtungen innerhalb der sozialdemokratischen Emigration zu einer Union unter den Vorsitz Hans Vogels zu pressen, dauerten die Richtungskämpfe in den USA innerhalb der GLD an. ${ }^{1094}$

Paul Hagen versuchte Thomas Mann als Vorsitzenden für den Council zu gewinnen, der diesem jedoch absagte und somit für einige Verwirrung sorgte. ${ }^{1095}$ Für Thomas Mann war es zu „voreilig“ und zu ,patriotisch“, einen solchen Exilrat zu gründen, da niemand „,nach unserer Meinung“ frage. ${ }^{1096}$

\footnotetext{
${ }^{1091}$ Füssl, Karl-Heinz: Deutsch-amerikanische Kulturbeziehungen, S. 119.

${ }^{1092}$ Vgl. ebd., S. 22f.

${ }^{1093}$ Vgl. Niemann, Heinz: Geschichte der deutschen Sozialdemokratie 1917 bis 1945, S. 450ff.

${ }^{1094}$ Vgl. Stampfer, Friedrich: Mit dem Gesicht nach Deutschland, S. 150.

1095 Bertolt Brecht zerwarf sich daraufhin vollends mit Thomas Mann, vgl. Lehnert, Herbert: Bert Brecht und Thomas Mann im Streit über Deutschland, in: Spalek, John M./Strelka, Joseph (Hrsg.): Deutsche Exilliteratur seit 1933, Bd. 1, München 1976, S. 62-88.

${ }^{1096}$ Thomas Mann an Paul Hagen, 06.08.1943, zitiert in: Krohn, Klaus Dieter: Der Council for a democratic Germany, S. 20f.
} 
Vorsitzender des Council wurde nun Paul Tillich, der Kontakte zum US-Präsidenten hatte und nicht minder als „Mittler zwischen den rivalisierenden ,think tanks“ der deutschen Emigration in New York“, der New York School for Social Research ${ }^{1097}$ und dem an der Columbia University untergekommenen Institute for Social Research um Max Horkheimer wirkte. Tillich gelang es zunächst, einen repräsentativen Querschnitt von Persönlichkeiten unter seinem Vorsitz zu vereinen. Albert Grzesinski, Friedrich Stampfer und Hedwig Wachenheim aus dem engeren Zirkel der GLD auf sozialdemokratischer Seite sowie Friedrich Baerwald oder Hubertus Prinz $\mathrm{zu}$ Löwenstein als ehemalige Zentrumsmitglieder bildeten das Grundgerüst des Initiativ-Kreises des Council for a Democratic Germany. ${ }^{1098}$ Folglich alles Bekannte Siegfried Marcks.

Doch wie bereits die Volksfrontbemühungen in Paris verdeutlichten, war die Gretchenfrage des Exils für eine effektive Zusammenarbeit auch im Council immer die der Kooperation mit der KPD. Kommunistische Mitglieder sollten erst ausdrücklich nach Verabschiedung eines gemeinsamen Programms dem Kreis beitreten können. Als jedoch der ehemalige von der $\operatorname{KPD}(\mathrm{O})$ zur KPD zurückgekehrte Schriftsteller Albert Schreiner in den Kreis eingeführt wurde, nahmen Hedwig Wachenheim und Friedrich Stampfer dies zum Anlass, dem Kreis den Rücken zu kehren. ${ }^{1099}$ Eigentlich waren sie dem Initiativ-Komitee des Councils beigetreten, um herauszufinden, welchen Einfluss die GLD auf die zukünftige Sammlung hätte nehmen können. Der Abgang Wachenheims und Stampfers ist als reiner Vorwand zu werten. ${ }^{1100}$ Dieses „Kindergartenverhalten“"1101 konnte Siegfried Marck nicht tolerieren, schloss sich deshalb aus Protest dem Initiativ-Ausschuss des Council an und verließ die GLD. Marck sprach mit Thomas Mann über den Council und die deutsche Frage, nachdem dieser in Marcks Buch Germany to Be or not to $B e$ ? gelesen hatte. ${ }^{1102}$ Darin versuchte Marck in Koautorenschaft mit Gerhard Seger die Frage zu beantworten, was Deutschland nach dem Krieg sein und tun werde. Mann wünschte Marck „,viel Glück zur Mitgliedschaft“ im Council, wenngleich er

1097 Siehe hierzu besonders: Ders.: Wissenschaft im Exil. Deutsche Sozial- und Wirtschaftswissenschaftler in den USA und die New School for Social Research, Frankfurt am Main 1987.

${ }^{1098}$ Ders.: Der Council for a democratic Germany, S. 30f.

${ }^{1099}$ Friedrich Stampfer an SOPADE vom 09.03.1944, in: Stampfer, Friedrich: Mit dem Gesicht nach Deutschland, S. $641 \mathrm{f}$.

${ }^{1100}$ Vgl. Krohn, Claus Dieter: Der Council for a Democratic Germany, S. 36f.

1101 Marck an Paul Tillich vom 01.03.1944, Harvard University, Nachlass Paul Tillich, H 5 (nachfolgend nur noch NL PT).

${ }_{1102}$ Mann, Thomas herausgegeben von Peter de Mendelssohn: Thomas Mann. Tagebücher 1944-1946, Frankfurt am Main 1986, S. 10, 40. 
ihm „eher abriet“ diesem Kreis beizutreten. „Aber so ist es auch ganz gut und Tillich ist jedenfalls ein braver Mann“, schrieb Mann weiter. ${ }^{1103}$

Bereits 1942 schloss Marck sich der Association of Free Germans an. Neben Rudolf Katz, Gerhart Seger, Toni Sender, Max Brauer, dem Initiator Albert Grzesinski und Friedrich Stampfer sprach Marck sich für Demokratie, Pazifismus und die Eingliederung Nachkriegsdeutschlands in die Weltgemeinschaft aus. ${ }^{1104}$ Siegfried Marck konnte nicht riskieren, dass sich seine ehemalige Gruppe, die GLD, weiter in „überlebtem Parteipatriotismus“ isolierte. ${ }^{1105}$ Viel zu sehr war ihm der Kampf der Arbeiterschaft ein wichtiges Anliegen, welches er nicht durch die Zerrüttung des politischen Exils in Gefahr sehen wollte. ${ }^{1106}$

Die GLD, die der Neuen Volkszeitung nahe stand bzw. vorwiegend aus ihr bestand, setzte sich faktisch nur noch aus Rudolf Katz, Gerhart Seger und Friedrich Stampfer sowie aus Max Brauer und Hedwig Wachenheim zusammen und propagierte gegen die Arbeit des Councils. Andere bekannte und ehemalige Gründungsmitglieder der GLD, wie Siegfried Aufhäuser, Albert Grzesinski, Paul Hertz, neben Käte Frankenthal, Marie Juchacz aber eben auch Siegfried Marck, waren bereits zum Council übergelaufen und saßen dort neben Bertolt Brecht oder Hermann Budzislawski dem Initiativ-Kreis bei. ${ }^{1107}$ Nun sollte es auch hier wieder darum gehen, einer möglichst breiten Masse öffentlichkeitswirksam die Ziele des Councils for a Democratic Germany nahezubringen. Im Mittelpunkt ihrer Deklaration, die von 57 prominenten Amerikanern unterschrieben wurde, stand die Gesamtverantwortung des deutschen Volkes für die nationalsozialistischen Verbrechen. Eine Unterscheidung sollte jedoch zwischen den Nazis selbst, den Helfershelfern und der deutschen Bevölkerung gemacht werden. Der Kampf galt dem preußisch-deutschen Militarismus, der Großindustrie, dem Junkertum, mehr noch den gefügigen Beamten, Richtern und Erziehern. ${ }^{1108}$

Von den Einheitsforderungen abgesehen enthielt die Deklaration in den Kernpunkten genau das, was auf den Konferenzen von Jalta und Potsdam als

\footnotetext{
1103 Thomas Mann an Marck, 15.04.1944. TMA.

${ }^{1104}$ Vgl. programmatische Richtlinien der Association of Free Germans - "Für das Freie Deutschland von Morgen”, in: Stampfer, Friedrich: Mit dem Gesicht nach Deutschland, S. 567ff.

1105 Marck an Tillich, 01.03.1944, NL PT.

${ }^{1106}$ Marck als Redner auf der Landeskonferenz der GLD am 03./04. Juli 1943, in: Stampfer, Friedrich: Mit dem Gesicht nach Deutschland, S. 151.

${ }^{1107}$ Krohn, Claus Dieter: Der Council for a Democratic Germany, S. 160.

${ }^{1108}$ Vgl. DeClaration des Council for a Democratic Germany am 03.05.1944, ebd., Dok. 1 u. 2. Das Original ist zu finden in: IISG, NL Paul Hertz, S. 16, 1c.
} 
gemeinsame Kriegsziele beschlossen werden sollte. ${ }^{1109}$ Die Reaktion der Öffentlichkeit war nicht nur durch die schlechte Presse der Neuen Volkszeitung geringer als man erwartetet hatte. Inhaltliche Ablehnung und Angriffe kamen, auch wenn sie in englischen Blättern erschienen, fast ausschließlich von deutschen Emigranten. ${ }^{1110}$ Der Aufbau, das Hauptorgan der deutsch-jüdischen Emigranten in den Vereinigten Staaten, diffamierte sogar die Unterzeichner der Deklaration mit jüdischen Wurzeln als „verwirrte Gemüter“ und stellte provokant die Frage, ob es für amerikanische Juden überhaupt rechtens sei - wenn sie den Council nicht „sponsoren“ - eine solche Deklaration zu unterschreiben. ${ }^{1111}$ Bereits zuvor hatte der Aufbau, für den mit der Gründung des Councils die Trennungslinie zwischen Immigranten und Exilierten gezogen wurde, folgende Position verdeutlicht:

„Kein Immigrant, der seine ersten Papiere herausgenommen und damit seine Trennung von Deutschland, Österreich usw. besiegelt hat, kann einem solchen Komitee angehören oder seine Ziele aktiv unterstützen. Es gibt eine ganze Anzahl von Persönlichkeiten, die aus diesem Grunde Gäste geblieben sind, und niemand wird deswegen gegen sie diskriminieren."

Siegfried Marck war keiner dieser „Gäste“, er unterzeichnete die Deklaration und unterstützte den von seiner ehemalig positiv gesinnten Neuen Volkszeitung abfällig als „Stalins New Yorker Coup“"1113 bezeichneten Council. ${ }^{1114} \mathrm{Zu}$ sehr interessierte er sich für die Belange seiner religiösen Herkunft. 1943 erfuhr er aus Studien des Institutes für Vergleichendes Recht, einer Abteilung der Freien Französischen Hochschule, die in New York unter dem Protektorat der New School for Social Research die großen Traditionen des französischen Geisteslebens und der Pariser Sorbonne fortsetzte, von den Schandtaten, dem gezielten Massenmord der Nationalsozialisten an den europäischen Juden. Fortan stand für ihn fest, dass das deutsche Volk „restlos und voll“ über die „wahnwitzigen Verbrechen“ aufgeklärt werden müsse, auch wenn dies Jahre in Anspruch nehmen würde. ${ }^{1115}$

\footnotetext{
1109 Ebd., S. 33.

${ }^{1110}$ Vgl. Paetel, Karl O.: Zum Problem einer deutschen Exilregierung, in: Vierteljahreshefte für Zeitgeschichte, Jg. 4 (1956), S. 286-301, hier S. 293.

1111 Vgl. Aufbau, 02.06.1944.

1112 O.V.:,Am Scheideweg“, in: Ebd., 12.05.1944.

1113 George, Manfred: Tatsachenbericht über die deutsche Frage, in: Ebd., 12.05.1944.

1114 Auch Richard Kroner, wie Marck ein Neukantianer und seit 1925 ein guter Freund Paul Tillichs sowie universitär durch Heidegger benachteiligt, den Marck bereits aus seiner Studienzeit in Breslau kannte, nahm im Unterausschuss des Councils für Erziehung und Wissenschaft teil. Auch sein Fernziel war es, ein neues demokratisches Deutschland aufzubauen.

${ }^{1115}$ Vgl. Marck, Siegfried: Die Tragödie der Juden in Europa: Pogrom-Hölle in Rechtsgestalt, in: Neue Volkszeitung, 24.07.1943.
} 
Siegfried Marck kehrte erst fünf Jahre später seiner Heimat vollends den Rücken und wurde amerikanischer Staatsbürger. ${ }^{1116}$ Für ihn waren die deutschen Nachkriegsbelange kein akademisches Problem, das es zu untersuchen galt. Indirekt kritisierte er somit beispielswiese seinen Freund Eduard Heimann, den ehemaligen jüdischen sozialdemokratischen Reichstagsabgeordneten und Sozialökonom, der als Dozent an der New Yorker New School for Social Research in den USA naturalisiert und integriert worden war und sich vollends, bis zu seiner Rückkehr nach Deutschland, mit wirtschaftswissenschaftlichen und soziologischen Themen befasst hatte. $^{1117}$

Doch auch dieser Council konnte in der Öffentlichkeit nicht auf das Gehör stoßen, das er sich gewünscht hatte. Die zahlreichen publizistischen Erklärungen stießen trotz vieler Förderer ${ }^{1118}$ bei den amerikanischen Entscheidungsträgern kaum auf Resonanz. Sein frühes, absehbares Ende nahm der Council mit den Beschlüssen der Konferenz von Jalta im Februar 1945. Nach dreieinhalbjähriger Aktivität löste die dort verabredete Zoneneinteilung Deutschlands sowie die Unterstellung der Gebiete östlich von Oder und Neiße unter eine polnische Verwaltung scheinbar unlösbare Kontroversen aus. ${ }^{1119}$ Nach der Potsdamer Konferenz zerfiel der Council komplett, ohne sich offiziell aufgelöst zu haben. ${ }^{1120}$ Für Marck, der stets gegen Faschismus und Vansittartismus ${ }^{1121}$ argumentierte und immer den Unterschied

1116 Certificate of Naturalization, Northern District of Illinois am 11.01.1949, NL SM. Auf der Neutralisationsurkunde erhält Siegfried Marck scheinbar fälschlicherweise den zweiten Vornamen "Curt” statt, wie in der Geburtsurkunde „Ernst“. Marck unterschrieb diese aus nicht bekannten Gründen auch mit „Curt“.

${ }^{1117}$ Vgl. Eduard Heimann an Tillich vom 22.03.1944, in: Krohn, Claus Dieter: Der Council for a Democratic Germany, S. 31.

1118 Hier sind besonders die American Friends of German Freedom unter der Leitung des amerikanischen Religionsphilosophen Reinhold Niebuhr zu nennen, vgl. ebd., S. 20.

${ }^{1119}$ Vgl. Ebd., S. 47f.

1120 Vgl. Baerwald, Friedrich: Zur politischen Tätigkeit deutscher Emigranten im Council for a Democratic Germany, in: Vierteljahreshefte für Zeitgeschichte, Jg. 28 (1980), S. 372-383, hier S. 375.

1121 Das nach dem britischen Diplomaten Robert Gilbert Vansittart benannte Konstrukt des Vansittatismus ging davon aus, dass die aggressive Expansionspolitik Deutschlands bereits im deutschen Nationalwesen verankert war und es demnach keinen Unterschied zwischen Deutschen und Nationalsozialisten gäbe. Deshalb könnte nur eine vollkommene Demilitarisierung Deutschlands nach einem gewonnenen Krieg, einen europäischen Frieden dauerhaft sichern, vgl. Radkau, Joachim: Die Exil-Ideologie vom ,anderen Deutschland“ und die Vansittartisten. Über die Einstellung deutscher Emigranten nach 1933 zu Deutschland, in: Aus Politik und Zeitgeschichte, 10. Januar 1970, S. 31-48. Wortführer der Vansittartisten in der amerikanischen Emigration war der ebenfalls aus Breslau stammende, zum Christentum konvertierte jüdische Schriftsteller Emil Ludwig. Diesen hatte Siegfried Marck in der Emigration niemals ganz für seine Europapolitik aufgegeben, siehe: Marck, Siegfried: Rückblick auf die Deutschland-Debatte, in: Neue Volkszeitung, 19.09.1942, Aufbau, 07.08.1942; Leopold Schwarzschild, der durchaus liberal, pazifistische Ursprünge hatte, und sich in den USA früh dem Wirtschaftsliberalismus und der ,harten Außenpolitik“ verschrieben hatte, kam bei Marck nicht so gut weg, siehe: Ders.: Ein Ueber-Vansittartist, in: Neue Volkszeitung, 27.02.1943; Marcks allgemeine Einstellung zum Vansittatismus ferner, in: Ders.: Um das deutsche Volk, in: Aufbau, 24.12.1943; Ders.: Nachlese zur Schumacher-Diskussion, in: Ebd., 07.11.1947. 
zwischen Deutschen und Nazis zu verdeutlichen versuchte, versinnbildlichte die Konferenz von Jalta die Gefahr eines „Super-Versailles“ und zudem einen „Niederschlag konstruktiver Kompromisse“. Die Auslieferung der europäischen Idee an außereuropäische Mächte ließ ihn in der europäischen wie auch in der deutschen Frage resignieren. Den Vansittartismus verstand Marck als „Antigermanismus“, als eine „Parallelerscheinung zum Antisemitismus“. ${ }^{1122}$ Nationalsozialisten und Deutsche waren für ihn nicht schlechthin identisch, obgleich das deutsche Volk eine Mitverantwortlichkeit für all das in seinem Namen Geschehene tragen und aufarbeiten müsse. ${ }^{1123}$

Ein Jahr zuvor hatte er noch die Möglichkeit für eine Zusammenarbeit von „Refugees und Besatzungsautoritäten“ gesehen. ${ }^{1124}$ Für ihn war „die [politische] Färbung von Politikern, die eine Meinung über die Zukunft des deutschen Volkes“ äußerten, noch „,belangloser als vorher“. ${ }^{1125}$ Die Abtretung der Ostgebiete, folglich auch die Breslaus, veranlasste ihn dazu sich von der Sowjetunion als Bundesgenossen zu distanzieren. Die Politik des „Welt-Direktoriums“ ließ ihn verzweifeln, er schlug dem politischen Exil von nun an vor, sich gegenwärtig mit Fragen der Grundversorgung der deutschen Bevölkerung zu befassen. ${ }^{1126}$ Marck provozierte mit diesen Aussagen Widerstand. Besonders Gerhart Seger widersprach ihm in der Russlandthematik. Seger betonte, dass „es schon lange vor der KrimKonferenz vorauszusehen [gewesen war], dass Deutschland als „Macht“ nach diesem Kriege zu bestehen aufgehört haben würde“ und dass „niemand, der ein Gegner des preußischen Militarismus“ gewesen sei, dies bedauern müsste. ${ }^{127}$ Doch Marck pochte weiter auf seinen Gedanken für ein nicht unter den Siegermächten aufgeteiltes Deutschland. Er sah eine Lösung, eine Befriedung des Kontinents, nicht nur im Verhältnis der Sieger von 1945 mit Deutschland, sondern auch in ihrer Behandlung des Besiegten. Überhaupt war die Koautorenschaft mit Seger für das Werk Germany, to Be or not to Be? für Marck nur eine „fachliche Heirat, von der wir beide wenig Freude hatten“. ${ }^{1128}$ Marck empfahl ein ,überwachtes, in vernünftigen Grenzen gehaltenes [und] in demokratischen Ansätzen bestärktes Deutschland, dessen Volk

\footnotetext{
${ }^{1122}$ Vgl. Ders.: Prozeß Deutschland, in: Neue Volkszeitung, 12.02.1944.

${ }^{1123}$ Vgl. Ders.: Ein halbes Jahrzehnt Krieg, in: Ebd., 02.09.1944.

${ }^{1124}$ Vgl. Ders.: Eine Klarstellung, in: Aufbau, 19.05.1944.

${ }^{1125}$ Vgl. Ders.: Nach der Konferenz von Yalta - Am Scheidewege (als Diskussionsbeitrag), in: Neue Volkszeitung, 24.02.1945; Ders.: Germany: To Be or Not To Be, S. 132.

${ }^{1126}$ Vgl. ebd.

${ }^{1127}$ Vgl. Seger, Gerhart H.: Müssen wir aufgeben? Antwort auf Dr. Siegfried Marcks Ausführungen, in: Neue Volkszeitung, 24.02.1945.

${ }^{1128}$ Marck an Hirsch, 22.01.1949, NL HH.
} 
das Zusammenleben in einer nicht aggressiven politischen Einheit gestattet wird.“1129 Eine Umerziehung, wie sie vor allem von den USA und Großbritannien gefordert wurde, lehnte er ab:

„Die Idee, fremde Lehrkräfte zugleich mit militärischen Polizeikräften nach einem besiegten Deutschland zu senden, ist mit Recht als abwegig kritisiert worden. Erzieherische Autonomie ist das elementarste Recht eines sich selbst bestimmenden Volkes. “" ${ }^{1130}$

Für den Erwachsenenbildner Marck stand fest, dass die Aufgabe einer erfolgreichen Umerziehung eines „so furchtbar in die Irre gegangenen Volkes“ nur gelingen könne, wenn Politiker, Ökonomen, Verwaltungsjuristen, Soziologen, Psychologen, Pädagogen und Psychiater zusammenarbeiteten. ${ }^{1131}$ Und für Marck brauchte der Wiederaufbau Deutschland vor allem eines - Zeit. „Es ist stets gut, dass uns eingeschärft wird, dass das gegenwärtigen deutsche Elend nur mit der Logarithmentafel ausgedrückt werden kann“" schreibt Siegfried Marck 1947 an den von der sozialistischen Jugendbewegung geprägten Karl Otto Paetel. Für Marck war dieses Elend gleichgesetzt mit „1648 hoch 1648“, folglich mit dem Westfälischen Frieden in exponentieller Form. Dabei bedauerte Marck das „crybaby-stadium“ Deutschlands, aus dem die Engländer, denen es ja nach dem Krieg auch „recht mäßig“" gehe, stets schneller herausfinden würden. ${ }^{1132}$

Marck, der seit 1949 amerikanischer Staatsbürger war, konnte sich nie ganz mit dieser Zugehörigkeit anfreunden. „Auch wenn ich 10x American citizen werde, ich kann dieses ,wir" mir nicht zu eigen machen“, schrieb Siegfried Marck an seinen Cousin Carl Misch und führt aus: „,ich weiß natürlich sehr gut, dass ich kein Recht habe ,wir Deutsche‘ zu sagen. Nicht mal Gott fürchte ich genug, was sich mit wachsendem Alter als unpraktisch erweist““. ${ }^{1133}$ Mit Carl Misch hatte Marck in nahezu allen Gremien seiner politischen Arbeit und insbesondere als Redakteur des Neuen Tagebuches, der Neuen Weltbühne, der Pariser Tageszeitung und dem Aufbau zusammengearbeitet. Beide hatten noch am 28.09.1938 zusammen in einem Pariser Café gesessen, den Krieg vorhergesehen und die Politik des Völkerbundes bedauert. $^{1134}$ Nun war der Krieg beendet, Deutschland besiegt und es herrschte

\footnotetext{
${ }^{1129}$ Vgl. Marck, Siegfried: „Man spricht von Krieg“, in: Aufbau, 08.03.1946.

${ }^{1130}$ Ders.: Die Liquidierung des „Dritten Reiches“, in: Neue Volkszeitung, 17.10.1943.

${ }^{1131}$ Vgl. Ders.: Der Psychiater hat das Wort, in: Ebd., 15.05.1943.

1132 Marck an Karl O. Paetel, 19.03.1947, Grenander Department of Special Collections \& Archives, State University of New York.

${ }^{1133}$ Marck nennt Misch in den Briefen als seinen Cousin. 08.03.1947, 24.02.1948, Grenander Department of Special Collections \& Archives, State University of New York (nachfolgend nur noch NL CL). Dabei ist nicht nachzuvollziehen, ob dies stimmt. Siegfried Marcks Vater hatte eine Schwester, Paula Auguste, die dreimal verheiratet war. Stammbaum der Familie Marck, LBI NY.

${ }^{1134}$ Marck an Misch, 11.03.1948, NL CM.
} 
Einigkeit: „Große Mächte setzen sich ihre Grenzen nicht selber, sie müssen ihnen von außen gesetzt werden.“, so Marck. ${ }^{1135}$

Unabhängig vom politischen Weltgeschehen war Siegfried Marck verärgert, über seine familiäre Konstellation und seine gesundheitliche Konstitution. Am Beispiel Max Brauers, dem nach zehn Jahren Emigration der Weg zurück nach Deutschland gelang, der Erster Bürgermeister von Hamburg wurde und den Marck aus vielen Gremien, der Volksfront oder der German Labour Delegation kannte, sah Marck, dass es möglich war, in der Heimat wieder Fuß zu fassen und politisch Karriere zu machen. Marck schrieb an Misch, den er gern um Ostern in Kentucky bei Pferderennen, einem seiner Hobbys ${ }^{1136}$, traf: „,wären nicht meine Privatverhältnisse gewesen und meine nicht $\mathrm{zu}$ feste Gesundheit, Brauers Weg wäre auch meiner gewesen, obgleich er naiv ist und ich dieses wohl am wenigsten bin.“1137 Diese Worte Marcks klingen etwas resigniert und das ist verständlich, immerhin scheiterten auch in den USA alle Bündnisse, denen Siegfried Marck angehörte. Neben allen Versuchen, die er unternahm, Sammelbände herauszubringen, die Emigrierten zu bündeln und in Deutschland hörbar zu machen, blieb Marck am Ende nur noch, seine wissenschaftliche Arbeit voranzutreiben und seine mittlerweile sehr bürgerlichen Kontakte zu pflegen. Damit war es letztlich genau das, was er den anderen und wissenschaftlich oftmals besser gestellten Kollegen wie Eduard Heimann vorgeworfen hatte - sich aus dem politischen Diskurs herauszunehmen und der wissenschaftlichen Karriere nachzugehen.

Das YMCA College in Chicago profitierte jedenfalls davon, dass sich Marck mehr in dessen Arbeit einbrachte, wenngleich es ihn 1945 als Abteilungsleiter des Faches Philosophie abgesetzt hatte. ${ }^{1138}$ Das College befand sich damals, wie bereits erwähnt, im Umbruch und es herrschten große Spannungen zwischen dem Präsidenten Sparling und dem Träger, dem YMCA.

\footnotetext{
„Hier hoffe ich mit den $72 \%$ der anderen Fakultätsmitglieder, dass alles im Herbst zu einer guten Lösung bei dem neuen Roosevelt College gekommen sein wird. Jedenfalls haben Sparling und Leys sich in der ganzen Krise als tatkräftige und liberalen Idealen ergebene Männer gezeigt. Auch unser Freund Hillmann war tatkräftig im Vordergrunde derjenigen, die den Kampf für die Unabhängigkeit des College von reaktionären Elementen in der YOrganisation führten. “1139
}

\footnotetext{
1135 Ebd.

${ }^{1136}$ Marck an Misch, 24.02.1948, NL CM. Daneben spielte Marck wohl gerne Tennis, nachdem er diesen Sport während seines Sprachaufenthaltes in England für sich entdeckte, vgl. Marck an Friedländer, 07.09.1940, NL WF.

${ }^{1137}$ Marck an Misch, 08.03.1947, NL CM.

${ }^{1138}$ Hirsch an Hedda Korsch, 01.12.1946, NL HH.

${ }^{1139}$ Marck an Friedländer, 14.06.1945, NL WF.
} 
Knapp zwei Jahre später konstatierte Marck, dass sein College die Gebäudeschwierigkeiten nun überwunden habe und es nun in großer Prominenz an den Michigan Boulevard ziehen würde. Das College hoffte auf rund 5000 Studierende und seine Fakultät hatte sich bereits auf 170 Mitglieder ausgedehnt. ${ }^{1140}$

Ernst Haase, der Sohn des zeitweiligen Vorsitzenden der USPD Hugo Haase, der in Chicago als Neurologe arbeitete, konnte es dann auch arrangieren, dass Kurt Schumacher nach Chicago kam und an Marcks College für die Labor Education Division sprach. ${ }^{1141}$ Als Dolmetscherin dieser Veranstaltung war Elisabeth MannBorgese, die jüngste Tochter Thomas Manns, tätig. ${ }^{1142}$ Hier traf Marck mit Schumacher den Mann, den er später ,als menschlichen Torso, zum leibhaftigen Symbol des amputierten und damals [bei Kriegsende] physisch gebrochenen Deutschland“ beschrieb. ${ }^{1143}$

Marck brachte in Chicago gemeinsam mit Arthur Hillmann, dem Vorsitzenden des soziologischen Instituts am Roosevelt College, das Fakultätsbulletin heraus ${ }^{1144}$ und verbrachte mit Ernst Haase in der zweiten Hälfte des Jahres 1948 viel Zeit - ärztlich und in politisch gesellschaftlichen Diskussionen. ${ }^{1145}$ Marck, der bekanntlich unter einem angeborenen Herzfehler litt, war bei Haase in Behandlung. Auch dieser konnte für sein Herzleiden keinen organischen Befund festmachen, sondern diagnostizierte eine Psychosomatik mit depressiven Verstimmungen. ${ }^{1146}$

Trotz der Auflösung des Councils blieb Siegfried Marck mit Paul Tillich in Kontakt. Schon nach der Konferenz von Jalta, nach der es zu großen Spannungen innerhalb des Councils gekommen war, „die in der vorigen Woche zu dem Austritt einzelner Mitglieder der Rechten geführt hat“, schrieb Tillich an Marck: „Wie die Dinge sich weiter entwickeln werden, ist noch nicht klar, ich bin aber in keiner Weise optimistisch. “1147 Wenige Tage zuvor hatte Siegfried Marck sich an Tillich gewandt. Dieser sollte für ihn ein Gutachten für die Rockefeller Foundation schreiben, da Marck hoffte, die Foundation könnte für sein abgefasstes Manuskript Idealismus in der nachfaschistischen $\ddot{A} r a^{1148}$ die Übersetzungskosten ins Englische

\footnotetext{
${ }^{1140}$ Marck an Friedländer, 10.03.1947, NL WF.

${ }^{1141}$ Marck an Friedländer, 15.10.1947, 05.12.1947, NL WF.

${ }^{1142}$ Hirsch, Helmut: Onkel Sams Hütte, S. 178.

1143 Marck, Siegfried: Große Menschen unserer Zeit, S. 82.

${ }^{1144}$ Friedländer an Marck, 05.12.1947.

${ }^{1145}$ Marck an Friedländer, 04.10.1948, NL WF.

1146 Marck an Friedländer, 10.03.1947, NL WF.

1147 Tillich an Marck, 20.10.1945, NL PT.

${ }^{1148}$ Das ist der von Marck vorgeschlagene Titel, den der Verlag nicht haben wollte.
} 
übernehmen. Marck beauftragte seine Tochter Claudia, das Manuskript Tillich in New York zu überbringen. ${ }^{1149}$ Tillich kam der Bitte Marcks nach und schrieb ein Gutachten. Dennoch dauerte es, bis Siegfried Marck Antwort von Rockefeller erhalten sollte. ${ }^{150}$ Auch ohne Zusage ermunterte Tillich Marck, die Übersetzung schon zu beginnen: „Warum machen Sie sie [die Übersetzung] nicht selbst und sprechen sie dann mit einem Studenten durch? Das würde die Sache verbilligen.“1151 Tillich befand Marcks Arbeit als „glänzend“ und konnte so ruhigen Gewissens versuchen Rockefeller zu überzeugen, die Übersetzung des Manuskripts zu fördern. ${ }^{1152}$ Für Marck war diese Übersetzung besonders wichtig, nur so konnte er auf dem amerikanischen Markt mehr Gehör finden. Dies war letztlich auch seine Schlussfolgerung, weshalb er keine Angebote für Summerschools und Vorlesungen in den Vereinigten Staaten erhielt - er war dort einfach nicht öffentlichkeitswirksam genug in Erscheinung getreten. ${ }^{153}$ Tillich machte Marck darauf aufmerksam, dass er sein Manuskript an das amerikanische Publikum anpassen müsste, dass es für jenes besser „lesbar“ gemacht werden sollte ${ }^{154}$ und so erhielt Marck den Zuschuss in Höhe von 250 Dollar. ${ }^{1155}$ Kurz danach beglückwünschte Tillich Marck und wünschte ihm auch persönlich alles Gute zu seiner Heirat mit Ilse Apt. Zuvor hatten sie sich in Chicago getroffen und sich auch über die persönlichen Konstellationen Siegfried Marcks unterhalten. ${ }^{1156}$ Die Übersetzungsarbeiten zogen sich in die Länge und Marck musste sich vor Rockefeller dafür rechtfertigen. ${ }^{1157}$ Darauf schlief der Kontakt mit Tillich knapp zehn Jahre lang ein. Marck nutzte Tillichs 70. Geburtstag, um in den Kant-Studien einen Überblick über dessen philosophisches Lebenswerk zu geben. Immerhin war Tillich für Marck mit seiner Außenwirksamkeit der Produktivste ,von uns ,16“, die auf der ersten Liste der Defamierten [sic]

\footnotetext{
1149 Marck an Tillich, 15.10.1945, NL PT. Marck benennt auch gleich die Person, welche die Übersetzung vornehmen könnte. Der Studiendekan des Roosevelt College Balduf, der in Chicago in einer deutschsprachigen Familie aufgewachsen war, dann das College im Zuge der Auseinandersetzung verließ, in Washington arbeite, zusammen Clarence Streit für UNION NOW aktiv war und nun wieder zurück an seine alte Wirkungsstätte gelangte.

${ }^{1150}$ Dies verdeutlichen die Briefe an Tillich, in denen Marck diesen drängt, erneut mit Rockefeller in Kontakt zu treten, da ihm nach die Zeit dränge, vgl. Brief Marck an Tillich, 15.03.1946, 24.03.1946 NL PT.

${ }^{1151}$ The Rockefeller Foundation an Tillich, 01.04.1946, Tillich an Marck, 05.04.1946, NL PT.

1152 Tillich an Marck, 09.01.1946, NL PT.

1153 Marck an Friedländer, 15.03.1948, NL WF.

1154 Tillich an John Marshall (Rockefeller), 28.03.1946, NL PT.

${ }^{1155}$ John Marshall an Marck, 10.04.1946, NL PT.

1156 Tillich an Marck, 18.04.1946, NL PT.

${ }^{1157}$ Marck an Tillich, 09.01.1947, NL PT.
} 
standen." ${ }^{1158}$ Im Frühjahr 1957, kurz vor Marcks Tod, trafen sie sich wieder in Chicago. Tillich bot Marck die Möglichkeit an, während eines Sommeraufenthaltes die Harvard University Library zu nutzen. ${ }^{1159}$ Doch dazu kam es nicht mehr.

Knapp zehn Jahre zuvor, im März 1948, schrieb Marck, entgegen seiner ursprünglichen Absicht, doch wieder über aktuelle Politik in der Neuen Volkszeitung: „Es dürfte an der Zeit sein, ernsthaft die Frage zu prüfen, wo eigentlich heute in nationalen und internationalen Zusammenhängen - aber die sind ja eins - der Hauptfeind der Sozialdemokratie steht." Marcks Antwort war einfach - der Kommunismus, dem er jetzt „,roten Faschismus“ vorwarf. ${ }^{1160}$ Marck spielte hierbei auf den „Februarumsturz“ 1948 in der Tschechoslowakei an, den er mit der nationalsozialistischen Machtergreifung 1933 verglich. Dabei suchte er nach Auswegen aus dem Dilemma der Arbeiterklasse, die sowohl der Propaganda der „Wall-Street“- als auch der Volksdemokratie ausgeliefert sei. Hierbei muss betont werden, dass 1948 zwei Kinder Siegfried Marcks in den politischen Brennpunkten jener Jahre lebten und er dies „als besonders niederdrückend“ empfand. ${ }^{1161}$ Sein erster Sohn Andreas lebte als Siedler in Palästina, seine Tochter Claudia, die aus der Ehe mit Kläre hervorgegangen war, lebte, mit dem Sohn eines prominenten Kommunisten verheiratet, in Prag.

Marck griff auf seinen bekannten Dritten Weg, auf seinen humanistischen Sozialismus zurück, den er in Frankreich für sich entdeckt hatte. Dabei reichte für Marck als Sozialdemokraten fortan ein „Nicht-Kommunismus“ nicht aus, er müsse zum „Anti-Kommunist“ werden. ${ }^{1162}$ Marck sah sich als Mann der Mitte, genau wie Thomas Mann, und wandte sich von jenem Radikalismus, dem er zeitweilig in Breslau angehangen hatte, ab. Seine politische Haltung bezeichnete er selbst als „kompromissloses Eintreten für den Kompromiss“. ${ }^{1163}$ Sein ehemals vorhandener Radikalismus war für ihn jetzt eine Haltung, die er in bestimmten Situationen wohl billigte, ihm als Selbstzweck jedoch unkritisch erschien. „Mag mit meinem zunehmenden Alter zusammenhängen, indessen mein Gehirn reagierte auch früher so, mein Temperament mag auch heute immer noch nicht so reagieren“ resümierte

${ }^{1158}$ Marck, Siegfried: Paul Tillich. Zum 70. Geburtstag, in: Kant-Studien, Bd. 48 Heft 1-4 (Januar 1957), S. 473-484.

${ }^{1159}$ Marck an Tillich, 02.02.1957, NL PT.

${ }^{1160}$ Marck, Siegfried: Ideologischer Zweifrontenkrieg, in: Neue Volkszeitung 27.03.1948.

${ }^{1161}$ Marck an Friedländer, 25.02.1948. Friedländer an Marck, 10.03.1948, NL WF.

1162 Marck, Siegfried. Ideologischer Zweifrontenkrieg.

${ }^{1163}$ Marck an Manfred George, 05.03.1949, DLA Marbach, NL George. 
Marck ein wenig altklug. ${ }^{1164}$ Zum hundertjährigen Jubiläum des Kommunistischen Manifestes und mit der Frage konfrontiert, was vom Marxismus blieb, war Marcks Antwort vage: ,AAlles und Nichts!“‘ 1165

Im Roosevelt College, ähnlich wie zwanzig Jahre zuvor in Breslau, existierte ein Socialist Club, dem Siegfried Marck beiwohnte. Auch von diesem distanzierte er sich 1948, er schien ihm immer mehr von Radikalen besetzt, welche die Besetzung der Tschechoslowakei guthießen. Marck schloss sich darauf der Gruppe Americans for Democratic Action an ${ }^{1166}$, folglich einer Gruppe, die eigentlich dem entsprach, was er in seinem freiheitlichen Sozialismus andeutete - Anhänger der Arbeiterparteien, der Liberalen und Theologen arbeiteten unter der Prämisse des Antikommunismus zusammen und kämpften für Freiheit, Frauen- und Bürgerrechte. Während Helmut Hirsch sich für die Socialist Party unter Norman Thomas engagierte und dessen Abzeichen an der Roosevelt University trug, stand Marck auf der Seite der Demokraten. Marck warf Hirsch vor, sich mit der Entscheidung für Norman Thomas ,vorläufig in die Gefolgschaft der Kommunisten zu begeben, was er stets abdankte“. ${ }^{1167}$ Darauf kam es zum Streit zwischen Hirsch und Marck, die Positionen waren zu verschieden. Marck warf Hirsch „politische Schweinereien“ vor. Dieser tadelte Marck ,sich selbst zu verurteilen, dasselbe Abzeichen zu erwerben und in der Schule und außerhalb der Schule zu tragen, wie es sich für einen Sozialisten gehört“. ${ }^{1168}$ Marck etwas lakonisch: „Indessen kann ich keine Abzeichen tragen, da meine citizenship mich schreckt und ein unvoter mit Abzeichen ist paradox “ ${ }^{1169}$. Helmut Hirsch war mit seiner strikt sozialistischen Haltung an der Roosevelt University allein, von ein paar Studierenden abgesehen. Der überzeugende Pariser Redner Marck war für ihn ,,in Rebellenehre ergraut “'1170 und dieser wiederum warf Hirsch und dessen Frau Eva vor, ,sie seien in ihrem linken Ungestüm in der Pubertät steckengeblieben“. ${ }^{1171}$ Dennoch machte Siegfried Marck Helmut Hirsch deutlich:

„Wenn Sie sagen, oder referieren, auf dem Campus hätten Sie keinen Freund, so möchte ich betonen, dass ich sachliche Differenzen sachlich auszutragen pflege. Gewiss bestehen solche zwischen uns. Das hat meine persönliche Einstellung zu Ihnen nicht geändert.“"1172

\footnotetext{
${ }^{1164}$ Marck an Hirsch, 28.05.1948, NL HH.

1165 Marck, Siegfried: Ein Jahrhundert Marxismus, München 1948, S. 1.

${ }^{1166}$ Marck an Hirsch, 28.05.1948, NL HH.

${ }^{1167}$ Marck an Hirsch, 08.11.1948, NL HH.

${ }^{1168}$ Hirsch an Marck, 11.08.1948, NL HH.

1169 Ebd.

${ }^{1170}$ Hirsch, Helmut: Onkel Sams Hütte, S. 183.

${ }^{1171}$ Ebd., S. 271.

${ }^{1172}$ Marck an Hirsch, 06.11.1948, NL HH.
} 
Marck fühlte sich in Chicago sehr einsam, seitdem sein Freund Walter Friedländer nach Berkeley gegangen war. Er versuchte gegenüber Hirsch seine politische und persönliche Haltung zu differenzieren, doch für ihn war der Sozialismus nicht mehr greifbar, der Begriff ausgewaschen und so ,vieldeutig geworden, dass er nunmehr fast meinungslos ist“. Er begriff sich als „Sozialen Demokraten mit ausgesprochenen und programmatisch reformistischen Tendenzen, genau als das, was der Radikale und Anarchist [Mc Donald] einen Liberalen nennt". Mehr noch verstand er sich als New Dealer, dem „Reiserecht mehr wert ist als Masse“. ${ }^{1173}$ Doch der Klassenkampf bestehe, das sei nicht zu leugnen. Diesen jedoch zum „Eckstein aller politischen Richtungen zu machen“, sei falsch. ${ }^{1174}$ Mit Blick auf die Jugend, für die er sich in Breslau so stark eingesetzt hatte, hatte er bereits 1940 konstatieren müssen:

„Ich würde auf den schlagkräftigen Radikalismus, der Erfolg verspricht, gern verzichten,
wenn ich ihn mit den geringsten Konzessionen an den Fascho-Kommunismus erkaufen
müsste. Ob ich dann als "alter Herr" der heutigen Jugend gegenüberstehe, kümmert mich gar
nicht. Denn die totalitäre Jugend erscheint mir teils als ein Objekt für Aschprügel, teils als
Objekt für heilende Individualpsychologie. Kurz, ich stimme mit denen, die Vorläufer des
Faschismus waren, in einem einzigen Punkte überein, ihrer Skepsis gegen den
Fortschrittsglauben. Eine bestimmte Art von Konservatismus scheint mir heute bedeutend
zukunftskräftiger, als jene Radikalismen, die sich immer weiter von den verhängnisvollen
Geistern des 19. Jahrhunderts: Marx, Nietzsche und Kierkegaard nähern, die wir einmal
überwinden oder Hegelisch aufheben müssen.“1175 Marck war ohne Frage „konservativer“ geworden und während Helmut Hirsch ihm politischen und vor allem charakterlosen Opportunismus vorwarf, konnte dieser sich nur verteidigen, in dem er auf die „Großen“ seiner Partei rekurrierte: „Diesen Opportunismus hatten gewiss auch unsere Großen: Ihr Landsmann Friedrich Engels, Jean Jaures, Leon Blum, August Bebel und die Mäßigen Eckstein, Mierendorf, Haubach und Leber.“1176 Interessant ist, dass Marck hier von „Ihr Landsmann“ spach. Siegfried Marck war zum Zeitpunkt des Briefes und im Alter von 59 Jahren bereits amerikanischer Staatsbürger geworden, während Helmut Hirsch demnächst zurück nach Deutschland ging. Marck selbst zog sich immer mehr aus den Diskursen um die Bundesrepublik zurück und bemerkte selbst Ende 1950: „Ich habe in letzter Zeit wenig deutsche Zeitungen und Zeitschriften in die Hand bekommen, weiß wenig über die Bewaffnungsdebatte und die Deutschen selbst.“1177

\footnotetext{
${ }^{1173}$ Marck an Hirsch, 22.01.1949, NL HH.

1174 Ebd.

1175 Marck an Broch, 02.03.1940, NL HB.

1176 Marck an Hirsch, 04.11.1949, NL HH.

${ }^{1177}$ Marck an Hirsch, 30.12.1950, NL HH.
} 
Doch Marck und Hirsch hatten ein gemeinsames Schicksal; sie waren beide Juden und an einer drittklassigen Universität tätig - sie hielten zusammen ${ }^{1178}$ und diskutierten über das Judentum. „Für [die] Auflösung [des Judentums] durch konsequente Mischehe hatte ich was übrig, in der Theorie und Praxis hatte ich es $3 \mathrm{x}$ nicht getan“ bemerkte Marck. „Die andere Alternative ist nur Zionismus, wie ich es nenne: die kleinjüdische aber durchaus nicht gedankenlose Lösung für eine Minorität ${ }^{\star 1179}$ - Lola und Marcks erster Sohn Andreas hatten diesen Weg gewählt. Überhaupt verstand sich Siegfried Marck sein ganzes Leben lang als nichtzionistischer Jude. Bereits in Breslau hatte er an der Freien Jüdischen Hochschule Vorlesungen und Arbeitsgemeinschaften gehalten, wirkte als Scharnier zwischen Judentum und Sozialdemokratie. In seinem letzten Lebensdrittel in den Vereinigten Staaten jedoch, verstand er sich vielmehr als deutsch-amerikanischer Sozialdemokrat, „der in seinen älteren Tagen nichts mehr anderes sein wird und will.“1180 Weitblickend musste er noch vor dem ersten israelischen Unabhängigkeitskrieg 1947 die von den Vereinten Nationen geplante Teilung Palästinas als eine „unheilbare Katastrophe“ verzeichnen. Er fühlte sich erinnert an das Münchener Abkommen von 1938, verachtete die ,angelsächsische Experimentalmethode“ und verwies auf die für ihn „unheimliche Parallele jüdischer und deutscher Schicksale“, die sich in „Zerstückelung“, „Wiederaufbau“ und „Verwirrung“ zu wiederholen schien. ${ }^{1181}$ Das Verhältnis zwischen dem Staat Israel und West-Deutschland, geprägt von Schuld und Verachtung, nahm Marck zum Anlass, darauf hinzuweisen, dass eine ,schrittweise Wiederzulassung Deutschlands in die Familie der Nationen“ langfristig notwendig und unumgänglich sei. Die „Brandmarkung“ der in der Bundesrepublik gebliebenen oder dorthin zurückgewanderten Juden und die Titulierung „Juden zweiter Klasse“ durch den Vorsitzenden des Generalrates des World Jewish Congress, Aryeh Leon Kubowitzki, konnte Marck nicht unkommentiert lassen. Kubowitzki hatte von allen jüdischen Organisationen verlangt, ihre Kontakte zu den ständigen jüdischen Gemeinden in Deutschland abzubrechen. ${ }^{182}$ Für Marck hatten sie diese Verachtung und diesen Boykott nicht verdient, waren es doch oftmals materielle Gründe, die für einen

\footnotetext{
${ }^{1178}$ Sie luden sich zu Geburtstagsfeiern ein siehe: Marck an Hirsch, 11.03.1949, NL HH.

${ }^{1179}$ Marck an Hirsch, 29.12.1948, NL HH.

${ }^{1180}$ Vgl. Ders.: Der Weg ins Chaos?, in: Aufbau, 02.04.1948.

${ }^{1181}$ Vgl. ebd.

${ }^{1182}$ Vgl. O.V.: Eine leidenschaftliche Erklärung Israels, in: Ebd., 06.10.1950.
} 
Verbleib in Deutschland sorgten, obgleich man die Zurückgegangenen unbelehrbar idealistisch nennen mochte. ${ }^{1183}$

Überhaupt war ihm in Chicago seine religiöse Heimat nicht gleichgültig geworden. Ein Bericht über die Zerstörung jüdischer Kulturdenkmäler in Breslau durch die Nationalsozialisten ${ }^{1184}$, folglich auch die des Alten Friedhofs in der Lothestraße, auf dem auch die Gräber seiner Eltern und Großeltern zu finden waren, nahm ihn sehr mit. Genauso wichtig für Marck war die Nachricht von dem ihm persönlich bekannten Oskar Lange, einem polnischen Ökonomen und dem späteren Wirtschaftsminister Polens, der zugleich ein Modell des Konkurrenzsozialismus entwickelte, dass das einst zerstörte Grab Ferdinand Lassalles wieder errichtet worden sei. ${ }^{1185}$

Die Arbeit am Roosevelt College, die Siegfried Marck als isolierend erlebte, empfand auch Hirsch gleichermaßen. Hirsch schien mehr und mehr außeruniversitär und für den Sozialismus aktiv zu sein, was von seinem Department nicht gutgeheißen wurde. „Es wäre gut, wenn der heiße Boden Ihres Departments sich abkühlt" schrieb Marck an Hirsch. „Aber man soll sich nicht in Familienangelegenheiten mengen.“ Marck selbst bemängelte in seinem Department den fehlenden Austausch und konnte Hirsch in seiner außeruniversitären Aktivität nur bestärken, wenngleich er inhaltlich nicht mit ihm übereinstimmte. ${ }^{1186}$

Dennoch: Siegfried Marck war stets jemand, der es wusste Menschen und politische Diskussionen um sich zu sammeln. In Breslau war sein Haus ein Versammlungsort für viele Jungsozialisten und überhaupt diskutierfreudiger Persönlichkeiten. Im Pariser Exil leitete er zeitweilig die Pariser Ortsgruppe der SPD von seiner Wohnung aus. In den Vereinigten Staaten entwickelte er 1948 einen Diskussionskreis, dessen geistiger Leiter er wurde und der noch über 25 Jahre nach seinem Ableben in regelmäßigen, aber abgeschwächten Treffen stattfand. „Das Bestehen auf dem Gebrauch der deutschen Sprache war ein Bekenntnis dafür, dass inmitten einer neuen Kultur, eines neuen Lebens, die alten Bindungen nicht abreißen sollten“, verdeutlichte Gertrude Schwerin, die Frau Kurt Schwerins, die dieser Gruppe beiwohnte und noch 1980 im Aufbau daran erinnerte. „Wir versuchten zwei Kulturen

\footnotetext{
${ }^{1183}$ Vgl. Marck, Siegfried: Israel und Deutschland, in: Ebd., 13.10.1950.

${ }^{1184}$ Vgl. O. V.: Jüdische Kulturdenkmäler in Breslau, in: Ebd., 08.10.1948.

${ }^{1185}$ Vgl. Marck, Siegfried: Die Gräber von Breslau, in: Ebd., 15.10.1948.

${ }^{1186}$ Marck an Hirsch, 10.01.1951, NL HH.
} 
$\mathrm{zu}$ verschmelzen, aber wir betonten unser geistiges Erbe“, so hob es Schwerin hervor. $^{1187}$

Einen wichtigen Meilenstein zur Identitätsbildung dieser Gruppe bildete Besuch aus Deutschland. Als Ernst Reuter gemeinsam mit Thomas Wimmer 1949 zu Vorträgen nach Chicago kam, gesellte sich Reuter, etwas überraschend, in die Wohnung von Martin Ferber. In dieser Wohnung traf sich ein „kleine[r] sozialistisch orientierte[r] Kern“, der an manchen Abenden 80 Personen umfasste - vorwiegend Emigranten, die in deutscher Sprache redeten und ausgiebig mit Reuter diskutierte. Nach den Diskussionen wurden stets Tee und Gebäck gereicht. ${ }^{1188}$ Dieser von Siegfried Marck und Martin Ferber, dem Leiter eines deutschsprachigen Radioprogramms, initiierte „Diskussionskreis zur Pflege der deutschen Sprache“, der unter den Teilnehmern auch nur „Die Gruppe“1189 genannt wurde, konnte auf eine breite Rednerliste verweisen. Dabei fanden die Treffen zuerst in größeren Privatwohnungen und später in einem Collegelesesaal statt. Meistens waren zwei Redner und ein Moderator eingeladen und es wurden Sommerfeste mit Rahmenprogramm angeboten. Marck koordinierte diese Treffen und gab die Koordination 1955 an seinen ehemaligen Studenten Kurt Schwerin ab. ${ }^{190}$ Schwerin schätze an Marck besonders „die Präzision seines Ausdrucks“, „die Tiefe seiner Darstellungskraft“ und „die Menschlichkeit seiner Gesinnung“. ${ }^{1191}$ Nach Marcks Ableben waren es insbesondere Gedenkstunden, die in diesem Forum abgehalten wurden - für Thomas Mann und Goethe natürlich, aber auch für Walter Rathenau, Gerhart Hauptmann, Georg Büchner oder Paul Tillich - um einige Beispiele zu nennen. ${ }^{1192}$ Dabei ließ der Reiz der Gruppe nach Marcks Tod nach: „Gestern war die erste Sitzung der deutschen Literarischen Gesellschaft, der Auftakt war wenig versprechend“, schrieb Ilse an Eva und Helmut Hirsch. „Ein langweiliger Mann aus New York sprach über den nicht sehr bedeutenden Dichter Anton Wildgans, der die Welt nicht sehr bereichert hat.“ So vermerkte es Ilse, die „verschlafen“ den Vortrag

\footnotetext{
${ }^{1187}$ Schwerin, Gertrude: Eine Großleistung der Exilgeschichte, in: Aufbau 14.03.1980. Siehe auch die persönlichen Erinnerungen Schwerins, LBI NY, S. 85f.

${ }_{1188}$ Ebd.

1189 Ebd.

${ }^{1190}$ Hirsch, Helmut: Siegfried Marck, S. 381f.

${ }^{1191}$ Nachruf Kurt Schwerin auf Marck, NL HH.

1192 Eine genaue Aufstellung bei Helmut Hirsch: Siegfried Marck, S. 382; Kurt Schwerin an Hirsch, 15.06.1966, NL HH; Schwerin, Gertrude: Eine Großleistung der Exilgeschichte.
} 
verließ. ${ }^{1193}$ Damit konnte sie genau das ausdrücken, was Helmut Hirsch an dieser Gruppe stets bemängelte, ihn gar „krank gemacht“ habe. ${ }^{1194}$

Die Gruppe löste sich 1971 aus Altersgründen auf und blieb den Teilnehmern unvergessen. ${ }^{1195}$ „Ich bin froh, wenn ich einen Sprecher für einen Abend finde“ schilderte Kurt Schwerin die Aktivitäten 1966 in einem Brief an Helmut Hirsch. „Ich habe nun seit 10 Jahren die Gruppe geleitet, und ich werde oft dessen müde“, führte er weiter aus. ${ }^{196}$ Das Auflösen der Gruppe war folglich unausweichlich. Für Siegfried Marck, der sein Leben in drei unterschiedlichen Kulturkreisen verbrachte, war diese Gruppe ein Rückzugspunkt. Hier konnte er mit Gleichgesinnten deutsche Kultur anpreisen, über seine Vorbilder Thomas Mann und Goethe diskutieren und der Isolation eines deutschen Sozialdemokraten mit jüdischen Wurzeln in Chicago entkommen.

Dass Siegfried und Kläre sich trennten, war nur die logische Konsequenz aus Marcks Auswanderung mit Ilse. Ilse selbst war eine alte Schulfreundin Kläres, was sich auch auf die kommenden Spannungen zwischen Fried und Kläre auswirkte. Im Rahmen des sich lang hinziehenden Scheidungsverfahrens, das im Nachlass Marcks gut zu verfolgen ist, nannte Marck Kläre einen „psychopathic case, not determined by rational consideration“" ${ }^{1197}$ und auch Ilse musste von „widerlichen Briefen“ Kläres an ihn berichten: „Der Brief ist schon der 2. oder 3., der vollkommen wie der einer Geisteskranken klingt.“1198 Kläre warf Ilse vor, sie käme aus einer „,widerlichen parvenue-Familie“ und Ilses Unverschämtheit hätte Kläre schon als junges Mädchen abgestoßen. ${ }^{1199}$ Grund für diese Streitigkeiten der ehemaligen Schulfreundinnen war, dass Kläre von Ilse auch nach Siegfried Marcks Ableben forderte, ihr weitere drei Jahre Unterhalt zu erhalten. ${ }^{1200}$ Trotz der schwierigen Lage soll Siegfried Marck bei seinen Besuchen in New York noch nach deren Scheidung bei Kläre genächtigt haben.

\footnotetext{
${ }^{1193}$ Ilse Marck an Familie Hirsch, 26.10.1957, NL HH.

${ }^{1194}$ Helmut Hirsch an Ilse Marck, 04.03.1958, NL HH.

${ }^{1195}$ Schwerin, Gertrude: Eine Großleistung der Exilgeschichte.

${ }^{1196}$ Kurt Schwerin an Hirsch, 15.06.1966, NL HH.

${ }^{1197}$ Marck an John Maass, 10.12.1955, NL SM.

${ }^{1198}$ Ilse Marck an Friedländers, 21.12.54, NL WF.

1199 Ebd.

${ }^{1200}$ Marck an John Maass, 07.11.1955, NL WF.
} 
Während Siegfried am College lehrte und seine Exfrau in New York beim American Jewish Committee ${ }^{1201}$ arbeitete, verdiente Ilse in den ersten Jahren ihrer Ehe mit Marck etwas Geld, indem sie im Kleiderverkauf tätig war. Ihr eigentlicher Wunsch war es jedoch, einen Office-Job zu bekommen, im besten Fall bei einem Arzt, wie es wahrscheinlich ihr ursprünglicher Job gewesen sein wird. ${ }^{1202}$ Erst nach der aufwändigen Scheidung von Kläre, in deren Verfahren es immer wieder zu Streitigkeiten wegen der Alimente und der Beteiligungen an einer damals zusammen abgeschlossenen Lebensversicherung ${ }^{1203}$ mit Kläre kam, heirateten Siegfried Marck und Ilse am 03. April 1946 in Chicago. ${ }^{1204}$ Im Zuge des Scheidungsverfahrens stimmte Marck auch zu, seinen Sohn Louis im Fall von Krankheit, oder wenn er sich nicht selbst versorgen könnte, $\mathrm{zu}$ finanzieren. ${ }^{1205}$ Dieser Fall war sehr wahrscheinlich, hatte er doch ein Kriegstrauma erlitten, bei dem Spätfolgen nicht auszuschließen waren. Für Marck und Ilse stellte diese Scheidung, in der vereinbart wurde, dass er Kläre jährlich 1.080 Dollar zu zahlen hatte, eine große finanzielle Belastung für das Ehepaar dar, in Anbetracht der Tatsache, dass er nur 2.950 Dollar im Jahr verdiente. ${ }^{1206}$

Später arbeite Ilse als Sekretärin an derselben Universität wie Marck. ${ }^{1207}$ Ilses Tochter Stephanie Steinberg lebte in Los Angeles. Im Februar 1948 gingen Marck und Ilse nach Los Angeles, wollten dort eigentlich ein Jahr bleiben, doch erlaubte es ihnen die finanzielle Lage nicht. Bereits auf der Hinreise nach Los Angeles hatte Marck versucht mit Vorträgen in Denver die Reisekasse etwas zu füllen. Für 50 bis 75 Dollar war ein Vortrag Siegfried Marcks damals zu haben. ${ }^{1208}$ Siegfried Marck hatte keine Vorlesungen und keine Summerschool organisieren können und Ilse, die eigentlich halbtags arbeiten wollte, konnte aufgrund des schlechten Arbeitsmarktes keinen Job aufnehmen. So waren beide gezwungen, den geliebten und warmen Westen der Vereinigten Staaten im Juni 1948 zu verlassen. Doch bot sich so die Gelegenheit Walter und Li Friedländer auf dem Rückweg zu besuchen und Marck

\footnotetext{
${ }^{1201}$ Zum American Jewish Committee siehe: Sanua, Marianne R.: Let Us Prove Strong. The American Jewish Committee, 1945-2006, New England 2007.

1202 Marck an Friedländer, 29.09.1946, NL WF.

${ }^{1203}$ Marck versicherte Kläre im Falle seines Todes, 1000 Dollar aus seiner Lebensversicherung zu erhalten. Doch wurde nur noch über Anwälte kommuniziert, John Maass an Julius Weigert, 22.09.1955, NL SM.

${ }^{1204}$ Certificate of Marriage, 03.04.1946, NL SM.

1205 Genaueres zu den Modalitäten der Scheidung, Decree of Devorce, 28.03.1946, NL SM.

${ }^{1206}$ Decree of Devorce, 28.03.1946.

${ }^{1207}$ Ilse Marck an Friedländers, 05.03.1957.

${ }^{1208}$ Marck an Friedländer, 25.02.1948, NL WF.
} 
machte stets deutlich, dass er nichts dagegen hätte, dauerhaft in Kalifornien zu leben. $^{1209}$

Das Collegeleben Siegfried Marcks war geprägt von „Verwirrung und wilder Fehde“, resultierend aus der schwierigen finanziellen Situation des Roosevelt Colleges. ${ }^{1210}$ Auch den unter Joseph McCarthy in den Vereinigten Staaten am College immer spürbareren Antikommunismus lehnte Marck strikt ab, warf ihm „faschistoide“ Züge vor. ${ }^{1211}$ Mit Helmut Hirsch blieb er weiter in Kontakt. Dieser konstatierte:

\begin{abstract}
„Allerdings trennt uns wahrscheinlich ein Hauptgegensatz. Was Sie auf der Ebene des Denkens fordern - Vernunft - will ich auf der Ebene des Handelns. Mir kommt es auf Theorie nicht so sehr an. Ich glaube nicht, dass das nur die zu sauren Trauben sind. Vielmehr meine ich wirklich verstanden zu haben, dass man alle Gedankengebäude so biegen kann, dass sie jeder Realität entsprechen, und dass umgekehrt die Realität sich auch der schönsten Gedankenstruktur nicht anpasst, wo die Kerle fehlen." ${ }^{\text {"1212 }}$
\end{abstract}

Dies war wohl wirklich der entschiedene Gegensatz zwischen dem vergeistigten Siegfried Marck, dem „Eckermann“ und dem handlungsorientierten Sozialisten Helmut Hirsch. Hirsch mied Marcks Veranstaltungen, die von Marck initiierte deutschsprachige Diskussionsgruppe und dessen Vorträge mehr und mehr, er war es leid, sich über die „Gassenbuben“, die mit ihren abfälligen Kommentaren über ihn herzogen, zu ärgern - seine Freizeit war ihm viel zu kostbar:

„Diese Leute wissen ganz genau, dass wir weder wirtschaftlich noch schulpolitisch oder gesellschaftlich stark sind, sondern brave Schluffen, die sich ausbeuten lassen; und damit sind wir ein ideales Futter bzw. ein ideales Ziel, auf das man mit dem Schmutz aus den Gossen der Leopoldstadt so schön werfen kann.““1213

Was Helmut Hirsch so geärgert hat, war für Siegfried Marck nicht nachzuvollziehen. ${ }^{1214}$ Hirsch jedoch traute sich 1957 zurück nach Deutschland, wo er wenig Entgegenkommen erfuhr, zudem war es schwer, mit 54 Jahren eine Professur in Deutschland zu bekommen. Allein durch die Fürsprache Johannes Raus erhielt er Lehraufträge und konnte sich so über Wasser halten. ${ }^{1215}$

Noch nach der Trennung von Fried hielt Kläre so manchen einflussreichen Kontakt in den USA aufrecht. So wurde sie für Max Horkheimer, der ja auch mit Marck in

\footnotetext{
${ }^{1209}$ Marck an Friedländer, 11.05.1948, NL WF.

${ }^{1210}$ Marck an Hirsch, 21.05.1953, NL HH.

${ }^{1211}$ Marck, Siegfried: Die Freigeborenen und die Schlammflut, in: Neue Vorwärts, 26.03.1954.

1212 Hirsch an Marck, 30.10.1955, NL HH.

${ }^{1213}$ Hirsch an Marck, 31.10.1956, NL HH.

1214 Marck an Hirsch, 01.11.1956, NL HH.

1215 Hirsch, Helmut: Onkel Sams Hütte, S. 94; Schon 1954 ging Hirsch für Lehraufträge nach Deutschland und ließ seine Frau mit dem gemeinsamen Sohn in den USA zurück, vgl. Ilse Marck an Friedländers, 21.12.1954, NL WF.
} 
Kontakt stand, zu einem „Lichtblick [s]einer New Yorker Zeit.“1216 Sie tauschten zum Teil recht private Angelegenheiten, wie den schwierigen Verlust von Horkheimers Mutter, aus. Horkheimer berichtet in einem Brief an Kläre wie folgt über die Zeit danach:

„Mein Leben fließt äußerlich ruhig dahin. In Wahrheit ist es ein fortwährender Kampf, meine verschiedenen wissenschaftlichen Interessen und die energischen Anforderungen des Arztes miteinander zu vereinigen. Es geht mir [nach dem Tod der Mutter] subjektiv besser, doch soll ich mich noch einige Monate sehr ruhig verhalten, damit der Herzmuskel Zeit hat, sich zu kräftigen. Trotz allem bin ich sehr glücklich, dass ich wenigstens in bescheidenem Umfang zum Nachdenken komme, und dann ist es ja hier [Kalifornien] auch so unendlich schön!“‘1217

Kläre selbst hatte Erfahrungen mit Herzkranken machen müssen, da sowohl Fried als auch dessen Mutter Rosa an Herzproblemen litten. Ohnehin beschrieb Kläre Horkheimer ihre ehemalige Schwiegermutter, „die im Jahr 1919 sozusagen [ihre] Mutter wurde“ als eine Person, die „durch Ärzte, Natur und Willen bis zum Jahre 1941 mit ihrem Leiden ein aktives Leben führte“. ${ }^{1218}$

Horkheimer und Kläre arbeiteten derzeit gemeinsam beim American Jewish Committee - Horkheimer als Direktor der wissenschaftlichen Abteilung und Kläre als Schreibkraft und damit deutlich unter ihren Fähigkeiten. Dennoch trafen sie sich $\mathrm{ab}$ und zu zum Lunch im Prince George Hotel ${ }^{1219}$ - in den Augen Horkheimers zu selten. ${ }^{1220}$ Kläre gehörte zu den sogenannten „Professionals III“, war damit eine bessere und gelangweilte Schreibkraft, wurde aber durch die Beziehungen zu Horkheimer während ihrer Besuche im besagten Restaurant „besser platziert“ als andere mit der gleichen Stellung. ${ }^{1221}$ Was Kläre in jenen Jahren fehlte, war „dass man sich mit einem ,Kollegen“ nicht mal gründlich aussprechen und ausschimpfen kann, ohne zu verletzen und ohne doch ein bisschen auf der Hut zu sein (was ich zu leicht vergesse... )“. ${ }^{1222}$ Sie empfand das American Jewish Committee als „Fabrik“, in der „,einige gute Dinge“ neben ,vielem Bluff zustande gebracht“ wurden. Kläre hatte stets Ärger mit ihrem Vorgesetzten und wurde versetzt. So wundert es nicht, dass Kläre sich an Horkheimer richtete und anmerkte: „Ich würde ganz gerne in ein anderes Department gehen, wo meine Sprach- und politischen Kenntnisse auch besser verwendbar wären, von meinen pädagogischen Erfahrungen ganz zu

\footnotetext{
${ }^{1216}$ Horkheimer an Kläre Marck, 22.03.1946. UBA Ffm Na 1 Nr. 81, 157.

1217 Ebd.

${ }^{1218}$ Kläre Marck an Horkheimer, 26.03.1946, UBA Ffm Na 1 Nr. 81, 154. Kläre weist in diesem Brief auf einen Freund der Familie hin, der zugleich als Arzt und Schüler Minkowskis in New York lebte und für Horkheimer eine gute Adresse dargestellt hätte.

1219 Ebd.

${ }^{1220}$ Horkheimer an Kläre Marck, 22.03.1946.

${ }^{1221}$ Kläre Marck an Horkheimer, 26.03.1946.

1222 Ebd.
} 
schweigen....“. ${ }^{1223}$ Überdies konstatierte Kläre, dass sich im Committee „eine Menge neuer Gestalten“ aufhielten, in überwiegender Anzahl männlich und begabt, „einige mehr ehrgeizig als begabt“, letztlich jedoch alle um ihr „Pöstchen“ besorgt. Dennoch verdienten sie mehr Geld als Kläre, die sich als „white collar worker“ begriff. ${ }^{1224}$ Ferner gab es dort „eine ganze Gruppe“, „die den ,European background“ nicht mögen“. Die Wurzel dieser Unstimmigkeiten sah sie im Bildungsneid der Amerikaner, die sie - etwas scherzhaft - für einen ,interessanten Gegenstand für Analysen psychologischer Art ${ }^{\text {‘1225 }}$ hielt:

„Hätte ich nicht die Erfahrung selbst hier in dieser Organisation gemacht, dass Eifersucht auf die andere Bildung, die niemand ja einfach als , besser' bezeichnet, die Wurzel von so vielen Maßnahmen und Konflikten ist, so würde ich wohl immer noch naiv herumlaufen. “1226

Kläre tauschte besonders familiäre Angelegenheiten mit Horkheimer und dessen Sekretärin, Margot von Mendelssohn; aus. Sie berichtete über ihre Kinder Claudia und Louis, die sich in jenen Jahren noch in der Ausbildung befanden, bei ihr lebten und unterstützt wurden. Dabei machte sie stets auf ihre schwere finanzielle Lage aufmerksam:

\begin{abstract}
„Wie ich es mache, die Familie zu ernähren, mich anständig anzuziehen, eine verhältnismäßig teure Miete für die kleinen möblierten Kabinen in der 98th Street zu zahlen, ist mir selbst manchmal schleierhaft. Mein Sohn studiert unter der G.I. Bill of Rights an New York University und soll einen kleinen monatlichen Zuschuss zu den ,Lebenshaltungskosten“ vom Government bekommen, den ich seit Oktober 1945 sozusagen täglich erwarte. Von Chicago, wo mein Mann ein sehr bescheidenes Gehalt hat, bekomme ich einen winzigen Zuschuss, und so schwindle ich mich eben durch. Manchmal wird es einem etwas über nach 13 Jahren Emigration, aber eines Tages wird schon die Wendung kommen - wenn nicht in dieser, dann in jener Welt....“"1227
\end{abstract}

Nachdem Kläre mit der gemeinsamen Tochter Claudia in die USA nachgekommen war, studierte Claudia am Barnard College, das für die Ausbildung der Freien Künste und der Wissenschaften für Frauen stand. Diese Ausbildung hatte die begabte Claudia in zweieinhalb Jahren absolviert und wollte nach dem Abschluss vorerst einmal praktisch arbeiten, „ehe sie überhaupt an irgendein Weiterstudieren denkt““. ${ }^{1228}$ Die Columbia University, an die das Barnard College formal angebunden war, stellte Claudia jedoch ein Fellowship in Europa in Aussicht, hatte sie doch einen sehr guten Abschluss gemacht. ${ }^{122}$ Der eigentliche Wunsch, vorerst praktisch zu

1223 Ebd.

1224 Ebd. Aus den Jahrbüchern des American Jewish Comittee geht hervor, dass Kläre auch als Übersetzerin tätig war, vgl. Schneiderman, Harry et al. (Hrsg.): American Jewish Yearbook, Volume 49 (1947-1948), S. 319, Volume 50 (1948-1949), S.viii.

${ }^{1225}$ Kläre Marck an Horkheimer/von Mendelssohn, 05.04.1946, UBA Ffm Na 1 Nr. 81, 152.

1226 Ebd.

${ }^{1227}$ Kläre Marck an Margot von Mendelssohn, 23.03.1946. UBA Ffm Na 1 Nr. 81, 155.

${ }^{1228}$ Kläre Marck an Horkheimer, 26.03.1946.

${ }^{1229} \mathrm{Ebd}$ 
arbeiten, wich dem Drang nach Europa zu gehen. Dort konnte sie für zehn Monate als Fellow an der Sorbonne forschen. ${ }^{1230}$ Einmal angekommen war sie jedoch nicht so sehr fasziniert von Paris, eher ,bedrückt durch die Dunkelheit und viel Elend, das sie zu sehen bekam“. ${ }^{1231}$ Zudem verliebte sie sich dort 1947 in Stanislav, der einer bekannten kommunistisch eingestellten tschechischen Familie entsprang. Sie gingen zusammen nach Prag, Claudia arbeitete für Radio Prag, wurde unehelich schwanger und wollte nicht zurück in die USA. Diese Entscheidung hießen sowohl Fried als auch Kläre nicht gut. Sie befürchteten, Claudia könnte es sich mit den amerikanischen Behörden verscherzen. ${ }^{1232}$ Außerdem sahen sie auch das Stipendium und die berufliche Ausbildung Claudias in Gefahr. Diese befand sich in einer äußerst schwierigen Situation, wie ihr 1948 geborener Sohn im Nachgang beschrieb: „Then the political situation became such that my father realised that it was a big political mistake to have married an American Jew from German origins. In these times, it was the worst combination possible." 1233 Die Frontlinie nach dem Einmarsch der Sowjetunion in die Tschechoslowakei verlief bildlich gesprochen genau durch die Familie. Es folgte die Scheidung. Claudia war isoliert, lebte in Hotels und hatte nur wenige Freunde in Prag. ${ }^{1234}$ Sie arbeitete kurze Zeit weiter für Radio Prag, bevor sie zurück nach Frankreich ging und dort erneut heiratete. Im weiteren Verlauf ihres Lebens machte sie sich einen Namen als Übersetzerin von französischer Literatur ins Tschechische und arbeitete zudem als Übersetzerin bei der OECD. ${ }^{1235}$ Sie starb 1981 in New York. ${ }^{1236}$

Kläre wiederum war 1946 eigentlich ,glücklich und dankbar“, dass ihr Sohn kurze Zeit zuvor aus Frankreich in die USA emigrieren konnte und nun „nach der langen, langen Trennung“ ein so „wunderbarer Hausgenosse“ für sie war. ${ }^{1237}$ Kläre war New York und ihren dortigen Job Leid, „die Sklaverei ist manchmal etwas viel“"1238 und sie überlegte in Kalifornien Urlaub zu machen, bei Margot von Mendelssohn auf der Couch zu nächtigen und leitete die ersten Schritte ein. ${ }^{1239}$

\footnotetext{
${ }^{1230}$ Marck an Friedländer, 29.09.1946, NL WF.

${ }^{1231}$ Marck an Friedländer, ohne Datum 1946, NL WF.

1232 Kläre Marck an Hirsch, 25.06.1947, NL HH.

1233 Interview mit Stan Neumann. http://www.radio.cz/en/section/one-on-one/communist-history-ofown-prominent-family-not-black-and-white-says-documentarian-stan-neumann [zuletzt aufgerufen am 26.05.2014]

1234 Ebd.

${ }^{1235}$ Persönliche Anmerkungen von Louis Marck an das LBI NY, 05.10.1983. LBI NY.

1236 Ebd.

${ }^{1237}$ Kläre Marck an Margot von Mendelssohn, 29.03.1946.

${ }^{1238}$ Kläre Marck an Horkheimer/von Mendelssohn, 05.04.1946, UBA Ffm Na 1 Nr. 81, 152.

${ }^{1239}$ Ebd. Antwort von Margot von Mendelssohn an Kläre Marck, 02.04.1946.
} 
Zudem lebte sie seit der Trennung von Fried nunmehr vier Jahre provisorisch im Hotel $^{1240}$, wie Claudia in Prag es auch tat.

Es bleibt festzuhalten, dass Kläre in einem viel persönlicheren und innigeren Kontakt mit Max Horkheimer stand, als es ihr Exmann Siegfried je tat. Sie verstand ihn anders, persönlich und nicht abgehoben, anzusprechen. Fried indes sah ihre Berufsaussichten stets problematisch und hoffte, dass diese sich nicht verschlimmerten, wenngleich er wusste, dass seine Alimente die finanzielle Basis von Kläres Leben darstellten. ${ }^{1241}$

Vieles deutet darauf hin, dass Siegfried den Kontakt zu Horkheimer überhaupt erst durch Kläre aufbauen konnte. So verweist Horkheimer in seinem ersten Schreiben an Marck auf ein Gespräch mit Kläre, die ihn bat, ein unpubliziertes Manuskript an ihren Noch-Ehemann zu schicken. ${ }^{1242}$ Das unveröffentlichte Manuskript, das Horkheimer Marck zukommen ließ, war das spätere Hauptwerk Horkheimers und Adornos Dialektik der Aufklärung. Marck verdeutlichte nach dessen Lektüre seine persönliche Gleichung:

„platonisch kantischer Idealismus und ,gemütlicher“ Liberalismus, dessen Lebenskraft Sie wie alle in ihren Ausgangspunkten stets durch Hegel und Marx bestimmten unterschätzen, lassen mich vielfach so reagieren wie Sie [es] gegenüber meinem Neuhumanismus taten: ich fühle mich ,gegen den Strich gebürstet‘. “'1243

Marck spielte hier auf eine Schrift Horkheimers an, die seinen im französischen Exil entwickelten Neuhumanismus geradezu verriss und Marcks „,weltanschauliches Einigungsprogramm“ und den von ihm sozialistisch angehauchten Liberalismus hart anging. ${ }^{1244}$ „Die richtigen Liberalen saßen damals nicht in der Frankfurter Zeitung, sondern im Direktorium der I.G. Farbenindustrie, und sie sind sich alle treu geblieben“" konstatierte Horkheimer. Überhaupt ließ Horkheimer nichts Gutes an Marcks Schrift, außer dem Versuch selbst vielleicht. So scheinen Marcks oben genannte Einwände verständlich. Während er in seinem Neuhumanismus die Neuformierung des liberalen Bürgertums forcierte, sprachen Adorno und Horkheimer vom „Zusammenbruch der bürgerlichen Zivilisation“. ${ }^{245}$ Dennoch wollte Marck Horkheimer ein ausführliches Memorandum zukommen lassen und bat

\footnotetext{
${ }^{1240}$ Kläre Marck an Horkheimer, ohne Datum (wahrscheinlich Mitte April 1946), UBA Ffm Na 1 Nr. $81,151$.

1241 Siegfried Marck an Mrs. Parker, 24.09.1954, NL SM.

${ }^{1242}$ Horkheimer an Marck, 10.10.1945, UBA Ffm Na 1 Nr. 81, 150c.

${ }^{1243}$ Marck an Horkheimer, 11.12.1945, UBA Ffm Na 1 Nr. 81, 150b.

1244 Schmidt, Alfred (Hrsg.): Max Horkheimer. Gesammelte Schriften, Bd. IV: Schriften 1936-1941, S. 295-307.

${ }^{1245}$ Vorrede von Max Horkheimer und Theodor W. Adorno: Dialektik der Aufklärung, in: Max Horkheimer: Gesammelte Schriften, Band 5, Frankfurt am Main 1987, S. 16ff.
} 
diesen, ob er auch zwei Kollegen das Manuskript zukommen lassen könnte. ${ }^{1246}$ Horkheimer zeigte sich froh, dass es mit Siegfried Marck „einen Menschen gibt, [dessen] Interesse in eine ähnliche Richtung geht wie das eigene.“ Wenngleich Horkheimer wünschte, mit Marck in „regelmäßige Verbindung treten zu können““1247, schlief der Kontakt zwischen beiden nahezu zwei Jahre ein, bis Marck im März 1948 ein Semester Sabathical Leave in Los Angeles verbrachte und wieder Kontakt zu Horkheimer suchte. ${ }^{1248}$

Im Dezember 1948 schlug Marck Horkheimer, nachdem er dessen Eclipse of Reason gelesen hatte und in dem er viel Gemeinsames fand, vor, „die Emigration in einer gewissen Vollständigkeit dem heutigen Deutschen“ vorzustellen und damit meinte Marck „die geistig produktive“ Emigration. Dabei ging es Marck darum, folgende Fragen aufzugreifen: „Was haben wir in der Zwischenzeit gemacht?“, „Was tatet ihr?“ und schlug einen „konstruktiven Gedankenaustausch in einem Sammelwerk“ vor. Marck selbst sah in sich „weder die Gelegenheit zu wissenschaftlicher Organisation noch große Fähigkeiten dazu“ und wollte Horkheimer damit betrauen. ${ }^{1249}$ Nun hatte er bei allen großen deutschen Exilanten in den USA versucht, sie dazu zu bewegen ein solches Buch herauszugeben - bei Thomas Mann, Albert Einstein und schließlich Max Horkheimer. Aus diesem Gedanken zu einem Sammelband wurde nichts. Der Kontakt zu Horkheimer schlief ganz ein, auch weil dieser zurück in die Bundesrepublik migrierte. Dies wurde sowohl von Siegfried Marck als auch von Walter Friedländer als logischer Schritt betrachtet, wenngleich es Horkheimer gelang, seine amerikanische Staatsbürgerschaft zu behalten und in Frankfurt zu lehren. ${ }^{1250}$ Horkheimer schrieb an Marck, bevor er nach Frankfurt ging:

„Nicht wenige der Herren in Deutschland haben vor unserer Rückkehr aus simplen Konkurrenzgründen Angst und möchten vorsorglich unsere künftige Wirksamkeit, die der Vermenschlichung der Verhältnisse dienen könnte und vorerst noch ziemlich große Aussichten auf Erfolg bei den besten Teilen der Studenten hat, durchs bewährte Mittel des Marxistenschrecks schon von vorhinein beeinträchtigen.“1251

\footnotetext{
${ }^{1246}$ Marck dachte an Prof. Weiskopf vom Roosevelt College und Prof. Kessler von der Law School University in Chicago vgl. Marck an Horkheimer, 11.12.1945.

${ }^{1247}$ Horkheimer an Marck, 22.01.1946, UBA Ffm Na 1 Nr. 81, 150a.

${ }^{1248}$ Marck an Horkheimer, 08.03.1948, UBA Ffm Na 1 Nr. 81, 150. Es ist nicht mehr nachvollziehbar, ob es zum persönlichen Gespräch kam.

${ }^{1249}$ Marck an Horkheimer, 26.12.1948, UBA Ffm Na 1 Nr. 8, 148.

${ }^{1250}$ Marck an Friedländer, 20.09.1949, Friedländer an Marck, 10.11.1949, NL WF.

${ }^{1251}$ Horkheimer an Marck, 29.12.1949, UBA Ffm Na 1 Nr. 81, 146.
} 
Den Schritt, zurück in die BRD zu gelangen, dort eine ordentliche Professur zu bekleiden und wieder auf die Jugend zu wirken, wäre Marck auch gern gegangen, doch blieb ihm dieser verwehrt.

Ähnlich wie mit Horkheimer verhielt es sich mit Helmut Hirsch, dem Kollegen und guten Freund Siegfried Marcks an der Roosevelt University in Chicago. Auch ihm schrieb Kläre regelmäßig von ihrem Arbeitsplatz beim American Jewish Commitee. Sie trafen sich zum Essen und sprachen über Claudia, die mit den amerikanischen Behörden auf Kriegsfuß gestanden haben soll. ${ }^{1252}$ Helmut Hirsch sollte sich auf seiner Europareise mit Claudia treffen und sie umstimmen, es sich mit den amerikanischen Behörden nicht zu verscherzen, so hoffte Kläre. Für sie war dies besonders wichtig, hatte sie sich doch 1933 in Genf geschworen, nie wieder nach Deutschland zurückzukehren und sie wollte nicht, dass ihre Tochter, das „oppositionelle Fräulein Claudia“, die Nabelschnur zu ihrer Exilheimat durchtrennte. $^{1253}$

Es scheint, dass Kläre und Fried sich trotz Frieds neuer Ehe vergleichsweise oft trafen. Er besuchte sie in New York, um an Familienfeiern teilzunehmen, übernachtete auch bei ihr. ${ }^{1254}$ Sicherlich gab es im Zuge des Scheidungsverfahrens und der Gerichtsverhandlungen Unstimmigkeiten, die für beide eine große Belastung darstellten, doch mit der Trennung von Kläre wurde Fried bürgerlicher. Helmut Hirsch machte gegenüber Kläre in jedem Fall deutlich: „Allein gefällt mir der Genosse Marck immer noch am besten....“1255

\footnotetext{
${ }^{1252}$ Kläre Marck an Helmut Hirsch, 25.06 1947, NL HH. Höchstwahrscheinlich handelt es sich hierbei um die Frage, welche Staatsangehörigkeit das Kind erhalten wird. Während Hirsch und ihr Exmann immer noch an eine Rückkehr nach Europa und insbesondere nach Deutschland glaubten, vertrat sie nun stets die amerikanischen Werte, die sie mit Helmut Hirsch auch gern argumentativ ausgefochten hätte, vgl. Brief Kläre Marck an Helmut Hirsch, 03.09.1947, NL HH.

${ }^{1253}$ Kläre Marck an Hirsch, 25.06 1947, NL HH.

${ }^{1254}$ Kläre an Hirsch, 03.09.1949, NL HH.

${ }^{1255}$ Hirsch an Kläre Marck, 22.11.1947, NL HH.
} 


\section{Die „Freundschaft“" mit Thomas Mann}

Es gab zwei Persönlichkeiten, die Siegfried Marck über sein ganzes Leben hinweg ein besonderer Bezugspunkt waren: Auf der einen Seite war es Goethe, an den er schon in Breslau auf vielen Gedenkfeiern erinnerte ${ }^{1256}$ und dessen Faust er auch mit in die Schützengräben des Ersten Weltkrieges nahm. Ein anderer hingegen war ihm noch wichtiger, über ihn diskutierte er nicht - Thomas Mann. Der Literaturnobelpreisträger avancierte für den Breslauer Sozialdemokraten zum Vorbild, zum ideologischen Anker. Schon früh beschäftigte er sich mit dem deutlich älteren Thomas Mann, schrieb Rezensionen über dessen Bücher und seinen politischen Werdegang in der Breslauer Volkswacht. Als Siegfried Marck 1922 über die Entpolitisierung der deutschen Kommunen schrieb, rekurrierte er auf Thomas Manns nicht unumstrittenes Werk Betrachtungen eines Unpolitischen. ${ }^{1257}$ Wirtschaftsliberale Strömungen hatten zuvor auf dem Städtetag, an dem Marck anwesend war, für die Entpolitisierung der Kommunen votiert. Marck hingegen war klar, dass eine „Entpolitisierung immer Entdemokratisierung“ bedeutete, dass Politik und Demokratie zusammengehörten, eine Einheit bildeten: „Wer dem an sich schon genug unpolitischen deutschen Volke Entpolitisierung rät, wo immer es sei, erweist ihm keinen guten Dienst, sondern dient, sehr häufig, wahrscheinlich unbewusst, den Tendenzen der Rückkehr zum Obrigkeitsstaat“, so Marck. ${ }^{1258}$

Thomas Mann, der wie Siegfried Marck zunächst ein Befürworter des Ersten Weltkrieges war, lehnte die Weimarer Republik vorerst ab. Vier Jahre später bekannte er sich in seiner Rede von deutscher Republik doch zu ihr. ${ }^{1259}$ Damit ist eine gewisse Parallelität zwischen Marck und dem 14 Jahre älteren Thomas Mann in der Hinwendung zur Republik zu erkennen, wenngleich Marck seinen Grenzgang im Schützengraben und früher als Mann vollzog, während Letztgenannter seinen am Schreibtisch erlebte, getrieben von äußeren Entwicklungen.

So verwundert es nicht, dass auch innerhalb der Breslauer Sozialdemokratie die Person Thomas Manns eine besonders umstrittene war. Als dieser im Januar 1925 für zwei Vorträge nach Breslau kam, waren unter den Zuhörern in der Breslauer Volksbühne sicherlich auch Siegfried und Kläre Marck sowie Fritz Sternberg anzutreffen. ${ }^{1260}$ Die ohnehin sehr belesene und klug auftretende Kläre sah in Thomas

\footnotetext{
${ }^{1256}$ Zum Teil groß beworben in der Breslauer Volkswacht, 29.04.1924, 06.09.1924, 21.10.1924.

${ }^{1257}$ Marck, Siegfried: Entpolitisierung der Kommunen?, in: Ebd., 24.05.1922.

1258 Ebd.

1259 Assheuer, Thomas: Krieg veredelt den Menschen, in: Die Zeit, 12.03.2010.

${ }^{1260}$ Breslauer Volkswacht, 14.01.1925.
} 
Mann „den kultiviertesten Prosaschriftsteller des ausgehenden 19. und beginnenden 20. Jahrhunderts“, mehr noch einen „Meister des Stils“, der mit seiner Kehrtwende und seinem Bekenntnis zur Republik nach dem Mord an Walther Rathenau seinen Entwicklungsgang verstetigt habe. ${ }^{1261}$

Fritz Sternberg indes warf Thomas Mann vor, dass er sich dem Problem des Kapitalismus in seinen Werken stets entzogen habe und überhaupt käme er, anders als Goethe seinerzeit, ,richtungsweisend für die jetzt lebende Generation überhaupt nicht in Frage“. ${ }^{1262}$ Mann flüchte sich in seinen Konflikt zwischen dem eines Bürgerlichen und eines Künstlers, mehr noch schreibt Sternberg:

„Ihr Problem [der lebenden Generation] ist, aus dem furchtbaren Krampf, der die notwendige Folge des Kapitalismus, des Imperialismus und damit auch des Militarismus ist, mit möglichst heilen Gliedern herauszukommen. Dafür ist Thomas Mann nicht Wegweiser, dafür kann er es nicht sein. Es ist geradezu erschütternd, wenn man Thomas Manns Kriegsbuch ,Betrachtungen eines Unpolitischen' liest, und spürt, wie hier ein wesentlicher Dichter und ein bis ins letzte reiner und verantwortungsbewusster Charakter auf die plumpen Schlagworte wildgewordener Professoren und übelsten Literaturgesindels hineinfällt und in vollem Ernst die Meinung verficht, dass der Krieg von 1914 für die deutsche organische Freiheit und Kultur gegen die dekadente westeuropäische Zivilisation war. “" 1263

Für Siegfried Marck jedenfalls arrivierte Thomas Mann zu einem Befürworter der Republik, ähnlich wie vielleicht Friedrich Ebert oder Walther Rathenau - er war „der Große seiner Zeit“, den es nun auch ideengeschichtlich zu untersuchen galt. Marck schrieb einen ersten wissenschaftlichen Artikel über „Thomas Mann als Dialektiker““1264, für den Thomas Mann sich bedankte: „Eine kluge, eindrucksvolle und erinnernde Arbeit" vermerkte Mann, der gleich einige Exemplare der Broschüre an Bekannte verschickte. ${ }^{1265}$ Aus der fachlichen Diskussion heraus entwickelte sich ein Briefwechsel, der für den mittlerweile selbst ausgebürgerten Thomas Mann jedoch eine untergeordnete Rolle spielte, da Marcks Briefe zu der Kategorie ,viele[r] gleichgültige[r] Briefe“" gehörten. ${ }^{1266}$ Thomas Mann erhielt während des Exils täglich eine Vielzahl an Briefen und stand mit so vielen Menschen Kontakt. Schätzungsweise 25.000 bis 30.000 Briefe soll Mann, der sich stets um die Aufrechterhaltung der Korrespondenz bemühte, geschrieben habe. ${ }^{1267}$

\footnotetext{
${ }^{1261}$ Marck, Kläre: Der Entwicklungsgang Thomas Manns, in: Ebd., 06.06.1925.

1262 Sternberg, Fritz: Thomas Mann, in: Ebd., 04.07.1925.

1263 Ebd.

${ }^{1264}$ Marck, Siegfried: Thomas Mann als Dialektiker, in: Philosophia Jg.2 1937, S. 112-138.

1265 Thomas Mann an Marck, 05.09.1936, TMA; Mann, Thomas herausgegeben von Peter de Mendelssohn: Thomas Mann. Tagebücher 1935-1936, Frankfurt am Main 1972, S. 360.

${ }^{1266}$ Ebd., S. 404; Bürgin, Hans: Die Briefe Thomas Manns: Regesten und Register, Bd. II die Briefe von 1934 bis 1943, Frankfurt am Main 1980, S. 139.

${ }^{1267}$ Vgl. Schöll, Julia: Joseph im Exil. Zur Identitätskonstruktion in Thomas Manns Exil-Tagebüchern und -Briefen sowie im Roman Joseph und seine Brüder, Würzburg 2004, S. 149
} 
Dennoch kam Mann seiner gefühlten Pflicht nach, Siegfried Marck auf dessen Briefe und Neujahrsgrüße zu antworten. ${ }^{1268}$ Thomas Manns Exil befand sich im schweizerischen Küsnacht und auch er hatte vor der Machtergreifung der Nationalsozialisten Deutschland verlassen und sollte vorerst nicht zurückkommen. Er war dort neben Carl Zuckmeyer, Walter Benjamin, Ernst Toller, Bertolt Brecht, Peter Weiss und einigen anderen einer der wenigen, die überhaupt politisches Asyl in der Schweiz erhielten und zugleich zur politischen Bescheidenheit ermahnt wurden. Zudem war die Schweiz mehr oder minder ein Transitland, das es bald wieder zu verlassen galt. ${ }^{1269}$ Auch wenn Mann längere Auslandsreisen gewohnt war, stellte dies eine neue und irritierende Situation für ihn dar, mit der er schwer umzugehen wusste. ${ }^{1270}$ Siegfried Marck fand sein Exil in Frankreich und wurde antifaschistisch tätig. Mit Blick auf Thomas Mann und sein Gastland musste Marck etwas neidvoll festhalten: „In der Zeit der spätkapitalistischen Staaten und der künstlichen Massenaufstände sind Zentren wie Weimar an die Schweizer Seen verlegt.“ Marck sprach Thomas Mann als seinen „Hochverehrten Meister“ an und forderte: „Möchte 1937 einen Schritt bedeuten zur Zurück-Eroberung der Zentren!“‘. ${ }^{1271}$ Marck war einige Tage zuvor zu Gast bei Thomas Mann in Küsnacht gewesen, sie hatten Tee getrunken und in Manns Arbeitszimmer diskutiert. ${ }^{1272}$ Bereits hier musste Marck bemerkt haben, dass Thomas Mann ein Exilant mit besonderen Privilegien war, der einen gehobenen Lebensstandard führen konnte ${ }^{1273}$; anders als er, der mit seinem Stipendium in Dijon gerade so über die Runden kam.

Siegfried Marck war in Frankreich mehr an eine Zusammenarbeit mit Heinrich Mann, dem älteren und ungleichen Bruder von Thomas Mann, gebunden. Mit ihm arbeitete er in vielen politischen antifaschistischen Organisationen zusammen. Dies änderte sich mit Marcks Emigration in die Vereinigten Staaten, bei der ihm und seiner Familie das Brüderpaar Mann - inzwischen selbst dorthin emigriert - behilflich war. Hier suchte er mehr noch als in Paris den Kontakt zu Thomas Mann. Siegfried Marck, Hermann Broch, Giuseppe Antonio Borgese und Hans Meisel diskutierten, kurz nachdem Marck in die USA gelangte, beim Tee mit Thomas Mann über den „Plan eine Sammelwerkes zur Vorbereitung eines

\footnotetext{
1268 Thomas Mann an Marck, 02.01.1937, TMA.

${ }^{1269}$ Schöll, Julia: Joseph im Exil, S. 35ff.

1270 Ebd., S. 41.

${ }^{1271}$ Marck an Thomas Mann, 30.12.1936, TMA.

1272 Mann, Thomas: Tagebücher 1935-1936, S. 380; Tagebücher 1937-1939, Frankfurt am Main 1980, S. 123,

${ }^{1273}$ Schöll, Julia: Joseph im Exil, S. 46f.
} 
restaurierten Abendlandes“, ${ }^{1274}$ auf das bereits eingegangen wurde. Überhaupt war Marck nun öfter bei Thomas Mann, sie aßen gemeinsam in Princeton zu Abend ${ }^{1275}$ und der Kontakt intensivierte sich.

Der Einmarsch deutscher Truppen in Holland, Belgien und Frankreich entfachte bei Thomas Mann einen „Druck, der einem das Schreiben in diesen Tagen fast unmöglich macht“"1276 und auch Marck bedauerte, dass Thomas Mann seinen 70. Geburtstag nicht in einem befreiten Deutschland feiern könnte, war er doch für Marck „der Erbe aller europäischen Werte“. ${ }^{1277}$ Thomas Mann war sich seiner besonderen Rolle im Exil bewusst, die sich von Siegfried Marcks unterschied:

„Sie dürfen nicht vergessen, dass meine politischen Exkurse nicht, wie Ihre Schriften, unter dem Gesichtspunkt absoluter Philosophie verfasst sind, sondern dass sie eine Art von höherer Propaganda darstellen und einen polemisch- pädagogischen Charakter haben.““278

Thomas Mann, der seit 1940 in Rundfunkreden über das nationalsozialistische Deutschland referierte, wurde noch deutlicher in einem Brief an Marck, indem er auf dessen Äußerungen zu seinem Artikel Germany's Guilt and Mission antwortete. In diesem machte Thomas Mann deutlich, dass Machtpolitik für die Deutschen Entmenschlichung bedeute ${ }^{1279}$ und ließ seiner Verbitterung über deutsche Tiefe freien Lauf:

„Für fünfzig Jahre, meine ich, sollte es den Deutschen verboten sein, von Tiefe zu reden. Bevor sie wieder das Recht haben werden tief zu sein, müssen sie etwas anderes erwerben, was ihnen unter der Hand völlig abhanden gekommen ist, nämlich decency, Anständigkeit. Erst dann wird auch der Deutsche Dichter und Schriftsteller wieder das Recht haben, deutsche Tiefe in Schutz zu nehmen gegen westlichen Rationalismus. Ich habe das einmal getan und kann nur sagen, dass ich ungeduldig bin, es wieder zu tun. Lassen Sie nur erst die Herrschaft angelsächsischer Anständigkeit auf dem europäischen Kontinent errichtet sein und Sie sollen sehen, wie ich mich auf die ,Betrachtungen eines Unpolitischen“ besinnen werde!“،1280

Mann und Marck waren damit in einer einzigen, aber entscheidenden Angelegenheit uneins - nämlich in der Frage, wie hart die künftige Behandlung Deutschlands nach dem Nationalsozialismus ausfallen dürfte. ${ }^{1281}$ Siegfried Marck machte sich mit Gerhart Seeger publizistisch Gedanken, wie Deutschland nach dem Krieg aussehen könnte. ${ }^{1282}$ Jenes Buch wollte Marck Thomas Mann widmen, der dieses als

\footnotetext{
${ }^{1274}$ Mann, Thomas: Tagebücher 1937-1939, S. 502.

1275 Ebd., S. 403; Ders.: Tagebücher, 1940-1943, S. 181; Tagebücher 1946-1948, S. 225.

1276 Thomas Mann an Marck, 09.06.1940, TMA.

1277 Marck an Thomas Mann, 02.06.1949, TMA.

1278 Thomas Mann an Marck, 19.09.1941, TMA.

${ }^{1279}$ Hirsch, Helmut: Thomas Mann und Siegfried Marck im US-Exil, in: Hefte der deutschen ThomasMann-Gesellschaft, Heft 6/7 (1987), S. 70-86, hier S. 72.

1280 Thomas Mann an Marck, 19.09.1941. TMA.

${ }^{1281}$ Hirsch, Helmut: Siegfried Marck, S. 379f.

${ }^{1282}$ Marck, Siegfried/Seger Gerhart: Germany to Be or Not to Be?.
} 
„gewinnbringenden Beweis dafür, dass es ein anderes Deutschland gebe“ lobte und betonte, dass er ohnehin nicht geglaubt habe, dass alle Deutschen ,idiotische Verbrecher“ seien, sie jedoch eine, ,unglückliche und irreparabel verpfuschte Geschichte“ hätten. ${ }^{1283}$

Thomas Mann selbst bemerkte in Hinblick auf Luftangriffe auf Berlin gegen Ende des Zweiten Weltkrieges, „dass man zu einer Art der Kriegsführung gezwungen ist, von der befürchtet werden kann, dass sie die Möglichkeit der Versöhnung ausschließt“. Mann vermerkt in seinem Tagebuch: „Offizielle Vorschläge Russlands an Polen in Dingen der Grenzziehung. Kompensierung Polens mit deutschem Gebiet“ und fragt sich „Was werden die deutsch-jüdischen Emigranten sagen nebst Seger, Marck und Brecht?“"1284 Für Marck bedeutete dies, dass seine Heimatstadt Breslau, in der seine Familie seit Jahrhunderten tätig war, dessen jüdische Gemeinde und Stadtpolitik die Marcks so prägten, an Polen und somit in sowjetisches Einflussgebiet fiel und er damit seinen eigenen Wurzeln entrissen wurde. Den „Bösen“ waren die Deutschen zwar los, doch „die Bösen sind geblieben“, wie Marck mit diesem Goethezitat an Adolf Grimme betonte. ${ }^{1285}$

Seit Anfang 1946 versuchte Siegfried Marck Thomas Mann für einen Vortrag nach Chicago zu locken ${ }^{1286}$, eine Einladung, die Thomas Mann erst 1949 nach vielerlei Absagen annahm. Mann wollte lieber nach Europa und überlegte: „Wenn ich überhaupt je wieder den Fuß nach Deutschland setzen will, ich es bald tun muss, da sonst - das merke ich mehr und mehr - die Kluft unüberbrückbar wird““. ${ }^{287}$

In diesem Zusammenhang muss berücksichtigt werden, dass sowohl die Roosevelt University als auch die University of Chicago öffentlichkeitswirksam als „kommunistisch verseucht angeprangert“ wurden und, das ist in diesem Zusammenhang noch bedeutender: Thomas Mann hielt seinen Vortrag nicht an der großen, ehrwürdigen und traditionsreichen University of Chicago, sondern in der kleinen universitären Neugründung in Chicago, an der Marck und Helmut Hirsch lehrten. Dieser Vortrag bildete die Generalprobe für Thomas Manns Goethe-Vortrag

\footnotetext{
1283 Thomas Mann an Marck, 28.01.1944, TMA.

${ }^{1284}$ Mann, Thomas: Tagebücher 1944-1946, Frankfurt am Main 1986, S.8

${ }^{1285}$ Marck an Grimme, 17.12.1947, NL AG.

${ }^{1286}$ Marck an Thomas Mann, 31.01.1946, TMA.

1287 Thomas Mann an Marck, 09.02.1946, 31.03.1947,TMA. Siehe insbesondere: Schröter, Klaus (Hrsg.): Thomas Mann im Urteil seiner Zeit. Dokumente 1891-1955, Frankfurt am Main 1999, S. 327415 .
} 
in Oxford. ${ }^{1288}$ Marck jedoch, der Initiator des Vortrages, wurde von einem seiner Studenten in einem Chicagoer Revolverblatt als Thomas Manns „Eckermann“ angegriffen, was er nur mit Verbitterung aufnehmen konnte. ${ }^{1289}$ Marck bezeichnete diese Zeilen, auf die ihn Helmut Hirsch aufmerksam machte, als „Puff im doppelten Sinne“; das „Gesudel der Revolverblätter“" lehne er sowieso ab, er „lache darüber“. Marck sah sich nicht in einem unverbindlichen Gefälligkeitsverhältnis mit Thomas Mann und die „Schmutzfinken“, wie er sie nannte, sollten „im Fette schmoren“. ${ }^{1290}$ Was Siegfried Marck indes noch mehr geärgert haben mag, war die Tatsache, dass bei dieser Veranstaltung nicht er eine Rede auf seinen „hoch verehrten Meister“ halten durfte, sondern ein „ungenannter Professor der Philosophie aus Deutschland“. Siegfried Marck war sehr getroffen, gerade weil die Äußerungen des Vortragenden „den konkreten Schriftsteller“ gar nicht berührten. Siegfried Marck konnte sich nicht „enthalten abzuhauen“. Marck selbst wertete dieses Ereignis als „Ausdruck der Erfolglosigkeit, zu der ich verdammt bin, respektive, die ich mir selbst arrangiert habe. “1291

Thomas Mann indes schätzte an Marck seinen „freien, tief und redlich prüfenden Geist“, seine „gütige Menschlichkeit“ und seine „kluge, warmherzige Aufmerksamkeit“, wie er ihm an seinem 60. Geburtstag unterbreitete. ${ }^{1292}$ So lud er Marck und dessen Frau Ilse, als sich diese während Marcks Sabathical Leave in Los Angeles befanden, in sein Haus zum Lunch ein. Marck musste seinem Cousin Carl Misch davon berichten: „Vorige Woche hatten wir nur mit dem Meister und seiner Frau Lunch im Hause von Thomas Mann“. Für Marck war dies sicherlich wieder wie eine andere Welt. Während er sich mit Ilse in ärmlichen Verhältnissen im kühlen Chicago durchschlagen musste, war das Haus Thomas Manns „wirklich paradiesisch gelegen““. ${ }^{1293}$ Thomas Mann lebte in den Vereinigten Staaten in Pacific Palisades, in Nachbarschaft mit Lion Feuchtwanger und zeitweilig auch mit Max Horkheimer. ${ }^{1294}$

Doch der Eckermann-Vorwurf kam nicht von ungefähr. Marck war Thomas Mann immer zur Seite gesprungen, etwa wenn dieser in Artikeln der Neuen Volkszeitung angegriffen wurde. Schon 1945 veröffentlichte Max Barth den Artikel

\footnotetext{
${ }^{1288}$ Hirsch, Helmut: Onkel Sams Hütte, S. $241 \mathrm{ff}$.

1289 Ebd.

${ }^{1290}$ Marck an Hirsch, 20.01.1950, NL HH.

${ }^{1291}$ Hirsch, Helmut: Siegfried Marck und Thomas Mann im Exil, S. 77f.

1292 Thomas Mann an Marck, 11.03.1949, TMA.

${ }^{1293}$ Marck an Carl Misch, 24.02.1948, 20.05.1948, NL CM.

${ }^{1294}$ Ridley, Hugh/Vogt, Jochen: Thomas Mann, Paderborn 2009, S. 18.
} 
„Abschied von Thomas Mann“"1295 in eben jener Zeitung und schrieb einen „Schimpfartikel“. ${ }^{1296}$ Siegfried Marck konnte diesen nicht unwidersprochen lassen; er wolle zwar „ungern, aber notgedrungen“ alle Beziehungen zur NVZ abbrechen, wenn diese ihn nicht mindestens eine kurze Erklärung schreiben ließe. ${ }^{1297}$ An Max Barth gestattete er sich in einem Brief einige Bemerkungen:

„Die von Ihnen zitierten Sätze aus Thomas Manns Brief haben auch mir wenig gefallen. Ich weiß jedoch ebenfalls wie Sie, dass viele andere die Hände freudig ergreifen würden, die sich ihnen mit dem Anerbieten sinnvoller Mitarbeit aus Deutschland entgegenstrecken würden. Unmöglich ist indessen der Ton Ihres Artikels, den ich ja leider aus ähnlichen Behandlungsweisen mir gegenüber durch andere Mitarbeiter der NVZ kenne. “1298

Auch Max Barth hatte im Ersten Weltkrieg gedient, war sieben Jahre jünger als Marck und hatte sich nach dem Krieg ebenfalls als Volksschullehrer über Wasser gehalten. Seit 1931 war der Pazifist Mitglied der KPD und auch seine Flucht glich einer Odyssee. Nachdem Barth 1933 wieder aus der KPD ausgeschlossen wurde, floh er nach Spanien, wurde von dort nach Frankreich abgeschoben und von den Nazis zum Tod verurteilt. Er floh illegal über Paris nach Prag, weiter nach Oslo, von dort weiter nach Schweden, wo er interniert wurde, bis ihm 1941 über Moskau, Wladiwostok und Manila endlich die Flucht in die USA glückte. Damit hatte Barth eine andere Migrationsgeschichte als Mann oder Marck. Barth kehrte 1950 nach Deutschland zurück. ${ }^{1299}$

Siegfried Marck jedenfalls attestierte solchen Artikeln, die sowohl seinen Mentor Thomas Mann als auch ihn selbst angriffen etwas Prinzipielles und brachte dies mit dem „deutschem Nationallaster der Neidkomplexe“ in Zusammenhang. Er verdeutlichte, dass die Deutschen gegenüber großen Männern nur die Alternativen der „Kritiklosigkeit oder der Hämischkeit“ sähen. Mehr noch und in Hinblick auf die Volksfronterfahrung war es die Intellektuellenfeindlichkeit innerhalb der Arbeiterbewegung, die Marck tief bedauerte. „Ich möchte einer erneuten deutschen Arbeiterbewegung die Mitarbeit von Intellektuellen wünschen, die sich einzuordnen, aber zugleich sich ihrer Haut zu wehren wissen““. 1300

\footnotetext{
1295 Barth, Max: Abschied von Thomas Mann: Ein unfreundlicher Kommentar zu einer unfreundlichen Erklärung, in: Neue Volkszeitung, 15.09.1946.

${ }^{1296}$ Mann, Thomas: Tagebücher 1944-1946, S. 700.

${ }^{1297}$ Marck an Mann, 12.04.1949. TMA

${ }^{1298}$ Marck an Max Barth, 16.09.1945, DNB.

1299 Siehe hierzu insbesondere: Barth, Max: Flucht in die Welt. Exilerinnerungen 1933-1950, Waldenkirch 1986.

${ }^{1300}$ Marck an Max Barth, 16.09.1945, DNB.
} 
Kurz bevor sich Thomas Mann auf seine erste Vortragsreise nach Deutschland machte, wo er auch die Goethe-Medaille ${ }^{1301}$ in Frankfurt und die Ehrenbürgerschaft der Stadt Weimar verliehen bekam, schrieb er an Marck:

„Viel steht mir noch bevor, auch der Besuch in Deutschland, vor dem man mich immer wieder warnt, den ich aber, wenn nicht ganz schwere politische Explosionen noch einfallen, dennoch abstatten werde, um nicht einer tapferen Handlung gegenüber, wie der Verleihung des Preises, als Feigling dazustehen. “1302

Diese Anspannung Manns resultierte auch daraus, dass er beim selben Besuch die Ehrenbürgerschaft der Stadt Weimar erhalten sollte, die bekanntlich dem sowjetischen Hoheitsgebiet zugeordnet war. Dies stieß wohl auch bei einigen Sozialdemokraten auf Ablehnung. Außerdem war Thomas Mann inzwischen amerikanischer Staatsbürger. ${ }^{1303}$

Doch Siegfried Marck hielt Thomas Mann nicht für unfehlbar. Gerade auf politischem Gebiet bescheinigte er Mann „nicht seltene Ungeschicklichkeiten“, die zu den oben genannten Spannungen führten. Marck sah seine Aufgabe darin, die entstandenen Missverständnisse zwischen Thomas Mann und der Sozialdemokratie publizistisch zu beseitigen und trat wieder an Adolf Grimme heran, dessen Kontakt er in dieser vertrackten Lage als den nützlichsten ansah. ${ }^{1304}$ Doch „Thomas Mann sprach sich bei dem Besuche, wie bereits in der Öffentlichkeit, recht pessimistisch über die Gefahren eines Neonazitums in Westdeutschland aus“, berichtete Marck seinem Freund Walter Friedländer. „Aber auch seine Haltung gegenüber dem Osten war höchst reserviert“ und „, nicht einmal die fließenden deutschen Ansprachen der russischen Generäle in Weimar konnten ihn zu einem wirklichen fellow traveler machen“, so Marck weiter. Jedoch war genau das, was Mann vorgeworfen wurde, „aber gewiss nicht sein Verschulden“. ${ }^{1305}$ Marck verteidigte Thomas Mann: „Über Thomas Mann diskutiere ich nicht, der ist für mich etwas Absolutes, ein Gegenstand durch dicke und dünne Ziele. Er ist für mich der größte lebende Mensch voila tout!“"1306 Anderseits sah Marck bei Mann auch Anlass für Kritik, immerhin trieb das „schwankende Boot“, in dem sich dieser befand, manchmal zu „weit nach rechts oder links“, wie Marck in seinem Vorwort von „Große Menschen“ festhielt. ${ }^{1307}$

\footnotetext{
${ }^{1301}$ Marck schenkte Thomas Mann zu Weihnachten 1948 ein Goethe-Kuriosum, was nicht mehr zu rekonstruieren ist.

1302 Thomas Mann an Marck, 10.05.1949 TMA.

${ }^{1303}$ Gut nachzuvollziehen bei Schröter, Klaus (Hrsg.): Thomas Mann im Urteil seiner Zeit, S. 522ff.

${ }^{1304}$ Marck an Grimme, 06.06.1949, NL AG.

${ }^{1305}$ Marck an Friedländer, 20.09.1949, NL WF.

${ }^{1306}$ Marck an Hirsch, 29.12.1948. NL HH.

${ }^{1307}$ Marck, Siegfried: Große Menschen unserer Zeit, S. 8.
} 
Und was war Siegfried Marck für Thomas Mann? Im Dezember 1950 verzeichnet Thomas Mann in seinem Tagebuch „Las in Marcks Manuskript ,Aus drei Kulturkreisen“،"1308 Marck hatte es ihm einige Tage zuvor zugesandt, in der Hoffnung, es würde Mann gefallen. Immerhin wollte er seinem „Meister“ dieses Werk widmen, obschon darin ein nicht zu kleines Kapitel über Thomas Mann zu lesen ist. Dieser hatte sich tagelang mit der Lektüre des Manuskripts beschäftigt:

„Es sind prächtige Dinge darin, namentlich die französischen Analysen, Gide, Valéry etc. haben mich sehr gefesselt, und überhaupt ist das Ganze eine wohl großartig zu nennende philosophisch-politisch-literarische Bestandsaufnahme unserer Zeit, klug beschäftigt mit allem, was da , los' ist, sodass das Buch eigentlich ein großes Publikum anziehen müsste, wenn Angst und Hass die Leute überhaupt noch zu ruhiger kritischer Vertiefung in die Probleme kommen ließen. “1309

Marck sah Thomas Mann als „Finder und Spender des Gleichgewichts“, dem er so ähnlich schien. ${ }^{1310}$ Mann lehnte die Widmung des Buches in seiner Bescheidenheit ab, genauso wie er es bei Germany to Be or Not to Be? tat. Er machte Marck darauf aufmerksam, dass für ihn die deutsche Ausgabe des Buches Priorität habe, da es „,bei aller Weite des Horizontes eben doch ein sehr deutsch denkendes Buch ist". Mann stand somit einer amerikanischen Ausgabe skeptisch gegenüber, auch wegen der schwierigen Übersetzung und den nicht vertrauenswürdigen Lektoren in den Vereinigten Staaten. Es sei besser, das Buch käme über Deutschland in die USA. ${ }^{1311}$ Knapp dreieinhalb Jahre später las Thomas Mann erneut in dem „von Druckfehlern wimmelnden Buch“ und fühlte sich „gerührt von einigem“, was Marck über ihn schrieb. ${ }^{1312}$ Dennoch war der Kontakt zwischen Siegfried Marck und Thomas Mann keine „Freundschaft“ auf Augenhöhe, die etwas lakonische Titulierung Marcks als „Eckermann“ von Seiten seiner Studenten beschreibt diese Beziehung doch recht passend, wenngleich Marck dies abstritt und sich dagegen zu wehren wusste. Der Literaturnobelpreisträger war der „Leuchtturm“ Siegfried Marcks in den Vereinigten Staaten. Sicherlich konnte er so, indem er mit dem - vielleicht neben Albert Einstein - bekanntesten in den USA lebenden Exil-Deutschen in Kontakt trat, seinen beruflichen Werdegang, seine Reputation und seine gesellschaftliche Stellung kompensieren.

\footnotetext{
${ }^{1308}$ Mann, Thomas herausgegeben von Peter de Mendelssohn: Tagebücher 1949-1950 Frankfurt am Main 1991, S. 307.

${ }^{1309}$ Mann an Marck, 18.12.1950, TMA.

${ }^{1310}$ Ebd.

${ }^{1311}$ Mann an Marck, 18.12.1950.

1312 Mann, Thomas herausgegeben von Inge Jens: Thomas Mann. Tagebücher 1953-1955 Frankfurt am Main 1995, S. 227.
} 


\section{Auf Vortragsreise nach Deutschland}

„In den ersten Jahren der Emigration habe ich fest mit einer Rückkehr nach Deutschland gerechnet" schrieb Siegfried Marck an seinen ehemaligen Protegé und Parteigenossen Adolf Grimme im Oktober 1946, doch „,der Ausgang des tollsten und fürchterlichsten Abenteuers der Weltgeschichte hat die Verwirklichung dieser Pläne unwahrscheinlich gemacht“. ${ }^{1313}$ Und diese Zeilen richtete Marck nicht ohne Grund an Grimme: „Indessen ist der Wunsch in mir sehr lebendig, wenigstens gastweise vor deutschen Menschen und vor unseren Freunden politische Philosophie zu entwickeln“. Marck selbst hoffte auf die Möglichkeit, dass ihn seine Universität ein Jahr beurlauben würde, da es auch in ihrem Interesse liege, wenn einer ihrer Professoren an europäischen Universitäten spräche und das Roosevelt College repräsentiere. ${ }^{1314}$ Marck wurde noch ein wenig deutlicher in seinem Anliegen:

„Nun dachte ich mir, ob ein Arrangement getroffen werden könnte, dass ich während eines
Jahres an verschiedenen deutschen Universitäten je 6-8 Wochen einen Vortragskurs abhielte.
Ich habe dabei aufgrund der ehemaligen Förderung, die Sie mir angediehen ließen, an
Hannover gedacht, ferner an Marburg, wohin ich zu dem Rektor Ebbinghaus Beziehungen
habe, Heidelberg, wo ich Jaspers, wenn auch nicht persönlich, so durch wissenschaftliche
Berührung kenne, München, wo ich zu Karl Vossler durch meinen in New York lebenden
Freund und Breslauer Amtsvorgänger Hoenigswald empfohlen werden kann, Frankfurt, wo
Professor Rheinstein die Sache arrangieren könnte u.a.."1315 Die Aussage spiegelt das typische Verhalten Siegfried Marcks, sich bei prominenteren Wissenschaftlern oder einflussreichen Personen des öffentlichen Lebens, Rat, Expertise oder Fürsprache einzuholen. Dies tat er nun auch bei Adolf Grimme, der bereits Minister für Erziehung in Hannover war und kurz vor seinem Sprung zum niedersächsischen Kultusminister stand.

Adolf Grimme antwortete vorerst nicht auf Marcks Schreiben. Dieser hatte jedoch in der Zwischenzeit ein Angebot aus München erhalten, dort im Sommer 1947 Vorlesungen zu halten. Dieses Angebot wahrzunehmen wäre für Marck auch eine Herzensangelegenheit gewesen. Sein Mentor und guter Freund Richard Hönigswald, der den dortigen Lehrstuhl besaß, war kurz zuvor verstorben und es „wäre schon ein Grund mehr, ihm in einer Vorlesung dort ein Denkmal zu setzen“. ${ }^{1316}$ Doch Marck war es aufgrund der kurzfristigen Benachrichtigung unmöglich, dieses Angebot anzunehmen. Aus einem Brief an Walter Friedländer wird deutlich, dass Marck gezielt seine Kontakte in Deutschland anschrieb und nennt

\footnotetext{
${ }^{1313}$ Marck an Grimme, 13.10.1946, NL AG.

${ }^{1314}$ Ebd.

1315 Ebd.

${ }^{1316}$ Marck an Friedländer, 05.08.1947, NL WF.
} 
hier „Hoegner, Grimme, Carl Jaspers, Georg Quabbe“. ${ }^{1317}$ Mit mäßigem Erfolg: Auch ein weiteres Angebot seines guten Bekannten, des Generalstaatsanwaltes Georg Quabbe aus Frankfurt am Main, der mit Gustav Radbruch die Angelegenheit besprochen haben soll und Marck sogar eine Einladung für die gesamte amerikanische Zone in Aussicht stellte, verlief im Sande. ${ }^{1318}$ Quabbe wird Marck noch aus Breslau gekannt haben, wo dieser erst der DNVP und später der Konservativen Volkspartei angehörte. Die Schwierigkeiten, die Marck im Falle seiner Einladung nach München sah, waren auch der langsamen Kommunikation geschuldet, für ihn umso ärgerlicher, da er von den Militärbehörden dort Unterbringung und Verpflegung in Aussicht bestellt kam. So verwundert es nicht, dass Marck erneut versuchte, Grimme für seinen alten Plan - Kombinationen von Vorlesungen an verschiedenen Universitäten - zu gewinnen. ${ }^{1319}$

Wie bereits erwähnt gingen anderen Genossen wie Max Brauer zurück nach Deutschland. Auch Rudolf Katz, ebenfalls jüdisch und zugleich Frontkämpfer im Ersten Weltkrieg, Sozialdemokrat und Exilant in den Vereinigten Staaten, der mit Marck bei der Neuen Volkszeitung zusammenarbeitete, migrierte zurück nach Deutschland. Nur Siegfried Marck, der es so gern wollte, konnte nicht:

\begin{abstract}
„Wäre ich nur für mich allein verantwortlich so würde meine innere Einstellung auch den Weg möglich machen, den Genossen Brauer und Katz gegangen sind. Die familiäre Situation - ich wurde nach langen Schwierigkeiten 1946 geschieden und heiratete dann wieder, habe jedoch teilweise für den in New York lebenden Familienteil zu sorgen, vielleicht auch meine gesundheitliche Situation macht das in diesem Falle so gut wie unmöglich.“1320
\end{abstract}

Marck wollte „für [sein] Leben oder besser für [sein] Sterben gern seinen Freunden drüben nochmal auf dem Heimatboden die Hand drücken“, er wollte sich ,an der Existenz des Guten freuen und zweifellos konstatieren, dass es wie immer gilt: ,Den Bösen seid Ihr los - die Bösen sind geblieben!،‘1321 Zudem wollte er sicherlich auch das begutachten, was ihm Friedländer verdeutlichte:

„In Deutschland sieht es in der Tat böse aus. Ich bewundere unsere Gesinnungsfreunde, die unter solchem Elend und Leiden die Verantwortung für Verwaltung und Rechtsprechung, für Moral und Erziehung auf sich nehmen. Was das gegenüber den Nazi-verseuchten Massen und besonders bei einer Jugend nach 12 Jahren Hitler bedeutet, können wir leider eher ermessen. Eine Reihe von meinen nächsten Mitarbeitern haben jetzt in Berlin nach dem Rücktritt der SEP leitende Posten, der neue Oberbürgermeister, die neue Dezernentin des Landesjugendamtes und der Parteivorsitzende der SPD, aber das allein macht ihre Arbeit nicht leichter." ${ }^{1322}$

\footnotetext{
${ }^{1317}$ Marck an Friedländer, ohne Datum 1946, NL WF.

1318 Marck an Grimme, 18.08.1947, NL AG.

${ }^{1319}$ Marck an Grimme, 18.08.1947, auch noch knapp zwei Jahre später 06.06.1949, NL AG.

${ }^{1320}$ Marck an Grimme, 17.12.1947, NL AG.

${ }^{1321}$ Ebd.

1322 Friedländer an Marck, 10.01.1947, NL WF. Otto Ostrowski und Friedländer kannten sich aus Berlin Prenzlauer Berg.
} 
Adolf Grimme antwortete immer noch nicht auf Marcks Briefe, auf seine Vorschläge, wie er nach Deutschland zu Vorlesungen gelangen könnte. Parallel versuchte Siegfried Marck Friedländer dazu zu gewinnen, sich für ihn für Summerschools an der amerikanischen Westküste stark zu machen. Friedländer warf die Idee auf, eine solche in Berkeley für Marck arrangieren zu können, doch glückte dies nicht. ${ }^{1323}$ Marck hatte von seinem College einen Sabathical Leave zugesagt bekommen, den er in L.A. verbringen wollte, falls sich der Aufenthalt in Deutschland nicht ergeben sollte und für ihn ,wäre eine anschließende Sommerschool-Tätigkeit in Berkeley etwas sehr Organisches““ ${ }^{1324}$ Zudem könnte er sich dort besser mit Friedländer austauschen, der dort lehrte. Friedländer setzte sich für Marck ein und sprach mit William Dennes, dem Leiter der Philosophischen Fakultät in Berkeley, ${ }^{1325}$ doch auch dies zerschlug sich. ${ }^{1326}$

Marck sah sich auch benachteiligt, da er am Roosevelt College lehrte, das in „freundlicher Rivalität" zur University Chicago stand und seine Kollegen nicht über genug „antifaschistische Prominenz“ verfügten. ${ }^{1327}$ Es war dann der Oberbürgermeister von Frankfurt am Main, Walter Kolb, der Siegfried Marck den Weg nach Deutschland bereitete. Doch Frankfurt kam für Marck als Anlaufstelle nicht mehr in Frage, da die dortige Universität Max Horkheimer soeben zurückberufen hatte und Marck und Horkheimer wissenschaftlich nicht zusammenpassten. Kolb sorgte dafür, dass der Rektor der Frankfurter Universität Marcks Wunsch an eine Reihe deutscher Universitäten weiterleitete - Marburg sagte schnell zu, doch die Finanzierung der Hin- und Rückreise blieb vorerst offen. ${ }^{1328}$ Grimme indes ließ endlich mitteilen, dass es ihn sehr freuen würde, wenn er mit Marck in Deutschland zusammentreffen würde. ${ }^{1329}$

Siegfried Marck ging im April 1951 zusammen mit Ilse nach Deutschland. Doch war nicht Marburg das erste Ziel, sondern die Hochschule für Arbeit, Politik und Wirtschaft in Wilhelmshaven, die vom niedersächsischen Kultusminister Adolf Grimme 1949 gegründet worden war, an die er „,vermittelt“ wurde und an der Wolfgang Abendroth als geschäftsführender Direktor arbeitete. Diese Schule besaß einen besonders hohen Anteil von Studierenden aus Arbeiterfamilien und hatte nur

\footnotetext{
${ }^{1323}$ Marck an Friedländer, 05.08.1947, Friedländer an Marck, 07.10.1947, NL WF.

${ }^{1324}$ Ebd.

${ }^{1325}$ Friedländer an Marck, 07.10.1947, NL WF.

${ }^{1326}$ Friedländer an Marck, 05.12.1947, NL WF.

${ }^{1327}$ Marck an Grimme, 06.06.1949 (74. Geburtstag von Thomas Mann), NL AG.

${ }^{1328}$ Marck an Grimme, 31.08.1949, NL AG.

${ }^{1329}$ Wenzlau (persönlicher Referent Grimmes) an Marck, 21.09.1949, NL AG.
} 
bis 1962 Bestand. Darauf wurde sie in die Sozialwissenschaftliche Fakultät der Universität Göttingen eingegliedert. ${ }^{1330}$ Gleichwohl wusste Marck auch ein halbes Jahr vor seiner Abreise nicht, wie hoch sein Gehalt sein würde und ob die Reisekosten für ihn und Ilse übernommen werden würden. ${ }^{1331}$ Es gelang ihm neben seiner Vorlesungstätigkeit in Wilhelmshaven 15 Extravorträge in Deutschland zu erhalten, die ihn nach Hamburg, Bremen, Hannover, Braunschweig, Marburg, Frankfurt am Main, und Baden-Baden führten und letztlich in Berlin ihren Abschluss fanden. Wolfgang Abendroth traf sich mit Ilse und Fried noch in Marburg zum Frühstück, nachdem er beide vom Bahnhof abgeholt hatte. Der Hochschule in Wilhelmshaven hatte Abendroth bereits den Rücken gekehrt und war nach Marburg gegangen. In Deutschland fand Siegfried Marck genau das, was er in den Vereinigten Staaten vermisste - gutes Essen, gute Hotels und wunderbares Theater. Marck zog es auch nach Bonn, er musste die neue Hauptstadt sehen, alte Freunde treffen und den Parteivorstand begutachten. Am eindrucksvollsten wird für Marck das Wiedertreffen mit Paul Löbe gewesen sein, den er auf der Terrasse des Restaurants im Bundeshaus traf. $^{1332}$

Adolf Grimme und Siegfried Marck trafen sich nicht mehr in Deutschland, da Grimme nicht die Möglichkeit sah, nach Wilhelmshaven zu gelangen. ${ }^{1333}$ Als es dann zu Zahlungsverzögerungen beim Nordwestdeutschen Rundfunk kam, bei dem er seine Vorträge einsprach, wandte sich Marck wieder an Grimme, der die Angelegenheit regelte. ${ }^{1334}$ Grimme war nämlich zwischenzeitlich zum Generaldirektor des Nordwestdeutschen Rundfunkes gewählt worden und stand damit der damals größten Rundfunkanstalt Deutschlands vor.

Siegfried Marck verließ Deutschland auf der Queen Mary wieder im Juli 1951 über den Reiseweg Hamburg-London-Southampton. ${ }^{1335}$ Auf der Rückreise traf er noch seinen Sohn Alfons, der zwischenzeitlich nach Großbritannien gegangen war und dort lebte. ${ }^{1336}$ Marck war es nach seiner Rückkehr besonders wichtig, seine Erfahrungen zuerst mit Helmut Hirsch zu teilen, bevor er dies im großen Kreis tat. ${ }^{1337}$ Marck konnte seinem Gefühl nachgehen, dem er seit seiner Flucht 1933 nachspürte: „Mit der alten Heimat fühle ich mich so verbunden, dass ich trotz

\footnotetext{
${ }^{1330}$ O.V.: An die Leine, in: Der Spiegel, 26.07.1961.

${ }^{1331}$ Marck an Friedländer, 17.10.1950, NL WF.

1332 Marck an Friedländer, 07.07.1951, NL WF.

${ }^{1333}$ Grimme an Marck, 03.07.1951, NL AG.

${ }^{1334}$ Marck an Grimme, 14.07.1951, NL AG.

${ }^{1335}$ Marck an Grimme, 11.06.1951, NL AG.

${ }^{1336}$ Marck an Friedländer, 07.07.1951, NL WF.

${ }^{1337}$ Marck an Hirsch, 03.10.1951, NL HH.
} 
amerikanischer Staatsbürgerschaft und der Offenheit für alles Positive in diesem Lande nie aufgehört habe, mich als Kulturdeutschen im Auslande zu betrachten. “1338

Auch Walter Friedländer konnte 1951 zurück in die Bundesrepublik reisen, nachdem ihn Otto Suhr dazu aufgefordert hatte und er mit einem FulbrightStipendium ausgestattet worden war, um ein sozialpädagogisches Institut aufzubauen. Friedländer wurde gebraucht, da durch den Krieg eine Vielzahl an fachkundigen Personen das Land verlassen oder ihr Leben verloren hatte. Es herrschte ein Mangel an wissenschaftlichem Personal, das sich unbelastet der Jugend annehmen konnte und sich in Erziehungstheorien auskannte. Überhaupt reiste er, besonders nach seiner Emeritierung, nach Europa auf Vortragsreisen und erhielt eine Gastprofessur an der Freien Universität Berlin, der Universität zu Köln und an der Fachhochschule Münster. ${ }^{1339}$ Damit ging dieser den Schritt in die alte Heimat, den Ilse Marck und Li Friedländer eigentlich nie gehen wollten. ${ }^{1340}$

Im Herbst 1954 zog es Marck erneut nach Deutschland, er berichtete Friedländer über seine ersten Pläne. Auch hatte Thomas Mann Marck in sein schönes neues Haus an den Zürichsee eingeladen. ${ }^{1341}$ Friedländer riet ihm, sich nicht zu übernehmen, auf seine und Ilses Gesundheit zu achten. ${ }^{1342}$ Marck folgte diesem Ratschlag jedoch nicht, sondern war froh, erneut in Deutschland und gefragt zu sein, dort als Gastprofessor in Bonn Vorträge und Seminare zu geben. Auch Thomas Mann wünschte ihm im Vorfeld einen angenehmen Europaaufenthalt. ${ }^{1343}$ Marck wohnte mit Ilse in Ippendorf etwas oberhalb von Bonn und war sogar so ausgebucht, dass er drei Vorträge, die er in Berlin halten sollte, absagte. Für Ilse war dieses Reiseerlebnis ein wenig anders:

„Man kann sich nichts spießigeres und engeres als diese Provinzstadt vorstellen, auch sind die Bewohner nicht sehr freundlich ihrem ganzen Temperament nach, ob das der rheinische Volkscharakter ist, oder das Ergebnis des zu hohen Pferdes, auf dem sie augenblicklich sitzen, haben wir noch nicht herausgefunden. “1344

Was Ilse störte war die Hektik, die schlechte Anbindung, die erhöhten Preise und die Unhöflichkeit der Bonner. Überhaupt hätten Köln oder Frankfurt bessere Hauptstädte abgegeben. „Der Alte [Adenauer] ist höchst unbeliebt und alle, die wir gesprochen

\footnotetext{
${ }^{1338}$ Marck an Gertrud von le Fort, 30.07.1949, DLA NL Le Fort.

${ }^{1339}$ Füssl, Karl Heinz: Deutsch-amerikanischer Kulturaustausch, S. 254ff.

1340 Eigentlich wollte auch Li Friedländer nicht mehr dauerhaft nach Deutschland, vgl. Brief Friedländer an Marck, 05.12.1947. NL WF.

${ }^{1341}$ Thomas Mann an Marck, 23.05.1954, TMA. Zu diesem Treffen kam es nicht.

${ }^{1342}$ Friedländer an Marck, 23.02.1954, NL WF.

1343 Thomas Mann an Marck, 22.08.1953, TMA.

${ }^{1344}$ Ilse Marck an Friedländers, 20.07.1955, NL WF.
} 
haben und nicht nur Parteigenossen, wundern sich, wer ihn eigentlich gewählt hat.

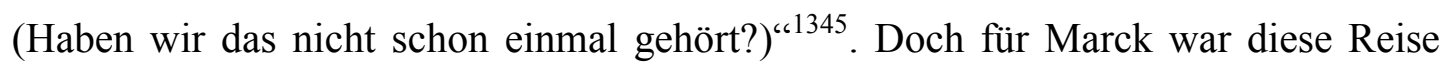
wichtig, sein Buch Aus drei Kulturkreisen war erschienen und er hoffte dadurch in der Bundesrepublik mehr Aufmerksamkeit zu erlangen. Den Höhepunkt des Aufenthaltes erlebte Marck am 08. Mai 1955, zehn Jahre nachdem der Zweite Weltkrieg beendet worden war: Thomas Mann hielt in Stuttgart seine Schillerrede, der auch Marck beiwohnen durfte. Mann selbst war in Deutschland unterwegs, um Reden zu Schillers 150. Todestag zu halten und hatte Marck im Vorfeld wissen lassen, dass es schön wäre, wenn Marck in Stuttgart oder München unter den Zuhörern sein könnte. ${ }^{1346}$ Zudem wohnten die Manns und die Marcks im selben Hotel, in dem auch der damalige Bundespräsident Theodor Heuss wohnte. ${ }^{1347}$ Noch wenige Tage zuvor hatte Marck in der Philosophischen Gesellschaft über Thomas Mann als Denker gesprochen und nun traf er seinen „hochverehrten Meister“ in Deutschland - ein besonderer Augenblick für Marck.

Doch wirklich freundschaftlichen Kontakt hatten die Marcks nur mit Theodor Litt, dem Bonner Kultur- und Sozialphilosophen, der zwar bereits emeritiert worden war, aber immer noch in Bonn eine glänzende Vorlesung über den Sinn der Geschichte hielt - unter den 500 Zuhörern hörte auch Siegfried Marck gern den Worten Litts zu. ${ }^{1348}$ Während der Treffen von Siegfried Marck und Theodor Litt wird auch über Marcks Buch Aus drei Kulturkreisen gesprochen worden sein. ${ }^{1349}$ Ein Brief Hans Georg Gadamers an die Deutsche Forschungsgemeinschaft verdeutlicht, dass Marck 1952 versuchte, in Absprache und nach Ermunterung von Litt, sein Werk durch die DFG zu fördern. Doch Gadamer, der in Breslau noch den Vorlesungen Siegfried Marcks zugehört hatte, ${ }^{1350}$ war nach kurzer Begutachtung klar:

„Es ist leider ganz unmöglich, dass die Forschungsgemeinschaft ihren Namen für diese Arbeit hergibt. Es handelt sich um Essays politisch-soziologischer Art, die jede Bezugnahme auf Quellen unterlassen. Es ist also ganz unabhängig von dem positiven oder negativen Werturteil, das man über das Manuskript hat, dass man es einfach um seines literarischen Gattungscharakters willen nicht unter Wissenschaft oder Forschung subsumieren kann.“1351

\footnotetext{
1345 Ebd.

1346 Thomas Mann an Marck, 19.01.1955, TMA.

${ }^{1347}$ Ilse Marck an Friedländers, 20.07.1955, NL WF.

1348 Ebd.

${ }^{1349}$ Das geht auch aus dem Vorwort hervor, Marck, Siegfried/Seger, Gerhart: Große Menschen, S. 7.

${ }^{1350}$ Kapferer, Norbert: Die Nazifizierung, S. 21.

1351 Hans Georg Gadamer an Deutsche Forschungsgemeinschaft, 17.12.1952, DLA Marbach, NL Gadamer.
} 
Gadamer, der für die DFG im Fachausschuss Philosophie als Gutachter tätig war, empfahl darauf, Theodor Litt das Werk zuzusenden und kein Gutachten anzufertigen: „Es ist zehn gegen eins zu wetten, dass er dann selber nein sagt.“1352

Marcks Gesundheitszustand war bereits in den USA nicht besonders gut, er übernahm sich ständig und sein Herz bereitete ihm Probleme. Es ging ihm zeitweilig so schlecht, dass er fast ein halbes Jahr unter schweren Herzproblemen litt. In Chicago konsultierte er oft seinen Freund Ernst Haase, den Vetter Walter Friedländers, der ihm jedoch immer versicherte, dass es sich nicht um ein organisches, sondern um ein psychisches Problem handle. ${ }^{1353}$ Augenscheinlich griff die Emigration, mit all ihren Problemen - beruflich und familiär - auch die Psyche des ehemaligen Breslauer Philosophieprofessors an. Daneben waren es insbesondere die feucht-kalten Winter Chicagos, die Marck aufs Gemüt drückten. Sich in Deutschland befindend, konsultierte er einen homöopathischen Arzt, der bei ihm gute Erfolge erzielt haben soll. Dennoch erlitt Marck immer wieder kleinere Herzattacken, ohne organischen Befund. ${ }^{1354}$ Seine Ärzte verboten ihm sogar, Grabreden für verstorbene Freunde zu halten, da ihn dies $\mathrm{zu}$ sehr mitnahm. ${ }^{1355}$ So wundert es nicht, dass Siegfried Marck im Alter von 63 Jahren sein Testament formulierte, das in der Familiengeschichte wohl den vollkommenen Bruch Frieds mit seinen Kindern und Exfrauen bedeuten musste: Während Ilse sämtlicher Besitz und Vermögen zugesprochen wurde, bekam Kläre nichts, was ihr nicht seit der Scheidung ohnehin zustand. Sein Sohn Louis, der bereits in Baltimore als Sprachlehrer arbeite, erhielt als Erbe 1 Dollar seines Vaters. ${ }^{1356}$ Diese Summe musste sowohl für Kläre als auch für Louis ein Schlag ins Gesicht gewesen sein, Claudia wurde nicht einmal erwähnt. Die anderen Kinder aus erster Ehe, Andreas und Alfons, fanden ebenfalls keine Berücksichtigung. Für Marck kam Wissenschaft vor Familie, das war spätestens seinem letzten Willen abzulesen.

Marck ließ drei Jahre später Grimme sein Buch Große Menschen unserer Zeit $^{1357}$ zukommen. Sein ehemaliger Fürsprecher, ohne den eine Berufung auf eine

\footnotetext{
1352 Ebd.

${ }^{1353}$ Marck an Friedländer, 10.03.1947, NL WF.

${ }^{1354}$ Marck an Hirsch, 18.03.1953, NL HH.

1355 Die Trauerreden hielt im Todesfall Ilse Neumanns Marcks Frau Ilse siehe: Marck an Hirsch, 12.06.1953, NL HH.

${ }^{1356}$ Last Will and Testament, 03.06.1952, NL SM.

1357 Siehe hier auch die ausführliche Rezension des Buches von Wolfgang Ritzel, in: Philosophischer Literaturanzeiger Bd. IX 1956, Heft 2, S. 57-63. Auch Carl Misch lobte das Buch im Aufbau als ein „gelehrtes Buch“, das die Erwartungen übertrifft, vgl. Aufbau, 11.06.1954.
} 
ordentliche Professur in Breslau nicht möglich gewesen wäre, bedankte sich und freute sich auf das Lesen eines Stückes ,,miterlebter Geschichte“. ${ }^{1358}$ Jenes Buch, das Marck im Jahr 1948 zu schreiben begonnen hatte und zwei Jahre später fertigstellte, war ihm ein besonderes: „Ich habe kaum jemals ein Buch mit so viel innerer Beteiligung geschrieben und glaube, dass es gut geworden ist. Seltsamerweise ist mir der französische Teil, den ich ursprünglich eigentlich mehr als Anhang plante, mit den analytischen Porträts über Blum, Gide, Valery, Sartre, Mounier, Benda der wichtigste geworden. ${ }^{1359}$ Siegfried Marck selbst wertete das Beenden eines Buches als Betrug. ${ }^{1360}$ Doch für dieses Werk bekam er endlich die Anerkennung, die ihm seit vielen Jahren fehlte, wenngleich es die Deutsche Forschungsgemeinschaft nicht fördern wollte. Nicht nur Grimme lobte sein Buch, auch Thomas Mann pries es an:

„Sie haben mir Ihr schönes, weites, reiches Buch von „Großen Menschen in unserer Zeit“ schicken lassen: herzlichen Dank dafür! Es hat mich gefesselt und gerührt - auch das: denn wie sollte mich nicht rühren, was Sie darin über ,mich' sagen, über Joseph besonders und die letzte Melancholie, die seine freundliche Gestalt umgibt. [...] Ihr Buch ist ausgezeichnet, ob es nun von John Dewey spricht oder Roosevelt (da besonders) oder Niebuhr oder die Franzosen. “1361

Marck hatte in seinem Werk Thomas Mann in seinem Kapitel „Die deutsche und europäische Krise im Spiegel des Lebenswerkes von Thomas Mann“ breite Aufmerksamkeit geschenkt. Doch die Melancholie Marcks blieb, trotz der Fürsprache Manns. In ihren Gemütszuständen waren Marck und Mann vielleicht gleichauf, ${ }^{1362}$ Manns Melancholie ist gut aus dessen Tagebüchern herauszulesen, Marcks aus dessen Briefen. Marck jedenfalls wirkte getrieben, resigniert und altklug zugleich. Eine Kulturkittung, folglich und im Marckschen Sinne die dialektische Aufhebung der Gegensätze des Amerikanismus und des Europäertums, die ihm sicherlich physisch und psychisch gut getan hätte, war ihm nicht gelungen.

Bereits vor seinem Tod stellte er an die Bundesrepublik an einen Antrag auf Wiedergutmachung, was damals in der Bundesrepublik ein bürokratisches Ungetüm war. ${ }^{1363}$ Dennoch war diese Möglichkeit bereits seit 1948 gegeben und es ist nicht zu rekonstruieren, weshalb Marck diesen Antrag nicht schon vorher gestellt hatte. Marck konnte Emeritenbezüge aus Deutschland erhalten, die jedoch vorerst auf einem Sperrkonto bei der Rhein-Ruhr-Bank in Düsseldorf ${ }^{1364}$ festgeschrieben und in

\footnotetext{
${ }^{1358}$ Grimme an Marck, 08.06.1954, NL AG.

${ }^{1359}$ Marck an Friedländer, 17.10.1950, NL WF.

${ }^{1360}$ Marck an Hirsch, 04.11.1950, NL HH.

${ }^{1361}$ Thomas Mann an Marck, 23.05.1954, TMA, auch im NL HH.

1362 Thomas Mann an Marck, 21.03.1947, TMA.

${ }^{1363}$ Bezirksamt für Wiedergutmachung an Ilse Marck, 28.10.1958, NL SM.

${ }^{1364}$ Kassenanweisung der Oberfinanzdirektion Düsseldorf, 28.11.1953, NL SM.
} 
monatlichen Raten von dort an ihn überwiesen wurden. ${ }^{1365}$ Wie absurd die Angelegenheit war, verdeutlichen folgende Zeilen der Oberfinanzdirektion Düsseldorf:

„Ihr Guthaben aus den internationalen Freicoupons ist nahezu aufgebraucht. Um die an Sie gerichteten Mitteilungen weiterhin per Luftpost absenden zu können, empfehle ich Ihnen wie es in sehr vielen Wiedergutmachungsfällen bereits geschehen ist - Ihre Sperrkontobank anzuweisen, einmalig meiner Oberfinanzkasse Düsseldorf, einen Betrag von 20 DM zur Deckung der in Ihrer Wiedergutmachungssache entstehenden Portomehrkosten zu überweisen. “1366

Ilse suchte sich vielleicht auch wegen solcher Äußerungen einen deutschen Anwalt. ${ }^{1367}$ Sie war verbittet über das ganze Procedere und nannte die Sachbearbeiterin in der Finanzdirektion ,einen Hitler in Hosentaschenformat“ ${ }^{1368}$ Auch mit Kläre musste sie sich weiter nach Frieds Tod über das Witwengeld streiten. ${ }^{1369}$ Es darf in diesem Zusammenhang nicht vergessen werden, dass die Familie Marck in Breslau zu den reichsten Familien gehört hatte. Rosa, die Mutter Siegfried Marcks, blieb bis zu ihrem Lebensende im April 1941 in Breslau und lebte dort recht vermögend von Renten und Dividenden. Das Haus der Familie Marck wurde 1939 zwangsweise verkauft und soll 50.000 Reichsmark gebracht haben. ${ }^{1370}$ Geld, das die Familie nie gesehen hat.

Am 16. Februar 1957 starb Siegfried Marck in Chicago. Der Neukantianer, Sozialist, Neuhumanist und Antifaschist verschied in seiner Wohnung an seiner Herzkrankheit. ${ }^{1371}$ In seiner Hand soll er Karl Jaspers „Vernunft und Wiedervernunft in unserer Zeit“" gehalten haben. ${ }^{1372}$ Sein Grab befindet sich auf dem jüdischen Friedhof in Oakridge. ${ }^{1373}$

\footnotetext{
1365 Siehe die verschiedenen Kassenanweisungen der Oberfinanzdirektion Düsseldorf im NL SM.

1366 Oberfinanzdirektion Düsseldorf an Marck, o. D., NL SM.

${ }^{1367}$ Hans Jacoby an Ilse Marck, 29.03.1958; Der deutsche Anwalt war Gotthard Paulus, ein Freund Marcks aus seiner Zeit der Gastvorlesungen in der BRD. Dabei war Paulus den Behörden und dem Verfahren sehr kritisch gegenüber eingestellt, da zum Teil über mehrere Jahre falsche Berechnungen der Bezüge, des Witwen- und Sterbegeldes gemacht wurden, vgl. Gotthard Paulus an Oberfinanzdirektion Düsseldorf, 10.05.1957, 11.05.1957, NL SM.

${ }^{1368}$ Paulus an Ilse Marck, 16.01.1958, NL SM.

${ }^{1369}$ Paulus an Ilse Marck, 02.08.1957, NL SM.

${ }^{1370}$ Bruno Hoppen an Hans Jacoby, 28.01.1958, NL SM.

${ }^{1371}$ Vgl. Certificate of Death, 18.02.1957, NL SM.

${ }^{1372}$ Vgl. Hirsch, Helmut: Siegfried Marck, S. 384.

${ }^{1373}$ Certificate of Death, 18.02.1957, NL SM.
} 


\section{Zusammenfassung und Schlussfolgerung}

„Fried hat nie irgendetwas Originäres zustande gebracht und war als Familienvater sehr schwach. Er war einfach ein armchair socialist und wie gerne wissen sich solche Menschen in der Aura der Arbeiterklasse geschwommen zu sein, sind aber bestenfalls mittelmäßige Fried bleibt für mich genau das was er anprangerte - kleinbürgerlich und langweilig. “"1374

War Siegfried Marck ein „armchair socialist“? Ein hartes Urteil seines Enkels, das zugleich ein Ansporn für den Verfasser war, zu verdeutlichen, dass Siegfried Marck doch etwas Originäres zustande brachte, dass er eben nicht langweilig war und zurücklehnend auf die Arbeiterklasse schaute, wie ihm aus Familienkreisen unterstellt wird. Dennoch, und das bleibt zu betonen und wird vorweggenommen der große wissenschaftliche Wurf, oder die große politische Karriere gelang Siegfried Marck nicht. Wissenschaftlich blieb Marck ein Mann der zweiten und politisch eine Figur der dritten Reihe. Seine Biographie als Theaterstück aufzuführen, würde einem bürgerlichen Trauerspiel ähneln. Immerhin rüttelte Marck mit seinem Engagement für die Arbeiterklasse an genau jener bürgerlichen Weltordnung, der seine Familie seit vielen Jahren angehört hatte und von der er sich selbst nie losriss. Dennoch sollen diese wenig wohlwollenden Worte eines nicht verbergen: Eben diese politische Biographie kann dazu dienen, die Lebenswelt eines Emigranten aufzuzeigen, der, wie die Mehrzahl der Vertriebenen, es nicht schaffte, wieder Fuß zu fassen. Aber Siegfried Marck war dran an den großen Debatten, er hatte Kontakt zur politischen und wissenschaftlichen Provenienz seiner Zeit. An solcher Stelle bleibt stets die Frage: Was wäre gewesen, wenn? Hätte Siegfried Marck politisch Karriere gemacht, wenn sein Name 1924 bei der Aufstellung zur Reichstagswahl nicht plötzlich vom Wahlzettel verschwunden wäre? Das Potential dazu hätte er gehabt. Er war intellektuell, konsensorientiert, engagiert und als Redner charismatisch und in der Sozialdemokratie gut vernetzt. Auf der anderen Seite stellt sich die Frage, ob Siegfried Marck wissenschaftlich ein prägenderes Werk gelungen wäre, ob er die Provinzuniversität in Breslau als Sprungbrett an eine bedeutende Philosophieprofessur seiner Zeit hätte nutzen können, wie es ein Richard Hönigswald oder Wilhelm Dilthey mit der Schlesischen Friedrich-Wilhelms-Universität taten? Dieses Potential hatte er nicht. Das verdeutlicht allein seine Berufung.

Siegfried Marck war ein „,politischer Grenzgänger“. Bei einer nüchternen Analyse seines Werdegangs muss ihm ein spezifisch intellektuelles Verhalten zugeschrieben werden, das sich in die „Alltagsbewältigungsstrategie“ in der ersten

${ }^{1374}$ Persönliche Nachricht John March an den Verfasser, 08.04.2014. 
Hälfte des 20. Jahrhunderts fügte, die „unabhängig von charakterlichen Eigenschaften aufgrund der Angebotssituation auf dem ideologischen Warenmarkt der Deutungsmöglichkeiten und der gemeinsamen Deutungsbedürfnisse und

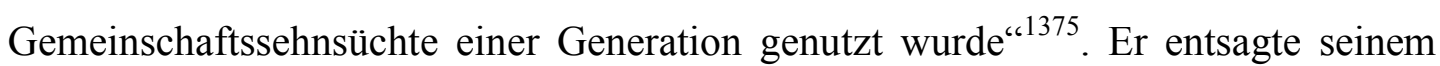
nationalliberalen Gedankengut und schloss sich der Sozialdemokratie an. Dies war in jenen Jahren nicht sonderlich außergewöhnlich: Die Grenzgänger der Zwischenkriegszeit kamen in den meisten Fällen aus der Generation der Frontkämpfer. Sie entstammten dem bürgerlichen Lager und hatten oftmals erst in den Schützengräben die ersten Kontakte mit der Arbeiterbewegung. ${ }^{1376}$ Zudem war dieses Phänomen nicht nur in Deutschland vorzufinden: In Frankreich waren es Marcel Déat, Jacques Doriot oder Pierre Laval, in Großbritannien Oswald Mosley, die zwischen den politischen Anschauungen schwankten. Gemeinsam war den Grenzgängern der Frontkämpfergeneration der Antiparlamentarismus, das Aufbegehren gegen den bürgerlichen Individualismus und Liberalismus und ganz besonders gegen die Werte von 1789, die in Weimar eine liberale, sozialistische und konservative Ausprägung erhalten hatten. Der Parteienstaat war für sie zum unfähigen Akteur geworden, der Antworten auf die sich entwickelnden Fragen einer sich stetig industrialisierenden Massengesellschaft schuldig blieb. ${ }^{1377}$ All jene sehnten sich nach einem starken Staat, oder wenigstens nach der Wiederherstellung einer starken politischen Autorität. Das waren die Berührungspunkte oder Zweigstellen mit den Kommunisten und Faschisten.

Siegfried Marck, dessen Leitmotiv im Zuge seines Lebens der Freiheitliche Sozialismus werden sollte, war da anders, obwohl er eigentlich alle Voraussetzungen für einen politischen Grenzgänger solchen Typus mitbrachte. Die Brüche bei ihm waren aber nicht so radikal. Marck, der ebenfalls dem bürgerlichen Lager entsprang, der auch als Frontkämpfer seine ersten Begegnungen mit der Arbeiterbewegung hatte, überwand zwar die Grenze seines eigenen Herkunftsmilieus, doch den Bürger in sich und das Suchen nach Stabilität tötete er nicht ab. Sicherlich bestand auch für ihn die Notwendigkeit nach den Erlebnissen des Ersten Weltkrieges mit

1375 Vgl. Schneider-Nehls, Gudrun: Grenzgänger in Deutschland. Untersuchung einer intellektuellen Verhaltensmöglichkeit in unserem Jahrhundert, Potsdam 1997, S. 14.

${ }^{1376}$ Vgl. Oschmann, Kersten: Hendrik de Man. Zwischen links und rechts, in: Lösche Peter/Walter, Franz (Hrsg.): Vor dem Vergessen bewahren. Lebenswege Weimarer Sozialdemokraten, S. 223- 251, hier S. $242 \mathrm{ff}$.

1377 Vgl. Ders.: Über Hendrik de Man: Marxismus, Plansozialismus und Kollaboration; ein Grenzgänger in der Zwischenkriegszeit, Freiburg 1987, S. $577 f$. 
„Sinnlosigkeits- und Kontingenzerfahrungen“1378 umzugehen und deshalb versuchte er sie in neu zu schaffende Sinnzusammenhänge zu stellen.

Doch bleiben wir bei dem, was Siegfried Marck ausmachte, was ihn antrieb: Sein kompromissloses Eintreten für den Kompromiss, sein Verlangen, in allen noch so verschiedenen Konstellationen und Gewichtungen, ein Gleichgewicht, eine Einheit $\mathrm{zu}$ finden. Dahinter stecken vor allem seine geistige Schule, die des Neukantianismus, seine Erfahrungen als politischer Grenzgänger und seine beruflichen und privaten Brüche. Marck wurde in seinem Leben mehr als einmal seinen Wurzeln entzogen und kappte familiär mehr als einmal ein Band. Mit dem Niedergang des Linksliberalismus in Breslau musste sich auch Siegried Marck politisch neuorientieren. Etwas böswillig könnte man behaupten, er sei mit dem Strom geschwommen, er sei Opportunist gewesen. Insbesondere wenn festgestellt werden kann, dass die Mehrzahl der jüdischen Abgeordneten im Norddeutschen Reichstag der Nationalliberalen Partei angehört hatten. Einige Jahre später, als sich die Sozialdemokratie zu stärksten Fraktion entwickelt hatte, waren die meisten jüdischen Abgeordneten Sozialdemokraten. ${ }^{1379}$ Folgte Siegfried Marck diesem „Trend“?

Denken wir einmal zurück an die Familie Marck, die seit vielen Generationen das Stadtbild und Gemeindeleben Breslaus mitzuprägen versuchte. Sie waren Kuratoren der Fraenkelschen Stiftungen, berieten Ferdinand Lassalles, sie verstanden sich als deutsche Juden, nationalliberal und stets in bildungs- und wohlfahrtspolitischen Einrichtungen aktiv. Schon sie mussten über Jahrzehnte ihren Standpunkt in Breslau aushandeln - erhielten Zugang zu politischen Ämtern, gründeten ein Bankhaus und waren in der jüdischen Gemeinde Breslaus verankert. Bereits hier wird Siegfried Marck gelernt haben, dass politische Teilhabe immer ein Prozess des Arrangierens, ein Bestandteil von Zugehörigkeit ist. Besonders seine Mutter Rosa, mit ihrer harmonisierenden und bezwingenden Freundlichkeit, ihrer inneren Ausgeglichenheit und kraftvollen Selbstlosigkeit, prägte Marck. Auf der anderen Seite stand sein Vater Alfons: Penibel, abergläubisch, ein Bürokrat, pflichtbewusst und kaisertreu bis in den Tod. Dieses Verhaltensmuster - versuchen nicht aufzufallen, nicht anzuecken und zudem stets wohltätig und akribisch arbeitend, fleißig und kulturfördernd sein zu wollen verdeutlicht doch letztlich den

${ }^{1378}$ Vgl. Schneider-Nehls, Gudrun: Grenzgänger in Deutschland, S. 49.

${ }^{1379}$ Vgl. Hamburger, Ernest: Juden im öffentlichen Leben Deutschlands, S. 518. 
Minderheitskomplex vieler deutscher Juden, die sich assimiliert hatten und dennoch nie ganz „dazu“ gehörten.

So ist es nur konsequent, dass die Brüder Siegfried und Lutz auf die besten Schulen gingen, welche einen Integrationscharakter besaßen. Dass Siegfried Marck sein Studium der Rechtswissenschaften aufgab, um Philosophie zu studieren, kann als erstes Indiz für eine Verhaltensänderung herangezogen werden. Immerhin hatten beinahe alle Marcks auf männlicher Seite Rechtswissenschaften studiert und waren Richter oder Anwälte in Breslau. Doch auch hier fand er sich, insbesondere als Sozialdemokrat und als einer von vier jüdischen Privatdozenten, zwischen den Stühlen des Neukantianismus wieder, und auch hier versuchte er lieber zwischen diesen, seinen philosophischen Lehrern, zu vermitteln, zu harmonisieren, als einen klaren Standpunkt zu ergreifen und anzuecken.

Auch im privaten Bereich hatte Siegfried Marck schwere Verhandlungen bezüglich der Ehe mit Lola Landau führen müssen. Nach vier Heiratsanträgen kam es zu einer Ehe, aus der zwei Söhne hervorgingen, aber die dennoch nicht lange fortbestand. Mit Beginn des Ersten Weltkrieges sollte sich einiges ändern. Lola Landau und ihr Ehemann waren damals ganz euphorisch und patriotisch gegenüber dem Krieg. Marck sollte sofort einberufen werden, wurde im März 1915 als Infanterist eingezogen und doch wegen eines chronischen Herzfehlers zurückgestellt. Darauf fühlte er sich minderwertig und versuchte mit seiner Deutschen Staatsgesinnung seinen „Dienst“ für sein Vaterland zu leisten. Hinzu kam, dass er sich gerne bei Kühnemann habilitiert hätte, dieser jedoch seit 1914 in den USA auf Vortragsreise war, Marcks wissenschaftliche Karriere also warten musste. Zudem starb sein Bruder früh in den Schützengräben für sein Heimatland. Marck wurde nach seiner Rückstellung Vertretungslehrer und sah sich nachweislich zum ersten Mal offenem Antisemitismus ausgesetzt. Gegen Kriegsende wurde er dann als Funker an die Westfront berufen und er erlebte mit Schrecken, was dort geschah. Er begriff sich nur noch als „Maschinenteil“, das zwischen Stacheldraht und Granatangriffen zu funktionieren hatte. Er begriff, dass es dort keinen Platz für seine Feingeistigkeit gab. Die Ehe ging aufgrund der Kriegstrennung und der „Revolutionsmasern“ der Eheleute zu Ende. Beide verliebten sich neu und heirateten wieder.

In den Schützengräben wurde Siegfried Marck nach einigem Zögern zum Sozialdemokraten, zu einem „Novembersozialisten“, der in der Breslauer Sozialdemokratie und besonders bei den Jungsozialisten Spuren hinterließ. Die 
Vortragsabende der Marxistischen Arbeitsgemeinschaft, die er gemeinsam mit Fritz Sternberg und Ernst Eckstein ins Leben gerufen hatte, die vielen Gespräche und Diskussionsabende in seinem Privathaus, die gemeinsamen Theateraufführungen mit den Jungsozialisten verdeutlichen, dass Siegfried Marck stets auf der Suche nach Anerkennung und Zugehörigkeit war. Ohne Zweifel müssen diese Jahre als die „glücklichsten“ Siegfried Marcks beschrieben werden; immerhin hatte er sich etabliert, schrieb gemeinsam mit seiner zweiten Frau Kläre Theaterstücke, die er gemeinsam mit den Jungsozialisten vor tausenden Zuschauen aufführte. Marck hatte in Breslau den Rat der geistigen Arbeiter mit initiiert und die Volkshochschule aufgebaut, zudem gelangte er nun in den Kreis um die Breslauer Volkswacht, einen „Klüngel“, der die Sozialdemokratie in Breslau formte. Immanuel Birnbaum, Max Tockus, Clara Zils und Ernst Eckstein sind Namen, die mit diesem Kreis verbunden werden können. Siegfried Marck war mit ihnen befreundet und betrieb gemeinsam mit ihnen Politik. Sie dienten ihm immer wieder als Vergleichsfolie. Ernst Eckstein etwa, mit dem er viele gemeinsame Abende im Breslauer Gewerkschaftshaus verbrachte, war in seinem Verhalten und seinen Äußerungen viel radikaler als Siegfried Marck. Während Marck stets als überzeugter Republikaner auftrat, versuchte Eckstein, der aus sehr einfachen Verhältnissen kam und sich nach seinem Fronterlebnis direkt dem linken Flügel der Breslauer Sozialdemokratie anschloss, stets gegen diese zu agieren und schreckte dabei auch nicht vorm Stürmen anderer Parteiveranstaltungen zurück. Auch dank Ernst Eckstein war Breslau seit Mitte der 1920er Jahre zu einer Hochburg des Linkssozialismus geworden, in der sich Fritz Sternberg oder Max Adler wiederfanden. Eckstein war zu Recht der Anführer der Breslauer Arbeiterschaft, zu der Siegfried Marck nur schwer einen Zugang bekam. Er versuchte lieber an der Universität, bei seinen sozialistischen Studenten, den Kampf um die Republik mit adeligen und geistigen Waffen zu schlagen. Er rief die Sozialistische Studentengemeinschaft ins Leben, der vor allem recht wohlhabende jüdische Studierende angehörten. In Breslau entstand ein Milieu von radikallinkssozialistischen Intellektuellen, die gemeinsam mit den jungsozialistischen Facharbeitern eine theoretisch anspruchsvolle Bildungsarbeit genossen, auch dank Siegfried Marck, der jedoch neben einem Fritz Sternberg, Max Adler oder Ernst Eckstein ein wenig verblasste. Marck jedenfalls brauchte den akademischen Nachwuchs für den Sozialismus und so initiierte er gemeinsam mit Paul Löbe einen Bund der Freunde sozialistischer Akademiker, der versuchen sollte, Arbeiterkindern 
den Weg an die Universität zu ebnen, gerade weil die Breslauer Universität nahezu „sozialistenrein“"war.

Siegfried Marck sah seine Aufgabe innerhalb der Volkswacht-Redaktion vor allem im Abfassen von Rezensionen diverser in den Jahren entstandener politischer, gesellschaftlicher aber auch lyrischer Schriften, denen besonders in der zweiten Beilage der Breslauer Volkswacht beinahe wöchentlich viel Platz bereitgestellt wurde. $\mathrm{Zu}$ seinem Portfolio gehörten beispielsweise Nachrufe und Rezensionen zu politisch-theoretischen Schriften. Wenn diese seiner kritischen Auseinandersetzung standhielten, empfahl er die Werke der Arbeiterjugend und den Jungsozialisten zur Lektüre. $^{1380}$

Siegfried Marck orientierte sich zuerst am rechten Rand seiner Partei und wurde gleich auf die Wahlzettel zur Stadtverordnetenversammlung gesetzt. Eine Liste, die von Paul Löbe angeführt und auf der Marck auf Platz 47 gesetzt wurde. Da die Mehrheits-SPD bei den Wahlen die absolute Mehrheit der Stimmen gewonnen hatte, profitierte auch Marck davon, wenngleich er zum ersten Mal erfahren musste, dass er als Redner auf Parteiveranstaltungen nicht unstrittig war und es teils $\mathrm{zu}$ heftigen und körperlichen Auseinandersetzungen kommen konnte. Seine Euphorie wich auch hier der Einsicht, eine stumpfsinnige und geistesstörende Arbeit zu tätigen, mehr noch wollte er sich auch nach Gesprächen mit Kläre gleich zu Anfang seines politischen Engagements aus der Parteipolitik zurückziehen. Doch er blieb der Sozialdemokratie treu und schwor ihr nicht ab, gegen alle Zweifel, die er gehabt haben mag. Er bemerkte, dass die junge Republik wieder aus dem Gleichgewicht geraten konnte, insbesondere seit dem Kapp-Putsch. Er wollte nicht wieder seiner politischen Heimat entrissen werden, schon gar nicht nach den Wahlverlusten der Weimarer Koalition bei den Reichstagswahlen 1920, und kämpfte weiter für die Weimarer Verfassung und gegen die Deutschnationalen. Es darf nicht vergessen werden, dass Siegfried Marck ein bekennender Jude war und die Republik ihm seine Rechte garantierte, ${ }^{1381}$ für die seine Familie lange gekämpft hatte. Sein Schlagwörter hießen „Bildung“ und „Kultur“, sei es im Rat der geistigen Arbeiter, in der Breslauer Volkshochschule, im Arbeiterbildungsausschuss oder in der Freien Jüdischen Volkshochschule und nicht minder bei den Jungsozialisten und seinen Studenten.

\footnotetext{
1380 Vgl. beispielsweise Breslauer Volkswacht, 03.03.1920, 27.08.1920, 23.04.1921, 04.05.1921, 25.06.1921, 23.07.1921, 20.08.1921,24.05.1922, 07.06.1922, 18.04.1923, 18.07.1923, 17.01.1924 02.04.1924, 10.09.1924, 24.09.1924, 27.09.1924, 15.04.1925, 22.04.1925, 15.07.1925, 14.04.1926, 02.03.1927, 04.06.1927, 14.09.1927, 01.09.1928

${ }^{1381}$ Vgl. Zimmermann, Mosche: Die deutschen Juden 1914-1945. Enzyklopädie deutscher Geschichte Bd. 43, hrsg. von Lothar Gall, München 1997, S. 28
} 
Dieses Engagement hatte Marck mit Immanuel Birnbaum gemein. Beide gingen bis zur ihrem Tod dieser - ihrer eigentlichen Passion - nach, wenn auch in unterschiedlichen Kulturkreisen. Während Siegfried Marck später in den USA lebte und immer wieder überlegte, zurück in die Bundesrepublik zu reisen und dies lediglich für eine Vortragsreihe Anfang der 50er Jahre tat, entschied sich Birnbaum vollends nach Deutschland zurückzukehren, wenngleich auch seine Heimatstadt Königsberg nicht zur Bundesrepublik gehörte.

Siegfried Marcks Engagement für die Breslauer Sozialdemokratie wurde ihm gedankt. Bei der Aufstellung der Kandidaten zur Reichstagswahl wurde Marck auf den aussichtsreichen dritten Platz gelistet, rutschte aber aufgrund innerparteilicher Personalpolitik auf den siebten Platz herunter. So wurde ihm der Einzug in den Reichstag verwehrt. Wenig später orientierte sich Marck politisch um, wirkte neben Fritz Sternberg, Max Adler und Ernst Eckstein in der Marxistischen Arbeitsgemeinschaft, später in der Klassenkampfgruppe. Daneben wurde er von einem seiner Schüler, der den Hakenkreuzlern angehörte und später Gauleiter von Schlesien wurde, beleidigt und mit antisemitischen Stereotypen versehen. Die Verbindung von linken und jüdischen Intellektuellen wie Marck, Birnbaum oder Eckstein mit den Jungsozialisten wurde innerhalb der Stadtverordnetenversammlung nun mit Misstrauen beäugt, gelang es doch hier unter dem Vorsitz von Ernst Eckstein und linken Metallarbeitern, diese zu unterwandern. Die Klassenkampfgruppe hatte den Weg zu Absplitterung von der Mutterpartei bereits angedeutet. Die Streitigkeiten um ein Friedrich-Ebert-Denkmal befeuerten diese und letztlich führte der Richtungskampf der SPD in Breslau zum Überlaufen vieler Jungsozialisten und Weggefährten Siegfried Marcks zur SAP - er ging nicht mit, es war ihm einfach nicht möglich, zu beharrlich glaubte er an die Tolerierungspolitik seiner Partei.

1927 hatte Marck sein Amt niedergelegt. Der politische Aufstieg war ihm verwehrt worden, er rückte nach links und ließ sich vom Austromarxismus inspirieren. Nach seinem Ausscheiden aus der Stadtverordnetenversammlung engagierte er sich noch mehr als „Kulturmensch“. Als Vorsitzender des Kulturbeirates der Schlesischen Funkstunde, in der er bis 1932 tätig war, trat er stets für eine lebendige Form des Radios ein, in dem Musik, Literatur und Vorträge 
miteinander kombiniert werden müssten. ${ }^{1382}$ Auch erhoffte Marck sich dadurch, „Breslau enger mit der übrigen Welt zu verbinden“. ${ }^{1383}$

Wenngleich Siegfried Marck seiner Fraktion innerhalb der Stadtverordnetenversammlung den Rücken kehrte, so konnte er doch nur durch seine Parteizugehörigkeit und nur mit entscheidender Hilfe des Kultusministers Adolf Grimmes, gegen alle Einwände seitens seiner Fakultät und der nationalen Studentenschaft, an eine ordentliche Professur gelangen, für die er wissenschaftlich eigentlich nicht geeignet war.

Trotzdem litt auch der Breslauer Philosoph unter dem „Aderlass“ der deutschen Philosophie. Marck floh zuerst zu Jonas Cohn, einem seiner Lehrer, nach Freiburg und schätze 1933 die Chancen auf „100 Prozent Faschismus“ als gering ein, er befürchtete vielmehr eine Renaissance der Monarchie mit parlamentarischem Einschlag. Wie sehr er sich irrte, bemerkte er schnell und floh weiter nach Frankreich, wo er an der altehrwürdigen Universität mit Unterstützung der Rockefeller Foundation in Dijon lehrte. Er war einer der ersten Professoren, die von den Nationalsozialisten 1933 aus dem Amt entlassen wurden. Und ohne Frage war er in Breslau denjenigen Denkern zuzurechnen, die der deutschen Philosophie eine „Verarmung und Vereinseitigung“ erspart hätten. ${ }^{1384}$ Marck jedoch begriff seine Entlassung selbst als ,glückliche Fügung“, hatte er doch so niemals die ganz akute Sorge um seine Existenz gehabt, anders als Eckstein, der in Breslau bei seinen Arbeitern blieb und dafür mit dem Leben bezahlte.

Politisch führte Marck seinen, in Breslau bereits spürbaren, Linksdrift fort und übernahm den Vorsitz der SPD-Ortsgruppe in Paris, die bereits zuvor den eigenen Parteivorstand in Prag in Frage gestellt hatte. Der Gruppe ging es nun - ganz im Sinne Marcks - um die organisatorische und politische Vereinheitlichung der revolutionären sozialistischen Bewegung, die einst aus der Arbeiterbewegung hervorgegangen war - ein für die damalige Zeit beinahe unmögliches Unterfangen, hatte sich doch die Fronstellung zwischen SPD und KPD aus Weimarer Jahren ins Exil tradiert. Obwohl die Einheitsbemühungen nicht sonderlich erfolgreich waren, gelang es doch zusammen mit der Auslandszentrale der SAP ein „Kampfkartell“ zu bilden, welches auf Grundlage eines revolutionären Marxismus versuchte, die

\footnotetext{
1382 Vgl. Schlesische Funkstunde, in: http://www.dra.de/rundfunkgeschichte/radiogeschichte/ organisation/pdf/SCHLES_1924-1933.pdf [zuletzt eingesehen am: 02.08.2010]; Breslauer Volkswacht, 16.11.1929.

${ }^{1383}$ Vgl. Breslauer Volkswacht, 27.05.1924.

1384 Vgl. Litt, Theodor/Ritzel, Wolfgang: Siegfried Marck, ein Nachruf, in: Zeitschrift für philosophische Forschung, Jg. 11 (1957), S. 602-606, hier S. 602.
} 
proletarische Einheit zu verwirklichen. Doch Marck konnte die Gruppe nicht zusammenhalten und er wurde nach neun Monaten im „Amt“ als Vorsitzender ersetzt. Somit erlebte Siegfried Marck zum zweiten Mal, dass die von ihm gedachten theoretischen Konzeptionen, folglich ein Zusammenarbeiten der unterschiedlichsten politischen Gruppen, nicht über den theoretischen Rahmen hinausgingen.

Fortan schloss sich Siegfried Marck einer Vielzahl von Bündnissen an, ohne dass diese eine Aussicht auf Erfolg im Kampf gegen den Nationalsozialismus gehabt hätten. Marck, zu dieser Zeit stark publizistisch für die Pariser Tageblatt/Tageszeitung tätig, erkannte sicherlich die Bodenlosigkeit, die das Exil für die SPD bedeutete. Hier waren alle Grundlagen ihrer Stärke verloren gegangen: die Organisation, die Presse, die Wählerschaft. Dagegen konnte die KPD von ihrer auf Konspiration eingestellten Kaderstruktur, dem Internationalismus sowie dem Rückhalt der Sowjetunion profitieren. Das Kräfteverhältnis schien sich umzukehren. ${ }^{1385}$ Wahrscheinlich auch deshalb und mit tiefem Glauben an die Einheit der Arbeiterbewegung, engagiert Marck sich während der Volksfrontbemühungen Mitte der dreißiger Jahre in Paris, in diesem heterogenen und fragilen, von Intellektuellen und Schriftstellern getragenen Bündnis. Bei einer Betrachtung der Biographien einzelner Akteure der Volksfront, wie beispielsweise die Heinrich Manns oder Leopold Schwarzschilds, zeigt sich, dass Marck sich dort in einem regelrechten Sammelbecken politischer Grenzgänger und Querdenker befand. Doch die synthetischen Gedanken Marcks waren spätestens mit den Moskauer Schauprozessen zunichte gemacht worden. Enttäuscht zog er sich zurück, sprach nur am Rande auf Trauerfeiern, behielt dabei jedoch seine Leidenschaft für die Erwachsenenbildung und gab Vorlesungen an der Deutschen Volkshochschule in Paris. Ernüchterung trat ein und Marck distanzierte sich vom linken Rand, er wurde bürgerlicher, nicht zuletzt durch den Einfluss Thomas Manns, mit dem er nun in Kontakt stand.

Von nun an orientierte er sich außerdem mehr an der Gruppe Esprit um Emmanuel Mounier, bewegte sich mehr und mehr fort vom Linkssozialismus und dogmatischen Marxismus, der eigentlich nur als Frustration über die Erfolglosigkeit der eigentlich von ihm für richtig gehaltenen sozialdemokratischen „Realpolitik“ zu werten ist. ${ }^{1386}$ Wenn es einer Schlüsselaussage Marcks über dessen politische Wandlungen bedarf, dann können seine folgenden Zeilen herangezogen werden:

\footnotetext{
${ }^{1385}$ Vgl. Radkau, Joachim: Die deutsche Emigration in den USA, S. 163.

${ }^{1386}$ Vgl. Walter, Franz: Siegfried Marck (1889-1957), S. 274.
} 
„Als ich mit Münzenberg und seiner Volksfront zusammenarbeitete, war ich von der Philosophie des Kommunismus meilenweit entfernt. Und als ich noch in Deutschland den Wegen Max Adlers folgte und in Synthesen von Kant und Marx dachte, war ich noch nicht völlig zu mir selbst gelangt. “1387 Marck entwickelte sich folglich weiter, wurde liberaler und bürgerlicher. Der in der Gruppe Esprit gedachte neuhumanistische Personalismus, den er freiheitlich-sozialistisch einzufärben versuchte, sah seinen Hauptfeind sowohl im Faschismus als auch im Sowjetkommunismus. Hier sah der Neuhumanist die Renaissance der Ideen von 1789, welche in Synthese mit Sozialismus und Liberalismus die Pfeiler einer nachfaschistischen Gesellschaft bilden sollten. Ferner begab Marck sich wieder als Mitinitiator des Bundes freiheitlicher Sozialisten, neben Heinrich Mann, Emil Julius Gumbel, Georg Bernhard, als Mittler zwischen die Fronten von SPD, KPD und Bürgertum - und auch dieses Unterfangen scheiterte, was bei ihm weitere Resignation hervorrief. In diesem Zusammenhang ist interessant, dass Marck nicht mehr die Sozialdemokratie oder den Marxismus als Lösung für „eine zweite Republik“ benötigte, es ging ihm um neue Formeln, jenseits von Konfliktlinien; er wollte „,intellektuell“ gegen den Faschismus antreten. Mehr noch war er in Gedanken daran beteiligt, eine deutsche Freiheitspartei zu schaffen, die das Kleinbürgertum mit einschloss. Hätte der Bund freiheitlicher Sozialisten größeren Nachklang hinterlassen und wäre eine solche Parteibildung vollzogen worden, Siegfried Marck hätte aller Voraussicht nach der Sozialdemokratischen Partei den Rücken gekehrt und sich dieser - liberal-bürgerlichen Partei - angeschlossen.

Auch in der von Willi Münzenberg initiierten Union Franco Allemande spielte Marck nur eine Nebenrolle. Er war in den letzten Jahren seines Exils in Frankreich jede Parteizugehörigkeit leid, er versuchte mit dem Bund freiheitlicher Sozialisten, mit der Idee der Verschmelzung von Arbeiterparteien und Bürgertum unter Anleitung von Intellektuellen, den Liberalismus, der nicht zuletzt mit dem Aufstieg des Nationalsozialismus in Weimar wegbrach, wiederzubeleben. Kurzum: Er versuchte, seine eigentliche politische Herkunft mit neuem Humus anzureichern.

Noch vor dem Einmarsch deutscher Truppen verließ er Frankreich wegen einer neuen Liebschaft. Er ließ seine Frau und seine Kinder im besetzen Frankreich zurück und hatte selbst große Probleme, sich in den USA wissenschaftlich zu „fixieren“. Er nahm zuerst eine Philosophiedozentur am eher bescheidenen Chicagoer CVJM-College an. Fünf Jahre später wurde er zum Mitbegründer der 
Roosevelt-University. Politisch argumentierte er nun in der New Yorker Neuen Volkszeitung, wo er Gerhart Seger kennenlernte, wieder am rechten Rand der Sozialdemokratie, obwohl er die antikommunistische Haltung der Neuen Volkszeitung und die daraus resultierende cliquenhafte Abgrenzung nicht gutheißen konnte. Im US-amerikanischen Exil avancierte Marck zum Europa-Politiker und ging Fragen nach einer europäischen Lösung des Krieges nach. In seinen Thesen zur Russlanddebatte, in denen er die Sowjetunion als den entscheidenden Bundesgenossen der Weltdemokratie darstellte und somit gegen die vorherrschende Meinung der Neuen Volkszeitungsredaktion argumentierte, verwies er jedoch darauf, dass die Sowjetunion weit entfernt von einem demokratischen Staat sei. Auch die Erfahrungen innerhalb der Volksfront ließen für Marck nur den Schluss zu, dass die Aufhebung der Komintern sowohl ein Dienst für die Arbeiterbewegung der Zukunft als auch für die angelsächsisch-russischen Beziehungen die beste Lösung des Problems sei. Zudem trat Marck für die Schaffung eines rein europäischen Völkerbundes ein, der von einem engen Zusammenschluss von Frankreich, Italien, Großbritannien und Deutschland geführt werden sollte. Somit sprach sich Marck nicht für eine Gleichberechtigung aller europäischen Staaten aus, anders als der SPDParteivorstand. Für Marck stand fest, dass es die Aufgabe Deutschlands sein musste, nach dem Ende des Weltkrieges als Bindeglied zwischen dem Osten und Westen zu dienen. Unabdingbar hierfür sei das Zurückstellen antikommunistischer Tendenzen in Deutschland und im deutschen Exil.

Marck brach mit der Neuen Volkszeitung, die für ihn überhaupt nicht mehr den Eindruck machte, als ob sie überhaupt Politik betreiben wollte und schloss sich dem Council for a Democratic Germany, einer Art Exil-Rat unter dem Vorsitz Paul Tillichs an. Doch wie bereits während der Volksfrontbemühungen kristallisierte sich auch hier das Verhältnis zur KPD als Gretchenfrage für ein effektives Funktionieren dieses Bündnisses heraus, das von Seiten der German Labor Delegation um Hedwig Wachenheim und Friedrich Stampfer attackiert wurde. Dem Council ging es um eine Gesamtverantwortung des deutschen Volkes für die nationalsozialistischen Verbrechen. Von einer Kollektivschuld der Deutschen, wie sie von Anhängern des Vansittartismus vertreten wurden, wollte Marck nichts wissen. Diese verstand er als „Antigermanismus“ und setzte sie parallel zum Antisemitismus. Auch sprach er sich gegen einen möglichen Ausschluss Deutschlands aus der Weltgemeinschaft aus, der zu einem „Super-Versailles“ führen würde. Allein hier wird deutlich, dass für Siegfried Marck die Welt 1918/1919 aus den Fugen geraten war, zu sehr hatten der 
Krieg und der Friedensvertrag sein Leben und seine politische Geisteshaltung beeinflusst. Die Politik des „Welt-Direktoriums“, die eine Zusammenarbeit von (Re-) Emigranten und Besatzungsmächten nach dem Sieg über den Nationalsozialismus unmöglich machte sowie die Abtretung der Ostgebiete, folglich auch die Breslaus, ließen ihn resignieren. Er distanzierte sich von der Sowjetunion und zog sich enttäuscht ganz aus der Exil-Politik zurück - ein Verhandeln war hier nicht mehr möglich.

Siegfried Marck traf in seinem Leben viele Menschen, die ihn nachhaltig politisch beeinflussten: Waren es in den Breslauer Jahren Personen wie Fritz Sternberg, der Austromarxist Max Adler oder Ernst Eckstein, die bei ihm einen erkennbaren Eindruck hinterließen, war es doch spätestens seit 1936 das Brüderpaar Heinrich und Thomas Mann, an deren Entwicklungen sich Siegfried Marck auch in persönlichen Belangen orientieren sollte. Besonders zu Thomas Mann, mit dem er in freundschaftlicher Beziehung stand, schaute er auf, sah diesen als seinen Mentor und „hochverehrten Meister“ an. ${ }^{1388}$ Einen Großteil seines Lebens verbrachte der Professor für Philosophie damit, das Leben und Wirken Thomas Manns publizistisch nachzuzeichnen ${ }^{1389}$, mit ihm über Neuhumanismus $\mathrm{zu}$ diskutieren sowie über Deutschland nach dem Zweiten Weltkrieg, er amalgamierte dessen Ideen. Festzuhalten bleibt: Ohne die Hilfe in Form von Bürgschaften Heinrich und Thomas Manns, hätten die Marcks nicht in die USA einreisen können, sie hatten weder die nötigen finanziellen Mittel noch gute Kontakte an die großen Universitäten in den USA. Siegfried Marck hätte großen Dank an Thomas Mann zu richten gehabt, indes echauffierte er sich, dass ihm die Rockefeller Foundation „erstickend umarmt“ habe. Spätestens hier wird Marck erkannt haben, dass er nur einer von vielen Emigranten war, die zwar eine glückliche Fürsprache genossen, denen jedoch der nötige wissenschaftliche und politische Einfluss fehlte. Er bemerkte, dass er zwar ein gut geknüpftes Netzwerk besaß, dieses jedoch nicht trug. So gelang es ihm auch in den USA nicht seine wissenschaftliche Karriere auszubauen, er lebte gemeinsam mit seiner dritten Frau in bescheidenen Verhältnissen in Chicago, mit den kalten Wintern, seinen Herzproblemen und seiner Niedergeschlagenheit. Er war isoliert, hatte wenige Freunde und versuchte stets wieder in seine alte Heimat zu gelangen. Eine Professur erhielt er auch dort nicht, anders als sein Freund Walter Friedländer,

\footnotetext{
${ }^{1388}$ Marck an Thomas Mann, 30.12.1936, TMA.

${ }^{1389}$ Vgl. Marck, Siegfried: Thomas Mann als Denker, in: Kant-Studien, Jg. 47 (1955/56), S. 225-233; Ders.: Große Menschen unserer Zeit, S. 88ff; Ders.: Thomas Mann: Dichter, Denker, politischer Mensch, in: Die Andere Zeitung, 02.06.1955.
} 
der dort gebraucht wurde. Siegfried Marck wurde nur noch für vereinzelte Vorlesungen nach Deutschland geladen, nach Breslau kehrte er nie zurück. Er suchte immer den Kontakt zu den großen Persönlichkeiten seiner Zeit, zu Albert Einstein, Max Horkheimer, Thomas Mann, um sich selbst aufzuwerten.

Innerhalb der von ihm mit initiierten Diskussionsgruppe zur Pflege der deutschen Sprache in Chicago, die über ein Vierteljahrhundert nach seinem Tod fortgeführt wurde und dessen Namen sie trug, fand Siegfried Marck eine Plattform, auf der er mit Gleichgesinnten über deutsche Kultur diskutieren und seiner Isolation entkommen konnte - hier konnte er glänzen.

Siegfried Marck war und blieb bis zu seinem Lebensende mit dem jüdischen Glauben in Berührung. „Ich denke immer gezeigt zu haben, dass ich mich essentiell und vor allem als Jude fühle“. ${ }^{1390}$ Er konvertierte nicht, um sich bessere Berufungschancen zu ermöglichen, wie es einige seiner Kollegen taten. Er kündigte seinen Glauben auch nicht für seinen neu entdeckten Sozialismus auf. Dennoch begriff er sich als „Staatenloser““1391, anders als sein erster Sohn, Andreas, der mit Lola nach Palästina ging. Marck konnte der Gründung Israels eine Menge abgewinnen, auch wenn diese nur durch Krieg durchzusetzen war. Gleichwohl war Marck froh, dass sein Sohn nur am Rande des Kriegsgebietes lebte und nicht direkt an der Front kämpfte. ${ }^{1392}$ Marck schreibt weiter von der „Stimme des Blutes“, die ihn heimsuchte, als „ein tollwütiger Diktator im Auftrage Moskaus einen jungen Staat und eine Einheit, die große kulturelle Leistungen aufzuweisen hat, ganz im Stile Hitlers mit Vernichtung bedrohte.“ Dass Marck dabei keinen individuellen Hass gegen „den Araber“ hatte, war für ihn selbstverständlich. ${ }^{1393}$

Was blieb, waren Marcks Gedanken um einen freiheitlichen Sozialismus, um ein Menschenbild nach Hitler. Mit Eduard Heimann diskutierte Marck nach dem Krieg über Faschismus und Liberalismus. Doch tat er dies nach den Enttäuschungen der Arbeit im Exil, den Zerwürfnissen und Beleidigungen, fortan in akademischen Kreisen. Für die Sozialdemokratie engagierte sich Marck bis zum Ende seines Lebens, schrieb auch im amerikanischen Exil im Vorwärts über „Formen des NachMarxismus“, indem er den in Frankreich von ihm entwickelten freiheitlichen Sozialismus mit den neuen Sozialismus-Konzeptionen Schumpeters, Lederers oder auch Heimanns zu verbinden suchte. Immerhin war der Freiheitliche Sozialismus nur

\footnotetext{
${ }^{1390}$ Marck an Hirsch, 05.01.1957, NL HH.

${ }^{1391}$ Marck an Andreas Marck 06.07.1945, in: Hirsch, Helmut: Mann und Marck im Exil, S. 77.

${ }^{1392}$ Vgl. Marck an Andreas Marck 06.04.1945, 17.04.1946, 28.11.1948 zitiert in: Ebd., S. $79 f$.

${ }^{1393}$ Marck an Hirsch, 05.01.1957, NL HH.
} 
ein „programmatische Schlagwort, dessen Erfüllung mit konkretem Inhalt eine langwierige, vielleicht ganze Generationen beanspruchende Aufgabe darstellt“. Dass dabei auch linke Flügel eine Rolle spielen würden, solange sie die „Stoßkraft einer Partei nicht lähmen“" würden, war Marck bewusst. Doch verstand er sie als „Sozialistisches Gewissen“, das ein Abgleiten ins „Nur-Sozialliberale“ für freiheitliche sozialistische Parteien verhindern könne. ${ }^{1394}$ Der linke Flügel diente Marck also nur noch als Korrektiv. 


\section{Literatur}

Berücksichtigte Tages-, Wochen- und Monatszeitungen

Breslauer Volkswacht, 1917-1933.

Blätter der Volkshochschule Breslau, 1922/23.

Freie Tribüne, 1919-1923.

Jüdisch-liberale Zeitung, 1921-1930.

Schlesische Zeitung, 1930.

Unsere Tribüne, 1924-1926.

Sozialistische Arbeiterzeitung,1931.

Der Jüdische Arbeiter, 1927-1934.

Kunst und Volk. Monatsheft der Breslauer Volksbühne, 1931.

Mitteilungsblatt des Sozialdemokratischen Intellektuellenbundes, 1926/27,1930.

Breslauer Jüdisches Gemeindeblatt, 1925-1933.

Das Neue-Tagebuch, 1933-1939.

Der deutsche Schriftsteller: Organ des Schutzverbandes Deutscher Schriftsteller, 1933-1938.

Die Neue Weltbühne, 1934.

Pariser Tageszeitung, 1936-1938.

Jüdische Revue, 1937.

Deutsche Mitteilungen Paris, 1938.

Zeitschrift für freie deutsche Forschung, 1938-1939.

Die Zukunft: Organ der deutsch-französischen Union, 1938-1940.

Neue Volkszeitung: Oldest Anti Nazi Newspaper, 1940-1949.

Sozialistische Mitteilungen, 1942.

Der Aufbau: Das jüdische Monatsmagazin, 1943-1957, 1980.

Der Sozialdemokrat, 1947.

Neuer Vorwärts, 1954.

\section{Archive und Nachlässe}

Archiv der Akademie der Künste: Briefwechsel Siegfried Marck mit Heinrich Mann; dort auch Hermann-Budzislawski-Archiv: Briefwechsel zwischen Hermann Budzislawski und Siegfried Marck, Willi Münzenberg und Marck.

Bundesarchiv: Briefwechsel Siegfried Marck mit Leopold Schwarzschild.

Deutsches Literaturarchiv in Marbach: Dort Nachlässe von Lola Landau, Armin Theophil Wegner, Hermann Broch, Getrud le Fort, Hans Georg Gadamer, Manfred George. 
Exilarchiv der Deutschen Nationalbibliothek Frankfurt am Main: Briefe Marck an Max Barth, Heinrich Mann an PEN - Zentrum deutschsprachiger Autoren im Ausland, Marck an Hubertus Prinz zu Löwenstein, Marck an die deutsche Akademie im Exil.

Geheimen Staatsarchiv Preußischer Kulturbesitz, Unterlagen zum Berufungsverfahren Siegfried Marcks, Briefwechsel zwischen Adolf Grimme und Siegfried Marck.

Greenander Department of Special Collections and Archives an der University at Albany in New York: Dort Nachlässe von: Siegfried Marck, Walter Friedländer, Carl Misch, Karl Otto Paetel.

Harvard University Library: Briefe zwischen Paul Tillich und Siegfried Marck.

Leo-Baeck-Archiv New York. Dort die Nachlässe von: Helmut Hirsch, Kurt Schwerin, Gertrude Schwerin, der Familie Marck.

Literaturarchiv Sulzbach-Rosenberg: Briefe von Marcks Angehörigen.

Salomon-Ludwig-Steinheim-Institut für Deutsch-Jüdische Geschichte: Briefwechsel Jonas Cohn und Siegfried Marck.

Staatsbibliothek zu Berlin - Preußischer Kulturbesitz, Handschriftenabteilung: Briefe Kläre Marcks an Gerhart Hauptmann.

Stadtbibliothek Wuppertal, Briefe zwischen Armin T. Wegner und Siegfried Marck.

Thomas Mann Archiv der ETH Zürich: Briefwechseln zwischen Thomas Mann und Siegfried Marck.

Universitätsarchiv Wroclaw, Promotionsakte Siegfried Marcks.

Universitätsbibliothek Frankfurt am Main: Briefwechsel Siegfried und Kläre Marck Max Horkheimer resp. Margot von Mendelssohn.

Dazu erfolgte die Kontaktaufnahme und Korrespondenz, mit Ilan Mark (Israel), John March (Bundesrepublik Deutschland) und Sibyl Stevens (Großbritannien), deren Auswertung in diese Arbeit mit eingeflossen ist. 


\section{Internetquellen}

Informationen zur Schlesischen Funkstunde sind einzusehen auf:

http://www.dra.de/rundfunkgeschichte/radiogeschichte/organisation/pdf/SCHLES_1 924-1933.pdf [zuletzt aufgerufen am 02.08.2010].

Interview mit Stan Neumann. http://www.radio.cz/en/section/one-onone/communist-history-of-own-prominent-family-not-black-and-white-saysdocumentarian-stan-neumann[zuletzt aufgerufen am 26.05.2014]

Interview of Edward James Sparling by Daniel Perlman, $10^{\text {th }}$ December 1971, in: http://www2.roosevelt.edu/library/oralhistory/06-Sparling.pdf [zuletzt eingesehen am 12.05.2014].

(BIOSP) Biographien Sozialdemokratischer Parlamentarier in den deutschen Reichsund Landtagen 1867-1933, in: http://biosop.zhsf.unikoeln.de/biosop_db/biosop_db.php [zuletzt eingesehen am 09.07.2013].

Allgemeinen Kongreß der Arbeiter- und Soldatenräte Deutschlands vom 16.-21. Dezember 1918 im Berliner Abgeordnetenhaus. Stenographische Berichte. S. 206, auf: http://edoc.huberlin.de/ebind/hdok/hp08_stenogr_berichte_1_1918/XML/ [zuletzt aufgerufen am 13.04.2013].

\section{Aufsätze und Monographien}

Abendroth, Wolfgang: Aufstieg und Krise der deutschen Sozialdemokratie, Köln 1978.

Alexander, Thomas: Carl Severing. Sozialdemokrat aus Westfalen mit preußischen Tugenden, Bielefeld 1992.

American Council on Education. College Study in Intergroup Relations, Bd. 1 (1950).

Andresen, Knud: Widerspruch als Lebensprinzip. Der undogmatische Sozialist Heinz Brandt (1909-1986), Bonn 2007.

Assheuer, Thomas. Krieg veredelt den Menschen, in: Die Zeit, 12.03.2010.

Bachler, Karl: Student in Breslau, in: Jahrbuch der Schlesischen Friedrich-Wilhelms Universität zu Breslau, Band III 1958, S. 7-20. 
Baerwald, Friedrich: Zur politischen Tätigkeit deutscher Emigranten im Council for a Democratic Germany, in: Vierteljahreshefte für Zeitgeschichte, Jg. 28 (1980), S. 372-383.

Baier, Deirdre: Die Biographie ist akademischer Selbstmord, in: Literaturen 7/8 (2001).

Bandur, G.: Eckstein, Ernst. in: Geschichte der deutschen Arbeiterbewegung. Biographisches Lexikon, Berlin 1970, S. 108-109.

Barth, Max. Flucht in die Welt. Exilerinnerungen 1933-1950, Waldenkirch 1986.

Bergbauer, Knut: Ernst Eckstein, in: Neue Gesellschaft, Frankfurter Hefte Bd. 5 (2013), S. 32-33.

Betz, Albrecht: Exil und Engagement. Deutsche Schriftsteller im Frankreich der dreißiger Jahre, München 1986.

Binkowski, Johannes: Die Rolle der Arbeiterbewegung in Schlesien, in: Lothar Bossle et al (Hrsg.): Nationalsozialismus und Widerstand in Schlesien, Sigmaringen 1989, S. 9-17.

Birnbacher, Dieter/Krohn, Dieter: Das sokratische Gespräch, Stuttgart 2002.

Birke, Ernst: Schlesien, in: Aschenbrenner, Viktor/ Kuhn et al (Hrsg.): Die Deutschen und ihre östlichen Nachbarn: ein Handbuch, Frankfurt 1967, S. 206-223.

Bödeker, Hans Erich (Hrsg.): Biographie schreiben, Göttingen 2003.

Bourdieu, Pierre: Die biographische Illusion, in: Ders: Praktische Vernunft, zur Theorie des Handelns, Frankfurt am Main 1998, S. 75-83. Das erste Mal aus dem Französischen übersetzt und erschienen sind diese Ausführungen in der Zeitschrift BIOS, vgl. Bourdieu, Pierre: Die biographische Illussion, in: BIOS, Zeitschrift für Biographieforschung und Oral History 3 (1990), S. 75-88.

Ders.: Der Habitus als Vermittlung zwischen Struktur und Praxis, in: Ders.: Soziologie der symbolischen Formen, Frankfurt am Main 1974, S. 125-158.

Brandt, Willy: Links und frei. Mein Weg 1930-1950, Hamburg 1982.

Brann, Marcus. Geschichte des Jüdisch-theologischen Seminars (Fraenkel'sche Stiftung) in Breslau: Festschrift zum fünfzigjährigen Bestehen der Anstalt, Breslau 1904. 
Bremer, Jörg: Die Sozialistische Arbeiterpartei Deutschlands (SAP). Untergrund und Exil 1933-1945, Frankfurt am Main 1978.

Brilling, Bernhard: Die Jüdischen Gemeinden Mittelschlesiens. Entstehung und Geschichte, Stuttgart 1972.

Bürgin, Hans. Die Briefe Thomas Manns: Regesten und Register, Bd. II die Briefe von 1934 bis 1943, Frankfurt am Main 1980.

Burkhardt, Kai: Adolf Grimme (1889-1963): eine Biographie, Köln 2007.

Carsten, Francis L.: Eduard Bernstein 1850-1932. Eine politische Biographie, München 1993.

Cazden, Robert Edgar: German exile literature in America 1933-1950, Chicago 1970 .

Conrads, Norbert (Hrsg.): Willy Cohn. Kein Recht, nirgends. Tagebuch vom Untergang des Breslauer Judentums 1933-1941 Bd.1, Köln 2006.

Crémieux-Brilhac, Jean-Louis: La France libre: de l'appel du 18 juin à la Libération, Paris 1996.

Darmaun, Jacques: Thomas Mann, Deutschland und die Juden, Tübingen 2003.

de Man, Hendrik: Die Intellektuellen und der Sozialismus, Jena 1926.

Depkat, Volker: Zum Ort der Biografik in der Arbeitergeschichtsschreibung, in: Mitteilungsblatt des Instituts für soziale Bewegungen. Biografische Ansätze zur Geschichte der Arbeiterbewegung im 20. Jahrhundert 45(2011), S. 21-37.

Die Presse der Sozialistischen Arbeiterpartei Deutschlands im Exil 1933-1945, herausgegeben von der Deutschen Bibliothek Frankfurt am Main, Sammlung Exilliteratur, München 1981.

Dilthey, Wilhelm: Der Aufbau der geschichtlichen Welt in den Geisteswissenschaften, 7. Auflage, Göttingen 1979.

Drechsler, Hanno: Die Sozialistische Arbeiterpartei Deutschlands (SADP). Ein Beitrag zur Geschichte der deutschen Arbeiterbewegung am Ende der Weimarer Republik, Meisenheim am Glan 1965.

Durzak, Manfred. Die Exilsituation in den USA, in: Ders. (Hrsg.). Deutsche Exilliteratur 1933-1945, Stuttgart 1997. 
Ebert, Andreas D.: Jüdische Hochschullehrer an preußischen Universitäten (18701924). Eine quantitative Untersuchung mit biografischen Skizzen, Frankfurt am Main 2008.

Elias, Norbert: Über den Prozess der Zivilisation. Soziogenetische und psychogenetische Untersuchungen, Band I, Frankfurt am Main 1978.

Euchner, Walter/Grebing, Helga (Hrsg.): Geschichte der sozialen Ideen in Deutschland, Sozialismus, Katholische Soziallehre, Protestantische Sozialethik, ein Handbuch, S.128-146.

Farzin, Sina: Inklusion/Exklusion; Entwicklungen und Probleme einer systemtheoretischen Untersuchung, Bielefeld 2006.

Feuchtwanger, Lion: Der Teufel in Frankreich. Ein Erlebnisbericht, München 1983.

Fried, Johannes: Wissenschaft und Phantasie. Das Beispiel der Geschichte, in: Historische Zeitschrift 263. Jg. (1996), S. 291-316.

Friederici, Hans-Jürgen: Ferdinand Lassalle: eine politische Biographie, Berlin 1985.

Friedrich, Manfred: Preuß, Hugo, in: Neue Deutsche Biographie (NDB). Bd. 20, Berlin 2001, S. 708-710.

Füssl, Karl Heinz. Deutsch-amerikanischer Kulturaustausch im 20. Jahrhundert, Frankfurt am Main 2004.

Gall, Lothar: Walther Rathenau. Portrait einer Epoche, München 2009.

Ders.: Bismarck: der weiße Revolutionär, Frankfurt am Main 1980.

Gestrich, Andreas: Einleitung: Sozialhistorische Biographieforschung, in: Ders. (Hrsg.): Biographie zeitgeschichtlich. 7 Beiträge, Göttingen 1988, S. 5-28.

Gilcher-Holtey, Ingrid: Konkurrenz um den „wahren“ Intellektuellen. Intellektuelle Rollenverständnisse aus Zeithistorischer Sicht, in: Kroll, Thomas/Reitz, Tilman (Hrsg.): Intellektuelle in der Bundesrepublik Deutschland. Verschiebung im politischen Feld der 1960er und 1970er Jahre, Göttingen 2013.

Dies.: Intellektuelle in der sozialistischen Arbeiterbewegung. Karl Kautsky, Heinrich Braun und Robert Michels, in: Rojahn, Jürgen (Hrsg.): Marxismus und Demokratie, Karl Kautskys Bedeutung in der sozialistischen Arbeiterbewegung, Frankfurt am Main 1992, S. 373-390.

Glotz, Peter: Der weiße Elephant, in: Süddeutsche Zeitung, 17.05.2010. 
Graf, Rüdiger: Die Zukunft der Weimarer Republik: Krise und Zukunftsaneignungen in Deutschland 1918-1933, München 2008.

Dies./Richart-Willmes, Peter: Denken in seiner Zeit. Ein Personenglossar zum Umfeld Richard Hönigswalds, Würzburg 1997.

Grassl, Roswitha: Breslauer Studienjahre: Hans Georg Gadamer im Gespräch, Schriften des Forschungsprojektes zu Leben und Werk Richard Hönigswalds, Mannheim 1996.

Grebing, Helga: Das Menschbild in der Sozialdemokratie nach dem Holocaust, in: Dies et al (Hrsg.): Sozialdemokratie und Menschenbild. Historische Dimension und aktuelle Bedeutung, Marburg 2012, S. 133-154.

Dies.: Die Rezeption Friedrich Eberts im Wandel: Historiografische und persönliche Rückblicke, in: Mitteilungsblatt des Instituts für soziale Bewegungen. Biografische Ansätze zur Geschichte der Arbeiterbewegung im 20. Jahrhundert 45(2011), S. 153163.

Dies.: Willy Brandt, Der andere Deutsche, Paderborn 2008.

Dies.: Jüdische Intellektuelle und ihre politische Identität in der Weimarer Republik, in: Mitteilungsblatt des Instituts für soziale Bewegungen, Heft 34 (2005), S. 11-23.

Dies.: Die linken Intellektuellen und die gespaltene Arbeiterbewegung in der Weimarer Republik, in: Alemann, Ulrich von et al (Hrsg.): Intellektuelle und Sozialdemokratie, Opladen 2000, S. 79-89.

Dies.: Jüdische Intellektuelle in der deutschen Arbeiterbewegung zwischen den beiden Weltkriegen, in: Archiv für Sozialgeschichte, Bd. 37 (1997), S. 19-38.

Dies.: Fritz Sternberg (1895-1963), in: Lösche, Peter et al (Hrsg.): Vor dem Vergessen bewahren. Lebenswege Weimarer Sozialdemokraten, Berlin 1988, S. 391 406.

Dies. (Hrsg.): Fritz Sternberg - Für die Zukunft des Sozialismus, Köln 1981.

Gross, Babette: Willi Münzenberg: eine politische Biographie, Stuttgart 1967.

Haenicke, Gunta: „Schücking, Levin Ludwig“, in: Neue Deutsche Biographie 23 (2007), S. 633-634.

Hamann, Birgitta: Lola Landau. Leben und Wert. Ein Beispiel deutsch-jüdischer Literatur des 20. Jahrhunderts in Deutschland und Palästina/Israel, Berlin 2000. 
Hamburger, Ernest: Juden im öffentlichen Leben Deutschlands: Regierungsmitglieder, Beamte und Parlamentarier in der monarchischen Zeit 18481918, Tübingen 1968.

Heid, Ludger: Die Kultur der osteuropäischen Juden im Deutschland der Weimarer Republik, in: Erler, Hans et al. (Hrsg.): Jüdisches Leben und jüdische Kultur in Deutschland. Geschichte, Zerstörung und schwieriger Neubeginn, Frankfurt am Main 2000, S. 174-201.

Ders.: „Dem Ostjuden ist Deutschland das Land Goethes und Schillers“. Kultur zu und Politik von ostjüdischen Arbeitern in der Weimarer Republik, in: Archiv für Sozialgeschichte, 37 (1997), S. 179-206.

Ders.: „Proletarier zu sein und Jude dazu, das bedeutet unsägliches Leid...“. Sozialisten zur „Ostjudenfrage“, in: Ders. et al. (Hrsg.): Juden und deutsche Arbeiterbewegung bis 1933, Tübingen 1992, S. 177-193.

Heimann, Horst/Meyer, Thomas (Hrsg.): Bernstein und der demokratische Sozialismus. Bericht über den wissenschaftlichen Kongreß ,Die historische Leistung und aktuelle Bedeutung Eduard Bernsteins‘, Berlin, Hannover 1978.

Hellman, John: Emmanuel Mounier and the Creation of the New Catholic Left 19301950. Toronto 1981.

Hensel, Jürgen/Nordblom, Pia (Hrsg.): Hermann Rauschning. Materialien und Beiträge zu einer politischen Biographie, Osnabrück 2003.

Hermann, Ursula (Hrsg.): August Bebel. Eine Biographie, Berlin 1989.

Hermand, Jost: Juden in der Kultur der Weimarer Republik, in: Grab, Walter/Schoeps, Julius H. (Hrsg.): Juden in der Weimarer Republik, Sachsenheim 1986, 9-38.

Hirsch, Helmut: Onkel Sams Hütte. Autobiographisches Garn eines Asylanten in den USA, Leipzig 1994.

Ders.: Thomas Mann und Siegfried Marck im US-Exil. Neues zur Biographie, in: Hefte der deutschen Thomas-Mann-Gesellschaft, Heft 6/7 (1987), S. 70-86.

Ders.: Siegfried Marck. Biographisches zur Wiederentdeckung des Philosophen, Soziologen und Sozialisten, in: Papcke, Sven (Hrsg.): Ordnung und Theorie. Beiträge zur Geschichte der Soziologie in Deutschland, Darmstadt 1986, S. 368-386.

Ders.: August Bebel in Selbstzeugnissen und Bilddokumenten. Reinbek 1973. 
Institut für Marxismus-Leninismus beim Zentralkomitee der SED (Hrsg.): Deutsche Widerstandskämpfer 1933-1945, Biographien und Briefe, Band 1, Berlin 1970, S. 206-208.

Höppner, Joachim/Seidel-Höppner, Waltraud: Der Bund der Geächteten und der Bund der Gerechtigkeit. In: Helmut Reinalter (Hrsg.): Politische Vereine, Gesellschaften und Parteien in Zentraleuropa 1815-1848/49. Schriftenreihe der Internationalen Forschungsstelle „Demokratische Bewegungen in Mitteleuropa 1770-1850“, Bd. 38. Frankfurt am Main u. a. 2005, S. 89-153.

Holl, Karl: In memoriam Konrad Reisner, in: Neuer Nachrichtenbrief der Gesellschaft für Exilforschung, Nr. 24 (2004), S. 11-12.

Holz, Friedbert, Kühnemann, Eugen, in: Neue Deutsche Biographie 13 (1982).

Ders.: Kroner, Richard, in: Neue Deutsche Biographie (NDB), Bd. 13, Berlin 1982, S. 84-86.

Holzhey, Helmut (Hrsg.): Ethischer Sozialismus. Zur politischen Philosophie des Neukantianismus, Frankfurt 1994.

Horkheimer, Max: Gesammelte Schriften, Band 5, Frankfurt am Main 1987.

Hüttenberger, Peter: Die Gauleiter. Studie zum Wandel des Machtgefüges in der NSDAP, Stuttgart 1969.

Humes, Edward: Over Here: How the G.I. Bill Transformed the American Dream, New York 2006.

Jahresbericht des Jüdisch-theologischen Seminars Fraenkel'scher Stiftung für das 1917, Breslau 1918.

Jakubaschk, Paul Willi: Helmuth Brückner: sein Kampf und Sieg um Schlesien; vom Frontsoldaten und Selbstschutzkämpfer zum schlesischen Führer, Oberpräsident und Staatsrat, Hirschberg 1933.

Jarausch, Konrad: Deutsche Studenten 1800-1970, Frankfurt am Main 1984.

Jersch-Wenzel, Stefi: Juden in Preußen - Preußischen Juden?, in: Tel Aviver Jahrbuch für deutsche Geschichte (TAJB), Bd. 20 (1991), S. 437-448.

Jessen-Klingberg, Manfred: Reventlow, Grafen zu, in: Neue Deutsche Biographie (NDB). Bd. 21, Berlin 2003, S. 474-476.

Judt, Tony: Past Perfect. French Intellectuals, 1944-1945, Berkely 1992. 
Kapferer, Norbert: Die Nazifizierung der Philosophie an der Universität Breslau 1933-1945, Münster 2001.

Ders.: Diese Art von Philosophiedozenten ist unser Ruin. Zwei Gutachten Martin Heideggers aus den Jahren 1929/1930, in: Neue Zürcher Zeitung, 09.09.2001.

Kessemeier, Gesa: Sportlich, sachlich, männlich. Das Bild der „Neuen Frau“ in den Zwanziger Jahren. Zur Konstruktion geschlechtsspezifischer Körperbilder in der Mode der Jahre 1920-1929, Dortmund 2000.

Klein, Christian: Grundfragen biographischen Schreibens, in: Ders. (Hrsg.): Handbuch Biographie. Methoden, Traditionen, Theorien, Stuttgart 2009, S. 424-428.

Köpke, Wulf: Die Flucht durch Frankreich. Die zweite Erfahrung der Heimatlosigkeit in Berichten der Emigranten aus dem Jahre 1940, in: Thomas Koebner et al (Hrsg.): Das jüdische Exil und andere Themen. Jahrbuch der Gesellschaft für Exilforschung, Bd. 4/1986, S. 229-242.

Kolb, Eberhard (Hrsg.): Albert Grzesinskis Erinnerungsbericht: Im Kampf um die deutsche Republik. Erinnerungen eines Sozialdemokraten, München 2009.

Kracauer, Siegfried: Die Biographie als neubürgerliche Kunstform, in: Ders: Das Ornament der Masse, Essays, Frankfurt am Main 1977, S. 75-81.

Ders.: Jacques Offenbach und das Paris seiner Zeit, Amsterdam 1937.

Kraus, Hans-Christof: Geschichte als Lebensgeschichte. Gegenwart und Zukunft der politischen Biographie, in: Ders. (Hrsg.): Geschichte der Politik. Alte und neue Wege, München 2007, S. 311-333.

Kraushaar, Luise: Deutsche Widerstandskämpfer 1933 bis 1945, Bd. 1, Berlin 1970.

Krohn, Claus Dieter: Deutsche Wissenschaftsemigration seit 1933 und ihre Remigrationsbarrieren nach1945, in: Rüdiger vom Bruch/ Brigitte Kaderas (Hrsg.): Wissenschaften und Wissenschaftspolitik. Bestandsaufnahme zu Formationen, Brüchen und Kontinuitäten im Deutschland des 20. Jahrhunderts, Stuttgart 2002, S. 437-453.

Ders.: Der Council for a Democratic Germany, in: Langkau-Alex, Ursula/Ruprecht, Thomas M. (Hrsg.): Was soll aus Deutschland werden? Der Council for a Democratic Germany in New York 1944-1945. Aufsätze und Dokumente, Frankfurt am Main 1995, S. 17-49.

Ders.: Wissenschaft im Exil. Deutsche Sozial- und Wirtschaftswissenschaftler in den USA und die New School for Social Research, Frankfurt am Main 1987. 
Lagiewski, Maciej: Breslauer Juden 1850-1944, Wroclaw 1996.

Ders.: Die Juden in Breslau 1850-1945, in: Kühnel, Horst (Hrsg.): Juden in Breslau 1850-1945. Beiträge zu einer Ausstellung, München 1993, S. 27-43.

Landau, Lola: Vor dem Vergessen. Meine drei Leben, Frankfurt am Main 1987.

Langkau-Alex, Ursula: Deutsche Volksfront 1932-1939. Zwischen Berlin, Paris, Prag und Moskau, Band 3: Dokumente, Chronik und Verzeichnisse, Berlin 2005.

Dies.: Deutsche Volksfront 1932-1939. Zwischen Berlin, Paris, Prag und Moskau. Band 2: Geschichte des Ausschusses zur Vorbereitung einer deutschen Volksfront, Berlin 2004.

Dies.: Deutsche Volksfront 1932-1939. Zwischen Berlin, Paris, Prag und Moskau, Band 1: Vorgeschichte und Gründung des Ausschusses zur Vorbereitung einer deutschen Volksfront, Berlin 2004.

Dies.: Die Zukunft der Vergangenheit oder die Zukunft der Zukunft?, in: Roussel, Helene/ Winckler, Lutz (Hrsg.): Deutsche Exilpresse und Frankreich 1933-1940, Bern 1992, S. 123-157.

Dies.: Fritz Lieb und die Volksfront-Politik. Der Weg zum „Bund freiheitlicher Sozialisten“, in: Karnetzki, Manfred/Rese, Karl-Johann (Hrsg.): Fritz Lieb. Ein europäischer Christ und Sozialist, Berlin 1992, S. 105-147.

Dies.: Erziehung nach Hitler. Richtlinien für ein neues Schul- und Erziehungsprogramm in Deutschland: Vergleich von Ideen der Deutschen Volksfront (1937) und des Council for a Democratic Germany (1945), in: Internationale wissenschaftliche Korrespondenz zur Geschichte der deutschen Arbeiterbewegung (IWK), Jg. 24 (1988), S. 16-43.

Dies.: Versuch und Scheitern der deutschen Volksfront, in: Exil H. 2 (1986), S. 1937.

Dies.: Zur Genesis des Begriffes „Volksfront“ 1932 bis 1934/35, in: Haupt, HeinzGerhard (Hrsg.): Soziale Bewegungen. Geschichte und Theorie. Jahrbuch 1: Arbeiterbewegung und Faschismus, Frankfurt am Main 1986, S. 82-105.

Lehmann, Klaus-Dieter (Hrsg.): Deutsche Intellektuelle im Exil. Ihre Akademie und die American Guild for German Cultural Freedom. Eine Ausstellung des Deutschen Exilarchives 1933-1945 der Deutschen Bibliothek, Frankfurt am Main, München 1993. 
Lepsius, Rainer M.: Die Sozialwissenschaftliche Emigration und ihre Folgen, in: Ders. (Hrsg.): Soziologie in Deutschland und Österreich 1918-1945. Materialien zur Entwicklung, Emigration und Wirkungsgeschichte, Sonderdruck der Kölner Zeitschrift für Soziologie und Sozialpsychologie Nr. 23, S. 461-487.

Lehnert, Herbert: Bert Brecht und Thomas Mann im Streit über Deutschland, in: Spalek, John M./Strelka, Joseph (Hrsg.): Deutsche Exilliteratur seit 1933, Bd. 1, München 1976, S. 62-88.

Lewkowitz, Albert: Festrede zu Eröffnung der Freien Jüdischen Volkshochschule zu Breslau (09. November 1919), Breslau 1919, S. 3-23.

Lewy, Fritz: Die soziologische Methode, Karlsruhe 1927.

Linder, Herbert: Von der NSDAP zur SPD. Der politische Lebensweg des Dr. Helmuth Klotz (1884-1943), Konstanz 1995.

Litt, Theodor/Ritzel, Wolfgang: Siegfried Marck, ein Nachruf, in: Zeitschrift für philosophische Forschung, Jg. 11 (1957), S. 602-606.

Llanque, Markus: Siegfried Marck und der Neuhumanismus als französisch-deutsche Sammlungsbewegung, in: Alfons Söllner (Hrsg.): Deutsche Frankreich-Bücher aus der Zwischenkriegszeit, Baden-Baden 2011, S. 273-293.

Löbe, Paul: Der Weg war lang. Lebenserinnerungen, Berlin 1954.

Löwe, Teresa: Der Politiker Eduard Bernstein. Eine Untersuchung zu seinem politischen Wirken in der Frühphase der Weimarer Republik 1918-1924. Historisches Forschungszentrum, Bonn 2000.

Lompe, Klaus/Neumann Lothar F.(Hrsg.): Willi Eichlers Beiträge zum demokratischen Sozialismus. Eine Auswahl aus dem Werk, Bonn 1979.

Longerich, Peter: Deutschland 1918-1933. Die Weimarer Republik. Handbuch zur Geschichte, Hannover 1995.

Lowenthal, Ernst G.: Juden in Preußen. Biographisches Verzeichnis. Ein repräsentativer Querschnitt, Berlin 1981.

Lützeler, Paul Michael: Hermann Broch. Eine Biographie. Frankfurt am Mai 1985.

Luhmann, Niklas: Inklusion und Exklusion, in: Ders.: Soziologische Aufklärung 6. Die Soziologie und der Mensch, Opladen 1995.

Maas, Liselotte: Handbuch der deutschen Exilpresse: 1933-1945, München 1976. 
Mache, Karl: Clara Zils-Eckstein, in: Arbeiterwohlfahrt, 6 (1931), Heft 9, S.274-277.

Mann, Heinrich: Verteidigung der Kultur. Antifaschistische Schriften und Essays, Berlin 1960, S. 483-486. Stellung zur Volksfront S. 256-299.

Mann, Thomas herausgegeben von Inge Jens: Tagebücher 1953-1955 Frankfurt am Main 1995.

Mann, Thomas herausgegeben von Peter de Mendelssohn: Thomas Mann. Tagebücher 1949-1950 Frankfurt am Main 1991.

Ders. (Hrsg.): Tagebücher 1946-1948, Frankfurt am Main 1989.

Ders. (Hrsg.): Thomas Mann. Tagebücher 1944-1946, Frankfurt am Main 1986

Ders.: (Hrsg.): Tagebücher, 1940-1943, Frankfurt am Main 1982.

Ders.: (Hrsg.): Thomas Mann. Tagebücher 1937-1939, Frankfurt am Main 1980

Ders. (Hrsg.): Thomas Mann. Tagebücher 1935-1936, Frankfurt am Main 1972

Ders. (Hrsg.): Thomas Mann. Tagebücher 1933-1934, Frankfurt am Main 1977.

Ders.: Von deutscher Republik, Berlin 1923.

Marck, Kläre: Carl Hauptmann. Zu seinem 70. Geburtstag, in: Kunst und Volk. Monatsheft der Breslauer Volksbühne, Heft 9 (1928), S. 262-266.

Marck, Siegfried: Paul Tillich. Zum 70. Geburtstag, in: Kant-Studien, Bd. 48 Heft 14 (Januar 1957), S. 473-484.

Ders.: Thomas Mann as a thinker, in: Ethics, Vol. LXVII No. 1, October 1956, S. $53-$ 56.

Ders.: Große Menschen unserer Zeit: Portraits aus drei Kulturkreisen, Meisenheim am Glan 1954.

Ders.: Ein Jahrhundert Marxismus, München 1948.

Ders./Seger, Gerhart: Germany: To Be or Not To Be?, New York 1943.

Ders.: „Am Ausgang des jüngeren Neukantianismus. Ein Gedenkblatt für Richard Hönigswald und Jonas Cohn“, in: Archiv für Philosophie, Jg. 3 (1949), 33-41.

Ders.: Der Neuhumanismus als politische Philosophie, Zürich 1938. 
Ders.: Vom romantischen Idealismus zum sozialistischen Neuhumanismus, in: Gumbel, Emil Julius (Hrsg.): Freie Wissenschaft. Ein Sammelbuch aus der deutschen Emigration, Strasbourg 1938, S. 113-124.

Ders: Thomas Mann als Dialektiker, in: Philosophia Jg.2 1937, S. 112-138.

Ders.: Freiheitlicher Sozialismus. Herausgegeben vom Bund freiheitlicher Sozialisten, Dijon 1937.

Ders.: Sozialdemokratie, Berlin 1931.

Ders.: Die Dialektik in der Philosophie der Gegenwart, 2 Halbbände, Tübingen 1929/31.

Ders.: Liberalismus, Fascismus [sic!], Sozialismus. Ein Kapitel politischer Ideologie, in: Der Klassenkampf, Nr.12 (1929), S. 373-377.

Ders.: Opportunistische Wehr, „Dialektik“, in: Der Klassenkampf, Nr. 5 (1929), S. 154-157.

Ders.: Max Adlers Lehrbuch der materialistischen Geschichtsauffassung, in: Der Klassenkampf, Nr. 24 (1930), S. 760-763.

Ders.: Dialektisches Denken in der Philosophie der Gegenwart, in: Logos: Zeitschrift für systematische Philosophie, Bd. 15 (1927-1928), S. 21-46.

Ders.: Das Gesetz, wonach $\mathrm{Du}$ angetreten! Kühnemann als praktischer Charakterologe, in: Mann, Alfred (Hrsg.): Festschrift für Eugen Kühnemann zum 28. Juli 1928, Breslau 1928, S. 26-40.

Ders.: Reformismus und Radikalismus in der deutschen Sozialdemokratie. Geschichtliches und Grundsätzliches, Berlin 1927.

Ders.: Marxistische Staatsbejahung, Breslau 1924.

Ders.: Rathenau als Denker, in: Logos: Zeitschrift für systematische Philosophie, Bd. 11 (1922-1923), S. 181-191.

Ders.: Imperialismus und Pazifismus als Weltanschauungen, Tübingen 1918

Ders.: Deutsche Staatsgesinnung, München 1917.

Maser, Werner: Friedrich Ebert: Der erste deutsche Reispräsident: eine politische Biographie, München 1987. 
Matull, Wilhelm: Ostdeutschlands Arbeiterbewegung, Abriß ihrer Geschichte, ihrer Leistung und Opfer, Ostdeutsche Beiträge aus dem Göttinger Arbeitskreis Würzburg Band LIII, Würzburg 1973.

Maurer, Trude: Ostjuden in Deutschland: 1918-1933, Hamburg 1986.

Michels, Robert: Zur Soziologie des Parteiwesens in der modernen Demokratie. Untersuchungen über die oligarchischen Tendenzen des Gruppenlebens (1911), Stuttgart 1989.

Miller, Susanne: Kommentare aus der deutschen Exilpresse zur Annexion Österreichs, in: Kreisler, Felix (Hrsg.): Fünfzig Jahre danach - der „Anschluss“ von Innen und Außen gesehen, Wien 1989.

Dies.: Zur Haltung jüdischer Sozialdemokraten im Ersten Weltkrieg, in: Grab, Walter (Hrsg.) Juden und jüdische Aspekte in der deutschen Arbeiterbewegung 1848-1918, Tel-Aviv 1977, S. 229-247.

Mittag, Jürgen: Biografische Forschung und Arbeiterbewegung: Einleitende Anmerkungen, in: Mitteilungsblatt des Instituts für soziale Bewegungen. Biografische Ansätze zur Geschichte der Arbeiterbewegung im 20. Jahrhundert 45(2011), S. 5-21.

Ders.: Wilhelm Keil (1870-1968). Sozialdemokratischer Parlamentarier zwischen Kaiserreich und Bundesrepublik. Eine politische Biographie, Düsseldorf 2001.

Model, Anselm: „Ich“ und „Selbst“. Zur Auseinandersetzung Jonas Cohns mit der Denkpsychologie Richard Hönigswalds, in: Schmied-Kowarzik, Wolfdietrich (Hrsg.): Erkennen - Monas - Sprache. Internationales Richard-HönigswaldSymposium, Kassel 1995, S. 145-159.

Mommsen, Hans: Die verspielte Freiheit. Der Weg der Republik von Weimar in den Untergang. 1918 bis 1933, Berlin 1989.

Mounier, Emmanuel: Das personalistische Manifest, Paris 1936.

Mühlen, Patrick von zur: Die SPD zwischen Anpassung und Widerstand, in: Schmädeke, Jürgen/Steinbach, Peter (Hrsg.): Der Widerstand gegen den Nationalsozialismus. Die deutsche Gesellschaft und der Widerstand gegen Hitler, München 1985, S. 86-98.

Mülhausen, Walter: Friedrich Ebert 1871-1925: Reichspräsident der Weimarer Republik, Bonn 2006. 
Müller, Theodor: Die Geschichte der Breslauer Sozialdemokratie, Bd. I. Bis zum Erlaß des Sozialistengesetzes, Bd. II. Das Sozialistengesetz, Breslau 1925.

Müller-Lemke, Sabine: Ethischer Sozialismus und soziale Demokratie. Der politische Weg Willi Eichlers vom ISK zur SPD, Bonn 1988.

Munzinger: Internationales biographisches Archiv 31/1982 vom 26. Juli 1982.

Na'aman, Shlomo: Ferdinand Lassalle. Deutscher und Jude, Hannover 1968.

Niemann, Heinz (Hrsg.): Auf verlorenem Posten? Linkssozialismus in Deutschland, Berlin 1991.

Ders.: Geschichte der deutschen Sozialdemokratie1917-1945, Frankfurt am Main 1982.

Niethammer, Lutz: Kommentar zu Pierre Bourdieu. Die biographische Illusion, in: BIOS 3 (1990) Heft 1, S. 91-93.

Nipperdey, Thomas: Deutsche Geschichte Bd. II. Machtstaat vor der Demokratie, München 1993.

Nolte, Ernst: Die Action Francaise, in: Vierteljahreshefte für Zeitgeschichte, Jg. 9 (1961), Heft 2, S. 124-164.

Notz, Gisela: „Her mit dem allgemeinen, gleichen Wahlrecht für Mann und Frau!“. Die internationale sozialistische Frauenbewegung zu Beginn des 20. Jahrhunderts und der Kampf um das Frauenwahlrecht, Bonn 2009.

Dies.: Maria Ansorge - „um unsere sozialistischen Ideen zu verwirklichen, dafür sind wir nie zu alt", in: Jahrbuch für Forschungen zur Geschichte der Arbeiterbewegung, Heft III 2002.

Nusser, Horst: Konservative Wehrverbände in Bayern, Preußen und Österreich 19181933, München 1973.

Oelker, Jürgen: Biographik - Überlegungen zu einer unschuldigen Gattung, in: Neue Politische Literatur 3 (1974), S. 296-309.

Oliwa, Theodor: Die deutsche Arbeiterbewegung in Breslau. Friedrich-EbertStiftung 2010.

Ders.: Paul Löbe. Ein sozialdemokratischer Politiker und Redakteur. Die schlesischen Jahre (1875-1919), Neustadt 2003. 
Oschmann, Kersten: Hendrik de Man. Zwischen links und rechts, in: Lösche Peter/Walter, Franz (Hrsg.): Vor dem Vergessen bewahren. Lebenswege Weimarer Sozialdemokraten, Berlin 1988, S. 223- 251.

Ders.: Über Hendrik de Man: Marxismus, Plansozialismus und Kollaboration; ein Grenzgänger in der Zwischenkriegszeit, Freiburg 1987.

Osterroth, Franz/Schiller, Dieter: Chronik der deutschen Sozialdemokratie, Bd. II. Vom Beginn der Weimarer Republik bis zum Ende des Zweiten Weltkrieges, Bonn 1980 .

Ders.: Biographisches Lexikon des Sozialismus, Bd.1. Verstorbene Persönlichkeiten, Hannover 1960.

Paetel, Karl O.: Zum Problem einer deutschen Exilregierung, in: Vierteljahreshefte für Zeitgeschichte, Jg. 4 (1956), S. 286-301.

Papcke, Sven: Deutsche Soziologie im Exil. Gegenwartsdiagnose und Epochenkritik 1933-1945, Frankfurt am Main 1993.

Paul, Hans-Holger: Marck, Siegfried, in: Neue Deutsche Biographie (NDB), Jg.16 (1990), S. 121-123.

Pfabigan, Alfred: Max Adler. Eine politische Biographie, Frankfurt am Main 1982.

Pickhan, Gertrud: „Gegen den Strom“. Der Allgemeine jüdische Arbeiterbund „Bund“ in Polen 1918-1939, Stuttgart/München 2001.

Dies.: The "Bund" in Poland and German Social Democracy in the Thirties, in: Proceedings of the Twelfth World Congress of Jewish Studies, Jerusalem, July 29 August 5, 1997, Division B: History of the Jewish People, Jerusalem 2000, S. 257263.

Pohl, Gerhart: Bin ich noch in meinem Haus? Die letzten Tage Gerhart Hauptmanns, Berlin 1953.

Pyka, Marcus: Jewish Studies, in: Klein, Christian (Hrsg.): Handbuch Biographie. Methoden, Traditionen, Theorien, Stuttgart 2009, S. 414-418.

Pyta, Wolfram: Geschichtswissenschaft, in: Klein, Christian (Hrsg.): Handbuch Biographie. Methoden, Traditionen, Theorien, Stuttgart 2009, S. 331-339.

Radkau, Joachim: Die deutsche Emigration in den USA. Ihr Einfluß auf die amerikanische Europapolitik 1933-1945, Düsseldorf 1971. 
Ders.: Die Exil-Ideologie vom ,anderen Deutschland“ und die Vansittartisten. Über die Einstellung deutscher Emigranten nach 1933 zu Deutschland, in: Aus Politik und Zeitgeschichte, 10. Januar 1970, S. 31-48.

Rahden, Till van: Juden und andere Breslauer. Die Beziehung zwischen Juden, Protestanten und Katholiken in einer deutschen Großstadt von 1869 bis 1925, Göttingen 2000.

Reichmann-Jungmann, Eva: Der Centralverein deutscher Staatsbürger jüdischen Glaubens, in: Dies.: Größe und Verhängnis deutsch-jüdischer Existenz, Heidelberg 1974, S. 22-32.

Reinke, Andreas: Gemeinde und Verein. Formen jüdischer Vergemeinschaftung im Breslau des 19. und beginnenden 20. Jahrhunderts, in: Ders. et al (Hrsg.): In Breslau zu Hause? Juden in einer mitteleuropäischen Metropole der Neuzeit, Hamburg 2003, S. 131-148.

Ridley, Hugh/Vogt, Jochen: Thomas Mann, Paderborn 2009.

Röder, Werner et al (Hrsg.): Biographisches Handbuch der deutschsprachigen Emigration nach 1933, München 1980.

Rothe, Wolfram: Von Hitler verbannt, unter Stalin umgekommen: Helmuth Brückner - vom Gauleiter zum Gulag-Häftling, in: Zeitgeschichte regional Bd. 12 (2008), S. 46-53.

Rudorff, Andrea: Breslau-Dürrgoy, in: Wolfgang Benz, Barbara Distel (Hrsg.): Der Ort des Terrors. Geschichte der nationalsozialistischen Konzentrationslager, Bd. 2: Frühe Lager, Dachau Emslandlager, München 2005, S. 83-86.

Sabrow, Martin: Der Rathenaumord. Rekonstruktion einer Verschwörung gegen die Republik von Weimar, München 1994.

Sallama, Hans: Breslau und Umgebung. Broschüre des Breslauer Verkehrsvereins, Breslau o. J.

Sander, Sabine: Nur für geladene Gäste. Der „Deutsche Lyzeumsclub“, in: Zwaka, Petra et al (Hrsg.): „Ich bin meine eigene Frauenbewegung“. Frauenansichten aus der Geschichte einer Großstadt, Berlin 1991, S. 52-57.

Schiller, Dieter: „In bewusstem Gegensatz zu der kommunistisch-ullsteinschen Bande“. Schwarzschilds Bund Freie Presse und Literatur in Paris, in: Anne Saint Sauveur-Henn (Hrsg.): Fluchtziel Paris. Die deutschsprachige Emigration 19331940. Metropol, Berlin 2002, S. 215-229. 
Schilmar, Boris: Der Europadiskurs im deutschen Exil 1933-1945, München 2004.

Schmidt, Alfred (Hrsg.): Max Horkheimer. Gesammelte Schriften, Bd. IV: Schriften 1936-1941.

Schneiderman, Harry et al (Hrsg.): American Jewish Yearbook, Volume 49 (19471948), Volume 50 (1948-1949).

Schneider-Nehls, Gudrun: Grenzgänger in Deutschland. Untersuchung einer intellektuellen Verhaltensmöglichkeit in unserem Jahrhundert, Potsdam 1997.

Schöll, Julia: Joseph im Exil. Zur Identitätskonstruktion in Thomas Manns ExilTagebüchern und -Briefen sowie im Roman Joseph und seine Brüder, Würzburg 2004.

Scholz, Arno/Oschilewski, Walther (Hrsg.): Ein großes Vorbild. Paul Löbe zum Gedächtnis. Berlin 1968.

Schopf, Wolfgang: Pariser Echo in der Krise: Das Münchener Abkommen in der Publizistik des Exils, in: M. Boyer-Weinmann et al (Hrsg.): Das Münchener Abkommen und die Intellektuellen. Literatur und Exil in Frankreich zwischen Krise und Krieg, Tübingen 2008, S. 217-226.

Schraepler, Ernst: August Bebel. Sozialdemokrat im Kaiserreich, Göttingen [u. a.] 1966.

Schröter, Klaus (Hrsg.): Thomas Mann im Urteil seiner Zeit. Dokumente 1891-1955, Frankfurt am Main 1999.

Schüler-Springorum, Stefanie: Juden, zur Sonne, zur Freiheit, in: Neue Gesellschaft, Frankfurter Hefte, Bd. 05 (2013), S. 18-19.

Schulz, Markus/Gemeiner, Jens: Deutsche Volksfront ohne Volk. Manifeste des Widerstandes, in: Lorenz, Robert/Klatt, Johanna (Hrsg.): Politische Manifeste, Göttingen 2011, S. 169-198.

Schulz, Markus: Der Konsensmacher, in: Spiegel-Online, 01.12.2009.

Schutte, Christoph: Die königlich Akademie in Posen 1903-1919 und andere kulturelle Einrichtungen im Rahmen der Politik zur „Hebung des Deutschtums“, Marburg 2008.

Schwabe, Klaus: Wissenschaft und Kriegsmoral. Die deutschen Hochschullehrer und die politischen Grundfragen des Ersten Weltkrieges, Göttingen 1969. 
Schwarz, Hans Peter: Der Historiker als Biograph oder: Was können wir von Lothar Gall lernen?, in: Hein, Dieter et al (Hrsg.): Historie und Leben. Der Historiker als Wissenschaftler und Zeitgenosse. Festschrift für Lothar Gall zum 70. Geburtstag, München 2006, S. 249-255.

Seebacher-Brandt, Brigitte: Bebel. Künder und Kärrner im Kaiserreich, Berlin/Bonn 1988.

Seeger, Wolfgang: Politik und Person Der Personalismus Emanuel Mounier's als politischer Humanismus, Freiburg 1968.

Seydewitz, Ruth und Max: Begegnungen, Berlin 1984.

Dies.: Alle Menschen haben Träume: Meine Zeit, mein Leben, Berlin 1980.

Sieg, Ulrich: Jüdische Intellektuelle im Ersten Weltkrieg. Kriegserfahrungen, weltanschauliche Debatten und kulturelle Neuentwürfe, Berlin 2001.

Sorkin, David: The transformation of German Jewry, 1780-1840, New York 1987.

Stampfer, Friedrich: Mit dem Gesicht nach Deutschland. Eine Dokumentation über die sozialdemokratische Emigration. Aus dem Nachlass von Friedrich Stampfer, ergänzt durch andere Überlieferungen, herausgegeben von Erich Matthias und bearbeitet von Werner Link, Düsseldorf 1968.

Specht, Heike: Die Feuchtwanger. Familie, Tradition und jüdisches Selbstverständnis, Göttingen 2006.

Stenzel, Elke (Hrsg.): „Den Nazis eine schallende Ohrfeige versetzen“. Zeitzeugen erinnern sich, Berlin 2009.

Stern, Fritz: Fünf Deutschland und ein Leben, München 2007.

Sternberg, Fritz: Der Imperialismus und seine Kritiker, Berlin 1929.

Ders.: Der Imperialismus, Berlin 1926.

Stichweh, Rudolf: Inklusion und Exklusion: Analysen zur Sozialstruktur und sozialen Ungleichheit, Wiesbaden 2009.

Szanto, Alexander: Im Dienste der Gemeinde 1923-1939, unveröffentlichtes Manuskript, Manchester 1968, LBI NY. 
Szöllösi-Janze, Margit: Lebens-Geschichte - Wissenschafts-Geschichte. Vom Nutzen der Biographie für Geschichtswissenschaft und Wissenschaftsgeschichte, in: Berichte zur Wissenschaftsgeschichte 23 (2000) S. 17-35.

Dies.: Fritz Haber 1868-1934. Eine Biographie, München 1998.

Tilitzki, Christian: Die deutsche Universitätsphilosophie in der Weimarer Republik und im Dritten Reich, Berlin 2002.

Tillich, Paul: Wessen Kriegsziele?, im Herbst 1941, in: Albrecht, Renate/Henel, Ingeborg (Hrsg.): Paul Tillich gesammelte Werke, Bd. 13: Impressionen und Reflexionen: ein Lebensbild in Aufsätzen, Reden und Stellungnahmen, Stuttgart 1972, S. 264-269.

Tippelt, Rudolf/Hippel, Aiga von (Hrsg.): Handbuch Erwachsenenbildung/ Weiterbildung, Wiesbaden 2010.

Töpner, Kurt: Gelehrte Politiker und politisierende Gelehrte: Die Revolution von 1918 im Urteil deutscher Hochschullehrer, Göttingen 1970.

Varga, Alexander: Bauch, Bruno, in: Neue Deutsche Biographie (NDB). Bd. 1, Berlin 1953, S. 630-631.

Vorholt, Udo: Die Sowjetunion im Urteil des sozialdemokratischen Exils 1933-1945. Eine Studie des Exilparteivorstandes der SPD, des Internationalen Sozialistischen Kampfbundes, der Sozialistischen Arbeiterpartei und der Gruppe Neu Beginnen, Frankfurt am Main 1991.

Wachenheim, Hedwig: Mitteilungen. Clara Zils-Eckstein, in: Arbeiterwohlfahrt 6 (1931), Heft 6.

Walter, Franz et al (Hrsg.): Von der Emanzipation zur Meritokratie. Betrachtungen zur 150-jährigen Geschichte von Arbeiterbewegung, Linksintellektuellen und sozialer Demokratie, Göttingen 2013.

Ders.: „Republik, das ist nicht viel“. Partei und Jugend in der Krise des Weimarer Sozialismus, Bielefeld 2011, S. 279-286.

Ders.: Vom Milieu zum Parteienstaat. Lebenswelten, Leitfiguren und Politik im historischen Wandel, Wiesbaden 2010, S. 22-29.

Ders.: Kritische Dialektik, in: Frankfurter Allgemeine Zeitung, 02.03.2007.

Ders.: Sozialistische Akademiker- und Intellektuellenorganisation in der Weimarer Republik, Bonn 1990. 
Ders./Kümmel, Michael: Zwischen Kant und Hegel, zwischen Bürgertum und Arbeiterbewegung. Siegfried Marck zum 100. Geburtstag, in: Jahrbuch der Schlesischen Friedrich-Wilhelms-Universität zu Breslau Band 30 1989, S. 185-213.

Ders.: Siegfried Marck (1889-1957). Linkssozialist, Realpolitiker und Neuhumanist, in: Lösche, Peter et al (Hrsg.): Vor dem Vergessen bewahren. Lebenswege Weimarer Sozialdemokraten, Berlin 1988, S. 251-280.

Ders.: Nationale Romantik und revolutionärer Mythos. Politik und Lebenswelten im frühen Weimarer Jungsozialismus, Berlin 1986.

Ders./Storm, Gerd: Weimarer Linkssozialismus und Austromarxismus. Historische Vorbilder für einen „Dritten Weg“ zum Sozialismus?, Berlin 1984.

Weber, Hermann: Die Ambivalenz der kommunistischen Widerstandsstrategie bis zur „Brüsseler“ Parteikonferenz, in: Schmädeke, Jürgen/Steinbach, Peter (Hrsg.): Der Widerstand gegen den Nationalsozialismus. Die deutsche Gesellschaft und der Widerstand gegen Hitler, München 1985, S. 73-85.

Webersinn, Gerhard: Dr. Hans Herschel, in: Jahrbuch der Schlesischen FriedrichWilhelms-Universität, Band XII 1967, S. 246-306.

Welskopp, Thomas: „Arbeiterintellektuelle“, „sozialdemokratische Bohemiens“ und „Chefideologen": Der Wandel der Intellektuellen in der frühen deutschen Sozialdemokratie, in: Aleman, Ulrich van et al (Hrsg.): Intellektuelle und Sozialdemokratie, Opladen 2000, S. 43-58.

Ders.: Banner der Brüderlichkeit. Die deutsche Sozialdemokratie vom Vormärz bis zum Sozialistengesetz, Bonn 2000.

Weisbrod, Bernd: The crisis of bourgeois society in interwar Germany, in: Bessel, Richard (Hrsg.): Fascist Italy and Nazi Germany: comparisons and contrasts, Cambridge University Press 1998, S. 23-39.

Wessel, Harald: Münzenbergs Ende: ein deutscher Kommunist im Widerstand gegen Hitler und Stalin: die Jahre 1933-1940, Berlin 1991.

Wiedemeyer, Malte: Philosophie der Übergegensätzlichkeit: Eine Kritik der Dialektikauffassung des sozialdemokratischen Theoretikers Siegfried Marck (18891957), Berlin 1983.

Wilpert, Paul: Ernst Hoffmann, in: Zeitschrift für philosophische Forschung, Bd. 7, Nr. 2 (1953), S. 265-275. 
Winkler, Heinrich August: Der lange Weg nach Westen. Deutsche Geschichte von 1806-1933, München 2000.

Ders.: Weimar 1918-1933. Die Geschichte der ersten deutschen Demokratie, München 1993.

Ders.: Der Schein der Normalität. Arbeiter und Arbeiterbewegung in der Weimarer Republik 1924-1930, Berlin/Bonn 1985.

Wipf, Hans Ulrich: Studentische Politik und Kulturreform. Geschichte der Freideutschen Bewegung 1896-1918, Schwalbach 2005.

Witt, Peter-Christian: Friedrich Ebert: Parteiführer - Reichskanzler Volksbeauftragter - Reichspräsident. 3. überarbeitete und aktualisierte Auflage, Bonn 1992.

Wittebur, Klemens: Die deutsche Soziologie im Exil 1933-1945. Eine biographische Kartographie, Hamburg 1991.

Woyke, Meik: Parteifunktionäre in der „zweiten Reihe“: Kontinuitäten und Brüche sozialdemokratischer Biografien im 20. Jahrhundert, in: Mitteilungsblatt des Instituts für soziale Bewegungen. Biografische Ansätze zur Geschichte der Arbeiterbewegung im 20. Jahrhundert 45 (2011), S. 129-145.

Zetkin, Clara: Zur Geschichte der proletarischen Frauenbewegung Deutschlands, Berlin 1958.

Ziatkowski, Leszek: Die Geschichte der Juden in Breslau, Wroclaw 2000.

Zimmermann, Mosche: Die deutschen Juden 1914-1945. Enzyklopädie deutscher Geschichte Bd. 43, hrsg. von Lothar Gall, München 1997.

Zühlsdorff, Volkmar: Deutsche Akademie im Exil, Berlin 1999.

Zwaka, Petra et al (Hrsg.): „Ich bin meine eigene Frauenbewegung“. Frauenansichten aus der Geschichte einer Großstadt, Berlin 1991, S. 52-57. 
Hiermit versichere ich an Eides statt, dass ich die eingereichte Dissertation „Siegfried Marck. Politische Biographie eines jüdisch-intellektuellen Sozialdemokraten" selbständig und ohne unerlaubte Hilfe verfasst habe. Anderer als der von mir angegebenen Hilfsmittel und Schriften habe ich mich nicht bedient. Alle wörtlich oder sinngemäß den Schriften anderer Autorinnen oder Autoren entnommenen Stellen habe ich kenntlich gemacht. Die Abhandlung ist noch nicht veröffentlicht worden und noch nicht Gegenstand eines Promotionsverfahrens gewesen.

Göttingen, den 09.11.2014 